Universidad deValladolid

PROGRAMA DE DOCTORADO EN ESPAÑOL: LINGÜÍSTICA, LITERATURA Y COMUNICACIÓN

TESIS DOCTORAL:

\title{
LA VALORACIÓN DEL ERROR POR PARTE DEL PROFESOR DE EDUCACIÓN PRIMARIA EN LAS PRODUCCIONES ESCRITAS DE ALUMNOS DE SEGUNDAS LENGUAS
}

Presentada por Susana Merino Mañueco para optar al grado de Doctora por la Universidad de Valladolid

Dirigida por:

DRA. Da. MARIA TERESA SOLIAS ARÍS

Valladolid, 2018 



\section{AGRADECIMIENTOS}

La presente Tesis Doctoral, fruto de un extenso y profundo período formativo, no se habría podido realizar sin la colaboración de varias personas que me han brindado su ayuda, sus conocimientos y su apoyo acompañándome a lo largo de este complejo y fascinante recorrido. Con estas líneas quisiera hacer constar mi profundo agradecimiento a todas esas personas.

Debo agradecer de manera especial y sincera a la Dra. Teresa Solias Arís por aceptar la dirección de esta Tesis, por ser un referente intelectual, un modelo profesional y un apoyo cercano. Su calidez personal, su confianza y su capacidad para guiar mis ideas han sido un aporte inestimable no solo en el desarrollo de esta Tesis sino también en mi formación como investigadora. Gracias por la dedicación brindada a este trabajo, por el respeto a mis sugerencias e ideas y por la dirección y el rigor que ha facilitado a las mismas.

A nivel institucional a la Universidad de Valladolid, por aceptar mi candidatura como doctoranda. Al programa de Doctorado en Español: Lingüística, Literatura y Comunicación y a todos los miembros del departamento de Lengua Española, tanto a su directora la Dra. Carmen Hernández González, como también a todos los profesores que me han otorgado su confianza, me han prestado su apoyo y me han inculcado su pasión por la investigación. 
A la institución donde desarrollo mi actividad profesional docente, Colegio Público de Educación Infantil y Primaria Francisco Pino de Valladolid, a mi equipo directivo y compañeros por facilitar la realización y finalización de esta Tesis.

Quiero extender un sincero agradecimiento a las instituciones de acogida durante la realización de mis estancias investigadoras entre las que se encuentra la Universidad de Texas en Austin y, de forma particular, a la Dra. Koike del Departamento de Español y Portugués y a la profesora de UT College of Liberal Arts, Rose Potter por haberme regalado su amistad, su tiempo y dedicación. También al profesor Dr. Lluís A. Natividad Sáez de la Universitat de Valencia por su apoyo durante la elaboración de los análisis estadísticos.

A mis compañeros, profesores de centros educativos de la ciudad de Valladolid y de la ciudad de Austin por permitir mi acceso a las aulas y por toda la ayuda prestada durante el proceso de recogida de datos.

También quiero expresar mi agradecimiento a mis padres, Peregrín y Pilar que me han apoyado de manera incondicional durante los días más difíciles de mi vida como estudiante. A Vicente, por su paciencia, comprensión y solidaridad con este proyecto. A la Dra. Dumbravescu y familia por ofrecerme su apoyo infinito y sus sabios consejos. A mis familiares, amigos y a todas las personas que me han animado en este largo camino. Mi agradecimiento por todo el apoyo moral y humano necesarios en los momentos difíciles de este trabajo. Sin su ayuda, esta memoria de Tesis nunca se habría escrito y, por eso, este trabajo es también el suyo.

A todos, muchas gracias. 


\section{ÍNDICE DE SIGLAS Y ABREVIATURAS}

AICLE: Aprendizaje Integrado de Contenidos y Lenguas Extranjeras

AC: Análisis Contrastivo

AE: Análisis de Errores

APD: Acto profesional docente / Actos profesionales docentes

CLIL: Content and Language Integrated Learning. Aprendizaje Integrado de Contenidos y

Lenguas Extranjeras

CLT: Communicative Language Teaching. Método comunicativo de enseñanza de lenguas

CVC: Centro Virtual Cervantes

Dr. / Dra.: Doctor / Doctora

DRAE: Diccionario de la Real Academia Española

EAP: English for Academic Purposes. Enseñanza de inglés con fines específicos

EEUU: Estados Unidos de América

ELE: Enseñanza del Español como Lengua Extranjera

ELLs: English language learners. Estudiantes de inglés

ESL: English as a Second Language. Inglés como segunda lengua

ESO: Educación Secundaria Obligatoria

FC: Feedback Correctivo

GU: Gramática Universal

IL: Modelo de interlengua

ISD: Independent School District. Distrito Escolar Independiente

L1: Lengua primera o materna

L2: Lengua segunda o extranjera

LE: Lengua Extranjera / Lenguas Extranjeras

LM: Lengua Materna

LOTE: Languages other than English. Lenguas extranjeras (distintas al inglés)

MCER: Marco Común Europeo de Referencia para las Lenguas: aprendizaje, enseñanza, evaluación

MECD: Ministerio de Educación, Cultura y Deporte

NTIC: Nuevas Tecnologías de la Información y de la Comunicación

ORDEN EDU/6/2006, de 4 de enero, por la que se regula la creación de secciones bilingües en centros sostenidos con fondos públicos de la comunidad autónoma de Castilla y León. 
PEPELF: Portfolio européen pour les enseignants en langues en formation initiale. Un outil de réflexion pour la formation des enseignants en langues. Portfolio Europeo para futuros profesores de idiomas. Una herramienta de reflexión para la formación de profesores de lenguas

RAE: Real Academia Española

SL: Second Language. Segunda/s lengua/s

SLA: Second Language Acquisition. Adquisición de segunda/s lengua/s.

TBE: Transitional Bilingual Education. Programa educativo bilingüe de transición al inglés

TEA: Texas Education Agency. Departamento de Educación del estado de Texas

TEKS: Texas Essential Knowledge and Skills. Estándares de aprendizaje establecidos por el Departamento de Educación del estado de Texas para el sistema educativo texano

TL: Target Language. Lengua meta.

UG: Universal Grammar. Gramática Universal.

WCF: Writing Corrective Feedback. Feedback correctivo para la enseñanza-aprendizaje de expresión escrita. 


\section{ÍNDICE}

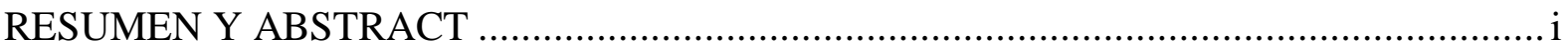

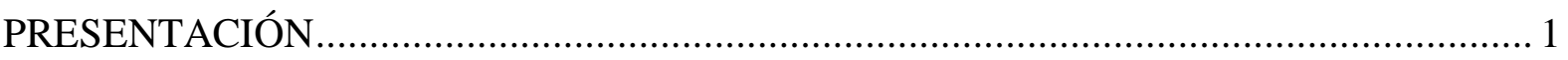

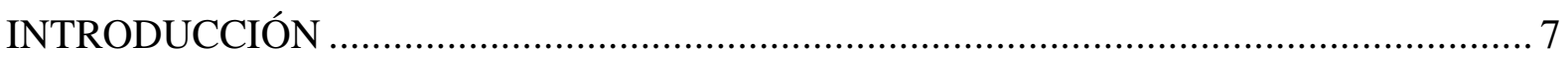

PARTE I: FUNDAMENTOS TEÓRICO-CONCEPTUALES DE LA INVESTIGACIÓN

Capítulo 1. CORRECCIÓN Y TRATAMIENTO DE ERRORES DESDE LA PERSPECTIVA DEL ALUMNO: ESTADO DE LA CUESTIÓN .................... 31

1.1. Algunas aclaraciones teórico-conceptuales en torno al error, a la corrección y

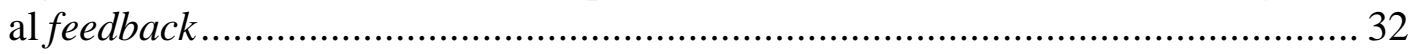

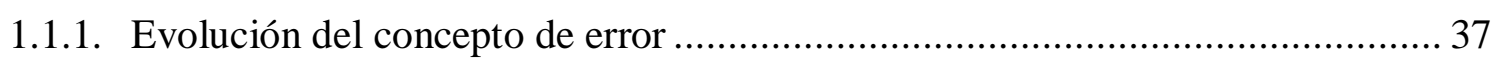

1.1.2. La corrección en las producciones escritas en L2 .......................................... 44

1.1.3. El feedback y su proyección en la enseñanza-aprendizaje de L2 ......................52

1.2. Causas y criterios en torno a la aparición del error............................................... 63

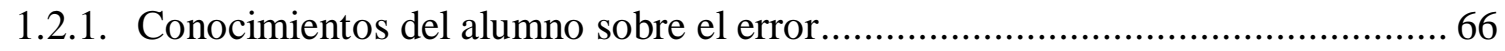

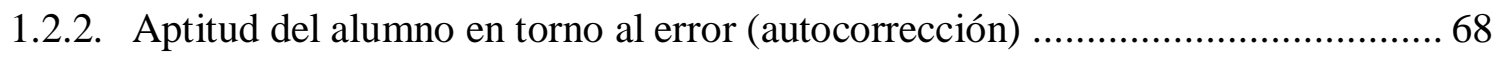

1.2.3. Actitud del alumno ante el error ................................................................ 71

1.3. Hacia una tipología de errores en las producciones escritas en L2 ........................ 79

1.3.1. Los errores de léxico y su papel en las producciones escritas en L2 .................. 82

1.3.2. La incidencia de los errores gramaticales en las producciones escritas en L2 .... 84

1.3.3. Los errores pragmático-culturales y su valor comunicativo en las producciones escritas en L2

Capítulo 2. FORMACIÓN DEL PROFESORADO DE L2: CORRECCIÓN Y

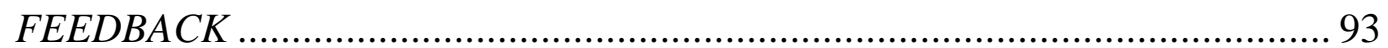

2.1. Consideraciones en torno a la corrección como acto comunicativo ....................... 94

2.1.1. La corrección de errores y sus funciones .................................................... 99

2.1.2. El tratamiento del error y sus funciones ..................................................... 105

2.1.3. De la corrección al feedback ....................................................................... 108

2.2. Formación del profesorado con respecto al error y a su corrección ....................... 116

2.2.1. Conocimientos del profesor sobre el error y su corrección .............................. 119

2.2.2. Aptitudes del profesor en torno al error y su corrección ................................. 122

2.2.3. Actitudes del profesor ante el error y su corrección ..................................... 125

Capítulo 3. ENSEÑANZA-APRENDIZAJE DE L2: MATIZACIONES CONTEXTUALES

3.1. Una perspectiva psicolingüística en torno al error en la enseñanza-aprendizaje de L2

3.1.1. Corrientes metodológicas y evolución del concepto del error en la enseñanza-aprendizaje de L2 
3.1.2. El componente afectivo y motivacional en la corrección del error y el feedback.....

3.2. Del objeto de enseñanza-aprendizaje a la expresión escrita............................... 153

3.2.1. De la lengua como medio de comunicación en L2 al discurso escrito .............. 156

3.2.2. Enseñanza-aprendizaje de la expresión escrita en L1 y L2 ............................ 161

3.3. Enseñanza-aprendizaje de L2: aspectos contextuales ..................................... 171

3.3.1. Programas de enseñanza-aprendizaje de inglés como L2 en el sistema educativo español. El caso de la ciudad de Valladolid .................................. 172

3.3.2. Programas de enseñanza-aprendizaje de español como L2 en el sistema educativo norteamericano. El caso de la ciudad de Austin

\section{PARTE II: ASPECTOS METODOLÓGICOS Y TÉCNICOS DE LA INVESTIGACIÓN}

\section{Capítulo 4. ESTRUCTURA Y ORGANIZACIÓN DEL PROCESO DE} INVESTIGACIÓN

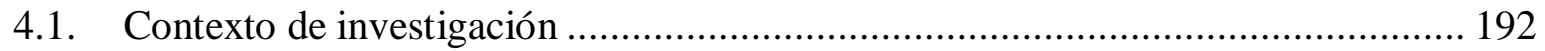

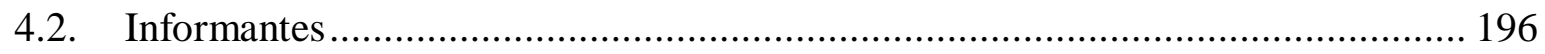

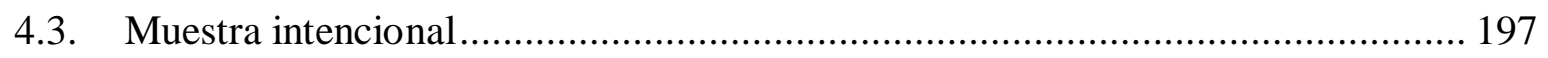

4.4. Instrumento para la recogida de información: el cuestionario .............................. 199

4.4.1. Concepción y elaboración del cuestionario .................................................... 200

4.4.2. Estructura del cuestionario y clasificación de los ítems .................................. 208

Capítulo 5. PERFIL DE LOS INFORMANTES........................................................... 215

5.1. Aspectos generales en torno al perfil de los informantes................................... 216

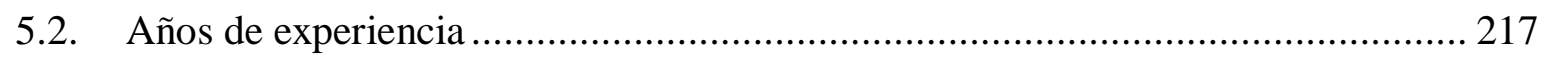

5.2.1. Análisis de los datos: años de experiencia de los informantes ........................ 219

5.2.2. Interpretación de los resultados: años de experiencia de los informantes......... 223

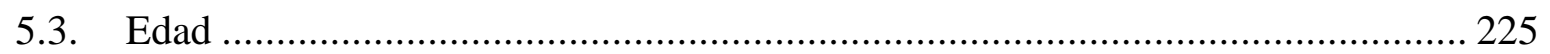

5.3.1. Análisis de los datos: edad de los informantes .............................................. 226

5.3.2. Interpretación de los resultados: edad de los informantes ............................. 229

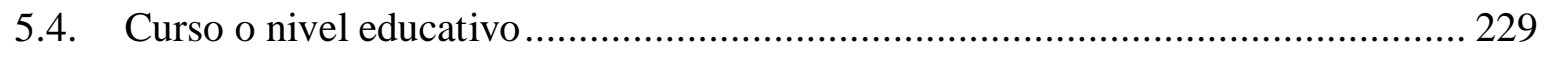

5.4.1. Análisis de los datos: curso o nivel educativo en el que los informantes ejercen su actividad docente .............................................................. 231

5.4.2. Interpretación de los resultados: curso o nivel educativo en el que los informantes ejercen su actividad docente .................................................. 233

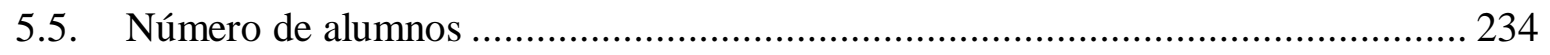

5.5.1. Análisis de los datos: número de alumnos de los informantes ....................... 235

5.5.2. Interpretación de los resultados: número de alumnos de los informantes......... 238

5.6. Interpretación de los resultados. Perfil de los informantes .................................. 239

Capítulo 6. COMPONENTE COMPETENCIAL I: CONOCIMIENTOS SOBRE EL ERROR, LA CORRECCIÓN Y EL FEEDBACK. 
6.1. Aspectos generales en torno al componente competencial I: conocimientos

6.2. Conocimientos sobre la actitud que muestra el alumno hacia una actividad de escritura dirigida en L2 .....

6.2.1. Análisis de los datos: conocimientos sobre la actitud que muestra el alumno hacia una actividad de escritura dirigida en L2

6.2.2. Interpretación de los resultados: conocimientos sobre la actitud que muestra el alumno hacia una actividad de escritura libre en L2

6.3. Conocimientos sobre la actitud que muestra el alumno hacia una actividad de escritura libre en L2

6.3.1. Análisis de los datos: conocimientos sobre la actitud que muestra el alumno hacia una actividad de escritura libre en L2

6.3.2. Interpretación de los resultados: conocimientos sobre la actitud que muestra el alumno hacia una actividad de escritura libre en L2 …........................... 259

6.4. Conocimientos sobre la reacción de los alumnos ante la ayuda ofrecida .............. 261

6.4.1. Análisis de los datos: conocimientos sobre la reacción de los alumnos ante la ayuda ofrecida.

6.4.2. Interpretación de los resultados: conocimientos sobre la reacción de los alumnos ante la ayuda ofrecida.

6.5. Conocimientos sobre la utilidad de las actividades de expresión escrita libre en

L2 .

6.5.1. Análisis de los datos: conocimientos sobre la utilidad de las actividades de expresión escrita libre en L2.

6.5.2. Interpretación de los resultados: conocimientos sobre la utilidad de las actividades de expresión escrita libre en L2

6.6. Conocimientos acerca del momento idóneo para la corrección de las producciones escritas en L2

6.6.1. Análisis de los datos: conocimientos acerca del momento idóneo para la corrección de las producciones escritas en L2

6.6.2. Interpretación de los resultados: conocimientos acerca del momento idóneo para la corrección de las producciones escritas en L2

6.7. Conocimientos sobre los tipos de errores que deben ser corregidos en las producciones escritas en $\mathrm{L} 2$

6.7.1. Análisis de los datos: conocimientos sobre los tipos de errores que deben ser corregidos en las producciones escritas en L2.....

6.7.2. Interpretación de los resultados: conocimientos sobre los tipos de errores que deben ser corregidos en las producciones escritas en L2

6.8. Interpretación de los resultados. Conocimientos sobre el error, la corrección y el feedback.....

Capítulo 7. COMPONENTE COMPETENCIAL II: APTITUDES EN TORNO AL ERROR, A LA CORRECCIÓN Y AL FEEDBACK

7.1. Aspectos generales en torno al componente competencial II: aptitudes 304

7.2. Aptitudes en torno a cómo presentar una actividad de escritura libre 306 
7.2.1. Análisis de los datos: aptitudes en torno a cómo presentar una actividad de escritura libre en L2

7.2.2. Interpretación de los resultados: aptitudes en torno a cómo presentar una actividad de escritura libre en L2....

7.3. Aptitudes en torno a la ayuda proporcionada a los alumnos durante la realización de actividades de escritura libre en L2 .

7.3.1. Análisis de los datos: aptitudes en torno a la ayuda proporcionada a los alumnos durante la realización de actividades de escritura libre en L2 .....

7.3.2. Interpretación de los resultados: aptitudes en torno a la ayuda proporcionada a los alumnos durante la realización de actividades de escritura libre en L2 .... 322

7.4. Aptitudes en cuanto a la elección de modalidades de corrección de las actividades de escritura libre en L2

7.4.1. Análisis de los datos: aptitudes en cuanto a la elección de modalidades de corrección de las actividades de escritura libre en L2.

7.4.2. Interpretación de los resultados: aptitudes en cuanto a la elección de modalidades de corrección de las actividades de escritura libre en L2

7.5. Aptitudes en torno a la dotación del feedback que acompaña a la corrección de errores de una actividad de escritura libre en L2

7.5.1. Análisis de los datos: aptitudes en torno a la dotación del feedback que acompaña a la corrección de errores de una actividad de escritura libre en L2 336

7.5.2. Interpretación de los resultados: aptitudes en torno a la dotación del feedback que acompaña a la corrección de errores de una actividad de escritura libre en L2

7.6. Aptitudes en torno a la evaluación de una producción escrita en L2.

7.6.1. Análisis de los datos: aptitudes en torno a la evaluación de una producción escrita en L2.

7.6.2. Interpretación de los resultados: aptitudes en torno a la evaluación de una producción escrita en L2

7.7. Aptitudes respecto a la forma de entrega de correcciones de las producciones escritas en L2.

7.7.1. Análisis de los datos: aptitudes respecto a la forma de entrega de correcciones de las producciones escritas en L2.

7.7.2. Interpretación de los resultados: aptitudes respecto a la forma de entrega de correcciones de las producciones escritas en L2.

7.8. Interpretación de los resultados. Aptitudes en torno al error, a la corrección y al feedback.

Capítulo 8. COMPONENTE COMPETENCIAL III: ACTITUDES ANTE EL ERROR, LA CORRECCIÓN Y EL FEEDBACK

8.1. Aspectos generales en torno al componente competencial III: actitudes... 366

8.2. Actitudes ante la corrección de errores y el feedback en una producción escrita en L2 
8.2.1. Análisis de los datos: actitudes ante el error, la corrección y el feedback en una producción escrita en L2 .

8.2.2. Interpretación de los resultados: actitudes ante el error, la corrección y el feedback en una producción escrita en L2.

8.3. Interpretación de los resultados. Actitudes ante el error, la corrección y el feedback.....

Capítulo 9. ANÁLISIS CORRELACIONAL DE LAS RESPUESTAS DE LOS INFORMANTES EN FUNCIÓN DE SU PERFIL.

9.1. Aspectos generales en torno al análisis correlacional ........................................ 380

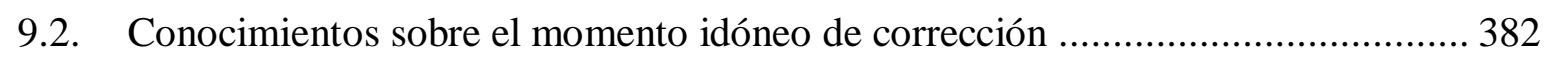

9.2.1. Conocimientos sobre el momento idóneo de corrección en relación con los años de experiencia en la enseñanza de L2

9.2.2. Conocimientos sobre el momento idóneo de corrección en relación con la edad

9.2.3. Conocimientos sobre el momento idóneo de corrección en relación con el curso

9.2.4. Conocimientos sobre el momento idóneo de corrección en relación con el número de alumnos

9.3. Aptitudes en torno a la forma de proporcionar feedback

9.3.1. Aptitudes en torno a la forma de proporcionar feedback en relación con los años de experiencia

9.3.2. Aptitudes en torno a la forma de proporcionar feedback en relación con la edad de los informantes

9.3.3. Aptitudes en torno a la forma de proporcionar feedback en relación con el curso

9.3.4. Aptitudes en torno a la forma de proporcionar feedback en relación con el número de alumnos

9.4. Actitudes ante la utilidad de la corrección de errores y el feedback

9.4.1. Actitudes ante la posible utilidad de la corrección de errores y el feedback en relación con los años de experiencia

9.4.2. Actitudes ante la posible utilidad de la corrección de errores y el feedback en relación con la edad

9.4.3. Actitudes ante la posible utilidad de la corrección de errores y el feedback en relación con el curso

9.4.4. Actitudes ante la posible utilidad de la corrección de errores y el feedback en relación con el número de alumnos.

9.5. Interpretación de los resultados obtenidos a partir del análisis correlacional 


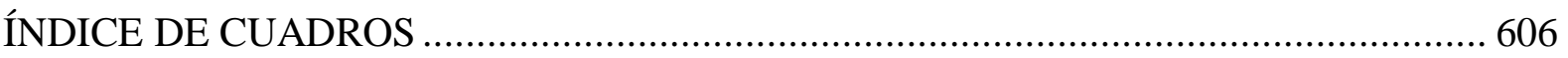

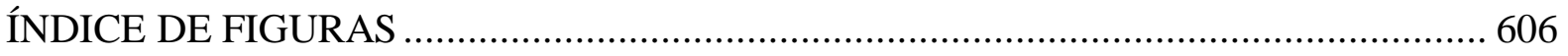

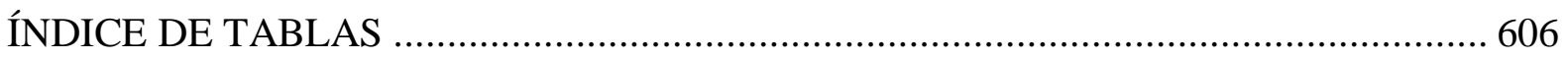

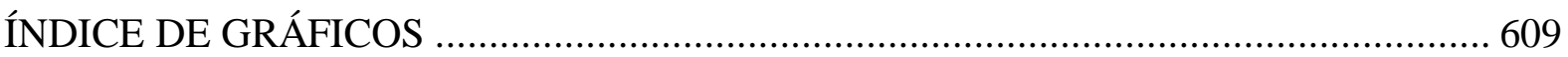

\section{ANEXOS}

Anexo I Cuestionario I. Cuestionario para profesores de Educación Primaria que imparten enseñanzas oficiales de inglés como segunda lengua (L2) en la ciudad de Valladolid, España

Anexo II Cuestionario II. Cuestionario para profesores de Educación Primaria que imparten enseñanzas oficiales de español como segunda lengua (L2) en la ciudad de Austin, Estados Unidos de América ....

Anexo III Carta de Presentación para profesores que imparten enseñanzas de inglés como segunda lengua en la ciudad de Valladolid, España. Modalidad de entrega del cuestionario: en mano

Anexo IV Carta de Presentación para profesores que imparten enseñanzas de español como segunda lengua en la ciudad de Austin, Estados Unidos de América. Modalidad de entrega del cuestionario: en mano

Anexo V Carta de Invitación para profesores que imparten enseñanzas de inglés como segunda lengua en la ciudad de Valladolid, España. Modalidad de entrega de los cuestionarios: enlace que da acceso al cuestionario online

Anexo VI Carta de Invitación para profesores que imparten enseñanzas de español como segunda lengua en la ciuad de Austin, Estados Unidos de América. Modalidad de entrega de los cuestionarios: enlace que da acceso al cuestionario online. 
RESUMEN Y ABSTRACT 



\section{RESUMEN Y ABSTRACT}

\section{Resumen}

El trabajo de investigación llevado a cabo se inscribe en el área interdisciplinaria de la Lingüística aplicada a la enseñanza-aprendizaje de L2, en la problemática de la corrección del error por parte del profesor y de la dotación de feedback, durante el desarrollo de actividades de producción escrita en L2 en la etapa educativa de Educación Primaria.

Se ha focalizado la atención en la dimensión afectiva por cuanto que esta ejerce una influencia significativa en la enseñanza-aprendizaje de una L2. Por su valor teórico y sus implicaciones prácticas para el ámbito educativo, la presente Tesis Doctoral se revela como útil y pertinente para la mejora de la enseñanza-aprendizaje de la expresión escrita en L2 en edades tempranas.

Se ha planteado como finalidad última contribuir a la formación continua de los maestros de L2 en torno al error como resultado de su fuerte impacto afectivo-motivacional en la corrección y el feedback. En este sentido, indagamos en las actitudes de los profesores de L2 de Educación Primaria en relación al error, a su corrección y a la retroalimentación o feedback con respecto a las producciones escritas a partir del análisis de los conocimientos y las aptitudes de dichos profesores.

Metodológicamente el trabajo de investigación se aborda desde la perspectiva descriptiva, con la aplicación de un análisis correlacional a través del cual estudiamos los resultados que obtienen los diferentes perfiles de informantes (dentro de cada grupo) según los años de 
experiencia, la edad, el curso en el que ejercen su actividad docente y el número de alumnos. Llevamos a cabo, por tanto, un tipo de investigación cualitativa que nos aporta una descripción de los contextos educativos implicados en el estudio, al tiempo que presenta información relevante relacionada con los conocimientos, las aptitudes y las actitudes de los informantes. Asimismo, desarrollamos un análisis cuantitativo con el propósito de precisar matices dentro de cada grupo de informantes involucrados en la presente investigación.

Se han delimitado como contextos de indagación:

- Centros educativos de Educación Primaria pertenecientes a la ciudad de Valladolid, Castilla y León, España.

- Centros educativos de Educación Primaria de la ciudad de Austin, Texas, Estados Unidos de América.

La muestra intencional se constituyó de profesores que ejercen su actividad docente en la enseñanza de inglés o español como L2.

Recurrimos al uso de la técnica de observación y como instrumento de investigación diseñamos y utilizamos un cuestionario constituido por 17 preguntas distribuidas en: preguntas de respuesta única, preguntas de opción múltiple y enunciados descriptivo-evaluativos.

El procesamiento de datos permitió validar nuestra hipótesis principal respecto a la presencia de una actitud positiva generalizada de los profesores en torno a los errores en las 
producciones escritas de L2 de los alumnos de Primaria y en torno al componente afectivo. Esta actitud positiva no siempre se manifiesta en las prácticas de corrección y, en virtud de ello, destacamos que, a nivel declarativo, todos los profesores valoran la presencia del error y lo reconocen como un paso previo hacia el éxito en el proceso de enseñanza-aprendizaje. Sin embargo, en la práctica, se usa como elemento principal de la evaluación, lo cual genera una actitud negativa en torno al error por parte de los alumnos.

Los resultados de la investigación pusieron de manifiesto que aquellos profesores que ejercen su actividad en el contexto educativo de la ciudad de Valladolid generalmente hacen uso del error como elemento de evaluación. En consecuencia, los alumnos temen expresarse en inglés porque saben que cometer errores les restará puntos en el cómputo de la evaluación y ello comporta actitudes negativas hacia la adquisición de la L2. Dichos profesores muestran un desconocimiento de la importancia que tiene el componente afectivo en el aula de L2 en general y sobre la repercusión que puede tener en las producciones escritas del alumno

Por otro lado, los profesores de Educación Primaria del contexto educativo de Austin utilizan el error como instrumento para el aprendizaje del español como L2. En dicho contexto educativo, los errores localizados en las producciones escritas no repercuten de forma directa, lo que promueve actitudes positivas en torno a la adquisición de la L2. Estos conceden gran importancia al componente afectivo en la enseñanza-aprendizaje de L2 y, consecuentemente, intentan llevar al aula actividades atractivas y motivadoras en las que la interacción entre profesor y alumno juegue un papel fundamental. 


\begin{abstract}
This research work falls into the scope of Applied Linguistics to L2 teaching and learning. It focuses on the problems of teacher error correction and feedback when conducting written activities in L2 in the educational stage of Primary Education.
\end{abstract}

Attention has been focused on the emotional dimension as it has a major impact on the L2 teaching and learning. This Doctoral Dissertation is shown to be useful and relevant for improving written proficiency in L2 at an early age within the teaching and learning process of a target language.

The final aim of the project is to contribute to L2 teachers' permanent training on error as a result of its strong affective-motivational impact on correction and feedback. For this purpose, we examine the attitudes of L2 teachers in Primary Education in relation to error, correction and feedback regarding written productions through the analysis of their knowledge and skills.

The research project is approached from a descriptive perspective, with the application of a correlational analysis in which we study the results obtained by the different informant profiles (within each group) according to years of experience, age, course and number of students. We therefore carry out a qualitative research that gives us a description of the educational contexts involved in the study, while presenting relevant information related to the knowledge, skills and attitudes of the informants. Likewise, we developed a quantitative analysis with the purpose of specifying differences of each group of informants involved in the present research. 
We have established as contexts of inquiry:

- $\quad$ Elementary schools in the city of Valladolid, Castilla y León, Spain.

- $\quad$ Elementary schools in the city of Austin, Texas, United States of America.

The survey sample was made up of teachers working in the field of teaching English or Spanish as L2 in Elementary schools.

We used the observation method and our research tool consisted of a questionnaire designed for this research and made up of 17 items distributed into: single answer questions, multiple choice questions and descriptive-evaluative utterances.

The analysis of data allowed us to validate our main hypothesis: at the declarative level all teachers recognize error as a previous step towards the success of the teaching and learning process. However, in practice, part of these teachers use it as the main element of the evaluation, which generates a negative attitude towards the error on the part of the students.

Through our research we were able to conclude that those teachers who work in the educational context of the city of Valladolid generally use the error as an element of evaluation. As a result, students are afraid to communicate in English because they know that making mistakes will reduce their score and this leads to negative attitudes towards the acquisition of L2. In addition, they show a lack of knowledge about the importance of the emotional component in the L2 classroom in general, as well as the impact it may have on the student's written productions. 
Furthermore, Primary Education teachers in Austin use error as an instrument for learning Spanish as L2. In this educational context, errors located in written productions do not have a direct impact, so no points are subtracted from the final score. This promotes positive attitudes towards the acquisition of L2. These teachers emphasize the affective component in the L2 teaching and learning and, consequently, they try to include attractive and motivating activities in the classroom where teacher and student interaction plays a major role. 


\section{PRESENTACIÓN}





\section{PRESENTACIÓN}

El presente trabajo titulado La valoración del error por parte del profesor de Educación Primaria en las producciones escritas de alumnos de segundas lenguas ha sido realizado dentro del marco del Programa de Doctorado de Español: Lingüística, Literatura y Comunicación de la Facultad de Filosofía y Letras. Constituye el trabajo final de investigación para acceder al Grado Académico de Doctora por la Universidad de Valladolid y se ha realizado bajo la dirección de la Dra. Da . Teresa Solias Arís.

Se ha llevado a cabo gracias a una licencia por estudios y otras actividades de interés para el sistema educativo en el ámbito de las enseñanzas no universitarias modalidad 1: licencias para finalizar estudios de carácter académico conducentes a la obtención de una titulación universitaria oficial de graduado o equivalente, o para realizar estudios para la obtención del título oficial de doctorado o máster universitario convocadas por la ORDEN EDU/332/2017, de 5 de mayo retribuida por la Consejería de Educación de la Junta de Castilla y León, curso escolar 2017/2018.

Los ámbitos científicos en los que se encuentra delimitado son la adquisición de segundas lenguas (ASL) y la enseñanza-aprendizaje de L2. El tema surge a partir de mis necesidades docentes como profesora de inglés y de español como segunda lengua en distintas instituciones de ámbito público españolas y extranjeras.

Los inicios de esta investigación se remontan a mi actividad docente como profesora visitante en los colegios Goodman y Rosa Parks Elementary School inscritos dentro del distrito 
escolar Fort Bend ISD en el estado de Texas, Estados Unidos de América durante los cursos escolares 2006-2009. Mi experiencia en años sucesivos como profesora de inglés como L2 y como profesora asociada de futuros maestros en la Universidad de Valladolid me lanzó hacia una profundización en mi observación sobre la conceptualización del error, y me impulsó hacia un deseo de formación en el tema que desembocó en el presente programa de doctorado. En este sentido, mis años de experiencia docente han suscitado la elección del tema de la presente Tesis Doctoral.

Las fuentes de conocimiento que se han tomado como referencia para la elaboración del trabajo han sido, por un lado, la bibliografía consultada, por otro, mi experiencia como docente en distintos ámbitos académicos y, por último, el trabajo de campo realizado en los dos contextos educativos que forman parte de la investigación. Dicho trabajo se llevó a cabo a través del uso de un cuestionario, instrumento diseñado para la presente investigación.

Para el desarrollo de la presente Tesis Doctoral, hemos contado con todo tipo de recursos técnicos y humanos recibidos por parte de la Universidad de Valladolid como centro de realización del trabajo de investigación. Además, he tenido la oportunidad de contar con otras experiencias investigadoras que se han llevado a cabo en dos instituciones educativas extranjeras: University of Texas at Austin, situada en la ciudad de Austin, Texas (Estados Unidos de América) y Spiru Haret University, ubicada en Bucarest (Rumanía). Se trata de dos contextos de investigación externos a los que he tenido acceso gracias a dos Ayudas de estancias breves en el desarrollo de Tesis Doctorales recibidas en sendas convocatorias (2015 y 2016) por parte de la Universidad de Valladolid. 
Durante mi primera estancia investigadora, tuve ocasión de documentarme en el centro académico de la Universidad de Texas donde se me permitió el acceso a bases de datos y se puso a mi disposición todos los recursos materiales y humanos necesarios para recoger información. Además, los profesores del Departamento de Español y Portugués y del Departamento UTeach-Liberal Arts fueron el nexo de unión con los profesores de Educación Primaria que permitieron mi observación en sus aulas y respondieron a mis cuestionarios.

La segunda estancia de investigación doctoral realizada en el Departamento de Filología de la Universidad Spiru Haret de Bucarest no solo me aportó el acceso a una gran experiencia cultural académica por haberse desarrollado en el contexto de una institución de enseñanza superior europea, sino que, además, me ofreció unas profundas satisfacciones intelectuales gracias al proceso de escritura llevado a cabo a lo largo de dicho periodo. La presente estancia posibilitó, gracias al acceso a los recursos bibliográficos proporcionados por la institución de acogida, una revisión atenta del borrador de la Tesis.

El error, entendido por Galisson y Coste (1982, p. 216) como "le role de révélateur des points faibles", se percibe como herramienta imprescindible en la clase de segundas lenguas (L2). Esta situación privilegiada que se le concede al error como "outil pour enseigner" (Constantinescu, 2011, p. 84) nos conduce a plantear la necesidad de una formación adecuada por parte del profesor en relación al error y a su corrección.

En la presente Tesis Doctoral proponemos indagar sobre la valoración del error entendida como la posición que toma el profesor de Educación Primaria ante este y el aprovechamiento y/o posible integración dentro del proceso de enseñanza-aprendizaje de L2. A partir de un estudio comparativo de los datos recogidos en dos contextos educativos: centros 
de Educación Primaria emplazados en la ciudad de Valladolid y centros de Educación Primaria ubicados en la ciudad de Austin, intentaremos examinar las actitudes de los profesores como un componente que, junto con los conocimientos y la aptitud, forman parte del concepto de competencia del profesor en torno al error a la corrección de errores y a la retroalimentación o feedback ${ }^{1}$.

\footnotetext{
${ }^{1}$ En la literatura de especialidad circulan los términos retroalimentación y feedback. En la presente Tesis Doctoral hemos optado por el uso del anglicismo feedback como sinónimo de retroalimentación tal y como aparece precisado en el Diccionario de términos clave de Enseñanza del Español como Lengua Extranjera (ELE) (19972017) del Centro Virtual Cervantes (CVC) en su edición electrónica. Adoptamos este neologismo inglés y no su correspondiente español por tratarse de un término que circula y es ampliamente utilizado tanto por didactas de la lengua como por lingüistas.
} 


\section{INTRODUCCIÓN}





\section{INTRODUCCIÓN}

\section{Justificación de la investigación}

En los últimos años, los conceptos de error, corrección y feedback han sido objeto de atención de numerosos estudios y teorías de enseñanza-aprendizaje y adquisición de la lengua, en general, y de la L2, en nuestro caso particular. El concepto del error, relacionado con el de corrección y feedback, forma parte de la toma de decisiones que el profesor adopta en cada uno de los Actos Profesionales Docentes (APD) (Guillén Díaz \& Castro Prieto, 1998; Roy, 1991), a saber: planificación, intervención y evaluación.

La concepción tradicional sobre el error ha sido negativa, aunque los más recientes enfoques han determinado a lingüistas y a especialistas en adquisición de segundas lenguas a considerar el error como algo positivo, algo que se tiene que valorar como estadio natural en el proceso de adquisición lingüística a pesar de que existen voces que apoyan la idea de que la corrección y el feedback no tienen tanta incidencia en el aprendizaje de lenguas (Truscott, 2007). Se han llevado a cabo numerosos estudios empíricos basados en recoger textos corregidos con sus correspondientes marcas y comentarios escritos por el profesor. Dichos estudios, proponen instrumentos y criterios para corregir los errores a partir de dicho análisis, pero como destacaba Cassany (1993) "no aportan información sobre cómo ayudar directamente al alumno en la perspectiva de «enmendar sus errores»"(p. 12). 
Dadas estas observaciones y orientaciones teórico-prácticas reflejadas en numerosos trabajos de investigación presentados por varios profesionales de la Lingüística aplicada se impone la necesidad de que los profesores manifiesten una actitud positiva y de confianza ante la presencia del error. O, según encontramos expresado en García-Heras Muñoz (2004), desarrollar una actitud de innovación y experimentación al exponer a los alumnos ante una actividad de expresión escrita en una nueva lengua.

En el presente trabajo nos aproximamos a la enseñanza-aprendizaje de L2, disciplina de amplio alcance que se encuentra dentro de la Lingüística aplicada y que abarca varios ámbitos, entre ellos la Didáctica de las lenguas (Alexopoulou, 2012).

\section{Problemática de la investigación articulada en interrogantes}

La presente Tesis Doctoral pretende dar cuenta de las actitudes de los profesores de Educación Primaria ante la presencia de los errores en las producciones escritas de los alumnos de L2 — desde la perspectiva de la corrección y el feedback como complemento a la corrección. Partimos de la propia experiencia profesional docente y de la concienciación de una situación educativa en la que observamos determinados desajustes.

La manifestación de actitudes positivas hacia el error se revela como un elemento constante en la enseñanza-aprendizaje de L2, especialmente en la etapa educativa de Educación Primaria. Sin embargo, encontramos que esta manifestación no siempre se corresponde con la realidad de 
las aulas, por lo que se hace patente la necesidad de que se realicen estudios que indaguen en las actitudes de los profesores ante el error, su corrección y el feedback. La falta de estudios empíricos hará que aquellos profesores de un determinado contexto educativo que no tengan la opción de llevar a cabo un programa de intercambio en el que se les exponga ante diferentes tipos de metodologías desarrolladas en otros países desconocerán otros planteamientos didácticos. En definitiva, quedarán anclados y tributarios a lo ya conocido y experimentado, a lo propio.

En la formulación de nuestro problema de investigación, partimos del planteamiento de García-Heras Muñoz (2004) por cuanto que el tipo de actitud manifestada por los profesores ante el error está directamente relacionada con sus conocimientos y sus aptitudes, es decir, determinada, en primer lugar, por su formación didáctica. Unido a esto, destacamos que sus actitudes son deudoras de un contexto educativo, unos patrones socio-culturales y unas restricciones curriculares. Asimismo, esperamos poder aportar una explicación y/o posible solución al problema planteado. Consideramos que existe una gran diferencia entre la realidad de la práctica en el aula y el nivel declarativo de los docentes con respecto a la actitud de los profesores ante la presencia de errores en las producciones escritas de los alumnos de L2. Generalmente, los profesores de L2 consideran la presencia de errores en las producciones escritas de sus alumnos como un "paso necesario para que el proceso de enseñanza aprendizaje se lleve a cabo con éxito" (García-Heras Muñoz, 2004, p.57). Sin embargo, no faltan las voces que apoyan la idea expresada por la misma autora respecto a que "en la práctica la realidad es bastante diferente" (p. 57). Desde este punto de vista, los distintos estudios llevados a cabo en torno a esta consideración concluyen que, a pesar de la importancia de mostrar actitudes positivas en torno al error, estas no siempre se manifiestan en el aula como consecuencia, según la mencionada autora, de "las exigencias de los currículos y 
de las pruebas de evaluación” (García-Heras Muñoz, 2004, p. 57) que, en ocasiones, no permiten al profesor llevar a cabo un acercamiento adecuado al error, a la corrección y al feedback.

Desde esta consideración formulamos nuestra hipótesis de investigación desde la perspectiva de que todos los profesores de L2 de Educación Primaria, independientemente del contexto educativo en el que se encuentren inmersos, vinculan el error con un síntoma de aprendizaje y, consecuentemente, lo reconocen como parte integrante del proceso de enseñanzaaprendizaje de una L2. De acuerdo con esto, todos los profesores presentan, a nivel declarativo, actitudes positivas en torno a la presencia del error en las producciones escritas de los alumnos de L2. Dichas actitudes positivas se revelan como "actitudes simuladas" puesto que no siempre se manifiestan en las prácticas de corrección. Asimismo, todos los profesores consideran el componente afectivo como parte fundamental del proceso de corrección y de dotación de feedback y, a nivel declarativo, defienden la idea de aportar feedback oral individual. Sin embargo, en la práctica, la corrección no siempre aparece acompañada de un feedback significativo ni adaptado a las necesidades educativas del alumno.

En virtud de todas estas afirmaciones, justificamos la investigación llevada a cabo y tras formular nuestra hipótesis de investigación, nos proponemos, a través del presente estudio, obtener información que pueda dar respuesta a las preguntas de investigación planteadas en torno a los elementos o rasgos específicos para cada uno de los dos contextos educativos analizados, a saber:

- ¿En qué medida la formación teórico-práctica de los profesores influye en la manifestación de unas actitudes positivas hacia el error? 
- ¿Qué elementos comunes se pueden identificar en los dos contextos educativos analizados?

- ¿En qué medida influye la formación del profesorado en las nuevas teorías de adquisición de L2 en la enseñanza-aprendizaje de L2?

- ¿En qué medida las políticas educativas respecto a la enseñanza-aprendizaje de L2 y a la corrección influyen en el fomento de unas actitudes positivas?

- ¿A qué tipo de modalidad de corrección adaptada a las necesidades educativas del alumno se recurre y en qué medida se concede atención al feedback que acompaña a la corrección?

- ¿En qué medida los profesores se muestran interesados en que el proceso de producción escrita (unido a la corrección y a la dotación de feedback) se convierta en un trabajo cooperativo entre profesor y alumno o alumnos con el propósito de fomentar las relaciones interpersonales en el aula de L2?

- ¿De qué forma determinados factores como la edad, los años de experiencia, el curso o nivel educativo en el que se ejerce la actividad docente y el número de alumnos en el aula inciden en la actitud hacia el error, la evaluación y el feedback?

\section{Del objeto de estudio a los objetivos de la investigación}

Consideramos que en los contextos de enseñanza-aprendizaje de L2 de las aulas de Educación Primaria existen situaciones en las que se concede una especial relevancia a la corrección consciente de forma masiva, señalando los errores, sin haber realizado previamente una evaluación de diagnóstico sobre las necesidades y la forma de corrección y sin seleccionar los tipos 
de error que deben ser marcados para llamar la atención del alumno. En relación a esto, encontramos actitudes orientadas a la obtención de una nota numérica que califique y valore las producciones escritas de los alumnos. Adoptamos la idea de Ancker (2000) por cuanto que, una predisposición a marcar todos los errores en las producciones escritas revierte en los alumnos en forma de actitudes negativas y reduce su participación activa y su entusiasmo por aprender a expresarse en una L2.

El error está íntimamente relacionado con la lengua objeto de enseñanza-aprendizaje y con el agente-profesor que gestiona el proceso de corrección de errores y el feedback que lo acompaña. Recurrimos al término de profesor tal y como señala d'Aquino (2016) como docente que desarrolla su actividad didáctica en un contexto educativo formal. Entre sus responsabilidades se incluye la de transmitir al alumno la importancia que tiene el aprendizaje de la lengua como vía de comunicación entre las personas, a través de la cual expresamos "conceptos, pero también vivencias, estados anímicos y deseos", puesto que, mediante su uso "se nos ofrecen y ofrecemos todo tipo de mensajes" (Ministerio de Educación, Cultura y Deporte [MECD], 2011, Introducción, 1). Desde esta consideración, se impone la necesidad de que sea este quien transmita a los alumnos los beneficios de contar con un buen dominio tanto de su lengua materna como de otras lenguas. Desde un punto de vista didáctico, el alumno será instado a trabajar su producción escrita de una manera organizada, utilizando un vocabulario rico y matizado ya que, "quien escribe de forma ordenada, con corrección ortográfica y con pulcritud, proyectará siempre una imagen positiva de sí mismo ante los demás” (MECD, 2011, Introducción, 2). En el documento lanzado en 2011, por la Secretaría de Estado de Educación y Formación Profesional del Ministerio de Educación, se pone de manifiesto que, los alumnos, especialmente durante la etapa de Educación Primaria, 
“deberán ir mejorando poco a poco en la redacción de textos breves, coherentes y bien organizados” (MECD, 2011, Introducción, 3). En virtud de ello, el profesor deberá solicitar al alumno que produzca una amplia variedad de textos escritos siempre relacionados con temas cercanos a sus intereses particulares, con el objetivo de que se lleve a cabo un aprendizaje significativo.

En una sociedad marcada por el auge evidente de las Nuevas Tecnologías de la Información y de la Comunicación (NTIC), en la que "la publicidad y la informática han modificado sustancialmente los cánones gráficos y la tecnología de la escritura” (Viñao Frago, 2002, p. 358) se impone conceder una especial atención a la expresión escrita de los alumnos de L2. El uso de redes sociales, programas, y aplicaciones informáticas que hemos incluido en nuestra vida diaria, nos obliga a comunicarnos constantemente a través de textos escritos los cuales, no necesitan ser textos completos y pulidos. No obstante, se impone que estos cumplan una función comunicativa. Es obvio que, en los mensajes de texto utilizados en chats y redes sociales se toleran determinados errores (como, por ejemplo, los de tipo ortográfico o de puntuación), pero, por otro lado, existen ciertos tipos que pueden llevar a confusiones y a una falta de comunicación. Entre estos, cabe mencionar el ejemplo de errores léxicos, gramaticales, pragmáticos y culturales, entre otros.

Podemos decir que, a pesar de la omnipresencia de la NTIC en nuestra sociedad actual todavía se demanda un tipo de escritura comprensible y legible tanto para el emisor como para el receptor o receptores. Consecuentemente, se impone que el profesor siempre procure introducir ejercicios que motiven al alumno con el propósito de que este mantenga una actitud positiva hacia el aprendizaje de la L2. Para ello, deberá recurrir a metodologías que favorezcan una actitud 
positiva hacia la lengua y hacia la diversidad lingüística, fomentar el placer por la lectura de textos y hacer ver al alumno la importancia de la interacción oral y escrita en una L2. En el aula de lengua en general y en el de L2, en nuestro caso particular, se impone como necesidad desarrollar la expresión escrita como destreza. Toda producción escrita, especialmente en una L2, conlleva implícitamente la idea de cometer errores ya que, a la hora de redactar, el alumno recurre a la interlengua $^{2}$ en su aprendizaje de L2.

Nos posicionamos en la línea de Cassany (1993), quien situaba la corrección como parte integrante de la práctica global de la expresión escrita en el aula. En definitiva, detrás de toda evaluación de una producción escrita hay un largo proceso de escritura en el que se incluye la elaboración por parte del alumno de diferentes borradores, la corrección de errores y la aplicación del feedback correctivo. Identificamos, por tanto, la corrección de errores como parte del proceso de evaluación de las producciones de textos escritos en una segunda lengua.

Por consiguiente, el error, como concepto, se revela como un elemento para la planificación en el aula ya que, en función de los errores detectados en las producciones escritas de los alumnos planificaremos las futuras clases con la intención de que estos no sean fosilizados. Los errores serán primero detectados, luego corregidos y, por último, reintegrados en el proceso de enseñanzaaprendizaje. Hay que mencionar, además, que el error debe estar presente en la intervención (como instrumento de aprendizaje) y también en la evaluación (como instrumento de diagnóstico e indicador del nivel o grado del aprendizaje del alumno que, una vez, identificado deberá ser integrado en el proceso de enseñanza-aprendizaje).

\footnotetext{
${ }^{2}$ El concepto de interlengua, propuesto por primera vez por Corder (1967) ha adoptado varias denominaciones, entre ellas la de "sistema transitorio" (Núñez-Méndez, 2001, p. 133).
} 
Junto con el error, el concepto de "error correction" (Durán, 2011, p. 62) es "one of the most controversial topics in the area of second language teaching" puesto que "it is generally considered to be a highly personal and complex issue" (p. 62). Y, a pesar de su importancia por representar, en palabras del mismo autor, "a major part of language teaching” (Burt, 1975, p. 53) no se le ha valorado de una manera justa. La corrección de errores no ha encontrado su lugar ni en la formación del profesorado ni en los libros de texto según deja constancia Burt (1985) al afirmar que "virtually nothing is said in textbook on how to deal with errors - except that they should be corrected" (p. 53).

\section{Aspectos metodológicos y contexto de investigación}

Optamos por un estudio descriptivo, con la aplicación de un análisis comparativo que explica los diferentes resultados en torno al tipo de conocimientos, aptitudes y actitud manifestados por los sujetos implicados en la investigación.

Delimitamos como contextos de indagación:

- contexto educativo de la ciudad de Valladolid (Castilla y León, España) en el que desarrollan su actividad profesores de inglés como L2 en centros educativos de Educación Primaria. 
- contexto educativo de la ciudad de Austin (Texas, Estados Unidos de América) en el que desarrollan su actividad profesores de español como L2 en centros educativos de Educación Primaria.

Acorde al objetivo general y a los objetivos específicos planteados nos situamos en dos contextos de educación formal de enseñanza de segundas lenguas impartidas en instituciones de enseñanza reglada de Educación Primaria: el contexto español, en el que se incluye un número determinado de centros escolares de la ciudad de Valladolid y el contexto norteamericano, representado por varios centros ubicados en la ciudad de Austin. Nos situamos ante dos contextos educativos que marcan el llamado "caso espejo" entendido esto en el sentido de representar contextos simétricos: profesores nativos de español que enseñan inglés como L2 en el sistema educativo de la comunidad de Castilla y León (concretamente en centros de la ciudad de Valladolid) y profesores nativos de inglés que enseñan español como L2 en la ciudad de Austin, estado de Texas.

Para la recogida de datos diseñamos un cuestionario adaptado a las necesidades investigadoras. Dicho instrumento de investigación se revela como uno de los más utilizados para evaluar determinados aspectos relacionados con la educación en general y la enseñanzaaprendizaje de lenguas, en particular. El análisis estadístico nos ofrece la posibilidad de extraer una serie de conclusiones de forma simple y rigurosa.

El cuestionario está organizado en 17 ítems distribuidos en: preguntas de respuesta única, preguntas de opción múltiple y enunciados descriptivo-evaluativos en los que utilizamos la Escala de Likert proponiendo cinco opciones de respuesta: mucho, bastante, poco, muy poco y nada, 
siguiendo las sugerencias de Sáez López (2017). Dicho cuestionario fue adaptado a los dos contextos educativos que forman parte de la investigación. A partir de este cuestionario se crearon las dos versiones (Cuestionario I y Cuestionario II) que se utilizaron para cada uno de los dos contextos y que se pueden encontrar en el Anexo I y en el Anexo II respectivamente.

Las dos versiones del cuestionario contienen 17 ítems idénticos y opciones de respuesta acordes a nuestro propósito investigador de llevar a cabo un estudio comparativo de los resultados del análisis de datos. Los datos obtenidos se presentarán en porcentajes, los cuales, se mostrarán de forma exacta (con decimales) en las tablas y con números enteros en los gráficos que serán el resultado de un redondeo de los anteriores. Así pues, en el análisis de los datos, haremos referencia a números decimales y a números enteros de forma indistinta, sabiendo que estos números enteros son el resultado de un redondeo, es decir, porcentajes aproximados.

También decidimos incluir una opción alternativa que aparece bajo el título de “otros”. Los informantes que lo consideren necesario podrán marcar dicha opción y añadir la información que estimen conveniente contribuyendo así de forma muy significativa a nuestro trabajo de investigación.

La información añadida que los informantes decidan incluir aparecerá en las tablas y gráficos del análisis como respuestas agrupadas bajo el formato "otros" y separadas del resto de opciones propuestas. La idea de mostrar y, posteriormente, analizar la información que los profesores han decidido añadir viene determinada por el gran valor que, en nuestra opinión, añadirá a nuestra investigación. Sin embargo, no podemos situar dichas aportaciones al mismo nivel que 
las opciones originales puesto que dichos informantes no contaban con ellas en el momento de cumplimentar el cuestionario. De haber sido así, podrían haber sido seleccionadas por un mayor número de profesores.

El contenido de las dos versiones no difiere a excepción del ítem número 3 en el que se pide a los informantes que señalen el curso en el que imparten sus clases de L2. En ambas versiones proponemos enunciados idénticos pero las opciones de respuesta varían en función del contexto educativo. Para el Cuestionario I, dirigido a los informantes de la ciudad de Valladolid, las opciones de respuesta son: $1^{\circ}, 2^{\circ}, 3^{\circ}, 4^{\circ}, 5^{\circ}$ o $6^{\circ}$ curso por ser estos los niveles o cursos educativos que comprende la etapa de Educación Primaria en Castilla y León. Para el Cuestionario II, destinado a los informantes de Austin, las opciones de respuesta son: $1^{\circ}, 2^{\circ}, 3^{\circ}, 4^{\circ}$ o $5^{\circ}$ siendo estos los niveles impartidos en los centros de Educación Primaria a los que hemos tenido acceso ${ }^{3}$.

El cuestionario consta de una serie de ítems centrales y otros que sirven para completar la información que nos proporcionan dichos ítems centrales. Se distribuye en dos partes diferenciadas. La primera comprende los ítems 1 al 4 confeccionados con el fin de conseguir información acerca del perfil del informante. La segunda parte comprende los ítems 5 al 17 y fue diseñada con la intención de provocar en los informantes una reflexión acerca del concepto que tienen sobre el error, la corrección y el feedback en las producciones escritas en L2 de sus alumnos. Esta segunda parte está organizada en torno a los tres componentes competenciales de nuestros informantes en relación al error, a la corrección y al feedback: los conocimientos, las aptitudes y

\footnotetext{
${ }^{3}$ Los centros educativos en algunos estados como es el de Texas no presentan la misma configuración en cuanto a distribución de los cursos o niveles educativos. Así es como, algunos centros de Educación Primaria incluyen los cursos de $1^{\circ}$ a $5^{\circ}$ otros ofrecen la posibilidad de cursar $1^{\circ}$ a $6^{\circ}$ de Primaria, etc. Los centros a los que tuvimos acceso en la presente muestra ofertan los cursos $1^{\circ}-5^{\circ}$ de Primaria.
} 
las actitudes. Planeamos para el tratamiento de los datos un análisis cualitativo, en la perspectiva de realizar una descripción de los contextos educativos implicados en el presente estudio, así como revelar situaciones y explicar sucesos relacionados con los conocimientos, las aptitudes y las actitudes de los informantes. A la vez, desarrollamos un tratamiento cuantitativo y, en este sentido, optamos por llevar a cabo un análisis correlacional a partir de una matriz de datos, que se muestran en tablas y gráficos generados por el programa SPSS. La finalidad última de dicho análisis es especificar los matices de cada grupo de informantes involucrados en la presente investigación correlacionando las respuestas obtenidas de los informantes de los dos contextos educativos estudiados con las características relativas a su perfil (años de experiencia, edad, curso y número de alumnos).

\section{Métodos de toma de datos y sistema de análisis}

Desde la propia práctica docente, de un proceso de reflexión y en busca de la resolución de problemas a los errores y de la manifestación de las actitudes del profesor de L2 ante estos nos proponemos realizar un estudio comparativo de los datos obtenidos a través del instrumento de investigación utilizado. Para la presente investigación recurrimos a un tratamiento de los datos tanto cualitativo como cuantitativo siguiendo las indicaciones de Sáez López (2017) quien recomendaba el uso de un enfoque complementario o mixto. Para el análisis cuantitativo de los datos recurrimos a una metodología correlacional con el propósito de buscar una relación o asociación entre las variables elegidas. El objeto de estudio es la práctica docente la cual, de acuerdo con Sáez López (2017), “busca la resolución de problemas a través de un proceso de reflexión" (p. 33). Recurrimos a las palabras del mencionado autor por cuanto que esta 
metodología "hace referencia a una intervención reflexiva, evaluadora y formativa en un contexto determinado, sin generalizar los resultados” (Sáez López, 2017, p. 33).

\section{Objetivos}

Nos situamos ante un tipo de investigación descriptiva, comparativa y correlacional cuyo objetivo general es indagar sobre las actitudes del profesorado de L2 ante el error, la corrección y el feedback en las producciones escritas de alumnos de L2 aproximándonos a dos contextos educativos con rasgos identificativos propios. Desde la reflexión sobre la propia práctica docente, somos conscientes de que unas actitudes positivas hacia el error y la corrección pueden llegar a contribuir de manera decisiva en la motivación del alumno y en el rendimiento respecto al aprendizaje de la L2.

Como objetivos específicos, nos proponemos:

1. Identificar la importancia que conceden los profesores al error, a la corrección y al feedback en la perspectiva de desarrollar la destreza de expresión escrita.

2. Dar cuenta de la incidencia de todos estos procesos en la responsabilidad docente respecto a la necesidad de dotar a los profesores de una formación centrada en la importancia del error.

3. Establecer las diferencias y similitudes entre dos sistemas educativos respecto a la corrección de producciones escritas en una lengua extranjera; a saber, el sistema educativo español y el norteamericano. 
A partir de nuestra hipótesis y de las preguntas de investigación formuladas nos proponemos acceder a un conocimiento más profundo sobre determinados aspectos relacionados con la corrección y el feedback correspondientes tanto al modelo educativo en el que nos encontramos inmersos como a otros modelos educativos que puedan inspirarnos en nuestras prácticas docentes con el fin de intentar mejorarlas.

\section{Estructura y organización de la Tesis Doctoral}

El contenido de la presente Tesis se estructura en dos partes precedidas por un Resumen, una Presentación y una Introducción.

La Parte I está dedicada a los fundamentos teórico-conceptuales de la investigación y engloba los Capítulos 1, 2 y 3. En esta damos cuenta del planteamiento teórico y empírico abordado.

El Capítulo 1, Corrección y tratamiento de errores desde la perspectiva del alumno: estado de la cuestión incluye las aclaraciones teórico-conceptuales en torno al error, a la corrección y al feedback y el estado de la cuestión del error desde la óptica del alumno. Además, se indaga en las teorías que giran en torno a las posturas de los alumnos ante el error y, por último, se hace mención 
de las distintas clasificaciones de errores realizadas por distintos autores escogiendo para nuestro ámbito de investigación los errores de léxico, los gramaticales y los pragmático-culturales. El propósito de este capítulo es establecer el contexto teórico y conceptual.

El Capítulo 2, Formación del profesorado de L2: corrección y feedback, incluye distintas consideraciones en torno a la corrección, al tratamiento de errores y al feedback. Justificada la importancia de la corrección de errores, abordamos la formación del profesorado en torno a los tres componentes de la competencia profesional docente: conocimientos, aptitudes y actitudes.

El Capítulo 3, Enseñanza-aprendizaje de L2: matizaciones contextuales, nos acerca al factor social y a las variables que determinan la adquisición lingüística de una L2 en edades tempranas dado que la presente investigación está orientada hacia el tratamiento del error por parte de profesores que llevan a cabo su actividad docente en la etapa de Educación Primaria. Además, se presentan las opciones de corrección lingüística y los factores que influyen de forma decisiva en el proceso de adquisición de una L2 en edades tempranas, a saber: el factor afectivo y el motivacional. Se presentan a continuación las corrientes metodológicas existentes en la enseñanzaaprendizaje de L2 y la evolución del concepto del error poniéndose de manifiesto cuáles son las teorías que justifican y apoyan la necesidad de elección, por parte del profesor de L2 en Educación Primaria, una buena opción de corrección, un adecuado tratamiento del error y un feedback significativo adaptado a las necesidades educativas del alumno. Se insiste en la importancia del proceso de composición escrita en el aula de L2 y se hace alusión a los distintos autores que han abordado las técnicas de producción escrita más utilizadas, las estrategias cognitivas y de 
composición a las que el alumno deberá recurrir para aprender a redactar un texto escrito. Se introducen, por tanto, las técnicas y estrategias que todo profesor debe conocer y aplicar en el aula de L2 puesto que, en la presente investigación, nos proponemos analizar los conocimientos de los profesores (junto con sus aptitudes y actitudes) en torno a estas nuevas teorías de adquisición lingüística y técnicas de composición escrita. El capítulo 3 se cierra con una contextualización de los programas bilingües existentes en cada uno de los dos contextos educativos analizados con el propósito de dar a conocer cuáles son los programas en los que nuestros informantes se encuentran inmersos.

La Parte II está estructurada en seis capítulos (Capítulo 4, 5, 6, 7, 8 y 9) y dedicada a los aspectos metodológicos y técnicos de la investigación.

En el Capítulo 4, Estructura y organización del proceso de investigación, se aborda la configuración estructural de la investigación. En este capítulo se presentan el contexto de investigación y los informantes, realizando una descripción de la muestra intencional. Asimismo, se identifica el instrumento diseñado y concebido para la presente investigación, a saber, un cuestionario. Dentro de esta descripción se presenta la forma en que fue concebido y elaborado este cuestionario, su estructura, las unidades y categorías de análisis y una clasificación de los ítems. A modo de cierre, se presenta la forma de validación del cuestionario.

El Capítulo 5, Perfil del informante, aborda el análisis de datos e interpretación de los resultados respecto al perfil de los informantes. Las variables elegidas dentro del perfil son: edad, años de experiencia, curso o nivel educativo en el que ejerce su actividad docente y número de 
alumnos en el aula. La decisión en torno a la elección de estas variables viene determinada por las preguntas de investigación que formulamos en la presente Introducción. Consideramos que la edad y años de experiencia de los profesores determinarán la aplicación en el aula de las nuevas teorías de corrección en la adquisición de L2. Asimismo, el curso o nivel educativo y el número de alumnos con los que el profesor cuente en el aula han de estar íntimamente relacionado con la elección por parte del profesor de un tipo de corrección de errores y una dotación de feedback específico.

El Capítulo 6, Componente competencial I: conocimientos sobre el error, la corrección y el feedback recoge el análisis de datos y la interpretación contrastiva de los resultados respecto a la categoría de análisis: conocimientos.

El Capítulo 7, Componente competencial II: aptitudes en torno al error, a la corrección y al feedback, engloba el análisis de datos y la interpretación contrastiva de los resultados respecto a la categoría de análisis: aptitudes.

El Capítulo 8, “Componente competencial III: actitudes ante el error, la corrección y el feedback aborda el análisis de datos y la interpretación contrastiva de los resultados respecto a la categoría de análisis: actitudes.

La elección de los tres componentes de la competencia profesional docente: conocimientos, aptitudes y actitudes como posibles categorías de análisis está determinada por la creencia de que tanto lo cognitivo, entendido como el conocimiento de los profesores sobre las nuevas teorías de 
adquisición de L2 respecto al tratamiento del error, el estatus del feedback en el aprendizaje y su impacto tanto en la motivación como en el rendimiento del alumno (conocimientos), como la capacidad de aplicar estos conocimientos en el aula (aptitudes) y la valoración o postura que mantiene el profesor respecto al error, la corrección y el feedback (actitudes) son determinantes en el proceso de producción escrita en la enseñanza-aprendizaje de L2.

En el Capítulo 9, Análisis correlacional de las respuestas de los informantes en función de su perfil se presenta un análisis de los resultados obtenidos en la presente investigación en función de las distintas características de los informantes que forman parte de nuestra muestra intencional, a saber: edad, años de experiencia, curso o nivel educativo que imparten en la actualidad y número de alumnos. En dicho análisis, se han cruzado datos y correlacionado las respuestas obtenidas a través del cuestionario con las características del perfil de los informantes.

El trabajo se cierra con un apartado dedicado a las Conclusiones estructuradas en torno a los resultados principales obtenidos, a las principales aportaciones de la investigación, a la verificación de la hipótesis de investigación y a la identificación de las futuras líneas de investigación apoyadas en los resultados obtenidos.

Todo lo expuesto se fundamenta en una Bibliografía de referencia y consulta estructurada en tres partes diferenciadas: Bibliografía general, Fuentes bibliográficas electrónicas y Disposiciones oficiales y otros documentos institucionales de referencia. 
Existe un índice de 6 cuadros, 4 figuras, 82 tablas y 82 gráficos insertados en el presente trabajo de investigación. Los Cuadros 1 y 2 son tomados de otras fuentes. Por el contrario, los Cuadros 3-6 son de elaboración propia y se incluyen con el propósito de clasificar los ítems del cuestionario. Las Figuras 1-4 están tomadas de otras fuentes e incluidas en el presente documento de Tesis Doctoral por ser representativas y por ilustrar de forma gráfica determinados aspectos relacionados con el presente trabajo. En el índice de tablas encontramos, por un lado, las Tablas 1-34 que muestran los resultados de las respuestas de los informantes (en forma de porcentajes) a los distintos ítems del cuestionario. Por otro, un conjunto de tablas de contingencia y pruebas chicuadrado (Tablas 35-82) que muestran los resultados del análisis correlacional (desarrollado en el Capítulo 9). En el índice de gráficos se incluyen los Gráficos 1-34 en forma de diagrama circular o diagrama de barras que representan los resultados de las respuestas de los informantes a los ítems del cuestionario. Además de estos, encontramos un conjunto de gráficos de barras agrupadas (Gráficos 35-82) que representan los resultados del análisis correlacional (Capítulo 9).

El presente documento de Tesis Doctoral se complementa con el apartado dedicado a los Anexos entre los que se encuentran los instrumentos de recogida de datos; a saber: dos versiones del cuestionario concebido y elaborado para la presente investigación (Cuestionario I y Cuestionario II) y las cartas que los acompañan (cartas de presentación y de invitación).

- Anexo I: Cuestionario I. Cuestionario para profesores de Educación Primaria que imparten enseñanzas oficiales de inglés como segunda lengua (L2) en la ciudad de Valladolid, España. 
- Anexo II. Cuestionario II. Cuestionario para profesores de Educación Primaria que imparten enseñanzas oficiales de español como segunda lengua (L2) en la ciudad de Austin, Estados Unidos de América.

- Anexo III: Carta de Presentación para profesores que imparten enseñanzas de inglés como segunda lengua en la ciudad de Valladolid, España. Modalidad de entrega del cuestionario: en mano.

- Anexo IV: Carta de Presentación para profesores que imparten enseñanzas de español como segunda lengua en la ciudad de Austin, Estados Unidos de América.

- Anexo V: Carta de Invitación para profesores que imparten enseñanzas de inglés como segunda lengua en la ciudad de Valladolid, España. Modalidad de entrega de los cuestionarios: enlace que da acceso al cuestionario online.

- Anexo VI: Carta de Invitación para profesores que imparten enseñanzas de español como segunda lengua en la ciudad de Austin, Estados Unidos de América. Modalidad de entrega de los cuestionarios: enlace que da acceso al cuestionario online.

A través de la presente investigación nos proponemos dar cuenta de los componentes de la competencia profesional docente: conocimientos, aptitudes y actitudes en torno al error desde la consideración del fuerte impacto afectivo-motivacional que tienen en la corrección y el feedback. De forma particular, nos proponemos indagar en las actitudes de los profesores de L2 que ejercen su docencia en dos contextos educativos simétricos con la intención de contribuir a la mejora de la metodología de enseñanza de segundas lenguas. 

PARTE I: FUNDAMENTOS

TEÓRICO-CONCEPTUALES

DE LA INVESTIGACIÓN 



\section{Capítulo 1. CORRECCIÓN Y TRATAMIENTO DE ERRORES DESDE LA PERSPECTIVA DEL ALUMNO: ESTADO DE LA CUESTIÓN}

1.1. Algunas aclaraciones teórico-conceptuales en torno al error, a la corrección y al feedback

1.2. Causas y criterios en torno a la aparición del error

1.3. Hacia una tipología de errores en las producciones escritas en L2 


\subsection{Algunas aclaraciones teórico-conceptuales en torno al error, a la corrección y alfeedback}

El error y su tratamiento han jugado un papel esencial en la enseñanza-aprendizaje de L2 ${ }^{4}$. Como ya se ha podido dar cuenta en la Introducción del presente trabajo, la concepción negativa que se ha tenido tradicionalmente del error se ha ido abandonando por una positiva pasando este a ser considerado un indicador de la situación de interlengua del alumno.

Tal y como encontramos en Vázquez (2009), los profesionales de la enseñanza, definían los errores como "rutinas" (p. 114) presentes en la enseñanza-aprendizaje de L2. Según la mencionada autora, para superar los errores, "es indispensable enfocar el aprendizaje como actividad consciente a partir de la adolescencia" (Vázquez, 2009, p. 114), y desde este punto de vista, la autora situaba el error y su corrección dentro del proceso de aprendizaje consciente de una L2 y al respecto consideraba que "aprender una L2 significa algo más que aprender un código: significa desarrollar estrategias para aprender muchas lenguas" (Vázquez, 2009, p. 114).

Hablar de aprendizaje nos lleva a acercarnos al concepto de adquisición ${ }^{5}$ que conlleva una serie de matizaciones conceptuales extraídas de distintos campos de investigación. Al respecto,

\footnotetext{
${ }^{4}$ Situándonos en la perspectiva de Stern (1983), decidimos utilizar en el presente trabajo de investigación los términos de lengua primera o L1 como sinónimo de lengua materna (LM) y el término de segunda lengua o L2 como sinónimo de lengua extranjera (LE). Recurrimos, por tanto, al uso alternativo de ambos términos: segunda lengua (L2) o lengua extranjera (LE) por ser considerados sinónimos tal y como aclara el mencionado autor. Reconocemos las diferencias entre estudiar una lengua en un contexto donde esta funciona como lengua nativa (L2) y estudiarla en un contexto o país donde no se habla esa lengua (LE). Sin embargo, de acuerdo con Larsen-Freeman y Long (1992), los investigadores deben explicar la ASL tanto si se trata de una L2 como si es una LE, por lo que, en el presente trabajo, decidimos utilizar la acepción de L1 para referirnos a la lengua materna y la de L2 para referirnos a la lengua de adquisición o de enseñanza-aprendizaje.

${ }^{5}$ Recurrimos al uso alternativo de los conceptos de adquisición y de enseñanza-aprendizaje, situándonos en la línea de Mayor (1994), respecto a que "la enseñanza o instrucción en una segunda lengua se encuentra estrechamente relacionada con la adquisición o el aprendizaje de dicha lengua" (p. 23). En este sentido, reconociendo las diferencias
} 
Vez, Guillén y Alario (2002), desde la Didáctica de la LE, destacaban que el propio "acceso al conocimiento de las LEs" (p. 154) supone abordar términos que resultan "ambiguos e incluso sinónimos para algunos autores que consideran el conocimiento lingüístico como el conjunto (complejo) de aspectos del lenguaje que el alumno debe dominar" (Vez et al., 2002, p. 154).

Dada la diversidad de situaciones en las que las lenguas y, en nuestro caso particular, las segundas lenguas tienen lugar, los dos conceptos: adquisición y enseñanza-aprendizaje de una L2 han sido objeto de interés científico tanto por lingüistas como por profesionales de la enseñanza. Corder (1967, 1981) ponía de manifiesto la idea de que los estudiantes de L2 adoptaban, durante su proceso de aprendizaje, el mismo tipo de estrategias que se toman durante el proceso de adquisición de la primera lengua. En este sentido, Corder (1981) hacía hincapié en la idea de que "some at least of the strategies adopted by the learner of a second language are substantially the same as those by which a first language is acquired." (Corder, 1981, p. 8).

A su vez, Mayor (1994) destacaba la estrecha relación existente entre los conceptos de adquisición de una segunda lengua con los de adquisición y aprendizaje de una L1 a lo que añadía la necesidad de contrastar ambos conceptos para, posteriormente, distinguirlos o considerarlos equivalentes.

Por su parte, autores como Fernández (1997); Muñoz Liceras (1992) y Vez et al. (2002) junto con muchos otros se situaban en la perspectiva de Krashen (1985) quien definió el concepto

que se han establecido entre ambos, respecto a la asociación del primero con un proceso "natural" que se lleva a cabo fuera de la clase y el segundo como un proceso que tiene lugar en el contexto aula, coincidimos con la mayoría de los investigadores en el presente campo, los cuales, utilizan ambos términos de manera indistinta. 
de aprendizaje como "conscious process for developing ability in language" (p. 102) mientras que el de adquisición aparece como "subconscious process for developing ability in language" (p. 100). Así pues, para el contexto educativo español, Fernández (1997, p. 37) estableció la misma diferencia entre las dos modalidades que existen a la hora de desarrollar una competencia lingüística, a saber, aprendizaje como "proceso consciente" mediante el cual, un hablante adquiere su L2, así como el "conocimiento sobre el lenguaje” y, adquisición como "proceso inconsciente" similar al que usan los niños en su L1.

Es evidente que existen una serie de rasgos diferenciadores que marcan los dos conceptos arriba mencionados, en lo que respecta al aprendizaje, este se ha manifestado como un proceso consciente y explícito, orientado más hacia lo formal, unido a un contexto institucional y en el que “el acercamiento a la nueva lengua se realice por vía de reflexión” (Fernández, 1997, p. 38). En contraste con lo anterior, en el proceso de adquisición, "se elaboran conocimientos implícitos" (p. 38) y, además, “está orientado más hacia el significado que hacia la forma” (Fernández, 1997, p. 38). La autora adopta las palabras de Krashen insistiendo en que "lo aprendido no se transforma en adquirido, aunque pueda controlar la producción siempre que se tenga tiempo de reflexionar" (Fernández, 1997, p. 38).

Por su parte, Vez et al. (2002) relacionan la adquisición con lo espontáneo y con el "uso real de esa lengua, en contexto natural, fruto de la experiencia y consistente en la capacidad para interpretar y producir un discurso independientemente de la conciencia lingüística del locutor” (Vez et al., 2002, p. 156). Además, Vez et al. (2002) manifestaban que la diferencia entre adquisición y aprendizaje está marcada por una serie de factores entre los cuales mencionan el 
contexto. El aprendizaje se realiza en un entorno formal, escolar mientras que la adquisición se lleva a cabo en un entorno informal o natural puesto que, según indican los citados autores, ambos procesos implican la presencia de factores que corresponden a diferentes planos. Además de la presencia de estos factores, los citados autores ponen de manifiesto que la adquisición supone la presencia subyacente de una serie de motivaciones profundas:

Para insertarse y afirmarse como individuo social, mientras que para el aprendizaje sólo existen motivaciones superficiales (es una materia escolar que hay que aprobar, o forma parte de una promoción profesional, etc.), de las que surgen las barreras manifestadas como inhibiciones, bloqueos, miedo al ridículo, etc. (Vez et al., 2002, p. 157)

Por otra parte, respecto al plano lingüístico, según los mismos autores:

En la adquisición, primero, tiene lugar la utilización de la lengua en el discurso y, después, se accede a la lengua sistema del medio escolar, mientras que en el aprendizaje se accede primero a la lengua en tanto sistema para después pasar a la lengua como discurso. (Vez et al., 2002, p. 157)

En este contexto, definimos enseñanza-aprendizaje de una L2 como el proceso que realizan los alumnos, los cuales ya poseen un determinado nivel de competencia comunicativa en su L1, interesados en poder comunicarse en otra lengua distinta a la primera. Dicho proceso tiene lugar 
en un contexto académico en el que el alumno se ayuda de los conocimientos que ya posee de su propia lengua.

A su vez, entendemos la adquisición de una L2, en términos propuestos por Dulay y Burt (1984) como "the acquisition of another language after having acquired the basics of the first" (p. 95). Y consideramos que este es un proceso que tiene lugar después del período crítico de adquisición de la L1 situando al alumno como un hablante competente de esta.

Volviendo a la "Teoría de Adquisición-Aprendizaje" de Krashen, la corrección de errores se ha de entender como una ayuda al aprendizaje consciente de la L2. Como estudiantes de esa L2, al recibir una corrección de un determinado error, en palabras de Krashen (2013), "we are supposed to change our conscious version of the rule" (p. 1). Podemos afirmar por tanto que la corrección de errores se manifiesta en el aprendizaje consciente y no en el proceso de adquisición de una L2.

Así es como, Krashen (2013) manifiesta, en su "Teoría del Monitor”, que el aprendizaje consciente y, por ende, las reglas gramaticales que aprendemos en una L2, nos sirven solamente para actuar como monitor o corrector. De acuerdo con dicha teoría, en el momento en que se realiza una producción oral en L2, esta es el resultado de una "subconsciously acquired competence" (Krashen, 2013, p. 2) pero, justo antes de producir dicha frase, la inspeccionamos y utilizamos nuestro "consciously learned system" (p. 2) para corregir los posibles errores.

En definitiva, consideramos que el error y su corrección son partes intrínsecas tanto de un proceso de adquisición como de un proceso de aprendizaje de una lengua. 


\subsubsection{Evolución del concepto de error}

Desde que Seneca sentenciase que "errare humanum est", el error ha sido analizado desde una multitud de perspectivas. Tanto desde una perspectiva didáctica como psicológica el error se aprecia como una falta o desviación con respecto a lo que es correcto. Sin embargo, desde una postura puramente psicológica enmarcada en un contexto educativo, Richelle (1998) en el Diccionario Akal de Psicología, lo relaciona con "un juicio evaluativo" (p. 215) por parte del profesor en torno a una producción lingüística del alumno.

El error ha estado presente a lo largo de la historia de la enseñanza-aprendizaje de L2. Tanto lingüistas como profesionales de la Didáctica coinciden en la idea de que la historia del error ha venido marcada por una fuerte controversia hasta en su propia definición. Además de tratarse de una cuestión controvertida (Durán, 2011; Lasagabaster \& Sierra, 2005), ha sido y es un tema de suma importancia para la enseñanza-aprendizaje de L2 (Burt, 1975; Constantinescu, 2011; Corder, 1967, 1981; d'Aquino, 2016; Galisson \& Coste, 1982; Guillén Díaz, 2004; Norrish, 1983 y Vez et al., 2002) por lo que, ya desde el siglo pasado, la figura del profesor ha intentado encontrar un posicionamiento sobre el error y su presencia en el aula.

Las numerosas definiciones aportadas por los profesionales de la Lingüística ponen de manifiesto la falta de una definición unívoca en torno al concepto del error. Asimismo, Corder (1967, 1981); d’Aquino (2016); Dulay, Burt y Krashen (1982) entre muchos otros, hacen una clara 
distinción entre faltas (mistakes) y errores (errors). Esta distinción viene determinada por los conceptos performance (actuación) y competence (competencia) definidos por Chomsky (1975). Aplicados estos términos a las teorías de adquisición de L2, algunos investigadores determinan que los errores de actuación (performance errors), o mistakes, son aquellos producidos por el cansancio o la falta de atención del alumno mientras que los errores de competencia (competence errors) o errors son los ocasionados por el desconocimiento de las reglas de la lengua. Además, d'Aquino (2016) insiste en que precisamente dicha distinción determina un tratamiento diferente. De esta forma, se han realizado numerosas clasificaciones de errores (d'Aquino, 2016), en función de los aspectos lingüísticos, de los aspectos de uso, de las estrategias que implican los errores, de los efectos comunicativos que ocasionan, así como de las causas mismas de su aparición.

Desde esta consideración, autores como Constantinescu (2011); Galisson y Coste (1982) y Pawlak (2014) no establecen distinción alguna entre error y falta. Pawlak (2014), los trata como sinónimos y afirma al respecto que "the terms error and mistake are treated as synonymous in the discussion to follow, with both of them being used to refer to the production of inaccurate forms in learners' oral and written output" (p. 5). Por su parte, Galisson y Coste (1982) hablan de faltas como resultado de un desconocimiento de las reglas de funcionamiento de la lengua o como resultado de un conocimiento inexacto de estas o en palabras de los autores "les fautes tenant à une méconnaissance ou à une connaissance incomplete ou inexacte des règles de la langue” (p. 215). Además, estos afirman que las faltas tienen lugar durante el proceso de adquisición de la lengua materna o durante el aprendizaje de una L2 y que, además, tienen "un caractère systématique (application de règles inadéquates, phénomènes d’interférence, etc.)” (p. 215) que ayuda a detectar las necesidades de aprendizaje del hablante. Dentro del mismo concepto de falta 
sitúan a aquellas que son atribuibles a fallos en la producción de enunciados: "lapsus, défault de prononciation, manque d'organisation, ruptura de construction, etc.” (p. 216) que tienen lugar debido a incidentes de carácter pasajero o temporal y a aquellas faltas originadas por causas patológicas que afectan a los órganos del habla. Como indican los mismos autores, se impone la necesidad de analizar las faltas o errores y los diferentes factores que las producen para, posteriormente, establecer una estrategia de corrección ya que, no es posible dejarnos llevar por primeras impresiones como por ejemplo, un "erreur d'orthographe, loin de résulter d'un défaut d'attention ou d'une ignorance des règles ou de l'usage graphiques peut être provoquée par une perception inexacte des phonèmes ou une mauvaise interprétation sémantique" (Galisson \& Coste, 1982, p. 216).

Entre los numerosos autores que se han ocupado de la categorización del error, recordamos a Norrish (1983) quien establece tres tipos de errores; discriminando, por una parte el "error" definido como "systematic deviation, when a learner has not learnt something and consistently 'gets wrong" " (p. 7), del "mistake" entendido como "inconsistent deviation" (p. 7) y del "lapse" al que presenta como "neither a mistake nor an error and can happen to anyone at any time" (p. 7). Todos estos tipos de errores son resultado de una serie de factores entre los que se encuentran la falta de concentración, cansancio o memoria corta.

Para el contexto didáctico español, Guillén Díaz (2004), definía el error como "una desviación sistemática de las reglas que rigen el funcionamiento de la LE, por efecto de la transferencia lingüística negativa o interferencia” (p. 627). Asimismo, el error se percibe como un 
elemento "inherente" al proceso de aprendizaje y se manifiesta por las faltas que el alumnado comete como muestra de las dificultades en su aprendizaje.

El error, por su presencia e importancia dentro de la enseñanza-aprendizaje, ha sido entendido como un "outil pour enseigner" (Constantinescu, 2011, p. 8), como una "estrategia de aprendizaje" (Durão, 2007, p. 20) o, desde el contexto francés como un "symptôme que 1'apprentissage se fait" (Galisson \& Coste, 1982, p. 216). La presencia del error en la enseñanzaaprendizaje de L2 es tal que se ha llegado a considerar como un fenómeno omnipresente, por lo que, "cometer errores es algo inevitable y, por lo tanto, nada grave y reprochable" (d'Aquino, 2016, p. 7) sino "necesario y útil” (d'Aquino, 2016, p. 7), en definitiva, un medio para aprender. También Serkan Ülgü y Griffiths (2013) destacan la omnipresencia del error en el aula de lenguas e insisten en que hay dos posibilidades en torno a su corrección: "Errors are somehow dealt either by being corrected in a variety of ways or purposefully neglected by the language teacher or the peers" (p. 229) haciendo hincapié en que la corrección, hoy en día, es un proceso que se puede realizar utilizando las NTIC. Más allá de su presencia e importancia, en todo momento se ha planteado la idea de la "utilidad del error" (d'Aquino, 2016, p. 8), idea compartida por Norrish (1983), quien dejaba claro en la introducción de su libro, "Language learners and their errors" que la presencia del error en el aula de L2 es no solo necesaria sino también sumamente útil (d’́Aquino, 2016; Norrish, 1983).

Durante los comienzos de la historia de la enseñanza-aprendizaje de L2 tanto el concepto del error como el propio proceso de corrección han sido entendidos en términos de faltas y/o sanciones que el alumno produce (Agustín Llach, 2011; Durán, 2012; Torijano Pérez, 2004 y Vez 
et al., 2002). Gracias a los nuevos enfoques comunicativos de la enseñanza-aprendizaje, el error ha sido reevaluado llegando a ser "entendido como aquel conocimiento o concepción del alumno que - por su carácter falso o incompleto - dificulta el proceso de aprendizaje y da lugar a hacer faltas" (Vez et al., 2002, p. 255).

El propio concepto del error ha conocido una evolución llegando a ser considerado como parte intrínseca o indisociable (Giovannini, Martín Peris, Rodríguez Castilla \& Simón Blanco, 1996) de la enseñanza-aprendizaje puesto que la propia corrección, en palabras de Constantinescu (2011, p. 84): “n'est plus une sanction mais une aide précieuse à l'apprentissage”. Y no pocas veces desde el área de la enseñanza-aprendizaje de L2 el error ha sido considerado una muestra del progreso del alumno (Dolz, Gagnon, Mosquera \& Sánchez, 2013; Durán, 2011; Ellis, 2008; Fernández, 1997; Giovannini et al.,1996 y Torijano Pérez, 2004).

Desde el contexto rumano, Vasilescu (2009, p. 52) considera los errores como "parte firească a învăţării limbii 6" (p. 52) y “un rezultat firesc al dezvoltării abilităţii comunicative ${ }^{7 " \prime}$ (p. 52) además de que han de estar "tolerate" (p. 52). En virtud de ello, apoya de idea de que “corectarea permanentă un numai că nu este necesară ci este chiar contraproductivă9" (Vasilescu, 2009, p. 52).

\footnotetext{
${ }^{6}$ Traducción del rumano al español "una parte evidente del aprendizaje de una lengua".

${ }^{7}$ Traducción del rumano al español "un resultado evidente del desarrollo de la habilidad comunicativa".

8 Traducción del rumano al español "tolerados".

9 Traducción del rumano al español "la corrección constante no solo que no es necesaria, sino que resulta contraproducente".
} 
Unido al término de error, se encuentra el concepto de interlengua que, como ya hemos comentado previamente, fue utilizado por vez primera por Corder (1967). Este término fue definido por Fernández (1997) como la "lengua propia del aprendiz" (p. 19). Posteriormente, Santos Maldonado (2002) lo definió como "una gramática propia, es decir, un sistema de reglas que pone a prueba cada vez que produce enunciados en dicha LE” (p. 80) y Durão (2007) como "un sistema lingüístico en construcción que está entre una lengua y otra(s)" (p. 23). A su vez, Henderson (1985) afirmaba que, desde la aparición de dicho término, este "has been generally accepted to mean the language learner's use of the Target Language (TL)” (p. 24).

Por su parte, Fernández (1997) planteaba la idea de la interlengua respecto al análisis de errores comentando al respecto que:

El análisis de la IL nace apoyándose en el análisis de errores, pero pronto alarga su campo de observación, ya que en ese «sistema aproximado» existen estructuras diferentes a las de la lengua meta-las formas «erróneas», pero también se producen muchas estructuras correctas de acuerdo con la norma de la nueva lengua. (Fernández, 1997, p. 19)

Pero es Spillner (1991) quien afirmaba que la hipótesis de la interlengua está fundamentada en la idea de que existen varios pasos o etapas por los que el aprendiz debe atravesar para pasar "from zero knowledge to a native speaker or near-native speaker competence" (p. IX). 
En términos de Barron (2003), la interlengua de un alumno de L2, no siendo idéntica a su L1 ni a su L2, "shares characteristics of both" (p. 35) a lo que añade que determinados elementos pertenecientes a su L1 o incluso a otras lenguas, "such as, for example, politeness rules and formulae" (p. 35), pueden ser traspasados e incluidos en su interlengua. Estas circunstancias son las que originan lo que Richards (1984) entiende por errores de interlengua los cuales son causados por la “interference of learner's mother tongue” (p. 173).

Retenemos la idea de Constantinescu (2011) y de Galisson y Coste (1982) manifestando nuestro acuerdo con dichos autores este respecto a la consideración del error como un "outil pour enseigner" (p. 8) o como un "symptôme que l'apprentissage se fait" (p. 216). Desde esta consideración, nos situamos en la línea de d'Aquino (2016) respecto a la importancia de la presencia del error en la enseñanza-aprendizaje de L2 y en la línea de Dolz, Gagnon, Mosquera y Sánchez (2013); Durán (2011); Ellis (2008); Fernández (1997); Giovannini et al. (1996) y Torijano Pérez (2004) por cuanto que cometer errores debe manifestarse como indicador del progreso del alumno.

Asimismo, nos aproximamos al concepto de interlengua por cuanto que se relaciona directamente con la presente investigación a través del concepto de error. Recurriendo a las palabras de Barron (2003) entendemos la interlengua como un sistema transitorio al que el alumno incorpora términos, expresiones o incluso elementos extralingüísticos de otras lenguas con las que va estableciendo contacto. Desde esta perspectiva, consideramos que las actitudes del profesor hacia la interlengua o sistema transitorio merecen un interés aparte en una investigación centrada en el error por el tipo de manifestación que estas cobran en las aulas. 


\subsubsection{La corrección en las producciones escritas en $L 2$}

El término corrección aparece definido, según el Diccionario de la Real Academia Española (DRAE) (2016) en su versión electrónica como "el acto de señalar los errores en los exámenes o trabajos de sus alumnos, generalmente para dar una calificación".

Es bien sabido que, en la práctica docente, la decisión sobre qué, cómo y cuándo corregir, puede convertirse en una tarea de difícil desempeño y en una experiencia frustrante (Dulay, Burt \& Krashen, 1982). A este respecto, Fernández (1997) insistía en la necesidad de corregir solo aquellos errores que corresponden al nivel de los alumnos puesto que: "corregir todo, especialmente con principiantes, es sólo una forma de intimidar al alumno" (p. 30) y, por otro lado, “corregir al hilo del esfuerzo comunicativo, además de ser inútil (...) sólo sirve para anular esa incipiente comunicación" (p. 30) y, finalmente, "no corregir nunca es un caos" (p. 30).

Respecto a las producciones escritas, la corrección tiene que adecuarse a las características propias de la lengua escrita. De acuerdo con Norrish (1983), en las actividades de este tipo de producción realizadas durante el proceso de enseñanza-aprendizaje de L2, "information has to be transmitted without any aid from sources other than the language itself" (p. 65) por lo que "more attention needs to be paid to the language as a code - in short, to the grammatical and lexical systems" (p. 65). Según el mencionado autor, "there is a danger that the language learner will tend to focus on the errors rather than on the presumed aim of the piece of writing" (p. 65). 
Estamos de acuerdo con la afirmación de García-Heras Muñoz (2004) respecto al momento idóneo para la corrección. En dicha afirmación, la autora insiste en la necesidad de revisar y corregir las producciones escritas de los alumnos "de forma inmediata para evitar que la distancia en el tiempo disminuya la eficacia en la corrección" (p. 65).

Ya a principios de los años 90, desde el ámbito educativo español, Cassany (1993) mencionaba la existencia de ciertos roles establecidos en el aula con respecto a la redacción de los textos escritos y su corrección. Dichos roles, en opinión de Cassany (1993) los asume, por una parte, el profesor quien "debe corregir todos los errores del texto" (p. 16); y por otra, el alumno a quien se le otorga "muy poca responsabilidad en el proceso global de trabajo" (p. 16) puesto que “es el maestro quien gestiona lo que escribe, cuándo y cómo lo hace” (p. 16). De esta forma, según destacaba el citado autor:

Escribir deja de ser el instrumento personal y creativo para desarrollar los propios pensamientos y sensaciones, para analizar el mundo desde un punto de vista íntimo e intransferible: escribir se convierte en algo lejano a uno mismo, en una obligación escolar más. (Cassany, 1993, p. 16)

Además, Cassany (1993) destacaba otro aspecto interesante, el de la necesidad de que los profesores renuncien a su "autoridad de maestros para aprender de lo que los alumnos escriben o quieren escribir, para entenderlos y ayudarles a saber decirlo" (p. 17). Asimismo, se plantea una visión constructiva del error (Cassany, 1993; d’Aquino, 2016) en la que la corrección ha de llevarse 
a cabo, según encontramos en d'Aquino (2016), “de una manera respetuosa hacia el productor del error, teniendo en cuenta el tiempo y los esfuerzos invertidos en estas producciones por más que sean defectuosas" (p. 10). A la vez d'Aquino (2016) manifestaba que los profesores “deberíamos hacer un esfuerzo para dar un tono más constructivo a la corrección” (p. 37) a lo que añade que: “valorando lo positivo al lado de los errores, adoptamos un punto de vista más neutro, somos más imparciales y le ofrecemos una valoración más justa al alumno" (d'Aquino, 2016, p. 37). Se realza por tanto la necesidad de "saber crear en el aula un espacio saludable y comprensivo, en el cual hacer faltas y corregirlas sea un hecho normal" (p. 43) tal y como precisaba Cassany (1993).

Desde esta consideración, d'Aquino (2016), refiriéndose a los diferentes métodos de corrección para las producciones escritas enumera la corrección evidenciadora, la resolutiva, la clasificadora y la mixta, pero también otras que tienen una implicación directa en la actividad de corrección del alumno; entre estas, resalta la corrección colectiva, en pareja o en grupo y cruzada. Estos métodos resultan sumamente provechosos puesto que implican la presencia de una actitud de reflexión, así como una dinámica basada en la cooperación bidireccional entre alumno-profesor además de un alto grado de autonomía por parte del alumno. La autocorrección también ocupa y debe ocupar un lugar destacado en las actividades de los alumnos con un alto nivel de L2.

En torno al acto de escribir, es una evidencia el hecho de que es una tarea compleja que implica varios aspectos: la presencia de una serie de etapas a seguir, movilizar determinadas estrategias y contar con un buen nivel de autocontrol por parte del autor de la producción escrita. Igual de complejo resulta el proceso de corregir las producciones escritas de los alumnos. Como se puede observar en el Cuadro 1 tomado de Merino Mañueco (en prensa) que se presenta a 
continuación, nos encontramos ante dos procesos de igual complejidad por la responsabilidad que atañe a sus realizadores. Por una parte, se espera del alumno que realice una redacción de calidad al tiempo que, el profesor espera encontrar en dicha redacción aquel barómetro que le indique en qué medida los objetivos de enseñanza-aprendizaje se han alcanzado.

\begin{tabular}{|l|l|}
\hline \multicolumn{1}{|c|}{$\begin{array}{c}\text { REDACCIÓN ESCRITA } \\
\text { (productor-alumno) }\end{array}$} & $\begin{array}{c}\text { CORRECCIÓN DE LAS PRODUCCIONES } \\
\text { ESCRITAS (agente-profesor) }\end{array}$ \\
\hline Actividad compleja: toma de decisiones & $\begin{array}{l}\text { Actividad compleja: toma de decisiones } \\
\text { ¿Qué corregir? }\end{array}$ \\
\hline Etapas a seguir & $\begin{array}{l}\text { ¿Cómo corregir? } \\
\text { ¿Cuándo corregir? }\end{array}$ \\
\hline $\begin{array}{l}\text { Estrategias a movilizar } \\
\text { Autocontrol }\end{array}$ & $\begin{array}{l}\text { Conocimientos: didáctica sobre el error, sobre la } \\
\text { importancia del error en la enseñanza-aprendizaje. } \\
\text { puntuación, morfología, sintaxis, semántica, } \\
\text { pragmática, etc.). }\end{array}$ \\
\hline $\begin{array}{l}\text { Aptitud ante la redacción/escritura: poner en } \\
\text { marcha una serie de estrategias lingüístico- } \\
\text { discursivas, socioculturales, etc. }\end{array}$ & $\begin{array}{l}\text { Aptitud: saber corregir según el objetivo } \\
\text { planeado; corregir lo pertinente para que el error } \\
\text { se convierta en fuente de aprendizaje. }\end{array}$ \\
\hline $\begin{array}{l}\text { Actitudes: lo emocional y afectivo. } \\
\text { Actitudes: lo emocional y afectivo. Valoración } \\
\text { positiva del error, actitud de empatía con el } \\
\text { alumno y esfuerzo por producir un texto de } \\
\text { calidad. }\end{array}$ \\
\hline
\end{tabular}

Cuadro 1. Redacción escrita vs corrección de las producciones escritas. Tomado de Merino Mañueco (en prensa)

Es evidente, que los dos procesos asumidos por el productor-alumno y el agente-profesor conllevan una importante carga emocional-afectiva. Para el alumno, dicha carga tiene que ver con la dificultad misma que supone la actividad realizada, así como con el producto final: la redacción.

Desde esta consideración, cuanto mejor resulte el producto final, menos errores se encontrarán lo cual influirá de manera decisiva en la propia actitud de autoestima y motivación del alumno ante la enseñanza-aprendizaje, tal y como representamos en la Figura 1 tomada de Merino Mañueco (en prensa) que aparece a continuación. 

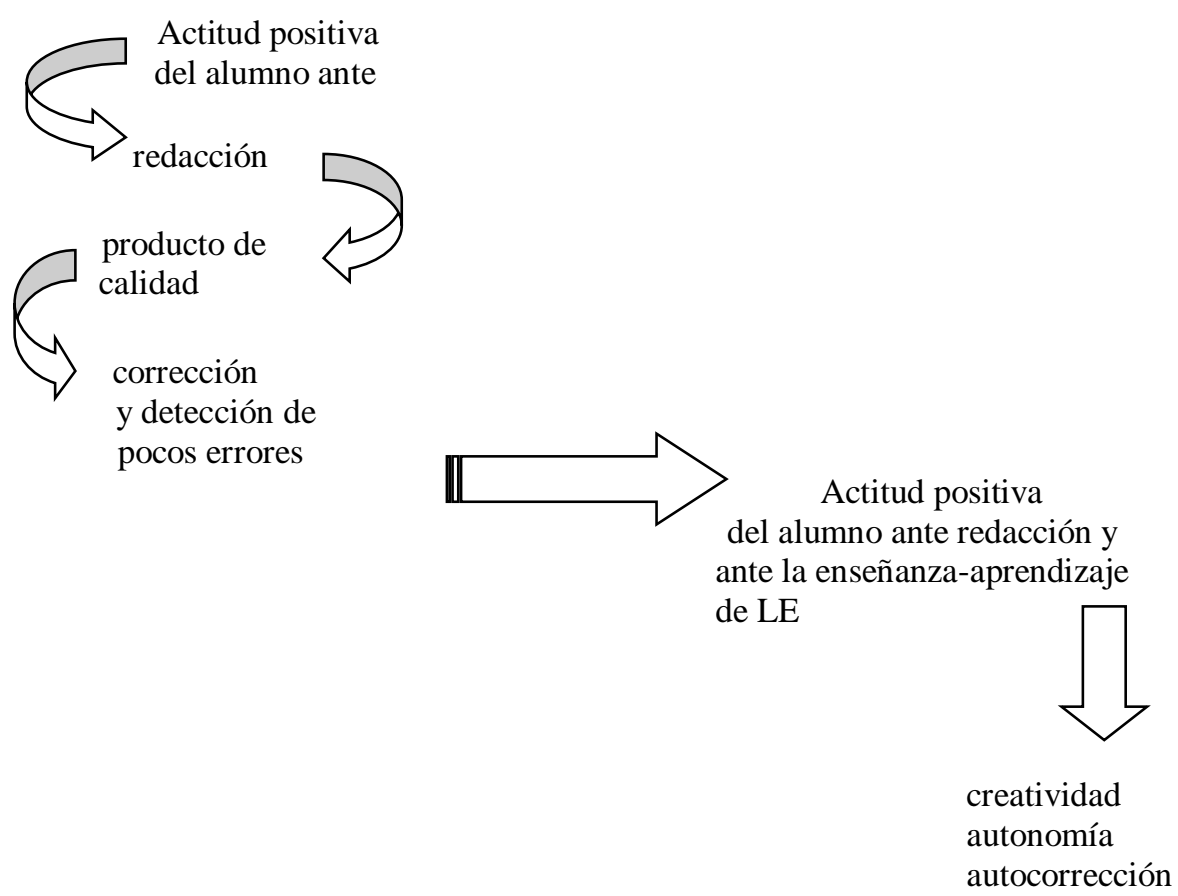

Figura 1 Importancia de la actitud positiva del alumno ante la redacción. Tomada de Merino Mañueco (en prensa)

En la Figura 1 se representa la incidencia de la actitud positiva por parte del alumno ante la redacción y ante la enseñanza-aprendizaje de una L2 a la hora de realizar una producción escrita de calidad traducida en términos de a través de autonomía y creatividad mientras realiza un ejercicio de autocorrección.

Por otra parte, para el agente-profesor, cuanto mejor sepa gestionar este proceso de corrección, es decir, cuanto mejor sepa centrarse en lo pertinente y acompañar dicho proceso de una actitud positiva y significativa, mayor incidencia positiva tendrá en la actitud del alumno ante la escritura y la enseñanza-aprendizaje de la L2. 
Tanto profesores como especialistas en Lingüística aplicada a la enseñanza de L2 reconocen la importancia de la corrección y, consecuentemente, de la presencia del error en la enseñanza-aprendizaje de L2. Dicha importancia reside en concienciar tanto al productor-alumno como al agente-profesor en la incidencia que tiene el cómo, el cuándo y el qué se corrige en las producciones escritas de los alumnos de L2.

La corrección tiene una doble función instrumental puesto que a través de ella el alumno puede aprender a partir de sus errores y, al mismo tiempo, es un "instrumento muy eficaz para la labor docente" (d'Aquino, 2016, p. 12). Nos encontramos ante una tarea de gran complejidad que implica un alto nivel de responsabilidad por parte de los profesores y, en virtud de ello, podemos llegar a afirmar que "es el profesor quien puede llegar a inhibir la creatividad y la motivación o, por el contrario, alimentar la imaginación y despertar la autonomía” (Merino Mañueco, en prensa).

Es Vázquez (2009) quien se detiene a marcar la diferencia entre corrección y evaluación afirmando que:

Por lo general se entiende bajo "corrección" la incidencia de la persona que enseña sobre la interlengua de quien aprende, a través de la interacción escrita u oral. No hay evaluación sin corrección, pero la corrección es siempre puntual y la evaluación es necesariamente global. (Vázquez 2009, p. 114) 
Para Burt (1975), la corrección de errores implica una serie de esfuerzos, los cuales "would comprise an important step towards producing more relevant teaching, more confident learners, and more effective communication" (p. 63). La corrección de errores solo alcanza su objetivo si se integra en la enseñanza-aprendizaje de L2 con el propósito de que el alumno llegue a conseguir la eficacia en la comunicación mostrando una actitud de confianza en sí mismo y en el aprendizaje. Desde esta perspectiva de concienciación y de reflexión sobre la corrección se pone de relieve el planteamiento de la integración del error en el proceso de enseñanza.

Por su parte, Durán (2011) refiriéndose al concepto de "error correction” (p. 62) considera que se trata de "one of the most controversial topics in the area of second language teaching" (p. 62) puesto que intervienen una serie de factores personales respecto al agente-profesor o en sus palabras "it is generally considered to be a highly personal and complex issue" (p. 62).

Sin embargo, como indicaba Burt (1975) respecto a la formación del profesorado orientada estrictamente a la corrección de errores, no existe una corrección específica puesto que "virtually nothing is said in textbooks on how to deal with errors - except that they should be corrected" (p. 53). A pesar de ser considerada unánimemente un aspecto de suma importancia en la enseñanza-aprendizaje de L2.

En relación a las modalidades de corrección Pawlak (2014) proponía la idea de que “error correction can be planned or spontaneous, it can vary along numerous dimensions, and it can be applied with the purpose of developing both the knowledge of rules and the ability to use them in real-time communication" (p. 2). 
Tanto la corrección como el tratamiento del error ha evolucionado de manera que las connotaciones negativas han sido sustituidas por otras positivas (Vez et al., 2002; Torijano Pérez, 2004). Al error se le atribuyen efectos favorecedores de la evolución siendo señal de lo que el alumno "no sabe y, por tanto, de lo que necesita aprender, informándole de la distancia que le separa del objetivo señalado" (Vez et al., 2002, p. 255). Giovannini et al. (1996) llegan a afirmar que determinados errores no son una ocasión de aprendizaje, sino que "son una prueba de que se está aprendiendo" (p.11). Esta idea del error como muestra de aprendizaje del alumno la han venido destacando ya desde principios de los años 90 autores como Santos Gargallo, 1994; y más recientemente Durán, 2011 y Torijano Pérez, 2004.

En función de todo lo arriba mencionado, consideramos que el error es una muestra de aprendizaje del alumno y, en virtud de ello, consideramos la corrección de errores como un proceso no solo de gran responsabilidad sino también de mucha utilidad para el profesor en el aula de L2 en cualquier etapa educativa. A través de la corrección, el profesor recibirá información de calidad sobre las necesidades educativas específicas del alumno, sobre su nivel de interlengua y sobre su forma de aprendizaje.

Dado que nuestra investigación aborda el tema del error en las producciones escritas de los alumnos en L2, nos centraremos en los distintos tipos de corrección existentes y en el momento idóneo para llevar a cabo dicha corrección en el aula de L2. Así es como, mostramos nuestro acuerdo con García-Heras Muñoz (2004) quien apoya la idea de una corrección inmediata que se lleve a cabo justo en el momento en que el alumno termina de realizar su producción escrita. Desde 
nuestro punto de vista, se impone como necesidad intrínseca una revisión general de las distintas corrientes existentes respecto al concepto del error y a la corrección de errores.

\subsubsection{El feedback y su proyección en la enseñanza-aprendizaje de L2}

Como ya mencionábamos en la Introducción de la presente Tesis Doctoral, recurrimos al término feedback como sinónimo de retroalimentación tal y como aparece en el Diccionario de términos clave de Enseñanza del Español como Lengua Extranjera (ELE) (1997-2017) del CVC en su edición electrónica y tal y como lo utilizan, entre otros, de la Torre et al. (1994); Fabián Martín-Arroyo (2016); García-Heras Muñoz (2004); Jericó (2013); Jiménez González y Muñetón Ayala (2002); López Hernández (2009); Mendoza Fillola (1998) y Vargas Venegas (2008). Adoptamos este término por tratarse este de una palabra de origen inglés que se usa en español sin necesidad de traducción y por ser este un término ampliamente utilizado por lingüistas.

Según el Diccionario de términos clave de ELE (1997-2017), el feedback o retroalimentación:

Consiste en el mecanismo mediante el cual el aprendiente de L2 incorpora a su discurso el efecto que este produce en sus interlocutores (ya sean estos sus compañeros, ya sea el profesor) y que ellos le manifiestan por medios tanto lingüísticos como paralingüísticos. (Diccionario de términos clave de ELE del CVC, 1997-2017, versión electrónica) 
En el Diccionario panhispánico de dudas (2005) de la Real Academia Española [RAE] aparece este anglicismo usado en distintas disciplinas científicas como algo inherente a cualquier tipo de interacción, que pueda llevarse a cabo entre seres humanos, entre máquinas o entre seres humanos y máquinas.

De acuerdo con Dulay, Burt y Krashen (1982), en términos de adquisición de lenguas, este vocablo hace referencia a la respuesta que da el oyente o lector al discurso o al texto escrito del alumno. Además, los mencionados autores hacen referencia a tres tipos de feedback. Al primero lo asocian con la propia corrección, el segundo es el denominado feedback positivo en el que el profesor hace una valoración positiva de los aciertos o logros conseguidos por el alumno incluyendo frases de ánimo y palabras de afecto hacia este. El tercero se revela como un feedback en el que el profesor busca una modificación del discurso oral o del texto escrito sin llamar la atención de una forma explícita.

López Hernández (2009), a su vez, asociaba el feedback con una "respuesta al error" (p. 66) afirmando que se trata de un juicio emitido por el profesor dirigido a la consecución de una corrección lingüística. Por consiguiente, el feedback se ha de entender como un mensaje elaborado por el profesor en el que intenta, en primer lugar, destacar "el valor comunicativo de la práctica de los alumnos" (López Hernández, 2009, p. 71) y, en segundo lugar, transmitir tanto los aciertos como los errores que aparecen en la producción en L2 pretendiendo por tanto "responder de forma holística a la práctica del alumno” (López Hernández, 2009, p. 66). 
Las distintas opiniones de profesores e investigadores sobre los beneficios o inconvenientes de proporcionar feedback a las producciones escritas de los alumnos tanto de L1 como de L2 se han sucedido y siguen sucediéndose a día de hoy. En este sentido, mostramos nuestro acuerdo con Ferris (2003) quien afirmaba que: "because teacher is the teacher, any feedback is likely to influence what students do subsequently-and experts disagree as to whether this influence is ultimately helpful or harmful" (p. 14). Según encontramos en Ferris (2003) durante las décadas de $\operatorname{los} 70$ y los 80 , los comentarios escritos por el profesor en las producciones escritas de los alumnos, considerados estos la forma de feedback más utilizada por el profesor, se han revelado como poco efectivos, llegando a ser menospreciados y calificados como pérdida de tiempo. Es a partir de los años 90 cuando comienza a surgir una valoración de los comentarios bien formulados por el profesor, empezando a ser valorados como ayuda para los alumnos.

Situándose en la perspectiva de varios autores, Zamel (1985) destacaba que, teniendo en cuenta el grado de importancia de las respuestas aportadas a las producciones escritas de los alumnos "by virtue of the time and effort invested" (p. 80), resulta llamativo el hecho de que "until very recently, little attention was paid to the nature of these responses" (p. 80). Sin embargo, hay pocos estudios empíricos orientados a "describe and investigate teachers' responses to student writing, since these responses are believed to reflect underlying assumptions about the nature and function of writing" (Zamel, 1985, p. 80). La mencionada autora, llevó a cabo un análisis de los comentarios escritos de 15 profesores en 105 textos de alumnos de ESL (English as a Second Language) intentando demostrar que dichos comentarios constituían una representación del comportamiento de los profesores informantes a la hora de responder a las producciones escritas 
en L2 de sus alumnos. El análisis puso de manifiesto que los comportamientos de los profesores de L2 eran similares a los de L1, de forma que:

ESL writing teachers misread student texts, are inconsistent in their reactions, make arbitrary corrections, write contradictory comments, provide vague prescriptions, impose abstract rules and standards, respond to texts as fixed and final products, and rarely make content-specific comments or offer specific strategies for revising the text. (Zamel, 1985, p. 85-86)

Por lo que la autora destacaba que "we need to change our responding behavior so that students better understand how to revise their writing" (Zamel, 1985, p. 94), puesto que "since most first drafts were seemingly read as final drafts, however, students did not have to take responsibility for addressing these important features of writing” (Zamel, 1985, p. 91).

Como consecuencia de un cambio en el enfoque pedagógico en la enseñanza de producción de textos escritos en L2 para el contexto educativo norteamericano, los profesores comenzaron a inclinarse por el uso de otros métodos de corrección y de feedback entre los que se encuentran las entrevistas personales entre profesor y alumno denominadas "one-to-one writing conferences" o "teacher-student writing conferences" (Ferris, 2003, p. 20). También se llevan al aula las denominadas sesiones de revisión por parte de uno o varios compañeros de clase o "peer review sessions" (p. 22) como práctica complementaria a las entrevistas con el profesor, en la que se insta a otros alumnos del aula a colaborar con el autor de la producción escrita. 
Zamel (1985) propone en su estudio utilizar el método de entrevista personal con los alumnos a partir de lo que ella denomina "cycles of revision" (p. 95) o borradores encadenados cuyo uso permitirá que los alumnos "better understand how to revise their writing" (p. 94). Este método se inscribe en el enfoque metodológico centrado en el proceso o producción del texto o “process-oriented pedagogy” al que Ferris y Hedgcock (1998, p. 197) hacen referencia afirmando que, a través de su aplicación en el aula, "students may be much better at idea generation and revision than they used to be" (p. 197). Además, el impacto de las nuevas tecnologías de la educación y su uso en el aula permiten desarrollar otro tipo de métodos como la grabación de los comentarios del profesor o "audiotaped feedback" (Ferris, 2003, p. 20), comentarios incluidos en el texto del alumno a través de un programa informático o incluso feedback enviado a través de correo electrónico o "email feedback” (Ferris, 2003, p. 20).

A su vez, Ferris (2003) manifiesta el hecho de que hoy en día todavía existen profesores de L2 que se limitan a enseñar la destreza de composición escrita a partir de la corrección de errores y posterior comentario o entrega de feedback de un único borrador elaborado por el alumno. Sin embargo, diversos estudios coinciden en señalar que "in North American academic settings, many teachers have made the shift over the past 15 years from being form-focused and product-oriented to providing feedback on a broad spectrum of issues in a multiple-draft, response-and-revision writing cycle" (p. 22).

Para el contexto español, encontramos a Cassany (2009), quien también pone de manifiesto la existencia de dos secuencias de producción escrita alternativas en el aula de L2. En la primera de ellas, el profesor corrige el producto final del alumno sin que exista interacción oral entre ellos 
durante el proceso de producción. Así pues, profesor y alumno solo interactúan “antes y después de la composición" (p. 62) asumiendo el profesor el rol de autoridad a través del cual "dispone lo que se escribe al principio" (p. 62) y “juzga como se ha hecho al final” (p. 62). Dicha secuencia se concretiza en lo que conocemos como "product-oriented pedagogy" o enfoque centrado en el producto o texto final. En la segunda secuencia, el autor del texto elabora su producción escrita ayudado del profesor y del resto de sus compañeros de aula. Todos ellos "pueden colaborar con el autor durante todo o parte del proceso de composición y de modos sustancialmente distintos” (p. 62) interactuando con él de forma oral. En esta secuencia, "la actividad de producción textual se convierte en un conjunto variado de subtareas (planificación, textualización, etc.)"(Cassany, 2009, p. 62) que el alumno lleva a cabo gracias a la cooperación de profesor y compañeros de aula. En este caso, el autor hace referencia al enfoque metodológico conocido como "process-oriented pedagogy" o enfoque centrado en el proceso de escritura. Nos situamos en la línea de Cassany (2009) respecto a la elección de esta segunda secuencia como la opción más adecuada para llevar al aula de L2.

Los comentarios escritos y la entrevista personal profesor-alumno, como métodos más utilizados, suelen aparecer combinados, sobre todo cuando en el proceso de composición de textos escritos se pide al alumno que produzca diferentes borradores acudiendo por tanto a la técnica de composición utilizada tanto en L1 como en L2 denominada borradores encadenados. De acuerdo con Campbell (1998), a través de dicha técnica, el profesor trabaja con los alumnos "guiding them through multiple drafts until the students realice they have produced their best written work" (p. 3). 
El sistema que conocemos bajo el nombre de borradores encadenados se materializa en una serie de entrevistas entre el alumno (autor) y el profesor en las que se puede incluir la presencia de otros compañeros de aula a los que se les ha pedido colaboración en el proceso de producción ayudando al autor en sus tareas de planificación, revisión, etc. El profesor solicita al alumno que, a partir de un primer esquema que contenga las ideas principales de un texto, elabore un primer borrador recordando las instrucciones para la composición de textos escritos en la que se habrá trabajado previamente. Tras la elaboración de ese primer borrador, el alumno será instado a aproximarse a una mesa especial ubicada en el aula en la que el profesor (en ocasiones acompañado de otro u otros alumnos) estará sentado a la misma altura dispuesto a comenzar la entrevista entre profesor y alumno (autor de la producción escrita). Tras la escucha atenta de la lectura por parte del alumno de su primer borrador, el profesor procederá a proporcionar el feedback correspondiente al alumno acompañado en ocasiones por ciertas contribuciones de los compañeros de clase. Este feedback podrá concretarse en feedback oral: comentarios que el profesor proporcionará al alumno en los cuales incluirá no solo consejos y recomendaciones sino también frases de apoyo y ánimo, gestos de complicidad y cercanía, etc. Y también en feedback escrito a saber: notas redactadas por el profesor durante el transcurso de la lectura. El alumno, habiendo recibido el feedback del profesor, será instado a volver al escritorio que ocupa normalmente para incorporar las recomendaciones y sugerencias a su composición escrita. Tendrá que elaborar un nuevo borrador a partir del primero ampliándolo y enriqueciéndolo con la ayuda del feedback proporcionado. Este proceso se repetirá en varias ocasiones hasta que el alumno complete su borrador final. 
Con el fin de contribuir a un aumento en el nivel de autonomía del alumno, la técnica de borradores encadenados plantea la posibilidad de hacer al alumno partícipe del proceso de corrección otorgándole un papel activo. Es el propio alumno quien lleva a cabo las correcciones bajo las orientaciones del profesor. Durante este proceso, el profesor ha de mostrar cercanía y complicidad a través de sus gestos haciendo al alumno consciente de su papel como guía u orientador. Todos estos aspectos relacionados con la posición, la postura y la gestualidad estarán dirigidos a motivar al alumno y a transmitirle la idea de autonomía y de cooperación bidireccional entre alumno-profesor, aspecto que mencionábamos en el epígrafe 1.1.2.

Encontramos a un gran número de autores, entre ellos, Martín Peris (1998) que hacen alusión en su obra a la necesidad de incrementar el grado de participación e implicación de los alumnos, no solo en el aula de L2 sino en todas las materias. Según el mencionado autor, los objetivos de las políticas educativas no deben limitarse al aumento de los conocimientos y habilidades de los alumnos, sino que debe incluir la "formación de ciudadanos adultos, críticos y responsables" (p. 89).

Se ha hablado mucho acerca del tipo de feedback que el profesor de L2 debe proporcionar en cada una de las etapas del proceso de escritura. En esta cuestión, volvemos a acercarnos a autores que centran su investigación en el proceso de escritura en L1 por tratarse de autores de referencia para la escritura en L2.

De acuerdo con determinados autores, durante la revisión de los primeros borradores no debemos fijar nuestra atención en errores de forma sino solo en los de contenido. Encontramos, 
por tanto, en el estudio que llevó a cabo Zamel en 1985 una crítica a los comentarios que los profesores de ESL habían escrito en las producciones escritas de los alumnos tras su revisión. Según ella, los profesores que formaron parte de su investigación, "viewing their students as language learners rather than developing writers, treat students' texts as final products to be edited" (p. 91).

Fathman y Whalley (1990), a su vez, realizaron un estudio en el que analizaban el impacto de la corrección y el feedback de los errores gramaticales (o errores de forma) con respecto a los errores de contenido concluyendo que "grammar and content feedback, whether given alone or simultaneously, positively affects rewriting” (p. 185). Asimismo, las mencionadas autoras, respondiendo a la pregunta sobre la efectividad de la corrección de errores gramaticales y el feedback del profesor de cara a mejorar las producciones escritas de los alumnos, señalaban que "when teachers underline gramatical errors in the students' texts, students showed significant improvement in grammatical accuracy. All students made fewer grammar errors in rewriting their compositions" (Fathman y Whalley, 1990, p.187).

Así pues, Fathman y Whalley (1990) se planteaban una serie de incógnitas acerca del momento idóneo para aportar al alumno feedback de forma ofeedback de contenido y acerca de la modalidad más adecuada (de forma conjunta o independiente) encontrando que "grammar and content feedback can be provided separately or at the same time without overburdening the student" (p. 187). Además, su estudio demostró que "students whose errors were underlined and who were given general comments on content improved significantly in both grammar and content when they rewrote their compositions" (p. 187). A la vez, las mencionadas autoras se preguntaban 
acerca de la eficacia del feedback de contenido en la mejora de la composición escrita a lo que respondían que "general comments giving encouragement and suggesting revisions helped improve the content of composition rewrites" (Fathman y Whalley, 1990, p. 187).

Años más tarde, Ferris (2003) insistía en esta misma idea de que el feedback que se proporciona a las producciones escritas de los alumnos de L2 puede ir dirigido tanto al contenido como a la forma, ya que, "L2 student writers have a tremendous need for expert feedback on their written errors" (p. 24) y, además, desde su punto de vista, cada alumno tiene unas necesidades particulares por lo que el feedback proporcionado debe ir dirigido a las necesidades específicas de cada uno.

Como mencionábamos al comienzo de este epígrafe, se han sucedido diferentes opiniones acerca de los beneficios del feedback en las producciones escritas de los alumnos tanto de L1 como de L2. Con respecto a este tema, Ferris (2003) apuntaba que "a number of L1 and L2 researchers have claimed that there is little evidence that teacher feedback helps students at all" (p. 28). La mencionada autora hacía alusión en su obra a aquellos investigadores que manifiestan, respecto a las correcciones de las composiciones escritas en L1 y L2 y a los comentarios del profesor que las acompañan, que estos pueden causar más daño que beneficios.

Por otro lado, Ferris (2003) afirmaba que las investigaciones más recientes sobre la técnica de borradores encadenados llevadas a cabo durante las últimas dos décadas, demuestran que “teacher feedback certainly can and often does help student writers to improve their writing from 
one draft to the next and over time" (p. 28) y que los propios alumnos "definitely feel that teacher feedback is valuable to them and that it helps them to improve their writing" (Ferris, 2003, p. 28).

A partir del estudio que Fathman y Whalley llevaron a cabo en 1990 con a un grupo de alumnos de ESL a los que se les expuso ante distintos tipos de feedback, se pudo concluir que la presencia o ausencia del feedback puede llegar a incidir favorable o negativamente en la calidad de su composición escrita.

Como conclusión, debemos destacar que los pocos estudios empíricos realizados en torno a este tema demuestran, en parte, la utilidad del feedback dentro del proceso de enseñanzaaprendizaje de L2 y la necesidad de su presencia en el aula, (Ferris, 2003; Ferris \& Hedgcock, 1998; Gascoigne, 2004 y Leki, 1990). El feedback queda como un proceso desconocido todavía, cuya incidencia se ha de verificar ya que como afirmaba Ferris (2003) "there is a lot to be learned about the best ways in which to give feedback and about how (and if) it facilitates students' writing development over time" (p. 41).

En la presente investigación, enfocamos el feedback como un proceso añadido a la corrección y que normalmente la complementa $\mathrm{y}$, al respecto, retenemos la idea de Campbell (1998) quien definía este término como: "the response of a teacher, mentor, peer, or some other outside reader to a writer's work, particularly as such response helps facilitate improved writing" (p. 84). Respecto al tipo de feedback que, desde nuestro punto de vista debe ser suministrado en las correcciones de alumnos de Educación Primaria, nos inclinamos hacia el denominado feedback positivo (Dulay, Burt \& Krashen, 1982) en el que el profesor hace una valoración positiva de los 
aciertos o logros conseguidos por el alumno incluyendo frases de ánimo y palabras de afecto hacia este. Nos mostramos a favor de la presencia de un feedback en forma de respuesta y revisión de los distintos borradores de los alumnos acompañando a la corrección de errores de las producciones escritas de alumnos de L2 de Educación Primaria en sintonía con autores como Ferris (2003). Consideramos que dicho feedback puede ir relacionado tanto con contenido como con la forma de la producción escrita y que será altamente efectivo y útil en las futuras producciones escritas de los alumnos siempre y cuando se proporcione de una forma cercana y amable.

\subsection{Causas y criterios en torno a la aparición del error}

Como hemos venido apuntando, son muchas las teorías que giran en torno a las posturas de alumnos y profesores ante el error. Dicho error se manifestaba en palabras de Corder (1981) como: "unfortunate but inevitable sign of human fallibility-for example, lack of attention or poor memory on the part of the learner, or, if they are modest enough, some inadequacy in their own teaching." (p. 65).

Desde el ámbito español, Fernández (1997) apoyaba la idea de que el alumno debe "asumir el error como un elemento no sólo ineludible, sino también necesario para aprender una lengua" (p. 261). Por tanto, según la autora, la aceptación del error “cambia la perspectiva, la valoración ante este fenómeno, la actitud del que aprende y la dinámica del aula” (Fernández, 1997, p. 261). 
Así pues, es interesante acercarnos a este como un posible fallo humano que puede generarse tanto por parte del alumno (por haber experimentado una falta de atención, un fallo de memoria, etc.), como por la ineficacia del profesor.

La actitud del alumno ante los errores se halla, de acuerdo con Fernández López (1995), en directa relación con la edad. En el caso de los adultos, los errores se muestran como indicadores de una incapacidad o conducta negativa según explicaba:

Para el que aprende una lengua, los errores, en una gran mayoría, se sienten como una limitación que, en el caso de alumnos adultos, conlleva muchas veces un recorte de la comunicación. En el aula pueden provocar además una sensación de infantilismo, o de inhibición adulta ante el no quedar bien, ante la corrección pública de los posibles fallos. (Fernández López, 1995, p. 204)

Por su parte, en el caso de los niños, el error no tiene una carga tan negativa y no influye tan decisivamente a la hora de comunicarse en una L2. Al tratarse de edades tempranas, el alumno no tiene una conciencia tan desarrollada en cuanto al error y a su impacto.

En lo que concierne a las causas asociadas al error Giovannini et al. (1996) ponían de manifiesto que "una causa frecuente de error es el estrés asociado al hecho de hablar una lengua extranjera de forma imperfecta, y a la posibilidad de que uno se sienta ridículo o rechazado por el grupo" (p. 13). Este estado de tensión, en opinión de los citados autores, "nos lleva a tener muchas dudas y vacilaciones y a cometer errores en el momento de hablar” (p. 13). 
Asimismo, Torijano Pérez (2004) también habla de este sentimiento de "ridículo o de impotencia" (p.17) que puede desembocar en lo que él llama "la temida inhibición del estudiante" (p. 17) y que, normalmente trae consigo el "desinterés y el abandono del proceso" (p.17). Desde esta consideración, el mencionado autor destaca que el comportamiento que muestran los estudiantes ante el error viene acompañado de un sentimiento de culpabilidad que le acercan a la creencia de que son ellos los responsables de evitar el error. Dicho comportamiento de miedo a cometer errores y a hacer el ridículo pueden llegar a ser "uno de los factores más inhibidores en cualquier situación formal de aprendizaje" (p. 17).

Como ya hemos apuntado en el epígrafe 1.1.2, en el aula de L2 no todos los errores han de ser corregidos y, en este sentido, Fernández (1997) establecía una jerarquía en torno a la corrección de errores. Así pues, Fernández (1997) planteaba "los conceptos de «gramaticalidad» y de «aceptabilidad»" (p. 30). En su visión, "la gramaticalidad hace referencia a la conformidad de la producción con el sistema de la lengua que se aprende" (p. 30) al tiempo que "la aceptabilidad se somete al juicio del informante, que, en cada situación concreta, valora si el mensaje se entiende, es confuso, es adecuado a la situación: es, en una palabra, aceptable o no". (p.30). Dichos conceptos resultan ser de gran importancia a la hora de determinar la gravedad de los errores por lo que: "desde una perspectiva comunicativa, el criterio prioritario es, evidentemente, el de la aceptabilidad. Un error será más o menos grave en la medida en que afecte al mensaje y dificulte o distorsione la comunicación.” (Fernández, 1997, p. 30). Se unen a los ya mencionados conceptos por una parte el nivel de competencia comunicativa en la L2 y, por otra parte, las necesidades lingüísticas de los aprendices. Es lo que la determina a insistir en la necesidad de establecer 
determinados criterios a la hora de valorar o de establecer una medida que pueda determinar el grado de gravedad de los errores de los alumnos. Como profesores, nos corresponde hacer ver a nuestros alumnos que "los primeros criterios que asumimos son los comunicativos: el logro o no de la comunicación y el mayor o menor grado de distorsión del mensaje” (Fernández, 1997, p. 31). La importancia de dar a conocer el valor que otorgamos al intento de comunicación por parte del alumno reside en la necesidad de evitar que los alumnos experimenten inhibición ante la producción en L2. Sin embargo, a pesar de los conceptos ya enumerados en torno al error, retenemos la idea de Fernández (1997) respecto a que "estos no son criterios objetivos, y aunque se elaboren escalas más o menos precisas, tal vez, como apuntábamos más arriba, no seamos los profesores, ni los estudiosos del tema, los árbitros más imparciales para dilucidar la efectividad comunicativa de los aprendices" (p. 31).

\subsubsection{Conocimientos del alumno sobre el error}

Como resultado de la "visión tradicional del error" (Torijano Pérez, 2004, p. 15) y de la “postura punitiva ante el error escolar" (Torijano Pérez, 2004, p. 16) los conocimientos que se han transmitido a los alumnos de L2 giran en torno a la idea de sanción y de la "creación de nuevos hábitos" (p. 16). No obstante, con la llegada de las nuevas teorías de enseñanza-aprendizaje de una L2 que ofrecen una visión positiva ante el error, se capacita al alumno como conocedor de la importancia que tiene su presencia en las producciones escritas en L2. 
Así pues, los conocimientos del alumno, han de estar orientados a la idea de identificar el error con un "learning step" o "paso de aprendizaje" (Torijano Pérez, 2004, p. 19) hacia su L2 aportando una "visión optimista del avance del estudiante" (p. 19).

Cassany (1993), se acerca a las figuras del profesor y del alumno con respecto a la corrección e indica cuales son los roles que corresponden a cada uno, algo que toda la comunidad educativa entiende y da por hecho. Es el profesor quien asume su papel de corrector mientras los alumnos esperan recibir sus producciones escritas corregidas. En este contexto, se plantea la idea de un modelo dicotómico "activo-pasivo" (p. 18) al que aludía Cassany (1993) mediante el cual, “el alumno se convierte en mero receptor callado del trabajo del maestro" (p. 18).

Consideramos por tanto una obligación de los alumnos conocer y aceptar el error como parte del proceso de enseñanza-aprendizaje de su L2. Así pues, Torijano Pérez (2004), haciendo suyas las palabras de Corder (1967) manifestaba que el conocimiento acerca de los errores es necesario para el profesor, para el investigador y, sobre todo, para el propio alumno ya que son instrumentos de aprendizaje que les sirve para probar la hipótesis con la que ellos cuentan sobre ciertos mecanismos de la L2.

Los alumnos de L2 deben mantener una visión de apertura ante el error y percibirlo como síntoma de progreso. Esta percepción favorecerá al alumno en el momento de evitar el bloqueo y la inhibición durante el desarrollo de actividades de producción tanto oral como escrita. Esta visión puede llegar a alcanzarse a través de un conocimiento profundo sobre el error entendido este como “punto de partida en el aprendizaje” (de la Torre et al., 1994, p. 116). De la Torre (1994) sugería 
que el concepto de error debía ser entendido por el alumno como un "estímulo de búsqueda y aprendizaje" (p.116) de su L2. Un "recurso de reflexión por parte de profesores y alumnos" (p. 42) que obliga a ambos a "revisar el proceso y averiguar en qué se ha fallado y por qué" (de la Torre et al., 1994, p. 42).

\subsubsection{Aptitud del alumno en torno al error (autocorrección)}

Constantinescu (2011) se centró en la eficacia de las actividades de aula propuestas por el profesor planteando la necesidad de adoptar una actitud de respeto ante el error. En relación a las actividades de producción oral insistía en "évite d'interrompre l'apprenant, lui donne toujours l'occasion de se corriger" (Constantinescu, 2011, p. 84). Asimismo, en relación a la corrección de producciones escritas proponía “privilégie l'autocorrection et le dialogue en proposant un corrige type élaboré par l'ensemble de la classe" (p. 85).

Generalmente se destaca la idea de la autocorrección de las producciones escritas de los alumnos, especialmente en los niveles avanzados (Cassany, 1993; Constantinescu, 2011; GarcíaHeras Muñoz, 2004; Guillén Díaz, 2004 y Vez et al., 2002) a lo que Vez et al., (2002) añaden que dicha corrección "requiere en gran medida promover la situación de autoevaluación por parte del alumno, junto a la intervención del profesor" (p. 255). Los mencionados autores proponen una “situación de autoevaluación” (p. 255) en la que el alumno cuente con: 
- Un cuadro de referencias en el que se expliciten los saberes y saber hacer requeridos.

- Un código -según el tipo de error- que le permita descubrir sus faltas, pues sabemos que si es el profesor quien ha corregido dando la forma correcta no van a ser tenidas en cuenta, pero así el alumno está atento al error, porque el profesor señala la falta con el código correspondiente al tipo de error y es el alumno quien debe buscar o descubrir el error y corregirlo. Reflexiona sobre las razones de las faltas detectadas. (Vez et al., 2002, p. 255)

A su vez, Cassany (1993) apoyaba la idea de incluir este procedimiento de autocorrección en el aula de manera que se haga sentir al alumno parte del proceso de corrección y, al mismo tiempo, responsable de sus propias producciones escritas. Según afirmaba, "en raras ocasiones los alumnos tienen la oportunidad de revisarse sus propios errores, de autocorregirse, de reformular sus borradores y mejorar paulatinamente su trabajo" (p. 16) lo cual origina una falta de interés por parte del alumno convirtiendo la redacción en algo "lejano a uno mismo, en una obligación escolar" (Cassany, 1993, p. 16).

Por su parte, García-Heras Muñoz (2004) reflexionaba sobre la importancia de involucrar al alumno en el proceso de escritura creando en este un hábito de autocorrección y una "actitud activa" (p. 65). La mencionada autora, afirmaba que, si los alumnos "se involucran intelectualmente en la actividad, es mucho más probable que aprendan de su propia experiencia" (p. 65). 
En el ámbito norteamericano, ya en el año 1967, Shaw advertía de la importancia de la corrección de los propios errores y posterior reflexión sobre estos sugiriendo a los alumnos que: "by concentrating upon one particular error at a time you can quickly master the sentence flaw involved and avoid it in future speaking and writing" (p. 113).

Acercando la idea de corrección de errores al feedback y centrándonos en el concepto de autocorrección, cabe destacar el trabajo de Ferris (2003) quien afirmaba que, para conseguir que nuestros alumnos de L2 lleguen a alcanzar un buen nivel de competencia en expresión escrita, se impone que el profesor proporcione el correspondiente feedback. Como complemento a dicho feedback, conviene añadir una intervención o respuesta por parte de un compañero de clase seguida de una autoevaluación guiada. Los tres elementos indicados constituyen una parte fundamental de la corrección de errores por lo que, como profesores de L2 somos responsables de crear situaciones de aprendizaje en las que se incluyan los mencionados elementos a partir de las cuales el alumno elabore producciones escritas. Además de servir de ayuda al alumno a la hora de enfrentarse ante una actividad de producción escrita en L2, esta combinación de tareas formada por el feedback del profesor junto con la mediación o ayuda de un compañero unidos estos a una actividad de autoevaluación aportará al alumno un grado de seguridad y confianza en sí mismo que se podría convertir en un gran estímulo de cara a futuras producciones escritas.

Consideramos que las aptitudes del alumno ante el error han de estar orientadas hacia una participación activa por parte del alumno en las tareas de corrección y, en este sentido, nos situamos en la línea de García-Heras Muñoz (2004) quien proponía la idea de crear un hábito de corrección por parte del alumno (bien en forma de corrección de las producciones de otros 
compañeros o de autocorrección) de manera que este se sienta implicado y comprometido con el propio proceso.

\subsubsection{Actitud del alumno ante el error}

Hablar de actitudes implica acercarnos a un "conjunto de representaciones mentales (creencias, valores, prejuicios) y sus manifestaciones en forma de opiniones y hábitos o normas de conducta" (Cassany, 2009, p. 56). El tema de las actitudes en general y de los profesores en particular ha captado la atención de numerosos especialistas en Psicología y Didáctica. Sin embargo, en lo que concierne a la actitud orientada al alumno, a pesar de su valor, no se le ha concedido la atención que merece.

Desde esta consideración, Cassany (1993) manifestaba que el alumno "no tiene que preocuparse por cometer errores, sino que tiene que saber que es un fenómeno natural y necesario para aprender" (p. 43) y añadía que "precisamente porque utiliza la lengua y se equivoca, puede aprender de sus errores” (p. 43). A su vez, más recientemente, d'Aquino (2016) resaltaba, por una parte, la importancia de la corrección de errores por cuanto que dicho proceso "permite que el aprendiente revise y reajuste su interlengua" (p. 8) y, por otra, la importancia instrumental del error por ser este considerado "un instrumento didáctico muy eficaz si se emplea de manera adecuada" (p. 7). La idea de que el alumno debe ser consciente de los errores cometidos en sus producciones, tanto orales como escritas, y aceptarlos como "motor de aprendizaje" es compartida por varios autores entre los cuales mencionamos a Giovannini et al. (1996, p. 12). 
En el contexto rumano, encontramos expresada la idea de Constantinescu (2011) de que los alumnos no solo "devront accepter leurs erreurs" (p. 85), sino que, además, deben ser conscientes de su presencia constante. Presencia ante la que deben adoptar una actitud positiva puesto que se trata de un sinónimo de progreso en su competencia lingüística. Como si fueran las dos caras de la misma moneda una valoración positiva de sus errores conducirá al alumno a experimentar un sentimiento de motivación, satisfacción y deseo de continuar con su aprendizaje. Por otra parte, la valoración negativa ante el error le llevará a actitudes negativas de frustración, decepción, desilusión e inhibición ante la producción del discurso escrito. Las actitudes transmitidas por el profesor basadas en evitar correr riesgos transmiten al alumno miedo, temor a lo desconocido, ansiedad y estrés que frenan el progreso y el avance del aprendizaje en L2.

Las autoras Santos Gargallo y Alexopoulou (2014) definen las actitudes de los alumnos como un "concepto un tanto impreciso" ya que "son un constructo difícil de delimitar por su fuerte carga de subjetividad" (p. 431). En su estudio de caso cuantitativo que realizan en torno a las creencias y actitud de profesores y alumnos griegos de ELE en relación con los errores, las autoras parten de la necesidad de analizar los factores individuales que intervienen a lo largo del proceso de aprendizaje de una L2, así como la necesidad de "reflexionar sobre las creencias, las actitudes con las que los alumnos llegan a clase" (p. 430). Se trata de creencias entendidas como representaciones mentales, las cuales: "son recursos cognitivos conformados por concepciones preestablecidas que posee el ser humano para organizar describir e interpretar el mundo y las experiencias que lo rodean. Constituyen una herramienta para procesar la información y funcionan como una guía de actuación”. (Santos Gargallo \& Alexopoulou, 2014, pp. 430-431) 
El análisis de los datos permitió a Santos Gargallo y Alexopoulou (2014) llegar a la conclusión de que las creencias de los alumnos griegos que estudian ELE varían en función del nivel de lengua que poseen. Asimismo, las citadas autoras tomando como referencia los niveles del Marco Común Europeo de Referencia para las Lenguas: aprendizaje, enseñanza, evaluación (MCER) (Consejo de Europa, 2002) indicaban que: “en el nivel A2 los alumnos consideran el error como algo positivo, mientras que en el nivel C1 predomina la consideración negativa” (p. 445). A partir de esta afirmación, podemos manifestar que "en los primeros estadios, los errores son vistos como signo de desarrollo del proceso, mientras que, en un nivel más avanzado son considerados objeto de frustración en el dominio de la lengua y en el desarrollo de su competencia comunicativa" (Santos Gargallo \& Alexopoulou, 2014, p. 445). Destacamos pues esta relación entre nivel de competencia lingüística y valoración de la corrección. Los alumnos con un nivel de L2 elevado muestran una valoración del error que suele manifestarse como negativa ya que lo consideran símbolo de frustración. No obstante, los alumnos con un nivel de L2 básico no experimentan dicho sentimiento y tienden a valorar el error de una forma positiva relacionándolo con una muestra de aprendizaje.

Por su parte, desde el ámbito de las matemáticas, Rach, Ufer y Heinze (2013), dentro del contexto educativo alemán, exponían con respecto al tema del error que los alumnos "are not familiar with reflections about their own learning processes and, in particular, with reflections about their own errors” (p. 28). En la misma línea, Rogers (2001) ya había puesto de manifiesto la dificultad que supone para el profesor exponer al alumno ante un proceso de reflexión sobre su propio aprendizaje, a pesar del potencial que tiene para obtener unos resultados satisfactorios. A 
su vez Park (2003), quien proponía la idea de solicitar a los alumnos la escritura de un diario en el que escribir acerca de las propias reflexiones afirmaba al respecto que "some students do not want to reflect on their learning experiences, it is unnatural or forces them to 'think too much' or in a different way" (p. 196). Podríamos aplicar esta teoría al ámbito de la enseñanza-aprendizaje de expresión escrita en L2 ya que nos atrevemos a suponer que, desde la óptica del alumno, son escasas las reflexiones hacia su propio proceso de enseñanza-aprendizaje en L2 puesto que, de acuerdo con Knutson (2003) "the reflection phase requires learners to engage actively with their own past acquisition experiences and focuses them on the future" (p. 53) a lo que añade el hecho de que este tipo de aprendizaje experimental que estimula la reflexión por parte del alumno "is not only time-consuming, but requires the creation of a comfortable, relaxed classroom atmosphere and skillful questioning on the part of the facilitator" (p. 55).

Truscott (1996), además, ponía de manifiesto la relación entre un aprendizaje eficaz y un proceso natural del cuerpo humano. A pesar de que el estrés, como sentimiento de tensión física o emocional incide negativamente en el aprendizaje, cuando se trata de corrección de errores los alumnos la piden. En virtud de ello, Truscott (1996) unía dicho sentimiento con la corrección y resaltaba el hecho de que, desde esta consideración, la corrección no puede incidir de manera exitosa o eficaz en la mejora del aprendizaje según indicaba: "first, learning is most successful when it involves only a limited amount of stress, when students are relaxed and confident and enjoying their learning; but the use of correction encourages exactly the opposite condition" (Truscott, 1996, p. 355). Además, es Truscott (1996), quien une la corrección con algo desagradable desde un plano emocional: 
On the surface, that students find correction unpleasant would seem to conflict with the frequent evidence that they want to be corrected. But there is nothing odd about people wanting things they find unpleasant; the only requirement is that they believe those things are helpful. Students obviously do think correction is helpful -and even necessary- so one should not be surprised that they want it in spite of its unpleasantness. In this context, it is also not surprising that students who believe in correction are still reluctant to work in any serious way with the corrections they receive, as noted previously. (Truscott, 1996, p. 355)

Si el citado autor indicaba que es el alumno quien generalmente solicita la corrección de errores, Leki (1990), en cambio, ya había manifestado que, existe una diferencia entre la enseñanza de L1 y la de L2 con respecto a las actitudes de los alumnos ante las correcciones y las marcas del profesor en las producciones escritas. La autora presenta los datos aportados por un estudio llevado a cabo por Burkland y Grimm en 1986 en el que se muestra que los estudiantes de L1 no valoran los comentarios o correcciones que el profesor incluye en sus producciones escritas considerando que no aportan información relevante que pueda servirles de ayuda. Sin embargo, una encuesta realizada en 1986 por estudiantes de inglés como L2 revelaba que estos no solo demandaban una corrección en la que todos los errores apareciesen marcados, sino que además reclamaban la incorporación de comentarios del propio profesor aportando pistas que les permitiesen corregir sus propios errores.

Por otra parte, Ferris (2003), mostrando su acuerdo con Leki (1990), no solo pone de manifiesto la demanda por parte del alumno de ser corregido sino también de recibir el feedback correspondiente. En este sentido, manifestaba su desacuerdo con Truscott (1996) respecto a su 
propuesta de apartar a los alumnos del feedback del profesor ya que, las conclusiones de los análisis de los estudios realizados por la autora sostenían la idea de que "L2 writing students find feedback of all types important and helpful" (p. 114).

Asimismo, Ferris (2003), sugiere a los profesores la elaboración de encuestas a partir de las cuales los alumnos puedan proporcionar información relacionada con sus preferencias en cuanto a la forma de corrección de errores y al tipo de feedback que les interesa recibir por parte del profesor. La autora propone esta actividad como un medio a través del cual podremos conocer información relativa a las opiniones de nuestros alumnos y sus posibles reacciones en torno a nuestra práctica docente. Así pues, como profesores se impone la necesidad de preguntar a los alumnos "about their preferences and to respect them as much as possible" (p. 92) ya que conocer sus gustos y preferencias, nos ayudará en nuestra tarea de desarrollar su motivación y estimulará el acercamiento entre profesores y alumnos.

Los resultados de los análisis de datos extraídos de distintas investigaciones, llevan a la misma autora a afirmar que:

1. Although L2 writers appreciate response on all aspects of their writing, they feel very strongly about receiving feedback about their language errors.

2. If they had to choose between forms of feedback, they clearly prefer teacher feedback, whether written or oral.

3. Students feel that a combination of feedback sources (teacher, peer, self) can also be beneficial to them. (Ferris, 2003, p. 114) 
En la misma línea, Gardner (2010) hablaba de las actitudes de los alumnos hacia el aprendizaje de su L2 mencionando el importante papel que juega la relación profesor-alumno en estas. Desde esta consideración, insiste en la idea de que la personalidad del profesor, su comportamiento y los métodos utilizados en el aula serán determinantes a la hora de establecer ese vínculo profesor-alumno. Así es como, el nivel de compromiso del profesor en su trabajo diario, la forma de dirigirse a los alumnos, su cordialidad y, sobre todo, el grado de confianza mostrado se manifestarán como aspectos que influirán de una manera decisiva en las actitudes de los alumnos hacia su L2.

La motivación, entendida por Gardner (2010) como parte intrínseca del proceso de enseñanza-aprendizaje de una L2 es un aspecto que el profesor debe tener en cuenta cuando se enfrenta a una corrección de errores. En este acercamiento, el mencionado autor señala que "when students are treated well, respected and encouraged they feel that their work is meaningful and as a consequence they will develop high levels of performance” (p. 186).

A finales de los años 90, Alfieri Lane (1997), preocupada por la corrección en la enseñanza de L2 y su impacto en el aprendizaje, realizaba una investigación centrada en las actitudes de los alumnos ante la corrección del error. Asimismo, Alfieri Lane (1997) partía, en su investigación, de la idea de que, a pesar de la existencia de numerosos estudios que demuestran que la corrección de errores no mejora el rendimiento académico, el alumno, en general, muestra una actitud positiva ante la corrección de sus errores y prefiere que estos sean corregidos afirmando que: 
Students, in fact, seem to prefer correction of their errors both orally and in writing. They often have a positive attitude toward error correction, in spite of the fact that much research shows that error correction brings little if any improvement to the students' performance. (Alfieri Lane, 1997, p. V)

Compartimos la opinión de Cassany (1993) respecto a la consideración de las actitudes del alumno hacia el error como un fenómeno natural cuya presencia es necesaria para poder aprender una L2.

Los conocimientos (en términos de identificación del error como un paso de aprendizaje), las aptitudes (entendidas como la participación activa del alumno en el proceso de corrección) y las actitudes de los alumnos en torno al error ${ }^{10}$ y a su corrección han sido objeto de estudio a través de las distintas teorías de enseñanza-aprendizaje de L2.

A nuestro juicio, estos tres componentes se configuran como fundamentales respecto a las causas y criterios de la aparición del error en las producciones escritas de los alumnos y, en este sentido, consideramos que se impone como necesidad la valoración de estos en el presente estudio de investigación.

\footnotetext{
${ }^{10}$ Como fenómeno natural que aparece en las producciones en L2.
} 


\subsection{Hacia una tipología de errores en las producciones escritas en L2}

Partiendo de la idea de la importancia del error y de su corrección en la enseñanzaaprendizaje de L2 a lo largo de las diferentes corrientes metodológicas existentes, nos posicionamos en la perspectiva de d'Aquino (2016) según la cual se han realizado numerosas clasificaciones de errores en función de los aspectos lingüísticos, de los aspectos de uso, de las estrategias que implican los errores, de los efectos comunicativos que ocasionan, así como las causas mismas de su aparición. En el presente epígrafe nos proponemos recoger una serie de clasificaciones de errores que algunos autores han puesto de manifiesto con el propósito de identificar las áreas de dificultad del proceso de corrección, así como los componentes formativos.

Un gran número de autores, entre estos Corder (1967, 1981); d'Aquino (2016); Ellis (2008) y Norrish (1983) hacen una clara distinción entre faltas (mistakes) y errores (errors). Además, d'Aquino (2016) manifiesta que precisamente dicha distinción determina un tratamiento diferente.

Como ya hemos comentado anteriormente, Norrish (1983, p. 7) establece tres tipos de errores; el primero de ellos definido como "systematic deviation, when a learner has not learnt something and consistently 'gets wrong"' (p. 7), el segundo, al que denomina mistake entendido como "inconsistent deviation" (p. 7) y el lapse, del que comenta que: "neither a mistake nor an error and can happen to anyone at any time" (Norrish, 1983, p. 7) como consecuencia de falta de concentración, cansancio, despiste, confusión o pérdida de memoria. 
Por su parte, Ellis (2008), quiso elaborar un listado de los errores más comunes de los aprendices de L2. En dicho listado incluyó “a comparison of the learner's idiosyncratic utterances with a reconstruction of those utterances in the target language" (p. 50). El mencionado autor proponía una taxonomía de errores basada en las categorías lingüísticas haciendo hincapié en la idea de que los errores más comunes son los errores de léxico seguidos de los errores gramaticales. Además, Ellis expresaba su acuerdo con otros autores respecto a la idea de que la frecuencia de los errores no es directamente proporcional a la dificultad que los alumnos presentan hacia estos. Asimismo, el autor introduce la idea de la ambigüedad de los errores cometidos por los aprendices de una L2. Según él, la mayoría de los errores son provocados por diferentes causas por lo que debemos ser precavidos a la hora de categorizar los errores.

Al mismo tiempo, Ellis (2008), haciendo referencia a la clasificación que establecía Corder en su estudio, mencionaba los tres tipos de errores que existen de acuerdo con su sistematicidad: los errores pre-sistemáticos (los cuales tienen lugar cuando el aprendiz desconoce una regla particular en su L2, errores sistemáticos (que tienen lugar cuando el aprendiz ha descubierto una nueva regla pero no la usa de manera adecuada) y errores post-sistemáticos (aquellos que surgen cuando el aprendiz conoce la regla pero no la usa de manera consistente).

Para el contexto educativo español Guillén Díaz (2004, p. 627), mencionaba la existencia de una variada tipología de errores entre los cuales se encuentran: sustituciones, calcos, hipercorrecciones e interferencias entre lengua oral y lengua escrita. Además, respecto a dicha tipología, Constantinescu (2011) matizaba que "la faute relève de la performance alors que l'erreur, elle, relève de la compétence transitoire de l'élève" (p. 84). Por lo que, de acuerdo con 
dicho autor, los errores se clasifican en dos grandes categorías; a saber: "les erreurs de compétence, recurrentes, que l'apprenant ne peut rectifier parce qu'il ne possède pas les savoirs nécessaires” (p. 84) y “les erreurs de performance, occasionnelles, asimilables à la faute, que l'apprenant peut rectifier parce qu'il dispose des savoirs adéquats et que ces erreurs sont dues à une distraction passagère" (Constantinescu, 2011, p. 84).

A la hora de hablar de tipología de errores y de establecer una clasificación de estos, debemos limitarnos a un tipo de discurso. Su detección, análisis y posterior tratamiento se llevará a cabo en función de su tipología. En nuestro caso particular, centraremos nuestra atención en el discurso escrito por lo que las características del tratamiento del error tendrán relación con las características del discurso escrito ya que, como destacaba Norrish (1983, p. 64): "writing is different, since it has the advantage of being permanent".

Por otra parte, Durán (2011) tras definir el concepto de interferencia como "negative transfer from the learner's first language to the second language” (p. 66) hace alusión a los componentes del sistema lingüístico que, según él, son susceptibles de verse perjudicados por las interferencias: el léxico, la gramática, la fonética y la pragmática. En palabras del mencionado autor, la interferencia es la causa principal de que los alumnos de L2 cometan errores y, al respecto, presenta en su artículo algunos ejemplos de errores comunes ocasionados por transferencia de alumnos españoles que estudian inglés como L2.

Partiendo de los aspectos de la lengua más afectados por las transferencias que menciona Durán (2011) en su obra: fonética, léxico, gramática y pragmática y centrándonos en nuestro 
contexto de investigación orientado hacia las producciones escritas en L2, escogemos como tipos de errores más representativos (en cuanto a la unidad o nivel implicado) los errores de léxico, los gramaticales y los pragmático-culturales. Decidimos no hacer referencia al aspecto fonético puesto que nuestra investigación se enmarca en el ámbito de las producciones escritas de los alumnos.

\subsubsection{Los errores de léxico y su papel en las producciones escritas en L2}

Consideramos necesario poner de relieve la importancia del error de léxico por afectar de manera importante en el contenido y en la transmisión del texto escrito. En virtud de ello, nos situamos en la línea de Santos Maldonado (2002) quien afirmaba que "no se puede hablar de apropiación de una lengua ni de comunicación sin tener en cuenta el componente léxico” (p. 264).

A su vez, Agustín Llach (2011) también hacía alusión a los errores de léxico apoyándose en la idea de que "the observation that vocabulary is central to language development has promoted this increase in research studies in the lexical field" (p. 9). Además, "learners consider vocabulary as the most important aspect of language" (Agustín Llach, 2011, p. 9). Por todo ello, "lexical errors have also occupied researchers in second language acquisition (SLA) and teaching in recent years" (Agustín Llach, 2011, p. 9).

Se ha constatado asimismo que la producción escrita no es tarea fácil para un estudiante de L2. Así pues, nos afirmamos en la necesidad, por parte de los alumnos, de contar con un amplio repertorio de léxico de la L2 para poder ser capaces de elaborar una producción escrita de calidad. 
Manifestamos nuestro acuerdo con Agustín Llach (2011) cuando afirmaba que "there is enough evidence to assume lexical errors to be important predictors of writing quality, relevant measures of lexical knowledge and crucial insights into the vocabulary acquisition process" (p. 10). En su estudio, la citada autora analiza la producción de errores de léxico de un grupo de alumnos de Educación Primaria a lo largo de dos años. A través de la observación y análisis de los errores cometidos por los alumnos, presentó como parte de sus conclusiones la idea de que, respecto a la destreza de expresión escrita en L2 "by examining the mechanisms that explain lexical errors we can start discovering the processes that are activated in lexical acquisition" (Agustín Llach, 2011, p. 10).

Basándose en sus experimentos dirigidos a estudiar la adquisición de la fluidez léxica, Kroll, Michael, Tokowicz y Dufour (2002) afirmaban que, en la adquisición de las representaciones léxicas en L2 de estudiantes adultos es evidente la existencia de una transferencia de la L1 a la L2 y que dicha transferencia "has been documented across many aspects of language processing" (p. 138).

Tanto Agustín Llach (2011) como Kroll et al. (2002) afirman que, en las primeras etapas del proceso de adquisición de una L2, el estudiante adulto realiza una asociación del término expresado en L2 con el correspondiente en su L1. No obstante, a medida que ese alumno se adentra en el proceso de adquisición, deja de establecer asociaciones y empieza a adquirir los términos en L2 sin tener que acudir a la representación en su L1. Además, según destacaban Kroll et al. (2002): "lexical development is affected by cognitive abilities" (p. 166) por lo que, el nivel de competencia léxica de un estudiante se medirá en función de sus habilidades cognitivas. 
En el estudio longitudinal que realizó Agustín Llach (2011) en torno a las producciones escritas realizadas por un grupo de alumnos desde $4^{\circ}$ hasta $6^{\circ}$ curso de Educación Primaria se analizaba el papel de los errores de léxico en la evaluación global de sus producciones escritas. En sus conclusiones ponía de manifiesto que "vocabulary has been traditionally seen as a positive indicator or predictor of the quality of a written text" (Agustín Llach, 2011, p. 144). Estas conclusiones lo llevaron a afirmar que: "lexical errors or a low lexical accuracy ratio implies a lower grade in the composition" (p. 144). Por lo que, podemos observar, situándonos en la perspectiva de dicha autora, que el contenido y la transmisión de las producciones escritas de los alumnos de L2 están en relación directa con el número de errores de léxico cometidos.

Asimismo, lo indicado por los autores arriba mencionados nos permite afirmar por tanto que el éxito de la producción de un texto en L2 depende directamente de la competencia léxica con la que cuente el alumno.

\subsubsection{La incidencia de los errores gramaticales en las producciones escritas en L2}

Los errores gramaticales forman una parte esencial del discurso escrito según precisaban Myhill y Whatson (2014). Teniendo en cuenta las palabras de dichas autoras, "there is a folk theorization of grammar as central to supporting students' accuracy as language users and in the eradication of errors from their speech and writing" (p. 45). 
Cuando aludían a los estudiantes de ESL, Ferris y Hedgcock (1998) afirmaban en su obra que estos son capaces de elaborar mejores textos tras haber sido expuesto a la denominada “process-oriented pedagogy” (Ferris \& Hedgcock, 1998, p. 197) como metodología de enseñanzaaprendizaje de expresión escrita en inglés como L2. A pesar de ello, estas producciones "may contain excessive grammatical and lexical inacuracies by the standards of academicians" (Ferris \& Hedgcock, 1998, p. 197) por lo que se impone la necesidad por parte de los profesores de enseñar a sus alumnos a desarrollar habilidades de revisión y corrección de textos.

En sintonía con Ferris y Hedgcock (1998), antes de que existiera este tipo de pedagogía, la corrección de errores y el feedback de los profesores estaban orientados exclusivamente a intentar reducir el número de errores cometidos por el alumno poniendo especial atención en los errores gramaticales. Sin embargo, con esta nueva pedagogía, los profesores dirigen su atención hacia la forma de elaborar una producción escrita, cómo revisarla y, en líneas generales, cómo mejorar el proceso en sí mismo. Este cambio de dirección provoca que un determinado número de profesores comience a dejar a un lado la enseñanza de reglas gramaticales a los alumnos de L2 y den un giro brusco hacia el otro extremo, "giving little or no attention to the morphosyntactic or lexical accuracy" (Ferris \& Hedgcock, 1998, p. 198). A esta idea se une el hecho de que "teaching grammar and editing skills to ESL writers can be tedious, difficult, and frustrating" (Ferris \& Hedgcock, 1998, p. 198).

Es a finales de los años 80 cuando aparece un nuevo enfoque orientado a la enseñanza de la producción escrita denominado "English for Academic Purposes (EAP) approach to writing instruction” (Ferris \& Hedgcock, 1998, p. 198). El enfoque se acercaba a la enseñanza del proceso 
de escritura a través de varios tipos de actividades como es el sistema de borradores encadenados, actividades de pre-escritura, de revisión y colaboración en parejas, etc. Con este enfoque se observa una clara preocupación por enseñar a los alumnos a producir un discurso escrito que pueda calificarse de correcto tanto en su contenido como en su forma. Como consecuencia de este nuevo enfoque, "in the 1990s, many experienced teachers feel that attention to both fluency and accuracy in student writing is not only possible but necessary" (Ferris \& Hedgcock, 1998, p. 198).

De la misma forma, Santos Gargallo (1994) manifestaba su acuerdo en lo que respecta a la corrección de los errores gramaticales afirmando que "el tratamiento de los errores y la reflexión sobre los mismos podrán ayudar a pulir y mejorar el conocimiento gramatical de los alumnos y, por ende, su capacidad para comunicarse de forma escrita" (p. 173). La autora insistía en la necesidad de mostrar a los alumnos una visión de apertura ante el error valorando sus esfuerzos por comunicarse sin dejar a un lado la corrección gramatical. En esta óptica, declaraba que tanto la comunicación escrita en L2 como la corrección gramatical del discurso escrito juegan un papel igual de importante. Sin embargo, como profesores de L2 hay situaciones en las que se impone establecer una serie de prioridades a la hora de otorgar primacía bien a la capacidad de comunicarse, en nuestro caso a través de un discurso escrito, o a la corrección gramatical escrita.

Todas estas ideas nos inscriben en la línea de la ya constante polémica en torno a la corrección o no de errores gramaticales en función de una serie de factores como la edad del alumno, el nivel de dominio de la lengua de enseñanza-aprendizaje, el nivel de competencia lingüística, la situación comunicativa, etc. 


\subsubsection{Los errores pragmático-culturales y su valor comunicativo en las producciones escritas en $\mathrm{L} 2$}

La competencia pragmática hace referencia, de acuerdo con Cenoz Iragui (2004), a las "relaciones entre signos y referentes y también a las relaciones entre usuarios de la lengua y contexto de comunicación" (p. 456) y engloba dos subcompetencias: la ilocutiva, que describe la relación existente entre el enunciado y la función que el hablante pretende realizar a través de su uso y la sociolingüística, que establece las condiciones que han de cumplirse para que un enunciado sea considerado correcto en una situación comunicativa determinada.

Nos situamos, por tanto, en la línea de Agustín Llach (2005) por cuanto que "la competencia pragmática se ha erigido en un componente básico de la competencia comunicativa" (p. 100). Así pues, "su consecución se convierte en una de las metas fundamentales de la enseñanza de LE, porque una competencia pragmática imperfecta genera errores pragmáticos que tienen graves consecuencias en la comunicación e incluso en la propia imagen del aprendiz de LE” (pp. 100-101).

En palabras de Bou Franch y Gregori Signes (1998), el dominio de los aspectos pragmáticoculturales constituye "una cuestión fundamental frecuentemente olvidada por los profesores de lenguas extranjeras, y de difícil enseñanza y aprendizaje” (p. 123).

Recurrimos a las palabras de Agustín Llach (2005) respecto a que: 
Para favorecer el más rápido y efectivo desarrollo de la competencia pragmática los profesores de LE deberían proporcionar a sus alumnos información contrastiva explícita sobre aspectos pragmáticos en Ll y LE, además de realizar práctica explícita del uso léxico en contextos comunicativos que reflejen la realidad. (p. 101)

En el contexto norteamericano, Koike (2012) indicaba como recursos pragmáticos "any pragmatic realizations (e.g. speech acts, deictic forms, implicatures, discourse markers, humor) that speakers and listeners employ to construct their intentions and understand those of others in interaction" (p. 176). Así pues, dentro de la categoría de errores pragmáticos se encuentran aquellos que tienen graves consecuencias en la interacción comunicativa entre hablantes y/o estudiantes de una misma lengua, en nuestro caso particular, alumnos de inglés o español como L2.

En torno a los errores pragmáticos Agustín Llach (2005) declaraba que estos pueden ocasionar un "malentendido entre los interlocutores que pueden llevar incluso a una interrupción de la comunicación ya que una comunicación efectiva depende de una buena competencia pragmática" (pp. 97-98).

El error pragmático es definido por el Diccionario de términos clave de ELE (1997-2017) del CVC en su edición electrónica como aquel "que es cometido, tanto en la producción como en la recepción, por un desconocimiento de las normas o valores socioculturales de la lengua”. La aparición del error pragmático está directamente relacionada con los factores extralingüísticos. Así 
pues, un enunciado puede contar con un valor comunicativo propio de la cultura perteneciente a la lengua en que se transmite.

Retenemos la idea de Woodfield (2012) por cuanto que la producción pragmática está directamente relacionada con las diferencias interculturales tan presentes en todo tipo de discurso oral o escrito. Estas representan una fuente importante de malentendidos culturales que, a su vez, son el resultado del desconocimiento de elementos culturales, de un bajo nivel de la lengua o simplemente de la falta de un conocimiento consciente de los elementos pragmáticos y culturales que están presentes en un mensaje transmitido en una lengua que no es la materna. En su estudio enmarcado en las interacciones interculturales entre estudiantes españoles de inglés y hablantes nativos, Bou Franch y Gregori Signes (1998) aluden a nuestra responsabilidad como profesores de hacer conscientes a los alumnos de las decisiones lingüísticas adoptadas en sus producciones en L2 y sus consecuencias.

A través de la pragmática damos cuenta de las normas socioculturales que rigen los intercambios comunicativos en una determinada lengua-cultura. En nuestro propósito de apoyar a nuestros alumnos en la perspectiva de superar los errores pragmático-culturales, debemos acercarlos a los elementos linguiísticos, léxicos y estructuras gramaticales con los que implementar esos actos comunicativos.

Se impone la necesidad de incluir un recorrido a través de los distintos tipos y clasificaciones de errores en nuestro estudio de investigación enfocado en las producciones escritas de los alumnos de L2 de la etapa educativa de Educación Primaria. Consideramos que dicho 
recorrido entra a formar parte de los conocimientos sobre la lengua de enseñanza en torno a los cuales se debe proporcionar formación al profesor de L2. La presente Tesis Doctoral se circunscribe al ámbito de la Lingüística por estar dirigida al conocimiento sobre la lengua que se enseña $\mathrm{y}$, en este sentido, nos aproximamos a la formación del profesorado en torno al conocimiento de la lengua, las aptitudes en torno a la corrección de posibles errores y las actitudes ante estos.

A todo este recorrido cabe añadir que, nuestro deber como profesores de L2 es plantear actividades de exposición de los alumnos ante determinados textos que contengan distintos tipos de errores para, posteriormente, pedirles que los identifiquen y corrijan. A nuestro juicio, cabe destacar el trabajo de Álvarez Piñeiro y Camiña Salgado (2005) quienes sugieren varias propuestas metodológicas a partir de la exposición de sus alumnos ante un conjunto de producciones escritas encontradas en la publicidad que contienen errores gramaticales, ortográficos y de léxico. En el estudio que llevaron a cabo, fueron los propios alumnos los encargados de detectar y corregir los errores presentados “dotando al proceso de aprendizaje de un componente lúdico que estimula la motivación" (p. 28).

A pesar de lo mucho que se ha escrito acerca del error, este sigue siendo un tema que, como ya hemos venido anunciando, origina un amplio debate entre especialistas de la lengua y profesionales de la enseñanza. El error unido a la idea de corrección y feedback constituye un elemento de análisis y reflexión de gran valor didáctico tanto para el alumno como para el profesor de L2. 
La valoración positiva del error por parte de profesores, alumnos y toda la comunidad de hablantes en general ha predominado gracias a la llegada de nuevas teorías de enseñanzaaprendizaje de L2. Esta postura de aceptación y de valoración del error ha de ser tomada por el alumno quien debe ser consciente de su importancia dentro del proceso de enseñanza-aprendizaje de la L2.

Es evidente que todos y cada uno de los errores juegan un papel importante en la enseñanzaaprendizaje de L2. A pesar de las muchas clasificaciones que se han hecho en torno al error y de los muchos intentos de categorizarlo, no debemos dejar a un lado la idea de que los errores, en repetidas ocasiones están originados por más de una causa. Tal y como se ha venido planteando se impone la necesidad de establecer unos criterios objetivos para la corrección de errores. Sin embargo, es también importante que siempre tengamos en cuenta las características individuales de cada alumno, de cada situación de enseñanza-aprendizaje, etc. 



\section{Capítulo 2. FORMACIÓN DEL PROFESORADO DE L2: CORRECCIÓN Y FEEDBACK}

2.1. Consideraciones en torno a la corrección como acto comunicativo

2.2. Formación del profesorado con respecto al error y a su corrección 


\subsection{Consideraciones en torno a la corrección como acto comunicativo}

Al plantear el tema de la corrección, nos situamos en la línea de Cassany (1993) y consideramos que esta forma parte esencial del proceso de producción de textos y representa, por tanto, una parte intrínseca de la destreza de la expresión escrita.

Según afirmaba recientemente d'Aquino (2016, p. 10), la corrección puede entenderse como "acto comunicativo" o "acto de comunicación" que se lleva a cabo con un único objetivo: “ayudar" (p. 11). En este acto entran en juego varios factores como la relación alumno-profesor, la jerarquía de conocimientos, la edad del alumno, la actitud del profesor y del alumno ante el error, el tono que emplea el profesor y la retroalimentación que deben tenerse en cuenta a la hora de corregir errores. Una corrección entendida en términos de "interacción” (d'Aquino, 2016, p. 10) puede llegar a adquirir una serie de connotaciones desde el punto de vista afectivo. Es el caso del "exceso de correcciones" (d'Aquino, 2016, p. 11) que puede convertirse en una fuente de frustraciones tanto para el profesor como para el alumno.

En relación a los comentarios que añadimos a las redacciones de nuestros alumnos, volvemos a hacer referencia a Cassany (1993), quien indicaba que existen numerosas cuestiones sin resolver para el docente relacionadas con estos, a saber: "¿son realmente apropiados y provechosos (...), hacemos demasiados o demasiado pocos?” (p. 11), “¿los entienden los alumnos?” (p. 11), “ppor qué estos, al rehacer el texto, sólo aprovechan algunos comentarios y olvidan otros?” (p. 11), o “por qué muchas veces la corrección fracasa y el alumno repite una y otra vez las mismas faltas?" Cassany (1993, p. 11). Como conclusión a todas estas cuestiones, 
Cassany (1993) afirmaba que "sabemos muy poco o nada de todo esto" (p. 12) a lo que añade que "la corrección requiere urgentemente el interés y la dedicación científica de maestros y pedagogos" (p. 12). En su obra, Cassany (1993) hace referencia a varios estudios realizados en castellano y catalán por varios didactas y profesionales de la Lingüística cuyas aportaciones, en palabras del propio autor, "son más útiles para los evaluadores (...) que para los maestros preocupados por buscar la forma más clara y eficaz de corregir las redacciones de los alumnos” (p. 12).

Por su parte, Fernández López (1995), refiriéndose a la reacción del corrector ante las producciones escritas de los alumnos, destacaba que "lo primero es reaccionar como interlocutores, no como correctores, porque distorsionamos el mismo proceso de aprender a escribir en la L2" (p. 212); asimismo "podemos proponer una corrección, lo más interactiva posible -de forma que el alumno tenga posibilidad de plantearse la duda, buscar, etc.- y centrada en lo que se está trabajando" (p. 212). Además, la citada autora insiste en que, en numerosas ocasiones, “si el aprendiz está intentando comunicar algo, con la atención centrada en el sentido, la corrección le pasa inadvertida" (p. 212) por lo que propone "practicar la «corrección comunicativa»: si somos uno más en la interacción, podemos intervenir como lo hacemos en una conversación normal, dando la palabra que falta, retomando una frase, resumiendo una postura, etc.” (p. 212) concediendo al alumno "la oportunidad de oír de forma correcta una determinada estructura" Fernández López (1995, p. 212) sin interrumpir en la comunicación.

A su vez, Truscott (1996, p. 355) alude a otro inconveniente que entraña la corrección como parte de la responsabilidad del docente: la cantidad de tiempo que el profesor debe emplear en las 
correcciones. Se trata, según apunta el autor, de una cantidad de tiempo desmesurada, sobre todo cuando el grupo de alumnos es numeroso, tal y como queda expresado a continuación:

The time problem is even greater-in fact, much greater-for teachers. In a class with many students and many writing assignments, correction of grammar errors can absorb an enormous amount of a teacher's time, time that could be spent more productively (and perhaps more pleasantly) on other things. (Truscott, 1996, p. 355)

También Cassany (1993), recordando el estudio de Sommers (1982) destacaba que la corrección de errores es “una de las tareas que consume más tiempo y esfuerzos del profesor” (p. 11) y, además, d’Aquino (2016) resaltaba que esta debe realizarse “de una manera respetuosa hacia el productor del error” (p. 7). Cassany (1993) planteaba la idea de necesidad de autorreflexión sobre el propio trabajo de corrección ya que, según él, los profesores emplean una cantidad de tiempo excesiva en corregir y en escribir una serie de comentarios en las producciones escritas de los alumnos que, en la mayoría de los casos, resultan prácticamente invisibles e inservibles para estos.

En el proceso de corrección, entendido este como una revisión hecha por el profesor con el propósito de ayudar al alumno a perfeccionar su producción, entran en juego los diferentes factores que se muestran en la Figura 2 presentada a continuación en cuya parte central se encuentran las características principales del profesor, sus criterios o actitudes y el rendimiento del alumno a la hora de enfrentarse a una prueba de evaluación. 


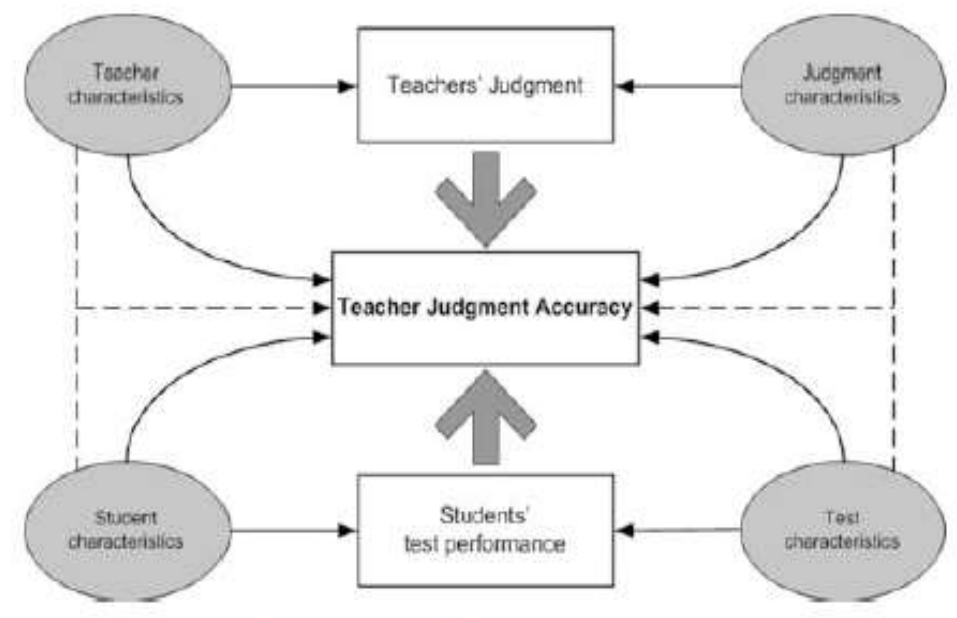

Figure 1. Heuristic model of teacher judgment accuracy.

Figura 2. Criterios de corrección adoptados por el profesor. Tomada de Südkamp, Kaiser y Möller (2014, p. 6)

En la figura 2, se indican los elementos que forman parte del proceso de corrección condicionados por las características que presenta cada uno de los agentes implicados en el proceso. Así pues, las características del profesor y las características propias de la evaluación influirán directamente en los criterios que elija para corregir. Por otro lado, las características del alumno y las propias de la prueba o test de evaluación ejercerán una clara influencia en los resultados de las pruebas de los alumnos. A su vez, todos estos elementos influirán de manera decisiva en el criterio de corrección del profesor. En relación a los criterios de corrección, Südkamp, Kaiser y Möller (2014) destacaban, en su trabajo de investigación, que las características personales del profesor influyen de manera decisiva en los criterios adoptados. De acuerdo con esto, los citados autores afirmaban que "many instructional decisions are determined by teachers' subjective judgments of their students' achievement" (p. 5). Sin embargo, esta subjetividad 
manifestada a nivel de criterios personales del profesor se encuentra en relación directa con lo objetivo, por cuanto que la corrección se plantea como algo que se debe medir con exactitud.

Según ponía de manifiesto Alfieri Lane (1997, p. 38), los errores son una parte natural del proceso de enseñanza-aprendizaje. La diversidad de situaciones en las que estos pueden aparecer también viene a resaltar la importancia de la corrección tanto en la producción del discurso escrito como en la del discurso oral (Alfieri Lane, 1997; Cassany, 1993). Así pues, Alfieri Lane (1997, p. 8) consideraba que "correction is necessary in communication activities because it helps accuracy and improves learning" (p. 8).

Desde nuestro punto de vista, la corrección de errores se ha de entender como un acto de comunicación e interacción que se establece entre profesor y alumno con el objetivo de ayudar al alumno en el proceso de aprendizaje de la lengua objeto de enseñanza- aprendizaje.

La idea de mantener una actitud positiva por parte del profesor hacia el error y hacia el proceso de corrección de este se impone, según señalaban varios autores (Barros Díez, 2008; Cassany, 1993; d’Aquino, 2016; de la Torre et al., 1994; Ferris, 2003 y Torijano Pérez, 2004) como una necesidad en el proceso de enseñanza-aprendizaje de una L2 ya que puede marcar de manera decisiva no solo en el aprendizaje del alumno sino también en su motivación. Asimismo, Cassany (1993) proponía la idea de realizar un intercambio de roles de manera que no se asigne siempre al profesor el papel de corrector. Sugiere que sean los compañeros del aula o bien los mismos alumnos los correctores haciéndoles partícipes de la actividad e integrándolos así dentro del proceso de aprendizaje. El alumno debe, por tanto, asumir su responsabilidad y desarrollar su 
autonomía durante el proceso de corrección para "poder defenderse solo, en un futuro inmediato, con la escritura" (Cassany, 1993, p. 16).

\subsubsection{La corrección de errores y sus funciones}

La corrección tiene una doble función instrumental puesto que, a través de ella, el alumno puede aprender a partir de sus errores y, al mismo tiempo, es un "instrumento muy eficaz para la labor docente" (d'Aquino, 2016, p. 12).

Tanto la corrección como el tratamiento de los errores son APD asumidos por el agente recurso humano-profesor (Guillén Díaz \& Castro Prieto, 1998; Roy, 1991). Dichos APD, como actividades que forman parte de la intervención didáctica y la evaluación del alumno son objeto de toma de decisiones en la enseñanza efectiva. La detección de errores, su corrección y tratamiento pueden ser indicadores para poder ofrecer solución a problemas concretos que han surgido en el aprendizaje causados, según encontramos expresado en d'Aquino (2016), por varios factores, entre estos, las dificultades propias de la lengua, interferencias con la lengua materna, interferencias con otras lenguas, aspectos emocionales y afectivos del alumno, procedencia lingüística y cultural, etc.

Hablar de corrección de errores y de su tratamiento en el aula implica contemplar la formación de los agentes-profesores y la adquisición de lo que denominamos competencia 
profesional docente entendida esta a partir de sus componentes; a saber, conocimientos, aptitudes y actitudes necesarios para llevar a cabo el APD de evaluación.

Es una evidencia el hecho de que la corrección de errores ha despertado el interés y la dedicación científica de lingüistas y, en consecuencia, se han realizado numerosos estudios tanto en el campo de la Lingüística, que enfocan distintos aspectos relacionados con esta.

En este contexto, Vez et al. (2002) contribuyen con sus conocimientos acerca de la corrección, e identifican dos tipos en función del momento en el que el profesor interviene en dicha actividad. Se trata de la corrección inmediata y la corrección en diferido; la primera, a su vez, se diversifica en corrección directa o indirecta, tal y como aparece indicado en el Cuadro 2 que se muestra a continuación tomado de los citados autores.

\begin{tabular}{|l|ll|}
\hline \multicolumn{2}{|c|}{ Directas } \\
\hline - Dar la forma correcta. & - Simular no haber entendido. \\
- Dar la forma correcta y hacer repetir. & - Retomar la frase entera \\
- Corrección $+\quad$ repetición & & $\begin{array}{l}\text { corrigiendo. } \\
\text { explicación. }\end{array}$ \\
- Iniciar la frase e indicar seguir. & & Pedir confirmación. \\
- Implicar a los compañeros. & \\
\hline Cuadro 2. Fórmulas directas e indirectas para la corrección inmediata. Tomado de Vez et al. (2002, p. 256)
\end{tabular}

La corrección inmediata, ya sea directa o indirecta, tiene lugar de manera automática y, en este sentido, su consecuencia suele concretarse en una obstaculización en la producción del alumno provocando en este bloqueos e impedimentos. Los mencionados autores proponen utilizar 
determinadas fórmulas tal y como se ha podido observar en el cuadro tomado de Vez et al. (2002, p. 256).

Por su parte, la corrección en diferido se realiza después de la producción de los alumnos. Permite que estos no sientan la presión de estar siendo evaluados y no interrumpe "la secuencia de sus producciones" (Vez et al., 2002, p. 256). Puede llevarse a cabo tanto de forma pública como privada y para conseguir una correcta ejecución, los autores aconsejan la utilización de una serie de fórmulas que señalamos en la siguiente cita:

- Anotar los errores por escrito (en privado en el registro del profesor).

- Anotar los errores por escrito (en público, en el encerado, a la vista de todos).

- Hacer pausas para la corrección.

- Proponer actividades o ejercicios de refuerzo muy selectivos. (Vez et al., 2002, p. 256)

Como ya hemos venido señalando, el contexto en que se sitúa el presente trabajo de investigación es el de alumnos de Educación Primaria que realizan sus producciones escritas de en inglés o español como L2. A nuestro juicio, la opción de corrección oral inmediata propuesta por García-Heras Muñoz (2004) en la que el profesor corrige y hace llegar sugerencias al alumno mientras este realiza su producción escrita es el tipo de corrección que mejor se ajusta a las particularidades de la situación educativa que nos compete, aunque consideramos que ambas alternativas pueden ser complementarias en situaciones muy específicas. 
Desde nuestro punto de vista, los alumnos deben tomar conciencia de sus propios errores ya que eso permitirá aumentar su competencia en la L2. Es por ello que, como profesores, debemos exponerlos ante situaciones en las que ellos mismos puedan detectar el error y, posteriormente, corregirlo. Encontramos en Vez et al. (2002) la misma idea de necesidad de mostrar al alumno los errores cometidos y de hacer pausas para que puedan detectarlos y, posteriormente, llevar a cabo actividades de refuerzo.

Después de conocer la propuesta de Vez et al. (2002) nos acercamos también a Ferris (2004) con el propósito de conseguir un marco de referencia que nos permita analizar la corrección de errores en profundidad. En la siguiente cita, la autora, partiendo de la idea de que la corrección de errores constituye una parte fundamental del aprendizaje de una L2, aporta seis recomendaciones para una corrección eficaz:

- Error treatment, including error feedback by teachers (is a necessary component of L2 writing instruction. We must prepare ourselves to do it competently, we must plan for it carefully in designing our courses, and we must execute it faithfully and consistently. In the majority of instances, teachers should provide indirect feedback that engages students in cognitive problem-solving as they attempt to self-edit based upon the feedback that they have received. (Exceptions may include students at lower levels of L2 proficiency, who may not possess the linguistic competence to selfcorrect). 
- Different types of errors will likely require varying treatments. Students may be less capable, for instance, of self-editing some lexical errors and complex, global problems with sentence structure than more discrete morphological errors.

- Students should be required to revise (or at least self-edit) their texts after receiving feedback, ideally in class where they can consult with their peers and instructor.

- Supplemental grammar instruction (in class or through individualized self-study materials recommended by the instructor) can facilitate progress in accuracy if it is driven by student needs and integrated with other aspects of error treatment (teacher feedback, charting, etc.).

- The maintenance of error charts, ideally by the students themselves with guidance from the instructor, can heighten student awareness of their weaknesses and of their improvement. (Ferris, 2004, pp. 60-61)

La propuesta de Ferris (2004) introduce el feedback como elemento constitutivo de la corrección de errores, pudiendo este concretarse en feedback directo o indirecto. Además, menciona el hecho de introducir una variedad de tratamientos en función de los tipos de errores entre los que se encuentran la revisión y/o autocorrección por parte del alumno después de recibir el feedback del profesor y el uso de tablas. Tablas en las que se presente un listado de posibles modelos de errores a modo de indicadores de la situación de enseñanza-aprendizaje en que se encuentran los alumnos. A nuestro juicio, la aportación de esta autora en torno a la presencia de todos los elementos anteriormente mencionados abre una perspectiva más amplia sobre la responsabilidad que asume el docente en la corrección de errores. 
Con el mismo objetivo de arrojar luz sobre la responsabilidad docente en la corrección de errores, Giovannini, Martín Peris, Rodríguez Castilla y Simón Blanco (1996) muestran, en su obra, una clara tendencia hacia la corrección en diferido afirmando que, durante el proceso de corrección, el profesor no debe transmitir a los alumnos la sensación de estar siendo evaluados. Hay estudios que llegan a afirmar que, si no se corrigen todos los errores, cabe la posibilidad de que el alumno los asocie con una producción correcta. No obstante, en palabras de los autores, los profesores nunca podremos estar seguros de que "percibimos todos los errores que presentan las producciones orales y escritas de nuestros alumnos" (Giovannini et al., 1996, p. 22). Es posible que, en ocasiones, resulte difícil detectar "los errores de interpretación de una regla o de un fenómeno" (p. 22) o hacer "una interpretación correcta de la intención de una expresión (oral o escrita)" (p. 22). Por todo ello, añaden que es preferible hacer saber al alumno que no corregimos todos los errores.

A lo largo de la historia de la enseñanza-aprendizaje de lenguas se han llevado a cabo numerosos estudios en torno a varios aspectos entre los cuales mencionamos: la corrección, la tipología de errores (Gorbet, 1974), la relación que se establece entre corrección y edad del que aprende, el nivel de aprendizaje, los objetivos planteados, el nivel de la tarea, la eficacia de las técnicas de corrección (Burt, 1975), la relación entre corrección y fluidez, y las actitudes de alumnos y profesores ante la corrección y el tratamiento de los errores. No son pocos los estudios sobre los conocimientos y la concepción de los profesores en torno a la corrección en función de la evolución de las teorías de enseñanza-aprendizaje de L2, aunque se necesitan muchos más estudios empíricos al respecto. 


\subsubsection{El tratamiento del error y sus funciones}

El tratamiento del error en el aula llega a tener múltiples funciones. Su atención para el ámbito de conocimiento de la Lingüística surge a partir de las nuevas teorías de aceptación del error como parte del proceso de enseñanza-aprendizaje.

Según ponía de manifiesto Guillén Díaz (2004), puede llegar a cumplir con la función de sensibilizar a los alumnos en los diferentes tipos de errores. Sin embargo, encontramos también funciones asociadas al tratamiento del error como la de verificar las hipótesis de aprendizaje (d'Aquino, 2016; Giovannini, et al., 1996). A su vez, d'Aquino (2016) identificaba otras funciones de la corrección entre ellas la reflexión sobre la lengua y la búsqueda de soluciones alternativas o nuevas hipótesis.

De acuerdo con Giovannini, et al. (1996), dichas hipótesis van apareciendo a medida que los alumnos interiorizan su aprendizaje, proceso durante el cual se producen numerosos "reajustes y replanteamientos" (p. 10) entre los que se dan episodios que tienen que ver con "la reaparición de formas anómalas o erróneas" (p. 10) y que, como profesores de L2, "muchas veces nos causa irritación” (p. 10). 
En torno al tratamiento del error en el aula de L2, Tedick y de Gortari (1998, p. 4) lanzaban cuatro propuestas fundamentadas en sus experiencias como docentes; a saber:

“Consider the context". Durante el diseño de las actividades de corrección y su puesta en práctica, debemos analizar el contexto en el que se enmarcan las producciones de los alumnos. Teniendo en cuenta dicho contexto, se procederá a llevar a cabo un determinado tipo de actividad de corrección de errores.

"Become aware of your current practices". Se impone la necesidad de valorar las opiniones de otros profesionales de la educación respecto a nuestra práctica docente. Los autores apoyan la idea de recurrir a la ayuda de un compañero de profesión que esté dispuesto a entrar en las aulas y observar la actuación respecto a las correcciones y el tratamiento de errores. A partir de esa tarea de observación, el profesor procederá a facilitar el feedback haciendo llegar sus impresiones. Dicho feedback permitirá la reflexión sobre la práctica docente en torno a la corrección y tratamiento del error.

"Practice a variety of feedback techniques". Se plantea la necesidad de estar abiertos a diferentes técnicas tanto de corrección como de feedback. Resulta imposible pensar que un determinado sistema de corrección o un mismo modo de facilitar feedback pueda tener el mismo impacto en todos los estudiantes. Se impone, por tanto, ajustar y seleccionar los distintos sistemas a las necesidades educativas de nuestros alumnos en todo momento. Cada uno de los alumnos presenta una serie de rasgos diferenciadores: edad, sexo, nivel de competencia comunicativa, situación de enseñanza-aprendizaje de L2, etc., en función de los cuales crearemos distintas situaciones de corrección de errores en el aula. Se espera que el profesor cuente con una serie de mecanismos de 
corrección y de feedback para poder hacer uso de aquel que mejor se ajuste a las características individuales de los alumnos.

"Focus on the learner-it's important to let the learner self-correct". La corrección de errores implica un complejo proceso de toma de decisiones por parte del profesor de L2. Mostramos nuestro acuerdo con Tedick y de Gortari (1998) por cuanto que debemos proporcionar ocasiones a los alumnos en las que sean capaces de detectar sus propios errores y, posteriormente, corregirse a sí mismos. La opción rápida de facilitar al alumno la respuesta correcta inmediatamente no contribuye al desarrollo de su competencia comunicativa ya que no tiene a su disposición el tiempo necesario para reflexionar sobre el propio funcionamiento de la lengua.

Desde el contexto español, Santos Gargallo (1994) proponía ciertas técnicas de tratamiento de errores y estrategias de corrección para alumnos de nivel intermedio de L2 que necesiten mejorar su competencia gramatical en la perspectiva de poder comunicarse por escrito. En primer lugar, propone la elaboración de listas que contengan una serie de errores típicos extraídos de determinadas producciones escritas tomadas como modelo. La exposición de los alumnos ante ciertos tipos de errores comunes facilitará la reflexión sobre el funcionamiento de la L2 y sobre el grado de importancia de cada uno de los errores.

La noción de tratamiento del error se sintetiza en una serie de estrategias y técnicas en las que se toma como punto de partida el error como herramienta de aprendizaje en el aula de L2. Estraemos la idea de Fernández (2012) por cuanto que, para poder llegar a contribuir desde el área de enseñanza-aprendizaje de L2 a optimizar el tratamiento del error, se impone la necesidad de una toma de conciencia de los errores tanto por parte del profesor como del alumno. 


\subsubsection{De la corrección al feedback}

Como hemos venido apuntando, todo proceso de enseñanza-aprendizaje de una L2 implica la presencia del error en las producciones del alumno. Dicha presencia conlleva el planteamiento de la corrección y posterior feedback en el aula de L2.

Desde esta óptica, reflexionamos sobre los términos de corrección y feedback los cuales, forman un todo indisoluble llegando a ser considerados las dos caras de una misma moneda. La corrección ocupa un lugar intermedio entre los dos ámbitos de conocimiento, a saber, la Lingüística y la Didáctica. En cambio, la atención hacia el feedback ha estado enfocada especialmente desde la Didáctica de la L2. Así es como, desde la Lingüística, se plantea la necesidad de estudios empíricos que pongan de manifiesto la relación entre corrección de errores y grados de dificultad de estos que puedan llegar a influir en el feedback, así como en la propia actitud del profesor ante el error.

En este sentido, Lee (2003) insiste en que, a pesar de los numerosos estudios centrados en la corrección de los errores escritos, en investigación hay una falta de atención sobre las creencias de los profesores hacia el feedback manifestando que "while research on error correction has focused a great deal on whether teachers should correct errors in student writing and how they should go about it, teacher beliefs and perceptions regarding error feedback have received relatively little attention" (p. 216). 
También Gascoigne (2004), afirmaba que son muy pocos los estudios en torno al feedback y a su impacto en la corrección de errores llevados a cabo hasta el momento. Según el mencionado autor, la concepción predominante de los profesores es la de que el feedback proporciona un efecto muy positivo en las correcciones de errores de los alumnos de L2.

Entre las muchas opiniones generadas en torno al uso del feedback encontramos las de Fathman y Whalley (1990), quienes ponían de manifiesto la idea de que "students made more improvement when feedback was given than when it was not" (p. 186). Como podemos observar, las conclusiones de su estudio pueden llegar a mostrar resultados contradictorios. Así pues, al comparar un número de producciones escritas de alumnos de L2 que, tras la corrección de errores recibieron feedback orientado a la gramática del texto con otro número de producciones llevadas a cabo por alumnos que no recibieron respuesta alguna por parte del profesor, concluyeron que "Students significantly improved the content and wrote longer compositions when they did revisions without any feedback, which suggests that rewriting is worthwhile and teacher intervention is not always necessary" (Fathman \& Whalley, 1990, p. 186). Sin embargo, dentro del mismo estudio se compararon producciones escritas de alumnos de L2 que habían recibido feedback de contenido con producciones de alumnos que no lo habían recibido y los resultados probaron que las primeras eran producciones de mayor calidad y que, por tanto, recibieron una nota numérica más alta. Por todo ello, según Fathman \& Whalley: "it appears from this study that even general comments that do not refer to specifics within the text can be effective" (Fathman \& Whalley, 1990, p. 186). Los autores mantienen una postura a favor del uso del feedback y, desde su punto de vista, este ha de proporcionarse en función de una serie de coordenadas, a saber: tiempo 
y forma de presentación, objetivos propuestos, necesidades del currículo, necesidades de los alumnos, etc. En palabras de los autores: "teachers can decide how, when, and to what extent they will respond to student errors given the constraints of their curriculum, the objectives of their program, and the needs of their students" (p. 187).

Evans, Hartshorn, McCollum y Wolfersberger (2010a) planteaban la idea de cooperación entre alumno-profesor durante el proceso de corrección de errores y posterior feedback. Desde esta consideración, se espera que "teachers may give good feedback, and students may be motivated to improve” (p. 449). No obstante, los mencionados autores destacaban la importancia de que el feedback aparezca contextualizado, en el sentido de ser parte integrante de otra actividad y no de manera aislada. Además, los autores recomiendan que esa actividad o actividades relacionadas con el feedback confieran un cierto grado de responsabilidad al alumno, así pues, puede incluirse en una actividad de detección de errores, de autocorrección, etc.

Con respecto a los comentarios que el profesor anota en las producciones escritas de los alumnos, Leki (1990) señalaba que "comments are time consuming, but teachers continue to write comments on students' papers" (p. 58) porque se mantiene la idea de que "our comments help writers improve" (p. 58). Asimismo, el profesor sigue un patrón tradicional de la enseñanza escribiendo estos comentarios ya que estos "seem more feasible and more thorough than conferences on every paper” (p. 58). Además, para la mayoría de los profesores de lengua, estos comentarios escritos son de gran ayuda en el proceso de evaluación ya que permitirán justificar las notas numéricas concedidas. 
Como destacaban Tedick y de Gortari (1998) dentro del contexto educativo norteamericano, desde finales del siglo pasado, el feedback en la corrección de errores ha sido objeto de atención desde que Hendrickson (1978) plantease las 5 preguntas clave que giran en torno a la corrección de errores: ¿deben ser corregidos?, siendo así, ¿cuáles son susceptibles de corrección?, ¿en manos de quién debemos dejar la corrección?, ¿cuál es el momento idóneo para ello?, ¿y la forma adecuada? Según los autores, dichos interrogantes aparentan ser cuestiones simples, sin embargo "these questions have been explored by scholars over the past two decades in a variety of L2 classroom settings and have been found to be quite complicated" (Tedick \& de Gortari, 1998, p. 1).

Se empieza a hablar del concepto conocido como "corrective feedback" (CF) o feedback correctivo definido por Lyster y Panova (2002) como "any reaction of the teacher which clearly transforms, disapprovingly refers to, or demands improvement of the learner utterance" (p. 574). Este feedback correctivo puede presentarse en su forma oral o escrita y se perfila como un tipo de enseñanza explícita en la que el profesor intenta alertar al alumno y hacer que sea consciente de sus errores exponiéndole a la forma correcta para que este pueda apreciar la diferencia entre dicha forma y su propuesta.

Basándose en el estudio de Lyster y Ranta (1997) llevado a cabo en Canadá, Tedick y de Gortari (1998) enumeran 6 tipos de feedback oral correctivo utilizado por profesores. El primero de ellos es el denominado "explicit correction". A través de este tipo de feedback, el profesor expresa de manera explícita el hecho de que una determinada forma es incorrecta proporcionando la forma correcta de manera inmediata. El segundo, al que los autores designan "recast" es aquel 
mediante el cual, el profesor no manifiesta de una manera directa que la producción del alumno sea incorrecta, sino que proporciona la frase correcta a través de una reformulación de lo que ha expresado el alumno. En el tercer tipo de feedback, "clarification request", el profesor, fingiendo no haber entendido la respuesta incorrecta del alumno, le pide a este que lo repita, intentando que el alumno advierta la presencia del error y modifique la respuesta. Mediante el uso del denominado "metalinguistic clues", el profesor, sin llegar a aportar la forma correcta, realiza una serie de comentarios que proporcionan las pistas necesarias para que el alumno sea capaz de formular la frase de una manera correcta. En el feedback designado con el nombre de "elicitation" el profesor estimula al alumno a través de diferentes preguntas cuyas respuestas proporcionan las pistas necesarias para que este sea capaz de encontrar la forma correcta. En el último modelo de feedback, llamado "repetition", el profesor repite el error del alumno recurriendo a un tipo de entonación enérgica para llamar su atención y hacerle saber que hay un error.

Unido al feedback oral correctivo, se encuentra la manifestación en forma escrita o Writing Corrective Feedback (WCF) entendido como los comentarios escritos que explican las correcciones de errores escritas por el profesor e incluidas en las producciones escritas de los alumnos de L2. Dichos comentarios pueden aparecer en la misma página donde se encuentra el texto del alumno o bien como un documento adjunto. La intención de estos comentarios escritos es la corrección por parte de los alumnos de sus propios errores lo cual incidirá de manera positiva en la mejora del aprendizaje. Según un estudio realizado por Evans, Hartshorn y Tuioti (2010b) en el que, a través de una encuesta a nivel internacional, se preguntaba a más de un millar de profesores de 69 países diferentes acerca del uso que realizaban del $W C R$ y los factores que les 
determinaban a usarlo; los resultados mostraron que había un uso generalizado de $W C R$ entre los profesores experimentados.

El feedback correctivo, a diferencia del feedback convencional, incluye los comentarios que sirven de apoyo y de complemento a la corrección de errores llevada a cabo por el profesor. Cuando hablamos de feedback convencional, nos referimos a los comentarios que el profesor utiliza para sugerir al alumno algunos cambios o modificaciones respecto a la forma de la producción escrita.

Truscott (2007), a través del estudio de investigación llevado a cabo en el año 2007, se planteaba en qué medida la corrección y posterior feedback pueden llegar a incidir de una forma negativa en el estudiante a la hora de usar su L2 (tanto de manera oral como escrita). A partir de los resultados de otros estudios y los del suyo propio, Truscott (2007) llegabs a la conclusión de que la corrección es un "clear and dramatic failure" (p. 271) y ponía de manifiesto su falta de eficacia, demostrando que el rendimiento del grupo de sujetos sometidos a corrección fue inferior con respecto al grupo no sometido a corrección. El mencionado autor afirmaba de forma rotunda que, quizá la pregunta: “How effective is correction?” (p. 271) debe ser sustituida por: "How harmful is correction?', (Truscott, 2007, p. 271).

Por su parte, Evans et al. (2010a) haciendo referencia al estudio de Truscott (2007) indican que, a pesar de sus conclusiones, son cada vez más los autores que defienden la corrección en la enseñanza-aprendizaje de una L2, a lo que añaden la existencia de una "growing evidence in favor of focused WCF" (Evans et al., 2010a, p. 446). Estos conflictos y diferencias de opiniones convierten al panorama de la enseñanza de escritura en L2 en un terreno sembrado de confusión, 
lo cual provoca que muchos profesores se pregunten "how to interpret these conflicting results" (p. 446) y también "how to identify the specific steps they can take to help their students write more accurately" (Evans et al., 2010a, p. 446).

En opinión de Evans et al. (2010a), todo este debate y las continuas investigaciones acerca de la enseñanza de escritura en L2 se realizan con el objetivo de "to embrace a more sophisticated view of the value of corrective feedback" (p. 459), De modo que, invitan a todos los profesores y estudiosos de la L2 a seguir analizando "the potential benefits and limitations of dynamic WCF" (p. 459).

Según destacan los mencionados autores existen numerosas variables, a las que Durán (2011) denomina "factores", que intervienen en el $W C F$ entre las que enumeran: la experiencia del alumno, su lengua materna, nacionalidad, identidad cultural, estilo de aprendizaje, valores, actitudes, creencias, estatus socioeconómico, motivaciones, ambiciones profesionales, etc. También, hay una serie de variables situacionales que Evans et al. (2010a) identifican como "instructional methodology", a saber: el profesor, el entorno, el ambiente de trabajo o incluso ciertas condiciones económicas y políticas. Dentro del conjunto de estas variables, los citados autores consideran que una de las más importantes es el profesor y explican que sus motivaciones, creencias, gustos o preferencias, filosofías de trabajo, personalidades o competencias pueden jugar un papel importante en el $W C F$ tal y como se destaca en la siguiente cita:

Even the highly motivated learner, for example, may miss the potential benefits of WCF when instructional methodologies or activities lack appropriate sequencing, effective 
pacing, or adequate practice and repetition, or when students are overwhelmed with so much feedback that they cannot adequately process or learn from it. For each unique learning context, we should ask how our students might benefit from WCF. We should identify what should be corrected, how it should be corrected and how. (Evans et al. 2010a, p. 450)

Refiriéndose a la forma y al momento idóneo de proporcionar feedback en las producciones escritas de los alumnos, Vázquez (2009) insistía en la necesidad de combinar las modalidades de feedback oral y feedback escrito de manera que al alumno se le inste a elaborar dos versiones de la misma producción: “una primera versión sólo con comentarios, que debe ser «reparada» por quien aprende o bien una primera versión con marcas, que se devolverá a la clase pasados unos días, para identificar errores debidos a la distracción o el cansancio" (p. 120). A partir de los comentarios o de las marcas realizadas por el profesor en esta primera versión, los alumnos llevarán a cabo una versión final de su texto.

Se ha venido subrayando la idea de proporcionar un feedback previamente planeado y contextualizado dentro de una actividad global de corrección realizada por el alumno (Ferris, 2002). Dicho feedback se ha de entender no como una actividad aislada sino integrado en actividades de corrección de las producciones escritas del alumno, especialmente en la etapa de Educación Primaria por ser este el momento en el que el alumno necesita contar con ese apoyo o ayuda del profesor. La presencia del feedback en la presente investigación se justifica por su estrecha relación con la corrección de errores. 


\subsection{Formación del profesorado con respecto al error y a su corrección}

Dada la importancia de la corrección de errores, la formación del profesorado en torno a esta se perfila como componente necesario tanto desde una perspectiva teórica como práctica. Refiriéndose a los manuales escolares y a las guías didácticas que los acompañan, instrumento considerado tradicional para la enseñanza-aprendizaje de lenguas, Burt (1975) ya venía destacando que estos no ofrecen una formación directa y explícita para una corrección eficaz, con lo cual se impone como necesidad una formación al respecto. En este acercamiento, la autora hacía hincapié en la formación del profesorado enfocada hacia los posibles errores ya que, en su opinión, se impone como imprescindible "to be prepared to handle the variety of errors that inevitably occur in student speech and writing" (p. 53).

La formación del profesorado, en palabras de Widdowson (2001), debería dar respuesta a las preguntas que todo profesor de L2 (cualquiera que sea la lengua meta) formula respecto al hecho de que los errores han de ser considerados logros o éxitos de los alumnos: "Does this mean that they should not be corrected under any circumstances? If there are circumstances where error correction is legitimate, what are they, and how does the teacher set about it without inhibiting learner development?" (Widdowson, 2001, p. 67).

La existencia de numerosos estudios realizados en torno a la enseñanza-aprendizaje orientados a identificar los factores generadores de errores en L2 resaltan, según encontramos en Stockman y Pluut (1999), la obligación de incluir dichos factores dentro de la competencia 
profesional docente del profesor de L2 o como ellos mismos destacan "a major goal of secondlanguage acquisition research is to identify factors that influence speaker/listener errors" (p. 185).

Así es como, se empieza a hablar de unas exigencias por parte de las instituciones de enseñanza de una formación de los profesores de L2 orientada en torno a la identificación, clasificación, explicación y corrección de errores.

El conocimiento del propio proceso de corrección de errores supondrá, en palabras de Torijano Pérez (2004), saber adecuarse a la realidad de la clase, a la personalidad del alumno, al tipo de error y a la frecuencia con que se repite haciendo al alumno:

Consciente de su capacidad: que no piense que ésta es nula porque recibe una corrección cada dos palabras, pero que tampoco se considere acreedor al nivel propio del nativo porque el profesor no le haya hecho notar ninguna de sus desviaciones. (Torijano Pérez, 2004, pp. 72-73)

Desde el contexto educativo rumano, Constantinescu (2011) insistía en la necesidad por parte del profesor de tener un conocimiento preciso de los errores de sus alumnos. En este sentido, propone exponerlos durante los primeros días de clase a una serie de actividades en las que se les solicitará la elaboración de varios textos en L2. A partir de la corrección y posterior análisis de dichas producciones escritas, el profesor podrá elaborar un corpus de errores, lo cual le permitirá posteriormente "de répertorier les erreurs et de les classer par rubriques: phonétique, morphosyntaxe, semantique, etc" (p. 85). Esta clasificación de los errores más frecuentes le 
ayudará a seleccionar las actividades "susceptibles de résoudre les difficultés d'apprentissages rencontrés par ses éleves" (p. 85).

La misma opinión la encontramos en Ferris (2004) quien, desde el contexto educativo norteamericano, afirmaba que los profesores deben prepararse para poder llevar a cabo un tratamiento de errores adecuado. Una formación que incluya no solo aspectos teóricos relacionados con la gramática de la L2 (cuyo conocimiento profundo les permitirá poder aportar una explicación sobre la norma gramatical correspondiente), sino también aspectos prácticos en torno a la localización de los errores y su posterior interpretación.

Nos situamos en la línea de la mencionada autora (2004) por cuanto que el profesor debe contar con la formación necesaria para poder ser capaz de proporcionar al alumno el feedback que acompañará y complementará a la corrección de errores. La forma de aproximarse al alumno y de hacerle llegar dicho feedback, sin que este consiga despistarlo o desanimarlo durante la elaboración de su producción escrita implica, en palabras de Ferris (2004) "some careful decision-making on the part of the teacher which considers the students' needs and backgrounds and the instructional context” (p. 59). A esta necesidad de formación del profesor en torno a la corrección de errores y alfeedback, se añade otro requisito imprescindible de la competencia profesional docente: el hecho de que los profesores de L2 enseñen a sus alumnos, desde edades tempranas, estrategias de revisión y de corrección de las producciones escritas para detectar y, posteriormente, aprender de sus propios errores. 


\subsubsection{Conocimientos del profesor sobre el error y su corrección}

Los conocimientos junto con las aptitudes y las actitudes del profesor sobre el error son los componentes que entran a formar parte de la competencia profesional docente que ya venimos mencionando. Desde las políticas lingüísticas europeas manifestadas en determinados documentos de referencia europeos se ha intentado conceder una atención a la formación del profesor orientada al error y a su corrección. Es el caso del MCER (Consejo de Europa, 2002) el cual, plantea la necesidad de que los profesores de L2 cuenten con un conocimiento preciso sobre las faltas y los errores de los alumnos estableciendo una clara diferencia entre estos. Del mencionado documento europeo extraemos la siguiente cita en la que se destaca la idea de proporcionar un tratamiento distinto para cada uno de los casos proponiendo determinadas claves que sustenten el desarrollo profesional docente:

a) el profesor debería corregir inmediatamente todos los errores y faltas;

b) se debería fomentar sistemáticamente la corrección inmediata por parte de un compañero y, de este modo, conseguir erradicar los errores;

c) se deben señalar y corregir todos los errores cuando esto no interfiera en la comunicación (por ejemplo: separando el desarrollo de la corrección del desarrollo de la fluidez);

d) los errores no sólo deberían corregirse, sino también analizarse y explicarse en el momento adecuado;

e) las faltas que son sólo simples deslices se deberían pasar por alto, pero los errores sistemáticos deben erradicarse; 
f) se deben corregir los errores sólo cuando interfieren en la comunicación;

g) los errores se deberían aceptar como «interlengua de transición» y no deberían tenerse en cuenta. (Consejo de Europa, 2002, p. 154)

Al hablar de conocimientos sobre la corrección de errores, debemos hacer alusión al papel que el profesor debe asumir como guía y orientador de los alumnos en su trabajo. Así es como, lejos de asumir el papel principal debe favorecer la autonomía del alumno. Encontramos este mismo concepto en autores como Blanco y Garrido (2013); Erdocia (2016); Fabián Martín-Arroyo (2016); Gómez Pazos y Hernando Gómez (2016); Loaiza Villalba y Galindo Martínez (2014) y Sánchez Godoy y Casal Madinabeitia (2016) quienes ponen de manifiesto la necesidad de que los alumnos adquieran un determinado grado de responsabilidad sobre su propio proceso de enseñanza-aprendizaje. Por tanto, se impone que los conocimientos teóricos y prácticos de los profesores de L2 orientados a la corrección de errores deben girar en torno a las técnicas de corrección en las que el alumno participe de una forma activa. Así pues, motivar a los alumnos para que sean ellos mismos quienes, con la ayuda del profesor, realicen el ejercicio de detección, revisión y autocorrección se configura como parte esencial de la competencia profesional docente orientada a la corrección de errores.

Recurrimos también a otro documento europeo Las competencias clave del profesorado de lenguas segundas y extranjeras lanzado por el Instituto Cervantes en el año 2012 que propone a los profesores de L2 "crear y desarrollar oportunidades de aprendizaje para todos los alumnos" (Instituto Cervantes, 2012, p. 13) promoviendo que estos tomen conciencia de sus propias necesidades comunicativas. Según el documento, los profesores son los responsables de crear 
situaciones de aprendizaje en las que sean los mismos alumnos quienes evalúen la tarea realizada identificando y corrigiendo sus propios errores.

Estamos de acuerdo con Cassany (1993) y Peters (1984) por cuanto que, asociamos los conocimientos del profesor en torno al error y a la corrección a todo un proceso de reflexión que debe acompañar al acto profesional didáctico de la corrección de errores. Así pues, Cassany (1993, p. 29), definiéndose a sí mismo como "maestro-corrector" que ha pasado muchos años "señalando errores a ciegas, sin saber exactamente para qué lo hacía" (p. 29), propone la idea de reflexionar y buscar la información que se quiere transmitir al alumno-receptor de nuestros comentarios o correcciones y, al mismo tiempo, "definir la utilidad didáctica" (p. 29) que se da a la corrección. Peters (1984), a su vez, destacaba la necesidad de entender la corrección como un proceso marcado por la reflexión del profesor y, en su opinión:

Reflection upon correct and incorrect (error analysis) actions or results comprises an important quality of didactical activity. Reflection can occur during all the phases of didactical activity: during planning; after completion of the planning; during the realization; after the realization has taken place. We can divide reflection into three types: pre-reflection; peri-reflection; post-reflection. These types of reflection follow one another; that is, they take place before, during and after interactive teaching. (Peters, 1984 , p. 22)

En la presente cita observamos que Peters (1984) también hace referencia a la necesidad de llevar a cabo todo este proceso de reflexión no solo al final de la actividad de corrección de 
errores, sino que, como hemos apuntado anteriormente, dicha reflexión ha de estar presente a lo largo de todo el proceso didáctico.

Por todo ello, los conocimientos del profesor, desde su vertiente reflexiva, influirán de manera decisiva tanto en las propias aptitudes, entendidas estas como futuras actuaciones llevadas a cabo en torno al error y a su corrección, como también en las actitudes o conductas que acompañan a dicho proceso.

\subsubsection{Aptitudes del profesor en torno al error y su corrección}

Podemos decir que, en ocasiones, el docente se encuentra ante varias incógnitas relacionadas con la corrección de errores no solo con respecto a su utilidad, sino también acerca de qué, cómo y cuándo corregir. Se impone que, para llevar a cabo todo el proceso de corrección debe demostrar y poner en práctica una serie de aptitudes. La aptitud, en palabras de Mallart (2004), aparece definida como la "capacidad latente de poder realizar alguna acción o de poder aprender alguna actividad" (p. 76). Sin embargo, Galisson y Coste (1982, p. 42), la entendían en términos de predisposición o "substrat constitutionnel" (p. 42) del sujeto que se manifiesta como "capacité directement mesurable" (p. 42). Se revela, por tanto, como "un ensemble de comportements" (p. 54) que podríamos traducir como una competencia dirigida hacia la corrección de errores. 
Volvemos a acudir a los documentos de referencia europeos observando que es el MCER (Consejo de Europa, 2002) el que lanzaba la idea de incluir los resultados extraídos de la observación y del análisis de errores de los alumnos en la programación general del curso. Asimismo, estos resultados podrán proporcionar orientación para la planificación de las actividades, la secuenciación didáctica y los materiales utilizados. Además, podrán ayudar al profesor en el proceso de evaluación de la enseñanza-aprendizaje de la L2 del alumno.

Desde el contexto norteamericano, Ferris (2002) señalaba la importancia de que los profesores de L2 estén capacitados para la corrección de errores en L2 afirmando que "before we can prepare our students to cope with errors in their writing, we must prepare ourselves" (p. 48). La autora admite en su estudio que muchos de los futuros profesores del programa de máster del que ella formaba parte, no eran capaces de aportar un análisis adecuado de los errores de las producciones escritas de sus alumnos. Considera, por tanto, que el profesor de L2 no solo necesita contar con aptitudes que le permitan saber escoger de entre una gran variedad de recursos, técnicas y materiales orientados al análisis de errores, sino también contar con un sólido conocimiento de la lengua respaldado de unas aptitudes en torno al análisis efectivo de errores.

Ferris (2002) formulaba y describía cuatro principios fundamentales que debe cumplir todo profesor de L2 en términos de corrección de errores. El primero de ellos alude a exigencia por parte de las instituciones de que los profesores tengan un dominio de aquellos aspectos gramaticales especialmente problemáticos para los hablantes no nativos; el segundo principio destaca la necesidad de que los profesores puedan ser capaces de reconocer e identificar los errores de las producciones escritas de los alumnos. Como tercer principio, la autora resalta la importancia 
de la enseñanza de la gramática de la L2 por parte del profesor unida a la necesidad de poseer un conocimiento profundo de lo que implica la enseñanza-aprendizaje de una L2.

Desde el contexto español, Cassany (1993) incluía en su obra un decálogo de recomendaciones respecto a qué, cómo y cuándo corregir los errores con el fin de intentar mejorar la expresión escrita de los alumnos de L2. En primer lugar, propone que se corrija solo lo que el alumno pueda aprender; en segundo lugar, que se lleve a cabo la corrección inmediatamente después de la producción para que el alumno pueda recordar el contexto y el motivo por el cual decidió utilizar una expresión en particular; la tercera recomendación gira en torno a la corrección de las versiones o borradores escritos por el alumno antes de llevar a cabo el texto final ya que dichas producciones aportarán una idea más amplia de las intenciones del alumno. Además, el autor propone al profesor que no sea él quien realice todo el trabajo de corrección, sino que intente crear situaciones de aprendizaje que se presten a la corrección en parejas, en grupos o a la autocorrección. A esta recomendación añade la de dar instrucciones concretas y prácticas, dejar tiempo en la clase para que los alumnos puedan leer y comentar las correcciones, hablar individualmente con cada alumno, proporcionar instrumentos que permitan realizar actividades de autocorrección: diccionarios, gramáticas...etc. asegurando la calidad de la corrección. La visión de Cassany (1993) es, en definitiva, la de utilizar la corrección como un recurso didáctico en sí.

Asimismo, como Cassany (1993) y Ferris (2002) planteaban, se impone la idea de contar con unas aptitudes relacionadas con la corrección además de un conocimiento profundo respecto al qué, cómo y cuándo corregir los errores de las producciones escritas de sus alumnos de L2, en definitiva, con una formación específica al respecto. 


\subsubsection{Actitudes del profesor ante el error y su corrección}

El término "actitud" cuenta con numerosas acepciones. Nos detenemos en la propuesta de Hobbs (2011) sobre las creencias de los profesores de L2, definiéndolas como "ideas, attitudes, assumptions, values and knowledge about teaching and learning that teachers accumulate and bring with them to the classroom" (p. 156) al destacar su importancia en el ámbito de la educación de los profesores de lenguas puesto que "examining them helps language teaching education researchers and educators to understand better the complex nature of the classroom" (p. 156).

Por su parte, Galisson y Coste (1982) definían el término actitud como una serie de disposiciones interiores de un individuo con respecto a los objetos, situaciones y acontecimientos sujetos a una apreciación valorativa. Dichas disposiciones interiores pueden variar considerablemente, según comentaba Alfieri Lane (1997, p. 7), de manera que existen: "educators who believe in the positive aspects of error correction and those who think that this practice is extremely harmful and detrimental to the process of acquisition" (p. 7).

Desde el contexto educativo rumano, Constantinescu (2011), en relación a la actitud adoptada por el profesor ante el error, introducía la idea de que "loin de sanctionner l'erreur, mieux vaut la placer au centre de la démarche pédagogique" (p. 84). 
Como hemos venido apuntando, corresponde a las responsabilidades del profesor identificar los errores e integrarlos en el proceso de enseñanza-aprendizaje de una L2, idea que encontramos en Alfieri Lane (1997, p. 16), quien consideraba que: “educators' beliefs and attitudes toward error correction" han de ser especialmente cuidados y analizados ya que son ellos los encargados de "implement error correction strategies" (p.16).

Refiriéndose a los estudios llevados a cabo respecto a la corrección de errores, Serkan Ülgü y Griffiths (2013) destacaban que los profesores no cuentan con una opinión fundamentada en los resultados de estudios empíricos, sino que parten generalmente de unas “intuiciones”, según ponen de manifiesto a continuación: “teachers' point of view on error correction options does not go beyond intuitionist ideas rather than being empirically evidenced" (Serkan Ülgü \& Griffiths, 2013, p. 229). Además, esta posición tan poco fundamentada es lo que determina a los profesores a optar por una corrección inmediata tanto de una producción escrita como también oral tal y como lo expresan los mencionados autores en su estudio llevado a cabo en el contexto educativo turco: “teachers want to correct their learners' errors. Teachers are in favor of immediate correction for written or oral errors" (Serkan Ülgü \& Griffiths, 2013, p. 237).

Esto se une a la idea de Truscott (1996) respecto a la corrección gramatical, tan utilizada en las clases de L2. Refiriéndose a esta, el mencionado autor destacaba la falta de relación directa entre corrección y aprendizaje. Es lo que le determinó a afirmar rotundamente que la corrección gramatical no es efectiva y, por lo tanto "grammar correction is not helpful and can be harmful" (Truscott, 1996, p. 355) desatando una fuerte polémica en el ámbito de la enseñanza-aprendizaje. Asimismo, Truscott (1996, p. 34) intentaba dar una explicación a esa popularidad de la corrección 
gramatical por parte de los profesores. Según él, dichos profesores no consiguen tener una visión de lo que es la interlengua y, sabiendo que esta implica un proceso de aprendizaje complejo, prefieren adoptar una visión simple de lo que es el aprendizaje.

Por esta razón, de acuerdo con Corder (1981), la responsabilidad de todo profesor ha de estar orientada hacia la necesidad de adoptar una actitud más realista ante la producción del alumno estimando necesario "a shift of emphasis in teaching away from a preoccupation with the grammar of the target language towards a concern with communication in the target language” (p. 78).

Es evidente que se pueden encontrar diferentes muestras de actitudes contradictorias hacia la presencia del error. Así pues, el MCER (Consejo de Europa, 2002) propone una tipología de actitudes existentes en torno a las faltas y a los errores de los alumnos, según se puede observar en la cita que se presenta a continuación:

a) los errores y las faltas demuestran el fracaso del aprendizaje;

b) los errores y las faltas demuestran una enseñanza ineficaz;

c) los errores y las faltas demuestran la voluntad que tiene el alumno de comunicarse a pesar del riesgo de equivocarse;

d) los errores son el producto inevitable y pasajero de la interlengua que desarrolla el alumno;

e) las faltas son inevitables en cualquier uso de la lengua, incluyendo el de los hablantes nativos. (Consejo de Europa, 2002, pp. 153-154) 
Nos posicionamos en la perspectiva de Gardner (2010) por cuanto que existe la necesidad por parte del profesor de crear "a relaxed atmosphere in the L2 classroom" (p. 188) que se asociará a una actitud positiva hacia el error y hacia la corrección. Diversos estudios coinciden en señalar el hecho de que un ambiente distendido y de confianza influirá en los alumnos a la hora de expresar sus ideas y opiniones de una manera libre. Según el mencionado autor, esto también implica que los profesores adopten una actitud de tolerancia ante el error mostrando cercanía hacia el alumno, aspecto que ya mencionábamos en el epígrafe 1.1.3. Una relación cercana entre alumno y profesor en un ambiente relajado en el aula será determinante para que el alumno sienta la motivación necesaria para realizar sus producciones escritas de una manera autónoma.

Con respecto a la actitud del profesor, según precisábamos en el artículo titulado "La corrección de errores en las producciones escritas de alumnos de L2", "como profesionales docentes, es nuestra responsabilidad adoptar una actitud abierta y positiva ante el error" (Merino Mañueco, en prensa). En dicho artículo, insistíamos en la necesidad de "evitar el miedo, los complejos y la timidez del alumno ante esta LE" (Merino Mañueco, en prensa) ya que, durante el proceso de producción escrita, el alumno pone en juego una serie de mecanismos psicológicos que influyen en la realización de la actividad de producción escrita en L2.

De acuerdo con García-Heras Muñoz (2004), la mayoría de los profesores de L2 consideran la presencia de errores en las producciones escritas de sus alumnos como un "paso necesario para que el proceso de enseñanza aprendizaje se lleve a cabo con éxito" (p. 57). Sin embargo, muchas voces apoyan la idea expresada por García-Heras Muñoz (2004) respecto a que "en la práctica la realidad es bastante diferente" (p. 57). Desde el punto de vista de la autora, los cuestionarios y 
encuestas llevadas a cabo en torno a este tema concluyen que, a pesar de la defensa de actitudes positivas en torno al error, estas no siempre se manifiestan en el aula. Uno de los motivos de esta posible contradicción, según la mencionada autora es resultado de "las exigencias de los currículos y de las pruebas de evaluación" (García-Heras Muñoz, 2004, p. 57) que, en ocasiones, no permiten al profesor llevar a cabo un acercamiento adecuado al error y a la corrección.

Como hemos venido indicando, a lo largo de la historia de enseñanza-aprendizaje de la L2 ha existido una evolución en torno a las actitudes de los profesores hacia la presencia del error y hacia su corrección. Desde esta consideración, podemos afirmar que, hoy en día, suelen predominar las actitudes positivas hacia este, al estar considerado parte fundamental del proceso de enseñanza-aprendizaje y al convertirse en indicador del nivel de progreso del alumno.

Tal y como indicábamos al comienzo del presente capítulo, la formación del profesorado en torno a la corrección de errores se configura como indicador de mejora. En este sentido, se manifiesta como una necesidad intrínseca contextualizar y dar cuenta de las distintas acepciones que se han dado a los tres componentes de la competencia profesional docente: conocimientos, aptitudes y actitudes. 



\section{Capítulo 3. ENSEÑANZA-APRENDIZAJE DE L2: MATIZACIONES CONTEXTUALES}

3.1. Una perspectiva psicolingüística en torno al error en la enseñanza-aprendizaje de L2

3.2. Del objeto de enseñanza-aprendizaje a la expresión escrita

3.3. Enseñanza-aprendizaje de L2: aspectos contextuales 


\subsection{Una perspectiva psicolingüística en torno al error en la enseñanza- aprendizaje de $\mathrm{L} 2$}

La enseñanza-aprendizaje de una L2 se ha de entender como un enfoque multidisciplinar. Así pues, en su estudio convergen las aportaciones de la Lingüística, en particular la aplicada cuyo desarrollo en el siglo XX, trajo consigo una gran preocupación por los problemas sociales que tienen que ver con el lenguaje, la Psicología, concretada en la Psicolingüística, la Sociolingüística y las disciplinas surgidas de las ciencias de la educación, puesto que todo proceso de adquisición de una L2 implica la incorporación de la actividad de enseñanza en particular de la Didáctica. Las mencionadas disciplinas aparecen en la Figura 3 presentada a continuación y tomada de Mayor (1994).

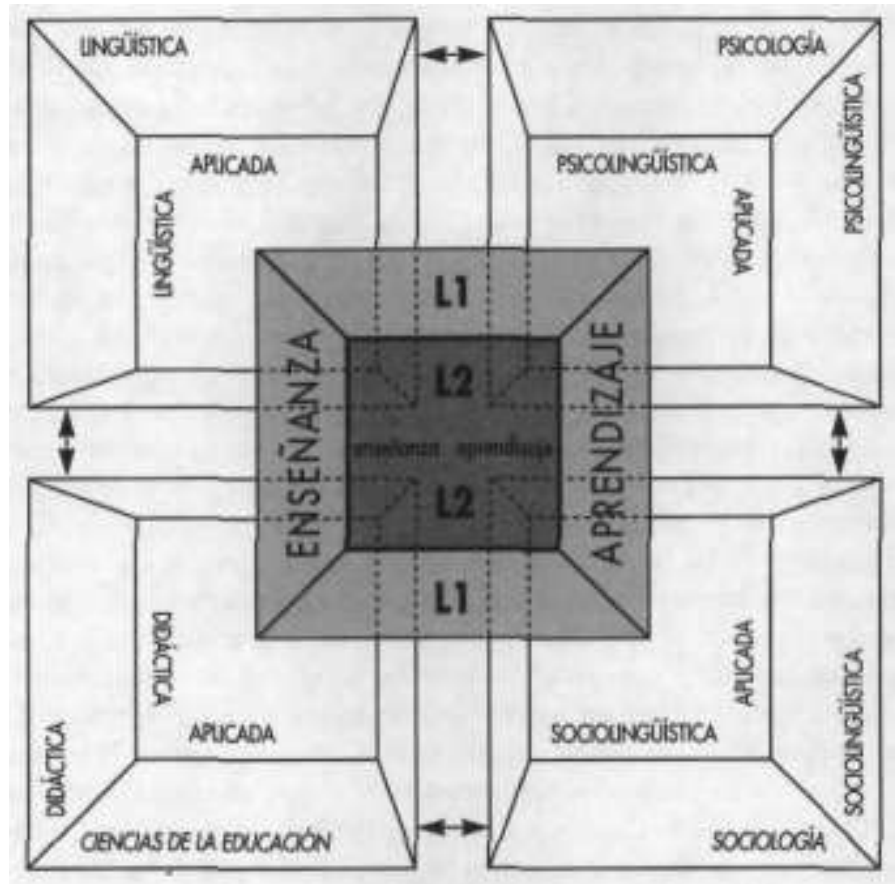

Figura 3: Disciplinas que forman parte de la enseñanza-aprendizaje de una L2. Tomada de Mayor (1994, p. 27) 
La figura de Mayor (1994) representa la confluencia de la Lingüística, la Psicología, la Sociolingüística y la Didáctica. Refleja un acercamiento progresivo desde dichas disciplinas teóricas que se encuentran en la parte más exterior, pasando por sus disciplinas aplicadas, las cuales ocupan la parte interna del recuadro hasta la adquisición de la lengua, posicionada en el centro. Dicho cuadro representa, en la parte externa, la adquisición de la L1, siendo el núcleo de este la enseñanza-aprendizaje de la L2. En palabras del autor, la figura representa "el progreso desde la teoría a la práctica y desde lo general a lo específico” (Mayor, 1994, p. 27).

En el marco de este enfoque multidisciplinar de la enseñanza-aprendizaje de L2 se han planteado distintas teorías en torno a los orígenes de la comunicación intencional (Serra, Serrat, Solé, Bel \& Aparici, 2000) que ha estado relacionada con el desarrollo cognoscitivo, como resultado de que el lenguaje está subordinado al pensamiento. Ya se había defendido la idea de que la interacción social entre bebé y adulto es lo que determina la aparición de la comunicación intencional, idea expresada por Serra et al. (2000), quienes indicaban el hecho de que "el desarrollo de las destrezas sociales y cognoscitivas en la relación de los bebés con los adultos desempeñará un papel fundamental en la construcción de la comunicación y el lenguaje" (p. 133). Aunque, como veremos más adelante, ha habido voces que defendían la teoría, según la cual los bebés nacen con una predisposición hacia la adquisición de la lengua.

Teniendo en cuenta la posición de Serra et al. (2000), nos acercamos al factor social en la adquisición tanto de la L1 como de la L2. La adquisición de la L1, en líneas generales se lleva a cabo dentro de un entorno social en el que el alumno está expuesto a esa lengua desde el momento de su nacimiento. Así pues, durante los primeros años, la exposición a la L1 tendrá lugar dentro 
del entorno familiar y social y, los años consecutivos, además, en un contexto académico. Sin embargo, la adquisición de una L2 estará directamente relacionada con el grado de exposición del alumno. En general, dicha exposición tiene lugar únicamente durante su período de permanencia en la institución académica en la que se lleven a cabo los estudios de esa L2, aunque podría producirse también en el ámbito familiar (además del contexto aula). En cada uno de los casos, estaríamos hablando de un tratamiento distinto.

En la presente investigación nuestros informantes, como ya hemos venido apuntado son, por un lado, profesores que imparten sus clases a alumnos españoles de inglés como L2 y, por otro, profesores que imparten español como L2 a alumnos norteamericanos. Las dos categorías de informantes ejercen su actividad profesional docente en las etapas educativas de Educación Primaria. Los alumnos del primer grupo de informantes son monolingües y estudian inglés desde los comienzos de la etapa de Educación Infantil (desde la edad de 3 años) en centros educativos de Educación Primaria de Valladolid. Su tiempo de exposición a la lengua inglesa se limita a las horas de permanencia en la institución académica-escuela recibiendo instrucción formal (que, en ocasiones, se refuerza con actividades extraescolares de inglés en otras instituciones de enseñanza). Este alumnado, en general no recibe ningún tipo de exposición a la lengua inglesa en ningún otro ámbito: familia, amigos, etc. En el caso de centros con sección bilingüe, los alumnos recibirán más horas de instrucción en inglés que los niños que acudan a centros que no cuenten con esta. Los alumnos del segundo grupo de informantes serán, por un lado, niños monolingües (angloparlantes) que siguen sus estudios en un centro con programa dual (inglés-español), sin ningún otro tipo de exposición al español fuera del contexto formal. Por otro, niños monolingües 
expuestos a la L2 en otro tipo de ámbito (aparte del contexto institucional-escuela), que cuentan con la presencia en su casa de familiares o amigos hispanohablantes.

Adoptando las palabras de Flynn (1989) en torno a las diferencias entre la adquisición de una L1 respecto a la de una L2, "the nature of acquisition principles that characterize L2 acquisition might differ in many ways from those which characterize L1 acquisition” (pp. 55-56). Dicha idea se fundamenta en la teoría chomskiana de la gramática generativo-transformacional (1957) que abrió un amplio debate en torno al carácter innato de la lengua. Esta teoría pone de manifiesto la existencia de un determinado número de reglas estructurales de la lengua o Gramática Universal (GU) (Universal Grammar, $U G$ ) que son innatas y no adquiridas. En este acercamiento, Montrul (2008) sostiene la idea de que los aprendices de una L2, al ser "unable to utilize deductive, domainspecific (i.e., purely linguistic) mechanisms like L1 learners" (p. 209) se verán obligados a recurrir al conocimiento global o a habilidades de resolución de problemas de forma inductiva utilizando técnicas como por ejemplo la analogía o la correspondencia de patrones. Así pues, la mencionada autora señalaba que, de acuerdo con esta teoría, aquellos alumnos que intenten aprender una L2 después de la pubertad, solo podrán acudir a través de los conocimientos que ya poseen de su L1 puesto que "access to Universal Grammar is subject to a critical period" (p. 209).

La hipótesis del período crítico en la adquisición del lenguaje, defendida por Lenneberg en los años sesenta se apoya en la existencia de un determinado período (desde el nacimiento hasta la pubertad) en el que se desarrollan las facultades neurológicas de aprendizaje de cualquier lengua. 
Dirigida a la adquisición de una L1, esta hipótesis explica que la existencia de una privación del lenguaje y de una interacción durante los años que abarca el período crítico supone un impedimento para el desarrollo de este puesto que, después de la pubertad, el cerebro pierde plasticidad. El lenguaje debe ser adquirido antes de que concluya dicha etapa para que este pueda formar parte de las funciones cerebrales. Es el caso de niños aislados desde su nacimiento e integrados en una comunidad pasada la etapa de su pubertad. Los resultados han demostrado que estos niños no son capaces de adquirir un dominio de la lengua equivalente al de un hablante nativo.

En relación a la adquisición de una L2, esta hipótesis indica, tal y como encontramos en la cita de Cook y Singleton (2014) que cuando el alumno accede a la L2 después de la etapa de la pubertad, este:

(1) Is no longer capable of attaining native-like levels of proficiency in the second language;

(2) and/or needs to expend more conscious effort than is typical of earlier second language acquisition;

(3) and/or makes use of different mechanisms from those deployed in second language acquisition during childhood. (Cook y Singleton, 2014, p. 26)

En torno a la hipótesis del período crítico, existen diversas voces como la de Baralo (1999) que afirman contar con datos suficientes para admitir que "los adultos consiguen adquirir una LE, con éxito desde un punto de vista comunicativo" (p. 25) y que no existen razones convincentes 
para determinar que "existe un periodo crítico, definitivo, en la pubertad, que deja inoperantes y pasivos los principios de la dotación genética específica para el proceso de adquisición de una LE una vez superado este periodo" (p. 25).

Larsen-Freeman y Long (1992) han enumerado en su obra un gran número de variables que determinan la adquisición de la L2. La primera y más significativa es la edad. Se ha constatado asimismo que el cerebro de un niño presenta un funcionamiento diferente al de un adulto, es decir, hablamos de individuos cerebralmente distintos. En relación a la adquisición de una L2, se dan diferencias en torno a la velocidad de aprendizaje y, al respecto, los mencionados autores afirman que los adultos tienen una velocidad superior de aprendizaje (sobre todo en la morfología y en la sintaxis de las primeras etapas), sin embargo, los alumnos en edades tempranas son capaces de llegar a utilizar la L2 al mismo nivel que un nativo sin que sea perceptible ningún tipo de acento. Estas investigaciones han llevado a determinados autores a confirmar la existencia de este período crítico que, como ya hemos comentado, tiene lugar desde los primeros meses de vida hasta los 1012 años de edad (aunque existen discrepancias en torno al período exacto comprendido) es decir, justo antes de que se empiecen a desarrollar en el cerebro las operaciones formales.

La segunda variable, de acuerdo con Larsen-Freeman y Long (1992), es la aptitud lingüística o condición del individuo para aprender una L2, considerada una variable cognitiva, que aparece al lado de las demás, denominadas afectivas. Existe un gran debate alrededor de si la habilidad para una L2 es innata o depende de experiencias anteriores. Además, hay voces que afirman que una enseñanza adecuada de la lengua podrá cubrir las necesidades de los alumnos supliendo las carencias por falta de aptitud lingüística. 
La siguiente variable identificada por Larsen-Freeman y Long (1992) son los factores socio-psicológicos. Estos abarcan la motivación del alumno por conocer esa L2 para poder llegar a acceder a una sociedad y a una cultura distintas a la propia, así como la actitud del alumno que, a su vez, estará determinada por la actitud que pueden transmitir los padres, los compañeros del aula o el profesor. La actitud de todos estos agentes influirá de manera positiva o negativa en la actitud del alumno hacia la L2.

Además, Larsen-Freeman y Long (1992) identificaban otras variables como la personalidad, el estilo cognitivo del alumno o la forma en que este procesa la información y la lateralización o especialización de los hemisferios en torno a la cual existen diversas teorías que apuntan al hecho de que cada uno de los hemisferios de nuestro cerebro podría ser responsable de un modo de pensamiento.

Entre las conclusiones a las que han llegado Larsen-Freeman y Long (1992) en los estudios realizados encontramos la idea de que "children ultimately win out not just quantitatively but also qualitatively: only child starters seem capable of attaining native-like SL abilities" (p. 166) a lo que añaden que "the evidence here is clearest for phonology but also exists for accent recognition, listening comprehension and syntax, with suggestively similar tentative findings for collocation, discourse and pragmatics" (p. 166).

Dado que en la presente investigación nos orientamos hacia el tratamiento del error por parte de profesores que llevan a cabo su actividad docente en la etapa educativa de Educación 
Primaria nos acercamos al concepto de adquisición lingüística en edades tempranas en contraposición con el concepto de adquisición lingüística en edades adultas.

Así pues, la adquisición de una L2 hasta una edad preadolescente se produce de una forma inconsciente, es decir, los niños en este intervalo de edad, en palabras de Solias Arís (2007), "son capaces de aprender una segunda lengua por los mismos procesos que utilizan para aprender la primera" (p. 83), mientras que, los adultos "necesitan fijar reglas conscientemente" (p. 83). Esto nos lleva a creer, de acuerdo con la mencionada autora en la existencia de "diferencias entre los procedimientos de aprendizaje lingüístico por parte de niños y adultos” (p. 83).

Basándonos en este tipo de diferencias, consideramos que el tratamiento del error también ha de ser distinto en alumnos de edades tempranas respecto a los alumnos adultos. Así pues, se impone que la corrección deba llevarse a cabo en ambos casos, aunque una corrección explícita podría provocar un sentimiento de bloqueo en el alumno-niño que le impida apreciar dicha corrección y entender su significado. Por su parte, el alumno adulto es capaz de valorar y de entender los códigos y las correcciones escritas que le permitirán rehacer el texto. Dichas correcciones escritas pueden motivarlo y estimularlo para la corrección y posterior aprendizaje. Sin embargo, en el alumno en edades tempranas, este tipo de correcciones en las que el error se subraya y/o se sanciona pueden determinar un bloqueo en la adquisición lingüística.

En el caso de la corrección del error en producción oral, se estima necesaria una corrección complementada con el tipo de feedback oral correctivo que mencionábamos en el epígrafe 2.1.3 denominado "recast" mediante el cual, el profesor, a partir del error del alumno proporciona la 
frase correcta a través de una reformulación de dicho error. Así pues, también cabría la posibilidad de complementar esa corrección con los tipos de feedback nombrados en el mismo epígrafe y denominados "metalinguistic clues" y "elicitation". No obstante, el alumno no sería capaz de apreciar ni entender una corrección explícita en la que el profesor declare de manera expresa el error acompañado de un comentario en torno a la equivocación. La emisión por parte del profesor de un juicio de este tipo solamente llevaría a un sentimiento de frustración ya que el niño solo entiende el hecho de no ser capaz de comunicarse correctamente.

Las mencionadas opciones pueden aplicarse a la corrección de las producciones escritas. El hecho de devolver al alumno su producción escrita en la que se adjuntan determinadas marcas o códigos presentados en tinta del mismo o de distinto color no tendrá impacto directo en el alumno. En su lugar, la propuesta de una corrección secuenciada en la que el alumno tenga ocasión de acercarse a la mesa del profesor y presentar su producción escrita se manifiesta como una opción alternativa. Tras dicha presentación, el profesor, de manera inmediata, procede a llevar a cabo las correcciones del texto interactuando de forma oral con el alumno, haciéndole saber de una manera afectuosa y amable cuáles son los aspectos susceptibles de corrección y que posteriormente sea este quien vuelva a su pupitre para la elaboración de un segundo borrador a partir de las correcciones dadas. Como hemos mencionado anteriormente, en situaciones de este tipo, el factor afectivo, así como el motivacional juegan un papel innegable en el proceso de adquisición de las lenguas. 


\subsubsection{Corrientes metodológicas y evolución del concepto del error en la enseñanza-aprendizaje de $\mathbf{L} 2$}

El concepto de error, como ya hemos venido apuntando, ha sufrido una clara evolución a lo largo de la historia de la enseñanza de L2, al estar bajo las influencias de las distintas corrientes metodológicas que se han ido sucediendo.

En las teorías conductistas que surgen a principios del siglo XX se concibe el aprendizaje de una L2 como la integración de una serie de hábitos, considerados habilidades para producir enunciados de manera automática. Por lo tanto, se estimaba imprescindible reforzar las formas gramaticales, al tiempo que evitar los errores se convertía en uno de los objetivos principales.

En los años 50, se da a conocer la teoría del Análisis Contrastivo (AC) (Fries, Lado) y se empieza a hablar de errores ocasionados por la influencia de la L1 en la L2. Se busca comparar las dos lenguas para poder llegar a detectar futuros errores en el proceso de enseñanza-aprendizaje de una L2. El error era todavía considerado como algo negativo, que debía evitarse puesto que no permitía crear hábitos correctos en la adquisición de la lengua. De acuerdo con Fernández (1997), el AC nace como resultado de una "preocupación didáctica" hacia la necesidad de predecir todos los errores "identificando las diferencias entre la lengua meta y la lengua materna (LM) del aprendiz" (p. 14). Se trata de una corriente asociada al conductismo y a "su teoría del aprendizaje por asociación de estímulo, respuesta, refuerzo y hábito" (Fernández, 1997, p. 15) en la que el error es considerado algo "intolerable". La mencionada autora definía esta corriente como "un aprendizaje sin errores a través de la repetición de enunciados, que de ese modo llegaría a mecanizarse de forma correcta" (p. 15). 
Sin embargo, a mediados de los años 60, el concepto del error deja de considerarse como algo negativo y comienza a apreciarse su utilidad. De acuerdo con Fernández (1997), "las aportaciones de las nuevas corrientes en Lingüística, Psicolingüística y Sociolingüística arrojan fuertes críticas a los planteamientos básicos del AC” (p. 16) atribuyendo a este un carácter limitado puesto que no tenía en cuenta la función comunicativa, ni el contexto que rodeaba al error.

Según destacaba Muñoz Liceras (1992) "sólo cuando se cuestiona el conductismo (...) y se adopta la visión del lenguaje como actividad creativa" (p. 12), los errores pasan de ser elementos que distorsionan la comunicación oral y escrita a ser considerados muestras reales del aprendizaje del alumno. En palabras de Corder (1981), "they are best not regarded as the persistence of old habits, but rather as signs that the learner is investigating the systems of the new language" (p. 12).

Como resultado de la aparición de esta nueva concepción del error surge el Análisis de Errores (AE) (Corder, 1967) como corriente de investigación inscrita en el ámbito de la teoría del aprendizaje de L2. Esta corriente llevó a nuevas reconsideraciones de la teoría del aprendizaje y, consecuentemente del tratamiento de errores (Santos Gargallo, 1994). Con respecto al AE, Corder (1981) afirmaba años más tarde que: "it aims at telling us something about the psycholinguistic processes of language learning" (p. 35). Además, para Spillner (1991) llegó a ser "the most important empirical method to get information about the function of cognitive processes in language production and language perception” (p. XI). Más adelante, Haded (1998) destacaba dos objetivos principales del AE "firstly, as a tool of general linguistics in order to elicit information 
on second language acquisition, and secondly, as a technique of applied linguistics dedicated for linguistic research and the improvement of teaching material" (p. 56).

El AE surge a partir del momento en que diversos investigadores y profesores advierten que muchos de los errores no son atribuibles a la influencia de la L1 del alumno. Este descubrimiento, junto con la aparición de la lingüística generativa de Chomsky y la teoría psicológica de Piaget, cuestiona esa idea de focalización del proceso de aprendizaje en el alumno para pasar a analizar los errores más frecuentes que hasta ahora se habían observado sin haber encontrado su explicación (Dulay, Burt \& Krashen, 1982). Es en este contexto en el que surge este movimiento como un intento de elevar el estatus del error a objeto de estudio.

Refiriéndose a la creación del AE, Liceras (1992) manifestaba que este aparece como rechazo al AC fundamentado en el conductismo y, es a partir de este momento, cuando se empiezan a analizar directamente las producciones reales de los aprendices. Los errores pasan a ser valorados y a reconocerse como indicadores del progreso del alumno. El AE difiere en gran medida de la corriente anterior (AC) con respecto a que, en esta, no se comparan las lenguas involucradas: L1 y L2, sino que se analizan directamente las producciones de los aprendices. En la entrevista llevada a cabo por Díaz Rodríguez (2010), Muñoz Liceras señalaba que la aportación del AC es el "poder predictivo" (p. 3) que presenta a partir del análisis. Por su parte, el AE solo cuenta con un "poder explicativo" (p. 3) sobre la aparición del error.

Según Santos Gargallo (1994), la concepción en torno al error del AE evolucionó pasando de las explicaciones en función de las "taxonomías gramaticales" (p. 172) a una valoración de los 
errores en función de su impacto en la comunicación. Dicha evolución incidió en la necesidad de plantear nuevas aplicaciones didácticas, así como mejorar el material didáctico para las aulas de L2.

Posteriormente, el AE se enriqueció gracias al surgimiento de un modelo metodológico conocido como el modelo de la Interlengua (IL) propuesto por Selinker en 1972 que pretende analizar las producciones lingüísticas del aprendiz en las diferentes etapas de su desarrollo para intentar dar cuenta de "lo que subyace a los constructos producidos por los aprendices de LE" (Durão, 2007, p. 33). A través de este se plantea el análisis de errores de transferencia presentes en las producciones llevadas a cabo por los alumnos en su estado de interlengua puesto que, en palabras de Selinker (1979) "predictions of behavioral events in a theory of second-language learning should be primarily concerned with the linguistic shapes of the utterances produced in ILs”. (p. 60). Este análisis, junto con la descripción de las actuaciones interlingüísticas, permitirá, de acuerdo con Alexopoulou (2010), que el profesor pueda reconocer las necesidades comunicativas de los alumnos en las sucesivas etapas de desarrollo lingüístico y trabajar a partir de estas.

Partiendo de la idea de Santos Maldonado (2002) de que los errores "lejos de ser considerados como algo que se debe evitar, se integran como un mecanismo inherente al proceso de aprendizaje" (p. 122), nos acercamos al concepto de error como una parte fundamental de dicho proceso lo cual implica que, debemos mostrar una actitud de respeto hacia este y hacia su corrección. Detección y corrección del error son dos procesos interrelacionados y, además, según 
Núñez-Méndez (2001) la detección debería pasar previamente por la identificación de las causas de la aparición del error para poder aplicar una corrección adecuada.

Desde Corder (1981) nos llega la idea de que el análisis de errores va más allá de la identificación de una taxonomía de errores, puesto que implica la existencia de determinados "psycholinguistic processes of language learning" (p. 35). Dicha taxonomía supone obligatoriamente pasar por un análisis profundo de dichos errores en busca de su causa para poder entender su naturaleza o en palabras del propio autor: "only when we know why an error has been produced can we set about correcting it in a systematic way" (Corder, 1981, p. 52).

Como hemos venido resaltando, los procesos de detección y análisis de errores han provocado innumerables debates en el ámbito de la enseñanza de L2. Así pues, dichos procesos han representado para muchos investigadores de la Linguística una manera de medir el rendimiento académico de los alumnos al tiempo que se han convertido en una fuente de información sobre el estado de interlengua del alumno; fuente importante tanto para el profesor como para el alumno mismo. Se ha podido observar que el concepto de error ha ido perdiendo su vertiente negativa, y se ha ido alejando de la idea de sanción siempre impuesta por el profesor y recibida por el alumno.

\subsubsection{El componente afectivo y motivacional en la corrección del error y el feedback}

Según las teorías psicolingüísticas de enseñanza-aprendizaje de L2 los componentes afectivos y motivacionales inciden de forma generalizada en el aprendizaje de una L2. Nos 
encontramos ante dos componentes que directa e indirectamente están relacionados con la presencia del error en las producciones escritas en L2.

Desde las teorías de Lado (1964a) el hombre como ser humano social necesita comunicación y, unido a esto, se encuentra el propio proceso de aprendizaje de una lengua. Es por eso que, el aprendizaje de la lengua se convierte en un medio para satisfacer la propia necesidad de comunicación, de ser capaz de utilizar la lengua, así como de entender los significados intrínsecos y las connotaciones del hablante. El autor resalta en su obra la importancia de aprender una L2 como principal motivación del alumno para llevar a cabo dicho proceso de aprendizaje.

Ya en 1996 García destacaba la importancia de la motivación en la enseñanza-aprendizaje de una L2. En su trabajo investigador, el autor, centrándose en dos grupos de alumnos pertenecientes a grupos étnicos diferentes, examinaba la relación existente entre motivación, actitudes y aptitudes en la enseñanza-aprendizaje de L2 dentro de un mismo contexto educativo afirmando que "attitudes towards the teacher, the class, the language, speakers of the language, and cultures of the language have all been found to be statistically significant" (García, 1996, p. 30).

Años más tarde, Gardner (2010) defendía fuertemente la idea de que "any teacher would agree that motivation is one of the most important factors in determining success or failure in any learning situation" (p. 182) pese a que, "many of them find it difficult to motivate their students and to keep them motivated" (Gardner, 2010, p. 182). 
En el epígrafe 1.1.3. mencionábamos a dicho autor quien hacía alusión al impacto que tiene la relación profesor-alumno en las actitudes de los alumnos hacia el aprendizaje de su L2. En 1985, Gardner incluía dentro del término motivación tres factores, a saber: las actitudes hacia el aprendizaje de la lengua, el deseo o la voluntad de aprender esa lengua y el nivel de motivación del alumno hacia el aprendizaje de dicha lengua.

Las actitudes del alumno hacia la comunidad de hablantes de la L2 y su cultura es otro factor relevante a la hora de determinar el nivel de motivación. Así es como estas actitudes “can influence their curiosity and attention to L2 learning" (Gardner, 2010, p. 187). Años antes, LarsenFreeman y Long (1992) mencionaban en su libro la misma idea de la importancia de la actitud y del deseo de acercamiento de los estudiantes a la sociedad y a la cultura de la L2 durante el proceso de enseñanza-aprendizaje. En este mismo acercamiento, la motivación del alumno hacia el aprendizaje de L2, en palabras de Gardner (2010), está relacionada con el componente cultural de esa lengua. Esta motivación se configura como una posición de apertura hacia la cultura de la L2.

Por su parte, Cumming (2006) utilizaba el término "goals" (p. 8) o metas en el aprendizaje de L2 concretadas en "personal beliefs, values, and actions, involvement in specific social contexts, and corresponding development of knowledge and abilities" (p. 8). Podemos identificar estas metas con las motivaciones que llevan al alumno a aprender una L2; metas que se han convertido en objeto de estudio de numerosas investigaciones en psicología educativa.

En la misma línea, Gentil (2006) realizó un estudio de investigación en el que analizaba las metas o motivaciones de los estudiantes a la hora de aprender una L2 en un contexto bilingüe 
inglés-francés en Canadá. Así pues, de este estudio extrajo la idea de que "the nature of goals for writing improvement in one language or another reflected the symbolic and instrumental value of the language for academic, study, work or social life" (Gentil, 2006, p. 156). Asimismo, consiguió demostrar las preferencias de los alumnos hacia el aprendizaje del inglés como L2. La causa principal, según el mencionado autor, se relaciona con una "increasing hegemony of that language in North America and in the world" (Gentil, 2006, p. 156).

Son varios los factores por los que el alumno puede perder esa motivación hacia el aprendizaje de la L2 que muestra durante los primeros días. De acuerdo con Gardner (2010), muchos de ellos se encuentran "beyond the control of the language teacher" (p. 183). En su obra, Gardner (2010) menciona algunos de estos factores como: "home background, physical tiredness, events in their personal life, health, previous educational experience, and personality" (p. 183). Sin embargo, hay un factor que puede influir en gran medida en la motivación de los alumnos en torno al aprendizaje de una L2 y es "teachers'professional and affective characteristics" (Gardner, 2010, p. 183). En este sentido, el componente motivacional involucra no solo al alumno sino también al profesor. Así pues, una enseñanza eficaz implica la necesidad de mantener la motivación en los profesores de L2. Un profesor motivado es aquel que conoce a los alumnos y su situación de interlengua, se adapta a sus necesidades educativas, fomenta su participación activa, mantiene altas sus expectativas, utiliza distintos métodos de enseñanza y trata a los alumnos con respeto. En palabras de Gardner (2010), no solo se muestra satisfecho con su trabajo "but also is empowered to strive for excellence and growth in instructional practice" (p. 191). Según el mencionado autor "patient and humorous teachers are inclined to create a pleasant and relaxed atmoshphere" (Gardner, 2010, p. 188) en el aula de L2. 
El componente afectivo concretizado en una actitud positiva y en la cooperación bidireccional entre alumno-profesor, objeto de atención en los epígrafes 1.1.2 y 1.1.3 de la presente Tesis Doctoral, se constituye en el fundamento de la corrección de errores y de la dotación de feedback. En virtud de esto, destacamos la existencia de determinados estudios como el realizado por Rodríguez García en 2017 en el que realiza una consulta a los propios alumnos acerca de su percepción en torno a la corrección y al feedback, demostrando que, en situaciones de cercanía hacia el alumno en el aula y de tolerancia hacia el error por parte del profesor, los alumnos se muestran motivados a la hora de realizar sus producciones escritas y presentan una actitud de respeto hacia el feedback ofrecido. El estudio mencionado resalta que los estudiantes de L2, en general, se muestran abiertos a todo tipo de corrección, aunque prefieren la corrección por parte de sus compañeros del aula o la autocorrección. Así pues, los alumnos muestran una tendencia hacia el uso de una corrección que favorezca su propia autonomía.

En la enseñanza-aprendizaje de L2 los aspectos socioculturales han constituido un tema de atención para profesores e investigadores, sobre todo en la segunda mitad del siglo XX. Así pues, lengua y cultura constituyen "un todo indisociable” (Guillén Díaz, 2002, p. 202; Merino Mañueco, 2015, p. 85) en el proceso de adquisición de la competencia comunicativa en una L2. El término cultura se configura como un concepto muy amplio ligado, en palabras de Santamaría Martínez (2010), a la Lingüística y a sus disciplinas, entre estas, la Pragmática, la Psicolingüística y la Semiótica. Ante esta última nos detendremos para analizar la situación pedagógica que actualmente nos ocupa en torno a la afectividad por parte del alumno-productor que recibe el feedback y del agente-profesor que tiene que ofrecerlo. 
Ya en el epígrafe 1.1.3 hacíamos referencia a los distintos tipos de corrección de errores y posterior dotación de feedback y encontrábamos que, la modalidad de entrega de feedback más utilizada tanto por profesores de L1 como de L2 que se disponían a corregir las producciones escritas de sus alumnos era la de comentarios escritos y la del feedback oral.

En el mencionado epígrafe, partíamos de la idea de Ferris (2003) desde el contexto norteamericano y de Cassany (2009) desde el español quienes identificaban dos grandes modalidades de corrección: la primera en la que el profesor solamente corrige el último borrador del alumno sin que se produzca ningún tipo de interacción oral entre alumno y profesor (o entre alumnos cuando estos intervienen en el proceso de corrección) durante el proceso de producción escrita y aquella en la que se alternan los comentarios escritos con las entrevistas en las que el profesor, ayudado en ocasiones por alumnos, proporciona feedback oral. Mostramos nuestro acuerdo con ambos autores respecto a la necesidad de adoptar esta segunda modalidad en las clases de expresión escrita en L2 de alumnos en edades tempranas.

Como ejemplo de técnica de corrección incluida en esta segunda modalidad mencionamos la denominada "cycles of revision" (Zamel, 1985, p. 95) o técnica de borradores encadenados, la cual se constituye de entrevistas individuales (aunque en ocasiones se puede contar con la presencia de uno o varios compañeros del aula) e incluye sesiones de interacción oral profesoralumno (o profesor-alumnos) y de interacción escrita. Así pues, el profesor, previa lectura en voz alta del texto por parte del alumno, proporcionará un feedback oral en el que comenzará señalando los aspectos positivos. Continuará con una breve explicación de las pautas que deberá seguir el 
propio alumno para reconducir y realizar las correcciones necesarias en su primer, segundo o tercer borrador hasta llegar al producto final. Siempre que lo considere necesario, el profesor podrá hacer uso de feedback escrito con el fin de complementar ese feedback oral a través del uso de breves notas que permitan al alumno recordar los comentarios del profesor. Dicho feedback oral deberá contener no solo refuerzo positivo, recomendaciones y consejos sino también frases de ánimo (Vázquez, 2000). En este sentido, el componente afectivo se revela como un elemento clave dentro del proceso de corrección de errores y posterior dotación de feedback durante la elaboración de las producciones escritas de los alumnos de L2. Dentro de esta técnica destacamos el papel importante que juega la Semiótica como teoría linguiística que, en palabras de Santamaría Martínez (2016), “analiza el valor de los signos dentro de la vida social, con sus códigos verbales, gestuales, iconográficos, etc.” (p. 21). Entre las expresiones kinésicas que pueden acompañar a todo proceso de corrección escrita, se incluye la semiótica paralingüística la cual, para Solias Arís (2007) incluye gestos y expresión facial además de rasgos suprasegmentales tales como la entonación o el acento (p. 77), cuya atención se estima imprescindible en el ámbito de conocimiento de la enseñanzaaprendizaje, en general y de L2, en particular.

Como ya mencionábamos en el epígrafe 1.1.3, la gestualidad, la proximidad y la expresión facial del profesor hacia el alumno juegan un papel muy importante durante el proceso de corrección y posterior dotación de feedback. El profesor, a través de su postura, la posición que ocupa en la mesa, el grado de proximidad con el alumno etc., ha de mostrarse como un guía o facilitador de la enseñanza-aprendizaje de L2 (Fonseca Mora, 2005). Se impone por tanto la necesidad de que, en el transcurso de las entrevistas, el profesor ocupe un lugar diferente al 
habitual, una mesa en la que pueda sentarse a la misma altura que el alumno o alumnos de modo que todos puedan interactuar de forma adecuada.

La consideración del alumno como parte del proceso de enseñanza-aprendizaje y su aceptación como sujeto-agente es, en palabras de Díaz Martínez (2012), un principio reconocido por todo profesional de la enseñanza-aprendizaje de L2 mencionado en varios documentos de referencia europeos para las lenguas extranjeras entre los que se encuentra el MCER (Consejo de Europa, 2002). Dicho principio indica la necesidad de cuidar de manera meticulosa el entorno social del aula, entendido este como las interacciones del alumno con sus propios compañeros o con el mismo profesor. Así pues, la idea planteada por Gardner (2010) en torno a la creación por parte del profesor de una "relaxed atmosphere in the L2 classroom" (p. 188) se convierte en una necesidad subjetiva dirigida al alumno. Los componentes afectivo-motivacionales deben estar presentes en el entorno social del aula de L2 y orientados de modo que incidan en el alumno para que este sea consciente de su aprendizaje autónomo en la producción escrita en L2.

En cuanto al grado de flexibilidad ante los errores de los alumnos Norrish (1983) aconsejaba a los profesores de L2 que fuesen tolerantes porque esta actitud fomentará en los alumnos una actitud positiva hacia el uso de la L2 que permitirá que estos produzcan de forma libre y se animen a tomar riesgos al tiempo que disfrutan de su propio proceso de aprendizaje en un ambiente agradable que les proporcione seguridad a la hora de producir en la L2. Esto nos permite afirmar que la corrección de errores debe tener lugar en un ambiente marcado por la comprensión y la tolerancia hacia estos teniendo siempre en cuenta que la enseñanza debe centrarse en la figura del alumno, adoptando el profesor el papel de guía y mediador que proporciona las estrategias 
necesarias al alumno para que este, a través de una toma de decisiones, asuma su responsabilidad sobre el propio aprendizaje. En este sentido, han de adoptarse técnicas de corrección dirigidas a estos objetivos.

En resumen, podemos afirmar que la combinación de un buen sistema de corrección y posterior tratamiento del error, junto con la dotación, por parte del profesor de un feedback oral y escrito pertinentes, incidirán de forma significativa en el nivel de eficacia de las producciones escritas de los alumnos en el aula de L2.

\subsection{Del objeto de enseñanza-aprendizaje a la expresión escrita}

El presente trabajo de investigación se inscribe en dos contextos educativos: por un lado, un conjunto de centros de Educación Primaria de la ciudad de Valladolid donde se imparten enseñanzas de inglés como L2 y, por otro, un grupo de centros de Educación Primaria de la ciudad de Austin donde se imparten enseñanzas de español como L2. En este acercamiento, abordamos el inglés y el español como dos lenguas de referencia que formarán parte de nuestra investigación.

Desde el MCER (Consejo de Europa, 2002) se han venido resaltando una serie de actividades de expresión escrita. En el planteamiento de dichas actividades se ha partido de interrogantes relacionados con su finalidad y con la capacitación del alumno para resolver dichas

actividades. Desde esta consideración, el mencionado documento señala que "las estrategias de 
expresión suponen movilizar recursos, buscar el equilibrio entre distintas competencias maximizando las cualidades y evitando las insuficiencias - con el fin de equiparar el potencial disponible con la naturaleza de la tarea" (Consejo de Europa, 2002, p. 66).

Dado que, en el presente trabajo de investigación nos centramos en la etapa educativa de Educación Primaria, abordaremos el aprendizaje de la escritura como un aspecto que se desarrolla progresivamente, en los diferentes niveles de las etapas que comprenden la educación obligatoria y que, en la perspectiva de Dolz et al. (2013), se considera un factor importante para poder alcanzar el éxito escolar de los alumnos y su socialización. En este sentido, en palabras de los mencionados autores "el descubrimiento de la escritura y de las posibilidades de comunicarse con los otros por escrito es parte de los objetivos prioritarios de la enseñanza básica” (p. 9).

Además, los citados autores respecto a las actividades de producción textual destacaban el hecho de que contribuyen "al desarrollo de la reflexión y de la cultura" (Dolz et al., 2013, p. 11). Unido a esto, los alumnos "construyen referencias culturales comunes, compartidas, en torno a la escritura y la textualidad, a la estructura y el funcionamiento de la lengua y, fundamentalmente, a la relación que la lengua mantiene con la cultura" (Dolz et al., 2013, p. 11). Así pues, podemos decir que este tipo de actividades llevadas al aula de L2 aportan al alumno una visión de apertura ante la cultura de esa L2.

El proceso de producción de un discurso escrito moviliza una serie de componentes cognitivos. Sin embargo, dentro del contexto del aula se limita, en ocasiones, a una redacción guiada para cuya elaboración el alumno necesita primero suficiente input comprensible y 
suficientemente rico para poder producir. Pasando por un proceso progresivo de acumulación lingüística llegará a ser capaz de adquirir autonomía en la redacción. Asimismo, todo este proceso progresivo de acumulación de conocimiento implica la presencia contante del error. Dicha presencia ha de ser valorada positivamente por el profesor e integrada dentro del proceso de enseñanza-aprendizaje. Así pues, este no debe ser entendido como un símbolo de fracaso sino como "un paso obligatorio que permite la apropiación de las convenciones de la escritura (Dolz et al., 2013, p. 26). Además, también moviliza una serie de factores afectivos. En este sentido, el nivel de motivación que experimente el alumno hacia el proceso de escritura y hacia los temas de producción textual propuestos por el profesor incidirán de manera decisiva en su compromiso hacia ella. El tipo de tratamiento del error por parte del profesor, también influirá de una forma determinante en las producciones de los alumnos.

Escribir puede convertirse en una experiencia frustrante que implica un gran nivel de dificultad a la hora de motivar a los alumnos (Buzea, 2013) ya que, de acuerdo con la citada autora: "composition writing involves a process of teaching students how to reach out and touch lives of those around them sensorially, emotionally and intellectually" (p. 35) a lo que se suma el hecho de que "students' unique individuality" (Buzea, 2013, p.35) aparecerá resaltada en las producciones escritas de esos alumnos. Este sentimiento de individualidad también se reflejará en el proceso de corrección y posterior dotación de feedback, los cuales han de concretizarse en actividades personalizadas y centradas en las características individuales del alumno. 


\subsubsection{De la lengua como medio de comunicación en $\mathrm{L} 2$ al discurso escrito}

Unido a la idea de lengua -como medio de comunicación en nuestra vida diaria y como vía de comunicación entre las personas con la que expresamos conceptos, así como “vivencias, estados anímicos y deseos" y, a través de la cual, "se nos ofrecen y ofrecemos todo tipo de mensajes" (MECD, 2011, introducción, 1)- encontramos la importancia que tiene el discurso escrito dentro de esta. Desde esta perspectiva, en palabras de Dolz et al. (2013), “el aprendizaje de la producción escrita es una de las finalidades fundamentales de la enseñanza de lenguas” (p. 9).

Widdowson (1996) definía el concepto de lengua como "a matter of observable fact, a universal feature of the species not attested in other animals, and therefore a genetic accomplishment" (p. 12). Según el mencionado autor, "human beings are born with a cognitive learning capability which is wired genetically into the brain" (p. 13). Adoptando sus palabras, la teoría lingüística "is concerned primarily with an ideal speaker-listener, in a completely homogeneous speech-community” (p. 91) además, estos hablantes y oyentes ideales poseen una competencia absoluta de la lengua que hablan y no se encuentran limitados por condiciones como "memory limitations, distractions, shifts of attention and interest, and errors (random or characteristic)" (Widdowson, 1996, p. 91). Se habla por tanto de un sistema ideal que no tiene en cuenta factores externos como distracciones, falta de atención o errores. Se puede decir que, este sistema, no cuenta con los obstáculos propios del que aprende una L2.

Respecto a la realización de productos lingüístico-discursivos, recurrimos a Vez et al. (2002), quienes destacaban el hecho de que para la obtención de un discurso escrito el alumno 
recurre a un proceso "propio y progresivo" (p. 155) y, desde esta consideración, "pone en funcionamiento determinados mecanismos, que le permiten pasar por unos esquemas sucesivos del conocimiento hasta integrar plenamente la información, siguiendo una serie de momentos o fases”. (Vez et al., 2002, p. 155). Además, los mencionados autores ponían de relieve la emergencia de las neurociencias "que centran sus estudios en el funcionamiento de los mecanismos cerebrales que rigen los actos de lenguaje” (p. 155). Asimismo, corresponde al profesor plantearse una serie de interrogantes respecto a las estrategias que pone en marcha el alumno para aprender, los factores que intervienen, los conocimientos previos, sus intenciones, así como sus comportamientos de aprendizaje.

Retenemos la idea de Leki (2001) por cuanto que la escritura en L2 "has received a great deal of research attention" (p. 1). Nos encontramos ante una destreza que, no solo permite demostrar el nivel de interlengua del alumno, sino que, a través de ella evaluamos las capacidades intelectuales de nuestros alumnos en otras disciplinas. Muchos de los conocimientos se evalúan a través de exámenes escritos por lo que las producciones escritas de los alumnos son clave en el proceso de evaluación y pueden "open and close doors to academic advancement for students in ways no other language skill does" (p. 1). Por esta razón, Leki (2001) observa que "teaching L2 writing has taken on enormous significance" (p. 1).

Según Leki (2001), la enseñanza de escritura en L2 no solo pone de manifiesto la existencia de un número determinado de estructuras gramaticales ordenadas, sino que va mucho más allá. La escritura debe plantearse como una forma de expresión del alumno y de su creatividad. Es así como 
retenemos la idea de Dolz et al. (2013) en cuanto a que "a través de la escritura, el alumno desarrolla su propio estilo, iniciándose en los juegos lingüísticos” (p. 11).

También Lado (1964b) establecía una diferencia entre el proceso de escritura y el de escritura creativa. El carácter formal que se le confiere a la escritura supone que toda producción escrita cuente con un contenido meditado y un estilo más cuidado que el que puede tener una conversación informal. No obstante, según el mencionado autor, la escritura creativa "requires talent and special training" (p. 248). Así pues, resulta obvio que cada alumno o grupo de alumnos presentará unas dificultades distintas. Así pues, dependiendo de la L1 del alumno, de la edad de este y en particular, de su experiencia previa respecto a la producción escrita en su L1, los estudiantes de L2 presentarán distintas singularidades y problemas a la hora de producir en esa L2. Por consiguiente, para los alumnos que nunca hayan estado expuestos a ningún tipo de producción escrita, todo este proceso resultará ser algo completamente nuevo. Sin embargo, para aquel alumno o grupo de alumnos que ya escriben en su L1, el proceso de escritura requiere la adquisición de nuevos hábitos. La aplicación de dichos hábitos, dejando a un lado los adquiridos, puede ocasionar conflictos y confusión que, según el autor "will persist through fairly advanced stages of control of the new language" (1964b, p. 249). La propuesta del autor en torno a la evaluación de las producciones escritas de los alumnos de L2, teniendo en cuenta las características de ese determinado grupo se revela útil y provechosa y se inscribe en el intento de todo profesor de acercarse al alumno y a su situación específica.

Se impone exponer a los alumnos a la vida social y política de los países donde se habla la L2 planteando actividades enmarcadas dentro de otras disciplinas, así como proponer actividades 
de aula en las que los alumnos puedan interactuar con hablantes nativos que puedan hacerles partícipes de la vida social de los países donde la L2 sea lengua oficial. Leki (2001) hace referencia en su obra a varios cursos y programas destinados a la enseñanza de escritura en L2, la cual, como destaca la mencionada autora, "is not considered to be an end by itself" (p. 1). Por el contrario, debemos considerar esta destreza como:

Learning to use a tool with a special capacity to link and integrate other language skills; to probe and consolidate budding disciplinary knowledge; to unite the L2 writers with other individuals and communities; and to facilitate access to different social, political and intellectual worlds. (Leki, 2001, p. 2)

En esta misma óptica, desde el contexto educativo de enseñanza-aprendizaje de L2 en universidades norteamericanas, Davidson (1978) había destacado que el acceso a estas instituciones de educación superior suponía un nivel avanzado de los alumnos en todas las destrezas lingüísticas, sin embargo, "writing is of major importance at this level of education" (p. 86) debido al hecho de que "the student is most often evaluated through written means such as research papers and essay examinations" (Davidson, 1978, p. 87). De acuerdo con esto, señalaba la importancia de intensificar la destreza de expresión escrita en alumnos cuya L1 no es el inglés durante las etapas educativas previas a la educación universitaria. Según el mencionado autor, estos alumnos "show the least proficiency in this area" (Davidson, 1978, p. 87) por lo que se impone la necesidad de entrenarlos de la forma más eficiente posible para que puedan ser capaces de adquirir el nivel de destreza necesario para poder formar parte del sistema de educación superior en universidades extranjeras. 
En su trabajo de investigación, Leki (2008) lleva a cabo un estudio longitudinal en el que analiza a lo largo de varios cursos académicos los retos y complejidades que experimenta un grupo de alumnos extranjeros que cursan estudios superiores en una universidad norteamericana. En este sentido, la mencionada autora destaca la necesidad de que exista una formación específica en producción textual en L2 durante las etapas anteriores a la educación superior. A través de esta formación, los alumnos serán capaces de alcanzar el nivel de competencia en expresión escrita necesaria para poder acceder a estudios superiores en universidades de los países donde se habla la L2 siempre que lo estimen conveniente.

El creciente interés de los estudiantes de inglés como L2 en formar parte de los programas de estudio de educación superior que oferta un gran número de universidades norteamericanas y el aumento de programas de intercambio de estudiantes entre distintas instituciones europeas trae consigo la necesidad de crear unas bases sólidas en la destreza de expresión escrita en los alumnos de L2 desde los niveles educativos más elementales de Educación Infantil y Primaria. Mostramos nuestro acuerdo con Leki (2008) por cuanto que se impone la necesidad de crear las bases en la destreza comunicativa en la expresión escrita en L2 desde los primeros niveles educativos. Se debe, por tanto, plantear una valoración a largo plazo de dicha destreza comunicativa ya que la adquisición de estas bases supondrá no solo un acercamiento a la lengua y cultura de la L2, sino que además permitirán al alumno la posibilidad de formar parte de otros sistemas educativos distintos al suyo durante las etapas educativas superiores. 


\subsubsection{Enseñanza-aprendizaje de la expresión escrita en L1 y L2}

Partiendo de la idea de que aprender una lengua no es lo mismo que aprender a escribir en esa lengua, consideramos que, tanto la enseñanza de comprensión como la de expresión escrita en L2, tienen lugar después de la enseñanza de las destrezas de comprensión y expresión oral. Sin embargo, en ocasiones, encontramos que "the clear separation between language and writing in the learning process of our native language is usually forgotten when teaching or learning a foreign language" (Lado, 1990, p. 93). De acuerdo con esto, encontramos situaciones en las que el profesor cae en el error de enseñar una lengua a través de su sistema de escritura.

La exposición del niño ante el lenguaje escrito tiene lugar mucho antes de que este se enseñe en las instituciones educativas. Así es como, en palabras de Teberosky (1992), los niños adquieren un conocimiento de dicho lenguaje antes del proceso de enseñanza formal de expresión escrita. Años más tarde, Domínguez Chillón y Barrio Valencia (1997) se expresarán en términos similares al señalar que, entender el proceso de aprendizaje de escritura del niño supone "indagar la génesis de su conocimiento sobre el lenguaje escrito, génesis que comienza antes del proceso formal de enseñanza escolar” (p. 41). Así pues, los primeros pasos de alfabetización de los niños "dependen de las experiencias personales que cada niño tenga, de modo que la familia y la comunidad son los primeros alfabetizadores de los niños" (Domínguez Chillón \& Barrio Valencia, 1997, p. 40). Desde esta consideración, podemos afirmar que el medio social y cultural que rodea al niño juega un papel clave en el desarrollo del lenguaje escrito. Esto conecta con la teoría sociocultural de Vygotsky, según la cual, el desarrollo cognoscitivo es, en gran medida, un proceso 
social. La mencionada teoría pone de manifiesto que, tanto las personas que rodean al niño durante su proceso de aprendizaje, como las creencias y actitudes sociales incidirán en su aprendizaje.

Así es como, a pesar de que los primeros procesos de alfabetización de los niños se desarrollan en el ámbito familiar, en todo proceso de aprendizaje deben tenerse en consideración que "la escritura y el lenguaje escrito obedecen a reglas o convenciones de funcionamiento" (Teberosky,1992, p. 76). Algunas de estas reglas y convenciones han de ser practicadas, entendidas y compartidas por otros, es decir, requieren una enseñanza reglada. Esta idea es expresada también por Salvador Mata (1997) quien añadía, desde una perspectiva psicolingüística, que las diferencias entre lenguaje oral y escrito están estrechamente relacionadas con el modo de adquisición. Así pues, la lengua oral se adquiere de forma natural, sin necesidad de instrucción formal y, por el contrario, la lengua escrita se adquiere a partir de la instrucción formal y tiene lugar en un contexto académico, como norma general. Coincidimos con este autor a la hora de afirmar que es en el contexto académico escolar donde se enseña a los niños los conceptos de gramaticalidad, corrección y organización del texto a través de consignas básicas en torno a la elección de las palabras apropiadas, su disposición y orden, etc., de este modo, "el niño toma conciencia muy pronto de la diversa funcionalidad del lenguaje oral y escrito" (Salvador Mata, 1997, p. 22).

Escribir es, en palabras de Lado (1964a), "to put down the graphic symbols that represent a language one understands, so that others can read these graphic symbols if they know the language and the graphic representation" (p. 143) y, de acuerdo con el mencionado autor, aprender a escribir comprende las siguientes etapas: "prewriting, copying read texts, transcribing, composition and literature" (p. 143). En el presente trabajo nos centraremos en la etapa de 
composición textual en la que el alumno todavía está aprendiendo la forma de representación, pero ya es capaz de comunicarse y de producir textos breves en L2.

Ya en 1994, Cassany, Luna y Sanz manifestaban su preocupación en torno a la concepción del proceso de composición textual por parte de alumnos y maestros. En su manual de Didáctica de la Lengua subrayaban la importancia de las clases de expresión escrita en las que el maestro debe fomentar determinados valores en torno a la lengua escrita. En su opinión, los alumnos "suelen concebir la escritura como el acto automático de llenar una hoja en blanco con letras" (Cassany et al., 1994, p. 261) sin preocuparse de hacer distintos borradores, revisarlos, etc. También el maestro puede llegar a transmitir a los alumnos, a través de sus actitudes, esta preocupación por el producto o borrador final de la composición sin tener en cuenta el proceso. Así es como, este tipo de comportamientos, conforman, en palabras de Cassany et al. (1994) "una imagen pobre de la composición escrita" (p. 261) por lo que se impone la necesidad de que los maestros animen a los alumnos a "elaborar sus textos: a buscar y a ordenar las ideas, a hacer borradores, a revisar, a autocorregir sus errores, a no tener prisa y a hacer las cosas bien” (p. 261). En este acercamiento, las recomendaciones de Cassany et al. (1994) se dirigen a "poner el mismo énfasis en el producto acabado y en la corrección que en el proceso de trabajo" (p. 261).

De acuerdo con Salvador Mata (1997), el proceso de composición escrita supone la apropiación de ciertos conocimientos como son el conocimiento social (que gira en torno a las relaciones entre interlocutores), el conocimiento conceptual (que abarca conceptos relacionados con el mundo y con el tema del texto) y el conocimiento lingüístico o textual (que incluye las formas lingüísticas y la forma del texto). 
En el mismo año, Cassany (1997) hacía alusión en su obra a un grupo de pedagogos y profesores de lenguas estadounidenses que, en los años setenta, observaron el comportamiento de los escritores profesionales y, a partir de la identificación de los subprocesos que intervienen en el acto de escribir: "buscar ideas, organizarlas, redactar, revisar, formular objetivos, etc.” (p. 31) utilizados por dichos escritores, decidieron elaborar un modelo teórico general de producción escrita. En su investigación observaron que, en contraposición, los estudiantes de lenguas, ante una actividad de expresión escrita libre "se limitan a capturar el flujo del pensamiento y a rellenar hojas, sin releer ni revisar nada" (Cassany, 1997, p. 31).

El mismo autor, se acercaría años más tarde a los procesos cognitivos que desarrollan los alumnos durante la elaboración de su producción escrita. Afirmando que "escribir es una tarea cognitivamente compleja, que va mucho más allá de la resolución de dudas ortográficas o de redacción” (Cassany, 2005, p. 41) y acercándose también a los procedimientos que llevan a cabo los escritores profesionales, afirmaba que, estos toman conciencia del contexto en el que se encuentra el texto que están a punto de redactar, analizan el perfil y los intereses de sus lectores, acuden a su memoria para recopilar datos pertinentes, se proponen una finalidad comunicativa para el texto, mantienen el control del propio proceso ideando planes de trabajo y revisan sus borradores de manera minuciosa como se muestra en la figura 4 extraída de Cassany (2005, p. 41). 


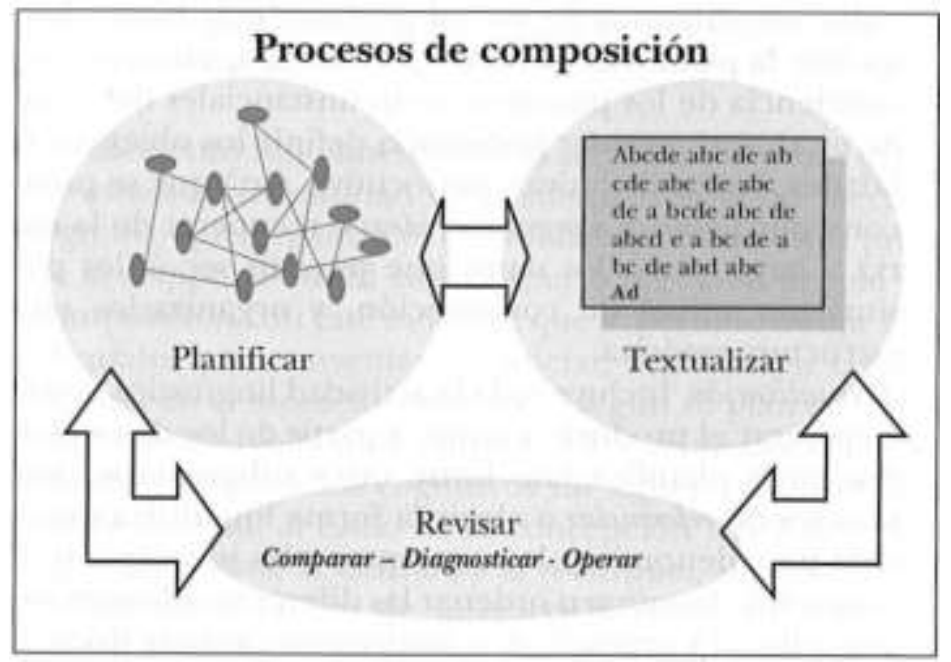

Figura 4: Proceso de composición. Tomada de Cassany, 2005, p. 41

El proceso de composición abarca, de acuerdo con Cassany (2005), todo lo que el autor piensa, hace y escribe desde que decide producir el texto hasta que concluye la versión definitiva o versión final. En la figura presentada, Cassany (2005) muestra los subprocesos que intervienen en el arte de escribir: planificación, textualización y revisión (en el que incluye las tareas de comparar, diagnosticar y operar) presentados de forma cíclica. Las flechas que aparecen en dicha figura son bidireccionales y representan el movimiento de un subproceso a otro de manera indistinta. El subproceso de planificación supone organizar, ordenar, clasificar la información y formular los objetivos propuestos para el texto que el autor se dispone a escribir. Este subproceso debería terminar con un esquema que permita la transición hacia el siguiente paso. Nos acercamos al subproceso de textualizar en el que transformaremos el esquema en texto. En la etapa de revisión, tendremos que releer el texto de forma global y también por partes. A partir de la revisión, tendremos que volver a rehacer el texto, lo cual nos puede llevar a cualquiera de los dos subprocesos: a la planificación o a la textualización que, a su vez nos conducirán de nuevo a la revisión hasta poder completar una versión final. 
Asimismo, Cassany (1997) proponía el uso de una serie de estrategias cognitivas y técnicas de composición utilizadas por escritores profesionales adaptadas previamente a las necesidades educativas. Entre las técnicas propuestas por el autor se encuentran las denominadas: "torbellino de ideas, estrella de las preguntas, escritura libre o automática" (Cassany, 1997, p. 32) a las que el alumno podrá recurrir cuando se disponga a buscar ideas; “ideogramas, mapas mentales, esquemas" (Cassany, 1997, p. 32) para organizar dichas ideas y "señales para leer, variar la frase, reglas de economía y claridad" (Cassany, 1997, p. 32) para redactar.

Entre las técnicas de composición escrita recomendadas por Corpas y Madrid (2007), encontramos la composición cooperativa que puede llevarse a cabo en parejas o en grupos, en cuanto a las técnicas de organización de textos proponen la elaboración de esquemas, lluvias de ideas, etc. En relación a las técnicas procesuales, los citados autores sugieren el trabajo cooperativo con los compañeros del aula y proponen al alumno solicitar la ayuda al profesor cuando se estime necesario. También el MCER (Consejo de Europa, 2002) recomienda acudir al profesor, asistente o a los propios compañeros de clase cuando el alumno se encuentre en el proceso de planificación del texto escrito.

Situándonos en la línea de Mendoza, López y Martos (1996), entendemos la evaluación como "una parte del proceso de enseñanza-aprendizaje que permite la obtención de información sobre los elementos implicados (progreso del alumno, programación, metodología...) para interpretarla, con el fin de tomar decisiones entre diferentes alternativas de enseñanza-aprendizaje" (pp. 388-389). Como profesores de L2, en lo que concierne a la evaluación de las producciones 
escritas de los alumnos de L2, Cassany (2005) se preguntaba: “¿consideramos solo la versión final de un escrito o también sus borradores?” (p. 79). En respuesta a dicha pregunta, el autor apuntaba que un solo escrito no puede "ser representativo de la capacidad expresiva de nadie" (Cassany, 2005, p. 79) por lo que se impone la necesidad de que analicemos las producciones intermedias o borradores que el alumno produce ya que estos, en palabras del autor "ofrecen datos relevantes sobre las capacidades compositivas del sujeto" (p. 79). Nos situamos en la perspectiva del mencionado autor respecto a dicha afirmación.

En este acercamiento, Cassany (2005) hace alusión a varias herramientas evaluadoras de la producción escrita las cuales analiza en su obra bajo un punto de vista formativo. Entre ellas, nos detenemos en las que él mismo denomina "cooperación entre iguales" y "tutoría entre docente y aprendiz". El autor afirma que dichas herramientas son, bajo su punto de vista las que están más orientadas a la formación del alumno; y, al mismo tiempo, las que "tienen menos tradición en el mundo hispano" (Cassany, 2005, p. 80). Dentro de la denominada cooperación entre iguales se incluyen todo tipo de actividades de corrección en las que los alumnos interactúen y colaboren entre sí (redacciones conjuntas, revisiones y correcciones entre sí, etc.). En cuanto a la entrevista docente-aprendiz, Cassany (2005) afirmaba que es una de las herramientas evaluadoras con mayor tradición en la cultura norteamericana. Como ya hemos mencionado anteriormente, este proceso de entrevista profesor-alumno comienza con una lectura en voz alta por parte del alumno-autor a lo que el profesor responde a través de un feedback oral en el que identifica posibles áreas de mejora acompañando su discurso de frases de apoyo y de ánimo -planteamiento que encontrábamos también en Vázquez (2000) -. Tras la dotación del feedback oral, el alumno será instado a elaborar un nuevo borrador en el que deberá incorporar dichos cambios y este será 
corregido a través de una segunda entrevista con el profesor. Estas entrevistas se repetirán hasta llegar al último borrador o producto final. Retenemos la idea del autor en relación a la utilidad de esta herramienta de corrección, en la cual, "la conducta del docente se asemeja a la de una relación de apoyo o ayuda, dejando que sea el propio aprendiz el que descubra los problemas del texto y los caminos para resolverlos" (Cassany, 2005, p. 80). Mostramos también nuestro acuerdo con Cassany (2005) respecto a que esta herramienta, junto con la de "cooperación entre iguales" así como las "pautas autocorrectivas" que incluyen todo tipo de actividades en las que se concede al alumno la oportunidad de revisar sus propios textos, son de gran utilidad y confieren al alumno un cierto grado de responsabilidad sobre su propio proceso de enseñanza-aprendizaje de la L2.

Además, Salvador Mata (1997) señalaba la existencia de varios procesos de composición escrita, a saber: el modelo centrado en el producto, el modelo basado en el proceso y el contextual o ecológico entendido, este último, como un proceso influenciado por el contexto en el que tiene lugar. En dicho contexto entran a formar parte determinados factores del aula: las personas que lo ocupan, los espacios, las relaciones interpersonales, etc., así como factores externos al aula como las experiencias que haya podido tener el alumno respecto al proceso de escritura.

Salvador Mata (1997) considera que el enfoque metodológico centrado en el producto es el más tradicional. Según el autor, dicho enfoque se centra en el texto o composición escrita como un producto y lo analiza desde la perspectiva lingüística. En esta óptica, el autor hace referencia a "un cambio en la enseñanza tradicional de la composición” (p. 25) de acuerdo con el cual, "se aboga por una enseñanza que establezca un ambiente de apoyo, en el que se considera al alumno como escritor, lo motive a asumir riesgos y lo comprometa en la construcción de significados” (p. 
25). Es a partir de este cambio cuando se aprecia una inclinación hacia el enfoque contextual o ecológico, el cual nos da la oportunidad de concienciarnos sobre los factores contextuales que influyen en el desarrollo de la competencia de expresión escrita del alumno y hacia el enfoque dirigido al proceso o enfoque cognitivo ya que este es, en palabras del propio autor, sin duda, el más elaborado y el que mejor explica tanto el proceso de producción escrita como los componentes cognitivos que forman parte de este. Respecto al proceso de composición, Salvador Mata (1997) lo define como un proceso interactivo de carácter flexible que está condicionado por determinadas variables tanto internas (el conocimiento de las restricciones lingüísticas y del tema de escritura) como externas (contexto y audiencia) e implica la activación de varios procesos cognitivos.

Ya en el epígrafe 1.1.3, hacíamos referencia al enfoque metodológico denominado processoriented pedagogy el cual, a diferencia del product-oriented pedagogy se centra en el propio proceso de escritura y no solamente en el producto final. Así pues, autores como Ferris (2003) desde el contexto norteamericano- y más tarde Cassany (2009) - desde el español- defendían el uso de este enfoque metodológico en el que se tienen en cuenta todos y cada uno de los borradores que el alumno produce. El uso de este enfoque permite a los profesores analizar y reflexionar acerca del nivel de interlengua del alumno a partir de los errores cometidos.

En 1996, Cassany ya hacía referencia a varios estudios de investigación cuyos resultados demostraban que la corrección, en la enseñanza-aprendizaje de expresión escrita, es positiva siempre y cuando se lleve a cabo durante el proceso de redacción del texto (es decir, cuando se corrigen los distintos borradores), sin embargo, esta no resulta útil cuando tiene lugar al final del proceso (cuando se corrige solo la versión final del alumno). 
El enfoque centrado en el proceso propio de escritura se configura como el modelo inherente a la técnica denominada por Zamel (1985) "cycles of revision” o borradores encadenados mencionada en el epígrafe 3.1.2 puesto que favorece la interacción y la cooperación entre alumnoprofesor y entre alumno (autor) y sus compañeros de clase. Asimismo, permite una corrección inmediata o automática de los errores encontrados en cada uno de los borradores de los alumnos. Este tipo de corrección se revela eficaz y provechosa puesto que posibilita que el alumno pueda recordar exactamente las razones que le llevaron a utilizar una forma concreta. El mencionado modelo puede ir acompañado de un feedback oral y personalizado en el que se incluya tanto feedback correctivo como sugerencias por parte del profesor en cuanto a la forma del texto. Como ya mencionábamos en el epígrafe 2.1.3, el feedback correctivo, tanto en su manifestación oral, como escrita se utiliza como apoyo y complemento a la corrección de errores.

Más allá de reconocer la importancia que tiene el uso del enfoque metodológico basado en el proceso, Cassany (2009) y Salvador Mata (1997) identifican una serie de subtareas o fases propias de dicho enfoque. La primera fase es la de planificación en la que el autor realiza un borrador mental de la futura composición escrita que deberá abarcar los siguientes componentes del texto: contenido, forma, sentido e intención significativa. La segunda fase es la de traducción o transcripción en la que el alumno deberá centrarse en la gramática, la puntuación, la grafía del texto, etc. La tercera y última fase es la de revisión que incluye dos sub-procesos: la evaluación de lo que se ha planeado y el posterior ajuste de las necesidades encontradas, así como la modificación del texto escrito. 


\subsection{Enseñanza-aprendizaje de L2: aspectos contextuales}

Hablar de adquisición y de enseñanza-aprendizaje de L2 nos hace recordar nuestras experiencias de formación escolar llevadas a cabo en un entorno formal. No obstante, hoy en día, la adquisición de una L2 se desarrolla tanto en contextos escolares, como no escolares. Distintos programas bilingües que se han ido sucediendo a lo largo de los años en Europa y en Estados Unidos de América se han configurado como programas en los que, de forma general, se intenta ayudar al alumno en la adquisición de una L2 manteniendo su L1. Así como Larsen-Freeman y Long (1992) han constatado, existe una gran variedad de programas de inmersión lingüística presentes en países como Canadá y Estados Unidos en los que los alumnos anglófonos realizan sus estudios de Educación Primaria en una L2; es el caso del programa dual presente en varios estados norteamericanos (entre los que se incluye el estado de Texas).

En este sentido, el cada vez más latente efecto de globalización impone la necesidad de comunicación entre los países por lo que se revela como imperante la adquisición y utilización de una L2 común que permita la posibilidad de llevar a cabo transacciones económicas, comerciales, relaciones diplomáticas, intercambios profesionales, etc. El inglés es la principal lengua internacional y la segunda lengua oficial en la mayoría de los países del mundo. Así pues, como ya mencionábamos en el epígrafe 3.1.2 de esta Tesis Doctoral, se puede decir que se ha constituido a lo largo de los últimos años como una lengua hegemónica. Esta hegemonía del inglés como lengua de comunicación (Cassany et al., 1994; Gentil, 2006; Leki et al., 2008 y Smolcic, 2011) y 
como lengua dominante en el ámbito académico, trae consigo innumerables "political and ideological discussions" (Leki et al., 2008, p. 61).

De acuerdo con Leki et al. (2008), todos los debates existentes en torno al proceso de enseñanza-aprendizaje de L2 están orientados al tema de la "hegemony of English" (p.61). La mencionada autora destacaba que "the study of scholarly writing in English in the last 25 years entailed the exploration of the global spread of English" (p. 60) que llevó a devastadoras consecuencias como por ejemplo el paso a un segundo plano de muchas otras lenguas.

Ya en el epígrafe 3.2, mencionábamos a Gentil (2006), cuya investigación analizaba las motivaciones de los estudiantes en cuanto al aprendizaje del inglés y del francés como L2 en el contexto bilingüe de una universidad canadiense. Los resultados de estos estudios consiguieron demostrar las preferencias de los alumnos hacia el aprendizaje del inglés como L2. La causa principal, según el mencionado autor, se relaciona con la mencionada "increasing hegemony" (Gentil, 2006, p. 156) del inglés en el mundo. Una hegemonía que, en sus propias palabras: "tipically works at the expense of speakers of other languages" (Gentil, 2006, p. 156).

\subsubsection{Programas de enseñanza-aprendizaje de inglés como L2 en el sistema educativo español. El caso de la ciudad de Valladolid}

El inglés, como resultado de los efectos de la globalización mundial en la educación, se posiciona como lengua franca, tal y como indican Lorenzo, Trujillo y Vez (2011), y se instaura a gran velocidad en todos los ámbitos, incluido el escolar, debido a una creciente demanda por parte 
de la sociedad, como ya hemos venido precisando. En respuesta a las políticas lingüísticas europeas establecidas por instituciones como la Unión Europea y el Consejo de Europa, se impone un cambio metodológico en la enseñanza de lenguas. Las consignas enviadas por las instituciones mencionadas se orientan hacia la adquisición de la competencia comunicativa del ciudadano europeo en, al menos, dos lenguas, además de la propia, para aumentar las posibilidades de desarrollo laboral y personal. Para ello, se empiezan a diseñar determinados modelos educativos de enseñanza de L2 que, posteriormente, serán incluidos en los sistemas educativos de los países miembros.

Así pues, se lanzan programas de inmersión total, parcial, clases de lenguas en torno a contenidos temáticos, etc., en los que se comienza a introducir la metodología CLIL (Content and Language Integrated Learning). Las primeras iniciativas del modelo de metodología CLIL aparecen, según el informe Content and Language Integrated Learning (CLIL) at School in Europe (Eurydice, 2006), en los años setenta, en zonas muy específicas, aunque poco a poco, se va dando a conocer por todas las zonas geográficas de los países miembros. El objetivo de estos programas es, en palabras de Lorenzo, Trujillo y Vez (2011), la "integración de diversas lenguas en la competencia comunicativa del estudiante, integración en la comunidad (real o potencial) de usuarios de una lengua, integración en la comunidad discursiva de las distintas áreas de conocimiento, integración en una comunidad multilingüe” (pp. 149-150).

En el ámbito educativo de la comunidad autónoma de Castilla y León (concretamente en la ciudad de Valladolid) se desarrollan dos programas de enseñanzas bilingües o enseñanzas integradas de contenidos y lengua extranjera en las etapas educativas de Educación Infantil, 
Educación Primaria y Educación Secundaria Obligatoria (ESO) conocidos como secciones lingüísticas. Por un lado, un programa de ámbito autonómico denominado secciones bilingües y por otro, un programa de ámbito nacional creado a partir de un convenio de colaboración entre el MECD y el British Council.

El programa designado como secciones bilingües, de acuerdo con Fernández (2010), fue incorporándose paulatinamente en un número importante de comunidades autónomas. La primera en poner en marcha este proyecto fue Andalucía en 1998; le siguieron Aragón y Galicia, Murcia, Castilla y León, Castilla La Mancha y Cantabria, Baleares, Madrid y Asturias. La implantación de secciones bilingües en centros educativos de Castilla y León comenzó en el curso 2006-2007 (ORDEN EDU/6/2006, de 4 de enero, por la que se regula la creación de secciones bilingüies en centros sostenidos con fondos públicos de la comunidad de Castilla y León) y, hoy en día, es uno de los programas más destacados en el que participan más del $31 \%$ del total de centros de Educación Primaria.

A efectos legales, se consideran centros de sección bilingüe aquellos que, una vez autorizados, utilicen una lengua extranjera europea (inglés, francés, alemán, italiano o portugués) para la enseñanza de contenidos de determinadas áreas o materias no lingüísticas. En el ámbito de la sección bilingüe se imparte docencia de dos o tres disciplinas no lingüísticas en la L2 propia de la sección, siempre que el total de horas impartidas en la lengua específica no supere el 50\% del horario total del alumnado. El horario de la enseñanza de la lengua específica de la sección podrá ser incrementado tanto en Educación Primaria como en Secundaria, con el fin de destinar más tiempo a la enseñanza de la disciplina "lengua extranjera". Además, los centros desarrollarán el 
proyecto bilingüe de forma progresiva, desde el primer curso de Educación Primaria hasta el último de la ESO.

El profesorado que imparte enseñanzas en la lengua extranjera de la sección bilingüe deberá contar con una acreditación en dicha lengua del nivel B2 definido en el MCER (Consejo de Europa, 2002). Junto al profesorado aparecen otros agentes implicados en estas enseñanzas, los auxiliares de conversación extranjeros, graduados y estudiantes universitarios en su último año académico de países europeos y extra-europeos, seleccionados mediante convocatoria anual del MECD para colaborar con el profesorado de los centros públicos en la enseñanza de la L2 y también de su cultura. Se dedicarán a reforzar las destrezas del alumno, especialmente las destrezas de comprensión y expresión oral. En Castilla y León desarrollan su actividad aproximadamente 225 auxiliares de conversación extranjeros.

Por su parte, el programa denominado Convenio MECD-British Council, tal y como encontramos en Llinares y Dafouz (2010), fue inaugurado en 1996 como parte de un convenio de colaboración entre el MECD y el British Council para llevar a cabo proyectos curriculares integrados y actividades educativas conjuntas. Su propósito es el de desarrollar un programa bilingüe español-inglés desde edades tempranas, poniendo especial atención en la alfabetización del inglés, impartiendo un currículo integrado que incluya los planes de estudio español y británico.

Este programa se desarrolla en centros escolares públicos, se inicia en Educación Infantil y concluye al final de la etapa de ESO. En la actualidad, se imparte en colegios públicos de 
Educación Infantil y Primaria y en institutos de ESO de Castilla y León además de estar presente en otras nueve comunidades autónomas y en dos ciudades autónomas. Este plan de estudios integrado está impartido por maestros españoles de lengua inglesa y de otras áreas, así como por asesores lingüísticos que también cuentan con la ayuda de auxiliares de conversación extranjeros.

La implantación de los programas secciones bilingües y convenio MECD-British Council tienen como objetivo la mejora de la competencia comunicativa de los alumnos en L2. El aumento del número de centros con sección bilingüe o con convenio MECD-British Council en los últimos años se debe al creciente interés por la adquisición de una L2, lo cual supone un hecho de vital importancia en nuestros días.

Los informantes del contexto educativo de Valladolid que han formado parte del presente trabajo de investigación llevan a cabo su actividad docente en centros de Educación Primaria donde se imparten clases de lengua inglesa desde el primer curso de Educación Infantil; algunos de estos centros cuentan con sección bilingüe inglés-español y en estos, además de clases de lengua inglesa, desde el primer curso de Educación Primaria, se imparten asignaturas no lingüísticas (Science, Arts and Crafts, Physical Education, Music, etc,) en inglés.

\subsubsection{Programas de enseñanza-aprendizaje de español como L2 en el sistema educativo norteamericano. El caso de la ciudad de Austin}

El estudio de lenguas extranjeras en el estado de Texas, denominado Languages Other Than English (LOTE) se remonta al año 1964 en el que el superintendente Harold Brantley del 
distrito escolar Laredo United Consolidated School District lanzó el primer programa bilingüe en Texas copiando la idea del primer programa bilingüe en Estados Unidos iniciado en Coral Way School en Dade County, Florida. Durante los años sesenta y setenta las políticas de enseñanza bilingüe apoyaron la implementación de lenguas y culturas extranjeras y es en este momento cuando se fundan los primeros programas bilingües modernos orientados a mejorar la competencia bilingüe en español e inglés de los hijos de refugiados cubanos y anglohablantes en el estado de Florida (Van Kuler, 2012). Sin embargo, estas orientaciones fueron cambiando a finales de los años ochenta y en la década de los noventa. En aquellos años varios políticos, padres angloparlantes y algunos medios de comunicación apostaron fuertemente por la imposición de la lengua oficial (inglés) a los grupos minoritarios.

En los últimos años la enseñanza-aprendizaje de español como L2 en EEUU ha experimentado un gran crecimiento motivado por un creciente interés hacia la lengua y la cultura de los ciudadanos hispanohablantes, grupo de población que cuenta con una presencia muy importante en este país. En consecuencia, se impuso la implantación de programas de educación bilingüe de calidad en los centros norteamericanos adaptados a la realidad del contexto educativo. Alguno de estos programas está orientado a ayudar a los niños hispanohablantes recién llegados a EEUU en su transición desde el español hacia el inglés. A través de los mencionados programas se planteaba el bilingüismo como ese apoyo a los alumnos cuya L1 no es el inglés (hispanohablantes en su gran mayoría) en la adquisición de inglés como L1, por lo que: "bilingualism is essential for making sure that non-English-speaking pupils receive the full range of educational opportunities to which they are right-fully entitled as much as any other students" (Nyquist 1978, p. 32). 
Los tres objetivos principales que conducen hacia una implementación y desarrollo de la enseñanza bilingüe en los centros escolares de Estados Unidos son, en opinión de Van Kuler (2012), el logro de un enriquecimiento lingüístico y cultural, la búsqueda de un equilibrio en la mezcla etnolingüística en las escuelas y el fomento de la enseñanza bilingüe en las comunidades latinoamericanas.

En el caso particular del estado de Texas, es el creciente aumento de población hispanohablante que ha tenido lugar durante los últimos años lo que motiva a llevar a cabo una gran inversión en educación y una búsqueda por parte de los distritos escolares de programas educativos bilingües efectivos dirigidos tanto a alumnos llegados de países de habla hispana como a estudiantes angloparlantes. Los modelos de programas bilingües que han tenido una mayor repercusión en los centros educativos de Educación Infantil, Primaria y Secundaria del estado de Texas son el denominado Transitional Bilingual Education Program $\left(\mathrm{TBE}^{11}\right.$ ) y el Dual Language (DL) Program $^{12}$. Mencionaremos también el programa ESL, el cual se desarrolla en el ámbito de determinados centros educativos que cuentan con un número de alumnos con necesidades específicas.

Los informantes del contexto educativo de Austin que han participado en el presente trabajo de investigación llevan a cabo su actividad docente como profesores de la asignatura Language Arts (lengua y literatura) impartida exclusivamente en español en centros de Educación Infantil y

\footnotetext{
${ }^{11}$ Transitional Bilingual Education program: programa de educación bilingüe transitorio.

12 Dual Language Program: programa de educación bilingüe dual
} 
Primaria que cuentan con programa dual en la ciudad de Austin. En los centros educativos en los que llevan a cabo su actividad docente se imparten clases de Educación Infantil (Kindergarten) y Primaria. No obstante, nuestra muestra intencional incluye solamente profesores que ejercen docencia en la etapa de Educación Primaria a alumnos monolingües anglohablantes (independientemente de su origen).

Destacamos el hecho de que todos los informantes que componen la muestra intencional de la ciudad de Austin desarrollan su actividad docente dentro del programa dual dado que tanto los programas de enseñanza general como el programa bilingüe $T B E$ no cuentan con un número suficiente de profesores que cumplan los criterios de selección de la muestra intencional: profesores de L2 cuyos alumnos nos sean hablantes bilingües sino alumnos que comenzaron a estudiar su L2 en el momento de su escolarización.

Con respecto a la tipología de programas de enseñanza bilingüe en EEUU, en su estudio de investigación, Thomas y Collier (1997), distinguían entre dos grandes grupos: “one-way bilingual programs" que incluye aquellos programas que se centran en servir a la comunidad que habla una lengua minoritaria (en este grupo incluimos TBE, ESL) y "two-way bilingual programs" (en el que se inserta el programa dual) incluye aquellos programas bilingües que se acercan a las dos lenguas (minoritaria y mayoritaria). Desde esta consideración, decidimos aproximarnos a los tres tipos de programas mencionados por ser estos los más comunes en los centros educativos norteamericanos de Educación Primaria. 
El TBE (o programa bilingüe) no es un programa de inmersión lingüística sino un programa en el que se provee instrucción en la lengua nativa al tiempo que se enseña inglés como L2 con el propósito de que gradualmente se produzca una transición de los alumnos de español (como L1) hacia el inglés. Es un programa adoptado por un gran número de centros de Educación Primaria (inglés-español) en el estado de Texas. De acuerdo con Torres-Guzmán y Etxeberría (2005, p. 516), este ha sido uno de los modelos de educación bilingüe más populares en EEUU. Está orientado a la introducción de contenidos en la L2 del alumno (inglés) de forma progresiva por lo que, durante los primeros cursos de la etapa educativa se imparten los contenidos de todas las asignaturas en la L1 (español) introduciendo la L2 (inglés) de forma gradual, de modo que, tal y como afirmaba Lamus (2008), "this means that L1 is phased out as proficiency in L2 increases" (p. 82). Por lo tanto, cuando los alumnos llegan a tercer curso se les realiza un examen de aptitud en su L2 (inglés) cuya nota determinará si el alumno debe continuar en el programa bilingüe o debe pasar a un programa de enseñanza general, en cuyo caso, pasarían a recibir toda la instrucción en inglés (Lamus, 2008). Al final de cada etapa educativa se espera que el alumno sea capaz de recibir todo tipo de instrucciones en su L2. De acuerdo con el mencionado autor, existen algunas variantes del programa $T B E$ denominadas "maintenance/enrichment model of bilingual education program" diseñadas para que los alumnos, independientemente de que pasen al programa de enseñanza general o se mantengan o en el programa bilingüe, seguirán recibiendo instrucción en las dos lenguas (L1 y L2) hasta completar la etapa educativa (Lamus, 2008, p. 82).

Los Dual Language (DL) Programs o programas de inmersión lingüística de enseñanza dual están enfocados en la enseñanza de contenidos curriculares (de asignaturas como matemáticas, ciencias naturales, sociales, etc.) en una L2. Los primeros programas de inmersión 
surgen en los años 60 en Canadá bajo la presión de los padres de alumnos que demandaban un cambio en la enseñanza bilingüe (inglés-francés). De acuerdo con Potowski (2007), la idea surge a partir de la solicitud por parte de padres de alumnos a un distrito escolar de Montreal de que se diseñara un programa de inmersión lingüística en francés en el aula de Educación Infantil (Kindergarten) para que sus hijos pudiesen adquirir un determinado nivel de competencia comunicativa en esa lengua "through its use as a natural means of comunication and instruction" (Potowski, 2007, pp. 7-8). Los mencionados programas de inmersión, fueron creados con el propósito de que los alumnos encontrasen en el aprendizaje de una L2 la misma motivación que tienen para aprender su L1, "particularly creating desire in the students to learn the L2 in order to engage in meaningful communication" (Potowski, 2007, p. 8). Poco después de su aparición, algunos educadores estadounidenses empezaron a interesarse por este tipo de programas de inmersión y, fue Campbell, quien decidió, en 1974, implantar el primer programa de inmersión en un centro educativo en Culver City, California, Estados Unidos de América.

A pesar de que existe una amplia gama de programas de enseñanza dual, en todos ellos se asignan determinadas asignaturas a una lengua en particular (L1 o L2). Al igual que el programa $T B E$, los primeros cursos se imparten en la lengua materna del alumno (en la mayor parte de las asignaturas) y el porcentaje va en aumento hasta llegar a un determinado curso en el que se establece, según el caso, un porcentaje que puede variar entre el $50 \%$ y el $90 \%$ de asignaturas impartidas en cada una de las dos lenguas (L1 y L2).

En 2018, la organización sin ánimo de lucro Center of Applied Linguistics fundada en 1959 en Washington DC lanzaba la tercera edición de Guiding principles for dual language education 
(2018) en el que se incluye una serie de niveles de referencia o indicadores que permitirán precisar si los elementos del programa dual que siguen en un determinado centro educativo están coordinados de tal forma que promuevan los tres objetivos básicos de dicho programa, a saber: "development of bilingualism and biliteracy, sociocultural competence, and grade-level academic performance" (Howard, E. R., Lindholm-Leary, K. J., Rogers, D., Olague, N., Medina, J., Kennedy, B., Sugarman, J., \& Christian, D., 2018, p. 5). Al final del documento se anexan unas hojas de autoevaluación como herramienta de autorreflexión dirigidas a toda la comunidad educativa: administradores, profesores, padres, alumnos, etc., de aquellos centros educativos interesados en valorar el nivel de implementación del programa dual en el centro.

El mencionado documento hace alusión a un gran número de estudios de investigación que demuestran que "higher levels of partner language proficiency when they participate in programs with higher levels of the partner language, that is, in 90:10 compared to 50:50 programs" (Howard, E. R., Lindholm-Leary, K. J., Rogers, D., Olague, N., Medina, J., Kennedy, B., Sugarman, J., \& Christian, D., 2018, p. 15). Prueba de ello es que "students rate their proficiency in Spanish and level of bilingualism higher in 90:10 than 50:50 programs" (p. 15). Además, "reading achievement measured in Spanish is higher in 90:10 than 50:50 programs" (p. 15).

Dentro del programa dual se localiza el llamado programa dual bidireccional que se encuentra cada vez más extendido en el estado de Texas. En dicho programa, alumnos de inglés como L2 y alumnos de español como L2 conviven en el aula y las dos lenguas son utilizadas al $50 \%$ como lenguas de instrucción. En un determinado momento de la jornada escolar, se reúne a los alumnos anglohablantes de dos clases distintas para que juntos acudan a un aula para recibir 
clase de español, mientras que a los alumnos hispanohablantes se les reúne para recibir clase de inglés. Durante el resto de la jornada escolar, alumnos anglohablantes e hispanohablantes comparten aula y reciben instrucción en las dos lenguas.

El programa denominado ESL se lleva a cabo con el objetivo de ayudar a aquellos alumnos recién llegados al país con necesidades especiales. Dichos alumnos salen del aula durante un determinado número de horas para reunirse con un profesor que, de forma personalizada, imparte clases de lengua inglesa. El mencionado programa se lleva a cabo desde Educación Infantil hasta la etapa de Educación Secundaria. Sin embargo, hay una serie de autores que no considera este programa como un modelo de enseñanza bilingüe puesto que no se utiliza la L1 como lengua de instrucción. La duración de este programa dependerá de las necesidades particulares del alumno.

Todos los centros educativos públicos o privados, independientemente del programa que sigan, han de ajustarse al diseño curricular estatal definido a través de los estándares de aprendizaje denominados Texas Essential Knowledge and Skills (TEKS) establecidos por la institución que lleva por nombre Texas Education Agency (TEA) o Ministerio de Educación del estado de Texas.

Determinados autores como Van Kuler (2012) señalan a los administradores de los distritos escolares como los responsables directos de que este tipo de programas bilingües se lleven a cabo con éxito dentro de los centros educativos. En este sentido, enumeran una serie de responsabilidades que deben asumir; a saber: hacer llegar la información correspondiente a la comunidad sobre la existencia de este tipo de programas en los centros, evaluar su efectividad, así como contratar profesores capacitados para impartir español como L2. Respecto a dichos 
profesores, Nyquist (1978) insistía en la necesidad de que fuesen "cognizant of and responsive to the linguistic and cultural needs of the students they serve" (p. 31). Por su parte, Avalos, Zisselsberger, Langer-Osuna y Secada (2015) proponen que sean profesores nativos los encargados de impartir clase en los centros con programa bilingüe o dual.

A este respecto, autores como Smolcic (2011) denuncian el hecho de que el grupo demográfico predominante en los profesores de L2 en el contexto educativo bilingüe en EEUU es "typically, White, monolingual, of middle-class background" (p. 15). De acuerdo con el mencionado autor, estos profesores traen a los centros educativos "a monolingual and dominant culture perspective to the task of teaching and cite their lack of experience with diversity" (Smolcic, 2011, p. 15), idea compartida por Avalos et al. (2015). Así pues, en la perspectiva del autor, "as classrooms become more diverse, the need for teachers to interact successfully with difference becomes more urgent" (Smolcic, 2011, p. 15)

Así pues, se impone que los profesores de enseñanza de español como L2 de los centros educativos norteamericanos sean conscientes y responsables de su propia formación recurriendo, cuando estimen necesario a los denominados programas bilingües y biculturales que se insertan en el plan de formación del profesorado organizado por los propios distritos escolares. Recurrimos a las palabras de Nyquist (1978) respecto a la idea de que dichos programas de formación bilingüe para profesores de L2 "must include useful experiences for those prospective teachers who will become bilingual educators in the truest sense" (p. 31). 
Los programas de enseñanzas bilingües, tanto en la comunidad de Castilla y León, como en el estado de Texas, persiguen un objetivo común: conseguir que los alumnos adquieran una mayor competencia comunicativa en la L2, durante el período de escolarización, promoviendo la reflexión lingüística y una mejor comprensión de su L1. Además, este desarrollo de la competencia lingüística fomentará un determinado tipo de actitudes de respeto hacia formas de vida y culturas distintas a la propia.

En síntesis, en lo que se refiere al proceso de adquisición lingüística se ha de tener en cuenta una serie de factores como la edad, las actitudes hacia el aprendizaje de la lengua-cultura, el contexto social que rodea al alumno, las necesidades comunicativas y las relaciones del alumno con las personas involucradas en el proceso de adquisición o de enseñanza-aprendizaje. A estos se añade el factor afectivo en su dimensión actitudinal que está presente en dicho proceso. El interés en torno a este ha ido aumentando de forma significativa en los últimos años desde que Krashen (1982) formulase la teoría del filtro afectivo. Dicha teoría describe la importancia que tienen las actitudes y el estado emocional de los alumnos en el proceso de adquisición de una L2 poniendo de manifiesto que el estado anímico del alumno, así como sus sentimientos y motivaciones incidirán de una forma positiva o negativa en los procesos de adquisición de esa L2. Consecuentemente, el alumno que tenga confianza en sí mismo, se encuentre motivado y relajado tendrá un filtro afectivo bajo, por lo que el proceso de adquisición se llevará a cabo de una forma adecuada. Por el contrario, el alumno desmotivado, tenso y con poca confianza en sí mismo tendrá el filtro afectivo alto que tendrá como consecuencia una recepción escasa de input (Krashen, 1982, p. 31). Además, Krashen (1988, p. 22) mencionaba la existencia de dos factores actitudinales que predicen el nivel de competencia en L2 del alumno. Por un lado, lo que él denomina integrative 
motivation (o motivación integrante) definida como el interés o deseo de comunicación con los hablantes de la L2 en el sentido de ser capaz de interactuar con ellos y compartir sus gustos, deseos e intereses. Por otro, el llamado instrumental motivation (motivación instrumental) descrito como el deseo de adquirir una segunda lengua por cuestiones prácticas. El alumno buscará interactuar con hablantes de L2 únicamente con propósitos funcionales. Desde esta óptica, la motivación instrumental desaparecerá una vez se hayan conseguido los objetivos propuestos en torno a la lengua, es decir, una vez se haya alcanzado el nivel de L2 deseado. Sin embargo, la motivación integrante se configura como un indicador importante del nivel de adquisición de L2 del alumno.

Respecto al proceso de adquisición de una L2 nos acercamos a la expresión escrita como destreza lingüística en la que intervienen una serie de procesos cognitivos, conocimientos gramaticales, recursos técnicos y estilísticos, a través de la cual se activan determinadas estrategias comunicativas. El alumno, como sujeto activo de su propio proceso de aprendizaje, interactúa con el medio desde el momento de su nacimiento. Así pues, a partir de sus primeras tomas de contacto con el lenguaje escrito, empezará a crear su propia concepción sobre este. Además, las conductas y actitudes que encuentre en su entorno familiar y social incidirán en el proceso de adquisición de la lengua. En virtud de ello, todos los estímulos que ofrezcan las personas de su entorno ejercerán una clara influencia en la consecución de un adecuado desarrollo cognoscitivo. 
Es evidente que, en un contexto de enseñanza formal, las conductas y actitudes ejercerán una gran influencia en el alumno. Se impone, por tanto, que el profesor mantenga su papel de facilitador, asesor y guía-colaborador motivando al alumno a escribir en una L2, compartiendo con él la responsabilidad del proceso y creando situaciones en el aula en las que el alumno sienta que es sujeto activo de su propio proceso de enseñanza-aprendizaje. 

PARTE II: ASPECTOS

METODOLÓGICOS Y TÉCNICOS

DE LA INVESTIGACIÓN 



\section{Capítulo 4. ESTRUCTURA Y ORGANIZACIÓN DEL PROCESO DE INVESTIGACIÓN}

4.1. Contexto de investigación

4.2. Informantes

4.3. Muestra intencional

4.4. Instrumento para la recogida de información: el cuestionario 


\subsection{Contexto de investigación}

La presente investigación se enmarca en dos sistemas educativos, a saber, el español y el norteamericano. Algunos de estos centros cuentan con sección bilingüe y otros son centros educativos sin sección, pero en todos ellos se imparte la asignatura de inglés como L2 desde el primer curso de Educación Infantil. Y por otra, de docentes que imparten enseñanzas oficiales de español como L2 en centros educativos que cuentan con programa dual en la ciudad de Austin, Texas, Estados Unidos de América. Como ya señalábamos en el epígrafe 3.3.2 de esta Tesis, el objetivo principal de este programa es promover que los niños (tanto hispanohablantes como anglohablantes) crezcan utilizando dos lenguas. Es un programa de doble inmersión que apoya el aprendizaje del inglés y del español como L2. La instrucción se lleva a cabo en las dos, asignando un grupo determinado de asignaturas a una lengua y otro grupo a la otra. En este sentido, nos encontramos con alumnos de inglés como L2 y de español como L2 que están en contacto directo con ambas lenguas.

Tras ejercer mi actividad docente en los dos contextos educativos y después de apreciar las diferencias existentes en torno al concepto de enseñanza-aprendizaje de L2 decidimos tomarlos como referencia en la presente investigación y que esta girase alrededor de ellos. Sin embargo, más allá de la propia experiencia didáctica ejercida en los dos contextos educativos a los que nos acercamos para contextualizar nuestra investigación, fundamentamos nuestra elección partiendo de la idea de que, para poder obtener una mejor perspectiva en torno a las actitudes del profesorado de L2 ante el error, la corrección y el feedback en las producciones escritas de alumnos de L2 debemos aproximarnos a dos contextos educativos semejantes. Así es como, nos acercamos a una 
serie de centros educativos de Educación Primaria en las ciudades de Valladolid y Austin por tratarse de dos casos simétricos por cuanto que en el primero se habla español como lengua mayoritaria y se enseña inglés como L2 y en el segundo se habla inglés como lengua mayoritaria y se enseña español como L2.

Esta decisión adoptada en torno a la elección de dos contextos educativos con rasgos identificativos propios pero que, al mismo tiempo, se manifiestan como simétricos, nos permitirá aportar el conocimiento empírico, resultado de la experiencia docente, llevada a cabo en los dos contextos aspirando a poder contribuir a la información obtenida in situ a través de la observación directa.

El criterio de elección de informantes se basa en que en ambos casos sean profesores de la asignatura "lengua inglesa" o "lengua española" como L2 independientemente del programa educativo en el que se encuentran inmersos.

Para la realización del análisis de esta investigación hemos seguido una dirección constante por cuanto que partimos del contexto local en el que se incluyen los centros de la ciudad de Valladolid en dirección a los centros localizados en Austin.

Los alumnos de cada uno de los dos contextos educativos cuentan con motivaciones distintas en cuanto al aprendizaje de la L2. A pesar de la percepción, por parte del alumnado, de una necesidad de dominio del inglés en las sociedades contemporáneas, de acuerdo con Uribe, Gutiérrez y Madrid (2008, p. 94), solo un 3\% de los españoles cuentan con un dominio de la lengua 
inglesa. Además, haciendo alusión a un estudio realizado por la Commission of the European Languages (2005), los mencionados autores afirman que solo un 36\% declara ser capaz de participar en una conversación en dicha lengua, muy por debajo de la media europea. En este sentido, los alumnos de inglés como L2 en Valladolid no cuentan con un contexto favorable hacia el inglés ya que su deseo de adquirir una L2 se limita a la obtención de unos fines prácticos. Desde esta consideración, podemos decir que estos alumnos estudian una L2 tratarse de una asignatura más del currículum. La mayoría no se da cuenta de los beneficios y de la utilidad del conocimiento del inglés o de otras lenguas en su futuro profesional y académico. Volvemos a situarnos en la perspectiva de Gardner (1985) quien apuntaba que este hecho provoca que las actitudes de este tipo de alumnado sean menos positivas que las de otros grupos de alumnos que estudian una L2 con el propósito de formar parte de la comunidad cuya lengua están aprendiendo. Por otro lado, en Valladolid no existe una presencia importante de hablantes nativos de lengua inglesa, por lo que, el contacto que los alumnos pertenecientes a este contexto pueden mantener con estos es muy limitado. Se trata de una ciudad monolingüe con una corta tradición de enseñanza de lenguas donde las ocasiones de interactuar con hablantes angloparlantes o de otras lenguas son escasas. Así pues, el uso del inglés tiene lugar exclusivamente en el ámbito escolar (salvo en determinadas excepciones) y, en consecuencia, las actitudes hacia esta L2 estarán directamente relacionadas con sus experiencias en el aula.

Por su parte, los alumnos de español como L2 en la ciudad de Austin cuentan con características socioeconómicas muy distintas. Como ya hemos mencionado anteriormente, el aumento de población de hispanohablantes en EEUU en general y en el estado de Texas en particular, ha conseguido alcanzar tal nivel que "su influencia es ya perceptible en todas las esferas 
y, con ella, la presencia del español en todos los aspectos de la vida en el país” (Lacorte \& Suárez García, 2014, p. 130). Así pues, el número de medios de comunicación en español aumenta cada día y con ellos, su audiencia. En el plano laboral, hablar español influye directamente en la consecución de un trabajo y en los sueldos que se perciben. Esto nos permite posicionarnos en la perspectiva de Lacorte y Suárez García (2014), quienes afirmaban que "más allá de leyes, el español forma parte de la realidad social de EE.UU. y se ha convertido, de facto y sin lugar a dudas, en una segunda lengua en el país” (p. 130). En este sentido, con el propósito de dar la cobertura necesaria al español como lengua mayoritaria, las instituciones educativas norteamericanas desarrollan diferentes programas bilingües (como ya hemos mencionado anteriormente) no solo dedicados a hispanohablantes sino también a estudiantes angloparlantes. Por consiguiente, la mayoría de los centros educativos de Educación Infantil y Primaria de Texas siguen los programas: TBE, Dual Language Program, ESL descritos en el epígrafe 3.3 .2 de la presente Tesis Doctoral.

Estamos ante una zona de gran tradición bilingüe en la que, consecuentemente, existe un gran interés por aprender lenguas extranjeras. Estos alumnos de español como L2 en los centros educativos de Texas cuentan con una gran presencia de hablantes de español nativos a su alrededor, lo cual se revela como una clara motivación de aprendizaje de dicha lengua. Desde esta consideración, tanto el contacto con los hablantes nativos como el conocimiento profundo de la cultura promueven actitudes positivas del alumno hacia la L2 que está estudiando.

Consideramos, por tanto, que un acercamiento y posterior observación reflexiva en torno a determinados aspectos relacionados con la corrección y el feedback en un contexto educativo con 
una amplia tradición en enseñanza de L2 como son los centros de Educación Primaria de la ciudad de Austin, puede resultar de gran utilidad y servirnos de inspiración en nuestras prácticas docentes.

\subsection{Informantes}

Los participantes de la presente investigación son, como hemos venido apuntando, por un lado, profesores hispanohablantes que ejercen su actividad docente en centros educativos de la ciudad de Valladolid (España) impartiendo enseñanzas de inglés como L2. Y por otro, docentes nativos angloparlantes que imparten clases de español como L2 en centros de la ciudad de Austin (Texas, Estados Unidos de América) que cuentan con programa dual (inglés-español).

Dentro de este marco, cabe señalar que los informantes de ambos contextos llevan a cabo su actividad profesional en instituciones de carácter público, concertado y privado de enseñanza oficial de Educación Primaria. En el caso de Valladolid, los sujetos implicados en nuestra investigación ejercen su docencia impartiendo clases de inglés como L2 en centros públicos y concertados de la ciudad. En el caso de Austin, se trata de profesores de español como L2 en centros públicos (incluidos en el Distrito Escolar Independiente -Austin ISD-) y en centros privados emplazados en la ciudad de Austin. 


\subsection{Muestra intencional}

Nuestra muestra intencional se constituye, por tanto, de profesores que imparten la asignatura de inglés como L2 en centros educativos de Educación Primaria de la ciudad de Valladolid, España y por otra de profesores que imparten la asignatura de español como L2 en la ciudad de Austin, Estados Unidos de América.

La elección de la muestra intencional, respecto a los informantes, profesores de L2 en la etapa de Educación Primaria que provienen de dos contextos tan diferentes, ha sido determinada, como ya hemos apuntado en el epígrafe 4.1 por la necesidad de observar, analizar y comparar propuestas de actitudes en torno al error, a la corrección y al feedback. En este sentido, consideramos que ambos aportan información relevante sobre los conocimientos, las aptitudes y las actitudes de los profesores de L2 partiendo de modelos de enseñanza-aprendizaje diferentes culturalmente, pero fundamentados en conceptos, ideologías y metodologías muy similares. Asimismo, nos situamos ante dos contextos educativos que, analizándolos y comparándolos desde el punto de vista científico, nos podrían suministrar un conocimiento más profundo y una perspectiva más amplia sobre aquellos factores afectivos que intervienen en el proceso de enseñanza-aprendizaje de una L2. Excluimos el área rural de la ciudad de Valladolid y de Austin, respectivamente, con el propósito de comparar grupos sociales semejantes.

Los criterios de acceso a la muestra intencional vienen determinados por:

El conocimiento previo de los dos contextos educativos. Como profesora bilingüe de un colegio público en Valladolid, he tenido contacto directo con varios centros y he podido 
conocer, a partir del intercambio de diferentes experiencias educativas a varios profesores de Educación Primaria que me han acercado a la realidad de sus aulas permitiendo la entrada a sus centros y accediendo a cumplimentar los cuestionarios proporcionados. Asimismo, la experiencia de formar parte del programa de Profesores Visitantes en Texas durante tres cursos escolares, me brindó la oportunidad de estar en contacto directo con un contexto de enseñanzaaprendizaje de español como L2. Esto me permitió un acercamiento a los programas bilingües del estado de Texas.

La estancia en University of Texas at Austin como investigadora becada por la Universidad de Valladolid, de septiembre a diciembre de 2015, posibilitó la recopilación de los datos necesarios para la investigación. Los profesores del Departamento de Español y Portugués y de UTeach-Liberal Arts me pusieron en contacto con profesores que formaron parte de la muestra intencional. Dicha estancia me permitió acceder a los centros educativos de Austin donde pude conocer personalmente a los informantes.

La muestra intencional se constituye, por un lado, de 33 informantes correspondientes a 33 centros educativos en los que se imparte inglés como L2 en Educación Primaria de los 81 existentes en la ciudad de Valladolid (39 públicos y 42 concertados). Por otro, de 40 informantes correspondientes a 40 centros educativos ubicados en la ciudad de Austin de un total de 102 (82 de ellos constituyen el distrito escolar Austin ISD y el resto son centros privados). El número de centros encuestados en la ciudad de Valladolid constituye un $39 \%$ respecto al número total de centros educativos de Educación Primaria (incluyendo públicos y concertados). En el caso de Austin, las encuestas realizadas configuran el $40 \%$ del total de centros. Contamos, por tanto, con 
porcentajes comparables y proporciones semejantes en cuanto al número de centros educativos encuestados y el número de centros educativos emplazados en cada una de las dos ciudades.

Para la muestra intencional elegimos las ciudades de Valladolid y Austin por tratarse de ciudades-capital (de provincia, de comunidad autónoma, de condado y/o de estado). Desde esta consideración, elegimos Valladolid por ser esta una ciudad capital de provincia (Valladolid) y de comunidad autónoma (Castilla y León). En el caso de Austin, hablamos de ciudad capital del Condado de Travis (Travis County) así como del estado de Texas.

\subsection{Instrumento para la recogida de información: el cuestionario}

Ha sido concebido y elaborado un cuestionario para la recogida de datos por considerarse un instrumento adecuado para una investigación relacionada con la educación en general y la enseñanza-aprendizaje de lenguas, en particular. Nos situamos en la línea de Noguerol Rodrigo (1998) por cuanto que la articulación de los instrumentos elegidos en una investigación será precisada en función de las necesidades del investigador o del grupo de investigadores. Así pues, elegimos el cuestionario como instrumento para la consecución de nuestro objetivo: recabar los datos necesarios que permitan validar nuestra hipótesis de investigación.

Desde nuestro propósito investigador de obtener información relativa a dos grupos de informantes pertenecientes a dos contextos educativos distintos recurrimos al cuestionario como instrumento de investigación, teniendo en cuenta las palabras de Sáez Pérez (2017) quien lo define como "un listado de preguntas estandarizadas que se utiliza como instrumento en la técnica de 
encuesta y permite obtener información relativa a grupos en el tema que se pretende investigar" (p. 87).

\subsubsection{Concepción y elaboración del cuestionario}

Recurrimos a la definición que aporta Martínez-Salanova Sánchez (2007) del término cuestionario, como "conjunto de preguntas sobre los hechos o aspectos que interesan en una evaluación, en una investigación o en cualquier actividad que requiera la búsqueda de información" (El cuestionario, 1). Al respecto, el citado autor insiste en que "se trata de un instrumento fundamental para la obtención de datos" (El cuestionario, 1). En la misma línea, García Muñoz (2003) destacaba que el cuestionario "es un instrumento muy útil para la recogida de datos, especialmente de aquellos difícilmente accesibles por la distancia o dispersión de los sujetos a los que interesa considerar, o por la dificultad para reunirlos" (p. 2), a lo que el propio autor añadía que su finalidad es "obtener, de manera sistemática y ordenada, información acerca de la población con la que se trabaja, sobre las variables objeto de la investigación o evaluación" (García Muñoz, 2003, p. 2). Asimismo, del trabajo de Sáez López (2017) se desprende que dicho instrumento "permite obtener información relativa a grupos en el tema que se pretende investigar" (p. 87) lo cual pone de manifiesto la necesidad de usar dicho instrumento en nuestro estudio investigador. 
En la producción del cuestionario hemos tenido en cuenta las características precisadas por García Muñoz (2003) quien apoyaba la idea de que todo cuestionario debe tener presente las siguientes consideraciones con respecto a la forma:

- Datos de identificación: entre los que nunca debe incluirse el nombre puesto que debe garantizarse el anonimato.

- Instrucciones sobre cómo ha de cumplimentarse el cuestionario: redactadas con claridad y precisión para que queden resueltas todas aquellas dudas que pudieran plantearse.

- Advertencias que se estimen necesarias.

En relación con la estructura, el diseño y la disposición de las preguntas, el mencionado autor apoya la idea de que todo cuestionario debe situarse bajo la condición de la claridad en la redacción, de manera que las preguntas sean:

- Fáciles, definidas y adecuadas al propósito que se persigue.

- Cortas y de fácil comprensión: evitando los términos que desconcierten al sujeto que cumplimenta el cuestionario.

- Claras y adecuadas al propósito que se persigue.

En este orden de ideas y de acuerdo con García Muñoz (2003), intentamos evitar la aparición en nuestro cuestionario de ciertos elementos que distorsionen la comunicación y que puedan provocar confusión en el sujeto que cumplimenta el cuestionario. Dichos elementos son: 
- Dobles negaciones.

- Términos técnicos especializados.

- Frases largas y con dobles negaciones.

- Ítems que encierren más de una cuestión.

En la misma línea, Sáez López (2017) propone en su obra diseñar los cuestionarios "con rigor para obtener datos fiables" (p. 88). Respecto a la formulación de preguntas, coincide con García Muñoz (2003) en que estas deben presentar un "lenguaje claro, en función de la edad y nivel cultural de los sujetos de la muestra que deben responder" (p. 88).

Siguiendo a estos tres autores, (García Muñoz, 2003; Martínez-Salanova Sánchez, 2007 y Sáez López, 2017) concebimos y elaboramos un cuestionario para profesores que imparten español/inglés como segunda lengua que se adaptó a los dos contextos educativos que forman parte de esta investigación. Así pues, a partir de este cuestionario se crearon dos versiones: el Cuestionario I para profesores que imparten enseñanzas oficiales de inglés como segunda lengua en la ciudad de Valladolid, España ${ }^{13}$ y el Cuestionario II para profesores que imparten enseñanzas oficiales de español como segunda lengua en la ciudad de Austin, Estados Unidos de América ${ }^{14}$.

En la concepción y elaboración del cuestionario seguimos el diseño propuesto por Dumbravescu (2014) ya que encontramos en este los rasgos planteados por los mencionados autores. Al mismo tiempo, observamos que está en relación con el tipo de datos que nos interesa

\footnotetext{
${ }^{13}$ El proyecto de Cuestionario I se encuentra en el Anexo I
}

${ }^{14}$ El proyecto de Cuestionario II se encuentra en el Anexo II 
recoger; datos de carácter subjetivo, pertinentes, válidos y confiables (Dumbravescu, 2014; Gómez Barrantes, 1998) y datos generales y objetivos (Dumbravescu, 2014; Muñoz-Repiso Izaguirre et al., 1995) relacionados con nuestro objeto de estudio. Adaptamos dicho cuestionario a nuestras propias necesidades investigadoras en torno a la valoración de la presencia del error por parte del profesor y al aprovechamiento de este como herramienta didáctica integrándolo dentro del proceso de enseñanza-aprendizaje de L2. En este sentido, el hecho de haber sido adaptado de otro autor aumenta la fiabilidad y la validez por cuanto que los resultados son transferibles a otras situaciones investigadoras. Ha sido analizada la validez del cuestionario para el estudio de su calidad. Posteriormente se llevó a cabo un análisis de su fiabilidad, el cual, trajo consigo la eliminación de alguno de los ítems por lo que fue necesario un análisis posterior de validez para la confirmación final.

Nos acercamos a la idea de Dumbravescu (2014) de que la versión impresa del cuestionario debe ofrecer "espacio suficientemente amplio entre los enunciados, las preguntas y las respuestas aportadas por los participantes en la investigación” (p. 229). En cuanto a su redacción, hemos seguido las mismas recomendaciones que encontramos en la misma autora respecto a la necesidad de contar con una terminología conocida por los participantes y con instrucciones claras que puedan guiarlos.

En cuanto a la lengua de redacción de los cuestionarios optamos por el español ya que los participantes son profesores hispanohablantes o profesores de español como L2 que poseen un nivel de dominio del español avanzado. Respecto a la necesidad de asegurar la confianza y de mantener su interés de participar en la investigación, según recomendaba Dumbravescu (2014), se 
ha dado la opción a los profesores de cumplimentar los cuestionarios en su lengua materna, en la perspectiva de expresar con más claridad sus ideas.

En torno a la forma de entrega de los cuestionarios, hemos recurrido a dos modalidades:

- Entrega en mano: a aquellos profesores cuyas clases tuvimos ocasión de observar. El cuestionario en su formato impreso fue entregado después de la observación.

- Envío de un enlace a través del correo electrónico que permitía el acceso al formato de cuestionario online realizado a través de la plataforma de encuestas y cuestionarios en línea denominada Zoho Survey.

Decidimos conjugar ambos formatos, el impreso y el electrónico para ampliar así nuestras opciones situándonos, por un lado, en la perspectiva de English (2004), el cual, defiende el formato "en mano" afirmando que "it is best to go to work locations, hand a survey to each person, and collect each one" (p. 94). Según él, "this method might not get 100 percent response, but it gets pretty close" (p. 94) a lo que añade que "it sure beats the return (as low as five to ten percent) and weeks involved in trying to get people to mail back their surveys" (p. 94). El mencionado autor insiste en la idea de que "people feel most relaxed and confident at their workstations and are most likely to be candid in their responses" (p. 94). Por otro lado, decidimos posicionarnos en la línea de Bourque (2003), quien opta por el formato electrónico señalando que "those of us who routinely work in survey research know that, as a group, we have a strong tendency to adopt new technologies as soon as they become available and to try to push the uses of new technologies to the maximum" (p. 107). Además, Bourque (2003) afirmaba al respecto que: 
The advantage of an online questionnaire over a paper-and-pencil questionnaire in terms of data entry is that the data are 'cleaner' - that is, if the questionnaire is properly programmed, a respondent cannot provide more than one answer to a question when only one answer is desired. (Bourque, 2003, p.111)

La conjunción de los formatos precisados se ha realizado partiendo de las ideas de los dos autores mencionados considerando que sus propuestas son, en definitiva, complementarias, por cuanto que aportan una mejor perspectiva del estado de la cuestión.

Para la modalidad de entrega en mano, se presentaron los cuestionarios acompañados de una carta de presentación dirigida al sujeto en la que se solicita su colaboración, se garantiza el anonimato y se expresa la importancia de su aportación concluyendo con un agradecimiento a todos los sujetos participantes. Siguiendo a García Muñoz (2003), en la carta de presentación hemos explicado la finalidad de nuestra investigación de una forma clara y utilizando siempre un lenguaje sencillo y adaptado al destinatario.

Para la modalidad de envío por correo electrónico del enlace que da acceso al cuestionario online, recurrimos a las palabras de Bourque (2003) quien declaraba que "online questionnaires are not accompanied by cover letters, but they do need introductions" (p. 114) así pues, los sujetos "may have received invitations to participate via an e-mail list to which they belong, or they may have been sent advance letters" (p. 114). Enviamos por tanto un email con una carta de invitación en formato electrónico a todos aquellos profesores que participaron bajo esta modalidad. 
Reconocemos, por tanto, la necesidad de adjuntar a los cuestionarios una carta de presentación o de invitación situándonos en la línea de Bourque (2003) quien indicaba que:

All surveyors advocate the use of professional letterhead for advance letters and cover letters because it helps establish the importance of the study, gives information about study sponsorship, and serves indirectly as a means of personalizing the contact with the respondent. (Bourque, 2003, p. 115)

Tomando como modelo las cartas de presentación que adjunta Dumbravescu (2014), elaboramos para la modalidad de entrega del cuestionario: en mano, una carta de presentación para profesores que imparten enseñanzas de inglés como L2 en la ciudad de Valladolid, España ${ }^{15}$ y una carta de presentación para profesores que imparten enseñanzas de español como segunda lengua en la ciudad de Austin, Estados Unidos de América ${ }^{16}$. Ambas cartas se entregaron en formato papel.

Asimismo, elaboramos para la modalidad de entrega: enlace que da acceso al cuestionario online una carta de invitación para profesores que imparten enseñanzas de inglés como L2 en la ciudad de Valladolid, España ${ }^{17}$ y una carta de invitación para profesores que imparten enseñanzas

\footnotetext{
${ }^{15}$ La Carta de Presentación dirigida a los informantes del contexto educativo de Valladolid se encuentra en el Anexo III

${ }^{16}$ La Carta de Presentación dirigida a los informantes del contexto educativo de Austin se encuentra en el Anexo IV

${ }^{17}$ La Carta de Invitación dirigida a los informantes del contexto educativo de Valladolid se encuentra en el Anexo V
} 
de español como segunda lengua en la ciudad de Austin, Estados Unidos de América ${ }^{18}$. Las dos cartas se entregaron en formato electrónico.

Las cartas de presentación y de invitación muestran un contenido similar y tienen una longitud aproximada, ninguna de ellas supera una página, y en ellas se deja constancia de la importancia de las informaciones aportadas para la realización de la investigación propuesta (Dumbravescu, 2014). Seguimos las indicaciones encontradas en Diop (2008); Dumbravescu (2014); Giroux y Tremblay (2004); Goode y Hatt (1970); Latorre Beltrán, Rincón Igea y Arnal Agustín (1996) y Torres González (1996), incluyendo en ellas los siguientes componentes:

- La categoría de informantes (en nuestro caso, profesores de inglés/español como L2) a la que se dirige.

- El propósito y los objetivos de la investigación.

- La importancia de su colaboración en la investigación.

- La garantía del anonimato y la confidencialidad, por cuanto que se utilizará de forma colectiva en la investigación.

- El agradecimiento por su colaboración en la investigación.

- Las pautas generales para cumplimentar el cuestionario.

En la redacción de estas cartas, nos ceñimos a las recomendaciones de Dumbravescu (2014) y Torres González (1996), respecto a la presentación, al formato, a los márgenes, al encuadre, a los espacios y a la redacción de los párrafos.

\footnotetext{
${ }^{18}$ La Carta de Invitación dirigida a los informantes del contexto educativo de Austin se encuentra en el Anexo VI
} 


\subsubsection{Estructura del cuestionario y clasificación de los ítems}

Como hemos mencionado anteriormente, en la presente investigación se diseñó un único cuestionario que, posteriormente se adaptó a los dos contextos educativos que forman parte de esta: el contexto educativo de Valladolid, España y el de Austin, Estados Unidos de América. A partir de este cuestionario se crearon las dos versiones (Cuestionario I y Cuestionario II) que se utilizaron para cada uno de los dos contextos y que se pueden encontrar en el Anexo I y en el Anexo II respectivamente.

Las versiones mencionadas aparecen bajo los títulos: "Cuestionario para profesores que imparten enseñanzas oficiales de inglés como segunda lengua en la ciudad de Valladolid, España” y "Cuestionario para profesores que imparten enseñanzas oficiales de español como segunda lengua en la ciudad de Austin, Estados Unidos de América” y son prácticamente idénticas, aunque cada una contiene algunos elementos característicos del contexto educativo de los informantes a los que van dirigidas.

Con respecto a la elaboración de los enunciados que forman parte del cuestionario, nos situamos en torno al planteamiento de Dumbravescu (2014) adaptando su propuesta a nuestra situación investigadora por cuanto que creamos: 
- Preguntas de respuesta única (ítems 1 y 4): a través de las cuales solicitamos información a nuestros informantes acerca de los años de experiencia (ítem 1) y el número de alumnos (ítem 4).

- Preguntas de opción múltiple (ítems 2, 3, 5, 6, 7, 8, 9, 11, 12,13, 14, 15 y 16): en las que intentamos recabar información sobre la edad de los informantes (ítem 2), el curso en el que imparten sus clases en la actualidad (ítem 3), así como información relacionada con:

○ los conocimientos del informante sobre la actitud que muestra el alumno hacia una actividad de escritura dirigida (ítem 5) y hacia una actividad libre (ítem 6), sobre la reacción de los alumnos ante la ayuda ofrecida (ítem 9), sobre el momento idóneo para la corrección de las producciones escritas (ítem 12) y sobre la tipología de errores que deben ser corregidos cuando hablamos de producciones escritas libres en L2 (ítem 15).

- las aptitudes del informante en torno a la forma de plantear una actividad libre (ítem 7), a su grado de intervención a la hora de proporcionar ayuda (ítem 8), a su grado de participación en la corrección de las producciones escritas (ítem 11), a la forma en que hacen llegar el feedback que acompaña a la corrección de errores (ítem 13), a la evaluación de una producción escrita (ítem 14) y a la conjunción de corrección, feedback y nota numérica en producciones escritas libres en L2 (ítem 16).

- Enunciados descriptivo-evaluativos (ítems 10 y 17): a los que recurrimos para conseguir información acerca de los conocimientos del informante sobre la posible 
utilidad de las actividades de expresión escrita (ítem 10) y acerca de su actitud respecto a la corrección de errores y dotación de feedback en las actividades de expresión escrita en L2 (ítem 17).

Respecto a la última modalidad utilizada: enunciados descriptivo-evaluativos, partiendo de los supuestos de Dumbravescu (2014), decidimos utilizar la Escala de Likert estructurada a partir de los siguientes descriptores: mucho, bastante, poco, muy poco, nada.

El cuestionario consta de una serie de ítems centrales y otros que sirven para completar la información que nos proporcionan dichos ítems centrales. Se distribuye en dos partes diferenciadas. La primera comprende los ítems 1 al 4 confeccionados con el fin de conseguir información relacionada con el perfil del informante. La segunda parte comprende los ítems 5 al 17 y fue diseñada con la intención de provocar en los informantes una reflexión acerca del concepto que tienen sobre el error, la corrección y el feedback en las producciones escritas en L2 de sus alumnos. Esta segunda parte está organizada en torno a los tres componentes competenciales de nuestros informantes en relación al error, a la corrección y al feedback: los conocimientos, las aptitudes y las actitudes.

Componente competencial I. Conocimientos. Cuando nos referimos a esta categoría, hacemos referencia a aquellos conocimientos que tiene el informante sobre:

- La actitud que muestra el alumno hacia las actividades de escritura dirigida en L2.

- La actitud que muestra ante las actividades de escritura libre en L2.

- La reacción de los alumnos ante la ayuda ofrecida. 
- La utilidad que presentan dichas actividades.

- El momento idóneo para la corrección de las producciones escritas en L2.

- La tipología de errores que deben ser corregidos.

$>$ Componente competencial II. Aptitudes expresadas en términos de "ser capaz de":

- Plantear una actividad de escritura libre de diferentes formas.

- Decidir sobre el grado de intervención a la hora de proporcionar ayuda a los alumnos durante la realización de actividades de escritura libre en L2.

- Tomar decisiones en torno a su grado de participación en la corrección de actividades de expresión escrita libre en L2.

- Proporcionar feedback al alumno después de la corrección de errores de una actividad de expresión escrita libre en L2.

- Evaluar una producción escrita en L2.

- Conjugar corrección, feedback y nota numérica.

$>$ Componente competencial III. Actitudes ante:

- La corrección de errores y el feedback en una producción escrita en L2.

Agrupamos por tanto los ítems de nuestro cuestionario en función del perfil del informante y de los tres componentes de la competencia profesional docente.

1. Perfil del informante: 
- Ítem 1. Años de experiencia en la enseñanza de segundas lenguas

- Ítem 2. Edad de los informantes

- Ítem 3. Curso o nivel educativo en el que imparte clases

- Ítem 4. Número de alumnos a los que imparte clase en la actualidad.

2. Conocimientos del informante sobre el error, la corrección y el feedback:

- Ítem 5. Conocimientos del informante sobre la actitud que muestra el alumno hacia una actividad de escritura dirigida en L2

- Ítem 6. Conocimientos del informante sobre la actitud que muestra el alumno hacia una actividad de escritura libre en L2

- Ítem 9. Conocimientos del informante sobre la reacción que presentan los alumnos ante la ayuda ofrecida en L2

- Ítem 10. Conocimientos del informante sobre la utilidad de las actividades de expresión escrita libre en L2

- Ítem 12. Conocimientos del informante acerca del momento idóneo para la corrección de las producciones escritas en L2

- Ítem 15. Conocimientos del informante sobre los tipos de errores que deben ser corregidos en las producciones escritas en L2.

3. Aptitudes del informante en torno al error, a la corrección y al feedback:

- Ítem 7. Aptitudes del informante en torno a cómo plantear una actividad de escritura libre 
- Ítem 8. Aptitudes del informante en torno a su grado de intervención a la hora de proporcionar ayuda a los alumnos durante la realización de actividades de escritura libre en L2

- Ítem 11. Aptitudes del informante en cuanto a la elección de modalidades de corrección de las actividades de escritura libre en L2

- Ítem 13. Aptitudes del informante en torno al feedback que acompaña a la corrección de errores de una actividad de escritura libre en L2

- Ítem 14. Aptitudes del informante en torno a la evaluación de una producción escrita en L2

- Ítem 16. Aptitudes del informante respecto a la forma de entrega de correcciones de las producciones escritas en L2

4. Actitudes del informante ante el error, la corrección y el feedback:

- Ítem 17. Actitudes del informante ante la corrección de errores y el feedback en una producción escrita en L2

Cada uno de los elementos indicados serán objeto de nuestra atención en los siguientes epígrafes.

Situándonos en la perspectiva de Sáez López (2017) quien afirma que el cuestionario debe validarse "creando un borrador y aportando el instrumento a jueces expertos que, a partir de su experiencia valorarán si los ítems tienen pertinencia y adecuación” (pp. 92-93) decidimos validarlo entregando dicho borrador a evaluadores expertos: director de Tesis, profesores de la 
Universidad de Valladolid y de University of Texas at Austin que realizaron una valoración cualitativa del contenido. A partir de las observaciones proporcionadas respecto a la pertinencia, adecuación y formulación de los ítems, así como a la extensión del cuestionario se reformula el primer borrador hasta conseguir la última versión de los Cuestionarios I y II. 


\section{Capítulo 5. PERFIL DE LOS INFORMANTES}

5.1. Aspectos generales en torno al perfil de los informantes

5.2. Años de experiencia

5.3. Edad

5.4. Curso o nivel educativo

5.5. Número de alumnos

5.6. Interpretación de los resultados. Perfil de los informantes 


\subsection{Aspectos generales en torno al perfil de los informantes}

Tal y como precisábamos en el epígrafe 4.2., nuestros informantes son profesores que pertenecen a dos sistemas educativos diferentes: el de la ciudad de Valladolid (sistema educativo de la comunidad autónoma de Castilla y León, en España) y el de Austin (sistema educativo del estado de Texas, Estados Unidos de América). Todos ellos ejercen su actividad docente en centros de enseñanzas oficiales de L2. Como se muestra en el Cuadro 3 los ítems que nos aportarán la información necesaria que nos permita construir el perfil del informante tienen en consideración:

- años de experiencia

- edad

- curso o nivel educativo en el que ejercen la actividad docente

- número de alumnos

\begin{tabular}{|c|c|}
\hline \multirow{4}{*}{ Perfil del informante } & $\begin{array}{l}\text { Ítem 1. Años de experiencia en la } \\
\text { enseñanza de } L 2\end{array}$ \\
\hline & Ítem 2. Edad de los informantes \\
\hline & $\begin{array}{l}\text { Ítem 3. Curso o nivel educativo en el que } \\
\text { ejercen su actividad docente }\end{array}$ \\
\hline & Ítem 4. Número de alumnos \\
\hline
\end{tabular}

Cuadro 3. Ítems de los cuestionarios dirigidos a la recopilación de información acerca del perfil del informante 
Los ítems que se muestran en el Cuadro 3 son concebidos e incluidos en los cuestionarios con el propósito de que las respuestas a dichos ítems puedan aportar información sobre los años de experiencia, la edad, el curso o nivel educativo en el que los informantes ejercen la actividad docente y el número de alumnos a los que atienden en el aula. En este sentido, los datos que nos disponemos a analizar forman parte de la categoría "perfil del informante".

Consideramos que todas estas variables ejercerán una influencia relevante respecto a la valoración que puedan tener nuestros informantes sobre el error, la corrección y el feedback en las producciones escritas de los alumnos de L2.

\subsection{Años de experiencia}

Solicitamos por tanto en el ítem número 1 de nuestro cuestionario que los sujetos faciliten los datos relativos a los años de experiencia como profesores de L2 a través de una pregunta abierta cuyas respuestas nos ayudarán a constituir el perfil del informante. Planteamos este ítem en nuestros cuestionarios puesto que consideramos que los años de actividad docente del informante ejercerán una clara influencia en la aptitud y en la actitud en torno a la valoración del error. En este acercamiento, partimos de la idea de que aquellos profesores conocedores de las corrientes pedagógicas actuales en torno al tratamiento del error en L2, mostrarán un mayor grado de tolerancia ante la presencia del error en las producciones escritas de los alumnos de L2 cuanto mayor sea su grado de experiencia. 
Nos atrevemos por tanto a inferir que los años de experiencia aportarán a aquellos profesores que cuenten con formación docente relacionada con las nuevas metodologías de tratamiento del error y que apliquen esos conocimientos en su aula de L2, una mayor oportunidad de concienciación y de reflexión en torno a los resultados de los alumnos en las actividades de expresión escrita. Desde esta consideración, la combinación de años de experiencia junto con el conocimiento y posterior aplicación de las metodologías de aceptación del error como parte del proceso de enseñanza-aprendizaje de L2 concederán al profesor actitudes positivas hacia este y fomentarán el uso de metodologías de corrección de errores dirigidas al proceso de producción escrita.

Sin embargo, cabe la posibilidad de que algunos informantes no hayan continuado con su formación respecto a la corrección de errores y por tanto no tengan conocimiento de las nuevas metodologías de tratamiento del error. Es el caso de profesores que puedan estar recurriendo a un método de corrección tradicional dirigida al producto o borrador final, marcando los errores y escribiendo la forma correcta junto con algún comentario en el primer y único borrador del alumno sin aprovechar esos errores ni integrarlos en el propio proceso de enseñanza-aprendizaje de L2.

En el epígrafe 1.1.2 nos situábamos en la línea de Burt (1975) quien destacaba que la corrección de errores solo alcanza su objetivo si se integra en la enseñanza-aprendizaje de L2 con el propósito de que el alumno llegue a conseguir la eficacia en la comunicación mostrando una actitud de confianza en sí mismo y en el aprendizaje. Desde esta perspectiva de concienciación y de reflexión sobre la corrección se pone de relieve el planteamiento de la integración del error en el proceso de enseñanza de una L2. 


\subsubsection{Análisis de los datos: años de experiencia de los informantes}

Las respuestas obtenidas a partir del ítem número 1 en el contexto educativo de Valladolid (teniendo en cuenta que 3 de los 33 informantes no responde a este ítem) se muestran en la Tabla 1 y el Gráfico 1 que presentamos a continuación:

\begin{tabular}{|lrrr}
\hline Años de experiencia en la enseñanza de segundas lenguas & Número de respuestas & Porcentaje \\
\hline 1 & 1 & $3.33 \%$ \\
\hline 2 & 2 & $6.67 \%$ \\
\hline 6 & 3 & $10.00 \%$ \\
\hline 7 & 1 & $3.33 \%$ \\
\hline 9 & 1 & $3.33 \%$ \\
\hline 11 & 1 & $3.33 \%$ \\
\hline 13 & 2 & $6.67 \%$ \\
\hline 15 & 4 & $13.33 \%$ \\
\hline 16 & 3 & $10.00 \%$ \\
\hline 18 & 2 & $6.67 \%$ \\
\hline 19 & 1 & $3.33 \%$ \\
\hline 25 & 3 & $10.00 \%$ \\
\hline 26 & 2 & $6.67 \%$ \\
\hline 34 & 3 & $10.00 \%$ \\
\hline Total & 1 & $3.33 \%$ \\
\hline
\end{tabular}

Tabla 1. Resultados sobre los años de experiencia de los informantes en Valladolid 

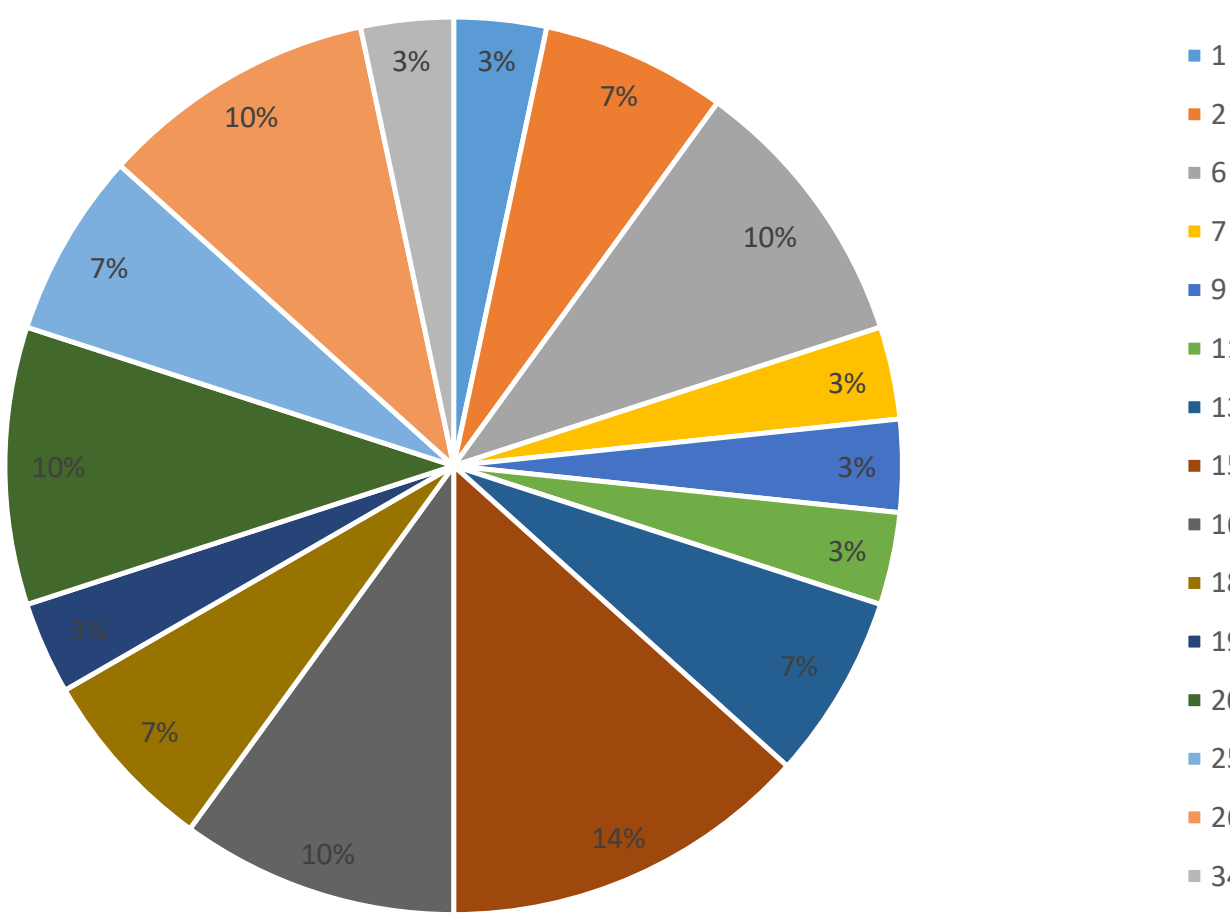

$\because 2$

$\square 6$

$=7$

- 9

- 11

- 13

- 15

- 16

- 18

- 19

- 20

- 25

$-26$

$-34$

Gráfico 1. Resultados sobre los años de experiencia de los informantes en Valladolid

Los porcentajes están calculados en función del número de informantes (30) que responden al ítem número 1. Clasificamos los resultados en tres intervalos. El primero: de 0 a 9 años de experiencia cuyo porcentaje es de 26\%, el segundo: de 10 a 19: con un porcentaje de $44 \%$ y el tercero de 20 años en adelante, con un porcentaje de $30 \%$.

En cuanto al contexto educativo de Austin, encontramos que todos los informantes responden a este ítem y obtenemos los resultados que aparecen en la Tabla 2 y el Gráfico 2 que se muestran a continuación: 


\begin{tabular}{|lrrr|}
\hline Años de experiencia en la enseñanza de segundas lenguas & Número de respuestas & Porcentaje \\
\hline 1 & 2 & $5.00 \%$ \\
\hline 2 & 2 & $5.00 \%$ \\
\hline 3 & 1 & $2.50 \%$ \\
\hline 5 & 3 & $7.50 \%$ \\
\hline 6 & 1 & $2.50 \%$ \\
\hline 7 & 1 & $2.50 \%$ \\
\hline 8 & 4 & $10.00 \%$ \\
\hline 9 & 1 & $2.50 \%$ \\
\hline 10 & 3 & $7.50 \%$ \\
\hline 11 & 2 & $5.00 \%$ \\
\hline 12 & 4 & $10.00 \%$ \\
\hline 13 & 1 & $2.50 \%$ \\
\hline 14 & 3 & $7.50 \%$ \\
\hline 15 & 6 & $15.00 \%$ \\
\hline 19 & 1 & $2.50 \%$ \\
\hline 20 & 2 & $5.00 \%$ \\
\hline 24 & 1 & $2.50 \%$ \\
\hline 28 & 1 & $2.50 \%$ \\
\hline 30 & 1 & $2.50 \%$ \\
\hline Total & $100.00 \%$ \\
\hline
\end{tabular}

Tabla 2. Resultados sobre los años de experiencia de los informantes en Austin 


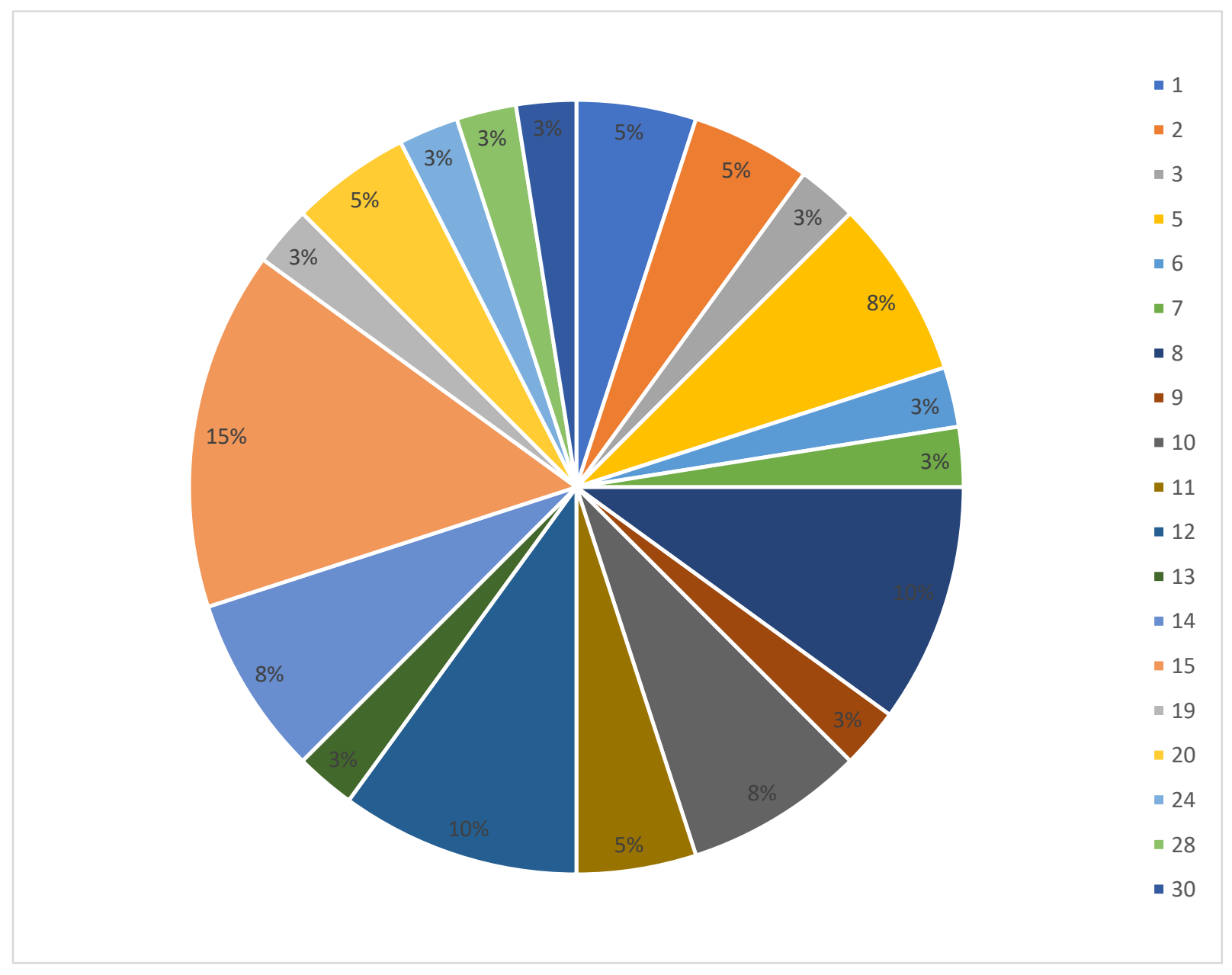

Gráfico 2. Resultados sobre los años de experiencia de los informantes en Austin

En cuanto a los años de experiencia de los informantes del contexto educativo de Austin, observamos que un 39\% tiene entre 0 y 9 años de experiencia, un $49 \%$ tiene entre 10 y 19 años y un $12 \%$ de informantes cuenta con más de 20 años de experiencia. 


\subsubsection{Interpretación de los resultados: años de experiencia de los informantes}

El análisis nos permite afirmar que nos encontramos ante contextos educativos que presentan algunas similitudes. La mayoría de los informantes tanto del contexto educativo de Valladolid (44\%) como del contexto de Austin (49\%) cuentan con una experiencia profesional docente entre 10 y 19 años. En el caso de Valladolid el número de profesores con menos de 10 años de experiencia es de un $26 \%$ frente al 39\% de Austin. Además, el porcentaje de informantes con más de 20 en Valladolid es muy superior (30\%) al de Austin (12\%).

Se puede concluir, por tanto, que los informantes de Valladolid cuentan con un mayor número de años de experiencia que los informantes que constituyen la muestra intencional de Austin.

Esto puede llevarnos a pensar que los profesores vallisoletanos cuentan con una mayor competencia en la enseñanza de inglés como L2 respecto a los profesores de Austin de español como L2. Sin embargo, en este acercamiento, estimamos necesario hacer referencia al contexto político y social de España. Los profesores que tienen una larga trayectoria profesional en Valladolid (superior a 20 años de experiencia docente) son aquellos que llevaron a cabo sus estudios de Educación Primaria y Secundaria coincidiendo con los años de la dictadura franquista. Teniendo en cuenta que, durante esta época el francés era la L2 que se impartía en todos los centros educativos del territorio español, muchos de estos profesores no tuvieron ocasión de establecer un contacto con la lengua inglesa hasta alcanzar su madurez. Es a finales de la década de los setenta cuando en las aulas españolas se empieza a introducir el inglés como L2 dividiendo a los españoles 
en dos generaciones: aquellos que estudiaron francés y los que estudiaron inglés como L2 durante la etapa de Educación Primaria.

Unido a esto, conviene subrayar el hecho de que la formación en L2 durante la época mencionada se limitaba a una metodología basada en el estudio de la gramática y en la traducción. El objetivo principal era la capacitación del alumno en la lectura de obras literarias escritas en la L2. Así pues, se introducen y se estudian en profundidad una serie de reglas gramaticales que servirán al alumno en la traducción de obras literarias. Las destrezas orales carecen de importancia centrando toda la atención en la comprensión y expresión escrita. Además, la competencia léxica se adquiría a partir de la elaboración de listas de vocabulario extraídas de las oraciones y de los textos empleados en el aula. Los alumnos se enfrentaban a la memorización de estas listas de palabras y a sus equivalentes en la L1 sin prestar atención al contexto.

Debemos tener en cuenta, por tanto, que un amplio porcentaje de informantes pertenece a esta generación de antiguos alumnos de inglés como L2 bajo la metodología gramática-traducción. En este sentido, cabe la posibilidad de que la variable: años de experiencia represente una desventaja puesto que una parte importante de estos profesores experimentados no cuenta con un dominio del inglés como L2. 


\subsection{Edad}

Relacionado con los años de experiencia incluimos el factor edad de los informantes en el ítem número 2 de nuestro cuestionario. Se pedirá a los informantes que maquen la opción que corresponda al intervalo edad; a saber: menor de 30, de 30 a 45 o mayor de 45 . La edad del informante junto con su experiencia docente como profesor de L2 puede aportar información sobre las distintas actitudes hacia el error. Nos atrevemos a suponer que los profesores de mayor edad, conocedores de las teorías de adquisición de L2, que hayan apostado por una formación continua y conozcan las nuevas metodologías de tratamiento y corrección de errores, mostrarán una actitud más tolerante respecto a los profesores más jóvenes por haber sido expuestos ante el error en un mayor número de ocasiones. Consideramos que la exposición a determinados tipos de errores redunda en un proceso de reflexión sobre la importancia de estos dentro del proceso de enseñanzaaprendizaje de una L2 que conduce al profesor hacia una mayor tolerancia ante dichos errores. Por su parte, nos atrevemos a suponer que los profesores más jóvenes y, por tanto, con menos experiencia adoptarán una postura menos flexible ante la presencia del error en el aula. Es posible que la falta de experiencia y, consecuentemente, de exposición ante el error estimule la aparición de actitudes negativas ante la presencia del error en las producciones escritas de sus alumnos de L2.

No obstante, el factor edad no está directamente relacionado con un tipo de actitud ante el error. Tampoco con el uso de una metodología de corrección orientada al proceso de producción escrita en la que se busque el aprovechamiento de este. Tanto edad como años de experiencia de los informantes debe ir unido al conocimiento por parte del profesor de las nuevas metodologías en torno al error y a su aplicación en el aula. Así pues, cabe la posibilidad de encontrarnos ante 
profesores que, independientemente de su edad o grado de experiencia, no hayan continuado con su formación y, por tanto, no tengan conocimiento de los avances pedagógicos recientes ni hayan puesto en práctica los enfoques metodológicos centrados en el proceso de escritura (processoriented pedagogy) mencionados por Ferris y Hedgcock (1998) los cuales, como hemos venido apuntando en el epígrafe 1.1.3, vienen apareciendo como los más avanzados y conocidos por los profesores no solo en el contexto norteamericano sino en la mayor parte de contextos educativos.

\subsubsection{Análisis de los datos: edad de los informantes}

Los resultados obtenidos del contexto educativo de Valladolid en torno a la edad de los informantes (ítem 2) se muestra en la Tabla 3 y el Gráfico 3 que aparecen a continuación. Dichos resultados se calculan en función del número total de informantes (33) ya que todos aportan su respuesta.

\begin{tabular}{|c|c|c|}
\hline Edad & $\begin{array}{l}\text { Número de } \\
\text { respuestas }\end{array}$ & Porcentaje \\
\hline De 30 a 45 & 20 & $60.61 \%$ \\
\hline Más de 45 & 11 & $33.33 \%$ \\
\hline Menor de 30 & 2 & $6.06 \%$ \\
\hline Total & 33 & $100.00 \%$ \\
\hline
\end{tabular}

Tabla 3. Resultados sobre la edad de los informantes en Valladolid 


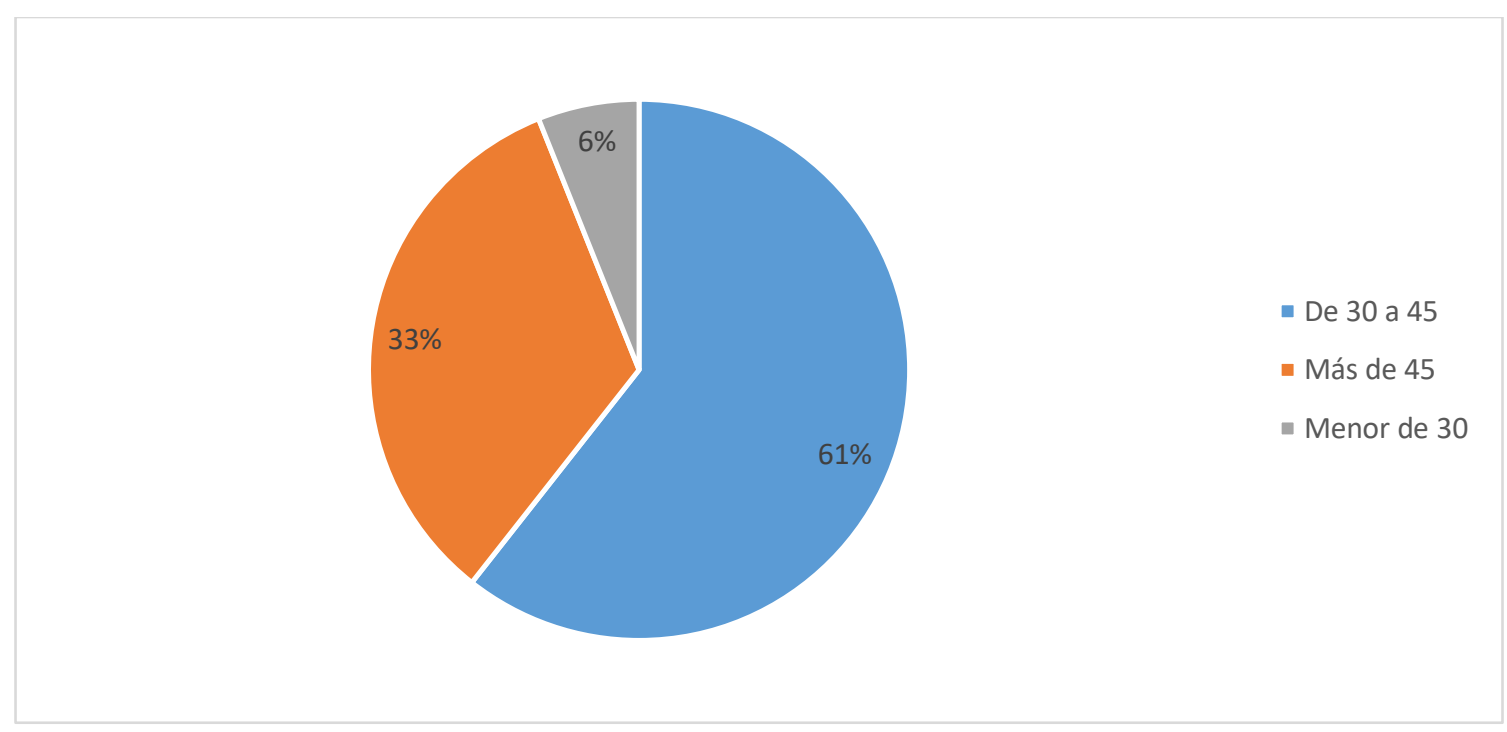

Gráfico 3. Resultados sobre la edad de los informantes en Valladolid

Los resultados nos indican que, en el contexto de Valladolid, más de la mitad de los informantes (61\%) se encuentran entre los 30 y los 45 años, un 33\% tiene más de 45 y solo un $6 \%$ son menores de 30 años.

Los datos numéricos correspondientes al contexto educativo de Austin en torno a la edad de los informantes (considerando que 2 de ellos decide no aportar información) se muestran en la Tabla 4 y en el Gráfico 4 que aparecen a continuación:

\begin{tabular}{|lrr|}
\hline Edad & Número de respuestas & Porcentaje \\
\hline De 30 a 45 & 27 & $71.05 \%$ \\
\hline Más de 45 & 5 & $13.16 \%$ \\
\hline Menor de 30 & 6 & $15.79 \%$ \\
\hline Total & 38 & $100.00 \%$ \\
\hline
\end{tabular}

Tabla 4. Resultados sobre la edad de los informantes en Austin 


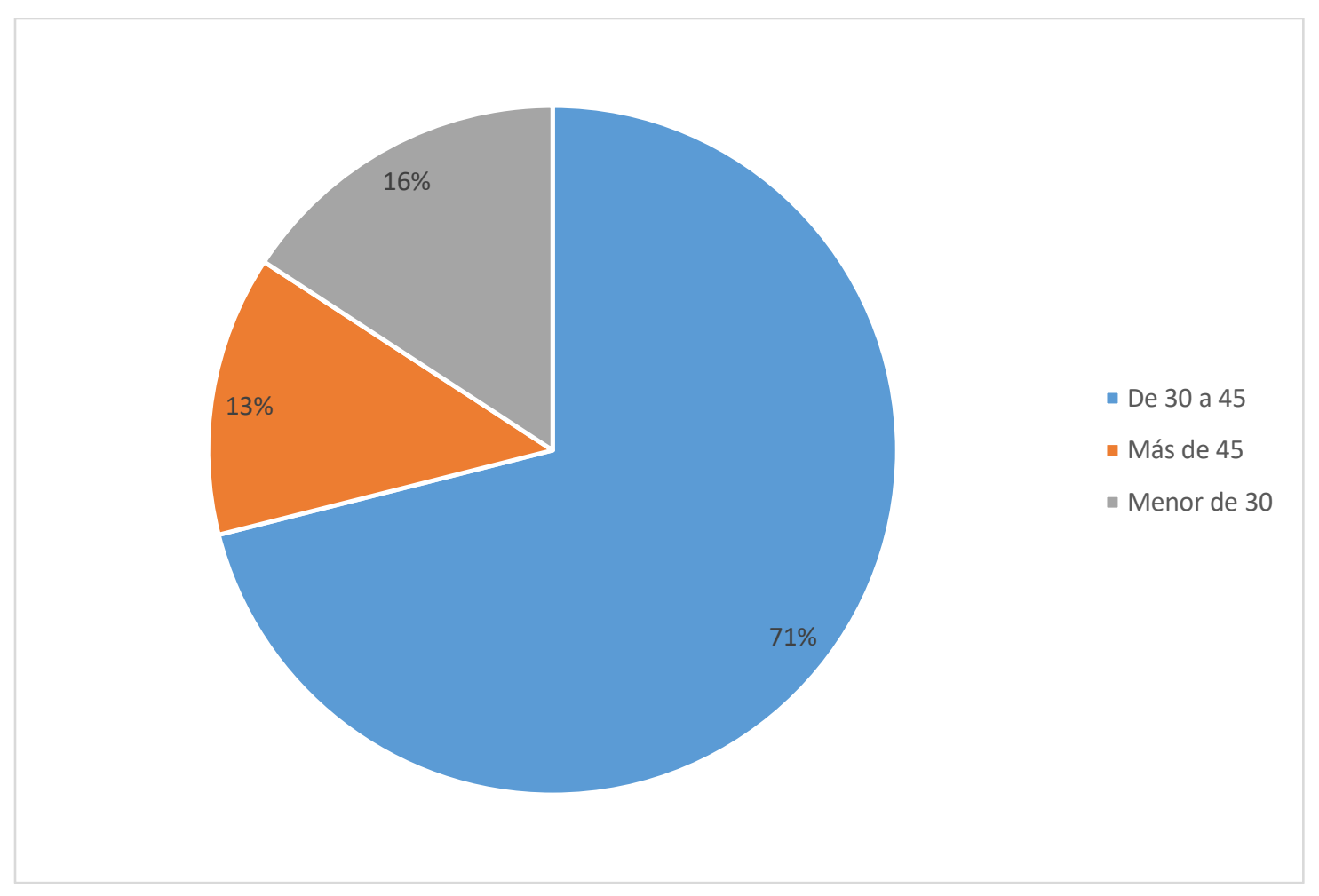

Gráfico 4. Resultados sobre la edad de los informantes en Austin

Los resultados correspondientes a la ciudad de Austin se han calculado en relación a los 38 informantes que deciden responder de un total de 40. Advertimos un porcentaje muy amplio de informantes que tienen entre 30 y 45 años (71\%) tratándose este del mayor rango de edad. Hay un $16 \%$ menores de 30 y un $13 \%$ de informantes mayores de 45 años. 


\subsubsection{Interpretación de los resultados: edad de los informantes}

El análisis de los dos contextos educativos nos indica que los informantes que predominan en ambos son los que tienen una edad comprendida entre los 30 y los 45 años. En el caso de Valladolid el porcentaje es de $61 \%$ frente al de Austin en el que contamos con un $71 \%$. Los informantes con más de 45 años representan un $33 \%$ en el contexto de Valladolid frente al 13\% de Austin. Por último, los menores de 30 años representan solo un 6\% en Valladolid frente al $16 \%$ en Austin.

Estos datos indican que los informantes que constituyen nuestra muestra intencional en la ciudad de Valladolid tienen una edad más avanzada que los informantes del contexto educativo de Austin.

\subsection{Curso o nivel educativo}

El curso o nivel educativo en el que imparten sus clases, consultado a través del ítem número 3, será determinante para los profesores en cuanto a la toma de decisiones acerca de la corrección de errores: qué, cómo y cuándo corregir. Estimamos necesaria la información relativa al curso escolar ya que la presencia de errores en las producciones escritas de los alumnos depende directamente del nivel de competencia lingüística del alumno en la L2, lo cual se relaciona con el nivel educativo. Como ya hemos mencionado, la etapa de Educación Primaria en España abarca 
desde $1^{\circ}$ hasta $6^{\circ}$ curso (de los 6 a los 11 años de edad) y son estos los cursos escolares que se ofertan en todos los centros educativos de Educación Primaria. En el caso de Estados Unidos, estos centros educativos reciben el nombre de Elementary Schools y no en todos se ofrece la posibilidad de cursar los mismos niveles educativos. Así, algunos ofertan $1^{\circ}$ a $5^{\circ}$ (de 6 a 10 años) otros amplían esta oferta de $1^{\circ}$ a $6^{\circ}$ (de 6 a 11 años) (MECD, 2016), etc. En los centros que conforman nuestra muestra intencional en la ciudad de Austin los alumnos cursan de $1^{\circ}$ a $5^{\circ}$ de Primaria. En lo que respecta a la edad de los alumnos, la correspondencia de edad entre los alumnos de los distintos cursos escolares en Educación Primaria es la misma en ambos contextos.

Abordamos en los cuestionarios la pregunta en relación al curso escolar en el que los informantes ejercen su actividad docente por estar directamente relacionado con la edad de sus alumnos. Como explicábamos en el epígrafe 2.1.2, la edad del alumno pertenece a ese conjunto de rasgos diferenciadores en función de los cuales se crearán diferentes situaciones de corrección de errores y de entrega de dotación de feedback en el aula. En este sentido, como ya apuntábamos en el mencionado epígrafe, se impone la necesidad de que el profesor cuente con distintos mecanismos de corrección y de feedback para poder hacer uso del que mejor se adapte a las características de los alumnos. 


\subsubsection{Análisis de los datos: curso o nivel educativo en el que los informantes ejercen su actividad docente}

Las respuestas aportadas por los informantes dentro del contexto de Valladolid (en este caso, el 100\% decide contestar al presente ítem) muestran los resultados que podemos observar en la Tabla 5 .

\begin{tabular}{|c|c|c|}
\hline Curso en el que imparte sus clases & $\begin{array}{l}\text { Número de } \\
\text { respuestas }\end{array}$ & Porcentaje \\
\hline 10 & 1 & $3.03 \%$ \\
\hline 20 & 1 & $3.03 \%$ \\
\hline 3은 & 4 & $12.12 \%$ \\
\hline 4은 & 9 & $27.27 \%$ \\
\hline 5은 & 8 & $24.24 \%$ \\
\hline 60 & 10 & $30.30 \%$ \\
\hline Total & 33 & $100.00 \%$ \\
\hline
\end{tabular}

Tabla 5. Resultados sobre el curso o nivel educativo en Valladolid

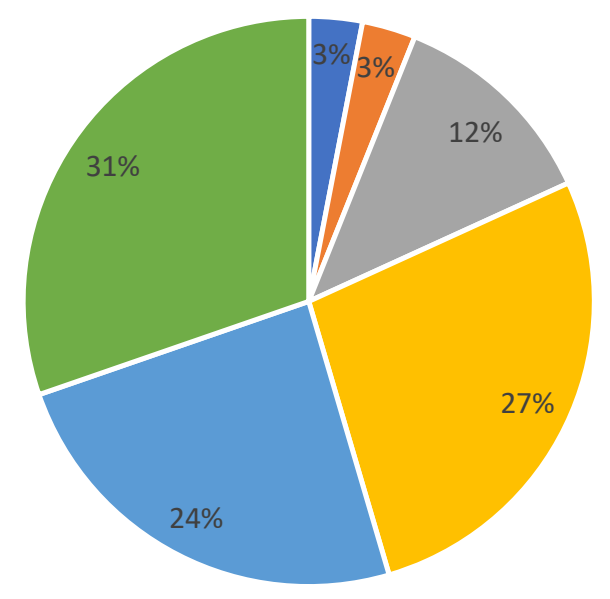


Observamos, a partir de los datos, que los informantes de la ciudad de Valladolid imparten clases de inglés como L2 mayoritariamente en los cursos $3^{\circ}$ a $6^{\circ}$. Así pues, encontramos que un $6 \%$ ejerce su actividad docente en los cursos de $1^{\circ}$ a $2^{\circ}$ de Educación Primaria frente al $94 \%$ que lo hace en los cursos de $3^{\circ}$ a $6^{\circ}$.

Los resultados de la ciudad de Austin (habida cuenta que hay 2 informantes que no responden a este ítem) se muestran en la Tabla 6 y el Gráfico 6 que aparecen a continuación:

\begin{tabular}{|l|rr|}
\hline Curso en el que imparte sus clases & Número de respuestas & Porcentaje \\
\hline 1 - & 2 & $5.26 \%$ \\
\hline 2 - & 3 & $7.89 \%$ \\
\hline 30 & 7 & $18.42 \%$ \\
\hline 40 & 12 & $31.58 \%$ \\
\hline 5o & 14 & $36.84 \%$ \\
\hline Total & 38 & $100.00 \%$ \\
\hline
\end{tabular}

Tabla 6. Resultados sobre el curso o nivel educativo en Austin

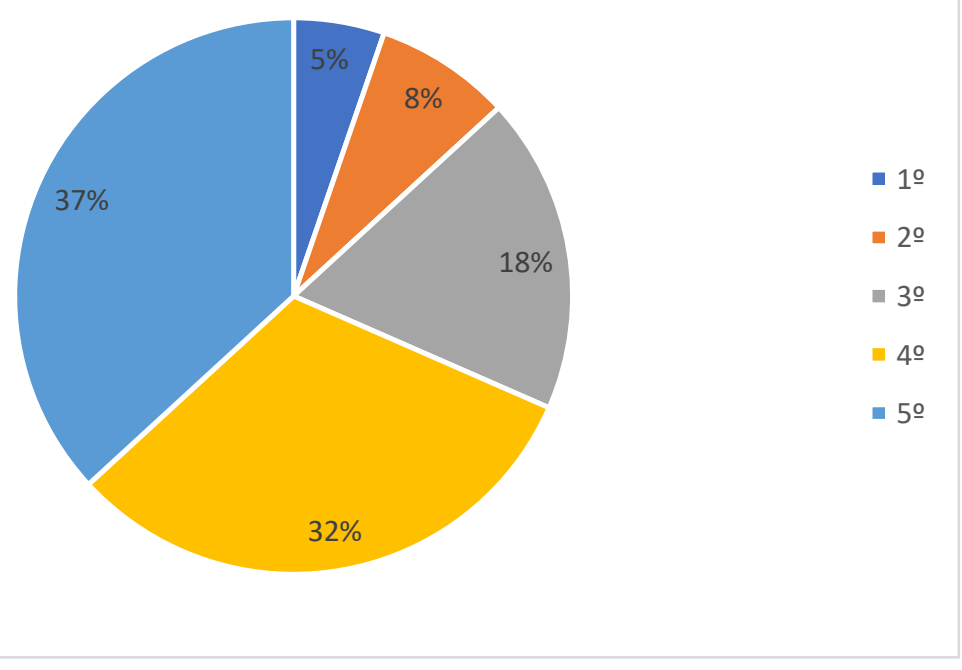

Gráfico 6. Resultados sobre el curso o nivel educativo en Austin 
Respecto a los resultados obtenidos de los informantes que forman parte del contexto educativo de Austin, podemos decir que, la gran mayoría desarrolla su actividad docente entre los cursos $3^{\circ}$ a $5^{\circ}$ de Educación Primaria. En términos de porcentajes (calculados estos a partir del número de informantes que ha decidido aportar información en este ítem, en este caso, 38 de un total de 40) los profesores que imparten clase en niveles educativos de $1^{\circ}$ a $2^{\circ}$ suman un $13 \%$ frente al $87 \%$ que lo hace en los cursos $3^{\circ}$ a $5^{\circ}$ de Primaria.

\subsubsection{Interpretación de los resultados: curso o nivel educativo en el que los informantes ejercen su actividad docente}

Los resultados de ambos contextos son bastante similares. Los cursos o niveles educativos en los que desarrolla la actividad docente la mayoría de nuestros informantes tanto en Valladolid (82\%) como en Austin (69\%) son de $3^{\circ}$ en adelante. Los informantes que imparten clases en $1^{\circ} \mathrm{y}$ $2^{\circ}$ curso de Primaria conforman un porcentaje poco significativo: $6 \%$ en el caso de Valladolid y $13 \%$ en el caso de Austin.

Decidimos establecer estos intervalos tomando como referencia el nivel educativo $3^{\circ}$ de Educación Primaria por tratarse este del curso en el que la destreza de expresión escrita se empieza a trabajar de una manera autónoma en una L2 en los dos contextos educativos.

El proceso cognitivo en cuanto a adquisición de L2 varía en función de la edad de los alumnos $\mathrm{y}$, en este sentido, en los cursos anteriores a $3^{\circ}$ de Primaria, se trabajan principalmente las destrezas orales y las producciones escritas en L2 son limitadas. Consideramos, por tanto, que la corrección 
de este tipo de producciones ha de tener unas características distintas a la de las producciones de alumnos pertenecientes a cursos superiores. De igual manera, los mecanismos y métodos de corrección serán diferentes puesto que estos estarán adaptados a la edad de los alumnos. A partir de nuestra experiencia docente y del trabajo de campo realizado en los dos contextos educativos hemos podido observar que la metodología de corrección utilizada en los niveles educativos inferiores ( $1^{\mathrm{o}}$ y $2^{\mathrm{o}}$ de Primaria) es la corrección inmediata que se lleva a cabo de manera oral y de forma general para el grupo clase. Es a partir de $3^{\circ}$ cuando el profesor empieza a adoptar unos mecanismos de corrección individualizada.

\subsection{Número de alumnos}

La especificación del número de alumnos a los que el sujeto imparte clase en la actualidad, que se encuentra en el ítem número 4 del cuestionario, precisará la forma en que nuestros informantes se enfrentan al error y a su corrección. Los métodos de corrección y la forma de facilitar el feedback correspondiente, varía de una manera decisiva en función del número de sujetos con que se trabaje en el aula. De acuerdo con esto, retenemos la idea de Truscott (1996) al que mencionábamos en el epígrafe 2.1 de esta Tesis Doctoral, el cual, insistía en subrayar el alto grado de dificultad que implica la corrección de las producciones escritas de los alumnos como parte de la responsabilidad docente. Además, el autor veía una clara relación entre dificultad en la corrección de errores gramaticales y el tamaño del grupo. Asimismo, el número de alumnos puede influir de manera decisiva en la atención dedicada al error, a la corrección y al posterior feedback. 
Por tanto, nos atrevemos a suponer que aquellos informantes que cuenten con un número elevado de alumnos (más de 20) presentarán una mayor dificultad a la hora de llevar a cabo la corrección de errores de las producciones escritas. Una corrección de errores inmediata en la que el profesor haga uso de entrevistas individuales con cada alumno es difícil de llevar a cabo cuando se trata de una clase numerosa ya que, en la mayoría de los casos, no es posible contar con el tiempo suficiente para ello. Cabe por tanto la posibilidad de que algunos de los profesores que afirmen utilizar un método de corrección en diferido (centrado en el producto o borrador final) lo hagan por decisión propia. Sin embargo, puede que exista un número de informantes a quienes las limitaciones propias de la falta de tiempo no les permitan utilizar un método de corrección inmediata centrado en el proceso.

\subsubsection{Análisis de los datos: número de alumnos de los informantes}

Las respuestas de los sujetos paricipantes en este ítem (considerando que uno de ellos no aportó respuesta) que ejercen su actividad docente en centros educativos de Valladolid se recogen en la Tabla 7 y en el Gráfico 7 que aparecen a continuación:

\begin{tabular}{|lrr|}
\hline Número de alumnos en el aula & $\begin{array}{c}\text { Numero de } \\
\text { respuestas }\end{array}$ & $\begin{array}{r}\text { Porcentaje } \\
0-15\end{array}$ \\
\hline $16-20$ & 1 & $9.38 \%$ \\
\hline más de 20 & 28 & $87.13 \%$ \\
\hline Total & 32 & $\mathbf{1 0 0 . 0 0 \%}$ \\
\hline
\end{tabular}

Tabla 7. Resultados sobre el número de alumnos en Valladolid 


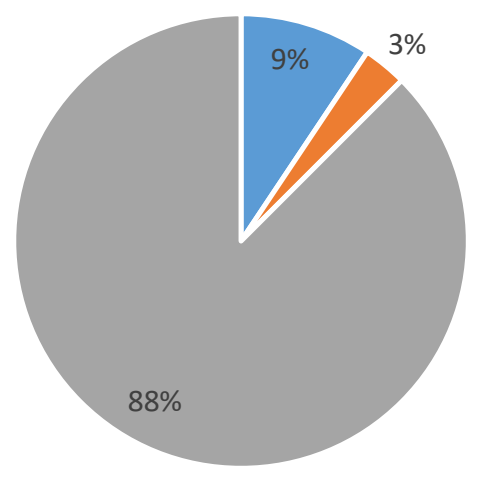

- $0-15$

- $16-20$

- más de 20

Gráfico 7. Resultados sobre el número de alumnos en Valladolid

En cuanto a la participación de los profesores en este ítem, nos encontramos ante 32 respuestas de un total de 33 informantes del contexto educativo de Valladolid. Observamos que la mayor parte de estos (88\%) cuenta con más de 20 alumnos en el aula. Solo un 9\% cuentan con menos de 16 alumnos y un 3\% tiene entre 16 y 20.

Los resultados obtenidos a partir de las respuestas de todos los informantes del contexto de Austin al ítem 4 (nos encontramos ante un 100\% de participación) se exponen en la Tabla 8 y el Gráfico 8 que se presentan a continuación.

\begin{tabular}{|lrrr|}
\hline Número de alumnos en el aula & Número de & & \\
respuestas & & Porcentaje \\
\hline $0-15$ & & 1 & $2.50 \%$ \\
\hline $16-20$ & & $25.00 \%$ \\
\hline más de 20 & & $72.50 \%$ \\
\hline Total & & $100.00 \%$ \\
\hline
\end{tabular}

Tabla 8. Resultados sobre el número de alumnos en Austin 


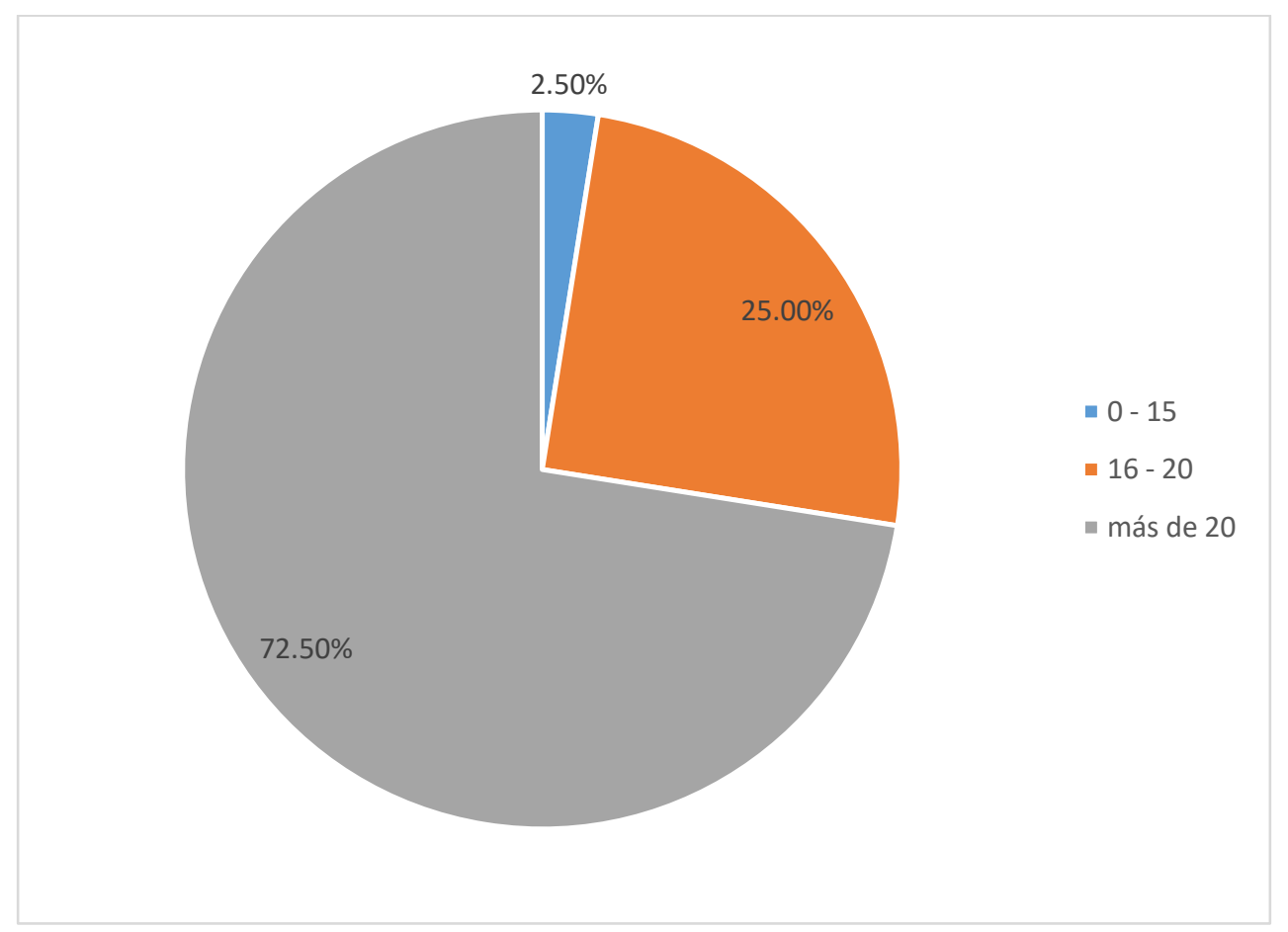

Gráfico 8. Resultados sobre el número de alumnos en Austin

En lo que respecta al contexto educativo de Austin, la mayoría de nuestros informantes cuentan también con más de 20 alumnos en el aula (el 72,5\%). Solo un 2,5\% de los profesores tiene menos de 16 alumnos y el 25\% cuenta con un número de alumnos comprendido entre los 16 $\mathrm{y} \operatorname{los} 20$. 


\subsubsection{Interpretación de los resultados: número de alumnos de los informantes}

El análisis de los dos contextos nos lleva a afirmar que una extensa mayoría de informantes tanto de la ciudad de Valladolid (88\%) como de la ciudad de Austin $(72,5 \%)$ cuenta con más de 20 alumnos en el aula. Nos encontramos ante porcentajes muy elevados en ambos contextos, aunque es el contexto vallisoletano el que presenta una cifra superior.

En Valladolid, encontramos un 9\% de profesores que tienen menos de 16 alumnos en su aula frente al 2,5\% de los profesores en Austin. Ambos son porcentajes muy significativos que señalan la existencia de un número muy reducido de clases que acogen esa cantidad de alumnos en los dos contextos.

En cuanto a los porcentajes de profesores cuyas aulas albergan entre 16 y 20 alumnos, encontramos un $3 \%$ en Valladolid frente al $25 \%$ de Austin, lo cual indica que es mucho más habitual encontrar aulas con una capacidad media de alumnos en los centros educativos de Austin respecto a los de Valladolid.

En definitiva, las cifras nos permiten afirmar que en los dos contextos educativos que estamos analizando, la cantidad de alumnos por aula es muy elevada (en la mayoría de los casos, superior a 20), si bien los informantes que cuentan con un mayor número de estudiantes son aquellos que ejercen su actividad docente en Valladolid. 
El conjunto constituido por los ítems 1, 2, 3 y 4 que denominamos "perfil del informante" fueron incluidos con el objetivo de recopilar la información que precisábamos en torno a los años de experiencia, la edad, el curso o nivel educativo en el que nuestros informantes ejercen su actividad docente y el número de alumnos con el que cuentan en el aula. Consideramos que el análisis de los datos correspondientes al perfil del informante podrá aportar a nuestra investigación información relevante en torno a la valoración que tienen que los profesores de Educación Primaria respecto al error en el desarrollo de actividades de producción escrita de los alumnos de L2.

\subsection{Interpretación de los resultados. Perfil de los informantes}

Las conclusiones que se desprenden de los datos obtenidos son: en ambos contextos educativos nos encontramos ante una mayoría de informantes con 10 - 19 años de experiencia, tienen entre 30 y 45 años de edad, ejercen su actividad docente en cursos de $3^{\circ}$ a $6^{\circ}$ de Primaria (en el caso de Valladolid) y de $3^{\circ}$ a $5^{\circ}$ de Primaria (en el caso de Austin) y cuentan en su clase con un número de alumnos superior a 20. Nos encontramos, por tanto, ante contextos educativos muy similares. Sin embargo, como hemos podido observar, los informantes de Valladolid cuentan con una trayectoria profesional docente más larga que los informantes de los centros educativos de Austin (ya que el porcentaje de profesores con más de 20 años de experiencia es ligeramente superior), tienen una edad más avanzada (el porcentaje de informantes con más de 45 años es superior) y cuentan en sus aulas con un mayor número de alumnos (puesto que el porcentaje correspondiente a clases con 16-20 alumnos es inferior respecto a Austin). 
Los informantes de nuestra muestra intencional imparten docencia a grupos de alumnos de edades tempranas y preadolescentes. Como ya mencionábamos en el epígrafe 3.1 situándonos en la perspectiva de Solias Arís (2007), este tipo de alumnado aprende una L2 a través de un proceso de adquisición lingüística inconsciente por lo que, el error ha de ser utilizado como una herramienta que permite al profesor identificar las dificultades de los alumnos sin que ellos lo perciban. Ante un proceso de este tipo, se impone una corrección implícita e inmediata a través de la cual, el profesor dirija la atención del alumno hacia sus propios errores concediéndole la posibilidad de localizarlos y, posteriormente, corregirlos. El aprendizaje de una L2 en edades tempranas se lleva a cabo de una forma instintiva, por lo que, una corrección explícita del error en el que este sea marcado y/o sancionado podría generar un sentimiento de confusión en el alumno y provocar el bloqueo por parte del mismo.

Junto a la importancia de proporcionar un determinado tipo de corrección del error en edades tempranas mencionábamos en el epígrafe 3.2.2 la importancia de aportar un feedback personalizado que, preferentemente debe manifestarse en su forma oral, aunque puede ir complementado con algunos comentarios escritos en forma de notas breves. Los alumnos en edades tempranas podrán ser capaces de aprender a partir de sus propios errores siempre que la corrección se lleve a cabo de una manera inmediata y el feedback sea proporcionado de una forma lo más cercana posible. El profesor, como ya indicábamos en el epígrafe 3.2.2, incluirá algunas sugerencias en cuanto a la forma y al contenido del texto que acompañará con frases de apoyo que le permitan acercarse al alumno y crear una atmósfera agradable en el aula que apoye un tipo de enseñanza interactiva en la que el alumno sienta que está siendo parte importante del propio proceso de corrección. 
Otro de los rasgos que cabe mencionar es la importancia de una actitud de apertura por parte del profesor hacia las producciones escritas en general y hacia el error en particular, especialmente ante alumnos de edades tempranas. Desde esta consideración, se impone que el profesor utilice en el aula ejercicios que motiven al alumno con el propósito de que este mantenga una actitud positiva hacia el aprendizaje de la L2. Para ello, deberá recurrir a metodologías que favorezcan una actitud positiva hacia la lengua, fomentar el placer por la lectura de textos y hacer ver al alumno la importancia de la interacción escrita en una L2. Una metodología basada en el Análisis de Errores (AE) que describíamos en el epígrafe 3.1.1., el cual, de acuerdo con Santos Gargallo (1994) evolucionó hacia una valoración de estos en función de su impacto en la comunicación. Un análisis de errores que, en palabras de Alexopoulou (2010), proporciona al profesor la posibilidad de reconocer las necesidades que tienen los alumnos en la etapa de desarrollo lingüístico en la que se encuentran para poder, posteriormente, trabajar a partir de estas.

Dentro de este marco, teniendo en cuenta los cursos académicos en los que se ejercen su actividad nuestros informantes, consideramos que el enfoque metodológico de tratamiento de error más factible en los dos contextos educativos es el denominado "process-oriented pedagogy" al que Ferris y Hedgcock (1998, p. 197) hacen referencia en su obra como metodología de enseñanzaaprendizaje de expresión escrita en L2. Una metodología centrada en el proceso o producción del texto escrito que, tal y como mencionábamos en el epígrafe 1.1.3 de esta Tesis Doctoral, propone una mayor concienciación sobre la corrección de errores y pone de relieve el planteamiento de la integración del error en el proceso de enseñanza de una L2. 



\section{Capítulo 6. COMPONENTE COMPETENCIAL I: CONOCIMIENTOS SOBRE EL ERROR, LA CORRECCIÓN Y EL FEEDBACK}

6.1. Aspectos generales en torno al componente competencial I: conocimientos

6.2. Conocimientos sobre la actitud que muestra el alumno hacia una actividad de escritura dirigida en L2

6.3. Conocimientos sobre la actitud que muestra el alumno hacia una actividad de escritura libre en L2

6.4. Conocimientos sobre la reacción de los alumnos ante la ayuda ofrecida

6.5. Conocimientos sobre la utilidad de las actividades de expresión escrita libre en L2

6.6. Conocimientos acerca del momento idóneo para la corrección de las producciones escritas en L2

6.7. Conocimientos sobre los tipos de errores que deben ser corregidos en las producciones escritas en L2

6.8. Interpretación de los resultados. Conocimientos sobre el error, la corrección y el feedback 


\subsection{Aspectos generales en torno al componente competencial I: conocimientos}

Cuando nos referimos a este componente competencial, hacemos referencia a aquellos conocimientos que tiene el informante sobre:

- La actitud que muestra el alumno hacia las actividades de escritura dirigida en L2.

- La actitud que muestra ante las actividades de escritura libre en L2.

- La reacción de los alumnos ante la ayuda ofrecida.

- La utilidad que presentan dichas actividades.

- El momento idóneo para la corrección de las producciones escritas en L2.

- La tipología de errores que deben ser corregidos.

Como se muestra en el Cuadro 4, los ítems que nos proporcionarán información con respecto a los conocimientos en torno al error, la corrección y el feedback son: 


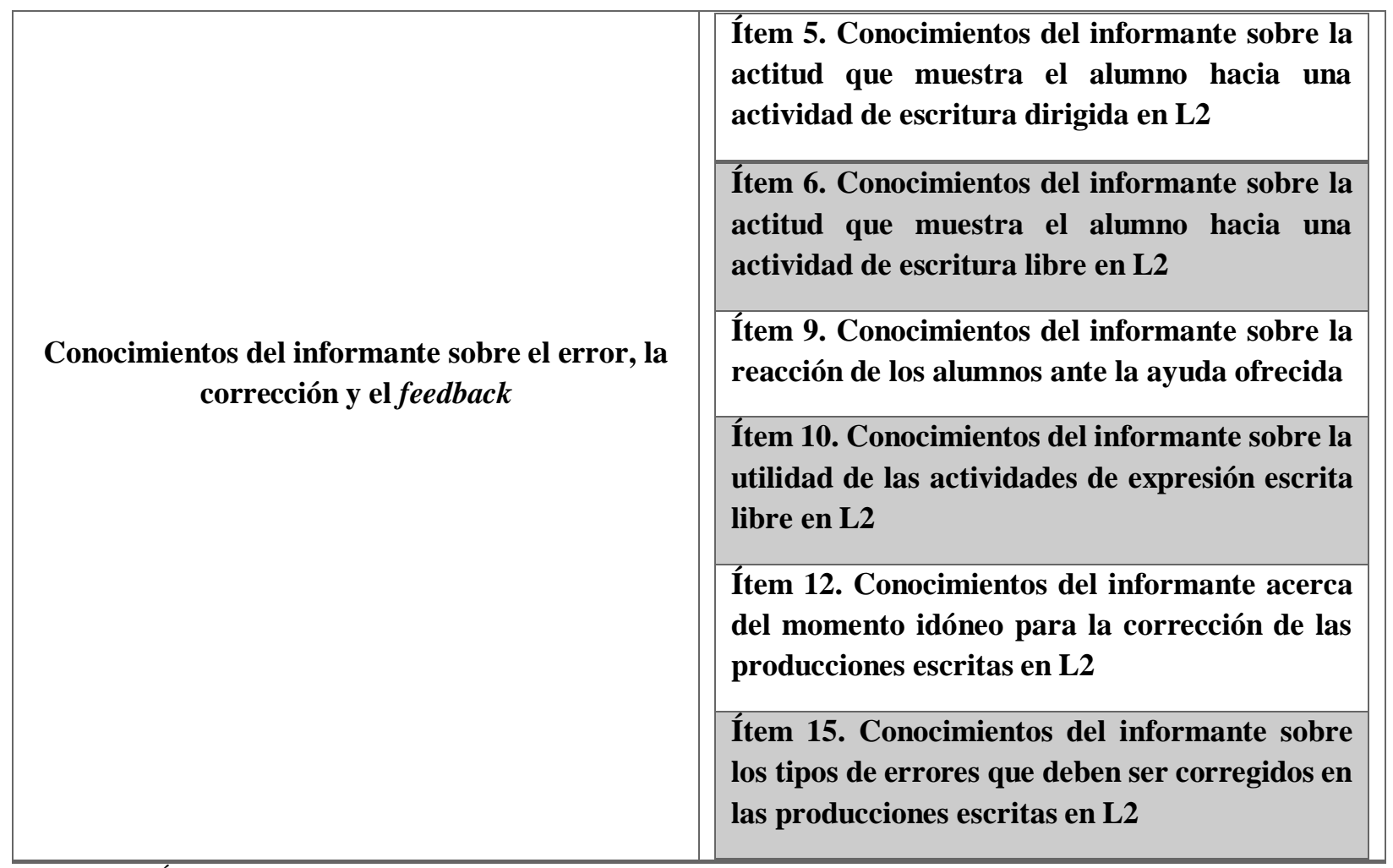

Cuadro 4. Ítems de los cuestionarios dirigidos a la recopilación de información acerca de los conocimientos del informante

Las respuestas a los ítems incluidos en esta categoría de análisis y presentados en la Cuadro 4 nos aportarán información relacionada con los conocimientos de los informantes sobre el papel del error, la corrección y el feedback en las producciones escritas de alumnos de L2. En este sentido, los datos que nos disponemos a analizar, forman parte del componente competencial "conocimientos". 


\subsection{Conocimientos sobre la actitud que muestra el alumno hacia una actividad de escritura dirigida en $\mathrm{L} 2$}

Desde nuestra experiencia profesional docente, estimamos que los profesores deben contar con una serie de conocimientos en torno a la actitud que muestran los alumnos hacia una actividad de escritura dirigida en L2. Dichos conocimientos vendrán determinados por la experiencia previa del profesor. Así pues, un profesor con varios años de experiencia que haya ejercido su actividad profesional con distintos grupos de alumnos, contará con un mayor conocimiento sobre ese tipo de actitudes. Consideramos por tanto que este aspecto está íntimamente relacionado con los años de experiencia del informante que encontrábamos en el epígrafe 5.2.

Los conocimientos del profesor sobre las actitudes típicas del alumno hacia las actividades de escritura dirigida en L2, consultado en el ítem número 5, podrá proporcionar información acerca de su proceso de planificación de las actividades de aula. Consideramos que el profesor diseñará las actividades de escritura dirigida que quiera llevar a cabo con los alumnos con los que cuenta en la actualidad a partir de sus experiencias previas como docente. Dichas experiencias previas determinarán la forma en que dichas actividades van a ser presentadas en el aula. Si el profesor ha percibido por parte de sus alumnos actitudes negativas hacia las actividades de escritura libre o dirigida en L2 en cursos anteriores, buscará una forma de presentación que pueda resultar atractiva e interesante acercándose siempre a los intereses de los alumnos. En definitiva, las respuestas de nuestros informantes podrán aportar información acerca del grado de implicación que tienen los profesores en las actividades de aula, así como el grado de interés por la evolución de sus alumnos en la clase de L2. 


\subsubsection{Análisis de los datos: conocimientos sobre la actitud que muestra el alumno hacia una actividad de escritura dirigida en $\mathrm{L2}$}

Analizamos los conocimientos de los informantes pertenecientes a centros educativos de Valladolid respecto al planteamiento de una actividad de escritura dirigida en L2. Los datos recogidos de este contexto educativo en el ítem 5 se muestran en la Tabla 9 y el Gráfico 9 que aparecen a continuación. Todos los informantes responden a este ítem por lo que el índice de participación es absoluto.

\begin{tabular}{|lrr|}
\hline $\begin{array}{l}\text { Ante una actividad de escritura dirigida, los alumnos muestran una } \\
\text { actitud: }\end{array}$ & $\begin{array}{r}\text { Número de } \\
\text { respuestas }\end{array}$ & $\begin{array}{r}\text { Porcentaje } \\
\hline \text { Positiva }\end{array}$ \\
\hline Negativa & $\mathbf{2 3}$ & $\mathbf{6 9 . 7 0 \%}$ \\
\hline De indiferencia & $\mathbf{1}$ & $\mathbf{3 . 0 3 \%}$ \\
\hline Otros: & $\mathbf{6}$ & $\mathbf{1 8 . 1 8 \%}$ \\
\hline Depende de muchos factores & 1 & $\mathbf{9 . 0 9 \%}$ \\
\hline Muestran dificultad & 1 & $3.03 \%$ \\
\hline Desinterés & 1 & $3.03 \%$ \\
\hline Total & 1 & $3.03 \%$ \\
\hline
\end{tabular}

Tabla 9. Resultados sobre la actitud de los alumnos ante una actividad de escritura dirigida en Valladolid 


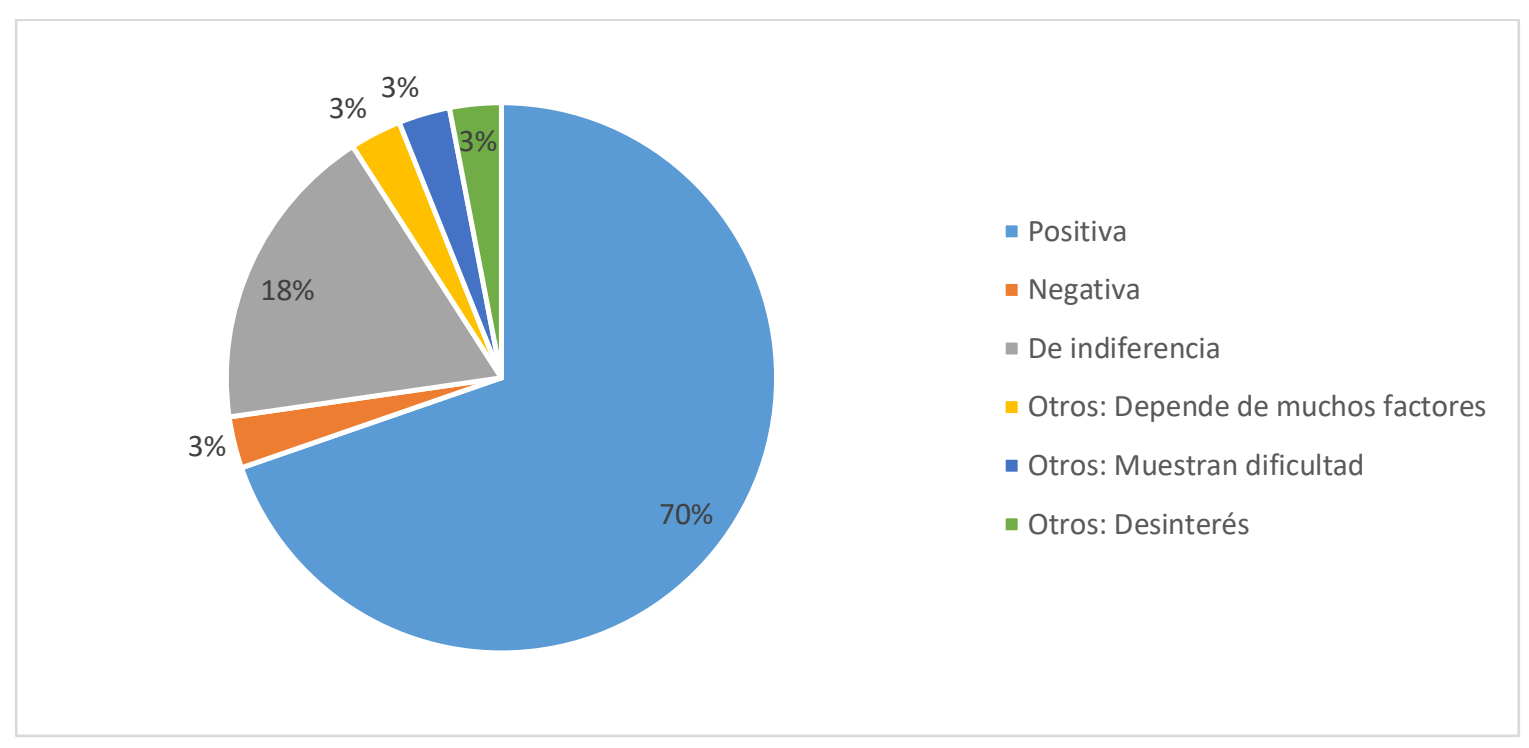

Gráfico 9. Resultados sobre la actitud de los alumnos ante una actividad de escritura dirigida en Valladolid

Se puede observar un alto porcentaje $(70 \%)$ de informantes que afirman que sus alumnos muestran una actitud positiva ante este tipo de actividades. Además, tan solo el 3\% declara que los alumnos muestran una actitud negativa. Estos datos nos permiten inferir que, en general, los alumnos se sienten cómodos y seguros ante una actividad de escritura dirigida a pesar de que un 18,18\% afirma que sus alumnos muestran indiferencia hacia este tipo de actividades.

Cabe mencionar la presencia de un 9,09\% de informantes que, habiendo escogido la opción que aparece bajo el título "otros" ha decidido ampliar la información respecto a la actitud de los alumnos ante una actividad de escritura dirigida. Estas aportaciones, como ya mencionábamos en el epígrafe 4.4.2, aparecerán agrupadas bajo el formato "otros" y separadas del resto de opciones propuestas a los informantes.

En la primera de estas opciones, el informante declara que existen muchos factores que determinan el tipo de actitud que mostrará el alumno hacia la actividad de escritura dirigida. Cabe 
la posibilidad de que nuestro informante se refiera a factores como el momento del día en que se lleve a cabo la actividad, la motivación del alumno o la forma en que se presente dicha actividad entre otros. La segunda respuesta hace alusión a la dificultad que presentan los alumnos y la tercera al desinterés mostrado hacia este tipo de actividades, puede que ambas respuestas estén relacionadas también con una falta de motivación por parte de los alumnos. Es posible que esta venga provocada por una forma de presentación de las actividades no adaptada al nivel de los alumnos y, por tanto, poco atractiva que puede desembocar en un sentimiento de temor o en una falta de interés por parte del alumno hacia este tipo de actividades.

En relación al planteamiento de una actividad de escritura dirigida en L2 en los centros educativos de la ciudad de Austin, recibimos los datos que se muestran en la Tabla 10 y el Gráfico 10 que aparecen a continuación. Los porcentajes se calculan a partir de las respuestas de todos nuestros informantes (que forman un total de 40).

\begin{tabular}{|lrr|}
\hline $\begin{array}{l}\text { Ante una actividad de escritura dirigida, los alumnos muestran una } \\
\text { actitud }\end{array}$ & $\begin{array}{r}\text { Número de } \\
\text { respuestas }\end{array}$ & $\begin{array}{r}\text { Porcentaje } \\
\hline \text { Positiva }\end{array}$ \\
\hline Negativa & 29 & $\mathbf{7 2 . 5 0 \%}$ \\
\hline De indiferencia & $\mathbf{2}$ & $\mathbf{5 . 0 0 \%}$ \\
\hline Otros: & $\mathbf{7}$ & $\mathbf{1 7 . 5 0 \%}$ \\
\hline Depende de su estado de ánimo & 2 & $\mathbf{5 . 0 0 \%}$ \\
\hline Depende de cada estudiante & 1 & $2.50 \%$ \\
\hline Total & 1 & $2.50 \%$ \\
\hline
\end{tabular}

Tabla 10. Resultados sobre la actitud de los alumnos ante una actividad de escritura dirigida en Austin 


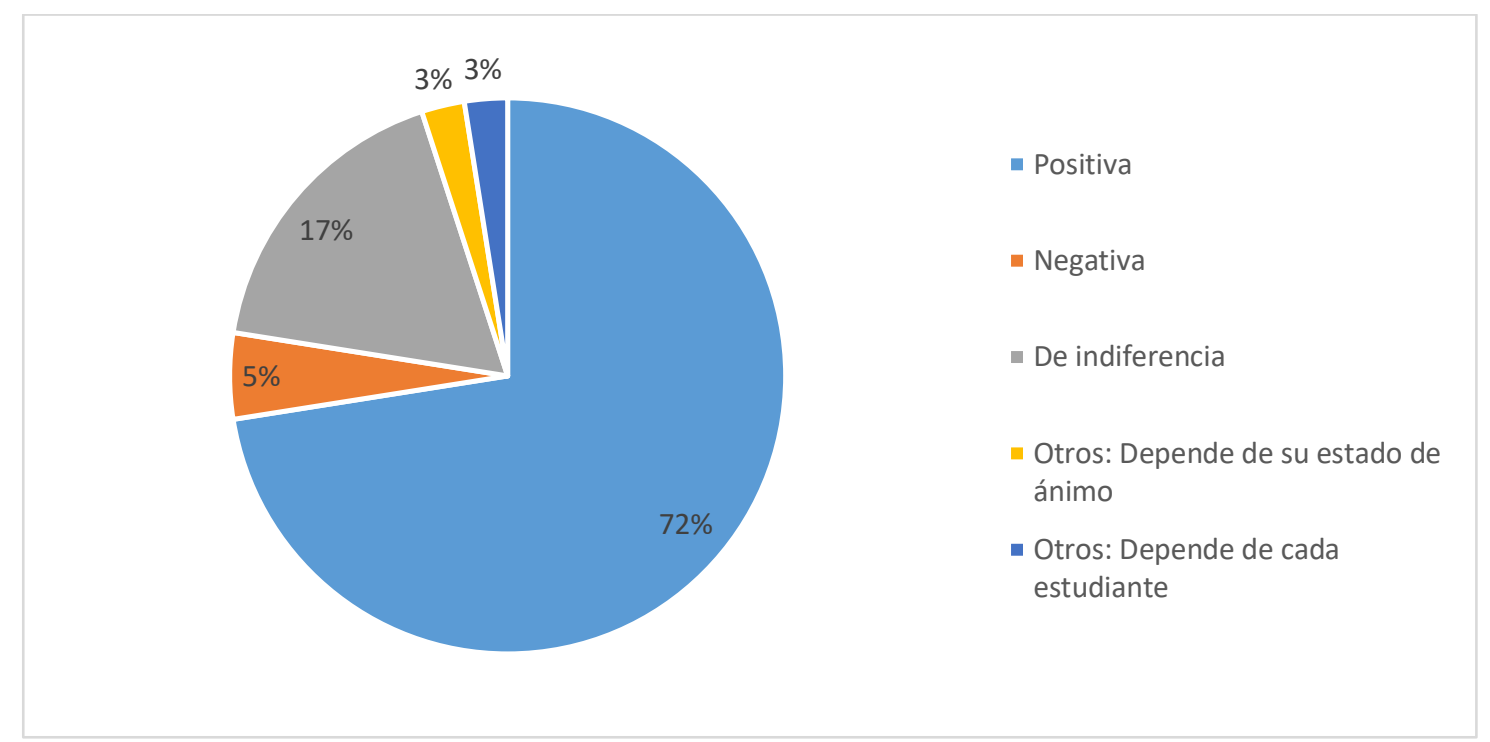

Gráfico 10. Resultados sobre la actitud de los alumnos ante una actividad de escritura dirigida en Austin

Podemos observar que el porcentaje de informantes que señala la existencia de una actitud positiva por parte de los alumnos también es amplio: $72 \%$. Solo un 5\% afirma que presentan actitudes negativas y un $17 \%$ considera que los alumnos manifiestan indiferencia.

Existe un 5\% correspondiente a dos informantes que decidieron escoger la opción "otros" añadiendo información al respecto. El primero de ellos afirma que es el estado de ánimo del alumno lo que influye en su actitud hacia ese tipo de actividades y el otro menciona la propia personalidad de cada uno de ellos como factor principal. De nuevo, nuestros informantes mencionan la existencia de distintos factores que ejercen una gran influencia en el alumno. 


\subsubsection{Interpretación de los resultados: conocimientos sobre la actitud que muestra el alumno hacia una actividad de escritura libre en L2}

Los resultados de los dos contextos educativos muestran que los estudiantes, en general, presentan una actitud positiva ante las actividades de escritura dirigida. El porcentaje de Valladolid es de $70 \%$ frente al $72 \%$ de Austin. En cuanto a actitudes negativas, de nuevo encontramos resultados muy similares: un 3\% en Valladolid frente al 5\% de Austin. Las actitudes de indiferencia son de un $18 \%$ en Valladolid frente al $17 \%$ de Austin.

Además, los informantes que han optado por ampliar la información eligiendo la opción "otros" coinciden en señalar que existen determinados factores que influyen en la actitud del alumno hacia este tipo de actividades. Nos atrevemos a suponer, a partir de las aportaciones de dos de los informantes de Valladolid que afirman que los alumnos muestran desinterés y dificultad que algunos profesores perciben la existencia de desmotivación por parte de sus alumnos provocada posiblemente por una forma poco atractiva de presentación de las actividades. Cabe la posibilidad de que este porcentaje de profesores no cuente con los conocimientos necesarios respecto a la forma de acercarse a los alumnos y de presentar este tipo de actividades por no tener experiencia docente.

Esta actitud positiva manifestada por los alumnos de ambos contextos nos hace pensar que los profesores de los dos contextos educativos en general, cuentan con conocimientos relacionados con la forma de planteamiento de las actividades de escritura dirigida. Dichos conocimientos puede haberlos adquirido durante su periodo de formación o bien a partir de sus experiencias previas como docente. Por otro lado, podría ser que esta actitud positiva pueda venir determinada por el 
nivel bajo de riesgo a cometer errores, puesto que, ante una actividad de escritura dirigida, los alumnos sienten un mayor grado de seguridad a la hora de producir.

Analizadas las respuestas, concluimos que, en función de los resultados obtenidos en el ítem 5 del cuestionario, los informantes de los contextos educativos de Valladolid y Austin muestran un conocimiento preciso de las actitudes típicas de los alumnos hacia las actividades de escritura dirigida y, en este sentido, diseñan actividades y utilizan una forma de presentación que pueda resultar atractiva y cercana a los intereses de los alumnos. En definitiva, podemos constatar la existencia de un alto grado de implicación de nuestros informantes en este tipo de actividades en el aula de L2.

\subsection{Conocimientos sobre la actitud que muestra el alumno hacia una actividad de escritura libre en L2}

Asimismo, nos interesa conocer la actitud que muestran los alumnos hacia una actividad de escritura libre en L2, aspecto que incluimos en el ítem número 6. El nivel de conocimientos del profesor acerca de las actitudes que muestran los alumnos hacia este tipo de actividades también aportará información sobre su grado de implicación en el diseño de actividades para las futuras clases y el uso que hace de herramientas que estimulen a los alumnos a ser partícipes de la actividad. El conocimiento acerca de las reacciones típicas de los alumnos ante un tipo de actividad concreto es un aspecto de gran relevancia en el aula. El profesor tomará conciencia del tipo de actividad a la que se enfrenta en el momento de planificación y, en virtud de ello, buscará la mejor 
forma de presentarla ante sus alumnos eligiendo también el momento más propicio para llevarla al aula.

Estimamos conveniente marcar la diferencia entre una actividad de escritura dirigida y una actividad de escritura libre en L2. Así pues, las actividades de escritura dirigida son aquellas que buscan que el alumno sea capaz de interrelacionar lectura, oralidad y escritura. Sin embargo, cuando hablamos de actividades de escritura libre hacemos referencia, de acuerdo con Cantero Serena y Mendoza Fillola (2003) a "la elaboración de un texto completo, que se baste a sí mismo, lingüísticamente correcto" (p. 53). Los mencionados autores hablan de la destreza de expresión escrita como sinónimo de composición escrita. Dicha destreza "equivale no a «transcribir/codificar» sino a «redactar»» (Cantero Serena \& Mendoza Fillola, p. 52). Algunos ejemplos de actividades de escritura dirigida son resúmenes, dictados, construcción de frases o párrafos a partir de una determinada estructura gramatical, actividades de recopilación de secuencias que ellos deben ordenar y ampliar para formar una historia, etc. Los alumnos muestran diferentes actitudes hacia los distintos tipos de actividades por lo que es responsabilidad del profesor conocer las características específicas que las definen. El grado de conocimiento del profesor respecto a las diferencias existentes entre ambas, influirá de forma relevante en su aptitud y su actitud en cuanto al diseño de las distintas actividades y su presentación en el aula.

Por otra parte, Vez et al. (2002) afirmaban que, a la hora de enfrentarse a la elaboración de una producción escrita, el alumno "pone en funcionamiento determinados mecanismos, que le permiten pasar por unos esquemas sucesivos del conocimiento hasta integrar plenamente la información, siguiendo una serie de momentos o fases" (p. 155). No obstante, como ya 
apuntábamos en el epígrafe 3.2, las actividades de producción escrita dentro del contexto del aula de L2 se limitan, en algunos casos, a una redacción guiada en la que no se ofrece al alumno suficiente input comprensible y variado como para que pueda elaborar un texto de calidad por sí mismo. Así pues, a la hora de proponer una actividad de producción escrita autónoma, corresponde al profesor plantearse una serie de interrogantes respecto a los mecanismos que el alumno pone en marcha a la hora de aprender, los factores que intervienen, los conocimientos previos, sus intenciones y sus comportamientos de aprendizaje.

\subsubsection{Análisis de los datos: conocimientos sobre la actitud que muestra el alumno hacia una actividad de escritura libre en L2}

Los resultados en torno a los conocimientos de los informantes que se inscriben dentro del contexto educativo de Valladolid sobre las actitudes típicas de los alumnos hacia las actividades de escritura libre en L2 se muestran en la Tabla 11 y en el Gráfico 11. Como podemos observar, 2 de los informantes no han participado y, por tanto, no han aportado su respuesta. 


\begin{tabular}{lrr} 
& Número de & \\
Ante una actividad de escritura libre, los alumnos muestran una actitud: & respuestas & Porcentaje \\
\hline Positiva & 15 & $\mathbf{4 8 . 3 9 \%}$ \\
\hline Negativa & 6 & $\mathbf{1 9 . 3 5 \%}$ \\
\hline De indiferencia & $\mathbf{5}$ & $\mathbf{1 6 . 1 3 \%}$ \\
\hline Otros: & $\mathbf{5}$ & $\mathbf{1 6 . 1 3 \%}$ \\
\hline Depende & 1 & $3.23 \%$ \\
\hline Muestran desidia & 1 & $3.23 \%$ \\
\hline Se muestran desconcertados & 1 & $3.23 \%$ \\
\hline Temor e indecisión & 1 & $3.23 \%$ \\
\hline Se sienten un poco perdidos, necesitan un poco de orientación & 1 & $3.23 \%$ \\
\hline Total & 31 & $\mathbf{1 0 0 . 0 0 \%}$ \\
\hline
\end{tabular}

Tabla 11. Resultados sobre la actitud de los alumnos ante una actividad de escritura libre en Valladolid

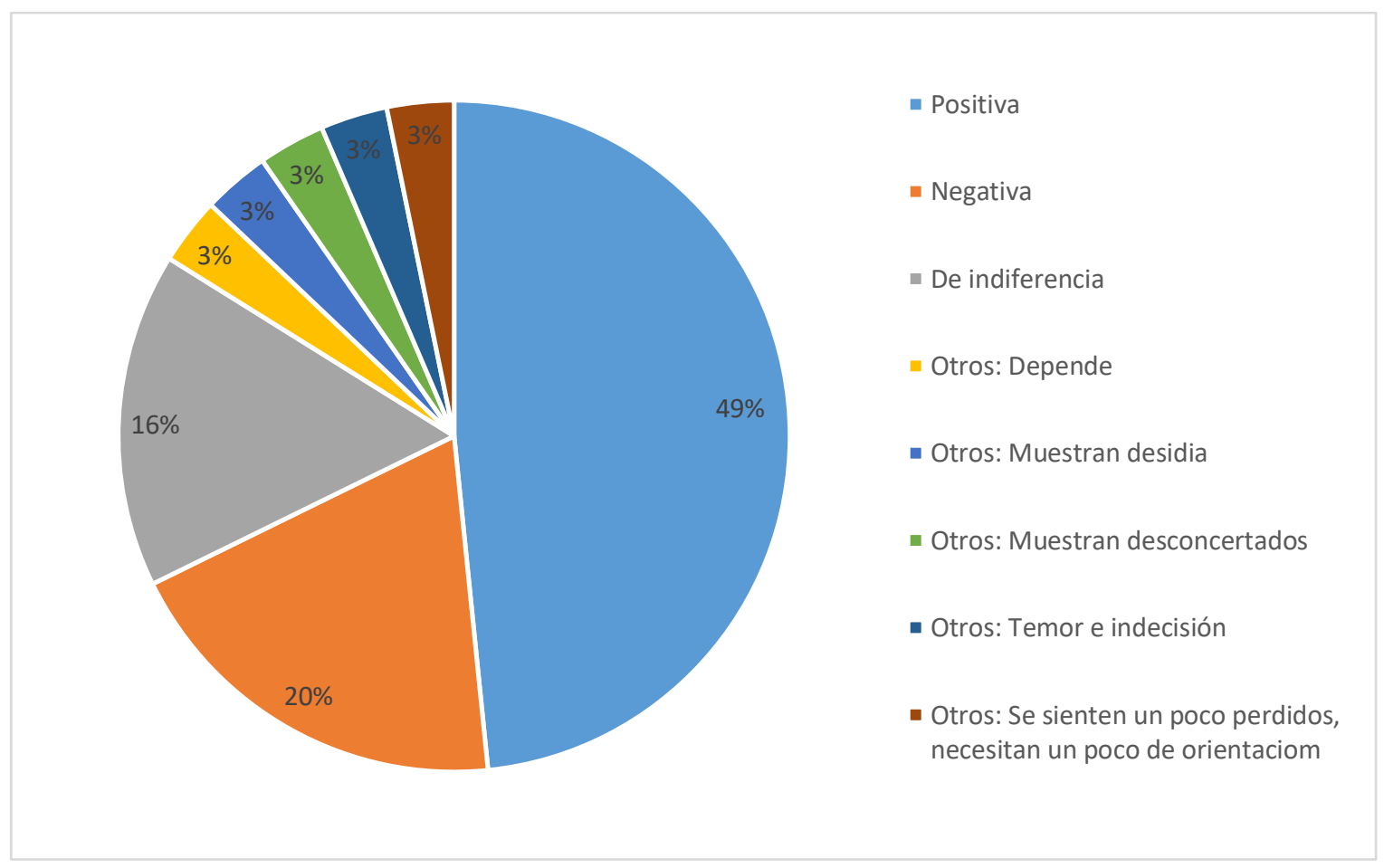

Gráfico 11. Resultados sobre la actitud de los alumnos ante una actividad de escritura libre en Valladolid

Según los datos obtenidos de los 31 participantes ( 2 de ellos decidieron no responder), alrededor del $49 \%$ afirma que los alumnos muestran una actitud positiva hacia las actividades de 
escritura libre en L2. Sin embargo, existe un 20\% (aproximadamente) que se sitúa en el polo opuesto señalando la presencia de una actitud negativa y un $16 \%$ que declara que los alumnos presentan una actitud de indiferencia.

El porcentaje de profesores que optaron por la respuesta: "otros" es de un 16\%. Dentro de esta opción, encontramos a un informante según el cual, la actitud mostrada depende del propio alumno. A partir de esta respuesta podemos inferir que cada estudiante presenta un tipo diferente de actitud hacia estas actividades y que, según este profesor, no existe una opinión generalizada desde el punto de vista de los alumnos. Asimismo, la respuesta por parte de otro informante indica que los alumnos muestran desidia, pereza y/o falta de interés hacia este tipo de actividades. Las siguientes aportaciones de tres informantes que eligieron la opción "otros" exponen que estos se muestran desconcertados, muestran temor e indecisión y se encuentran perdidos cuando son expuestos ante este tipo de actividades. Estas tres últimas respuestas demuestran que, según estos profesores, los alumnos presentan un alto nivel de dificultad a la hora de realizar una producción escrita libre por su cuenta y, cuando se tienen que enfrentar a este tipo de actividades, muestran temor, indecisión, desorientación, etc. Las respuestas ponen de manifiesto la complejidad de este tipo de actividades por cuanto que los informantes consideran que los alumnos necesitan orientación previa por parte del profesor. Podríamos asociar estos sustantivos (temor, indecisión) y adjetivos (desconcertados, perdidos) mencionados por los informantes en sus respuestas con una sensación de inseguridad que acompaña al alumno cuando se dispone a realizar una producción escrita libre en L2. Dicha inseguridad puede estar motivada por el temor a cometer errores, así como por la forma en que el profesor plantea dichas actividades. Cabe la posibilidad de que a estos alumnos no se les haya proporcionado las estrategias necesarias ni el suficiente input comprensible 
y variado como para hacerles sentir que pueden elaborar un texto de manera autónoma. Entendemos por input los datos que los alumnos reciben (tanto en forma oral como escrita) cuando están en contacto con la lengua que aprenden.

Los resultados respecto al planteamiento de una actividad de escritura libre en L2 en los centros educativos de la ciudad de Austin se exponen en la Tabla 12 y el Gráfico 12. En estos se aprecia una participación del número total de informantes (40).

\begin{tabular}{|lrr|}
\hline Ante una actividad de escritura libre, los alumnos muestran una actitud & $\begin{array}{r}\text { Número de } \\
\text { respuestas }\end{array}$ & $\begin{array}{r}\text { Porcentaje } \\
\hline \text { Positiva }\end{array}$ \\
\hline Negativa & $\mathbf{2 9}$ & $\mathbf{7 2 . 5 0 \%}$ \\
\hline De indiferencia & $\mathbf{2}$ & $\mathbf{5 . 0 0 \%}$ \\
\hline Otros: & $\mathbf{5}$ & $\mathbf{1 2 . 5 0 \%}$ \\
\hline Muestran confusión & $\mathbf{4}$ & $\mathbf{1 0 . 0 0 \%}$ \\
\hline Muestran emoción e incertidumbre: todavía están descubriendo que & 1 & $2.50 \%$ \\
\hline pueden expresar sus sentimientos en papel & & \\
\hline Depende de su estado de ánimo & 1 & $2.50 \%$ \\
\hline Depende del estudiante & 1 & $2.50 \%$ \\
\hline Total & 1 & $2.50 \%$ \\
\hline
\end{tabular}

Tabla 12. Resultados sobre la actitud de los alumnos ante una actividad de escritura libre en Austin 

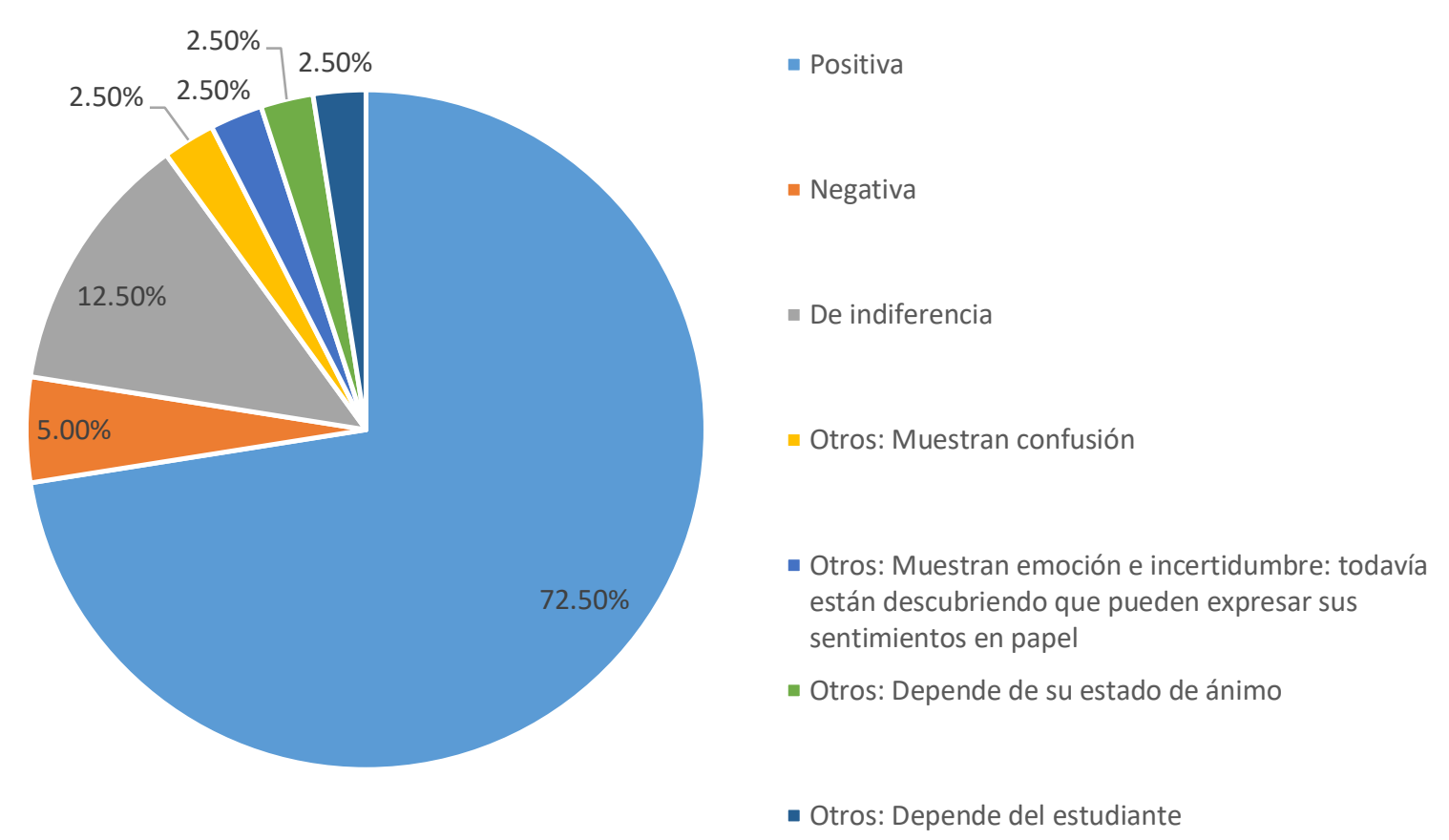

Gráfico 12. Resultados sobre la actitud de los alumnos ante una actividad de escritura libre en Austin

En el caso de Austin, los datos muestran un $72 \%$ de informantes que manifiestan encontrar actitudes positivas en los alumnos. Solo un 5\% declara que las actitudes son negativas y el $12 \%$ considera que sus alumnos presentan una actitud de indiferencia ante estas actividades.

Existe un 10\% de informantes que, habiendo elegido la opción “otros" añade información adicional. Dentro de este grupo, encontramos una diversidad de respuestas respecto al tipo de actitud. En primer lugar, nos encontramos ante un informante cuya declaración coincide con las tres últimas respuestas del grupo "otros" en la ciudad de Valladolid. En este sentido, podemos relacionar la confusión con el hecho de que el alumno se encuentre desconcertado, perdido, muestre temor e indecisión ante este tipo de actividades. En definitiva, consideramos que dicha 
confusión viene también provocada por la misma sensación de inseguridad que presentan los alumnos cuando no cuentan con las estrategias necesarias para crear un texto de manera autónoma. El siguiente informante dentro del grupo "otros" afirma que los estudiantes muestran una actitud de emoción e incertidumbre puesto que empiezan a descubrir que pueden expresar sus sentimientos en papel. Nos encontramos ante una respuesta que nada tiene que ver con la anterior ya que, en este caso, el informante afirma que sus alumnos muestran una actitud positiva. Es posible que dicho profesor, a la hora de presentar este tipo de actividades ante los alumnos, les inculque la idea de que la escritura se ha de entender como un mensaje subjetivo, cargado de emoción. Las dos últimas respuestas de este bloque "otros" insisten en la existencia de distintas actitudes hacia este tipo de actividades en función del alumno y en función de su estado de ánimo.

\subsubsection{Interpretación de los resultados: conocimientos sobre la actitud que muestra el alumno hacia una actividad de escritura libre en L2}

Todos estos resultados nos permiten afirmar que, en la ciudad de Valladolid, aproximadamente la mitad de nuestros informantes consideran que las actitudes de los alumnos hacia este tipo de actividades son positivas. Por otro lado, el porcentaje de profesores que consideran que estas son negativas, es bastante elevado (20\%). A dicho porcentaje podríamos añadir las tres últimas respuestas incluidas en el grupo "otros" puesto que hacen alusión a elementos relacionados con una actitud negativa: desidia, temor, etc. Además, un 16\% considera que los alumnos muestran una actitud de indiferencia. 
Sin embargo, los porcentajes obtenidos a partir de los datos relativos a la ciudad de Austin difieren en gran medida de los datos de Valladolid. Así pues, alrededor de un $72 \%$ de los informantes de Austin declara que los alumnos muestran actitudes positivas, un 5\% considera que son negativas y un $12 \%$ señala que presentan indiferencia. Asimismo, encontramos en el grupo "otros" una respuesta que podemos relacionar con actitudes negativas: aquella que habla de confusión y otra que podemos relacionar con actitudes positivas (emoción) por parte de los alumnos.

Los resultados parecen indicar que, entre los alumnos de la ciudad de Valladolid se encuentra un número más elevado de actitudes negativas hacia las actividades de expresión escrita libre respecto a los alumnos de Austin. A partir de estos datos y de las aportaciones de aquellos informantes que decidieron ampliar la información en ambos contextos, nos atrevemos a suponer que los profesores de esta ciudad, a la hora de elaborar sus unidades didácticas, no planean ni diseñan actividades cercanas a los intereses de los alumnos, no buscan una forma atractiva de presentar este tipo de actividades ante los alumnos ni tampoco les proporcionan el input ni las herramientas necesarias que puedan ayudarlos o transmitir seguridad y confianza en sí mismos. Cabe la posibilidad de que dichos profesores no cuenten con la experiencia ni con la formación necesaria que les permita conocer las directrices que han de proporcionar al alumno. Cuando ellos afirman en un porcentaje tan amplio que sus alumnos muestran actitudes negativas, podemos inferir que dichos profesores entienden este tipo de actividades como la exposición del alumno ante una hoja en blanco instándoles a escribir de forma autónoma sin dirección. Es posible que estos alumnos elaboren un único borrador que será recogido y, posteriormente corregido por el 
profesor anotando sus correcciones y nota numérica en el mismo sin recibir ningún tipo de feedback oral que les permita rehacer el texto hasta conseguir un producto final.

También cabe la posibilidad de que los alumnos sientan temor a cometer errores en una actividad de escritura libre. Podría darse el caso de que los alumnos sean sancionados por cada error cometido. Dicha sanción puede estar relacionada directamente con un descenso en la nota final trimestral o en la nota de final de curso.

Analizadas las respuestas correspondientes al ítem 6 de los dos contextos concluimos, en función de los resultados que, los informantes de Austin demuestran conocer las actitudes típicas de los alumnos hacia las actividades de expresión escrita libre y, en este sentido, planean, diseñan actividades y utilizan una forma de presentación que pueda resultar atractiva y cercana a los intereses de los alumnos. En definitiva, podemos intuir la existencia de un mayor grado de implicación de nuestros informantes de Austin respecto a los informantes vallisoletanos en este tipo de actividades en el aula de L2.

\subsection{Conocimientos sobre la reacción de los alumnos ante la ayuda ofrecida}

El ítem número 9 nos aporta información acerca del nivel de conocimiento que tiene el profesor sobre las reacciones que presentan los alumnos ante la ayuda prestada cuando son expuestos ante una actividad de escritura (tanto libre como dirigida) en L2. Este conocimiento también está relacionado con el ítem número 1: años de experiencia que se enmarca dentro del 
perfil del informante. A través del presente ítem, nos proponemos investigar en qué medida los profesores conocen las reacciones típicas de los alumnos hacia la ayuda ofrecida. Estos conocimientos se manifiestan como indicadores que podrían determinar el nivel de confianza y el grado de apertura que muestran los profesores hacia los alumnos. En este acercamiento, partimos de la idea que mencionábamos en el epígrafe 3.2.2 en el que hacíamos referencia al factor situacional como uno de los factores, junto con la naturaleza del niño que ejercen una clara influencia en la evolución de la lengua escrita infantil. Dicho factor hace referencia a la situación en la que tiene lugar la adquisición de la lengua escrita y está íntimamente relacionado con el componente afectivo. Extraemos la idea de Salvador Mata (1997) respecto a que este componente influye de manera decisiva en la evolución de la lengua escrita infantil. En este factor se incluye la relación profesor-alumno y las actitudes de ambos. Reflexionamos sobre estos dos aspectos incluidos en dicho factor situacional concluyendo que incidirán de forma importante en la demanda de ayuda por parte del alumno. Así pues, el grado de cercanía que muestre el profesor hacia el alumno determinará las reacciones de este hacia la ayuda ofrecida.

En el epígrafe 3.2.2 de esta Tesis mencionábamos a Corpas y Madrid (2007) los cuales coincidían con el MCER (Consejo de Europa, 2002) en cuanto a que los alumnos deben ser capaces de buscar las estrategias y los recursos necesarios durante la fase de planificación de su producción escrita. Incluimos entre dichos recursos la solicitud de ayuda al profesor, al asistente de aula si lo hubiera o a los propios compañeros fomentando el trabajo cooperativo como técnica procesual. En nuestra opinión, los conocimientos del profesor respecto a la necesidad de una interacción en el aula entre alumno-profesor, alumno-asistente de aula o alumno-alumno durante el proceso de producción escrita, tendrán un papel determinante en las producciones de los alumnos. 
Los ítems 5, 6 y 9 están interconectados por cuanto que, todos ellos se han diseñado con el propósito de recopilar información relacionada con el grado de implicación del profesor en la enseñanza-aprendizaje de expresión escrita en L2. Las respuestas obtenidas aportarán información relacionada con el interés que muestra el profesor por conocer a sus alumnos, cuáles son sus actitudes o reacciones típicas ante determinadas prácticas o actividades, y, en definitiva, en qué medida dicho profesor ha realizado un ejercicio de reflexión ante la propia actividad docente desde el conocimiento profundo de las necesidades de sus alumnos.

Nos proponemos, por tanto, analizar las respuestas aportadas por los informantes de los dos contextos educativos al ítem número 9 de los cuestionarios.

\subsubsection{Análisis de los datos: conocimientos sobre la reacción de los alumnos ante la ayuda ofrecida}

Los datos obtenidos del contexto educativo de la ciudad de Valladolid (contando con que 6 de los 33 participantes no responden a este ítem) se muestran en la Tabla 13 y el Gráfico 13 que aparecen a continuación:

\begin{tabular}{|lrr|}
\hline & Número de & \\
\hline ¿Cómo reaccionan los estudiantes ante esa ayuda? & respuestas & Porcentaje \\
\hline La mayoría lo pide cuando lo necesita & 23 & $\mathbf{8 5 . 1 9 \%}$ \\
\hline La mayoría no pide ayuda e intenta realizar la actividad por su cuenta & 4 & $\mathbf{1 4 . 8 1 \%}$ \\
\hline Total & 27 & $100.00 \%$ \\
\hline
\end{tabular}

Tabla 13. Resultados sobre la reacción de los alumnos ante la ayuda ofrecida en Valladolid 


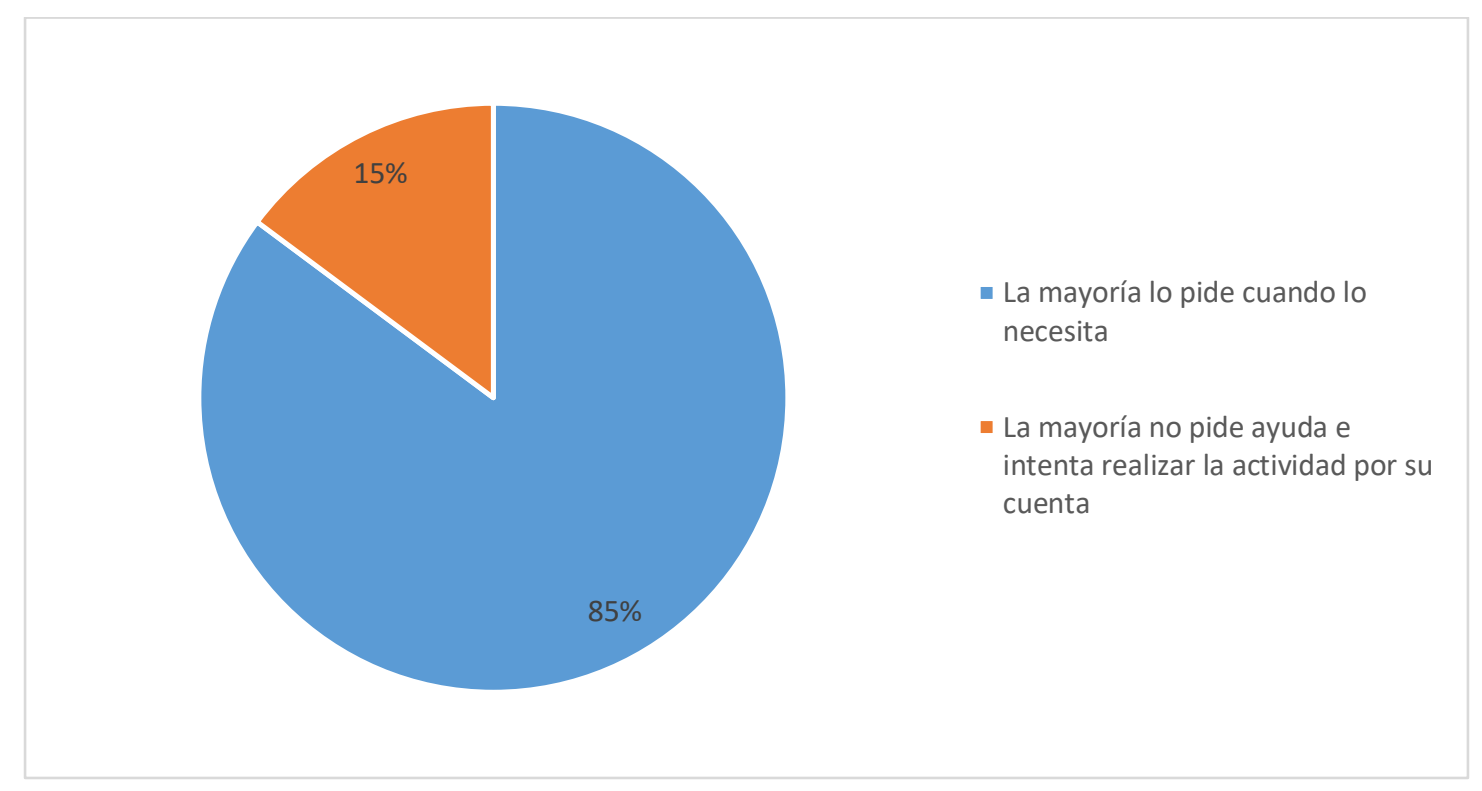

Gráfico 13. Resultados sobre la reacción de los alumnos ante la ayuda ofrecida en Valladolid

Como podemos observar, un elevado porcentaje de los 27 informantes vallisoletanos que responden a este ítem afirma que la mayoría de los alumnos, ante una actividad de escritura, solicita ayuda cuando lo necesitan (85\%). Por otro lado, existe un $15 \%$ que señala que estos no piden ayuda. Este elevado porcentaje muestra que, de acuerdo con la experiencia de los informantes, los alumnos suelen solicitar ayuda ante una actividad de escritura, posiblemente con el fin de evitar errores.

Los datos extraídos de las respuestas de los informantes que desarrollan su actividad docente en los centros educativos de Austin se muestran en la Tabla 14 y el Gráfico 14. Destacamos el hecho de que 2 de los informantes (de un total de 40) decidieron no responder al presente ítem. 


\begin{tabular}{|c|c|c|}
\hline ¿Cómo reaccionan los estudiantes ante esa ayuda? & $\begin{array}{l}\text { Número de } \\
\text { respuestas }\end{array}$ & Porcentaje \\
\hline La mayoría lo pide cuando lo necesita & 29 & $76.32 \%$ \\
\hline La mayoría no pide ayuda e intenta realizar la actividad por su cuenta & 7 & $18.42 \%$ \\
\hline Otros: & 2 & $5.26 \%$ \\
\hline $\begin{array}{l}\text { Los alumnos tienden a escribir por su cuenta, quizá el } 10 \% \text { pide ayuda. } \\
\text { terminar yo les corrijo, doy pautas y ellas/os hacen su copia final con mi } \\
\text { comentarios }\end{array}$ & 1 & $2.63 \%$ \\
\hline $\begin{array}{l}\text { Algunos la piden para terminar más rápido, otros prefieren hacerlo de } \\
\text { manera autónoma }\end{array}$ & 1 & $2.63 \%$ \\
\hline Total & 38 & $100.00 \%$ \\
\hline
\end{tabular}

Tabla 14. Resultados sobre la reacción de los alumnos ante la ayuda ofrecida en Austin 


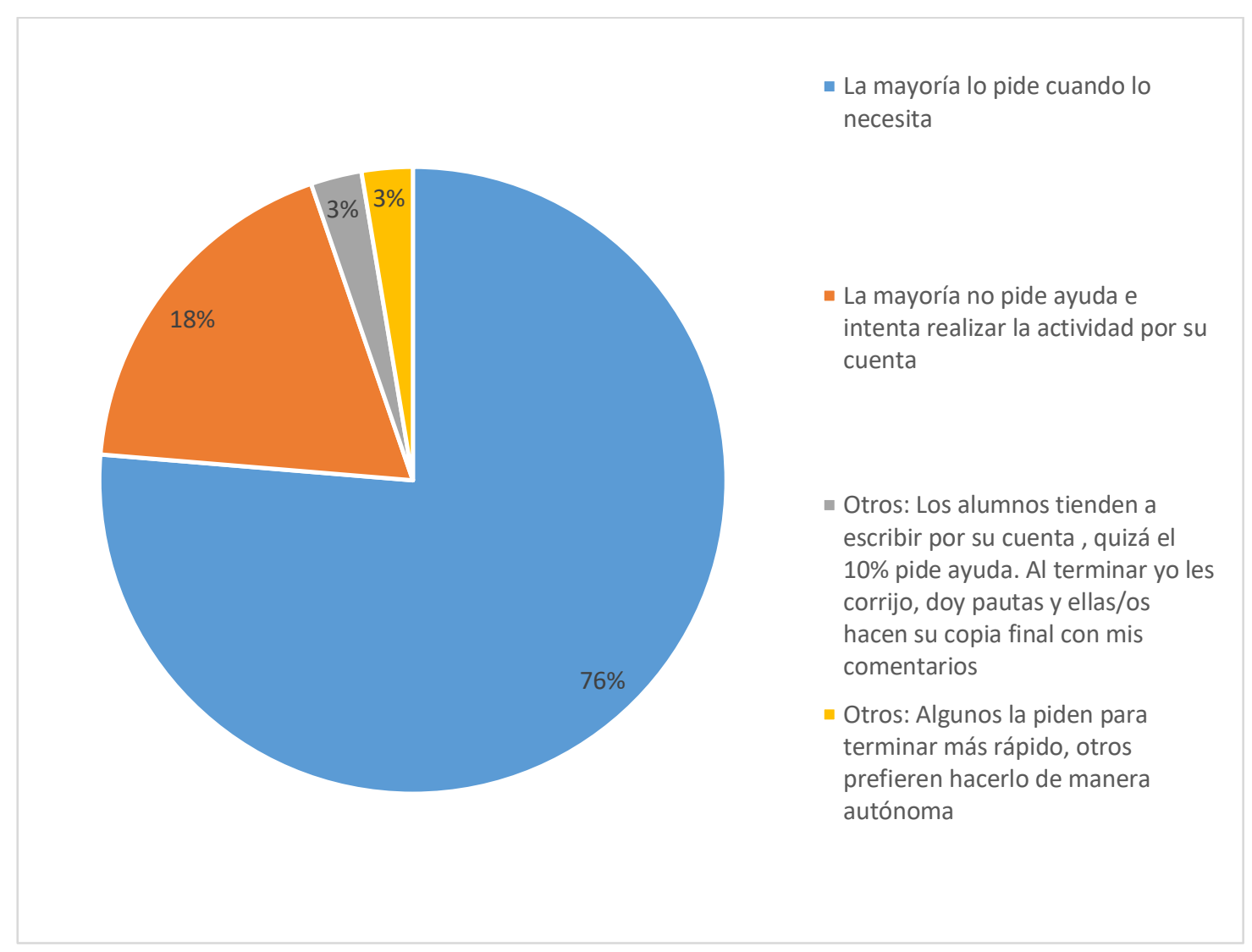

Gráfico 14. Resultados sobre la reacción de los alumnos ante la ayuda ofrecida en Austin

En cuanto a los porcentajes correspondientes a los 38 informantes del contexto educativo de Austin que contestaron al ítem número 9 del cuestionario encontramos que un $76 \%$ manifiesta que la mayoría de los alumnos pide ayuda cuando la necesita y un $18 \%$ declara que no la pide e intenta realizar la actividad por su cuenta. En cuanto a la opción "otros", encontramos a un informante que afirma que la mayoría no pide ayuda a lo que añade información acerca del proceso de corrección que lleva a cabo. En dicho proceso, es el mismo profesor quien proporciona pautas de actuación sin necesidad de que el alumno pida ayuda y, a partir de estas, deberá realizar un nuevo borrador. Consideramos que dicha respuesta ofrece información de gran relevancia ya que el profesor nos acerca al proceso de escritura de borradores encadenados que usa en su clase de 
L2. Consideramos que la intención de dicho informante ha sido resaltar el hecho de que los alumnos, generalmente tienden a escribir por su cuenta cuando se les solicita, pero es el profesor el encargado de actuar como guía y orientador dentro del proceso de escritura y el que, a partir de las pautas proporcionadas tras revisar el borrador, solicita al alumno rehacer el texto. Encontramos por tanto a un informante que afirma hacer uso de la técnica de borradores encadenados. En lo que concierne a la segunda aportación incluida en el apartado "otros", podemos inferir que el informante ha querido resaltar el hecho de que cada estudiante actúa de forma diferente en función de sus propias necesidades.

\subsubsection{Interpretación de los resultados: conocimientos sobre la reacción de los alumnos ante la ayuda ofrecida}

Nos encontramos ante resultados que presentan ciertas diferencias. El porcentaje de informantes que declara que, de forma general, sus alumnos solicitan ayuda durante el transcurso de las actividades de expresión escrita en L2 en la ciudad de Valladolid es del 85\% frente al 76\% de la ciudad de Austin. En cuanto a los informantes que afirman que sus estudiantes no piden ayuda, existe un $15 \%$ en Valladolid frente al $18 \%$ de Austin. A este porcentaje podríamos añadir el 3\% del primer informante incluido en la categoría "otros" puesto que este también afirma que, en general, no solicitan ayuda. En definitiva, nos encontramos ante un $21 \%$, porcentaje considerablemente superior al de Valladolid.

De acuerdo con las respuestas de los informantes de ambos contextos, los alumnos, en general, presentan un alto grado de confianza en sus profesores y, en este sentido, acuden a ellos 
ante cualquier tipo de duda o consulta. Cabe la posibilidad de que aquellos alumnos que no pidan ayuda no sientan la necesidad de hacerlo puesto que es el propio profesor quien guía al alumno a partir de la lectura de los distintos borradores proporcionándole pautas, a partir de las cuales, tendrá que elaborar un nuevo borrador. Desde esta consideración, aquellos informantes que afirman que la mayoría de alumnos no pide ayuda podrían estar haciendo uso de la técnica de borradores encadenados que se inscribe en el enfoque metodológico centrado en el proceso o producción del texto.

A partir del análisis de las respuestas al ítem número 9 de los dos contextos educativos, podemos inferir que nuestros informantes, a nivel declarativo, conocen las actitudes típicas de los alumnos ante la ayuda ofrecida en el aula de L2. Cabe la posibilidad de que, en el contexto de Valladolid, los informantes entiendan el factor afectivo en el sentido de mostrar un alto grado de apertura hacia los alumnos con el fin de que estos tengan la confianza suficiente para realizar las consultas necesarias durante el proceso de producción escrita. De acuerdo con esto, la formación de estos profesores puede estar orientada hacia la idea de que los alumnos deben ser capaces de buscar las estrategias y recursos necesarios durante la fase de planificación de su producción escrita. La formación recibida por parte de los informantes de la ciudad de Austin respecto a la ayuda prestada durante la realización de producciones escritas en L2 está orientada a una interacción en el aula entre alumno-profesor, alumno-asistente de aula o alumno-alumno durante el proceso de producción escrita.

Como ya hemos señalado previamente, los ítems 5, 6 y 9 se relacionan entre sí y, en este sentido, están diseñados para recabar información relacionada con el grado de implicación del 
profesor en la enseñanza-aprendizaje de expresión escrita en L2. Los datos que se desprenden de las respuestas a estos tres ítems nos muestran una mayor implicación por parte de los informantes que pertenecen al contexto educativo de Austin respecto al de Valladolid. Dichos datos revelan que son los informantes de Austin quienes conocen las metodologías actuales de elaboración de producciones escritas y llevan estos conocimientos al aula. Por su parte, los informantes de Valladolid no aportan información sobre estas, lo cual nos lleva a pensar que, probablemente recurran en sus clases a metodologías tradicionales de expresión escrita en L2 en las que el alumno se enfrenta a una hoja en blanco que debe cumplimentar sin haber recibido previamente las correspondientes orientaciones ni tampoco suficiente input comprensible y variado. Cabe la posibilidad de que dichos informantes no hayan recibido la formación necesaria ni tampoco hayan insistido en investigar acerca de las metodologías vigentes de enseñanza de expresión escrita. Consideramos que esta falta de formación y de interés por parte de los profesores vallisoletanos no contribuye al ejercicio de reflexión ante la propia actividad docente ni al acercamiento hacia un conocimiento profundo de las necesidades de sus alumnos.

\subsection{Conocimientos sobre la utilidad de las actividades de expresión escrita libre en L2}

Nos acercamos a los conocimientos de nuestros informantes respecto a la utilidad que tienen las actividades de expresión escrita dentro del proceso de enseñanza-aprendizaje de una L2. Para ello, acudimos al ítem número 10 a partir del cual, pretendemos averiguar: en qué medida consideran los profesores que las producciones de los alumnos pueden resultar beneficiosas por cuanto que muestran la destreza de estos a la hora de expresarse en esa L2, hasta qué punto sirven 
de apoyo en el aprendizaje de esta, en qué forma ofrecen información necesaria sobre el nivel de interlengua en el que se encuentran los alumnos y hasta dónde contribuyen al enriquecimiento de los conocimientos que tienen sobre su L1.

Ya en el epígrafe 3.2.1 de la presente Tesis nos situábamos en la línea de Leki (2001) quien afirmaba que la escritura en L2 ha recibido una gran cantidad de atención en investigación por cuanto que no solo nos da a conocer el nivel de interlengua en el que se encuentra el alumno, sino que también es una pieza clave en el proceso de evaluación de cualquier disciplina. En esta óptica, los ensayos escritos son una herramienta de evaluación de contenidos tanto en disciplinas lingüísticas como no lingüísticas por cuanto que aportan información sobre los conocimientos del alumno en torno a unos contenidos determinados. En este sentido, recurríamos a las palabras de la mencionada autora, quien señalaba que la enseñanza de escritura en L2 va más allá de una serie de estructuras gramaticales ordenadas. Los alumnos han de ser capaces de desarrollar actividades en L2 enmarcadas dentro de otras disciplinas. También deben ser capaces de demostrar una competencia comunicativa que les permita integrarse con facilidad a nivel lingüístico en las comunidades pertenecientes a los países donde la L2 es lengua oficial.

Teniendo en cuenta la importancia atribuida a la destreza de la expresión escrita, nos proponemos como objetivo principal conocer, desde el punto de vista de nuestros informantes, cuál es la posición que ocupa como destreza dentro de la adquisición de la competencia comunicativa en una L2. Nos interesa por tanto averiguar cuál es el nivel de relevancia que ellos otorgan a dicha destreza. Proponemos a los informantes una serie de adverbios de cantidad: mucho, 
bastante, poco, muy poco o nada con el fin de que elijan el correspondiente en función de su experiencia y punto de vista.

\subsubsection{Análisis de los datos: conocimientos sobre la utilidad de las actividades de expresión escrita libre en L2}

Los datos relacionados con los conocimientos de los informantes que realizan su actividad profesional en la ciudad de Valladolid (teniendo en cuenta que el 100\% responde a este ítem) respecto a la utilidad de las actividades de expresión escrita libre en L2 se muestran en la Tabla 15 y el Gráfico 15 que aparecen a continuación:

\begin{tabular}{|c|c|c|c|c|c|}
\hline $\begin{array}{l}\text { ¿En qué medida considera que las actividades de } \\
\text { expresión escrita libres en una L } 2 \text { o extranjera } \\
\text { sirven a la hora de mejorar los siguientes } \\
\text { aspectos? }\end{array}$ & Mucho & Bastante & Poco & $\begin{array}{l}\text { Muy } \\
\text { poco }\end{array}$ & Nada \\
\hline $\begin{array}{l}\text { Mostrar la destreza de un alumno a la hora de } \\
\text { expresarse en una L2 }\end{array}$ & $33.33 \%$ & $45.45 \%$ & $12.12 \%$ & $3.03 \%$ & $6.06 \%$ \\
\hline Servir de apoyo en el aprendizaje de la L2 & $33.33 \%$ & $48.48 \%$ & $9.09 \%$ & $0.00 \%$ & $9.09 \%$ \\
\hline $\begin{array}{l}\text { Ofrecer al profesor una muestra sobre el nivel } \\
\text { conocimiento de la L2 que tiene el alumno }\end{array}$ & $48.48 \%$ & $36.36 \%$ & $9.09 \%$ & $0.00 \%$ & $6.06 \%$ \\
\hline $\begin{array}{l}\text { Mejorar los conocimientos sobre su lengua } \\
\text { materna }\end{array}$ & $29.03 \%$ & $35.48 \%$ & $16.13 \%$ & $6.45 \%$ & $12.90 \%$ \\
\hline Total, número de respuestas: 33 & & & & & \\
\hline
\end{tabular}




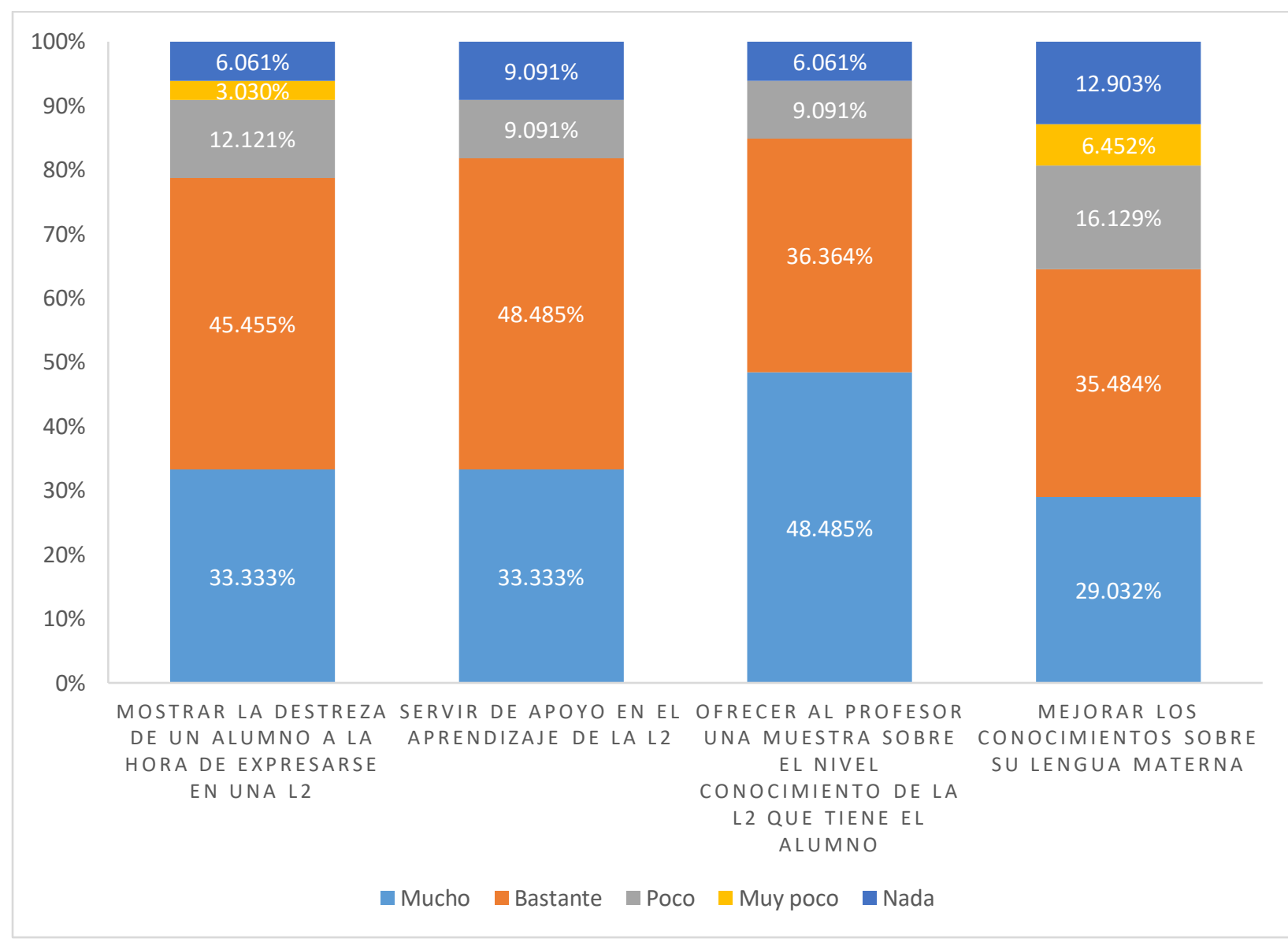

Gráfico 15. Resultados sobre la utilidad de las actividades de expresión escrita libre en L2 en Valladolid

Encontramos resultados similares respecto a los tres primeros aspectos precisados. Así pues, los tres muestran un porcentaje superior al 75\% combinando las respuestas "mucho" y "bastante". El resto de las opciones presenta porcentajes que apenas tienen trascendencia. Inferimos por tanto que una gran mayoría de informantes del contexto educativo de Valladolid está de acuerdo en que las actividades de expresión escrita libre en el aula de L2 contribuyen de una manera decisiva (mucho o bastante) en la mejora de una serie de aspectos relacionados con la L2: la destreza de los alumnos a la hora de expresarse o el aprendizaje de la L2 en general. Además, de acuerdo con estos informantes, este tipo de actividades permite que el profesor pueda contar 
con una muestra importante del nivel de interlengua del alumno lo cual le aportará una gran cantidad de información que podrá utilizar en la planificación de sus futuras actividades.

Sin embargo, en la última columna advertimos la existencia de un porcentaje relativamente amplio de respuestas que aparecen recogidas bajo el título de "poco", "muy poco" y "nada". Los datos muestran que solamente un $29 \%$ de informantes piensa que estas actividades contribuyen de una forma significativa (mucho) en la mejora de los conocimientos sobre su lengua materna, un $35 \%$ considera que contribuyen bastante, un $16 \%$ manifiesta que lo hacen de forma escasa (poco), un $6 \%$ afirma que contribuyen muy poco y casi un $13 \%$ expone que dichas actividades no aportan conocimiento sobre su L1 (nada).

Los datos proporcionados por todos los informantes que llevan a cabo su actividad profesional docente en el contexto educativo de la ciudad de Austin (nos encontramos ante un 100\% de participación) se presentan en la Tabla 16 y en el Gráfico 16 que aparecen a continuación:

\begin{tabular}{|l|l|l|l|l|l|}
\hline $\begin{array}{l}\text { ¿En qué medida considera que las } \\
\text { actividades de expresión escrita libres en } \\
\text { una segunda lengua sirven a la hora de } \\
\text { mejorar los siguientes aspectos? }\end{array}$ & Mucho & Bastante & Poco & $\begin{array}{c}\text { Muy } \\
\text { poco }\end{array}$ & Nada \\
\hline $\begin{array}{l}\text { Mostrar la destreza de un alumno a la hora } \\
\text { de expresarse en una segunda lengua }\end{array}$ & $40.00 \%$ & $55.00 \%$ & $2.50 \%$ & $0.00 \%$ & $2.50 \%$ \\
\hline $\begin{array}{l}\text { Servir de apoyo en el aprendizaje de la } \\
\text { segunda lengua }\end{array}$ & $52.50 \%$ & $42.50 \%$ & $2.50 \%$ & $0.00 \%$ & $2.50 \%$ \\
\hline $\begin{array}{l}\text { Ofrecer al profesor una muestra sobre el } \\
\text { nivel conocimiento de la segunda lengua que } \\
\text { tiene el alumno }\end{array}$ & $47.50 \%$ & $40.00 \%$ & $10.00 \%$ & $0.00 \%$ & $2.50 \%$ \\
\hline $\begin{array}{l}\text { Mejorar los conocimientos sobre su lengua } \\
\text { materna }\end{array}$ & $33.33 \%$ & $48.72 \%$ & $15.38 \%$ & $0.00 \%$ & $2.56 \%$ \\
\hline \begin{tabular}{l} 
Total, número de respuestas: 40 \\
\hline
\end{tabular} & & & & & \\
\hline
\end{tabular}

Tabla 16. Resultados sobre la utilidad de las actividades de expresión escrita libre en Austin 


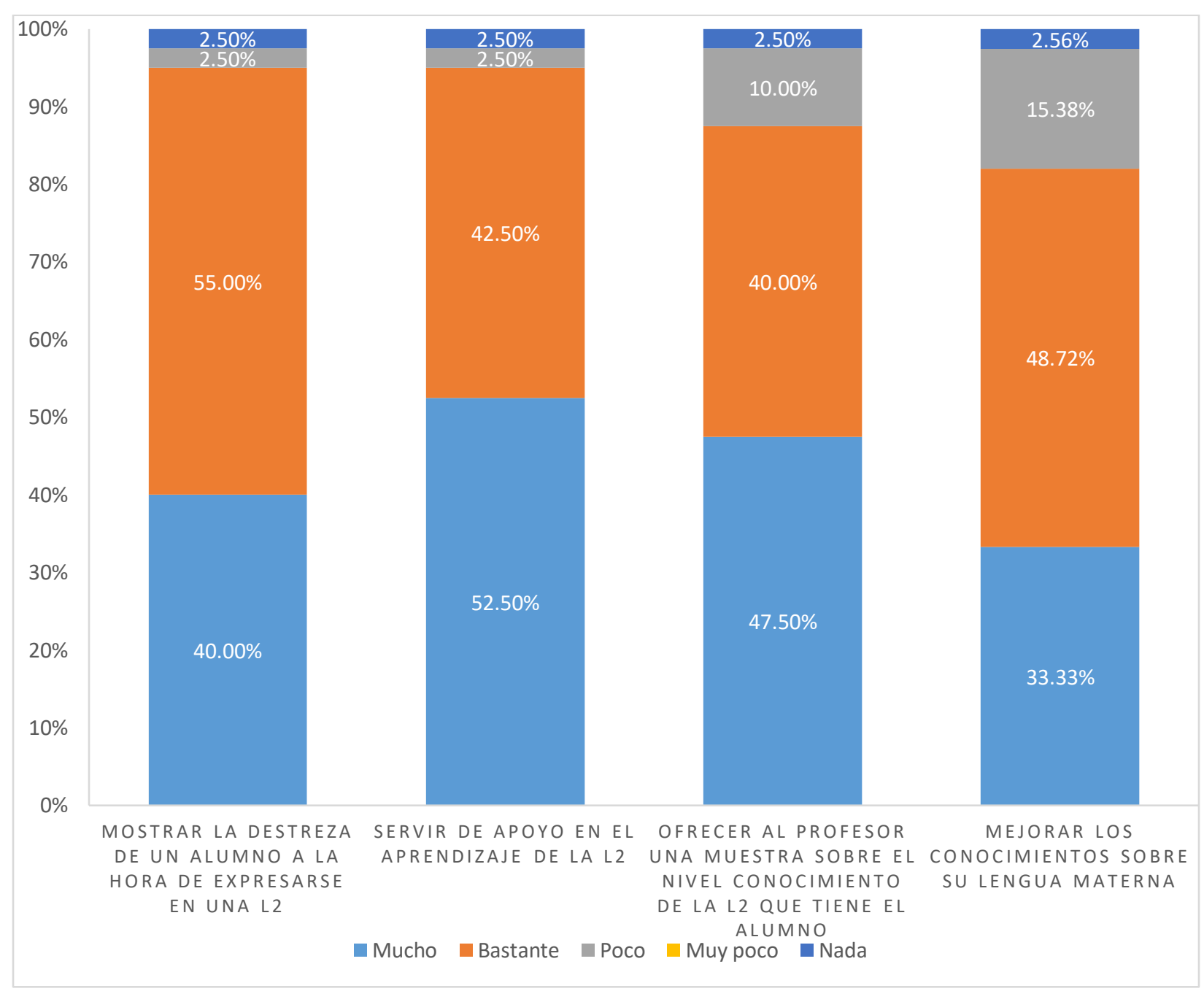

Gráfico 16. Resultados sobre la utilidad de las actividades de expresión escrita libre en Austin

En la Tabla 16 y Gráfico 16 observamos de nuevo porcentajes similares respecto a los tres primeros aspectos. El cuarto muestra una pequeña diferencia en cuanto a cifras, aunque en este caso no es significativa. Los tres primeros muestran un porcentaje cercano o superior al $90 \%$ combinando las respuestas "mucho" y "bastante" y el cuarto muestra un porcentaje del $80 \%$. El resto de las opciones (poco, muy poco y nada) presentan porcentajes inapreciables. Esto indica que una extensa mayoría de informantes del contexto educativo de Austin considera beneficiosas las actividades de expresión escrita libre en L2 por cuanto que contribuyen a la mejora de las 
habilidades comunicativas del alumno, al aprendizaje de L2 en general y, además, aportan información sobre el nivel de interlengua del alumno. El 80\% considera que, además, contribuyen mucho o bastante a mejorar los conocimientos sobre su lengua materna.

\subsubsection{Interpretación de los resultados: conocimientos sobre la utilidad de las actividades de expresión escrita libre en L2}

A partir de los datos expuestos, apreciamos en ambos contextos un número elevado de informantes que consideran que las actividades de expresión escrita son útiles y que, por tanto, contribuyen de forma significativa en la mejora de las distintas destrezas. En los dos contamos con una amplia mayoría de informantes que se muestran a favor de este tipo de actividades por ser estas beneficiosas para el aprendizaje de una L2.

En el contexto vallisoletano encontramos un número más amplio de informantes que afirma que dichas actividades contribuyen de una forma escasa en la mejora de los conocimientos de los alumnos de su lengua materna respecto al contexto de Austin. Sin embargo, podemos decir que las cifras, en general, muestran numerosas coincidencias.

Analizamos los datos proporcionados por los informantes de los dos contextos educativos que forman parte de nuestra investigación respecto al ítem 10. Dichos datos nos llevan a poner de manifiesto que cuando los informantes de ambos contextos afirman en un porcentaje elevado que las actividades de expresión escrita libre en una L2 son muy útiles a la hora de proporcionar al 
alumno una serie de destrezas relacionadas con dicha L2, podemos inferir que conocen los beneficios que aportan dichas actividades en el aprendizaje.

\subsection{Conocimientos acerca del momento idóneo para la corrección de las producciones escritas en $\mathrm{L} 2$}

El término corrección alberga cierta complejidad como ya mencionábamos en el epígrafe 1.1.2 y se ha convertido en objeto de investigación para el ámbito científico de la Lingüística y de la Didáctica. La propia complejidad de la corrección de errores nos determina a examinar el nivel de conocimiento sobre las estrategias, las etapas a seguir y los diferentes roles que el informante debe tomar cuando se enfrenta a la corrección de las producciones escritas de los alumnos. Así pues, nos proponemos, a través del ítem 12 indagar acerca de los conocimientos del informante sobre el momento idóneo para llevar a cabo las correcciones. Ya en el epígrafe 1.1.3 mencionábamos la importancia del qué, cuándo y cómo corregir en el ejercicio de la práctica docente y recurríamos a García-Heras Muñoz (2004) quien ponía de manifiesto la necesidad de revisar y corregir los errores de las producciones escritas de forma inmediata con el fin de lograr una corrección eficaz. La corrección inmediata, junto con la corrección en diferido, definidas por Vez et al. (2002), aparecen también presentadas en el epígrafe 2.1.1 de la presente Tesis Doctoral. Solicitamos por tanto información sobre el momento de corrección elegido por nuestros informantes por considerar que este influirá de una manera significativa en las futuras producciones escritas de los alumnos de L2. 
Nos situamos en la línea de García-Heras Muñoz (2004) por cuanto que a la hora de corregir se estima necesario el uso de una corrección inmediata. Desde esta óptica, manifestamos nuestra consideración respecto a que, aquellos profesores que cuenten con unos conocimientos acerca del momento idóneo de corrección serán aquellos que marquen la respuesta que hemos denominado “justo a continuación”. No obstante, no debemos dejar de mencionar el factor tiempo al que hacíamos referencia en el ítem número 4. Habida cuenta de las limitaciones que el profesor puede encontrar respecto a la disponibilidad del tiempo necesario para la corrección en el aula, cabe la posibilidad de que un determinado número de informantes utilice una corrección en diferido no por voluntad propia ni por desconocimiento sobre el momento idóneo de corrección sino por las limitaciones de tiempo, sobre todo, como ya hemos mencionado anteriormente, cuando se cuenta con un número elevado de alumnos en el aula.

\subsubsection{Análisis de los datos: conocimientos acerca del momento idóneo para la corrección de las producciones escritas en L2}

En la Tabla 17 y el Gráfico 17 que se muestran a continuación se encuentran los datos correspondientes a las respuestas proporcionadas por los informantes del contexto educativo de Valladolid. Encontramos la presencia de 6 de los 33 informantes que decidieron no aportar ninguna respuesta. 


\begin{tabular}{lrr|}
\hline $\begin{array}{l}\text { Cuando usted corrige las producciones escritas de los alumnos, ¿En } \\
\text { qué momento lo hace? }\end{array}$ & $\begin{array}{l}\text { Número de } \\
\text { respuestas }\end{array}$ & $\begin{array}{r}\text { Porcentaje } \\
\hline \text { Justo a continuación }\end{array}$ \\
\hline $\begin{array}{l}\mathbf{5} \\
\text { Después de unos días }\end{array}$ & $\mathbf{7}$ & $\mathbf{2 5 . 9 3 \%}$ \\
\hline $\begin{array}{l}\text { Otros: } \\
\text { A continuación, o dentro de los días que siguen (máx. 2). Dependiendo } \\
\text { de la disposición horaria. }\end{array}$ & 1 & $\mathbf{1 4 . 8 1 \%}$ \\
\hline Lo antes posible & 1 & $3.70 \%$ \\
\hline Cuando tengo un hueco & 1 & $3.70 \%$ \\
\hline En cuanto puedo & 1 & $3.70 \%$ \\
\hline Total & 27 & $\mathbf{1 0 0 . 0 0 \%}$ \\
\hline
\end{tabular}

Tabla 17. Resultados sobre el momento idóneo para la corrección de las producciones escritas en L2 en Valladolid

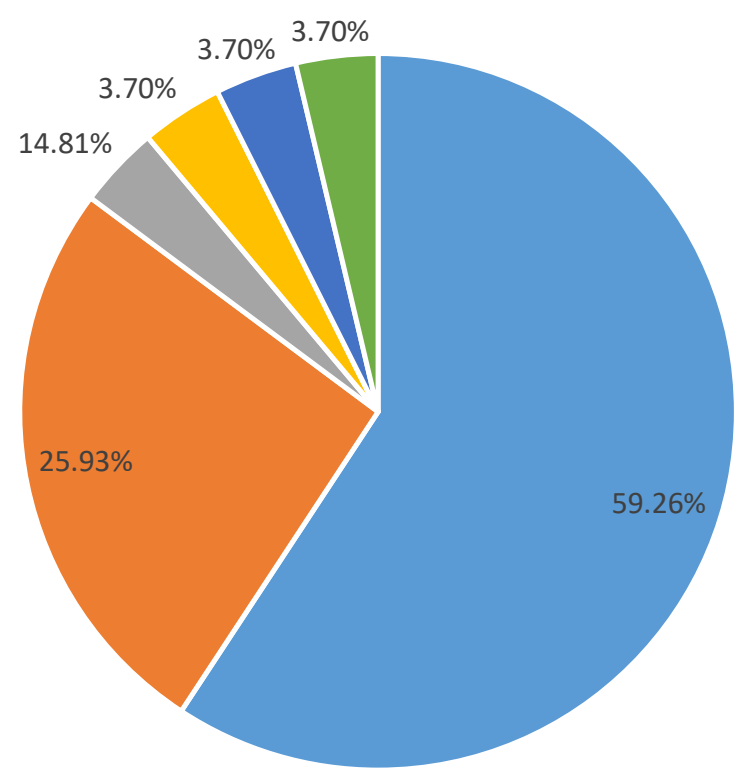

- Justo a continuación

- Después de unos días

- Otros: A continuación o dentro de los días que siguen ( $\max 2)$. Dependiendo de la disposición horaria.

- Otros: Lo antes posible

- Otros: Cuando tengo un hueco

- Otros: En cuanto puedo

Gráfico 17. Resultados sobre el momento idóneo para la corrección de las producciones escritas en L2 en Valladolid

Un 59\% de los informantes vallisoletanos que participaron en este ítem (27 de un total de 33) declara corregir las producciones escritas justo a continuación, es decir, momentos después de 
que el alumno entregue el trabajo al profesor, además, el 26\% expone que lo hace después de unos días.

En el apartado "otros", encontramos a un informante que afirma corregir a continuación o al cabo de unos días (máximo 2) (4\%). Podemos relacionar dicha respuesta con la siguiente en la que otro informante declara corrigir lo antes posible (4\%). Decidimos conectar las dos respuestas por considerar que hacen alusión a un mismo concepto y sumar sus porcentajes al 59\% correspondiente a la primera opción formando un total de $67 \%$ de informantes que optan por la primera opción presentada en este ítem (“Justo a continuación”). En ambos casos, los informantes mencionan la idea de corregir en el momento en que tienen ocasión, aunque siempre intentando que sea lo antes posible. Entendemos, por tanto, que los dos primeros informantes incluidos dentro del apartado "otros", conociendo la necesidad de una corrección inmediata, intentan corregir en el momento en que reciben la producción escrita, aunque en ocasiones no cuenten con el tiempo suficiente y se vean obligados a alternar corrección inmediata con corrección en diferido.

Las dos últimas respuestas incluidas en este apartado pertenecen a un informante que afirma corregir "cuando tiene un hueco" (4\%) y a otro que corrige "cuando puede" (4\%). En ambos casos hacen referencia a la idea de llevar a cabo la corrección cuando tienen tiempo libre, es decir, no muestran intención de hacerlo justo a continuación. Sumamos, por tanto, los porcentajes correspondientes a estos dos informantes que han contestado en tercera y cuarta posición dentro del apartado "otros" (8\%) al 26\% de informantes que escogieron la segunda opción propuesta: "Después de unos días" formando un total de $34 \%$. 
Los datos correspondientes a los resultados obtenidos a partir de las respuestas de los 40 participantes que forman nuestra muestra intencional sobre el momento idóneo para la corrección de las producciones escritas en L2 en la ciudad de Austin se presentan en la Tabla 18 y el Gráfico 18:

\begin{tabular}{|lrr|}
\hline $\begin{array}{l}\text { Cuando usted corrige las producciones escritas de los alumnos, ¿En qué } \\
\text { momento lo hace? }\end{array}$ & $\begin{array}{r}\text { Número de } \\
\text { respuestas }\end{array}$ & $\begin{array}{r}\text { Porcentaje } \\
\hline \text { Justo a continuación }\end{array}$ \\
\hline Después de unos días & $\mathbf{2 8}$ & $\mathbf{7 0 . 0 0 \%}$ \\
\hline $\begin{array}{l}\mathbf{7} \\
\text { Otros: }\end{array}$ & $\mathbf{9}$ & $\mathbf{2 2 . 5 0 \%}$ \\
\hline Con ellos & 1 & $2.50 \%$ \\
\hline Durante el proceso de escritura & 1 & $2.50 \%$ \\
\hline $\begin{array}{l}\text { Realizo las correcciones delante de ellos al día siguiente o al cabo de unos } \\
\text { días }\end{array}$ & 1 & $2.50 \%$ \\
\hline $\begin{array}{l}\text { A veces después de unos días cuando nos reunimos con ellos de manera } \\
\text { individual para realizar las correcciones junto a ellos }\end{array}$ & 1 & $2.50 \%$ \\
\hline A veces en el momento o el mismo día, otras veces en 2 o 3 días & 1 & $2.50 \%$ \\
\hline Depende de la longitud del escrito. Trato de corregirlo lo antes posible & 1 & $2.50 \%$ \\
\hline Depende de la disponibilidad & 1 & $2.50 \%$ \\
\hline Cuando tengo tiempo libre & 1 & $2.50 \%$ \\
\hline Cuando puedo & 1 & $2.50 \%$ \\
\hline Total & 1 & $100.00 \%$ \\
\hline
\end{tabular}

Tabla 18. Resultados sobre el momento idóneo para la corrección de las producciones escritas en L2 en Austin 


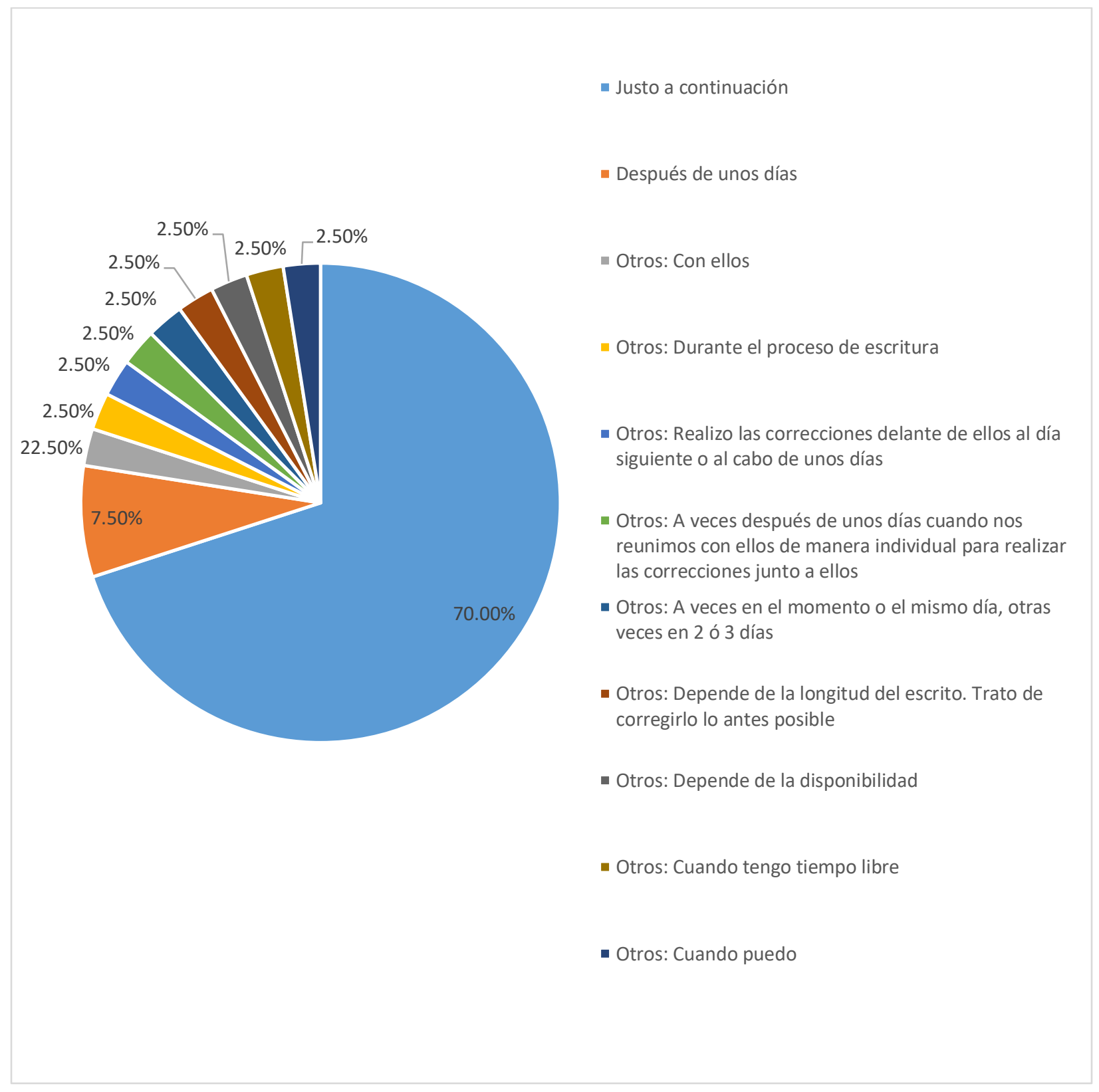

Gráfico 18. Resultados sobre el momento idóneo para la corrección de las producciones escritas en L2 en Austin

En relación a los datos del contexto educativo de Austin, encontramos un $70 \%$ de informantes que afirma corregir justo a continuación y solo un 7,5\% reconoce hacerlo después de unos días. 
En el apartado "otros" encontramos a nueve informantes. En función del contenido y el mensaje implícito de dichas respuestas, asociamos las seis primeras a la primera opción que aparece bajo el título de: "Justo a continuación" (70\%). Consideramos que todas estas respuestas hacen alusión a la intención de corregir durante el propio proceso de escritura o justo a continuación: el primer informante del apartado "otros" reconoce que lleva a cabo la corrección "con ellos" (2,5\%), el segundo destaca que lo hace "durante el proceso de escritura" (2,5\%). Estas dos respuestas nos permiten afirmar que los dos llevan a cabo las correcciones al tiempo que el alumno está escribiendo, lo cual nos hace suponer que utilizan la técnica de borradores encadenados en la cual, los profesores realizan sus aportaciones de forma oral a cada uno de los borradores del alumno permitiendo que sea él mismo quien modifique su propio texto. En este sentido, reconocemos que estas dos respuestas se relacionan con la intención de corregir durante o justo después del proceso de escritura $\mathrm{y}$, por eso, decidimos sumar los porcentajes correspondientes al 70\% de la primera opción.

Encontramos otras dos respuestas en dicho apartado que también decidimos relacionar con la primera de las opciones propuestas "Justo a continuación” (70\%). La primera de ellas aparece bajo el título: "Realizo las correcciones delante de ellos al día siguiente o al cabo de unos días" $(2,5 \%)$ y la segunda: “A veces después de unos días cuando nos reunimos con ellos de manera individual para realizar la corrección junto a ellos” (2,5\%). Dichas respuestas hacen alusión a la misma técnica de borradores encadenados que los informantes llevan a cabo esta vez después de varios días por no poder hacerlo en el momento. Es posible que los informantes cuenten con un número elevado de alumnos que no permita poder realizar la corrección en el momento. Sin embargo, estas respuestas nos transmiten la intención de corregir al tiempo o inmediatamente 
después de que el alumno realice su producción escrita. Así pues, decidimos sumar sus porcentajes correspondientes al 70\% de la primera opción.

Las respuestas que aparecen en posición 5 y 6 del apartado “otros”, cuyos enunciados son: “A veces en el momento o el mismo día, otras veces en 2 o 3 días" (2,5\%) y "Depende de la longitud del escrito. Trato de corregirlo lo antes posible" (2,5\%) muestran que estos informantes, conociendo la importancia de la corrección automática, intentan corregir en el momento. En los dos casos, los informantes también hacen referencia a la intención de corregir en el momento en que tienen ocasión, aunque siempre intentando que sea lo antes posible por lo que decidimos asociar estas respuestas a la primera opción.

Así pues, sumamos los porcentajes correspondientes a las seis primeras respuestas incluidas en el apartado "otros" obteniendo un total de 15\%. Dicho porcentaje se añade al 70\% de la primera opción: "Justo a continuación” obteniendo un resultado final de $85 \%$.

En cuanto a las tres últimas respuestas de este apartado: "Depende de la disponibilidad" (2,5\%), "Cuando tengo tiempo libre" (2,5\%) y "Cuando puedo" $(2,5 \%)$ representan a tres informantes que llevan a cabo una corrección en diferido durante su tiempo libre. Estas respuestas aluden a una corrección en cualquier momento y, a diferencia de las dos anteriores, los informantes no mencionan la necesidad de que esta se realice durante o inmediatamente después de que los alumnos hayan ejecutado su producción escrita. La suma de los porcentajes de estas tres respuestas forma un total de 7,5\% que añadimos al 7,5\% correspondiente a la segunda opción: "Después de unos días" formando un total de $15 \%$. 


\subsubsection{Interpretación de los resultados: conocimientos acerca del momento idóneo para la corrección de las producciones escritas en L2}

A partir de las respuestas obtenidas del contexto educativo de Valladolid podemos inferir que, tanto los informantes que eligieron la opción de corregir a continuación (59\%) como los dos primeros que escogieron la respuesta "otros": "A continuación o dentro de los días que siguen (máx. 2). Dependiendo de la disposición horaria" (4\%) y "Lo antes posible" (4\%), conocen la importancia de una corrección inmediata y la llevan a cabo siempre que las circunstancias lo permiten. Decidimos, por tanto, sumar los porcentajes: $59 \%+4 \%+4 \%$ obteniendo un total del $67 \%$ de informantes que llevan a cabo una corrección automática siempre que es posible puesto que conocen las teorías existentes sobre los beneficios de esta en la enseñanza-aprendizaje de expresión escrita en L2. Por otro lado, agrupamos a los informantes que afirman realizar la corrección después de varios días (26\%) junto con los dos últimos dentro del apartado "otros": "Cuando tengo un hueco" (4\%) y "En cuanto puedo" (4\%), cuyos porcentajes forman un total del 34\%. Este porcentaje corresponde al número de informantes vallisoletanos que afirman realizar las correcciones cuando pueden sin buscar el momento apropiado. No conocen la repercusión que tiene la corrección inmediata en las producciones escritas de los alumnos por lo que cabe la posibilidad de que no hayan estado expuestos a las nuevas teorías de adquisición de L2 en torno a la existencia de un momento idóneo para llevar a cabo la corrección de las producciones escritas de los alumnos. 
En cuanto a las respuestas proporcionadas por los informantes de Austin, observamos que el 70\% indica que corrigen justo a continuación. Asimismo, las seis primeras respuestas incluidas en el apartado "otros": "Con ellos" (2,5\%), "Durante el proceso de escritura" (2,5\%), "Realizo las correcciones delante de ellos al día siguiente o al cabo de unos días" $(2,5 \%)$, "A veces después de unos días cuando nos reunimos con ellos de manera individual para realizar las correcciones junto a ellos" (2,5\%), “A veces en el momento o el mismo día, otras veces en 2 o 3 días" (2,5\%) y "Depende de la longitud del escrito. Trato de corregirlo lo antes posible" (2,5\%) hacen alusión a la intención de llevar a cabo una corrección inmediata. Este grupo de informantes cuyas respuestas hemos asociado a la primera opción $(70 \%+2,5 \%+2,5 \%+2,5 \%+2,5 \%+2,5 \%+2,5 \%)$ forman un total del $85 \%$ que declaran su intención de corregir lo antes posible, aunque no siempre pueden hacerlo en el momento. La segunda opción propuesta: "Después de unos días" es elegida por el 7,5\% de los informantes. Asociamos las tres últimas respuestas incluidas en el apartado "otros": "Depende de la disponibilidad", "Cuando tengo tiempo libre" y "Cuando puedo" con esta segunda opción $(7,5 \%+2,5 \%+2,5 \%+2,5 \%)$ formando un total del $15 \%$. Consideramos que todos estos informantes afirman llevar a cabo la corrección durante su tiempo libre sin que este sea necesariamente el mejor momento puesto que desconocen la existencia de un momento idóneo de corrección.

De los datos analizados en ambos contextos se desprende la idea de que son los informantes del contexto educativo de Austin quienes recurren de forma significativa a la revisión y corrección de los errores de las producciones escritas de forma inmediata con el fin de lograr una corrección eficaz. Por el contrario, los informantes de Valladolid, no siempre recurren a la corrección inmediata por desconocimiento respecto a su eficacia en la corrección de producciones escritas en L2. 
Los datos obtenidos a partir de las respuestas a este ítem no solo proporcionan información relacionada con el momento idóneo de la corrección de errores. A través de las distintas aportaciones de los informantes hemos podido recabar información acerca de su nivel de conocimiento sobre las estrategias, las etapas a seguir y los diferentes roles que el informante debe tomar cuando se enfrenta a la corrección de las producciones escritas de los alumnos. Asimismo, en las respuestas del contexto educativo de Austin encontramos alusiones constantes a las técnicas más modernas de corrección. Cuando ellos afirman realizar las correcciones “con ellos", "durante el proceso de escritura", "delante de ellos" o "cuando se reúnen con ellos" están haciendo referencia a las entrevistas personales con alumnos en las que el profesor actúa como guía y orientador en el proceso de enseñanza-aprendizaje. Reconocen por tanto utilizar la técnica de borradores encadenados mientras que, en el contexto educativo de Valladolid no encontramos alusiones al uso de dichas técnicas. Los comentarios localizados en el apartado "otros" de dicho contexto educativo: "a continuación o después de unos días", "cuando tengo un hueco", "en cuanto puedo" parecen indicar que un gran número de informantes muestra una tendencia general hacia la corrección en diferido de un único borrador en el que añaden la nota numérica junto con las anotaciones pertinentes.

Teniendo en cuenta las respuestas analizadas podemos afirmar que, dentro del contexto educativo de la ciudad de Valladolid, no existe un proceso específico que tenga que ver con la corrección por lo que podemos inferir que los profesores no cuentan con los conocimientos respecto al momento idóneo en que esta debe ser ejecutada. Los profesores de los centros educativos vallisoletanos, a diferencia de los profesores de los distritos escolares de la ciudad de 
Austin no llevan a cabo un proceso de corrección de las producciones escritas específico compuesto por una serie de reuniones con el alumno en las que se proporciona feedback. Es el profesor quien realiza el proceso de corrección sin llevar a cabo reuniones con los alumnos, sin aportar feedback de manera individual y sin que ambas figuras: profesor y alumno trabajen juntos en la configuración de esa producción o producto final. Sin embargo, en el contexto educativo de Austin, especialmente en las etapas educativas correspondientes a Educación Primaria, los alumnos siguen unas pautas generales durante el proceso de escritura (en el cual, se incluye la corrección) guiados por el profesor que será quien les ayude a mejorar y a complementar sus producciones escritas tras una serie de reuniones individuales en las que ambos negocian y coordinan el proceso de escritura que les llevará a obtener un último borrador con el menor número de errores posible que constituirá el producto final.

Analizados los datos correspondientes al ítem 12 en los dos contextos educativos, interpretamos que los informantes de Valladolid cuentan con menos conocimientos metodológicos sobre enseñanza y adquisición lingüística respecto a los informantes de Austin en relación al momento idóneo de corrección de las producciones escritas de los alumnos de L2.

\subsection{Conocimientos sobre los tipos de errores que deben ser corregidos en las producciones escritas en $\mathbf{L 2}$}

Nos acercamos al concepto de error a través del ítem número 15. Como apuntábamos en el epígrafe 1.1.1 de esta Tesis, este concepto ha estado marcado por una gran controversia a lo largo 
de la historia de enseñanza-aprendizaje de L2. Son muchas las definiciones que se le han atribuido, por lo que consideramos que se trata de un término que, junto con la corrección, encierra un elevado nivel de complejidad que merece nuestra atención.

Nos disponemos a analizar los conocimientos de los informantes respecto a los distintos tipos de errores preguntándoles cuáles de ellos, en su opinión, deben ser corregidos en las producciones escritas en L2. Nos encontramos ante un aspecto que tiene una relación directa con la edad del alumno, el curso o nivel educativo en el que se desarrolla la actividad docente, el tipo de actividad que se esté llevando a cabo en el momento y los objetivos que se pretenden conseguir.

Como ya mencionábamos en el epígrafe 1.1.2, la corrección de errores es un cometido de difícil desempeño. La decisión por parte del profesor en torno a qué corregir no es fácil de acometer. Junto con la elección del tipo de errores que deben ser corregidos, el profesor deberá adoptar el tipo de tratamiento del error más adecuado a la edad de los alumnos. Los alumnos en edades tempranas y preadolescentes aprenden la L2 de una forma instintiva a partir del input proporcionado como ya hemos apuntando en los epígrafes 3.1 y 5.6 de la presente Tesis Doctoral. Se impone, por tanto, la elección, por parte del profesor, de un tratamiento de errores en el que se lleve a cabo una corrección implícita y en el que el error no se subraye ni se penalice. Por otra parte, en lo que respecta a los tipos de errores, situándonos en la perspectiva de Fernández (1997) insistimos en la necesidad de corregir solamente aquellos errores que corresponden al nivel de competencia lingüística de los alumnos. 
En relación a la tipología de errores que deben ser corregidos en las producciones escritas de los alumnos y volviendo al epígrafe 1.3 de esta Tesis Doctoral, destacamos la importancia de la corrección de errores gramaticales, léxicos y pragmático-culturales. En este acercamiento, partimos de la idea de Norrish (1983), por cuanto que, cuando el alumno se enfrenta a este tipo de actividades deberá transmitir información sin otra ayuda que la del lenguaje en sí mismo por lo que, de acuerdo con este autor, se ha de conceder una especial atención a los dos sistemas, a saber: el gramatical y el léxico. Además, siguiendo a Guillén Díaz (2002) y a Merino Mañueco (2015), a las que hacíamos mención en el epígrafe 3.1.2 respecto a que lengua y cultura constituyen un término indisoluble, incluimos los errores pragmático-culturales como una de las tipologías a la que se debe prestar especial atención.

Reconocemos la importancia que tienen estos tipos de errores y la necesidad de tenerlos en cuenta en las correcciones de las producciones escritas de los alumnos de L2. No obstante, desde nuestro punto de vista, en la etapa de Educación Primaria los errores que deben ser corregidos y a los que los profesores debemos prestar especial atención son aquellos que dificultan la comprensión general del texto. Se impone por tanto la necesidad de fomentar en los alumnos el desarrollo de la competencia comunicativa (tanto oral como escrita) en las distintas etapas educativas y en Educación Primaria de forma particular de manera que, es responsabilidad del profesor transmitir a los alumnos la importancia de producir sin temor a cometer errores. En este sentido es importante hacerles saber que, durante el transcurso de determinadas actividades, nos limitaremos a corregir solamente aquellos errores que dificulten la comunicación escrita. 
Consideramos necesaria la información que pueden proporcionarnos las respuestas con respecto al estudio de errores que realiza el informante a partir de las producciones escritas a las que se expone. Nos proponemos analizar en qué medida este conoce la naturaleza de los errores para poder determinar las necesidades de sus alumnos o el nivel de interlengua en el que se encuentran. Además, las respuestas a este ítem nos acercarán a las aptitudes y a las actitudes que presentan nuestros informantes ante la presencia del error. Podemos decir, por tanto, que nos encontramos ante un ítem que, estando incluido en la categoría de análisis: conocimientos de los informantes, mantiene una estrecha relación con las categorías aptitudes y actitudes.

\subsubsection{Análisis de los datos: conocimientos sobre los tipos de errores que deben ser corregidos en las producciones escritas en $\mathrm{L} 2$}

Considerando que dos de los informantes de Valladolid decidieron no aportar una respuesta a este ítem, los datos obtenidos a partir de las 31 respuestas se muestran en la Tabla 19 y en el Gráfico 19.

\begin{tabular}{|lrr|}
\hline $\begin{array}{l}\text { ¿Qué tipos de errores son, bajo su punto de vista, los que necesitan ser } \\
\text { corregidos? }\end{array}$ & $\begin{array}{r}\text { Número de } \\
\text { respuestas }\end{array}$ & $\begin{array}{r}\text { Porcentaje } \\
\hline \text { Todos los errores }\end{array}$ \\
\hline Los errores ortográficos & $\mathbf{4}$ & $\mathbf{1 2 . 9 0 \%}$ \\
\hline Los que dificultan la comprensión general del texto & $\mathbf{1 6 . 1 3 \%}$ \\
\hline Ninguno, lo importante es que el alumno produzca en otra lengua & $\mathbf{5 8 . 0 6 \%}$ \\
\hline Otros: & $\mathbf{2}$ & $\mathbf{6 . 4 5 \%}$ \\
\hline $\begin{array}{l}\text { Aquellos errores gramaticales relacionados con el tema que se esté } \\
\text { trabajando }\end{array}$ & 1 & $\mathbf{6 . 4 5 \%}$ \\
\hline Depende de lo que quieras trabajar & 1 & $3.23 \%$ \\
\hline Total & 31 & $\mathbf{1 0 0 . 0 0 \%}$ \\
\hline
\end{tabular}



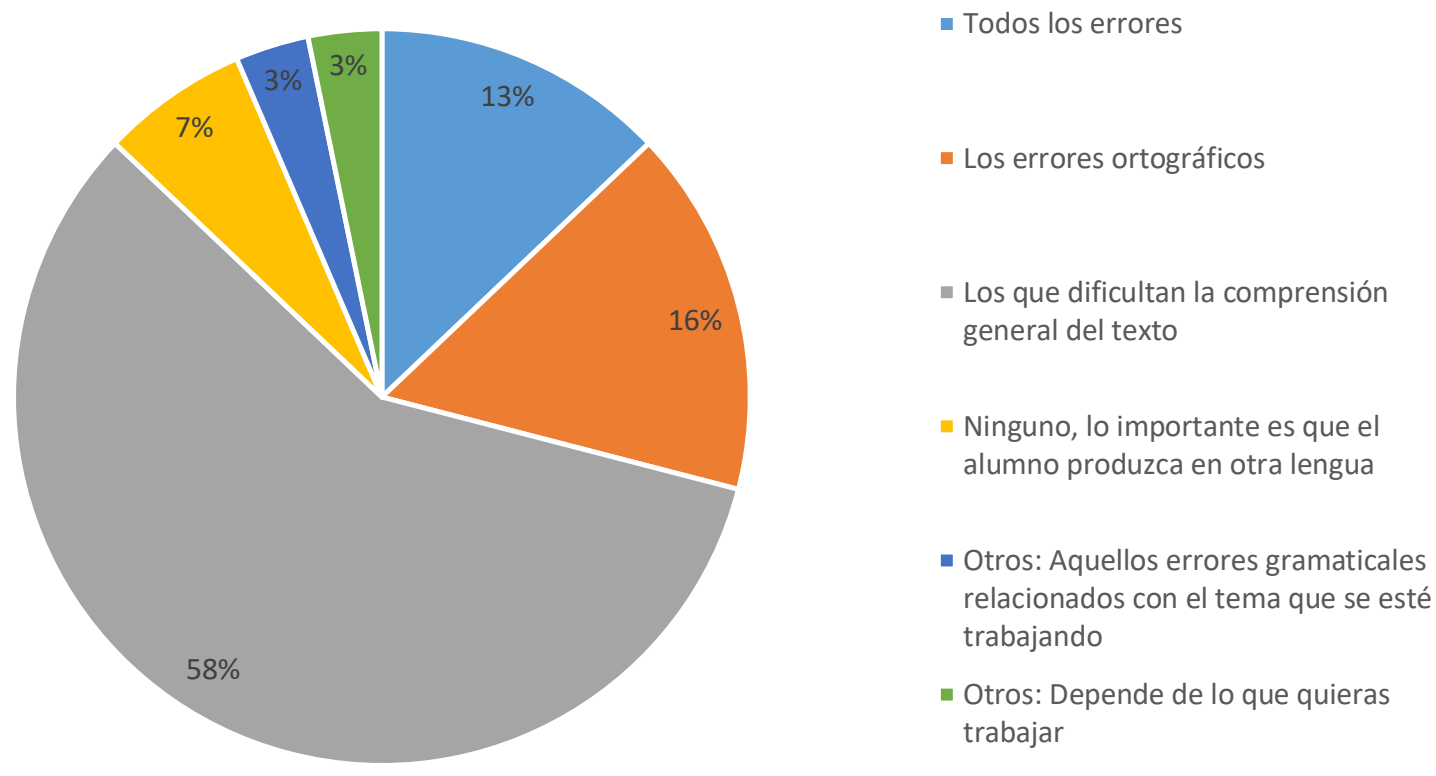

- Otros: Depende de lo que quieras trabajar

Gráfico 19. Resultados sobre los tipos de errores que deben ser corregidos en las producciones escritas en L2 en Valladolid

Como podemos observar, un $13 \%$ de los 31 informantes que decidieron participar en Valladolid (de un total de 33) opina que deben corregirse todos los errores cometidos por los alumnos en sus producciones escritas y un $16 \%$ cree que son los errores ortográficos los únicos que deben ser corregidos. Existe una amplia mayoría (58\%) que afirma corregir solamente los errores que dificulten la comprensión general del texto, y solamente un $7 \%$ considera que estos no deben corregirse. Es posible que estos profesores muestren rechazo hacia la corrección por ser esta la causante de la inhibición de los alumnos cuando estos se disponen a producir en una L2. 
En el apartado que aparece bajo el nombre "otros" encontramos a dos informantes que deciden añadir información complementaria a su respuesta. El primero de ellos afirma que solo deben corregirse los errores gramaticales correspondientes al tema en el que los alumnos estén trabajando. El segundo informante también habla de centrar la corrección solo en aquellos aspectos que se hayan trabajado o se dispongan a trabajar en el aula de L2.

La idea general que nos transmiten los resultados es la de la importancia que se concede a la corrección de errores que impiden o dificultan la comprensión general del texto, lo cual nos indica que los informantes conocen las teorías recientes de adquisición de una L2 en las que se concede importancia a la consecución, por parte de los alumnos de L2, de las cuatro destrezas que componen la competencia comunicativa, a saber: comprensión oral, comprensión escrita, expresión oral y expresión escrita. Sin embargo, también observamos que los informantes conceden especial importancia a los errores ortográficos.

Los datos obtenidos del contexto educativo de la ciudad de Austin se reflejan en la Tabla 20 y el Gráfico 20 que aparecen a continuación. Como podemos observar, uno de los informantes de este contexto (de un total de 40) no aportó respuesta a este ítem. 


\begin{tabular}{|c|c|c|}
\hline $\begin{array}{l}\text { ¿Qué tipos de errores son, bajo su punto de vista, los que necesitan ser } \\
\text { corregidos? }\end{array}$ & $\begin{array}{l}\text { Número de } \\
\text { respuestas }\end{array}$ & Porcentaje \\
\hline Todos los errores & 8 & $20.51 \%$ \\
\hline Los errores ortográficos & 3 & $7.69 \%$ \\
\hline Los que dificultan la comprensión general del texto & 16 & $41.03 \%$ \\
\hline Ninguno, lo importante es que el alumno produzca en otra lengua & 7 & $17.95 \%$ \\
\hline Otros: & 5 & $12.82 \%$ \\
\hline Depende de la edad del alumno & 1 & $2.56 \%$ \\
\hline Depende del nivel de los estudiantes & 1 & $2.56 \%$ \\
\hline $\begin{array}{l}\text { Depende del objetivo de la actividad. No siempre hay que corregir los } \\
\text { errores }\end{array}$ & 1 & $2.56 \%$ \\
\hline $\begin{array}{l}\text { Depende del tema trabajado. Suelo dirigir su atención sobre aspectos } \\
\text { puntuales tratados en las clases }\end{array}$ & 1 & $2.56 \%$ \\
\hline $\begin{array}{l}\text { Depende de las destrezas que quiero que trabajen esa semana. Es } \\
\text { importante que el alumno no se sienta sobrepasado }\end{array}$ & 1 & $2.56 \%$ \\
\hline Total & 39 & $100.00 \%$ \\
\hline
\end{tabular}

Tabla 20. Resultados sobre los tipos de errores que deben ser corregidos en las producciones escritas en L2 en Austin 


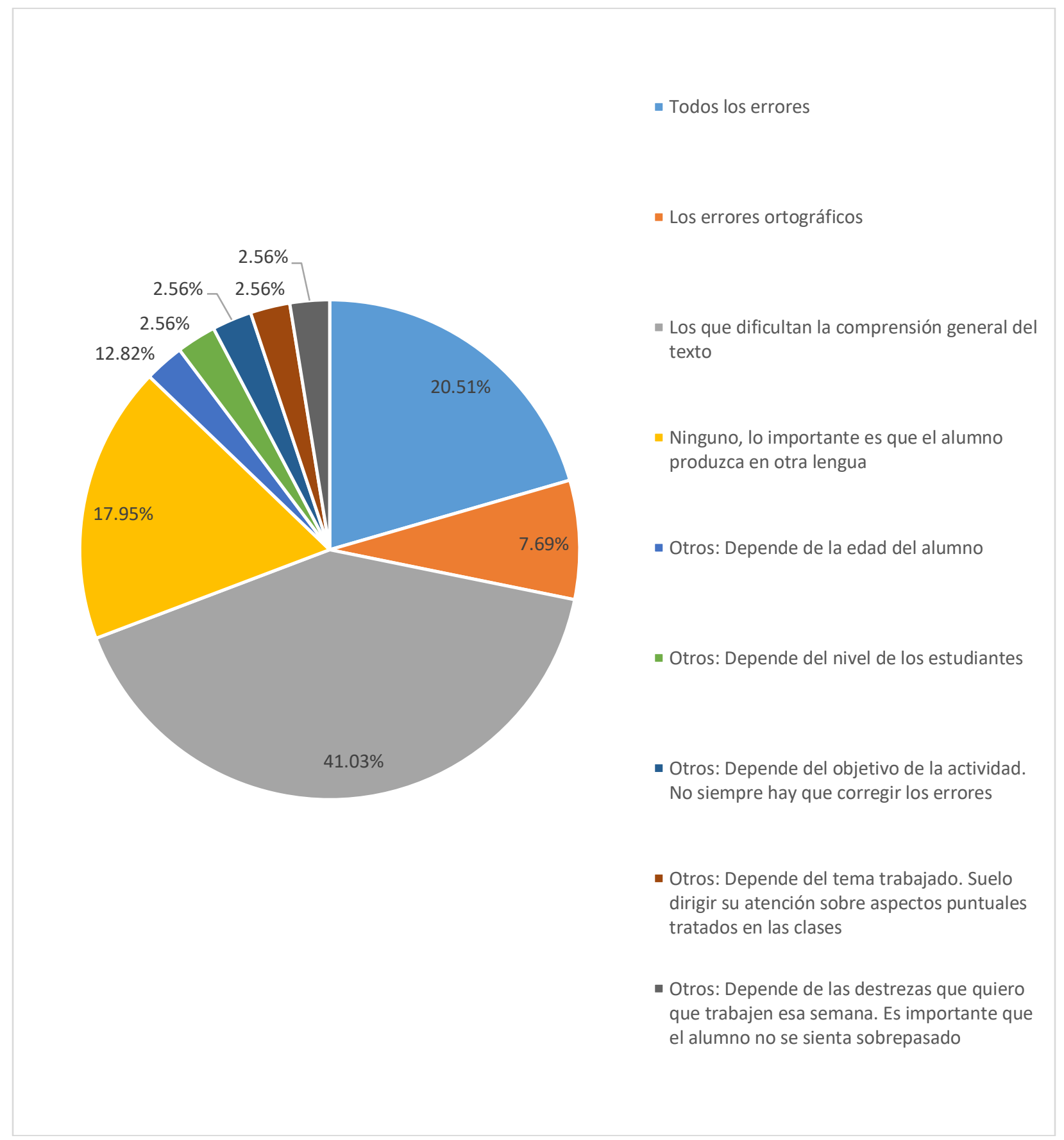

Gráfico 20. Resultados sobre los tipos de errores que deben ser corregidos en las producciones escritas en L2 en Austin

Observamos que un $20 \%$ de los 39 profesores de Austin que respondieron afirma corregir todos los errores de las producciones escritas de sus alumnos, un $8 \%$ corrige solo los errores de ortografía. Hay un $41 \%$ que declara corregir los errores que dificultan la comprensión general del texto y un $18 \%$ dice no corregir ningún error. 
En lo que concierne al apartado "otros" observamos la existencia de una amplia variedad de respuestas. El primer informante que eligió esta opción manifiesta que la corrección de errores debe llevarse a cabo en función de la edad de los alumnos, el segundo habla del nivel de L2, el siguiente informante considera que la corrección debe realizarse en relación a los objetivos planteados para la actividad de expresión escrita. Los dos últimos informantes que pertenecen a la sección "otros" declaran corregir únicamente las estructuras o las destrezas que se encuentran trabajando en el momento en el aula con el propósito de centrarse más en las necesidades comunicativas del alumno.

Los resultados nos revelan que los informantes de la ciudad de Austin, al igual que los de Valladolid, conocen, en general, las teorías de adquisición de L2 y otorgan especial relevancia a la selección de errores durante el proceso de corrección con el propósito de que el alumno intente comunicarse sin temor a cometer errores. Advertimos a través de las respuestas complementarias de algunos informantes que han optado por ampliar información, que la corrección de errores en la ciudad de Austin se realiza en función de varios factores: edad, nivel de L2 de los alumnos, objetivos marcados para la propia actividad, etc. Los conocimientos que los informantes de Austin comparten acerca de la corrección de errores ponen de manifiesto la idea de que no existe una necesidad de marcar y, posteriormente corregir las producciones escritas de los alumnos en todo momento. Así es como, en general, nuestros informantes transmiten la idea de realizar una selección previa mediante la cual se determinan cuáles son los tipos de errores que deben ser marcados y/o corregidos. 


\subsubsection{Interpretación de los resultados: conocimientos sobre los tipos de errores que deben ser corregidos en las producciones escritas en L2}

Examinados los datos respecto al tipo de errores que deben ser corregidos, encontramos que en Valladolid existe un $13 \%$ de informantes que defienden la idea de corregir todos los errores que se encuentran en las producciones escritas de los alumnos frente al $20 \%$ de la ciudad de Austin. Un $16 \%$ de nuestros informantes vallisoletanos cree que solo deben corregirse los errores ortográficos frente al $8 \%$ de los informantes de Austin. En ambos casos, los porcentajes más amplios se presentan en la corrección de aquellos errores que dificulten la comprensión general del texto (un $58 \%$ en Valladolid frente al $41 \%$ de la ciudad de Austin). Solo un $7 \%$ en la ciudad de Valladolid considera que no debe corregirse ni marcarse ningún error respecto al 18\% de Austin.

Observamos la existencia de varias similitudes entre las opciones incluidas en el apartado “otros" en ambos contextos. Así pues, uno de los informantes de la ciudad de Valladolid afirma que la corrección debe llevarse a cabo en función de lo que se quiera trabajar en el aula. Por su parte, uno de los informantes de la ciudad de Austin que también decidió elegir la opción "otros" y aportar información complementaria, expone que la corrección debe realizarse en base al tema trabajado. El hecho de que dos informantes (cada uno dentro de un contexto educativo) hayan coincidido en su respuesta nos hace pensar en una posible implementación del cuestionario de cara a futuras investigaciones. En este sentido, nos situamos ante la posibilidad de incluir una opción que haga alusión a la corrección de errores en función del tema que se esté trabajando en el momento en el aula de L2 entre las opciones originales del cuestionario en caso de utilizarlo en un futuro trabajo de investigación. 
Tras comparar los resultados, observamos que existe una diferencia considerable respecto a los porcentajes de aquellos informantes que afirman corregir solo los errores ortográficos (16\% en Valladolid respecto al 8\% de Austin). Esta diferencia nos hace pensar en la gran importancia concedida a la ortografía en Valladolid respecto a Austin. Cabe la posibilidad de que el uso de la pedagogía orientada al proceso de escritura en la ciudad de Austin determine que, en ocasiones, bajo la insistencia de producir en una L2, algunos profesores sitúen en un segundo plano la parte normativa de la L2. Como ya mencionábamos en el epígrafe 1.3.2 de esta Tesis, como consecuencia de la aparición de lo que denominamos "process-oriented pedagogy" (Ferris \& Hedgcock, 1998, p. 197) como metodología de enseñanza-aprendizaje de expresión escrita en L2, algunos profesores comienzan a centrar su atención en la forma de elaborar una producción escrita, cómo revisarla y cómo mejorar el proceso en sí mismo dejando a un lado la enseñanza de reglas gramaticales a los alumnos de L2 (Ferris \& Hedgcock, 1998, p. 198).

Los resultados obtenidos a partir del análisis del ítem 15 de nuestro cuestionario nos permiten afirmar que los informantes de ambos contextos cuentan con los conocimientos necesarios respecto a las nuevas teorías de adquisición de L2 puesto que, en ambos casos, los informantes coinciden en apoyar la idea de realizar una selección de aquellos errores que impiden o dificultan la comunicación escrita sin marcar el resto para evitar la posible inhibición de los alumnos.

Sin embargo, cuando los informantes del contexto educativo de Austin afirman en un porcentaje considerablemente alto que los errores no deben corregirse, podemos inferir la 
presencia de una actitud más respetuosa y flexible ante la presencia del error frente a los de Valladolid. En las aportaciones de los informantes de este contexto educativo observamos una insistencia en la búsqueda de criterios de corrección. Esto nos lleva a pensar que la formación del profesor respecto al proceso de corrección en la ciudad de Austin está dirigida a seleccionar solo aquellos errores que necesiten ser corregidos en el momento incluso, en determinados casos a no corregir ninguno. Es posible que el objetivo sea favorecer la soltura del alumno durante el proceso de producción escrita y, al mismo tiempo, promover en este actitudes positivas que le permitan alcanzar un nivel óptimo de adquisición de la L2. Nos atrevemos a suponer, por tanto, que estos profesores conocen la hipótesis del filtro afectivo de Krashen (1982) que ya presentábamos en el epígrafe 3.3.2, según la cual, el grado de motivación, autoestima, seguridad y confianza del alumno en sí mismo pueden aumentar o limitar considerablemente el nivel de adquisición de la L2.

Por todo esto, podemos afirmar que los profesores de ambos contextos cuentan con un nivel adecuado de conocimientos sobre el tipo de errores que deben ser corregidos. Estos conocimientos estarán relacionados con unas aptitudes dirigidas a corregir de una forma moderada y a proporcionar feedback oral al alumno de forma inmediata siempre que sea necesario y sin necesidad de que este tenga que estar expuesto a las correcciones por escrito. Además, dichos conocimientos representan una actitud por parte del profesor de L2 de respeto y tolerancia hacia la presencia del error y hacia los alumnos en general. A pesar de que los dos grupos de informantes muestran tener un nivel de conocimientos apropiado, podemos inferir, a partir del elevado porcentaje de profesores de Austin que defiende la postura de la no corrección de errores que estos otorgan prioridad a la motivación del alumno y, en virtud de ello, se aseguran de que este tenga la 
posibilidad de llevar a cabo sus producciones en un ambiente relajado que le permita alcanzar el éxito en el aprendizaje.

Los datos obtenidos del análisis de los ítems 5, 6, 9, 10, 12 y 15 del cuestionario arrojan luz en torno al componente competencial: conocimientos y, en este sentido, nos han proporcionado la información necesaria acerca de los conocimientos sobre el error, la corrección y el feedback de los informantes. De estos datos se desprenden las conclusiones que se presentan en el siguiente epígrafe.

\subsection{Interpretación de los resultados. Conocimientos sobre el error, la corrección y elfeedback}

Los resultados parecen indicar que los informantes del contexto educativo de Valladolid conocen cuáles son las actitudes de los alumnos hacia las actividades de escritura dirigida. Cabe la posibilidad de que no hayan recibido la formación suficiente respecto a la forma de presentar las actividades de escritura libre ante los alumnos de manera que puedan resultar atractivas. Nos atrevemos a suponer que recurren a técnicas tradicionales de exposición de los alumnos ante una hoja de papel en blanco sin aportar el suficiente input comprensible ni las estrategias necesarias. En relación a la ayuda ofrecida a los alumnos cuando estos se disponen a realizar una actividad de expresión escrita, los datos relativos a los informantes de Valladolid evidencian una formación orientada a mostrar a los alumnos que han de ser ellos quienes desarrollen sus propias estrategias (uso de diccionario o gramática, acudir al profesor, etc.) para llevar a cabo una producción escrita de la manera más autónoma posible. El informante, conoce los beneficios que aportan las 
actividades de expresión escrita en el aprendizaje de una L2, sin embargo, muestra desconocimiento respecto al momento idóneo de corrección de errores. Considera que los errores más importantes son los que dificultan la comprensión general del texto, dando prioridad a la producción y a la comunicación en general, pero no muestra una actitud de apertura ante el error ni da especial importancia a la corrección ortográfica. Esto nos hace pensar que lleva a cabo la corrección de un único borrador sobre el cual escribe sus marcas y anotaciones que será lo que constituya el feedback dirigido al alumno. Prioriza la corrección escrita sin necesidad de dotar al alumno de un feedback oral que pueda ayudarlo en su tarea de reconstrucción del texto.

En el contexto educativo de Austin, nos encontramos ante profesores que, de acuerdo con los resultados obtenidos, conocen las actitudes típicas de los alumnos hacia las actividades de expresión escrita dirigida y libre y, en virtud de ello, buscan la forma de presentar dichas actividades de una forma atractiva y fácil para el alumno. En lo concerniente a la ayuda ofrecida, es evidente que dichos informantes conocen la importancia del componente afectivo en la enseñanza-aprendizaje de L2 y, en consecuencia, utilizan metodologías actuales de producción escrita dirigidas al proceso en las que este componente juega un papel fundamental. El profesor forma un equipo junto con el alumno de forma que este siente que puede acudir a él cuando lo estime necesario. Conocen y han sido formados respecto a los beneficios de las actividades de expresión escrita en el aprendizaje de una L2 y siguen unas pautas generales durante el proceso de escritura de los alumnos. Así pues, los alumnos elaboran un borrador inicial que el profesor corrige de forma inmediata proporcionando feedback oral justo en el momento en que el alumno concluye dicho borrador. A partir de las correcciones y feedback del primer borrador, los alumnos van implementando su texto hasta llegar al borrador final. En general, estos informantes conocen la 
importancia de los errores que dificultan la comprensión general del texto, y se esfuerzan en hacer una selección de aquellos errores que deben ser corregidos en el momento para evitar un sentimiento de frustración en el alumno. Muestran unos conocimientos amplios sobre el error, lo cual los lleva a adoptar unas aptitudes de corrección orientadas a la interacción oral con el alumno (dotación de feedback oral) y a unas actitudes de respeto y de apertura hacia el error y hacia los propios alumnos. 



\section{Capítulo 7. COMPONENTE COMPETENCIAL II: APTITUDES EN TORNO AL ERROR, A LA CORRECCIÓN Y AL FEEDBACK}

7.1. Aspectos generales sobre el componente competencial II: aptitudes

7.2. Aptitudes en torno a cómo presentar una actividad de escritura libre en L2

7.3. Aptitudes en torno a la ayuda proporcionada a los alumnos durante la realización de actividades de escritura libre en L2

7.4. Aptitudes en cuanto a la elección de modalidades de corrección de las actividades de escritura libre en L2

7.5. Aptitudes en torno a la dotación del feedback que acompaña a la corrección de errores de una actividad de escritura libre en L2

7.6. Aptitudes en torno a la evaluación de una producción escrita en L2

7.7. Aptitudes respecto a la forma de entrega de correcciones de las producciones escritas en L2

7.8. Interpretación de los resultados. Aptitudes en torno al error, a la corrección y al feedback 


\subsection{Aspectos generales en torno al componente competencial II: aptitudes}

Cuando nos referimos al componente competencial II, hacemos referencia a las aptitudes o capacidades que tiene el informante en torno a:

- La presentación de las actividades de escritura libre en L2

- La ayuda proporcionada a los alumnos durante la realización de actividades de escritura libre en L2

- La elección de modalidades de corrección de las actividades de escritura libre en L2

- La dotación del feedback que acompaña a la corrección de errores de una actividad de escritura libre en L2

- La evaluación de una producción escrita en L2

- La forma de entrega de correcciones de las producciones escritas en L2

Como se muestra en el Cuadro 5 los ítems que nos aportarán información con respecto a las aptitudes en torno al error, la corrección y el feedback son: 


\begin{tabular}{|c|c|}
\hline \multirow{6}{*}{$\begin{array}{l}\text { Aptitudes del informante en torno al error, } \\
\text { a la corrección y al feedback }\end{array}$} & $\begin{array}{l}\text { Ítem } 7 \text {. Aptitudes del informante en torno } \\
\text { a la presentación de una actividad de } \\
\text { escritura libre en L2 }\end{array}$ \\
\hline & $\begin{array}{l}\text { Ítem } 8 \text {. Aptitudes del informante en torno } \\
\text { a la ayuda proporcionada a los alumnos } \\
\text { durante la realización de actividades de } \\
\text { escritura libre en L2 }\end{array}$ \\
\hline & $\begin{array}{l}\text { Ítem 11. Aptitudes del informante en } \\
\text { cuanto a la elección de modalidades de } \\
\text { corrección de las actividades de escritura } \\
\text { libre en L2 }\end{array}$ \\
\hline & $\begin{array}{l}\text { Ítem 13. Aptitudes del informante en } \\
\text { torno a la dotación del feedback que } \\
\text { acompaña a la corrección de errores de } \\
\text { una actividad de escritura libre en L2 }\end{array}$ \\
\hline & $\begin{array}{l}\text { Ítem 14. Aptitudes del informante en } \\
\text { torno a la evaluación de una producción } \\
\text { escrita en L2 }\end{array}$ \\
\hline & $\begin{array}{l}\text { Ítem 16. Aptitudes del informante } \\
\text { respecto a la forma de entrega de } \\
\text { correcciones de las producciones escritas } \\
\text { en } \mathrm{L} 2\end{array}$ \\
\hline
\end{tabular}

Cuadro 5. Ítems de los cuestionarios dirigidos a la recopilación de información acerca de las aptitudes del informante

La relación de ítems expuestos en el Cuadro 5 son concebidos e incluidos en los cuestionarios con el propósito de que las respuestas a dichos ítems puedan aportar información sobre las aptitudes del informante en torno al error, a la corrección y al feedback en las 
producciones escritas de los alumnos de L2. En este sentido, los datos que nos disponemos a analizar forman parte del componente competencial "aptitudes".

\subsection{Aptitudes en torno a cómo presentar una actividad de escritura libre}

Nos acercamos, en el ítem número 7, a la forma en que el informante presenta las actividades de expresión escrita libre a sus alumnos. A través de la información recogida intentaremos conocer en qué medida el profesor tiene en cuenta los factores afectivo y motivacional en la presentación de las actividades de expresión escrita. Factores a los que Krashen (1982) y otros expertos conceden especial importancia puesto que, como ya apuntábamos en el epígrafe 3.1, juegan un papel innegable en el proceso de adquisición de una L2. Ya en el epígrafe 3.3.2 hacíamos referencia a la teoría del filtro afectivo de Krashen (1982). De acuerdo con esta, el estado anímico del alumno, influye decisivamente en el proceso de adquisición de una L2. Así es como, un filtro afectivo alto (caracterizado por un elevado nivel de ansiedad, inseguridad y baja autoestima) representa un alto nivel de probabilidades de que el alumno no prospere en su proceso de aprendizaje. En cambio, un filtro afectivo bajo posibilitará un mejor nivel de adquisición de la L2. En la teoría del filtro afectivo, Krashen (1982) examinará algunos aspectos que intervienen de una forma positiva o negativa en la adquisición de la L2, a saber: la motivación, la confianza y la actitud del alumno hacia la L2.

La tarea de escribir puede convertirse en una experiencia frustrante para el profesor ya que, como constatábamos en el epígrafe 3.2 de esta Tesis, implica un gran nivel de dificultad a la hora 
de motivar a los alumnos (Buzea, 2013). Por todo ello, estimamos necesario analizar, a través de las respuestas aportadas, las aptitudes de nuestros informantes en cuando al planteamiento de actividades de expresión escrita libre en el aula de L2.

La aptitud de los profesores respecto a la forma de presentación de las actividades de expresión escrita será determinante a la hora de conseguir que el alumno pueda producir un buen trabajo de producción textual. Como ya mencionábamos en el epígrafe 3.2.1, el nivel de motivación que experimente el alumno hacia el proceso de escritura y hacia los temas de producción textual propuestos por el profesor incidirán de manera decisiva en su compromiso hacia la producción escrita.

Consideramos que las dos primeras opciones son las que todo profesor tendrá en consideración a la hora de presentar una actividad de escritura libre en alumnos de Educación Primaria. Como primera opción, hacemos referencia al planteamiento de una actividad de este tipo como algo divertido, es decir, algo cercano a sus intereses particulares. En el epígrafe 3.3.2 de esta Tesis hacíamos alusión a Krashen (1988) quien hablaba de la existencia de dos factores actitudinales que predicen el nivel de competencia en la L2 del alumno: la motivación integrante y la instrumental. La primera de ellas se define como el interés o deseo de comunicación con los hablantes de la L2 en el sentido de ser capaz de interactuar con ellos y compartir sus gustos, deseos e intereses. La segunda está relacionada con el deseo de adquirir una segunda lengua por cuestiones prácticas. Es esta motivación integrante la que, como profesores intentaremos conseguir en nuestros alumnos y es este factor al que hacemos mención a través de la primera opción. 
En la segunda opción, planteamos la idea de presentar este tipo de actividades como si se tratase de un juego. De acuerdo con esto, nos disponemos a introducir el factor lúdico: el juego como elemento pedagógico en el aula de L2, el cual, en palabras de Álvarez Piñeiro y Camiña Salgado (2005) “estimula la motivación” del alumno durante su proceso de aprendizaje (p. 28).

Las dos primeras opciones cuentan con algunas similitudes puesto que ambas buscan un planteamiento de la actividad como algo atractivo, aunque, al mismo tiempo, presentan diferencias considerables. Dentro del juego siempre se incluyen unas normas (ya sean sociales como en juego de rol o de otro tipo) que no se pueden transgredir. Sin embargo, plantear la actividad como algo divertido supone asociar dichas actividades con canciones, cuentos, vídeos, etc. sin necesidad de proponer normas. Por su parte, los juegos no están relacionados obligatoriamente con algo divertido. Dichos juegos conllevan frecuentemente un desafío intelectual, un entretenimiento que no necesariamente implica diversión.

Como tercera opción, planteamos la idea de presentar una actividad de este tipo de la misma forma que lo haríamos con cualquier otra, es decir, aportando las explicaciones pertinentes, sin que esta se presente asociada al componente diversión o al carácter lúdico.

Considerando la dificultad que implica motivar a los alumnos de Educación Primaria cuando nos disponemos a presentar las actividades de expresión escrita libre inferimos que, aquellos profesores que manifiesten sus preferencias hacia la presentación de este tipo de actividades como algo divertido o como si se tratase de un juego, serán aquellos que tengan en cuenta los intereses particulares del alumno. Por el contrario, nos atrevemos a suponer que, aquellos informantes que 
afirmen presentarlas como cualquier otra actividad, no estarán contando con el componente motivacional en el aula de L2.

\subsubsection{Análisis de los datos: aptitudes en torno a cómo presentar una actividad de escritura libre en L2}

Analizamos las aptitudes de los informantes pertenecientes a centros educativos de Valladolid respecto a la forma de presentación de una actividad de escritura libre en L2. Los datos recogidos en el ítem 7 se muestran en la Tabla 21 y el Gráfico 21 que aparecen a continuación. Debemos tener en cuenta que 2 de los informantes no contestaron a esta pregunta.

\begin{tabular}{|lrr|}
\hline $\begin{array}{l}\text { ¿De qué manera presenta una actividad de escritura libre a sus } \\
\text { alumnos? }\end{array}$ & $\begin{array}{r}\text { Número de } \\
\text { respuestas }\end{array}$ & \begin{tabular}{c} 
Porcentaje \\
\hline Como algo divertido
\end{tabular} \\
\hline Como si se tratase de un juego & $\mathbf{1 5}$ & $\mathbf{4 8 . 3 9 \%}$ \\
\hline Como cualquier otra actividad & $\mathbf{8}$ & $\mathbf{2 5 . 8 1 \%}$ \\
\hline Otros: & $\mathbf{7}$ & $\mathbf{2 2 . 5 8 \%}$ \\
\hline Un reto en el que ellos tienen algo personal que expresar & 1 & $\mathbf{3 . 2 3 \%}$ \\
\hline Total & 1 & $3.23 \%$ \\
\hline
\end{tabular}

Tabla 21. Resultados sobre la presentación de una actividad de escritura libre en L2 en Valladolid 


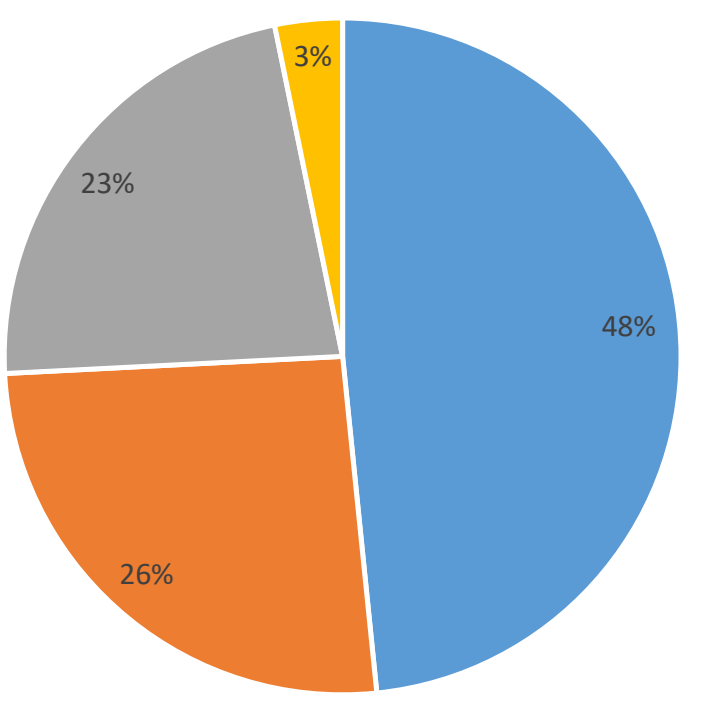

- Como algo divertido

- Como si se tratase de un juego

- Como cualquier otra actividad

- Otros: Un reto en el que ellos tienen algo personal que expresar

Gráfico 21. Resultados sobre la presentación de una actividad de escritura libre en L2 en Valladolid

Respecto a los porcentajes, calculados a partir de los 31 informantes (de un total de 33), que aportaron su respuesta observamos que un $48 \%$ reconoce presentar estas actividades como algo divertido, es decir, intentando acercar la actividad a los intereses particulares del alumno. La segunda opción con un porcentaje más alto de respuestas (26\%) es la de aquellos que deciden introducir el componente lúdico en las actividades de expresión escrita. Encontramos un porcentaje bastante aproximado al anterior (23\%) en los informantes que presentan este tipo de actividades como si se tratase de cualquier otra.

En la sección "otros" recibimos una aportación por parte de uno de nuestros informantes quien afirma presentar este tipo de actividades como si fuese un reto personal para el alumno (3\%). Consideramos que esta aportación comparte similitudes con la opción: "como algo divertido" 
puesto que, en ambos casos el profesor busca la estimulación y la motivación del alumno. Sin embargo, un reto personal no necesariamente contiene el componente diversión ni tampoco el componente lúdico por lo que podemos decir que nos encontramos ante una respuesta independiente de las opciones originales.

Los resultados respecto a cómo presentar una actividad de escritura libre en la ciudad de Austin (considerando que uno de los 40 informantes no escogió respuesta) se presentan en la Tabla 22 y el Gráfico 22 que aparecen a continuación:

\begin{tabular}{|lrr|}
\hline $\begin{array}{l}\text { ¿De qué manera presenta una actividad de escritura libre a sus } \\
\text { alumnos? }\end{array}$ & $\begin{array}{r}\text { Número de } \\
\text { respuestas }\end{array}$ & $\begin{array}{r}\text { Porcentaje } \\
\hline \text { Como algo divertido }\end{array}$ \\
\hline Como si se tratase de un juego & $\mathbf{2 5}$ & $\mathbf{6 4 . 1 0 \%}$ \\
\hline Como cualquier otra actividad & $\mathbf{5}$ & $\mathbf{1 2 . 8 2 \%}$ \\
\hline Otros: & $\mathbf{7}$ & $\mathbf{1 7 . 9 5 \%}$ \\
\hline \multicolumn{1}{|c|}{ Siempre con intención comunicativa ligada a su realidad } & 1 & $\mathbf{5 . 1 3 \%}$ \\
\hline Utilizando videos, fotos, cuentos, libros y otros materiales de apoyo & 1 & $2.56 \%$ \\
\hline Total & 39 & $\mathbf{1 0 0 . 0 0 \%}$ \\
\hline
\end{tabular}

Tabla 22. Resultados sobre la presentación de una actividad de escritura libre en L2 en Austin 


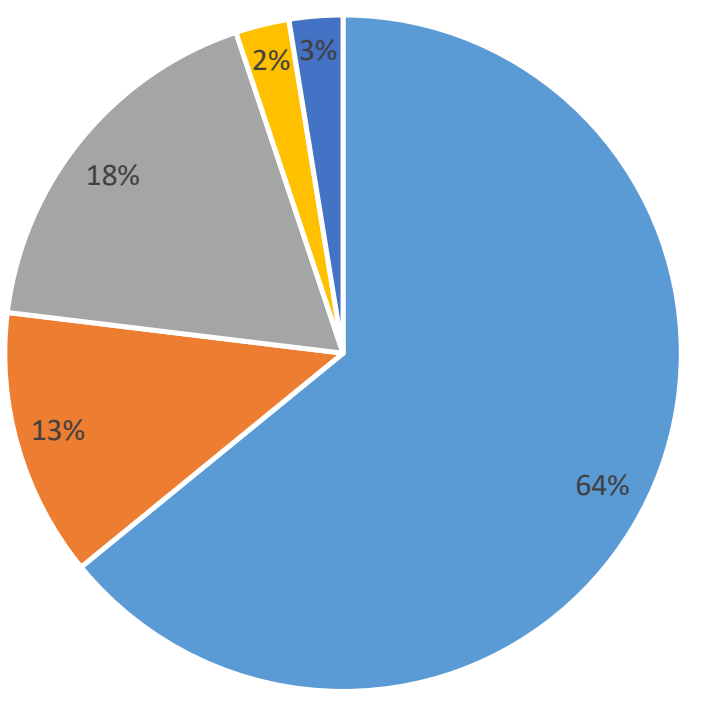

- Como algo divertido

- Como si se tratase de un juego

- Como cualquier otra actividad

- Otros: Siempre con intención comunicativa ligada a su realidad

- Otros: Utilizando videos, fotos, cuentos, libros y otros materiales de apoyo

Gráfico 22. Resultados sobre la presentación de una actividad de escritura libre en L2 en Austin

En cuanto al planteamiento de las actividades de escritura libre en la ciudad de Austin a partir de las 39 respuestas aportadas (de un total de 40 informantes) observamos que existe una amplia mayoría (64\%) que presenta este tipo de actividades como algo divertido, un $13 \%$ lo hace como si fuera un juego y un 18\% las presenta como cualquier otra actividad. En la sección "otros" se incluyen un informante que manifiesta la importancia de acercar este tipo de actividades a los intereses particulares del alumno (a su realidad) con el propósito de facilitar la tarea al alumno (2,5\%). La idea de ligar este tipo de actividades a la realidad del alumno se constituye como algo esencial puesto que, el planteamiento de un tema conocido y cercano a este permitirá que se sienta cómodo y motivado en el momento de producir. El segundo informante (que representa un 2,5\%) decide nombrar los materiales de apoyo que utiliza a la hora de presentar la actividad de expresión escrita: videos, fotos, cuentos, libros, etc. De nuevo nos acercamos al tema de la búsqueda de la motivación del alumno a la hora de presentar una actividad de expresión escrita, aunque 
consideramos que estas dos aportaciones son independientes de las propuestas originales por lo que decidimos no asociarlas a ninguna de ellas.

\subsubsection{Interpretación de los resultados: aptitudes en torno a cómo presentar una actividad de escritura libre en $\mathrm{L} 2$}

A la hora de analizar los dos contextos educativos encontramos que ambos cuentan con porcentajes similares. Así pues, el $48 \%$ de los informantes de Valladolid insiste en presentar este tipo de actividades como algo divertido frente al $64 \%$ de Austin. Un 26\% de los vallisoletanos afirma hacerlo como si se tratase de un juego frente al 13\% de Austin y, por último, un 23\% en Valladolid frente al 18\% de Austin lo hace como si fuese cualquier otra actividad.

Como ya hemos señalado anteriormente, la tarea de escribir puede convertirse en una experiencia frustrante para el profesor puesto que esta implica un gran nivel de dificultad a la hora de motivar a los alumnos. Cuando un profesor solicita a sus alumnos que lleven a cabo una actividad de escritura libre, entra en juego la denominada carga emocional-afectiva. Para el alumno, lo emocional-afectivo puede llegar a tener un fuerte impacto a la hora de redactar e incluso en el producto final.

Las opciones que más se aproximan al intento de motivar a los alumnos y por tanto las que consideramos que todo profesor de Educación Primaria debe tener en cuenta a la hora de proponer una actividad de expresión escrita en el aula de L2 son las que plantean la actividad como algo divertido o como un juego. En este sentido, sumando los porcentajes de las dos primeras opciones 
$(48 \%+26 \%=74 \%$ en Valladolid) y $(64 \%+13 \%=77 \%$ en Austin) encontramos resultados muy aproximados en cada uno de los dos contextos. Además, las aportaciones de aquellos informantes que decidieron ampliar información en el apartado "otros" tanto en un contexto como en el otro hablan de reto, de ligar la actividad a su realidad y del uso de materiales de apoyo atractivos: videos, fotos, cuentos, etc. En una palabra, los datos proporcionados parecen indicar que los profesores de ambos contextos educativos, a la hora de presentar una actividad de escritura libre buscan lo que Krashen (1988) llamaba "motivación integrante" o ese deseo de comunicarse con los hablantes de L2, en este caso, de forma escrita.

A partir de los resultados obtenidos de las respuestas al ítem número 7 en los dos contextos educativos, concluimos que los informantes de ambos contextos cuentan con aptitudes o capacidades respecto a la búsqueda de la motivación del alumno cuando a este se le propone una actividad de escritura libre en L2.

\subsection{Aptitudes en torno a la ayuda proporcionada a los alumnos durante la realización de actividades de escritura libre en $\mathrm{L} 2$}

En el ítem número 8, abordamos el grado de intervención de los informantes a la hora de proporcionar ayuda a sus alumnos durante el desarrollo de actividades de expresión escrita libre en L2, así como su nivel de implicación. Haciendo nuestras las palabras de Cassany (2005) comentábamos en el epígrafe 3.2.2 que escribir puede convertirse en una "tarea cognitivamente compleja, que va mucho más allá de la resolución de dudas ortográficas o de redacción” (Cassany, 
2005, p. 41). En este sentido, nos interesa saber si se proporciona ayuda al alumno durante el desarrollo de las actividades de producción escrita y, de ser así, si se trata de una ayuda interna: la del propio informante u otro tipo de ayuda (como puede ser la ayuda de algún compañero del aula).

Retenemos la idea de Corpas y Madrid (2007) a quienes mencionábamos en el epígrafe 3.2.2 del presente trabajo de investigación respecto a que, la solicitud de ayuda por parte del alumno se revela como una de las técnicas procesuales más utilizada. Asimismo, el MCER (Consejo de Europa, 2002), documento al que hacemos referencia en el mismo epígrafe, también plantea la petición de ayuda como un recurso al que el alumno debe acudir siempre que lo considere necesario.

Reflexionamos acerca del grado de intervención didáctica por parte del profesor en las actividades de expresión escrita libre destacando la idea de que el profesor o, en su lugar, el ayudante o asistente de aula es quien debe dirigir y orientar al alumno de Educación Primaria durante el proceso de producción textual. La consecución de unos resultados óptimos en las actividades de expresión escrita de los alumnos dependerá no solo de su motivación hacia la actividad sino también del tipo de intervención del profesor. Consideramos que este debe guiar y acompañar en todo momento al alumno durante el proceso haciéndole llegar sus comentarios, recomendaciones y sugerencias a través de feedback oral durante el transcurso de entrevistas privadas. Dicho feedback oral puede aparecer acompañado de breves notas que permitan al alumno recordar esos comentarios del profesor cuando estos se dispongan a reformular sus borradores. 
A través del presente ítem, recabamos información sobre las aptitudes de los informantes a la hora de ofrecer y gestionar la posible ayuda a los alumnos durante el proceso de composición escrita en L2.

\subsubsection{Análisis de los datos: aptitudes en torno a la ayuda proporcionada a los alumnos durante la realización de actividades de escritura libre en L2}

Los datos obtenidos del análisis del contexto educativo de Valladolid se muestran en la Tabla 23 y el Gráfico 23 que aparecen a continuación. Habida cuenta que todos los informantes responden a esta pregunta, podemos hablar de participación absoluta en el presente ítem.

\begin{tabular}{lrr|}
$\begin{array}{l}\text { Durante la realización de una actividad de escritura, cel alumno recibe } \\
\text { alguna ayuda por su parte o por parte de otro profesional de la } \\
\text { educación que se encuentre en el aula? }\end{array}$ & $\begin{array}{r}\text { Número de } \\
\text { respuestas }\end{array}$ & $\begin{array}{r}\text { Porcentaje } \\
\hline \text { Sí, yo le dirijo durante el transcurso de la actividad }\end{array}$ \\
\hline No, se trata de una actividad completamente libre & $\mathbf{2 5}$ & $\mathbf{7 8 . 1 3 \%}$ \\
\hline Otros: & $\mathbf{4}$ & $\mathbf{1 2 . 5 0 \%}$ \\
\hline Recurren a un diccionario o piden ayuda al profesor & $\mathbf{3}$ & $\mathbf{9 . 3 8 \%}$ \\
\hline Reciben ayuda cuando la solicitan & 1 & $3.13 \%$ \\
\hline Reciben mi ayuda si la requieren & 1 & $3.13 \%$ \\
\hline Total & 1 & $3.13 \%$ \\
\hline
\end{tabular}

Tabla 23. Resultados sobre las aptitudes del informante orientadas a la ayuda proporcionada durante la realización de actividades de escritura libre en L2 en Valladolid 


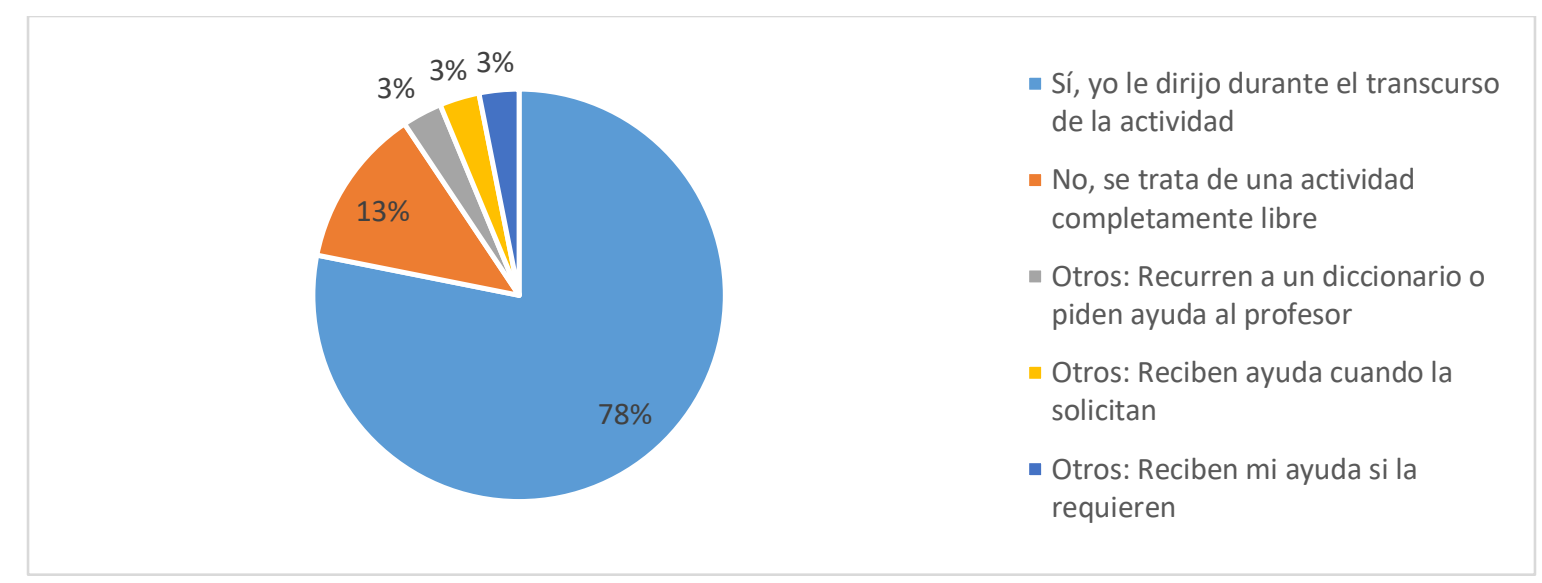

Gráfico 23. Resultados sobre las aptitudes del informante orientadas a la ayuda proporcionada durante la realización de actividades de escritura libre en L2 en Valladolid

Encontramos un elevado porcentaje de informantes en Valladolid (78\%) que optan por proporcionar ayuda a los alumnos durante el transcurso de las actividades de expresión escrita libre en L2. Un $13 \%$ afirma que, tratándose de una actividad libre, no proporciona ayuda con el objetivo de que sea el alumno quien realice la actividad por su cuenta.

En la sección "otros" contamos con un 9\% de profesores cuyas respuestas permiten suponer que los tres informantes no dirigen la actividad y su grado de intervención es mínimo. Así pues, el primero de ellos (3\%) menciona que los alumnos recurren a la ayuda de un diccionario o del propio profesor solo cuando estos lo necesitan. Las dos últimas aportaciones ponen de manifiesto la intervención del profesor solo cuando el alumno lo solicita. Consideramos que las respuestas de estos tres informantes que afirman intervenir en momentos puntuales, se aproximan a la segunda opción: "no, se trata de una actividad completamente libre” y, por esta razón, decidimos que el porcentaje de informantes que eligieron la opción "otros" (9\%) debe sumarse al de dicha respuesta obteniendo un resultado de $22 \%$. 
Los datos obtenidos a partir de las respuestas de los informantes de la ciudad de Austin, aparecen en la Tabla 24 y el Gráfico 24 que se muestran a continuación. Debemos tener en cuenta que uno de los 40 informantes decidió no participar en el presente ítem.

\begin{tabular}{|c|c|c|}
\hline $\begin{array}{l}\text { Durante la realización de una actividad de escritura, cel alumno recibe } \\
\text { alguna ayuda por su parte o por parte de otro profesional de la } \\
\text { educación que se encuentre en el aula? }\end{array}$ & $\begin{array}{l}\text { Número de } \\
\text { respuestas }\end{array}$ & Porcentaje \\
\hline Sí, yo le dirijo durante el transcurso de la actividad & 21 & $53.85 \%$ \\
\hline No, se trata de una actividad completamente libre & 4 & $10.26 \%$ \\
\hline $\begin{array}{l}\text { Hay un asistente en el aula que ayuda y dirige al alumno cuando lo } \\
\text { necesita }\end{array}$ & 6 & $15.38 \%$ \\
\hline Otros: & 8 & $20.51 \%$ \\
\hline Los ayudo solo cuando ellos lo necesitan & 1 & $2.56 \%$ \\
\hline $\begin{array}{l}\text { Sobre todo, les dirijo cuando se trata de una actividad de escritura cuyo } \\
\text { resultado final será publicado. Les indicaré en todo momento cuáles son } \\
\text { las estrategias para mejorar la escritura }\end{array}$ & 1 & $2.56 \%$ \\
\hline Yo les dirijo al principio, pero después tienen libertad & 1 & $2.56 \%$ \\
\hline $\begin{array}{l}\text { Damos instrucciones y ejemplos de lo que se espera y los dejamos } \\
\text { después libremente. Pasamos constantemente a monitorear, pero no los } \\
\text { dirigimos }\end{array}$ & 1 & $2.56 \%$ \\
\hline Depende del producto & 1 & $2.56 \%$ \\
\hline En ocasiones la escritura es dirigida y en otras es libre & 1 & $2.56 \%$ \\
\hline $\begin{array}{l}\text { Depende. Hay ocasiones en las que se deja que ellos escriban sin ayuda. } \\
\text { En otras ocasiones les dirijo }\end{array}$ & 1 & $2.56 \%$ \\
\hline Los alumnos trabajan en grupos ayudándose unos a otros & 1 & $2.56 \%$ \\
\hline Total & 39 & $100.00 \%$ \\
\hline
\end{tabular}

Tabla 24. Resultados sobre las aptitudes del informante orientadas a la ayuda proporcionada durante la realización de actividades de escritura libre en L2 en Austin 


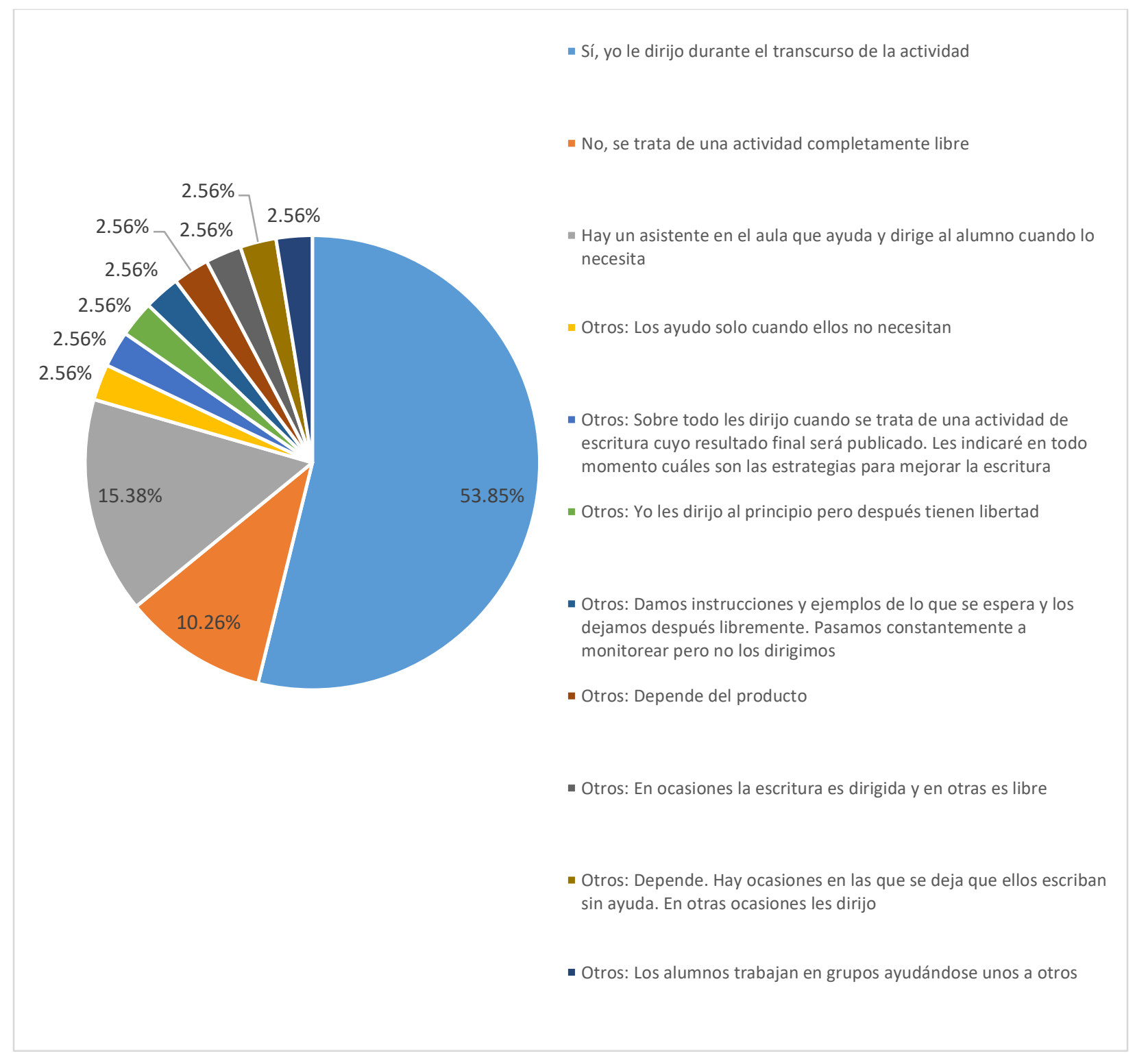

Gráfico 24. Resultados sobre las aptitudes del informante orientadas a la ayuda proporcionada durante la realización de actividades de escritura libre en L2 en Austin

Los datos revelan que un 53,85\% de los 39 informantes que contestaron dirigen al alumno durante el transcurso de la actividad de expresión escrita en L2 y el 10,26\% no proporciona ningún tipo de ayuda. 
Encontramos un $21,51 \%$ de informantes que optan por ampliar sus respuestas tras elegir la opción "otros". El primero de ellos afirma proporcionar ayuda a los alumnos solo cuando estos lo necesitan. Consideramos que el porcentaje correspondiente a este informante $(2,56 \%)$ debe sumarse al obtenido a partir de la opción: "no, se trata de una actividad completamente libre" $(10,26 \%)$ puesto que se habla de una intervención que se lleva a cabo solo en momentos puntuales, con un resultado final del $12,82 \%$.

El segundo informante que eligió la opción "otros" afirma que dirige a los estudiantes, sobre todo en las actividades cuyo borrador final sea publicado. La información que nos hace llegar, nos permite afirmar que interviene de una forma activa durante el proceso de expresión escrita de los alumnos, haciendo hincapié en aquellas actividades cuyo objetivo es producir un borrador final que los alumnos expondrán posteriormente en el aula. Decidimos por tanto sumar el porcentaje correspondiente a este informante (2,56\%) al 53,85\% de la primera respuesta: “sí, yo les dirijo durante el transcurso de la actividad" obteniendo así un 56,41\%.

Las dos respuestas siguientes: "yo les dirijo al principio, pero después tienen libertad" $(2,56 \%)$ y “damos instrucciones y ejemplos de lo que se espera y los dejamos después libremente. Pasamos constantemente a monitorear, pero no dirigimos" $(2,56 \%)$ incluidas dentro de la sección “otros" nos acercan a la idea de dirigir al alumno solamente durante el comienzo de la actividad aportando las instrucciones correspondientes, pero no durante todo el transcurso de esta por lo que se trata de respuestas independientes que no asociamos a ninguna de las originales. 
Las tres respuestas presentadas a continuación: "depende del producto" (2,56\%), “en ocasiones la escritura es dirigida y en otras es libre" (2,56\%) y "depende. Hay ocasiones en las que se deja que ellos escriban sin ayuda, en otras ocasiones les dirijo" $(2,56 \%)$ nos transmiten la idea de que los tres informantes proporcionan ayuda en función de distintas circunstancias y no en el transcurso completo de la actividad. En este sentido, volvemos a encontrarnos con respuestas independientes no asociadas a ninguna de las opciones originales.

La última aportación que encontramos en el apartado "otros": "los alumnos trabajan en grupos ayudándose unos a otros" $(2,56 \%)$ hace alusión a un planteamiento de la actividad de expresión escrita libre en el que los miembros de un mismo grupo participan de forma conjunta en el proceso de producción escrita. Dicha aportación nos sitúa ante una propuesta totalmente distinta al tipo de actividad que planteábamos en el enunciado del ítem número 8, por lo que decidimos no asociarla a ninguna otra respuesta. Cabe mencionar que, la actividad planteada por este informante, tiene relación directa con las sesiones de revisión por parte de uno o varios compañeros de clase o "peer review sessions" (Ferris, 2003, p. 22) que poníamos de relieve en el epígrafe 1.1.3 de esta Tesis como práctica complementaria a las entrevistas con el profesor. Este tipo de sesiones se llevan a cabo durante el proceso de corrección y en ellas, se insta a otros alumnos del aula a colaborar con el autor de la producción escrita. Como ya apuntábamos en el epígrafe mencionado, este tipo de prácticas surgen como consecuencia de un cambio en el enfoque pedagógico en la enseñanza de producción de textos escritos en L2 para el contexto educativo norteamericano. Se ha constatado asimismo que, la presencia de compañeros de aula en el proceso de revisión de borradores o de corrección constituye una fuente de motivación para el alumno ya que este, como 
se ha podido confirmar a través de varios estudios de investigación, en general, manifiesta su preferencia en torno a la revisión y corrección por parte de otros alumnos.

\subsubsection{Interpretación de los resultados: aptitudes en torno a la ayuda proporcionada a los alumnos durante la realización de actividades de escritura libre en L2}

En el análisis de datos encontramos un $78 \%$ de informantes vallisoletanos que afirma dirigir a los alumnos durante el transcurso de la actividad de expresión escrita frente al 56,41\% de Austin. Se trata, en ambos casos, de porcentajes elevados por encima del 50\%. Asimismo, el $22 \%$ de los informantes de Valladolid manifiesta no realizar intervenciones frente al 12,82\% de Austin.

Los resultados obtenidos a partir de las respuestas al ítem número 8 en los dos contextos educativos nos permiten afirmar que los informantes de ambos cuentan con aptitudes respecto al grado de intervención durante la realización de actividades de escritura libre en L2 por parte de los alumnos. De acuerdo con sus respuestas, tanto los informantes del contexto educativo de Valladolid como los que ejercen su actividad docente en la ciudad de Austin intervienen de forma activa ayudando y guiando a los alumnos durante el proceso de producción textual.

Los datos parecen indicar que la solicitud de ayuda es un recurso utilizado frecuentemente por los alumnos de los dos contextos educativos. En relación al acompañamiento y la ayuda proporcionada por los profesores, nos preguntamos si esta se materializa en comentarios, 
recomendaciones y sugerencias a través de feedback oral emitidos durante el transcurso de conferencias privadas con el alumno, en el uso de breves notas que les ayuden a reformular sus borradores o se trata simplemente de comentarios aislados que el profesor emite en voz alta dirigiéndose al grupo clase.

\subsection{Aptitudes en cuanto a la elección de modalidades de corrección de las actividades de escritura libre en $\mathrm{L} 2$}

El ítem número 11 del cuestionario está diseñado con el propósito de indagar sobre las aptitudes de los profesores respecto a la elección de modalidades de corrección de errores y su grado de participación en estas. Las opciones de respuesta para este ítem aportarán información a nuestro estudio acerca del tratamiento del error utilizado en el aula de L2. La elección, por parte de los informantes, de una de las dos primeras opciones: "siempre yo" o "mi asistente" nos permitirá afirmar que son ellos (o los asistentes de aula) quienes se enfrentan, de manera individual a las producciones escritas, detectan los errores y los marcan para, finalmente, proporcionar la respuesta correcta al alumno. El feedback que acompaña a este tipo de corrección suele materializarse en una serie de comentarios y/o nota numérica que el profesor escribe en el mismo papel donde se encuentra la producción escrita del alumno. Se trata, en nuestra opinión de un feedback insuficiente que no permite al profesor poder expresarse de una forma libre. El hecho de presentarse de forma escrita impide el uso de lenguaje kinésico el cual se configura como un elemento primordial de apoyo al discurso oral. Consideramos que este tipo de corrección no promueve la reflexión del alumno acerca de sus errores o del propio funcionamiento de la lengua. 
Además, se trata de un tipo de corrección orientada al producto final. No obstante, a través de la elección de las dos últimas opciones de respuesta (corrección por parte de compañeros de aula o autocorrección), nuestros informantes nos darán a conocer su interés por fomentar la reflexión del alumno sobre sus propios errores. Teniendo en cuenta que estos dos tipos de corrección promueven la creación de un aprendizaje significativo de la L2 nos atrevemos a suponer que dichos profesores utilizarán técnicas de corrección orientadas al proceso (como puede ser la técnica de borradores encadenados en la que el alumno corrige sus propios errores a partir de las recomendaciones del profesor) e impulsarán el trabajo cooperativo y la interacción entre alumnos, así como entre alumno-profesor.

Como ya destacábamos en el epígrafe 2.1.2, los autores Tedick y de Gortari (1998) proponían, entre otras, determinadas prácticas de corrección de errores centradas en el alumno. Mostramos nuestro acuerdo con dichos autores respecto a la importancia de proporcionar ocasiones a los alumnos en las que estos puedan detectar sus propios errores y corregirse a sí mismos. Consideramos que dicha opción, junto con la de corrección de las producciones de los compañeros de aula posibilitarán la reflexión del alumno sobre sus propios errores y sobre el funcionamiento de la lengua en general. Esta reflexión se revela como parte fundamental del tratamiento de errores, y, de acuerdo con Santos Gargallo (1994) ayudará a pulir y a mejorar las producciones escritas en L2, como ya mencionábamos en el epígrafe 2.1.2.

Asimismo, en el epígrafe 1.1.3 de este trabajo, apuntábamos que, como consecuencia de un cambio en el enfoque pedagógico en la enseñanza de producción escrita, los pedagogos y profesionales de la enseñanza de L2 comienzan a inclinarse hacia un tipo de corrección en la que 
el profesor, los compañeros del aula y el propio alumno (autor) se revelan como sujetos activos dentro de dicho proceso. En virtud de ello, los métodos de entrevistas personales entre profesor y alumno denominadas por Ferris (2003) "one-to-one writing conferences" o "teacher-student writing conferences" comienzan a ser habituales en los centros educativos, así como las sesiones de revisión por parte de uno o varios compañeros de clase o "peer review sessions" en las que se pide la colaboración de otros alumnos del aula con el autor de la producción escrita.

El presente ítem está directamente relacionado con los ítems 13, 14 y 16. A partir de los datos proporcionados nos proponemos averiguar si nuestros informantes hacen uso del enfoque metodológico de producción escrita centrado en el producto (“product-oriented pedagogy”) o el enfoque centrado en el proceso ("process-oriented pedagogy”) ambos mencionados en el epígrafe 1.1.3 y 3.2.2 de este trabajo de investigación. Como ya hemos venido apuntando, el primero de ellos se centra únicamente en el producto o borrador final, por el contrario, el segundo analiza el propio proceso de escritura del alumno.

A nuestro juicio, el tipo de corrección adoptado se encuentra directamente relacionado con el enfoque metodológico utilizado en el momento de plantear actividades de expresión escrita en las aulas de L2. De acuerdo con esto, asociamos el uso de un tipo de corrección centrada exclusivamente en la intervención del profesor o asistente de aula con un enfoque metodológico orientado al producto. Por el contrario, nos atrevemos a suponer que, aquellos informantes que se inclinen por una corrección que promueva la reflexión por parte del alumno, estarán aproximándose a un enfoque orientado al mismo proceso de producción escrita en L2. 


\subsubsection{Análisis de los datos: aptitudes en cuanto a la elección de modalidades de corrección de las actividades de escritura libre en L2}

Los resultados obtenidos a partir de las respuestas de los informantes de Valladolid (considerando que 4 de los 33 informantes no aportaron dicha respuesta) al ítem número 11 se muestran en la Tabla 25 y el Gráfico 25 que aparecen a continuación:

\begin{tabular}{|lrr|}
\hline ¿Quién corrige las producciones escritas de sus alumnos? & Número de respuestas & Porcentaje \\
\hline Siempre yo & $\mathbf{8}$ & $\mathbf{2 7 . 5 9 \%}$ \\
\hline Los alumnos se corrigen unos a otros & 10 & $\mathbf{3 4 . 4 8 \%}$ \\
\hline Los alumnos se corrigen a sí mismos (autocorrección) & $\mathbf{9}$ & $\mathbf{3 1 . 0 3 \%}$ \\
\hline Otros: & $\mathbf{2}$ & $\mathbf{6 . 9 0 \%}$ \\
\hline Casi siempre entre ellos y a veces yo & 1 & $3.45 \%$ \\
\hline Yo con ellos delante & 1 & $3.45 \%$ \\
\hline Total & 29 & $100.00 \%$ \\
\hline
\end{tabular}

Tabla 25. Resultados sobre las aptitudes del informante en cuanto a la elección de modalidades de corrección de las actividades de escritura libre en L2 en Valladolid

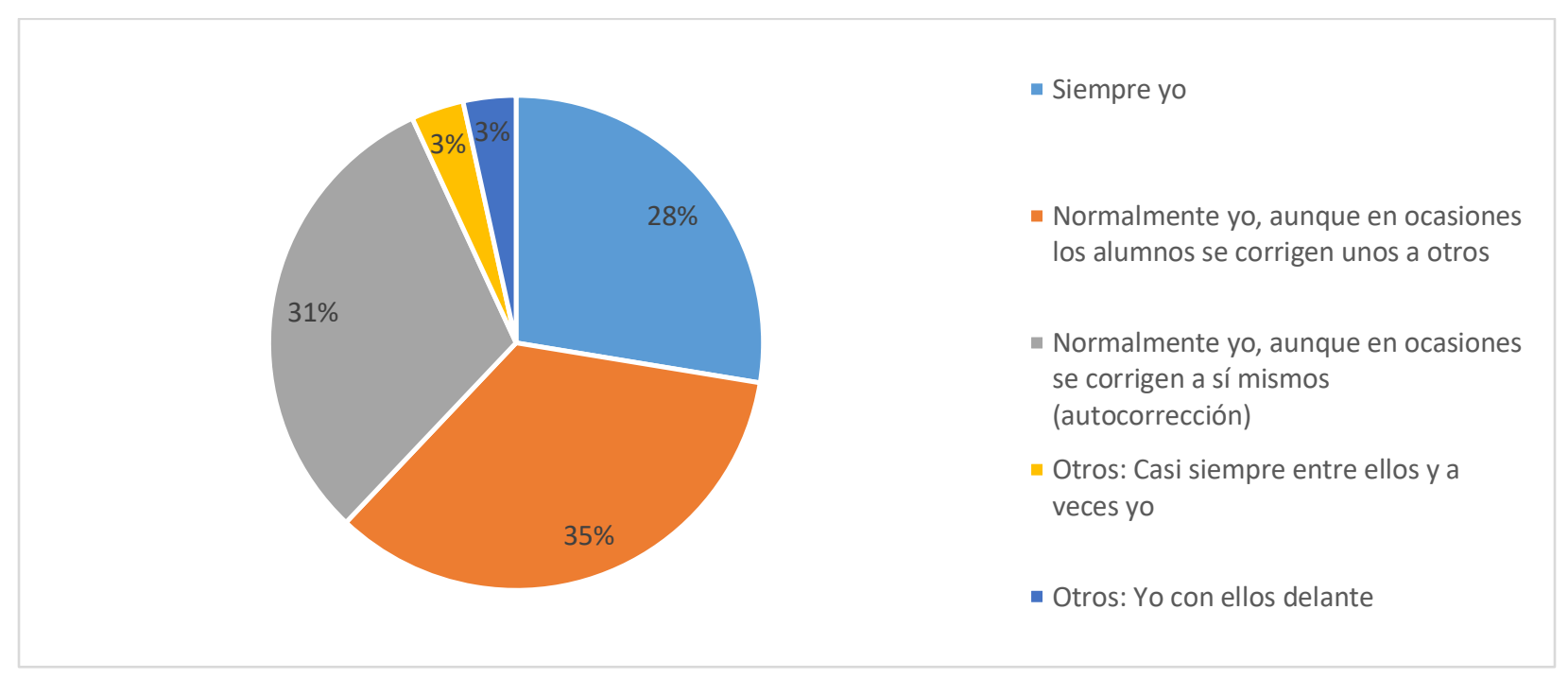

Gráfico 25. Resultados sobre las aptitudes del informante en cuanto a la elección de modalidades de corrección de las actividades de escritura libre en L2 en Valladolid 
En lo concerniente a los porcentajes correspondientes a los 29 informantes (de un total de 33) de la ciudad de Valladolid que contesta a esta pregunta, un $28 \%$ afirma que son ellos quienes corrigen siempre las producciones escritas de sus alumnos, un $35 \%$ entrega dichas producciones a otros compañeros del aula para que lleven a cabo las correcciones pertinentes y un $31 \%$ utiliza un sistema de autocorrección.

En el apartado "otros" nos encontramos ante dos informantes que han querido ampliar información. El primero de ellos $(3,45 \%)$ comenta que, normalmente son los propios alumnos quienes corrigen las producciones de sus compañeros, aunque en ocasiones es el quien lo hace. El segundo informante $(3,45 \%)$ afirma que él dirige el proceso de corrección, aunque siempre contando con la presencia de los propios alumnos para que estos puedan entender el significado de las correcciones.

Los datos proporcionados por los informantes del contexto educativo de la ciudad de Austin (contando con que uno de ellos no aportó respuesta) se muestran en la Tabla 26 y el Gráfico 26 que aparecen a continuación: 


\begin{tabular}{|lrr|}
\hline ¿Quién corrige las producciones escritas de sus alumnos? & $\begin{array}{c}\text { Número de } \\
\text { respuestas }\end{array}$ & $\begin{array}{r}\text { Porcentaje } \\
\hline \text { Siempre yo }\end{array}$ \\
\hline Mi asistente & $\mathbf{2}$ & $\mathbf{2 3 . 0 8 \%}$ \\
\hline Los alumnos se corrigen unos a otros & $\mathbf{5 . 1 3 \%}$ \\
\hline Los alumnos se corrigen a sí mismos (autocorrección) & $\mathbf{2 0 . 5 1 \%}$ \\
\hline Otros: & $\mathbf{1 6}$ & $\mathbf{4 1 . 0 3 \%}$ \\
\hline $\begin{array}{l}\text { Al principio del curso escolar, corrijo yo, pero después de las nueve } \\
\text { primeras semanas, son ellos mismos quienes se corrigen unos a otros }\end{array}$ & $\mathbf{1 0 . 2 6 \%}$ \\
\hline $\begin{array}{l}\text { La persona líder de clase con apoyo del asistente } \\
\text { Con la ayuda de mi asistente, corregimos y editamos los textos escritos } \\
\text { de nuestros alumnos }\end{array}$ & 1 & $2.56 \%$ \\
\hline $\begin{array}{l}\text { Leo en voz alta algunas de las composiciones escritas mostrándoles } \\
\text { cómo corregir partir de una tabla de criterios. Después, serán ellos } \\
\text { quienes corrijan su propia composición }\end{array}$ & 1 & $2.56 \%$ \\
\hline Total & 1 & $2.56 \%$ \\
\hline
\end{tabular}

Tabla 26. Resultados sobre las aptitudes del informante en cuanto a la elección de modalidades de corrección de las actividades de escritura libre en L2 en Austin

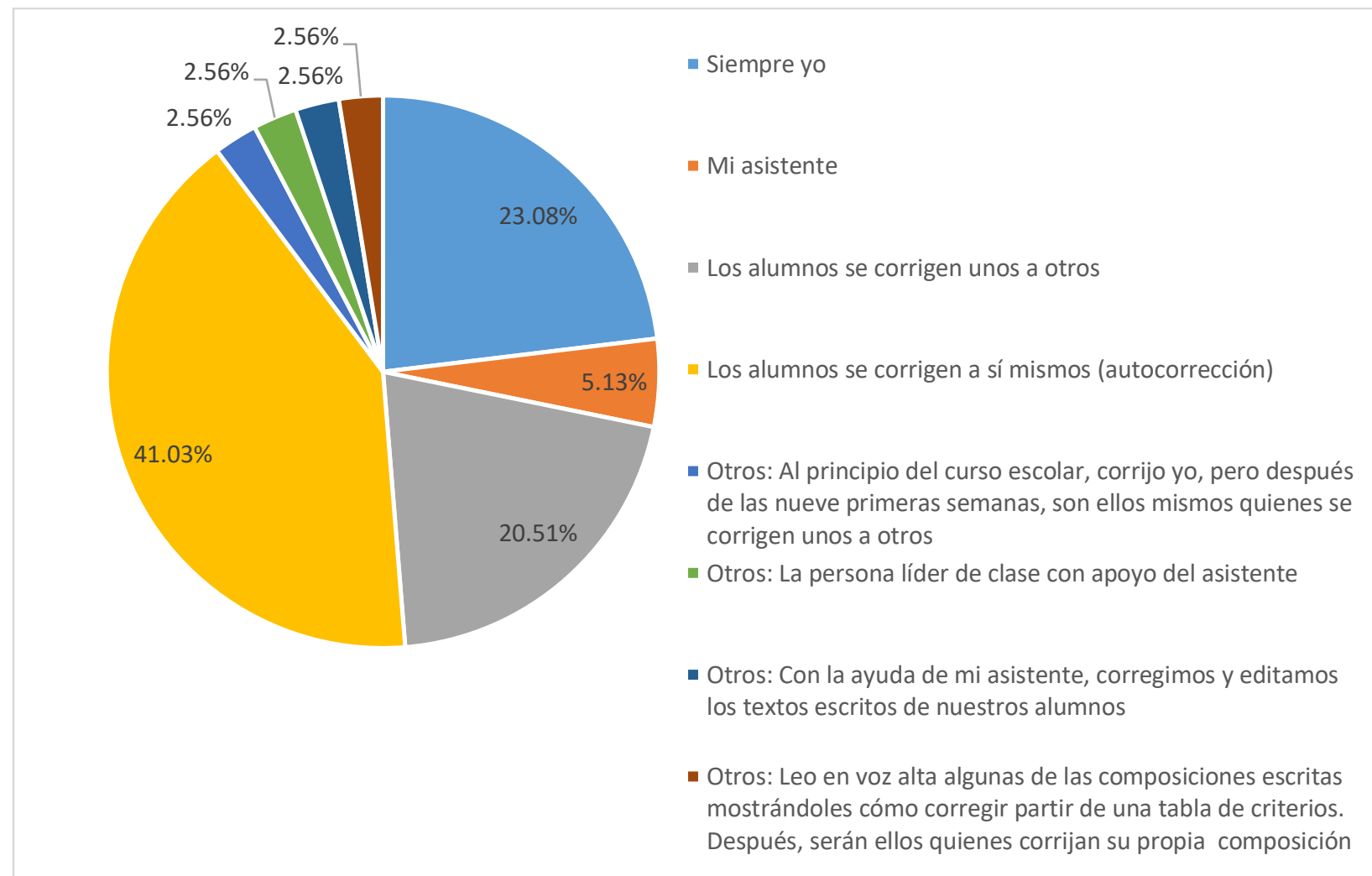

Gráfico 26. Resultados sobre las aptitudes del informante en cuanto a la elección de modalidades de corrección de las actividades de escritura libre en L2 en Austin 
En el contexto educativo de la ciudad de Austin encontramos que 39 de los 40 informantes contesta a la pregunta. Un 23,08\% de dicha cifra declara ser él mismo quien realiza las correcciones en todo momento, un 5,13\% afirma que es su asistente de aula, un 20,51\% destaca que son los propios alumnos quienes corrigen las producciones escritas de sus compañeros y un 41,03\% revela que los alumnos corrigen sus propias producciones.

El apartado "otros" engloba a cuatro informantes que optaron por ampliar su respuesta con información complementaria. Así pues, el primero de ellos $(2,56 \%)$ indica que las nueve primeras semanas es él quien lleva a cabo las correcciones. Pasado este tiempo, y después de haber mostrado y entrenado a los alumnos, serán ellos mismos quienes corrijan sus propias producciones. El segundo informante $(2,56 \%)$ escoge a un alumno de la clase; dicho alumno será quien realice las correcciones con la ayuda del asistente del aula. El siguiente informante revela ser él mismo quien corrige las producciones con la ayuda de su asistente. Consideramos que, el porcentaje correspondiente a esta respuesta. "con la ayuda de mi asistente corregimos y editamos los textos escritos de nuestros alumnos" $(2,56 \%)$ debe sumarse al total obtenido en la primera opción presentada "siempre yo" $(23,08 \%)$ por tratarse de opciones que expresan la misma idea, obteniendo así un total de 25,64\%. En la última intervención de la sección "otros" (2,56\%) encontramos a un profesor que declara leer en voz alta algunos ejemplos de composiciones escritas mostrándoles posteriormente su método de corrección en el que hace uso de unas tablas de criterios para que, posteriormente, a partir de las direcciones presentadas, sean ellos quienes corrijan su propia composición. Teniendo en cuenta que esta respuesta refleja la idea de solicitar al alumno que corrija sus propias producciones tras haber sido entrenado para ello, sumamos el porcentaje 
correspondiente $(2,56 \%)$ al de la opción presentada en cuarta posición: "los alumnos se corrigen a sí mismos (autocorrección)" (41,05 \%), formando un total de 43,61\%.

\subsubsection{Interpretación de los resultados: aptitudes en cuanto a la elección de modalidades de corrección de las actividades de escritura libre en L2}

Al comparar los datos relativos a los dos contextos educativos observamos que un $28 \%$ de los informantes vallisoletanos siempre lleva a cabo las correcciones de sus alumnos frente al 25,64\% de los informantes de Austin. Podemos constatar asimismo la carencia de asistentes en las aulas de L2 de Valladolid puesto que, ninguno de los profesores hace alusión a ellos en contraposición con el contexto de Austin en el que, un 5\% de informantes afirma asignar las tareas de corrección a su ayudante. Un 35\% de los profesores de Valladolid adopta una modalidad de corrección mediante la cual, los propios alumnos corrigen las producciones de sus compañeros frente al 20,51\% de la ciudad de Austin. Algo semejante ocurre en cuanto a la modalidad de autocorrección por parte de los propios alumnos. En Valladolid encontramos un porcentaje del $31 \%$ respecto al $43,61 \%$ de la ciudad de Austin.

Según los resultados, los informantes de los dos contextos educativos muestran, a través de las opciones de corrección elegidas, un gran interés por fomentar la reflexión del alumno sobre sus propios errores. Observamos que ambos utilizan determinadas modalidades de corrección que promueven el aprendizaje significativo de la L2 siendo las modalidades de corrección más elegidas aquellas en las que los propios alumnos son protagonistas y responsables directos del proceso de corrección. Por todo ello, nos atrevemos a suponer que dichos profesores utilizarán técnicas de 
corrección orientadas al proceso de producción escrita en L2 (como puede ser la técnica de borradores encadenados en la que el alumno corrige sus propios errores a partir de las recomendaciones del profesor) y fomentarán el trabajo cooperativo y la interacción oral en el aula.

Al analizar los resultados obtenidos a partir de las respuestas al ítem número 11 en los dos contextos educativos, concluimos que los informantes de ambos cuentan con aptitudes o capacidades respecto a la elección de modalidades de corrección de las actividades de escritura libre en L2.

\subsection{Aptitudes en torno a la dotación del feedback que acompaña a la corrección de errores de una actividad de escritura libre en $\mathrm{L} 2$}

A través de los cuestionarios nos acercamos al término feedback como un término ligado al de corrección. Entender cuáles son las aptitudes que tiene el profesor en torno a su uso durante el proceso de producción escrita de los alumnos de L2 constituirá una de nuestras prioridades en esta investigación.

Desde nuestra propia experiencia profesional docente consideramos el feedback una parte esencial del proceso de enseñanza-aprendizaje de la expresión escrita en L2. Los profesores, en palabras de Llopis García (2007) tienen su participación activa en el proceso de escritura del alumno por lo que, se impone la necesidad de que estos recurran al uso del feedback el cual, permite a los alumnos "saber si van por el camino correcto" (p. 137) para, posteriormente "continuar con 
la tarea, motivados por el acompañamiento y trabajo del profesor con ellos” (p. 137). Dicho feedback se revela como una herramienta útil y provechosa que el profesor utilizará con el fin de aportar ideas (a través del uso de pistas) y sugerencias dirigidas al alumno o grupo de alumnos para que estos puedan llevar a cabo cada uno de los pasos que componen el proceso de producción escrita con confianza y seguridad. Estos consejos y recomendaciones del profesor deberán ir acompañados, como ya mencionábamos en el epígrafe 1.1.3, de frases de apoyo, gestos de complicidad y cercanía, etc., que ejerzan un refuerzo positivo en el alumno.

Ya en el epígrafe 2.1.3 poníamos de manifiesto los distintos tipos de consideraciones y/o actitudes mostradas por diferentes autores hacia el feedback como parte del proceso de producción escrita y de corrección de errores. Entre estos mencionamos a Lee (2003) o Gascoigne (2004) quienes evidenciaban una falta de atención hacia el feedback fundamentada en la existencia de un número reducido de estudios existentes en torno a este y a sus posibles beneficios. En el mencionado epígrafe, hacíamos referencia a un elevado número de autores que muestran su apoyo respecto a la idea de suministrar los comentarios correspondientes a la corrección de las producciones escritas, a saber: Evans et al. (2010a); Fathman y Whalley (1990); Lee (2003) y Leki (1990). Nos situamos en la perspectiva de estos autores manifestando nuestro acuerdo hacia dicha idea.

Nos proponemos, a través del ítem número 13, recabar información sobre la forma y el momento en que el informante aporta feedback al alumno. En este sentido, nos interesa averiguar si este facilita el feedback durante el mismo proceso de producción escrita (a través de conferencias individuales con el alumno o grupo de alumnos, haciendo uso de un tipo de corrección inmediata) 
o bien lo hace una vez concluida la actividad de expresión escrita libre en L2 (lo cual nos llevaría a pensar en una corrección en diferido). Además, a partir de las respuestas respecto a la forma de dotación de feedback (oral-individual, oral dirigida al grupo-clase, escrita en el propio papel donde se encuentra la producción, escrita con código o escrita en hoja aparte) intentaremos averiguar si nuestros informantes hacen uso del enfoque metodológico de producción escrita centrado en el producto ("product-oriented pedagogy") o el enfoque centrado en el proceso ("process-oriented pedagogy"), cuyo uso apoyamos en el presente trabajo de investigación.

Unido al término feedback se encuentra lo que Gardner denominaba “teachers'professional and affective characteristics" (Gardner, 2010, p. 183) factor que influye en gran medida en la motivación de los alumnos en torno al aprendizaje de una L2 como ya destacábamos en el epígrafe 3.1.2. En toda interacción entre profesor-alumno, el factor afectivo juega un papel fundamental ya que influirá directamente en la motivación que el alumno muestre hacia esa L2. Como indicábamos en el mencionado epígrafe, un profesor motivado es aquel que conoce a los alumnos y su situación de interlengua, se adapta a sus necesidades educativas, fomenta su participación activa, mantiene altas sus expectativas, utiliza distintos métodos de enseñanza y trata a los alumnos con respeto. Compartimos la opinión de Gardner (2010) respecto a la importancia de la motivación en los profesores en consonancia con una actitud y a unas aptitudes centradas en un tipo de feedback oral, individual (o en grupo reducido) con una manifestación amable en el que el alumno se encuentre relajado y receptivo ante las sugerencias del profesor.

Los comentarios añadidos por el profesor a las producciones de los alumnos permiten, en palabras de Leki (1990) justificar las notas numéricas asignadas. En el epígrafe 2.1.3 
mencionábamos la existencia de un gran número de profesores que insiste en la necesidad de anotar sus comentarios y/o nota numérica en las mismas producciones escritas de los alumnos. Nos situamos en la línea de la mencionada autora respecto a que, aquellos profesores que manifiestan sus preferencias hacia este tipo de comentarios escritos por considerarlos más valiosos que las conferencias individuales, siguen un patrón tradicional de enseñanza de L2. Asimismo, mostramos nuestro acuerdo con Cassany (1993) respecto a que, esta forma de hacer llegar el feedback al alumno no favorece la presencia de un aprendizaje significativo a partir de la exposición ante sus propios errores puesto que, como ya hemos mencionado anteriormente, dichos comentarios escritos resultan, en la mayoría de los casos, imperceptibles para los alumnos de Educación Primaria, especialmente cuando estos van acompañados de nota numérica, ya que el alumno tiende a centrar su atención en esta.

Nos atrevemos a suponer que, aquellos profesores que marquen la opción de proporcionar el feedback oral de forma individual, estarán utilizando un enfoque centrado en el proceso de producción escrita en el que se tiene en cuenta el aprendizaje del alumno a partir de sus propios errores. La decisión por parte de nuestros informantes de utilizar un tipo de feedback oral general para toda la clase (segunda opción) muestra un interés implícito por el producto final y no por el proceso de producción escrita. Consideramos que este tipo de propuesta en la que se expone a los alumnos a todo tipo de errores de manera conjunta no atiende a las necesidades específicas del alumno centrándose en conseguir un producto final de calidad. Además, podemos inferir que, aquellos profesores que afirmen escribir los comentarios en el mismo papel donde se encuentre la producción escrita (tercera opción) estarán utilizando una corrección en diferido centrada también en el producto, es decir, en el borrador final en la que el alumno no tiene ocasión de interactuar 
con el profesor para poder aclarar sus dudas. Por último, los informantes que, habiendo elegido la cuarta opción de respuesta reconozcan utilizar un código de corrección, serán aquellos que utilicen un formato de corrección en diferido dando prioridad a la producción escrita o producto final. Esta opción pone de relieve la idea de código dirigido a la autocorrección que no siempre aparece acompañado de feedback oral, en cuyo caso puede generar confusión e inseguridad en el alumno en edades tempranas.

Consideramos, por tanto, que aquellos profesores que escojan la primera respuesta serán aquellos que cuenten con aptitudes óptimas para la dotación del feedback en el proceso de producción escrita de los alumnos de L2. Los formatos de feedback que ofrecen la segunda, tercera y cuarta opción nos acercan a la idea de corrección en diferido orientada al producto final, es decir, transmiten la imagen de un tipo de corrección tradicional que no favorece el aprendizaje significativo y en la que no se da importancia al proceso de aprendizaje de L2 a partir de los errores de los alumnos.

Como ya hemos mencionado anteriormente, desde nuestra experiencia como docentes de L2, consideramos que el feedback se constituye como una herramienta útil y provechosa siempre que se presente bajo el formato adecuado que, en nuestra opinión, se concreta en un discurso oral acompañado de breves anotaciones que contengan las sugerencias del profesor. En este sentido, manifestamos nuestro acuerdo con Evans et al. (2010a) respecto a que el feedback es una actividad que no se ha de realizar de manera independiente sino relacionada con una actividad que corresponde a la responsabilidad del alumno planteando, de esta manera, la idea de cooperación entre profesor y alumno en la corrección de errores. Nos situamos en la línea de Vázquez (2009) 
respecto a la necesidad de proporcionar un tipo de corrección orientada al proceso de escritura y no al producto en el aula de L2 de Educación Primaria.

7.5.1. Análisis de los datos: aptitudes en torno a la dotación del feedback que acompaña a la corrección de errores de una actividad de escritura libre en $\mathbf{L} 2$

En la Tabla 27 y el Gráfico 27 se muestran los datos obtenidos a partir de las respuestas de los informantes del contexto educativo de Valladolid al ítem número 13 del cuestionario. Debemos señalar la existencia de 2 informantes que deciden no aportar respuesta.

\begin{tabular}{|c|c|c|}
\hline $\begin{array}{l}\text { ¿De qué manera hace llegar a los alumnos sus comentarios o feedback } \\
\text { sobre las producciones escritas que han realizado? }\end{array}$ & $\begin{array}{l}\text { Número de } \\
\text { respuestas }\end{array}$ & Porcentaje \\
\hline De forma oral individualmente con cada alumno & 11 & $35.48 \%$ \\
\hline $\begin{array}{l}\text { De forma oral de manera conjunta (en voz alta) para que todos puedan } \\
\text { aprender de los errores de sus compañeros }\end{array}$ & 13 & $41.94 \%$ \\
\hline $\begin{array}{l}\text { Escribiendo los comentarios que considere oportunos con tinta de otro } \\
\text { color en el mismo papel donde se encuentra la producción escrita }\end{array}$ & 6 & $19.35 \%$ \\
\hline $\begin{array}{l}\text { Utilizo un código de corrección que mis alumnos ya conocen y señalo los } \\
\text { errores con dicho código en las propias producciones escritas de mis } \\
\text { alumnos }\end{array}$ & 1 & $3.23 \%$ \\
\hline Total & 31 & $100.00 \%$ \\
\hline
\end{tabular}



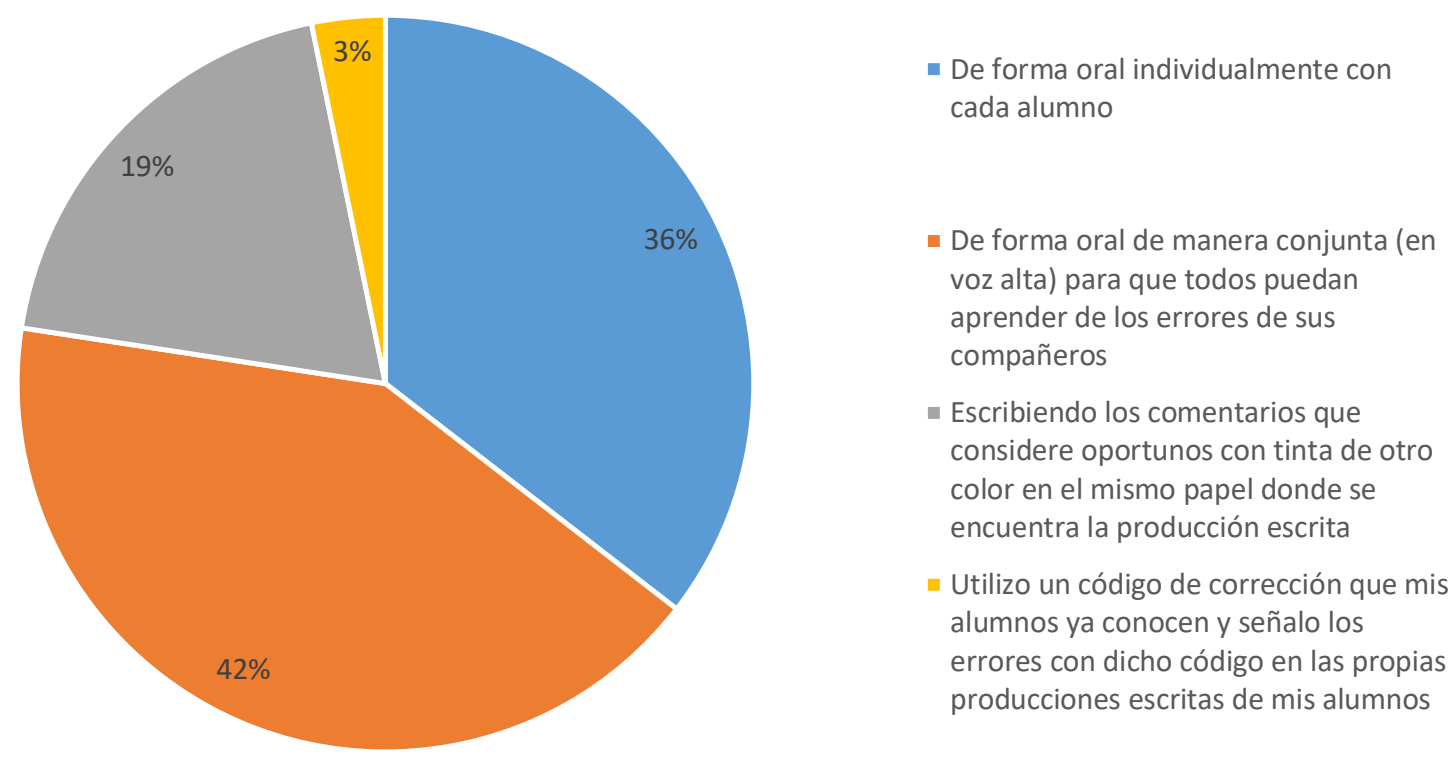

Gráfico 27. Resultados sobre las aptitudes del informante en torno al feedback que acompaña a la corrección de errores de una actividad de escritura libre en L2 en Valladolid

Observamos, a partir de los datos del contexto educativo de Valladolid (tomados de las 31 respuestas de los 33 participantes) la existencia de un 36\% de informantes que declara hacer llegar el feedback correspondiente a la corrección de las producciones escritas de los alumnos de L2 de forma oral, individualmente con cada alumno. Un $42 \%$ afirma hacerlo de manera conjunta en voz alta con el propósito de que todos puedan aprender de los errores de sus compañeros. El 19\% opta por escribir comentarios en la propia producción escrita y el 3\% marca los errores en el texto de los alumnos y señala el tipo de error para que estos realicen las correcciones a partir del código de corrección que ellos conocen. En el presente ítem, ninguno de los informantes elige la opción “otros" por lo que, no contamos con información adicional a las opciones propuestas. 
Nos acercamos a los datos del contexto educativo de la ciudad de Austin, los cuales, podemos encontrar en la Tabla 28 y el Gráfico 28 que se muestran a continuación. Dichos datos revelan la existencia de un $100 \%$ de participación en el presente ítem.

\begin{tabular}{|c|c|c|}
\hline $\begin{array}{l}\text { ¿De qué manera hace llegar a los alumnos sus comentarios o feedback } \\
\text { sobre las producciones escritas que han realizado? }\end{array}$ & $\begin{array}{l}\text { Número de } \\
\text { respuestas }\end{array}$ & Porcentaje \\
\hline De forma oral individualmente con cada alumno & 32 & $80.00 \%$ \\
\hline $\begin{array}{l}\text { De forma oral de manera conjunta (en voz alta) para que todos puedan } \\
\text { aprender de los errores de sus compañeros }\end{array}$ & 3 & $7.50 \%$ \\
\hline $\begin{array}{l}\text { Escribiendo los comentarios que considere oportunos con tinta de otro } \\
\text { color en el mismo papel donde se encuentra la producción escrita }\end{array}$ & 3 & $7.50 \%$ \\
\hline $\begin{array}{l}\text { Utilizo un código de corrección que mis alumnos ya conocen y señalo los } \\
\text { errores con dicho código en las propias producciones escritas de mis } \\
\text { alumnos }\end{array}$ & 1 & $2.50 \%$ \\
\hline Otros: & 1 & $2.50 \%$ \\
\hline $\begin{array}{l}\text { Escribo en las composiciones, marco errores y explico qué cosas pueden } \\
\text { mejorar. También hago comentarios de forma individual. }\end{array}$ & 1 & $2.50 \%$ \\
\hline Total & 40 & $100.00 \%$ \\
\hline
\end{tabular}

Tabla 28. Resultados sobre las aptitudes del informante en torno al feedback que acompaña a la corrección de errores de una actividad de escritura libre en L2 en Austin 

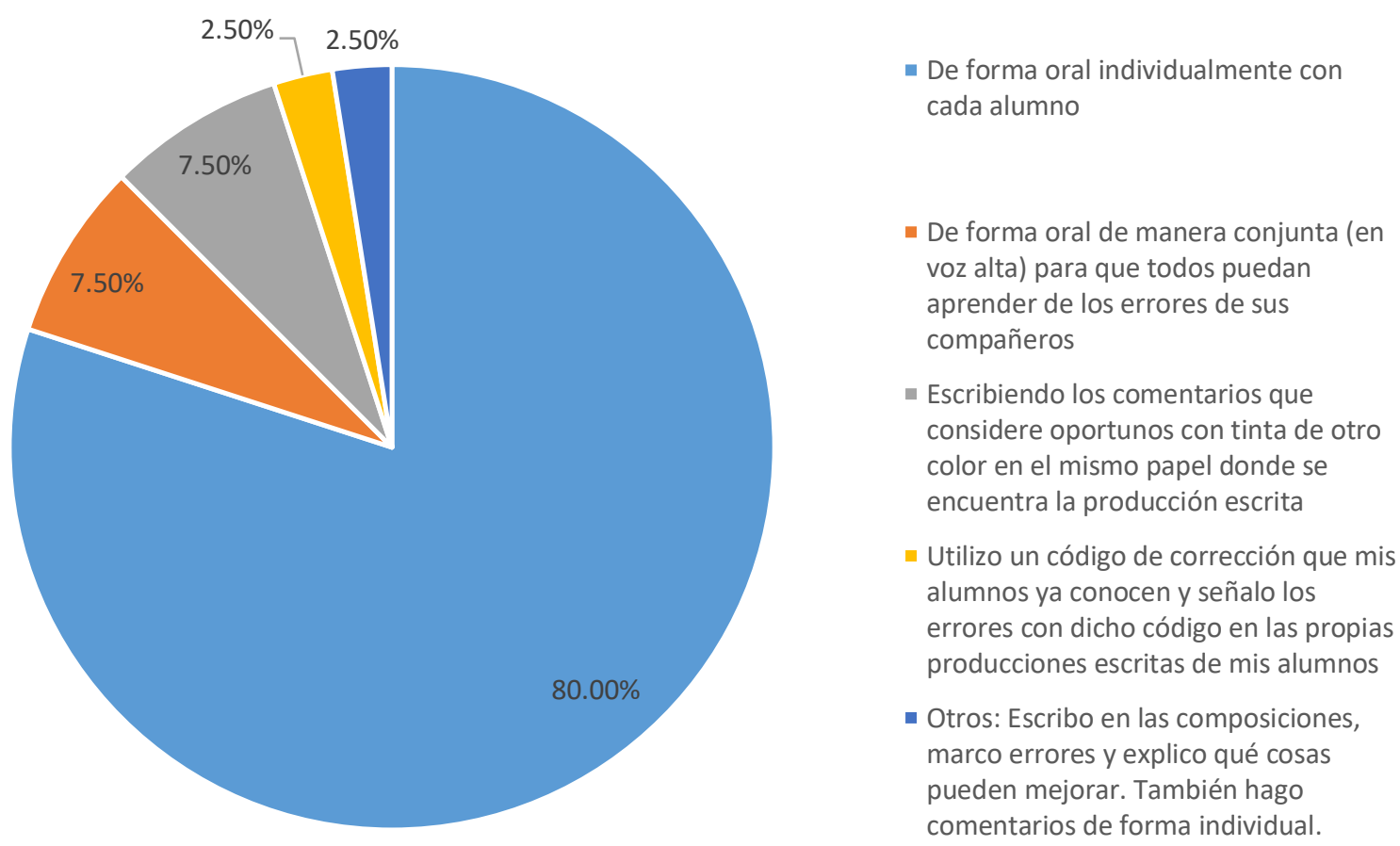

- Escribiendo los comentarios que considere oportunos con tinta de otro color en el mismo papel donde se encuentra la producción escrita

- Utilizo un código de corrección que mis alumnos ya conocen y señalo los errores con dicho código en las propias producciones escritas de mis alumnos

- Otros: Escribo en las composiciones, marco errores y explico qué cosas pueden mejorar. También hago comentarios de forma individual.

Gráfico 28. Resultados sobre las aptitudes del informante en torno al feedback que acompaña a la corrección de errores de una actividad de escritura libre en L2 en Austin

En el contexto educativo de Austin apreciamos la existencia de un porcentaje muy elevado de informantes (80\%) que afirma proporcionar el feedback que acompaña a la corrección de errores de forma oral individualmente con cada uno de los alumnos. Solo un 7,5\% declara hacerlo de forma conjunta (en voz alta dirigida al grupo clase), un 7,5\% escribe comentarios en el mismo papel donde se encuentra el texto del alumno y un 2,5\% utiliza un código de corrección.

En la sección "otros" nos encontramos ante un informante que, a través de su aportación nos hace saber que utiliza varias modalidades de dotación de feedback tales como: marcar los errores o escribir comentarios aportando feedback oral, que se lleva a cabo de forma individual cuando el alumno lo necesita. Consideramos que dicha aportación está relacionada con la dotación 
de feedback oral individual (que se combina con anotaciones escritas en la propia producción escrita). Decidimos, por tanto, asociar la respuesta de este informante que eligió la opción "otros" $(2,5 \%)$ con la primera respuesta: "De forma oral individual con cada alumno" $(80 \%)$ obteniendo un porcentaje total de $82,5 \%$.

\subsubsection{Interpretación de los resultados: aptitudes en torno a la dotación del feedback que acompaña a la corrección de errores de una actividad de escritura libre en L2}

El análisis de datos nos permite afirmar que nos encontramos ante dos contextos educativos con elementos identificativos diferentes. Así pues, descubrimos un $36 \%$ de informantes vallisoletanos que proporciona un feedback oral a cada uno de los alumnos frente al 82,5\% de la ciudad de Austin. En cuanto a la dotación de feedback en voz alta de manera conjunta, encontramos un $42 \%$ en Valladolid frente al 7,5\% de Austin. La práctica consistente en añadir comentarios escritos por parte del profesor en el texto del alumno se lleva a cabo por un $19 \%$ de los informantes de Valladolid frente al 7,5\% de Austin y el uso de código de corrección es usado por un 3\% en Valladolid frente al 2,5\% en Austin.

Los resultados obtenidos a partir de las respuestas al ítem número 13 diseñado para obtener información sobre la modalidad de feedback utilizada y el momento en el que el informante proporciona dicho feedback al alumno en los dos contextos educativos nos acercan a una serie de conclusiones. 
En primer lugar, una amplia mayoría de informantes del contexto educativo de Valladolid hace llegar el feedback al alumno una vez concluida la actividad y no durante el mismo proceso de producción escrita, lo cual nos lleva a pensar en el uso de una corrección en diferido. Además, a partir de las respuestas respecto a la forma de dotación de feedback, podemos inferir que estos hacen uso de un enfoque metodológico orientado al producto final, es decir, a la propia composición escrita del alumno y no al proceso de producción. Los resultados parecen indicar que utilizan un tipo de corrección tradicional en la que no se impone un modelo de aprendizaje de L2 a partir de los propios errores del alumno. En virtud de ello, nos atrevemos a afirmar que los informantes de este contexto educativo no cuentan con unas aptitudes o capacidades óptimas respecto al uso del feedback que acompaña a la corrección de errores de una actividad de escritura libre en L2. Cabe la posibilidad de que dichos informantes no cuenten con formación respecto a las metodologías de corrección y de feedback actuales.

En segundo lugar, una dilatada mayoría de informantes pertenecientes al contexto educativo de la ciudad de Austin (82,5\%) opta por proporcionar un feedback oral individual lo cual nos lleva a considerar que estos utilizan una corrección inmediata orientada al enfoque metodológico de producción escrita centrado en el proceso ("process-oriented pedagogy") y hacia un aprendizaje significativo en el que el la interacción alumno-profesor juegue un papel protagonista durante el proceso de producción escrita y en el que se otorgue el nivel de relevancia correspondiente al factor afectivo. Los resultados nos permiten afirmar que los profesores de este contexto educativo cuentan con las aptitudes necesarias respecto al uso y a la forma de dotación del feedback que acompaña a la corrección de errores de una actividad de escritura libre en L2. 


\subsection{Aptitudes en torno a la evaluación de una producción escrita en L2}

Las respuestas al ítem número 14 nos permitirán analizar el nivel de aptitud de nuestros informantes con respecto a la evaluación de una producción escrita en L2.

La evaluación, junto con la corrección y el tratamiento de los errores son APD que, como mencionábamos en el epígrafe 2.1.1, han de ser asumidos por el agente recurso humano-profesor. Dichos APD, como actividades que forman parte de la intervención didáctica y la evaluación del alumno son objeto de toma de decisiones en la enseñanza-aprendizaje de una L2.

Así pues, nos interesa obtener información sobre la toma de decisiones que llevan a cabo nuestros informantes en torno a la evaluación de las producciones escritas en L2 de los alumnos, a saber, cuáles son las modalidades de puntuación a las que recurren, los tipos de códigos de evaluación utilizados y los mecanismos que activan a la hora de valorar una producción escrita en L2.

Cassany (2005), a quien mencionábamos en el epígrafe 3.2.2 de la presente Tesis Doctoral, hacía alusión en su obra a la disyuntiva surgida ante los profesores cuando estos se disponen a evaluar una producción escrita. Cabe preguntarse por tanto si la evaluación del borrador final debería ser suficiente o se impone la corrección de los borradores intermedios, concluyendo que, según su punto de vista, un solo ejemplar no es representativo de la capacidad de producción escrita 
de un alumno y que, además, son los productos intermedios los que nos aportan detalles sobre dicha capacidad. Nos situamos en la perspectiva del mencionado autor manifestando nuestro acuerdo respecto a la corrección y valoración de todos los borradores elaborados por los alumnos cuando nos disponemos a evaluar sus producciones escritas.

Los informantes, a través de la opción seleccionada, indicarán cuál es la herramienta evaluativa elegida para valorar las producciones escritas de los alumnos de L2. Planteamos como primera opción la asignación de un grado o nota numérica por parte del profesor o bien una nota general: excelente, muy bien, bien, regular.... a la producción escrita del alumno. Esta nota numérica es el resultado de la suma de los puntos asignados a cada una de la partes o aspectos que se quieran evaluar. Por su parte, el grado o nota general puede representarse a través de distintas escalas de valor. La escala propuesta: excelente, muy bien, regular...etc., es solo un ejemplo representativo. La segunda opción hace alusión a la utilización de un método de autoevaluación guiada en el que el alumno, ayudado de un compañero de clase y/o del propio profesor, sea instado a valorar su propia producción.

Abordamos el término de herramienta evaluativa acercándonos a Cassany (2005) quien apoyaba el uso de herramientas dirigidas a la formación del alumno enumerando las tres que consideraba más efectivas: cooperación entre iguales, tutoría docente-aprendiz y pautas autocorrectivas. De acuerdo con el mencionado autor, las dos primeras cuentan con una mayor tradición en la cultura norteamericana, no estando extendido su uso por el mundo hispano, como ya apuntábamos en el epígrafe 3.2.2. 
Nos atrevemos a suponer que los informantes que escojan la opción de asignación de un nota numérica o general estarán utilizando una tipología de evaluación tradicional en la que el profesor valore un único borrador entregado por el alumno. A nuestro juicio, dicha tipología de evaluación no promueve la reflexión por parte de este por lo que consideramos que se trata de la opción menos adecuada para el aula de L2. Por el contrario, aquellos informantes que recurran a la autoevaluación guiada, estarán haciendo uso de determinadas herramientas como por ejemplo la "tutoría docente-aprendiz" o las "pautas autocorrectivas" que mencionaba Cassany (2005) en su obra. Compartimos la opinión con el mencionado autor respecto a la importancia del uso de este tipo de herramientas en el aula de L2, las cuales, proporcionan al alumno oportunidades de reflexión sobre sus propios errores y, consecuentemente, manifestamos nuestro acuerdo respecto al uso de una autoevaluación guiada. El uso de autoevaluación guiada como herramienta de corrección y de evaluación podría indicar que los informantes están utilizando la técnica de corrección enfocada en entrevistas personales profesor-alumno o bien profesor-grupo reducido de alumnos denominada por Zamel (1985) "cycles of revision” o borradores encadenados y a la que hacíamos referencia en el epígrafe 1.1.3 del presente trabajo de investigación.

En este sentido, la primera opción se aproxima al perfil de informante que se centra en el producto final y que denota un alto interés por la designación de una nota numérica o general. Por su parte, aquellos que elijan la opción de autoevaluación guiada estarán utilizando un enfoque orientado al proceso, en el que se evalúen todos y cada uno de los borradores producidos por el alumno y en el que, como norma general, no se emite ningún tipo de nota numérica. 


\subsubsection{Análisis de los datos: aptitudes en torno a la evaluación de una producción escrita en L2}

Analizamos las aptitudes de los informantes pertenecientes a centros educativos de Valladolid respecto a la evaluación de una producción escrita en L2. Los datos recogidos en este contexto educativo (que ponen de manifiesto la falta de respuesta por parte de 2 de los 33 participantes) a partir del ítem número 14 se muestran en la Tabla 29 y el Gráfico 29 que aparecen a continuación:

\begin{tabular}{|lrr|}
\hline ¿Cómo evalúa las producciones escritas? & $\begin{array}{r}\text { Número de } \\
\text { respuestas }\end{array}$ & Porcentaje \\
\hline $\begin{array}{l}\text { Asigno una nota numérica o nota general: excelente, muy bien, } \\
\text { bien, regular... }\end{array}$ & 26 & $\mathbf{8 3 . 8 7 \%}$ \\
\hline Utilizo un método de autoevaluación guiada & 4 & $\mathbf{1 2 . 9 0 \%}$ \\
\hline Otros: & 1 & $\mathbf{3 . 2 3 \%}$ \\
\hline Existe un baremo fijado en las programaciones & 1 & $3.23 \%$ \\
\hline Total & 31 & $\mathbf{1 0 0 . 0 0 \%}$ \\
\hline
\end{tabular}

Tabla 29. Resultados sobre las aptitudes del informante en torno a la evaluación de una actividad de escritura libre en L2 en Valladolid 


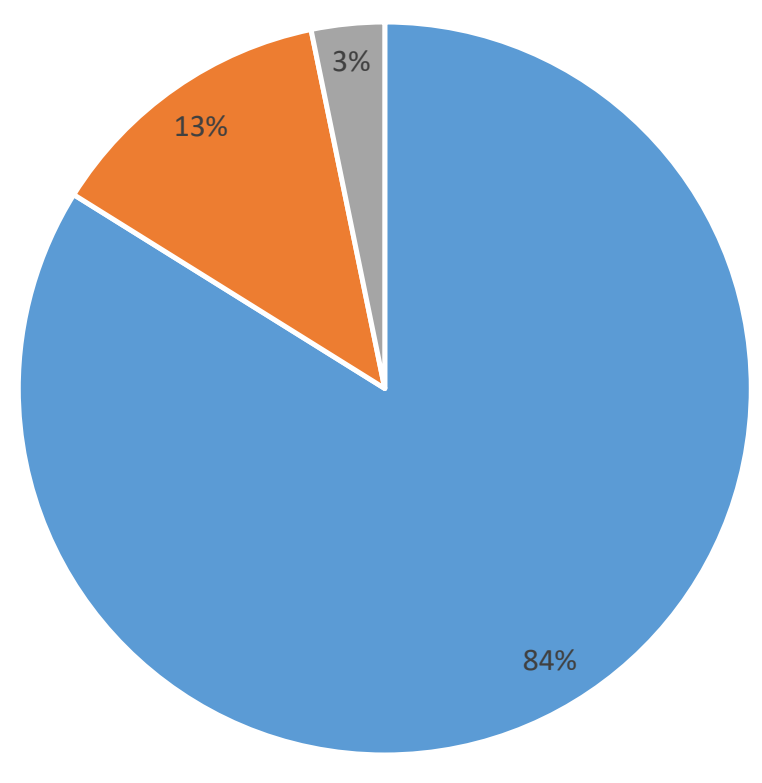

- Asigno una nota numérica o nota general: excelente, muy bien, bien, regular...

- Utilizo un método de autoevaluación guiada

- Otros: Existe un baremo fijado en las programaciones

Gráfico 29. Resultados sobre las aptitudes del informante en torno a la evaluación de una actividad de escritura libre en L2 en Valladolid

Podemos observar que, de las 31 respuestas encontradas, un porcentaje mayoritario (84\%) de informantes que afirman asignar una nota numérica o general a la producción escrita del alumno. La nota numérica se obtiene, como ya hemos venido destacando, a partir de la suma de los puntos asignados a cada uno de los aspectos que se quieran evaluar y la nota general muestra, a través de distintas escalas de valor una apreciación global de la actuación del alumno en su trabajo de producción escrita. Un 13\% de los informantes de este contexto educativo opta por el uso de una metodología de autoevaluación guiada en la que es el alumno quien corrige sus propios errores y, posteriormente evalúa su producción escrita. 
En el apartado "otros" encontramos a un informante (3\%) que hace referencia al uso del baremo que aparece en las programaciones didácticas de los libros de texto del alumno como método de evaluación utilizado. Se trata de una tabla numérica o rúbrica en la que aparecen las recomendaciones respecto a la puntuación que se debe asignar a las producciones escritas en función de los objetivos propuestos para esa actividad. Acercamos esta respuesta a la primera opción presentada originalmente en el cuestionario: "asigno una nota numérica o general" puesto que, la elección de uso de dicho baremo, vendrá determinada por la asignación de una nota numérica a la producción escrita del alumno. Como resultado, obtenemos un $87 \%(84 \%+3 \%)$ de informantes que elige la opción de proporcionar nota numérica o nota general a las producciones escritas de los alumnos de L2 en Valladolid.

Los datos relativos a la evaluación de una producción escrita en L2 en el contexto educativo de la ciudad de Austin revelan que solo uno de los 40 informantes decidió no aportar respuesta. Dichos datos se muestran en la Tabla 30 y el Gráfico 30 que se presentan a continuación. 


\begin{tabular}{|c|c|c|}
\hline ¿Cómo evalúa las producciones escritas? & $\begin{array}{l}\text { Número de } \\
\text { respuestas }\end{array}$ & Porcentaje \\
\hline $\begin{array}{l}\text { Asigno una nota numérica o nota general: excelente, muy bien, bien, } \\
\text { regular... }\end{array}$ & 9 & $23.08 \%$ \\
\hline Utilizo un método de autoevaluación guiada & 23 & $58.97 \%$ \\
\hline Otros: & 7 & $17.95 \%$ \\
\hline A través de una tabla de evaluación & 1 & $2.56 \%$ \\
\hline Uso una escala de valoración & 1 & $2.56 \%$ \\
\hline Uso una rúbrica & 1 & $2.56 \%$ \\
\hline $\begin{array}{l}\text { Utilizo una rúbrica en la que se incluyen los aspectos que quiero } \\
\text { evaluar }\end{array}$ & 1 & $2.56 \%$ \\
\hline Evalúo el proceso del alumno desde el primer borrador hasta el último & 1 & $2.56 \%$ \\
\hline $\begin{array}{l}\text { No asigno grado o nota numérica. Los alumnos realizan sus borradores, } \\
\text { revisan sus comentarios, editan... }\end{array}$ & 1 & $2.56 \%$ \\
\hline $\begin{array}{l}\text { No asigno grados o notas, hablo de manera individual con cada uno de } \\
\text { ellos y analizamos juntos las producciones escritas }\end{array}$ & 1 & $2.56 \%$ \\
\hline Total & 39 & $100.00 \%$ \\
\hline
\end{tabular}

Tabla 30. Resultados sobre las aptitudes del informante en torno a la evaluación de una actividad de escritura libre en L2 en Austin 


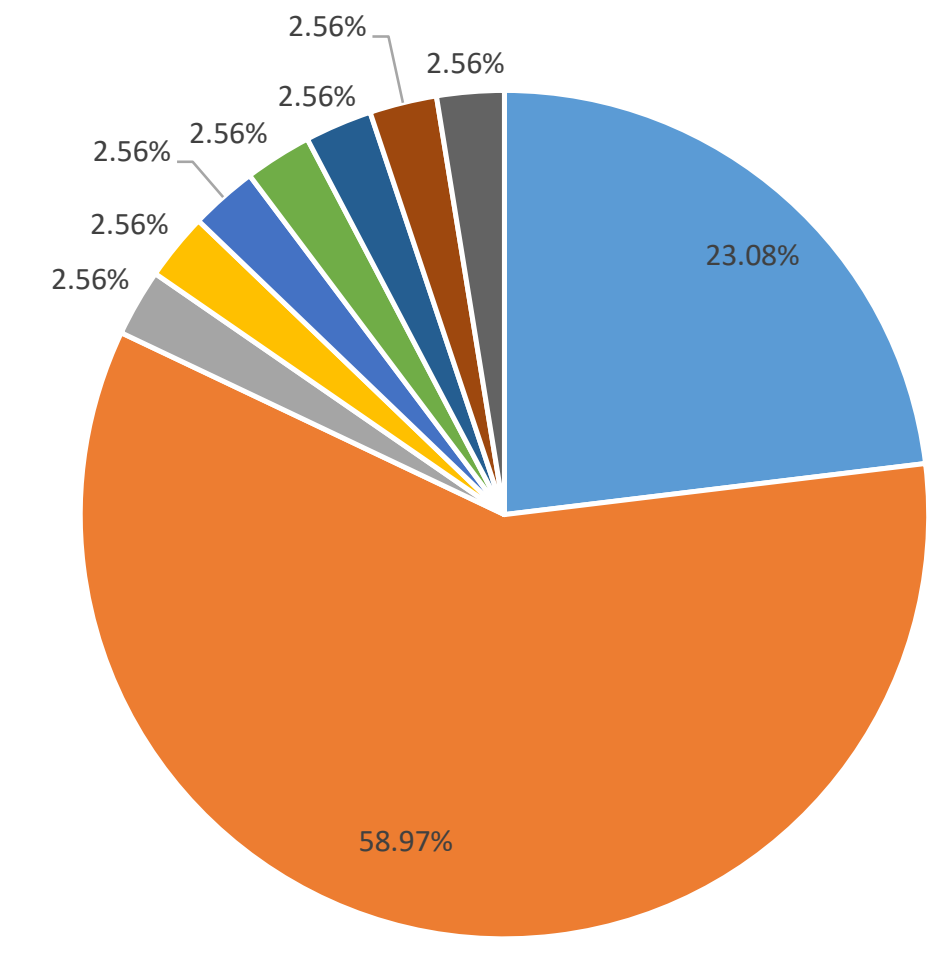
- Asigno una nota numérica o nota general: excelente, muy bien, bien, regular...
- Utilizo un método de autoevaluación guiada

- Otros: A través de una tabla de evaluación

• Otros: Uso una escala de valoración

- Otros: Uso una rúbrica

- Otros: Utilizo una rúbrica en la que se incluyen los aspectos que quiero evaluar

- Otros: Evalúo el proceso del alumno desde el primer borrador hasta el último

- Otros: No asigno grado o nota numérica. Los alumnos realizan sus borradores, revisan sus comentarios, editan...

- Otros: No asigno grados o notas, hablo de manera individual con cada uno de ellos y analizamos juntos las producciones escritas

Gráfico 30. Resultados sobre las aptitudes del informante en torno a la evaluación de una actividad de escritura libre en L2 en Austin

Encontramos que un 23,08\% (de los 39 informantes del contexto educativo de la ciudad de Austin que participaron en esta respuesta) confiesa asignar una nota numérica o general a las 
producciones escritas de los alumnos mientras que, un 58,97\% afirma utilizar un método de autoevaluación guiada.

En la sección "otros" encontramos un 17,95\% de informantes que decidieron aportar información respecto a la modalidad de corrección adoptada. Los primeros cuatro informantes nos acercan a la idea del uso de una tabla o rúbrica que les dirige en el proceso de evaluación. Estas cuatro primeras aportaciones a las que hacemos referencia aparecen bajo los siguientes enunciados: "a través de una tabla de evaluación" (2,56\%), "uso una escala de valoración" $(2,56 \%)$, "uso una rúbrica" $(2,56 \%)$ y "utilizo una rúbrica en la que se incluyen los aspectos que quiero evaluar" $(2,56 \%)$. Teniendo en cuenta la cantidad de informantes que hacen alusión a la idea del uso de una rúbrica, y que, además, en el contexto educativo de Valladolid también encontramos a un informante que, hace referencia a la misma idea, nos planteamos que, en una posible implementación del cuestionario se debería incluir una opción relacionada con este concepto entre las alternativas originales propuestas para este ítem. Estas cuatro primeras aportaciones hacen alusión al uso de rúbricas (al igual que hizo el informante del contexto de Valladolid). Entendemos que dicho uso se lleva a cabo con el propósito de asignar una nota numérica o general a la producción escrita del alumno, por lo que decidimos unir el porcentaje correspondiente a estos cuatro informantes $(10,24 \%)$ al $23,08 \%$ que representa a los informantes que optaron por la primera opción: asignar una nota numérica o general, obteniendo un 33,32\% final.

Los informantes que aparecen en quinta, sexta y séptima posición dentro de la sección “otros" cuyas respuestas atienden a: "evalúo el proceso desde el primer borrador hasta el último" 
(2,56\%), "no asigno grado o nota numérica. Los alumnos realizan los borradores, revisan sus comentarios..." (2,56\%) y "no asigno grados o notas, hablo de manera individual con cada uno de ellos y analizamos juntos las producciones escritas" $(2,56 \%)$ ponen de manifiesto la idea de una autoevaluación guiada haciendo uso de herramientas como la "tutoría docente-aprendiz". Decidimos, por tanto, sumar el porcentaje que representa estas tres respuestas $(7,68)$ al porcentaje obtenido a partir de la respuesta "utilizo un método de autoevaluación guiada" $(58,97)$ formando un total de $66,65 \%$.

\subsubsection{Interpretación de los resultados: aptitudes en torno a la evaluación de una producción escrita en L2}

Los datos obtenidos a partir del análisis de los dos contextos educativos difieren en gran medida por lo que, podemos afirmar que nos encontramos ante dos contextos que contienen elementos identificativos muy específicos. Así pues, un $87 \%$ de los informantes de la ciudad de Valladolid afirma asignar una nota numérica o general a las producciones escritas de los alumnos mientras que, en Austin, solamente un 33,32\% asigna nota numérica. En lo que respecta al uso de la autoevaluación guiada también contamos con diferencias significativas en cuanto a resultados y, en este sentido, contamos con un $13 \%$ de informantes que acude a esta metodología de evaluación frente al 66,65\% de la ciudad de Austin. Encontramos por tanto que la práctica de autoevaluación guiada está mucho más extendida en la ciudad de Austin respecto a Valladolid, cuyos informantes optan, de manera generalizada por la asignación de una nota numérica o general. 
Estos resultados nos permiten afirmar que, en la ciudad de Valladolid, la tendencia general es la de usar un tipo de evaluación tradicional en el que el profesor es el único agente involucrado. Será él quien evalúe la actuación del alumno sin contar con su opinión ni su participación. Como ya comentábamos al comienzo del epígrafe, asociamos dicha tipología de evaluación con un tipo de corrección orientada al producto final que no promueve la reflexión por parte del alumno por lo que y consideramos que no es la más adecuada para el aula de L2.

Con respecto a los informantes de la ciudad de Austin, cuando ellos optan por el uso de un método de autoevaluación guiada en un porcentaje tan elevado (superior al 50\%), inferimos que estos tienen en cuenta la valoración del alumno sobre su propia composición escrita fomentando la reflexión sobre sus propios errores. Además, asociamos este modelo de evaluación con un modelo de corrección orientado hacia el proceso de escritura en el que se evalúan todos y cada uno de los borradores producidos por el alumno y en el que, como norma general, no se proporciona ningún tipo de nota numérica o general.

Retenemos la idea de Ferris (2003) autora a la que citábamos en el epígrafe 1.1.2 según la cual, la dotación de un feedback significativo por parte del profesor junto con una intervención por parte de uno o varios compañeros de clase (en forma de ayuda o mediación) y una autoevaluación guiada formarán una combinación de elementos altamente eficaz que aportará al alumno un grado de seguridad y confianza en sí mismo que le servirá de ayuda a la hora de enfrentarse a futuras producciones escritas. 
Situándonos en la línea de la mencionada autora y en la de Cassany (2005), concluimos, a partir de los resultados obtenidos de las respuestas al ítem número 14 que, una gran mayoría de informantes que se incluyen en el contexto educativo de la ciudad de Valladolid no cuenta con las aptitudes respecto al uso de una metodología de evaluación eficaz de las producciones escritas de los alumnos de L2. Consideramos que la falta de aptitudes puede estar relacionada con un desconocimiento provocado por una falta de formación respecto a las modalidades de evaluación que mejor se ajustan a las actividades de composición escrita en una L2.

En lo que respecta al contexto educativo de Austin, los resultados nos permiten afirmar que más de la mitad de los informantes $(66,65 \%)$ cuentan con un grado de aptitud estimable en torno a la evaluación de producciones escritas de los alumnos de L2.

\subsection{Aptitudes respecto a la forma de entrega de correcciones de las producciones escritas en L2}

A través del ítem número 16 estudiaremos las aptitudes del informante en torno a la forma de entrega de las correcciones de las producciones escritas en L2. Nos proponemos reflexionar sobre la forma en que se devuelven dichas producciones escritas: si estas presentan alguna marca, anotación, comentario añadido o, por el contrario, se devuelven sin marcas acompañadas únicamente del feedback oral del profesor. Los resultados que consigamos respecto a las aptitudes de los informantes nos aportarán información respecto a la forma que tienen de conjugar corrección, feedback y/o nota general o numérica. 
En el epígrafe 2.1 de esta Tesis hacíamos alusión al uso de marcas y comentarios a modo de feedback utilizados por el profesor. Mencionábamos también otros aspectos como el volumen de texto escrito que añade el profesor a las producciones escritas y el tipo de lenguaje que se debe utilizar con el fin de facilitar la comprensión por parte de los alumnos. Apoyamos la idea de dotación de un feedback oral transmitido de manera individual al alumno puesto que, en nuestra opinión, la transmisión en forma oral admite el uso de gestos u otros elementos, suprasegmentales que facilitan un adecuado nivel de comprensión por parte del alumno. Además, manifestamos nuestro acuerdo con Cassany (1993), a quien mencionábamos en el mismo epígrafe, respecto a que los profesores emplean una cantidad de tiempo excesiva en corregir y en escribir una serie de comentarios en las producciones escritas de los alumnos que, en la mayoría de los casos, resultan prácticamente invisibles e inservibles para estos. Consideramos por tanto que, la entrega de comentarios escritos que acompañan a la corrección en la misma producción escrita constituye una forma poco útil de hacer llegar al alumno las correcciones y sugerencias.

Nos atrevemos a suponer que, aquellos informantes que elijan la opción de entregar siempre a los alumnos sus producciones con las correcciones, comentarios y/o nota numérica estarán reconociendo que utilizan un método de corrección orientado al producto sin considerar el uso de un feedback oral puesto que todo lo que el profesor quiere transmitir al alumno está escrito en esos comentarios. Nos encontraremos ante un perfil de profesor que apoya el uso de marcas en las producciones escritas junto con comentarios o sugerencias con el propósito de que el alumno reflexione sobre sus propios errores. Por el contrario, suponemos que, aquellos informantes que escojan la opción de no devolver (o hacerlo solamente en ocasiones) las producciones escritas a 
los alumnos utilizarán en el aula actividades que fomenten la reflexión a través del uso de un feedback oral.

Como afirmábamos en el epígrafe 3.1, consideramos que la propuesta de una corrección secuenciada en la que el profesor pueda llevar a cabo una corrección inmediata interactuando con el alumno de forma oral se manifiesta como una opción conveniente para los alumnos en general y para los de Educación Primaria en particular. Por el contrario, la práctica llevada a cabo por determinados profesores centrada en devolver al alumno su producción escrita acompañada de marcas, comentarios y/o nota numérica no tendrá impacto directo en este. Además, como ya mencionábamos en el mismo epígrafe, una corrección explícita podría provocar un sentimiento de bloqueo en el alumno-niño que impida que este pueda llegar a apreciar dicha corrección y a entender su significado.

\subsubsection{Análisis de los datos: aptitudes respecto a la forma de entrega de correcciones de las producciones escritas en L2}

Los datos correspondientes a las respuestas de los informantes del contexto educativo de Valladolid (considerando que 2 de los 33 participantes no optó por ninguna respuesta) se presentan en la Tabla 31 y el Gráfico 31: 


\begin{tabular}{lrr}
$\begin{array}{l}\text { ¿Devuelve usted el trabajo corregido a sus alumnos con las correcciones, } \\
\text { comentarios y/o nota numérica? }\end{array}$ & $\begin{array}{c}\text { Número de } \\
\text { respuestas }\end{array}$ & $\begin{array}{r}\text { Porcentaje } \\
\hline \text { Siempre }\end{array}$ \\
\hline A veces & $\mathbf{2 5}$ & $\mathbf{8 0 . 6 5 \%}$ \\
\hline Otros: & $\mathbf{5}$ & $\mathbf{1 6 . 1 3 \%}$ \\
\hline Nunca nota numérica, pero sí con código de corrección (emoticono) & 1 & $3.23 \%$ \\
\hline Total & 1 & $3.23 \%$ \\
\hline
\end{tabular}

Tabla 31. Resultados sobre las aptitudes del informante en cuanto a conjunción de corrección, feedback y nota numérica en Valladolid

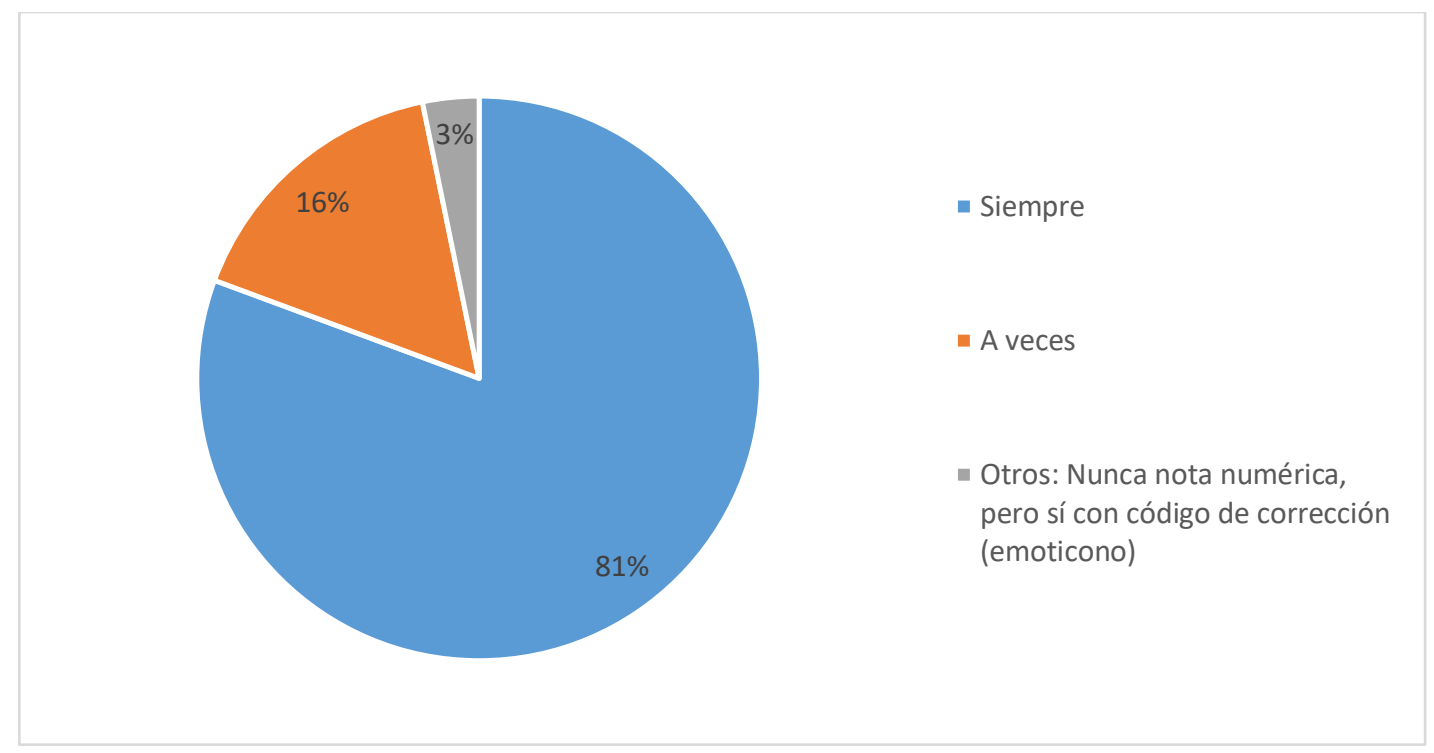

Gráfico 31. Resultados sobre las aptitudes del informante en cuanto a conjunción de corrección, feedback y nota numérica en Valladolid

Los datos revelan una participación de 31 participantes en el presente ítem de los 33 que constituyen la muestra intencional de la ciudad de Valladolid. El 81\% de estos devuelve siempre los trabajos corregidos a sus alumnos con las correcciones, comentarios y/o nota numérica escritos en el mismo texto del alumno, un $16 \%$ lo entrega a veces. 
Dentro del apartado "otros" encontramos a un informante que afirma entregar la producción escrita al alumno acompañada de un emoticono. Entendemos que el mencionado informante devuelve siempre el trabajo corregido a sus alumnos asignando un código de corrección cuyos símbolos representarán una nota general por lo que decidimos sumar el 3\% que corresponde a esta respuesta al $81 \%$ de la primera respuesta: "siempre" obteniendo un total del $84 \%$.

Los datos correspondientes al contexto educativo de la ciudad de Austin se muestran en la Tabla 32 y el Gráfico 32 que aparecen a continuación. Observamos que uno de los 40 informantes no aportó respuesta a este ítem.

\begin{tabular}{|lrr|}
\hline $\begin{array}{l}\text { ¿Devuelve usted el trabajo corregido a sus alumnos con las } \\
\text { correcciones, comentarios y/o nota numérica? }\end{array}$ & $\begin{array}{r}\text { Número de } \\
\text { respuestas }\end{array}$ & $\begin{array}{r}\text { Porcentaje } \\
\hline \text { Siempre }\end{array}$ \\
\hline A veces & $\mathbf{2 2}$ & $\mathbf{5 6 . 4 1 \%}$ \\
\hline Otros: & 16 & $\mathbf{4 1 . 0 3 \%}$ \\
\hline Se entregan semanalmente o al final del año escolar & 1 & $\mathbf{2 . 5 6 \%}$ \\
\hline Total & 39 & $2.56 \%$ \\
\hline
\end{tabular}

Tabla 32. Resultados sobre las aptitudes del informante en cuanto a conjunción de corrección, feedback y nota numérica en Austin 

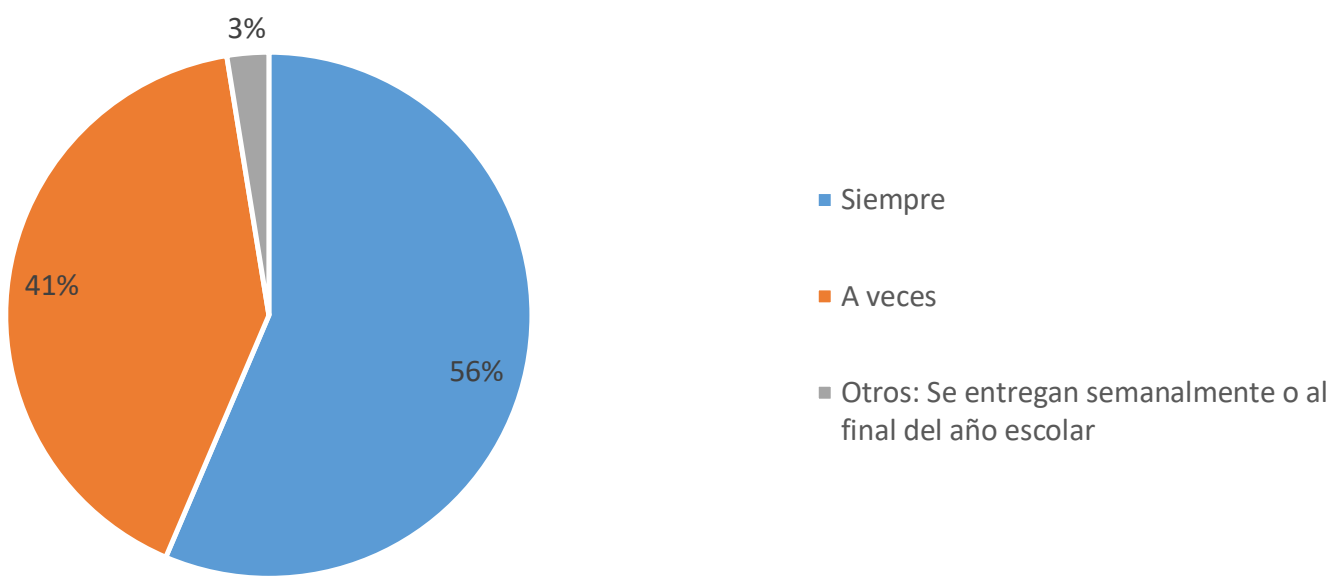

Gráfico 32. Resultados sobre las aptitudes del informante en cuanto a conjunción de corrección, feedback y nota numérica en Austin

Partiendo de las 39 respuestas de los 40 que conforman la muestra de la ciudad de Austin el 56\% de los informantes entrega las producciones corregidas al propio alumno mostrando en estas sus correcciones, comentarios y/o nota numérica, el $41 \%$ lo hace en ocasiones.

Hay un único informante que, habiendo elegido el apartado "otros", nos informa de que, en su centro educativo, como norma general, se entregan las producciones escritas semanalmente o al final del curso escolar. Entendemos que dicho informante nos quiere hacer saber que los borradores finales de los alumnos se van guardando en una carpeta para entregárselos de manera periódica o bien al finalizar el curso escolar para que el alumno pueda archivarlo, mostrarlo en casa, etc. Esto nos permite inferir que, en esta clase, los alumnos reciben feedback oral (o escrito en breves notas) que usan para rehacer sus borradores hasta llegar al producto final. 


\subsubsection{Interpretación de los resultados: aptitudes respecto a la forma de entrega de correcciones de las producciones escritas en L2}

El análisis de los datos nos muestra que un $84 \%$ de los informantes vallisoletanos devuelven siempre las producciones escritas a sus alumnos con correcciones, comentarios y/o nota general o numérica frente al 56\% de los informantes de la ciudad de Austin. Un 16\% de los informantes de Valladolid entrega dichas producciones a veces frente al $41 \%$ de los informantes de Austin.

Los datos confirman un uso mayoritario de conjunción de corrección, feedback y/o nota general o numérica en un mismo papel en el contexto educativo de Valladolid. Sin embargo, los datos correspondientes al contexto educativo de Austin proporcionados a través de este ítem muestran que esta práctica no está tan extendida puesto que nos encontramos ante un número importante de informantes que declara devolver los trabajos solo en ocasiones. La información proporcionada a través de este ítem puede relacionarse con la que hemos obtenido en ítems anteriores acercándonos a un uso generalizado de corrección inmediata acompañada de un feedback oral durante el cual, profesor y alumno tienen ocasión de interactuar y trabajar en equipo favoreciendo la reflexión por parte del alumno y permitiendo que se sienta parte del proceso de corrección y de evaluación sin necesidad de la asignación de una nota general o numérica.

Los datos obtenidos a partir de las respuestas al ítem número 16 en los dos contextos educativos, parecen indicar que los informantes del contexto educativo de Valladolid no cuentan con las aptitudes o capacidades respecto a la conjunción de corrección, feedback y nota general o numérica (si la hubiese). Como hemos venido mencionando, consideramos que la conjunción de 
estos tres elementos en la propia producción escrita del alumno no ejercerá ningún impacto en el alumno. Consideramos que la entrega por parte del profesor de las producciones acompañadas de los elementos mencionados no solo no aportará beneficios en el aprendizaje del alumno, sino que, además, puede provocar un sentimiento de bloqueo que impida que este pueda llegar a apreciar dicha corrección y a entender su significado.

En contraste con lo anterior, por lo que se refiere a los informantes del contexto educativo de Austin, concluimos, a partir del análisis de los datos que estos cuentan con dichas aptitudes respecto a la conjunción de corrección, feedback y/o nota numérica.

La información recogida a partir del análisis de los ítems 7, 8, 11, 13, 14 y 16 del cuestionario forma parte del componente competencial "actitudes" y nos ha proporcionado la información que buscábamos en torno a las actitudes ante el error, la corrección y el feedback de los informantes en las producciones escritas de los alumnos de L2. De estos datos se desprenden las conclusiones que se presentan a continuación.

\subsection{Interpretación de los resultados. Aptitudes en torno al error, a la corrección y al feedback}

En relación con las aptitudes, los resultados del presente estudio sugieren que los informantes del contexto educativo de Valladolid cuentan con aptitudes respecto a la búsqueda de 
motivación del alumno a la hora de proponer una actividad de escritura libre en L2. En este sentido, sí se evidencia un claro interés por parte del profesor por presentar este tipo de actividades de una manera atractiva para los alumnos introduciendo el factor diversión y/o el componente lúdico. También cuentan con aptitudes respecto al grado de intervención durante la realización de actividades de escritura libre. Es así como, de forma generalizada, participan de una forma activa ayudando y guiando a los alumnos durante el proceso de producción textual. De acuerdo con las respuestas proporcionadas, estos informantes, utilizan modalidades de corrección que promueven el aprendizaje significativo de una L2. Sin embargo, a partir de los datos podemos inferir que los informantes que componen este contexto educativo no cuentan con las aptitudes respecto al uso del feedback que acompaña a la corrección de errores. Es posible que esta carencia de aptitudes pueda venir determinada por una falta de formación al respecto. En relación con esta información, encontramos que gran parte de estos informantes tampoco cuenta con aptitudes respecto al uso de una metodología de evaluación eficaz. De este modo, los resultados revelan que, dichos informantes hacen uso de un tipo de evaluación tradicional a partir de la cual, el profesor valora la actuación de los alumnos sin tener en cuenta su grado de participación. Finalmente, los datos relativos a la entrega de las producciones escritas de los alumnos por parte del profesor nos permiten afirmar que estos tampoco cuentan con las aptitudes respecto a la conjunción de corrección, feedback y/o nota general o numérica. Encontramos que estos se limitan a devolver la producción escrita al alumno con marcas y anotaciones propias a través de las cuales, el profesor muestra algunas sugerencias que suelen acompañar a la nota numérica. Consideramos que, este tipo de dotación de feedback no ejercerá impacto positivo sobre el alumno ni aportará beneficios en su aprendizaje. Por el contrario, el hecho de presentar las marcas y anotaciones acompañando 
a la nota numérica puede provocar que el alumno concentre su atención exclusivamente en dicha nota, pasando así desapercibidas las marcas y sugerencias del profesor.

El uso de este tipo de modalidades de corrección en las que solo se tiene en cuenta el último borrador, la dotación de feedback a partir de comentarios escritos en la propia producción escrita y de un tipo de evaluación en el que se da importancia a la nota numérica o general nos lleva a pensar que los informantes del contexto educativo de Valladolid buscan motivar al alumno en cuanto al planteamiento de actividades de escritura libre en L2, aunque utilizan un enfoque metodológico orientado a las puntuaciones, al producto final y no al alumno como responsable directo del proceso de corrección ni al propio proceso de producción escrita en L2. Asimismo, demuestra que los profesores de este contexto conceden mucha importancia a la nota numérica y al error.

En relación a los informantes del contexto educativo de Austin, los datos nos permiten afirmar que estos cuentan con aptitudes respecto a la búsqueda de motivación del alumno a la hora de presentar las actividades de expresión escrita libre. Además, intervienen de forma activa en el proceso de producción textual orientando y aportando sugerencias al alumno, utilizan modalidades de corrección que fomentan un aprendizaje significativo. Los datos proporcionados nos informan de que los informantes de este contexto educativo cuentan con aptitudes respecto al uso de un tipo de feedback oral, individual en el que se fomenta la interacción entre alumno y profesor lo cual, nos lleva a pensar en el uso de una corrección inmediata orientada al enfoque metodológico de producción escrita centrada en el proceso de escritura y no en el producto final. En lo que concierne al sistema de evaluación, optan por el uso de un sistema de autoevaluación guiada teniendo en 
cuenta la valoración del alumno sobre sus propias composiciones escritas fomentando así la reflexión sobre sus propios errores y sin tener en consideración las cifras o notas numéricas.

Los informantes del contexto educativo de Austin cuentan, por tanto, con aptitudes respecto al planteamiento de una corrección, una evaluación y un feedback adecuados y adaptados a las necesidades educativas de los alumnos que favorezcan la reflexión y el aprendizaje significativo de la L2 y que, además, permitan que el alumno pueda sentir que es parte del proceso de corrección y de evaluación. 



\section{Capítulo 8. COMPONENTE COMPETENCIAL III: ACTITUDES ANTE EL ERROR, LA CORRECCIÓN Y EL FEEDBACK}

8.1. Aspectos generales sobre el componente competencial III: actitudes

8.2. Actitudes ante el error, la corrección y el feedback en una producción escrita en L2

8.3. Interpretación de los resultados. Actitudes ante el error, la corrección y el feedback 


\subsection{Aspectos generales en torno al componente competencial III: actitudes}

Al referirnos a este componente competencial, hacemos referencia a las actitudes del informante ante el error, la corrección de errores y el feedback en una producción escrita en L2. Con el propósito de recabar información respecto a dichas actitudes, incluimos en el cuestionario el ítem número 17 que se expone en el Cuadro 6.

Actitudes del informante ante el error, la corrección y el feedback
Ítem 17. Actitudes del informante ante la corrección de errores y el feedback en una producción escrita en $\mathrm{L} 2$

Cuadro 6. Ítem de los cuestionarios dirigido a la recopilación de información acerca de las actitudes del informante

A partir de las respuestas al ítem número 17, nos planteamos indagar sobre la actitud o postura adoptada por los informantes ante la presencia del error, la corrección de errores y la dotación de feedback como complemento a la corrección en las producciones escritas de los alumnos de L2. Así es como, los datos que nos disponemos a analizar formarán parte del componente competencial: "actitudes".

\subsection{Actitudes ante la corrección de errores y el feedback en una producción escrita en L2}

Nos interesa conocer el punto de vista de nuestros informantes respecto a la utilidad de la corrección y del feedback en la perspectiva de que el alumno sea consciente de su propio proceso de aprendizaje, le permita establecer conexiones entre su lengua materna y la L2, le aporte 
información sobre cómo trabajar las distintas destrezas comunicativas y le ayude a ver los errores no como algo negativo sino como indicador de su progreso en el proceso de aprendizaje.

Nos proponemos analizar, a partir de las respuestas obtenidas, en qué medida nuestros informantes están interesados en que los alumnos reciban las correcciones y el feedback o si, por el contrario, estiman que el alumno no debe ser expuesto a estos insistiendo en el desarrollo de su autonomía y autoestima hacia las propias capacidades creativas.

A través de cuatro subapartados (a, b, c y d), proponemos a los informantes un ejercicio de reflexión sobre el papel que desempeña el error, la corrección y el feedback en el proceso de enseñanza-aprendizaje de una L2 y su posible utilidad.

La decisión de incluir los subapartados "a" y "d" se lleva a cabo con el propósito de averiguar si los profesores consideran que la exposición del alumno ante sus propios errores permite que este consiga aceptarlos como algo positivo y tomar consciencia de su propia evolución en el proceso de aprendizaje de la L2. El subapartado "b" se incluye con el fin de que el profesor reflexione acerca de las posibles conexiones que puedan establecer los alumnos entre la estructura de su L1 y la de la L2. En el subapartado "c" se intenta recabar información acerca de la utilidad de las correcciones y del feedback del profesor a la hora de trabajar las distintas destrezas lingüísticas.

Nos interesa, por tanto, obtener datos de nuestros informantes respecto a su postura en torno a la corrección puesto que, como afirmábamos en el epígrafe 1.1.2, "la actitud manifestada por el profesor hacia la corrección de errores puede llegar a inhibir la creatividad y la motivación o, por 
el contrario, alimentar la imaginación y despertar la autonomía de los alumnos” (Merino Mañueco, en prensa). Además, a partir del ítem mencionado intentamos conocer la disposición que muestran hacia la idea de proporcionar feedback al alumno, como complemento de la corrección de una actividad de producción escrita en L2.

\subsubsection{Análisis de los datos: actitudes ante el error, la corrección y el feedback en una producción escrita en L2}

Los datos aportados por todos los informantes (33) que ejercen su actividad docente en el contexto educativo de Valladolid se muestran en la Tabla 33 y el Gráfico 33 que aparecen a continuación:

\begin{tabular}{|c|c|c|c|c|c|}
\hline $\begin{array}{l}\text { Califique en qué medida la corrección de errores } \\
\text { de sus alumnos y su feedback (crítica o } \\
\text { comentario) es útil o va a ser útil }\end{array}$ & Mucho & Bastante & Poco & $\begin{array}{l}\text { Muy } \\
\text { poco }\end{array}$ & Nada \\
\hline $\begin{array}{l}\text { Para que el alumno sea consciente de su propio } \\
\text { proceso de aprendizaje }\end{array}$ & $48.48 \%$ & $36.36 \%$ & $0.00 \%$ & $3.03 \%$ & $12.12 \%$ \\
\hline $\begin{array}{l}\text { Le permita establecer conexiones entre su lengua } \\
\text { materna y la L } 2 \text { o extranjera }\end{array}$ & $24.24 \%$ & $30.30 \%$ & $21.21 \%$ & $3.03 \%$ & $21.21 \%$ \\
\hline $\begin{array}{l}\text { Le aporte información sobre cómo trabajar las } \\
\text { distintas destrezas comunicativas }\end{array}$ & $42.42 \%$ & $39.39 \%$ & $3.03 \%$ & $0.00 \%$ & $15.15 \%$ \\
\hline $\begin{array}{l}\text { Le ayude a ver los errores no como algo negativo } \\
\text { sino como indicador de su progreso en el proceso } \\
\text { de aprendizaje }\end{array}$ & $54.29 \%$ & $31.43 \%$ & $0.00 \%$ & $0.00 \%$ & $14.29 \%$ \\
\hline Total, número de respuestas: 33 & & & & & \\
\hline
\end{tabular}

Tabla 33. Resultados sobre las actitudes del informante ante la corrección de errores y el feedback en una producción escrita en L2 en Valladolid 


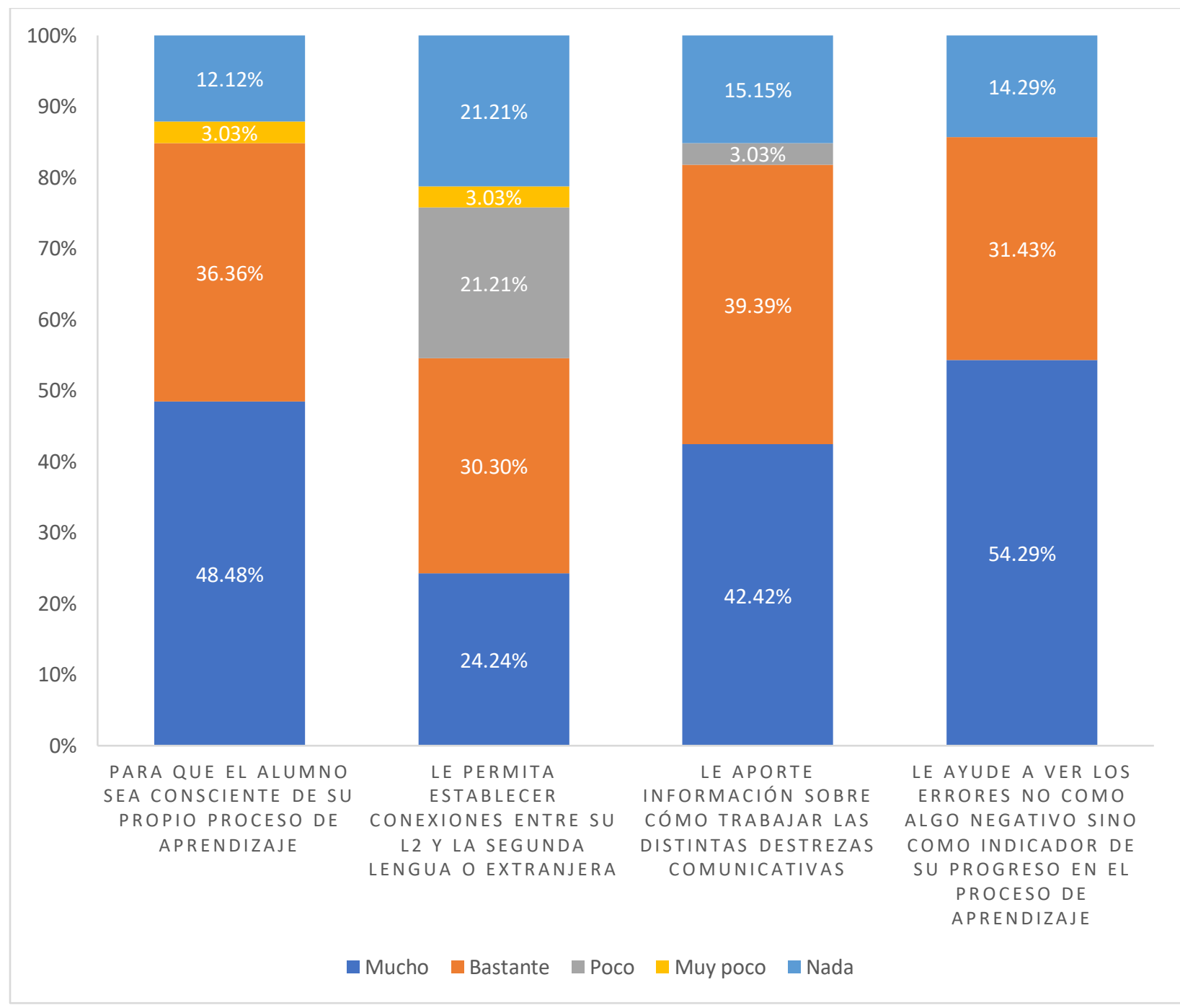

Gráfico 33. Resultados sobre las actitudes del informante ante la corrección de errores y el feedback en una producción escrita en L2 en Valladolid

Observamos que, ante las preguntas: ¿en qué medida la corrección de errores de sus alumnos y su feedback (crítica o comentario) es útil o va a ser útil para que el alumno sea consciente de su propio proceso de aprendizaje?, ¿en qué medida es útil para que le aporte información sobre cómo trabajar las distintas destrezas comunicativas? y ¿en qué medida es útil para que el alumno pueda ver los errores no como algo negativo sino como indicador de su progreso en el aprendizaje? las opciones "mucho" y "bastante" son las elegidas por un mayor número de informantes. Las tres 
opciones restantes: "poco", "muy poco" y "nada" cuentan con unos porcentajes poco significativos. Sin embargo, ante la pregunta: ¿en qué medida la corrección de errores de sus alumnos y su feedback (crítica o comentario) es útil o va a ser útil para que el alumno pueda establecer conexiones entre su lengua materna y la L2? encontramos una serie de respuestas que difieren de las anteriores. Es así que, un 24,24\% de los informantes considera que son "muy útiles", un $30,30 \%$ destaca que son "bastante útiles", un 21,21\% cree que son "poco útiles", un 3,03\% “muy poco útiles" y un 21,21\% manifiesta que no tienen ninguna utilidad.

Los resultados obtenidos parecen mostrar unas actitudes positivas por parte de nuestros informantes vallisoletanos hacia la corrección de errores y el feedback que lo acompaña. En este sentido, los datos parecen indicar que, bajo su punto de vista, estos dos elementos se configuran como muy útiles o bastante útiles en la perspectiva de intentar alcanzar determinados objetivos docentes: que el alumno sea consciente de su propio proceso de enseñanza-aprendizaje, aportar información sobre cómo trabajar las distintas destrezas comunicativas y, por último, permitir que reconozca los errores no como algo negativo sino como indicador de su progreso en el proceso de enseñanza-aprendizaje de la L2. Encontramos un número reducido de informantes que no muestran su acuerdo respecto a que, el uso de una modalidad de corrección apropiada y de un feedback orientado hacia el aprendizaje significativo pueda ayudar al alumno a establecer conexiones entre su lengua materna y la L2.

Concluimos, por tanto, que, de forma general, nuestros informantes cuentan con el mismo punto de vista respecto a los efectos positivos del uso de una modalidad adecuada de corrección acompañada de un feedback efectivo. La única excepción que encontramos es la de aquellos 
informantes que no muestran seguridad acerca de la utilidad de estos en cuanto a ayudar al alumno a establecer conexiones entre la L1 y la L2. Asimismo, a partir de las respuestas presentadas, podemos inferir que, en el contexto educativo de Valladolid, se observa una actitud positiva hacia el uso de una modalidad de corrección de errores y un tipo de feedback efectivos que promuevan la reflexión por parte del alumno y que impulsen el aprendizaje significativo por parte de este en el aula de L2.

Los resultados correspondientes a las respuestas de todos los informantes (40) del contexto educativo de Austin se presentan en la Tabla 34 y el Gráfico 34 que aparecen a continuación:

\begin{tabular}{|c|c|c|c|c|c|}
\hline $\begin{array}{l}\text { Califique ¿en qué medida la corrección de } \\
\text { errores de sus alumnos y su feedback (crítica o } \\
\text { comentario) es útil o va a ser útil }\end{array}$ & Mucho & Bastante & Poco & $\begin{array}{l}\text { Muy } \\
\text { poco }\end{array}$ & Nada \\
\hline $\begin{array}{l}\text { Para que el alumno sea consciente de su propio } \\
\text { proceso de aprendizaje }\end{array}$ & $52.50 \%$ & $45.00 \%$ & $2.50 \%$ & $0.00 \%$ & $0.00 \%$ \\
\hline $\begin{array}{l}\text { Le permita establecer conexiones entre su } \\
\text { lengua materna y la segunda lengua }\end{array}$ & $37.50 \%$ & $50.00 \%$ & $10.00 \%$ & $0.00 \%$ & $2.50 \%$ \\
\hline $\begin{array}{l}\text { Le aporte información sobre cómo trabajar las } \\
\text { distintas destrezas comunicativas }\end{array}$ & $19.23 \%$ & $24.36 \%$ & $5.13 \%$ & $0.00 \%$ & $51.28 \%$ \\
\hline $\begin{array}{l}\text { Le ayude a ver los errores no como algo negativo } \\
\text { sino como indicador de su progreso en el } \\
\text { proceso de aprendizaje }\end{array}$ & $65.00 \%$ & $27.50 \%$ & $5.00 \%$ & $0.00 \%$ & $2.50 \%$ \\
\hline Total, número de respuestas: 4 & & & & & \\
\hline
\end{tabular}

Tabla 34. Resultados sobre las actitudes del informante ante la corrección de errores y el feedback en una producción escrita en L2 en Austin 


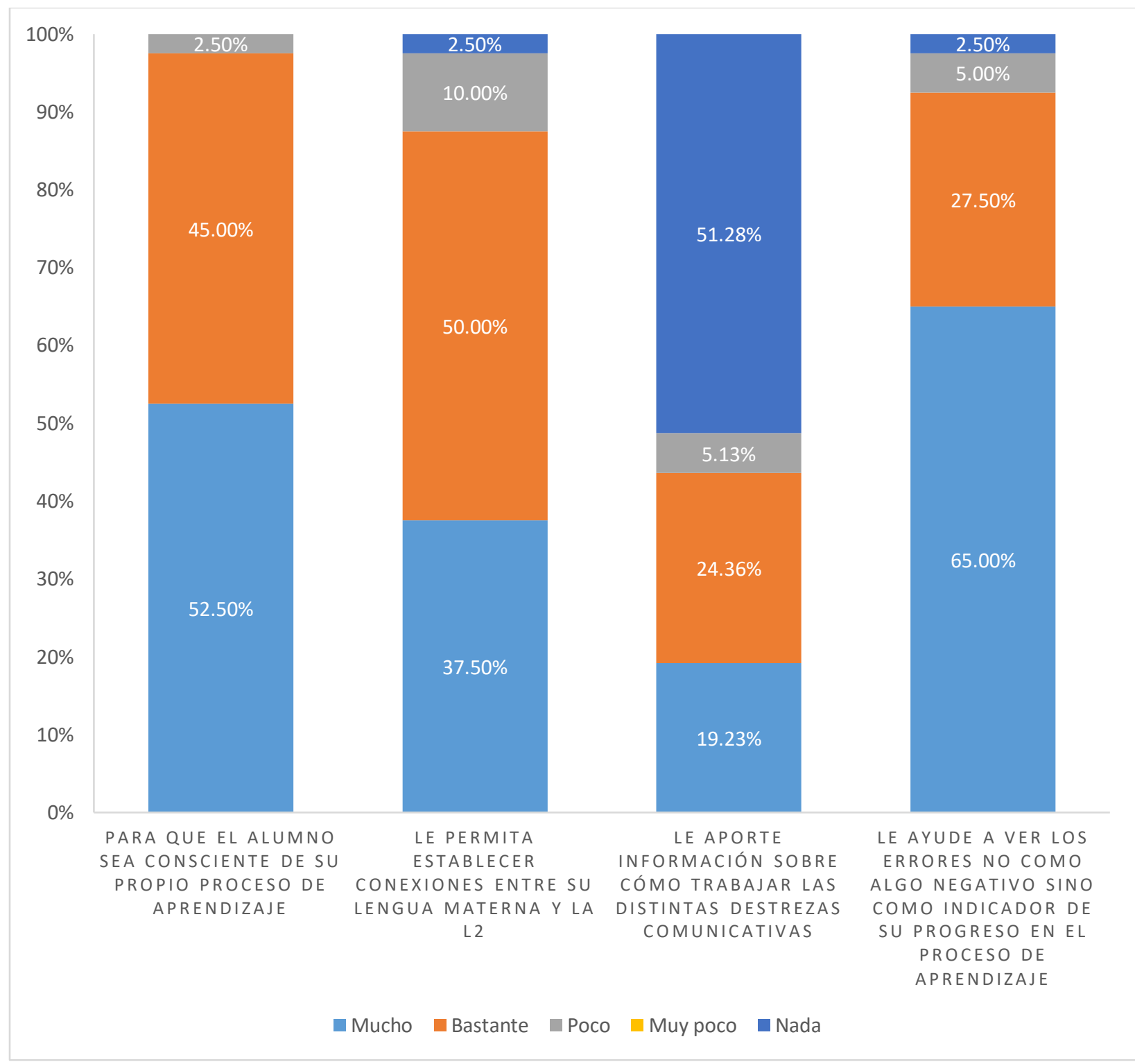

Gráfico 34. Resultados sobre las actitudes del informante ante la corrección de errores y el feedback en una producción escrita en L2 en Austin

En el contexto educativo de Austin, observamos que, una gran mayoría de informantes muestra su acuerdo en cuanto al efecto beneficioso que tiene la exposición del alumno ante el error, la corrección y el feedback. No obstante, existe un número considerable de profesores que manifiesta dudas en relación a los posibles beneficios que puedan proporcionar a la hora de trabajar las destrezas comunicativas. 
Con respecto a las preguntas: ¿en qué medida la corrección de errores de sus alumnos y su feedback (crítica o comentario) es útil o va a ser útil para que el alumno sea consciente de su propio proceso de aprendizaje?, ¿en qué medida le permite establecer conexiones entre su L1 y su L2? y ¿en qué medida es útil para que el alumno pueda ver los errores no como algo negativo sino como indicador de su progres en el aprendizaje? las opciones "mucho" y "bastante" son las elegidas por un mayor número de informantes. Así pues, las tres opciones restantes: "poco", "muy poco" y "nada" cuentan con unos porcentajes poco significativos. No obstante, ante la pregunta ¿en qué medida la corrección de errores de sus alumnos y su feedback (crítica o comentario) es útil o va a ser útil para que el alumno aprenda a trabajar las distintas destrezas? encontramos una serie de resultados que difieren en gran medida de los anteriores. Encontramos por tanto un 19,23\% de informantes que define la corrección y el feedback como elementos "muy útiles", un 24,36\% considera que son "bastante útiles", un 5,13\% cree que son "poco útiles" y un 51,28\% manifiesta que dichos elementos no presentan ninguna utilidad en la perspectiva de aportar conocimientos nuevos sobre cómo trabajar las destrezas lingüísticas.

Los resultados obtenidos en este contexto educativo también evidencian unas actitudes positivas hacia la corrección de errores y el feedback que lo acompaña. Así pues, los datos parecen indicar que, en su opinión, estos dos elementos se revelan en general como muy "útiles" o "bastante útiles" a la hora de intentar alcanzar determinados objetivos docentes: que el alumno sea consciente de su propio proceso de enseñanza-aprendizaje, ayudar al alumno a establecer conexiones entre su lengua materna y la L2 y, por último, permitir que reconozca los errores no como algo negativo sino como indicador de su progreso en el proceso de enseñanza-aprendizaje de la L2. No obstante, 
encontramos un número significativo de informantes que muestran desacuerdo respecto a que, una buena modalidad de corrección y un feedback orientado hacia el aprendizaje significativo pueda aportar información sobre cómo trabajar las distintas destrezas comunicativas

A modo de conclusión, los resultados revelan una actitud positiva por parte de nuestros informantes ante el uso de una modalidad adecuada de corrección acompañada de un feedback efectivo. La única excepción que encontramos es la de aquellos informantes que no se muestran seguros acerca de la utilidad de estos en cuanto a proporcionar al alumno información sobre cómo trabajar las destrezas comunicativas. Asimismo, a partir de las respuestas presentadas, inferimos que, en el contexto educativo de la ciudad de Austin, se observa una actitud positiva hacia el uso de una modalidad de corrección de errores y un tipo de feedback que favorezcan la reflexión por parte del alumno y que impulsen el aprendizaje significativo en el aula de L2.

\subsubsection{Interpretación de los resultados: actitudes ante el error, la corrección y el feedback en una producción escrita en L2}

Nos encontramos ante dos contextos educativos cuyos sujetos muestran actitudes muy similares con respecto al error, a la corrección y al feedback. Los informantes de ambos defienden no solo la presencia del error como objeto de aprendizaje e indicador de progreso en la L2, sino también la importancia de que los alumnos reciban las producciones escritas con las correspondientes correcciones. Por último, la opinión generalizada de los informantes de ambos contextos gira en torno a los efectos beneficiosos del feedback en el alumno por tratarse de un elemento que permite un acercamiento entre profesor y alumno. 


\subsection{Interpretación de los resultados. Actitudes ante el error, la corrección y el feedback}

Como ya venimos apuntando, los resultados obtenidos a partir de las respuestas al ítem número 17, parecen indicar, a primera vista, que los informantes de los dos contextos educativos cuentan con actitudes positivas ante la presencia del error, ante la corrección de errores y el feedback que acompaña. Sin embargo, a pesar de contar con posturas semejantes, observamos, a partir del análisis de las respuestas a los ítems que conforman el cuestionario que, ambos contextos educativos difieren en la praxis o aplicación de dichas creencias a la realidad educativa.

Así pues, los profesores del contexto educativo de Valladolid afirman contar con una actitud de confianza ante el error y su corrección. A pesar de ello, los resultados de las respuestas aportadas en el cuestionario evidencian un desaprovechamiento del error ya que este no llega a ser utilizado como instrumento pedagógico dentro del proceso de enseñanza-aprendizaje de la L2. Tal y como hemos venido observando en las conclusiones de los capítulos 6 y 7, los informantes vallisoletanos desconocen la importancia de escoger un tipo y un momento idóneo de corrección de errores, factores a los que hacíamos alusión en el epígrafe 1.1.2 llevando a cabo un tipo de corrección centrada en marcar los errores en la propia producción escrita del alumno y añadiendo comentarios propios (que normalmente aparecen acompañando a la nota numérica) que el alumno leerá cuando el profesor haga entrega de aquel primer y único borrador que realizó el día anterior o en días anteriores. Estas marcas y anotaciones serán lo que constituya su feedback. Podemos decir, por tanto, que, en este contexto educativo, los profesores optan, generalmente por un tipo de feedback 
escrito sin sentir la necesidad de dotar al alumno de un feedback oral que pueda ayudarlo en su tarea de reconstrucción del texto.

A tenor de las respuestas de los informantes, en lo concerniente a la actitud ante el feedback, nos atrevemos a afirmar que los profesores del contexto educativo de Valladolid no muestran confianza hacia su posible utilidad ni ante sus funcionalidades $y$, en este sentido, recurren a un tipo de feedback que se limita a una serie de notas escritas y no a un feedback dialogado a través del cual, el profesor identifique tanto los puntos débiles como los puntos fuertes de la producción escrita y pueda hacer llegar a los alumnos sus sugerencias y frases de apoyo haciéndole partícipe del proceso de corrección. Consideramos que la elección de este tipo de feedback viene determinado por el uso de una pedagogía tradicional en la que se impone marcar el error en las producciones del alumno y también por una posible falta de confianza en la corrección de errores y en el correspondiente feedback. Esta mentalidad tradicional impide el desarrollo de las relaciones interpersonales entre profesor y alumno imposibilitando que el alumno tome confianza con el profesor. Mostramos nuestro acuerdo con Carless (2015) por cuanto que la confianza es un elemento de gran importancia en educación puesto que esta permitirá que los alumnos se impliquen en las actividades de aprendizaje

Por lo que se refiere a los informantes pertenecientes al contexto educativo de la ciudad de Austin, como ya mencionábamos en los capítulos 6 y 7, el análisis de las respuestas de los ítems correspondientes parecen indicar que estos muestran unos conocimientos amplios sobre el error, lo cual los lleva a adoptar unas aptitudes de corrección orientadas a la interacción oral con el alumno (dotación de feedback oral) y a unas actitudes de respeto y de apertura hacia el error y 
hacia los propios alumnos. Esto nos hace pensar que dichos informantes cuentan con las aptitudes necesarias respecto al uso de un modelo de corrección de errores adaptado a las necesidades educativas específicas y a la edad del alumnado: corrección inmediata y uso de un tipo de feedback que fomente la interacción entre alumno y profesor.

Los datos relativos al ítem 17 del cuestionario incluido dentro del componente competencial “actitudes" nos han proporcionado la información que precisábamos sobre las actitudes ante el error, la corrección y el feedback de los informantes en las producciones escritas de los alumnos de L2. 



\section{Capítulo 9. ANÁLISIS CORRELACIONAL DE LAS RESPUESTAS DE LOS INFORMANTES EN FUNCIÓN DE SU PERFIL}

9.1. Aspectos generales en torno al análisis correlacional

9.2. Conocimientos sobre el momento idóneo de corrección

9.3. Aptitudes en torno a la forma de proporcionar feedback

9.4. Actitudes ante la utilidad de la corrección de errores y el feedback

9.5. Interpretación de los resultados obtenidos a partir del análisis correlacional 


\subsection{Aspectos generales en torno al análisis correlacional}

En el presente capítulo nos disponemos a realizar un análisis correlacional con el propósito de valorar el grado de asociación entre las variables más representativas del estudio con las variables relativas al perfil del informante. Nos proponemos, como objetivo principal conocer los resultados que obtienen los diferentes perfiles de informantes dentro de cada uno de los dos contextos educativos: Valladolid y Austin y, a partir de estos, poder precisar distintos matices dentro de cada grupo.

Acudimos a esta técnica de análisis de información con base estadística porque responde a nuestras necesidades investigadoras. Se trata, en palabras de Sáez López (2017), de un tipo de análisis que intenta "buscar y establecer las relaciones entre dos o más factores o variables que actúan en una situación analizada" (p. 30).

El análisis llevado a cabo muestra una correlación entre las respuestas aportadas por nuestros informantes a los ítems 12, 13 y 17 con las características relativas a su perfil: años de experiencia (ítem 1), edad (ítem 2), curso en el que imparten sus clases (ítem 3) y número de alumnos (ítem 4). La elección de los ítems 12, 13 y 17 viene determinada por representar cada uno de ellos a los tres componentes competenciales docentes; a saber: "conocimientos", "aptitudes" y “actitudes”. Así pues, consideramos que el ítem número 12 es representativo de todos aquellos ítems que hacen referencia a la categoría: “conocimientos”. El ítem 13 representa a todos aquellos que hacen referencia a la categoría: "aptitudes” y el ítem número 17 a la categoría: "actitudes”. 
Este último ítem (17) presenta cuatro alternativas: a, b, c y d cuyos contenidos semánticos se enuncian en el epígrafe 8.2.

Las variables consideradas se presentan bajo el título:

- Variable "Años de experiencia". Correspondiente al ítem 1. Años de experiencia en la enseñanza de una segunda lengua (L2).

- Variable "Edad". Correspondiente al ítem 2. Edad.

- Variable "Curso". Correspondiente al ítem 3. Curso en el que imparte sus clases.

- Variable "Número de alumnos". Correspondiente al ítem 4. Número de alumnos.

- Variable momento idóneo de corrección. Correspondiente al ítem 12. Cuando usted corrige las producciones escritas de los alumnos, ¿en qué momento lo hace?

- Variable "Forma de proporcionar feedback". Correspondiente al ítem 13. ¿De qué manera hace llegar a los alumnos sus comentarios o feedback sobre las producciones escritas que han realizado?"

- Variable "Utilidad de la corrección de errores y del feedback". Correspondiente al ítem 17. Califique ¿En qué medida la corrección de errores de sus alumnos y su feedback (crítica o comentario) es útil o va a ser útil?

o Variable 17a. [Para que el alumno sea consciente de su propio proceso de aprendizaje].

- Variable 17b. [Le permita establecer conexiones entre su lengua materna y la L2].

○ Variable 17c. [Le aporte información sobre cómo trabajar las distintas destrezas comunicativas]. 
- Variable 17d. [Le ayude a ver los errores no como algo negativo sino como indicador de su progreso en el proceso de aprendizaje].

Para poder llevar a cabo el mencionado análisis agrupamos algunas de las respuestas de los informantes en distintas categorías de análisis. Así pues, las respuestas respecto a los años de experiencia las hemos clasificado en tres intervalos: de 0 a 10 años, de 11 a 20 años y más de 20; la edad en tres intervalos: menor de 30, de 30 a 45 y mayor de 45; el curso escolar en dos intervalos: de $1^{\circ}$ a $3^{\circ}$ y de $4^{\circ}$ a $6^{\circ}$ y el número de alumnos en tres intervalos: de 14 a 22 , de 23 a 52 y más de 52. Además, las respuestas del ítem 17 las hemos clasificado bajo la forma: "Mucho", "Bastante"= "útil", "Poco", "Muy poco", "Nada" = "poco útil", obteniendo dos grupos: "útil” y "poco útil”.

Dado el tamaño de la muestra y las características de las variables implicadas (categóricas) se calculó el coeficiente de asociación de naturaleza no paramétrica "chi cuadrado de Pearson" $\left(\chi^{\wedge} 2\right)$. Las variables fueron tanto dicotómicas como politómicas y los análisis se realizaron mediante tablas de contingencia (tablas cruzadas o Cross-Tables).

Los análisis se realizaron para el grupo de informantes de Catilla y León, para el grupo de informantes de Austin y para la muestra total.

\subsection{Conocimientos sobre el momento idóneo de corrección}

Los resultados conseguidos a partir del análisis del ítem número 12 en torno a los conocimientos de los informantes sobre el momento idóneo para la corrección de las producciones 
escritas en L2 en ambos contextos educativos se muestran en el epígrafe 6.6 de la presente Tesis Doctoral.

A partir del ítem 12 intentábamos indagar acerca del momento en que nuestros informantes corrigen las producciones escritas de los alumnos. Las respuestas propuestas: "justo a continuación” y “después de unos días" pretendían recabar información acerca de los conocimientos de los profesores sobre el momento idóneo de corrección. Desde esta óptica, consideramos que aquellos que eligieron la opción "justo a continuación" son los que conocen la importancia de la corrección inmediata y llevan al aula un sistema de corrección basado en el proceso como ya mencionábamos en el epígrafe 6.2. Por el contrario, aquellos que optaron por la respuesta "después de unos días" presentan un desconocimiento acerca del momento idóneo de corrección por realizarlo cuando tienen ocasión. Estos profesores recurren a un proceso de corrección en diferido centrado en el producto o borrador final.

En el subepígrafe 6.6.2 se reflejan los porcentajes finales respecto a la elección de respuestas de nuestros informantes. Así es como el $67 \%$ de los informantes vallisoletanos reconocieron corregir justo a continuación, es decir, en el momento en que el alumno realiza su producción escrita y el 34\% afirmaba corregir después de unos días. En relación al contexto educativo de Austin, el $85 \%$ de los informantes optaron por corregir en el momento y solo un $15 \%$ eligió la opción: después de unos días.

Los datos ponían de manifiesto el hecho de que los profesores de Valladolid, a diferencia de los de la ciudad de Austin, no desarrollan un proceso de corrección específico. Es decir, no se 
realiza un encuentro individual entre el profesor y el alumno en el que ambos negocien y ejecuten la producción escrita, a partir de sus aportaciones para poder llegar al producto o borrador final con el menor número de errores posibles. A partir de estas afirmaciones inferíamos que los profesores de Valladolid no cuentan con los conocimientos metodológicos relativos al momento idóneo de corrección de las producciones escritas en L2 a diferencia de los profesores del contexto educativo de Austin, los cuales demuestran contar con dichos conocimientos.

Después de hacer mención de todas estas indagaciones en torno a los conocimientos de los profesores sobre el momento idóneo de corrección (cuyos resultados aparecen expuestos y analizados en el epígrafe 6.6) nos disponemos a cruzar los datos obtenidos (correspondientes a la variable resultante del ítem 12 a la que hemos denominado "Momento idóneo de corrección”) con los relativos al perfil del informante ("Años de experiencia", "Edad", "Curso" y "Número de alumnos"). Para ello, planteamos una serie de análisis estadísticos cuyos resultados se reflejan en los subepígrafes siguientes.

\subsubsection{Conocimientos sobre el momento idóneo de corrección en relación con los años de experiencia en la enseñanza de $L 2$}

En el presente subepígrafe nos aproximamos a los conocimientos sobre el momento idóneo de corrección en relación con los años de experiencia en la enseñanza de L2. En la tabla que aparece 
a continuación (Tabla 35) se muestran las pruebas de chi-cuadrado "Años de experiencia" * "Momento idóneo de corrección” * “Grupo".

\begin{tabular}{|l|l|c|c|c|}
\hline \multicolumn{5}{|c|}{ Pruebas de chi-cuadrado } \\
\hline Grupo & Valor & gl & $\mathrm{p}$ \\
\hline Valladolid & Chi-cuadrado de Pearson & 1,540 & 2 &, 463 \\
\hline Austin & Chi-cuadrado de Pearson & 0,578 & 2 &, 749 \\
\hline Total & Chi-cuadrado de Pearson & 1,016 & 2 &, 602 \\
\hline
\end{tabular}
Tabla 35. Pruebas de chi-cuadrado "Años de experiencia" * "Momento idóneo de corrección" * "Grupo"

A partir de los datos expuestos en la Tabla 35 se puede afirmar que, para la presente muestra, no existe una asociación significativa entre los años de experiencia en la enseñanza de segundas lenguas de los participantes y el momento en que realiza las producciones escritas de sus alumnos, ni en el caso de Valladolid, ni en el de Austin ni a nivel total (en todos los casos, p > $.05)$.

Investigamos acerca de los conocimientos de nuestros informantes respecto al momento idóneo de corrección en relación con sus años de experiencia y, para ello, realizamos una tabla de contingencia (ver Tabla 36) para las variables "Años de experiencia" * "Momento idóneo de corrección” * “Grupo”.

Los años de experiencia de los informantes han sido distribuidos en tres categorías (como ya se ha mencionado previamente): de 0 a 10, de 11 a 20 y más de 20. 


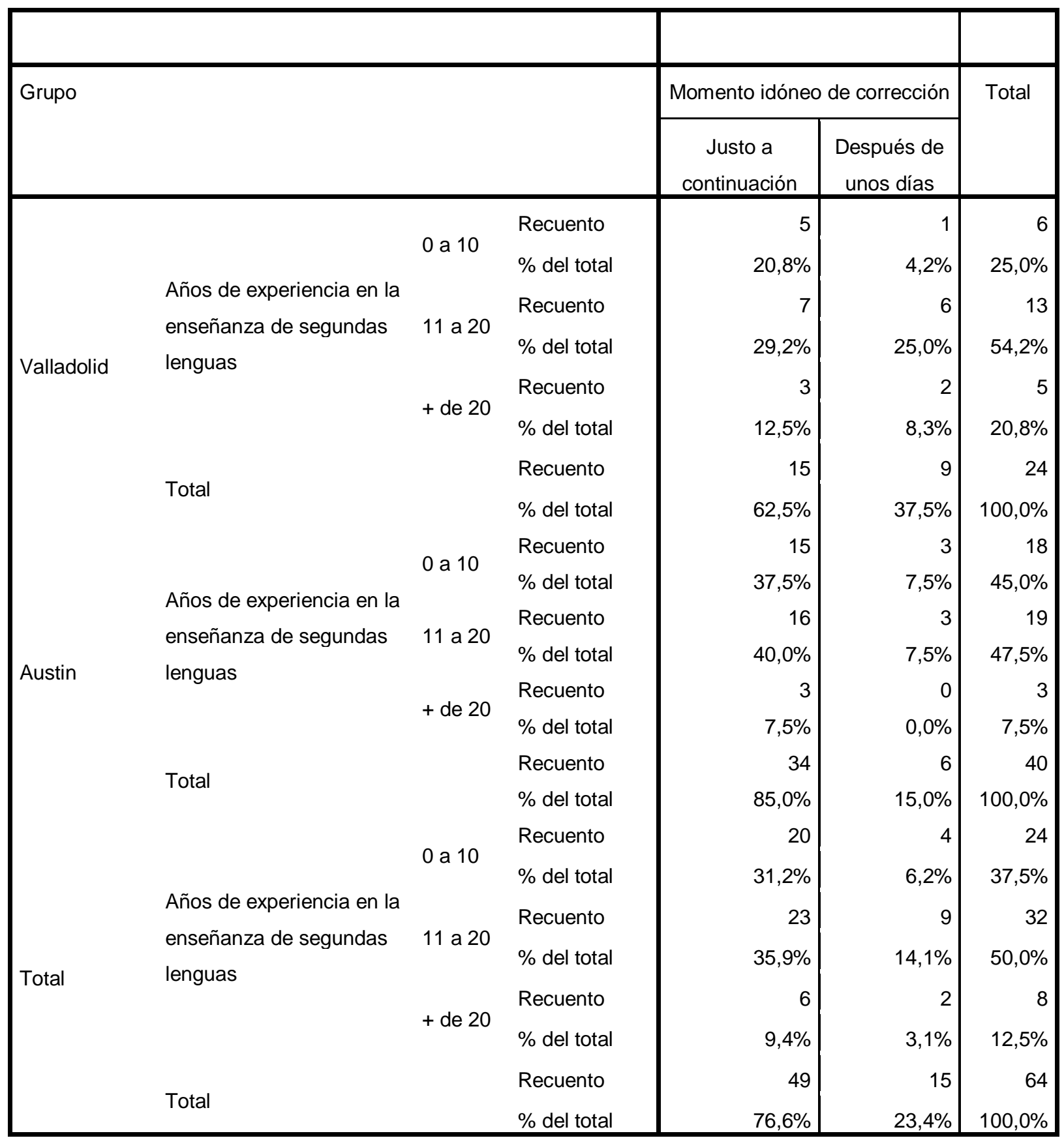

Tabla 36. Tabla de contingencia "Años de experiencia" * "Momento idóneo de corrección" * "Grupo"

La tabla 36 no muestra una asociación estadísticamente significativa y en esta se refleja cómo, independientemente del contexto educativo (Valladolid o Austin) y de los años de experiencia en la docencia, la mayoría de los profesores manifiesta realizar la corrección "justo a continuación" 
y no "después de unos días". De manera más específica, en el caso de Valladolid un 63\% de informantes reconoce realizar la corrección justo a continuación, un 85\%, en el caso de Austin y, considerada la muestra a nivel total, un $77 \%$. Destacamos la existencia de un porcentaje representativo respecto a la opción de corrección "transcurridos unos días". Entre los docentes de Valladolid, encontramos que aquellos que cuentan con 11 a 20 años de experiencia manifiestan en un $25 \%$ realizar la corrección al cabo de unos días. Por su parte, la misma franja de años de experiencia en el contexto de Austin presenta un 7,5\%. Nos encontramos por tanto ante una diferencia significativa de porcentajes entre los informantes que se sitúan en una misma franja de años de experiencia.

Salvo esta excepción, se observa que dentro de cada contexto los informantes eligen la opción “justo a continuación” son muy similares (téngase en cuenta que los porcentajes son totales y, por tanto, hacen referencia al número de participantes dentro de cada categoría para cada contexto educativo y la muestra total).

En resumen, más de las dos terceras partes de la muestra total manifestaron corregir "justo a continuación" y, como se ha reseñado, las variables implicadas no mostraron un grado de asociación significativo. Es muy importante tener en cuenta la participación de los informantes en relación a esta respuesta. En el caso de Valladolid participaron $n=24$ docentes (de los 33 que representan la muestra total) y en el de Austin $\mathrm{n}=40$ (es decir, el 100\% de la muestra total) formando un total de $\mathrm{N}=64$ informantes. 
Los siguientes gráficos de barras agrupadas (gráficos 35 y 36) reflejan de forma gráfica los resultados comentados.

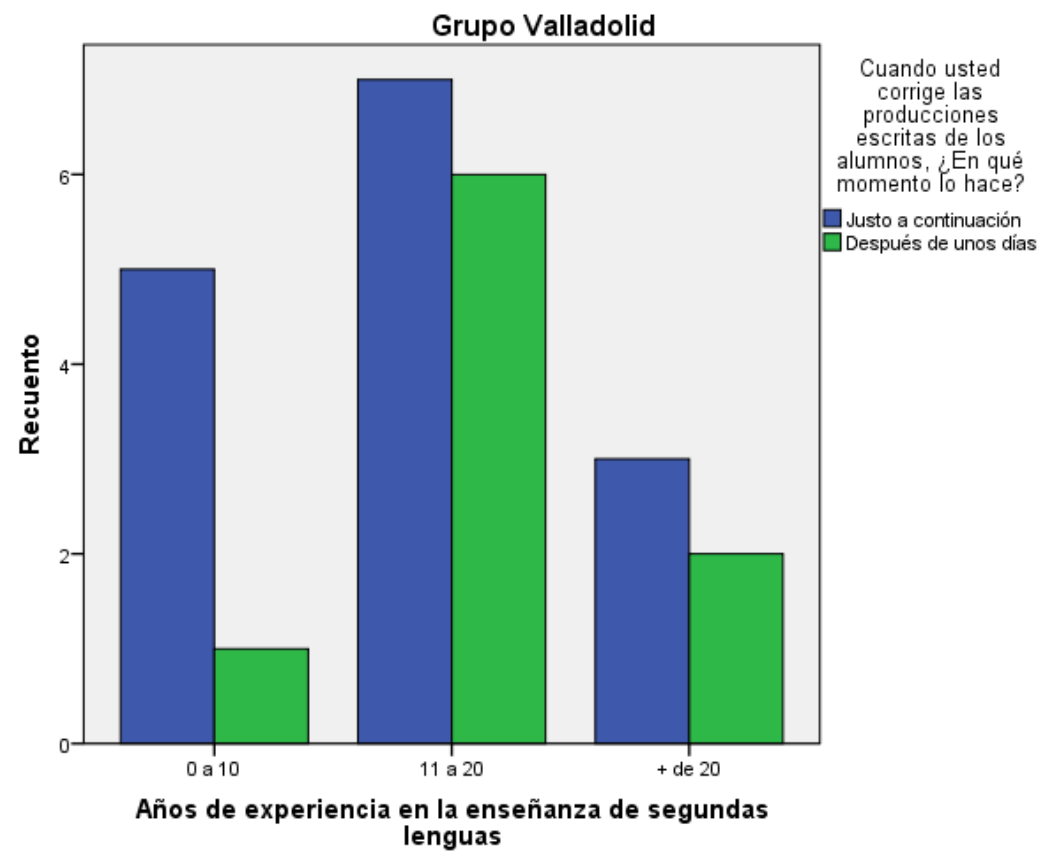

Gráfico 35. Recuento Años de experiencia - Momento idóneo de corrección- Grupo Valladolid

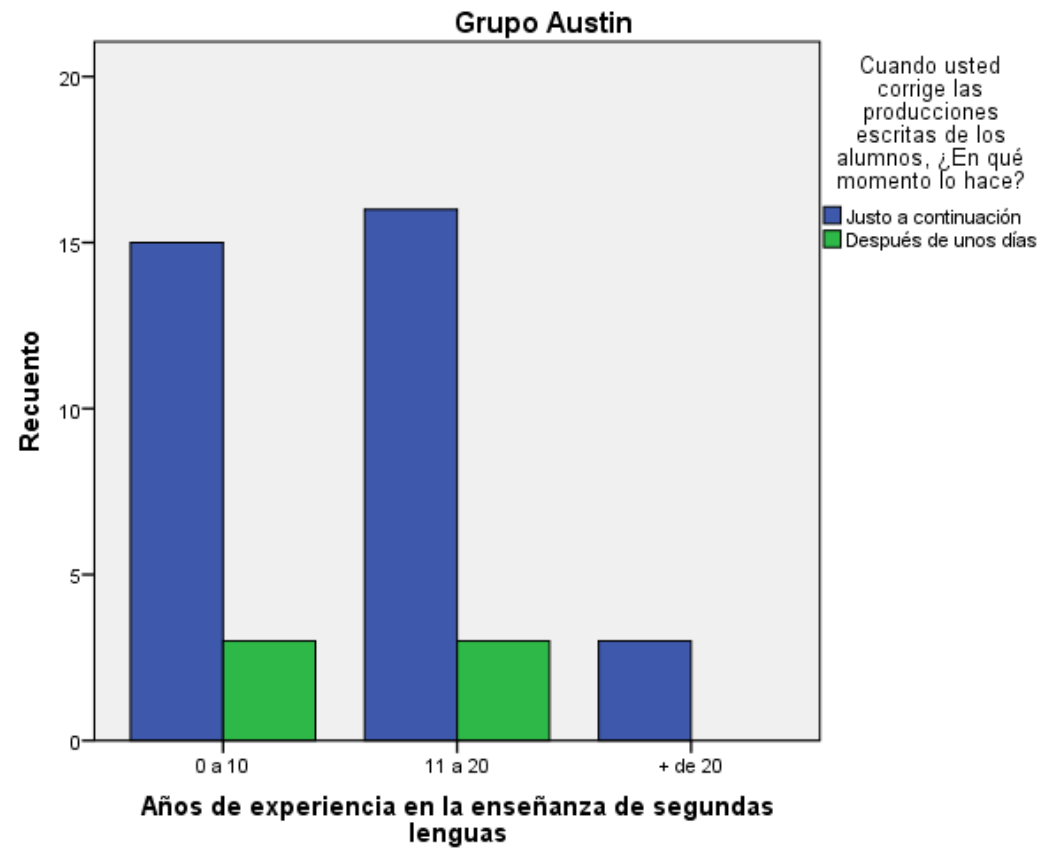

Gráfico 36. Recuento Años de experiencia - Momento idóneo de corrección - Grupo Austin 
En el epígrafe 6.6.2 de la presente Tesis Doctoral dedicado al componente competencial: conocimientos acerca del momento idóneo para la corrección de las producciones escritas en L2 señalábamos que los profesores de los centros educativos de Valladolid no siempre recurren a la corrección inmediata por desconocimiento de su eficacia en las producciones escritas en L2 mientras que en Austin, recurren de forma significativa a la revisión y corrección de errores de forma inmediata con el fin de lograr una corrección eficaz.

Al cruzar esta variable: "Momento idóneo de corrección” con la de "Años de experiencia" encontramos que no existe una relación estadísticamente significativa entre estas. Sin embargo, la información de los gráficos nos hace llegar a varias conclusiones.

Tal y como podemos observar, los profesores más experimentados adoptan, tanto en un contexto como en el otro, la modalidad de corrección inmediata de forma generalizada. Por su parte, los que tienen más de 10 años de experiencia muestran una diferencia significativa entre contextos ya que en Valladolid optan por los dos modelos de corrección y en Austin, la gran mayoría practica en el aula un modelo de corrección inmediata (en el caso de los profesores con más de 20 años de experiencia, hablamos del 100\%).

Esto indica que los profesores españoles de menor experiencia cuentan con los conocimientos relativos a los beneficios de una corrección inmediata y lo aplican en el aula, por lo que los resultados entre el contexto educativo de Valladolid y de Austin son similares. Esto muestra unas perspectivas de futuro muy positivas. Por el contrario, una gran cantidad de profesores de L2 que llevan desempeñando su labor docente durante más de 10 años siguen 
practicando la corrección en diferido. Es posible que estos cuenten con una carencia de conocimientos en la L2 (en este caso, el inglés) por haber recibido una enseñanza tradicional centrada en la gramática, en la traducción de obras literarias y en la memorización léxica, morfológica y sintáctica que no les permita llevar a cabo una corrección inmediata. Por otro lado, cabe la posibilidad de que estos no hayan recibido una formación respecto al momento idóneo de corrección (que mencionábamos en el epígrafe 1.1.2 haciendo alusión a García-Heras Muñoz, 2004). También podríamos inferir que estos profesores no llevan al aula actividades de expresión escrita susceptibles de corregir de forma inmediata.

\subsubsection{Conocimientos sobre el momento idóneo de corrección en relación con la edad}

Nos proponemos indagar acerca de los conocimientos de nuestros informantes respecto al momento idóneo de corrección en relación con su edad. En este sentido realizamos las pruebas de chi-cuadrado "Edad" * "Momento idóneo de corrección” * "Grupo" cuyos resultados se muestran en la Tabla 37 que aparece a continuación:

Pruebas de chi-cuadrado

\begin{tabular}{|l|l|c|c|c|}
\hline \multicolumn{2}{|l|}{ Grupo } & Valor & gl & $\mathrm{p}$ \\
\hline Valladolid & Chi-cuadrado de Pearson & 1,125 & 2 &, 570 \\
\hline Austin & Chi-cuadrado de Pearson & 2,346 & 2 &, 309 \\
\hline Total & Chi-cuadrado de Pearson & 0,039 & 2 &, 981 \\
\hline
\end{tabular}

Tabla 37. Pruebas de chi-cuadrado "Edad" * "Momento idóneo de corrección" * "Grupo" 
Respecto a los datos analizados, encontramos que las variables no presentan una asociación significativa para el caso de Valladolid ni para el de Austin ni tampoco para la muestra total (en todos los casos, $\mathrm{p}>.05)$.

En la siguiente tabla de contingencia (Tabla 38) se presenta la relación entre las variables "Edad" * "Momento idóneo de corrección” * “Grupo".

Como hemos mencionado anteriormente, clasificamos la edad de los informantes en tres grupos:

- Menos de 30

- $\quad$ De 30 a 45

- Más de 45 


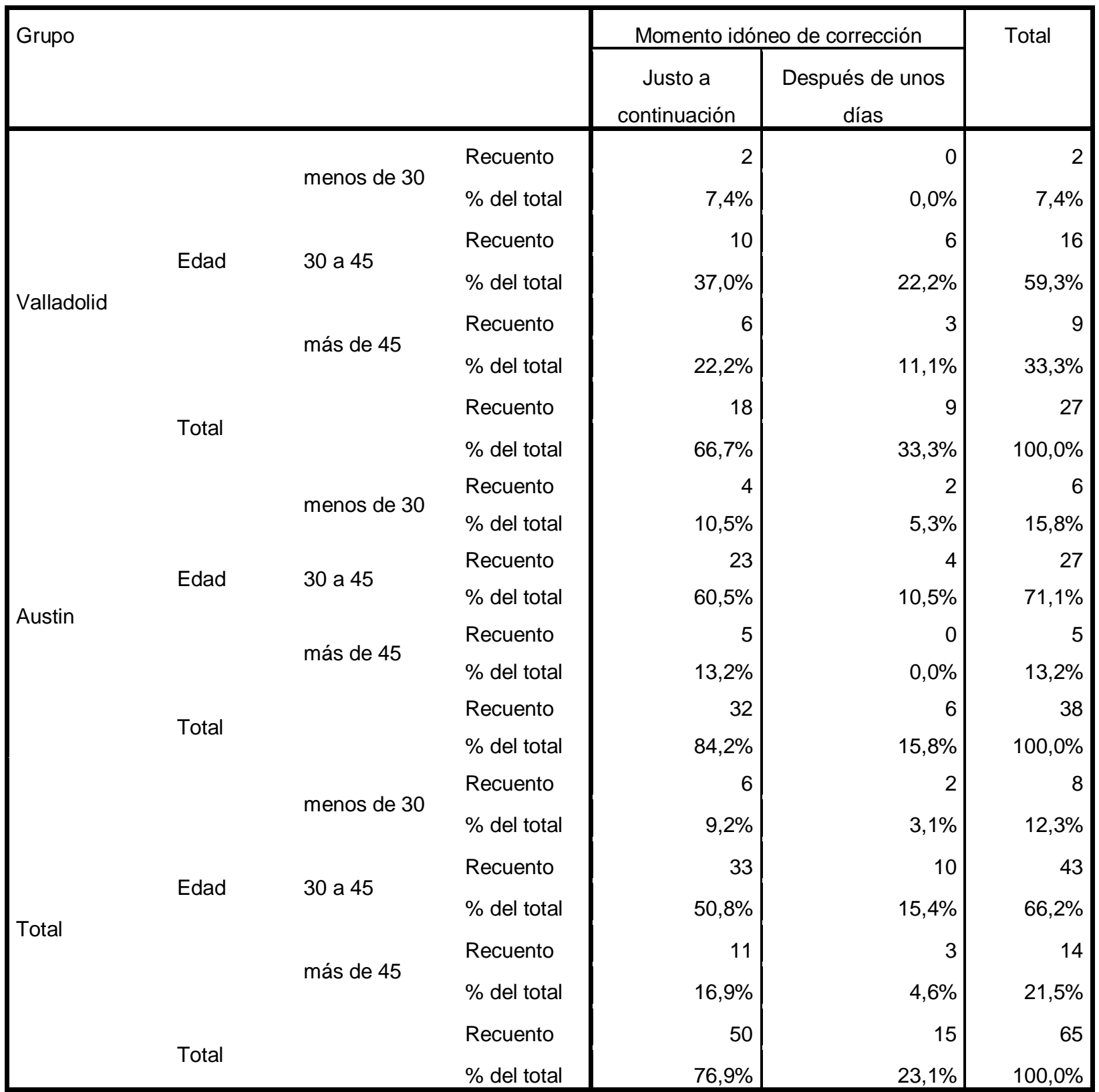

Tabla 38. Tabla de contingencia "Edad" * "Momento idóneo de corrección” * "Grupo"

En la tabla 38 se reflejan los resultados estadísticamente no significativos. En este sentido, podemos afirmar que no existe una relación representativa entre la edad de los participantes y la variable "Momento idóneo de corrección". Independientemente de la franja de edad de los participantes y del contexto educativo en el que se insertan, los resultados son similares. Los porcentajes indican que la corrección la realizan de manera generalizada "justo a continuación". 
Así pues, en Valladolid, existe un 66,7\% de informantes que manifiesta realizar la corrección justo a continuación, un 84,2\%, en el caso de Austin y un 76,9\% del porcentaje total de informantes. En Valladolid no hay informantes menores de 30 años que hayan elegido la opción de corregir después de unos días. Por su parte, en el contexto educativo de Austin, ningún informante mayor de 45 años declara corregir las producciones escritas de sus alumnos transcurridos unos días. Estos resultados parecen indicar que, en Valladolid, son los informantes más jóvenes aquellos que son conscientes de la importancia de una corrección inmediata. Este tipo de corrección está orientada hacia el uso de un enfoque metodológico de producción escrita centrada en el proceso ("processoriented pedagogy"). En el contexto de Austin, como ya hemos comentado, existe una amplia mayoría de informantes en todos los rangos de edad que realizan una corrección inmediata recurriendo al enfoque metodológico dirigido al proceso o "enfoque cognitivo" que mencionaba Salvador Mata (1997) y más tarde Ferris (2003) y Cassany (2009). Sin embargo, son los informantes de mayor edad (mayores de 45 años) quienes recurren en su totalidad a este tipo de corrección. Nos atrevemos a intuir la existencia durante muchos años de una formación del profesorado respecto al uso de una forma de corrección y dotación de feedback adecuada en la ciudad de Austin (ya que todos los rangos de edad, incluido el de mayores de 45, apuestan por una corrección inmediata).Cabe la posibilidad de que este tipo de formación orientada hacia la corrección comience a llevarse a cabo en el contexto educativo de Valladolid de una manera relativamente reciente (y por eso sean los informantes más jóvenes quienes, habiendo recibido esa formación, se inclinen hacia esta tipología de corrección inmediata orientada hacia el propio proceso de escritura). 
Para el presente análisis tuvimos en cuenta la participación de los informantes en relación a esta respuesta: $\mathrm{n}=27$ docentes de Valladolid (de los 33 que representan la muestra total) y $\mathrm{n}=$ 38 de Austin (de los 40 que componen la muestra total). Total: $\mathrm{N}=65$ informantes.

Los gráficos de barras agrupadas para Valladolid y Austin que reflejan los resultados comentados se muestran en los siguientes gráficos (Gráfico 37 y Gráfico 38):

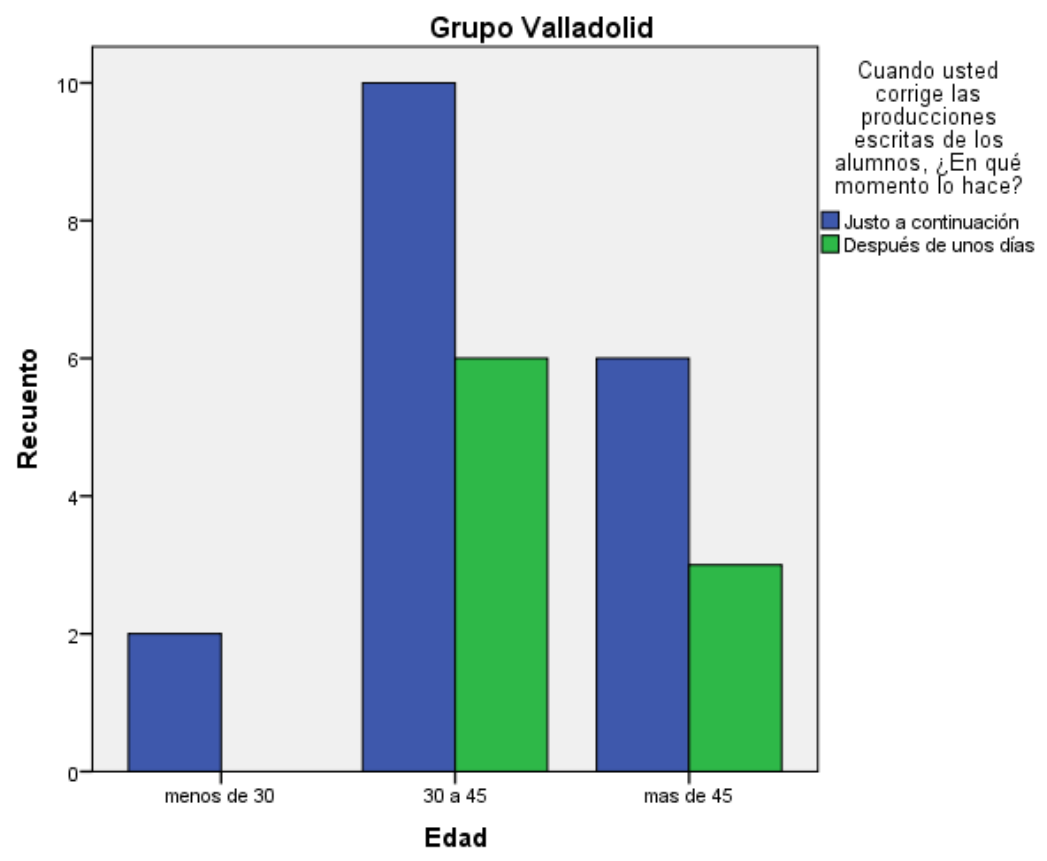

Gráfico 37. Recuento Edad - Momento idóneo de corrección - Grupo Valladolid 


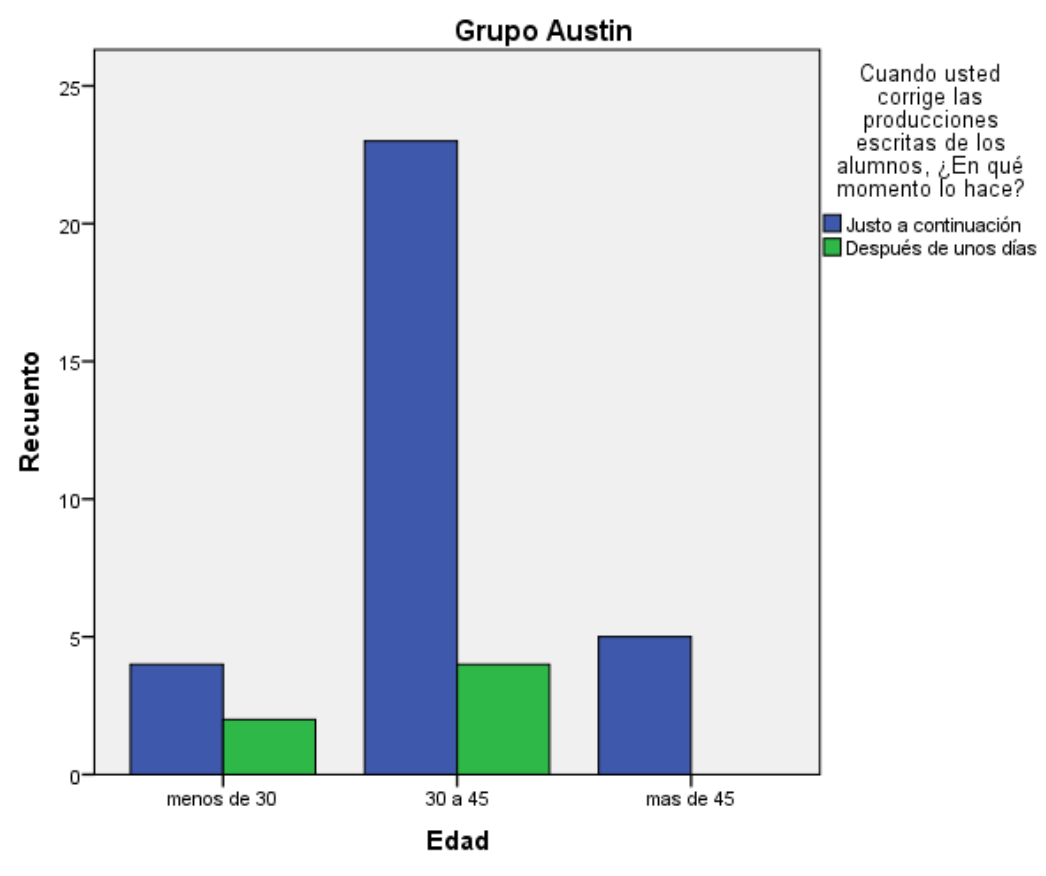

Gráfico 38. Recuento Edad - Momento idóneo de corrección - Grupo Austin

Como ya venimos observando, no existe una relación significativa entre el momento idóneo de corrección en relación a la edad de los informantes. No obstante, al analizar los datos encontramos que todos los informantes vallisoletanos menores de 30 años realizan la corrección de las producciones escritas “justo a continuación”. Esto revela un gran avance en el contexto educativo de Valladolid y demuestra que, como veíamos anteriormente, los informantes con menos años de experiencia (que a la vez son los más jóvenes) ya están en proceso de formación en torno a la importancia de la corrección inmediata orientada hacia el uso de un enfoque metodológico de producción escrita centrada en el proceso (process-oriented pedagogy). Además, estos resultados parecen indicar que son los profesores más mayores (y con más experiencia, como hemos podido comprobar en el epígrafe anterior) aquellos que realizan la corrección en diferido. Este perfil de profesores, habiendo cursado sus estudios de Primaria y Secundaria durante los años de dictadura franquista, cuentan con una visión tradicional del error como indicador de una "incapacidad" o “conducta negativa" tal y como explicábamos en el epígrafe 1.2 recurriendo a las palabras de 
Fernández López (1995). Asimismo, reciben un tipo de formación como profesores de L2 vinculado a una pedagogía tradicional orientada predominantemente a la marcación de errores en las producciones escritas de los alumnos.

En el caso de Austin, existe una amplia mayoría de informantes en todos los rangos de edad que cuentan con los conocimientos necesarios en cuanto a la importancia de realizar una corrección inmediata centrada en el proceso. No obstante, son los informantes de mayor edad (mayores de 45 años) quienes recurren de forma unánime a este tipo de corrección. Encontramos un porcentaje de informantes jóvenes que recurren a un tipo de corrección en diferido. Es posible que estos lleven al aula actividades que necesitan preparación previa. También cabe la posibilidad de que no tengan suficiente nivel de competencia lingüística en español frente a los de mayor edad que parece que tienen una formación plena en cuanto a conocimientos y a metodología. Esto nos hace pensar que, en este contexto educativo, los profesores se han venido formando en torno a la aceptación del error como un "outil pour enseigner" (Constantinescu, 2011, p.8) o como una "estrategia de aprendizaje" (Durão, 2007, p. 20), definiciones que presentábamos en el epígrafe 1.1.1. Una formación en la que la actitud positiva por parte del profesor juega un papel fundamental durante el proceso de corrección puesto que esta tiene una gran incidencia en la actitud del alumno ante la escritura y ante la enseñanza-aprendizaje de L2 en general (tal y como señalábamos en el epígrafe 1.1.2). 


\subsubsection{Conocimientos sobre el momento idóneo de corrección en relación con el curso}

En el presente epígrafe abordamos los conocimientos de nuestros informantes respecto al momento idóneo de corrección en relación con el curso escolar en el que ejercen su actividad docente. Por consiguiente, procedemos a ejecutar las pruebas de chi-cuadrado "Curso" * "Momento idóneo de corrección” * “Grupo" cuyos resultados se reflejan en la Tabla 39 que se muestra a continuación:

\begin{tabular}{|l|l|c|c|c|}
\hline \multicolumn{2}{|l|}{ Grupo } & Valor & gl & $\mathrm{p}$ \\
\hline Castilla-León & Chi-cuadrado de Pearson & 0964 & 1 &, 326 \\
\hline Austin & Chi-cuadrado de Pearson & 0,241 & 1 &, 623 \\
\hline Total & Chi-cuadrado de Pearson & 1,055 & 1 &, 304 \\
\hline
\end{tabular}

Los datos analizados demuestran que, para la presente muestra, no existe una asociación significativa entre el curso que imparten los profesores de segundas lenguas y el momento en que realiza las producciones escritas de sus alumnos, ni en el caso de Valladolid, ni en el de Austin ni a nivel total (en todos los casos, $\mathrm{p}>.05$ ).

Desarrollamos la siguiente tabla de contingencia (ver Tabla 40) para la variable "Curso" * "Momento idóneo de corrección” * "Grupo".

Como ya hemos venido indicando, clasificamos el curso en el que los informantes imparten sus clases de L2 en dos categorías: de $1^{\circ}$ a $3^{\circ}$ y de $4^{\circ}$ a $6^{\circ}$. 


\begin{tabular}{|c|c|c|c|c|c|c|}
\hline \multirow[t]{2}{*}{ Grupo } & & & & \multicolumn{2}{|c|}{ Momento idóneo de corrección } & \multirow[t]{2}{*}{ Total } \\
\hline & & & & $\begin{array}{c}\text { Justo a } \\
\text { continuación }\end{array}$ & $\begin{array}{c}\text { Después de } \\
\text { unos días }\end{array}$ & \\
\hline \multirow{6}{*}{ Valladolid } & \multirow{4}{*}{ Curso } & \multirow{2}{*}{$1^{\circ}$ a $3^{\circ}$} & Recuento & 5 & 1 & 6 \\
\hline & & & $\%$ del total & $18,5 \%$ & $3,7 \%$ & $22,2 \%$ \\
\hline & & \multirow{2}{*}{$4^{\circ}$ a $6^{\circ}$} & Recuento & 13 & 8 & 21 \\
\hline & & & $\%$ del total & $48,1 \%$ & $29,6 \%$ & $77,8 \%$ \\
\hline & \multirow{2}{*}{ Total } & \multirow{4}{*}{$1^{\circ}$ a $3^{\circ}$} & Recuento & 18 & 9 & 27 \\
\hline & & & $\%$ del total & $66,7 \%$ & $33,3 \%$ & $100,0 \%$ \\
\hline \multirow{6}{*}{ Austin } & \multirow{4}{*}{ Curso } & & Recuento & 12 & 2 & 14 \\
\hline & & & $\%$ del total & $30,0 \%$ & $5,0 \%$ & $35,0 \%$ \\
\hline & & 40 & Recuento & 22 & 4 & 26 \\
\hline & & & $\%$ del total & $55,0 \%$ & $10,0 \%$ & $65,0 \%$ \\
\hline & Tatal & & Recuento & 34 & 6 & 40 \\
\hline & Tolal & \multirow{3}{*}{$1^{\circ}$ a $3^{\circ}$} & $\%$ del total & $85,0 \%$ & $15,0 \%$ & $100,0 \%$ \\
\hline \multirow{6}{*}{ Total } & \multirow{4}{*}{ Curso } & & Recuento & 17 & 3 & 20 \\
\hline & & & $\%$ del total & $25,4 \%$ & $4,5 \%$ & $29,9 \%$ \\
\hline & & & Recuento & 35 & 12 & 47 \\
\hline & & $4-\mathrm{d} 0$ & $\%$ del total & $52,2 \%$ & $17,9 \%$ & $70,1 \%$ \\
\hline & \multirow{2}{*}{ Total } & & Recuento & 52 & 15 & 67 \\
\hline & & & $\%$ del total & $77,6 \%$ & $22,4 \%$ & $100,0 \%$ \\
\hline
\end{tabular}

Tabla 40. Tabla de contingencia "Curso" * "Momento idóneo de corrección" * "Grupo"

A partir de la tabla de contingencia (Tabla 40) observamos que no existe relación significativa entre el curso impartido (en dos categorías) y la variable "Momento idóneo de corrección”. Así pues, independientemente del curso que imparten los participantes y del contexto educativo al que pertenecen (Valladolid o Austin), la mayoría de ellos realizan las correcciones “justo a continuación”. Tal y como podemos observar, en Valladolid existe un 66,7\% de informantes que manifiesta realizar la corrección justo a continuación. El porcentaje, en el caso de Austin, es bastante más elevado (85\%). La opción correspondiente a la corrección de las 
producciones escritas de los alumnos de L2 “justo a continuación” constituye un 77,6\% del total de informantes.

A pesar de esto, observamos la existencia de algunos porcentajes más elevados en cuanto a la corrección “después de unos días". Los informantes del contexto educativo de Valladolid que imparten sus clases a alumnos de $4^{\circ}$ a $6^{\circ}$ de Educación Primaria $(29,6 \%)$ son aquellos que presentan un porcentaje más elevado en relación a esta respuesta. Los resultados obtenidos permiten inferir que estos profesores apoyan la corrección inmediata como norma general, aunque añaden especial énfasis en los alumnos en edades tempranas. Cuando se trata de alumnos en cursos superiores un buen porcentaje de profesores procura hacerlo de manera inmediata, aunque existe aproximadamente un $30 \%$ que lo hace después de unos días.

En cuanto al grado de participación de los informantes en relación a esta respuesta podemos decir que participaron $n=27$ docentes de Valladolid (de los 33 que representan la muestra total) y $\mathrm{n}=40$ de Austin (100\% de la muestra). Total: $\mathrm{N}=67$ informantes.

A continuación, se muestran los gráficos de barras agrupadas para Valladolid y Austin que reflejan los resultados analizados (Gráfico 39 y Gráfico 40): 


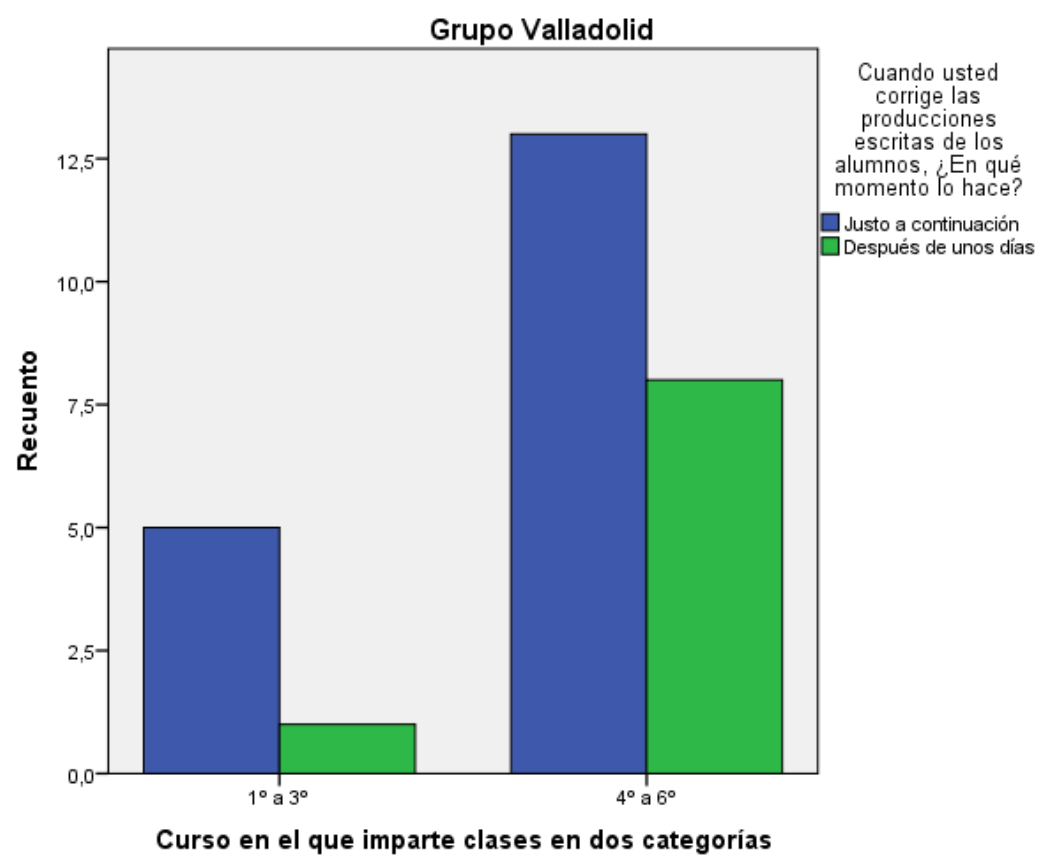

Gráfico 39. Recuento Curso - Momento idóneo de corrección - Grupo Valladolid

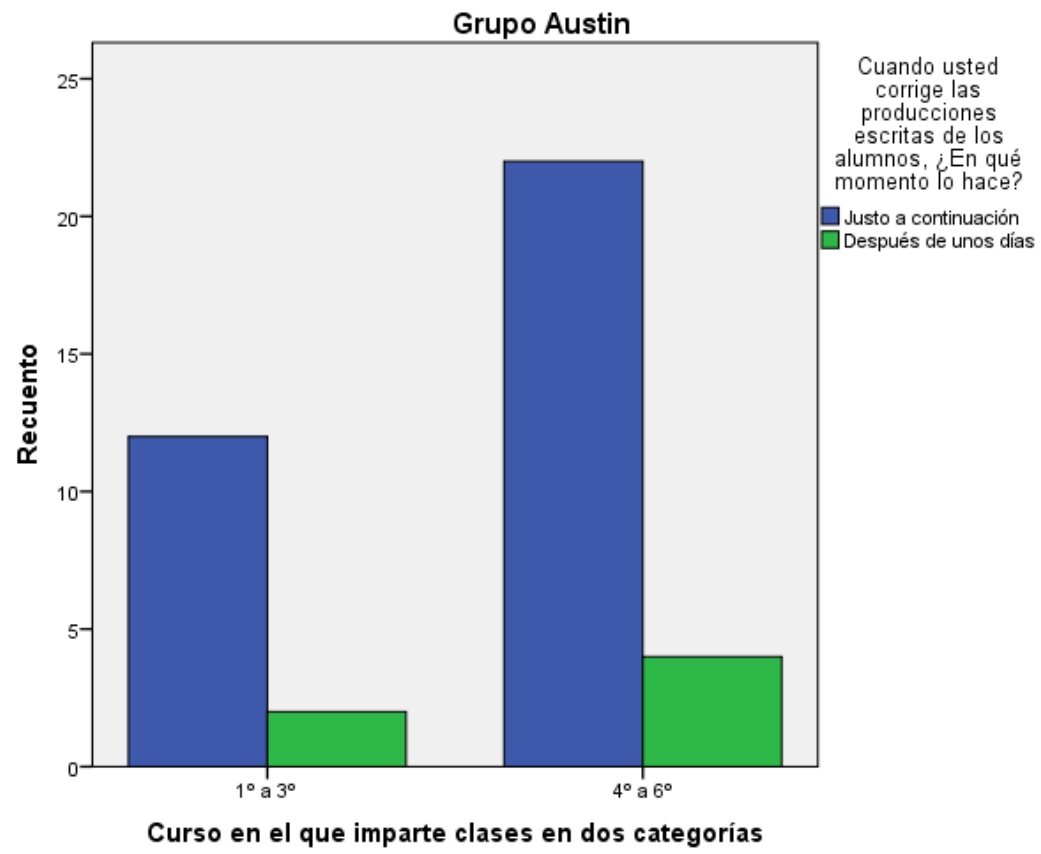

Gráfico 40. Recuento Curso - Momento idóneo de corrección - Grupo Austin 
Las variables "Curso" y "Momento idóneo de corrección” tampoco presentan asociación significativa, por lo que a los datos estadísticos se refiere. No obstante, en los gráficos 39 y 40 encontramos una gran cantidad de información relevante que arroja luz a nuestro trabajo de investigación. Como podemos observar, los profesores de ambos contextos, apuestan por la corrección inmediata en los cursos inferiores (de $1^{\circ}$ a $3^{\circ}$ ) sin embargo, en cursos superiores nos encontramos ante una gran diferencia entre un contexto educativo y otro.

Así es como, una cantidad elevada de profesores vallisoletanos optan por un tipo de corrección en diferido en cursos superiores, lo cual, podría ser indicador de ciertas carencias en cuanto a su competencia lingüística en inglés. Cabe la posibilidad de que estos, a diferencia de los informantes de Austin no tengan una base consolidada respecto a conocimientos léxicos, y/o gramaticales en la L2 y, por esta razón, se sientan obligados a realizar las correcciones de las producciones escritas de los cursos superiores en el despacho (después de unos días) y no directamente en el aula. En este sentido, podríamos inferir que una parte de los informantes no llevan al aula la técnica de borradores encadenados en cursos superiores ya que dicha técnica implica la presencia de una corrección y dotación de feedback inmediatos para lo que pueden no sentirse preparados. Por el contrario, sí lo hacen en los cursos inferiores lo cual puede hacernos pensar que sí se sienten preparados para corregir directamente este tipo de producciones, las cuales, cuentan con un nivel de menor complejidad respecto a las de los cursos superiores.

En cuanto al contexto de Austin, encontramos un número muy reducido de profesores que optan por la corrección en diferido. En este grupo, la diferencia entre los que imparten cursos inferiores y superiores es poco significativa. 


\subsubsection{Conocimientos sobre el momento idóneo de corrección en relación con el número de alumnos}

Nos aproximamos a los conocimientos de nuestros informantes respecto al momento idóneo de corrección en relación con el número de alumnos. Las pruebas de chi-cuadrado "Número de alumnos" * "Momento idóneo de corrección” * “Grupo” se presentan a continuación en la Tabla 41:

\begin{tabular}{|l|l|r|r|r|}
\hline \multicolumn{2}{|l|}{ Grupo } & Valor & gl & p \\
\hline Valladolid & Chi-cuadrado de Pearson & 2,350 & 2 &, 309 \\
\hline Austin & Chi-cuadrado de Pearson & 0,623 & 2 &, 732 \\
\hline Total & Chi-cuadrado de Pearson & 2,800 & 2 &, 247 \\
\hline
\end{tabular}
Tabla 41. Pruebas de chi-cuadrado "Número de alumnos" * "Momento idóneo de corrección" * "Grupo"

Los datos analizados indican que, para la presente muestra, no existe una asociación significativa entre el número de alumnos que tienen los profesores de segundas lenguas y el momento en que realizan la corrección de las producciones escritas ni en el caso de Valladolid, ni en el de Austin ni tampoco a nivel total (en todos los casos, $\mathrm{p}>.05$ ).

A continuación, se presenta la tabla de contingencia (Tabla 42) para la variable "Número de alumnos" * "Momento idóneo de corrección” * “Grupo”.

La clasificación en cuanto al número de alumnos con los que cuentan los informantes se distribuye en tres categorías (como ya se ha venido indicando): de 14 a 22, de 23 a 52 y más de 52. 


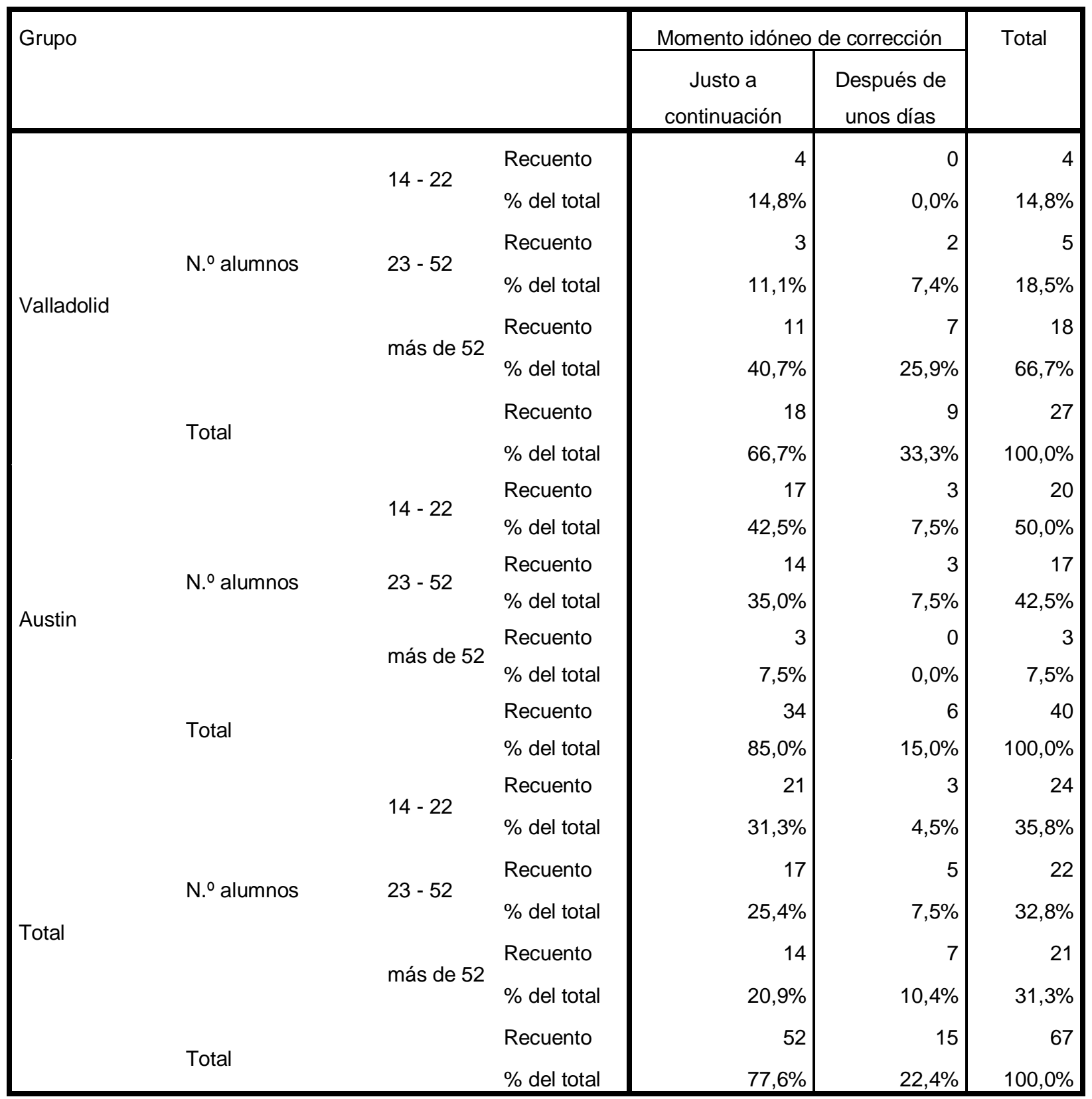

Tabla 42. Tabla de contingencia "Número de alumnos" * "Momento idóneo de corrección" * "Grupo"

La tabla de contingencia (Tabla 42) no presenta una asociación estadísticamente significativa para el caso de Valladolid, ni para el de Austin ni tampoco para la muestra total entre las dos variables mencionadas. Se demuestra por tanto que no existe relación significativa entre el 
"Número de alumnos a los que atienden los participantes" (en tres categorías) y la variable "Momento idóneo de corrección”. Así es como, independientemente del contexto educativo (Valladolid o Austin) y de la cantidad de alumnos que tienen los informantes, la mayoría de profesores manifiestan realizar la corrección “justo a continuación” y una minoría afirma corregir “después de unos días”. De manera más específica, en el caso de Valladolid un 66,7\% de informantes opta por realizar la corrección justo a continuación, un 85\%, en el caso de Austin y, considerada la muestra a nivel total, un $77,6 \%$. Observamos que, todos los docentes de Valladolid que cuentan con un número de alumnos entre 14 y 22 afirman realizar la corrección "justo a continuación”. Además de esto, nos llama la atención el hecho de que en Valladolid exista un porcentaje importante de informantes con más de 52 alumnos $(25,9 \%)$ que realizan la corrección “después de unos días" a diferencia de la ciudad de Austin en la que todos los docentes con más de 52 alumnos (100\%) lo hacen “justo a continuación”. Resulta llamativa la diferencia entre un contexto educativo y otro. Contando con que un número elevado de alumnos dificulta la tarea de corrección inmediata nos sorprende observar que en determinados casos esta se impone como prioridad absoluta. Esto nos hace pensar en la gran importancia que se da a esta en el contexto educativo de Austin puesto que se lleva a cabo a pesar de las dificultades.

Sin embargo, más de las dos terceras partes de la muestra total manifestaron corregir "justo a continuación” y, como se ha reseñado, las variables implicadas no mostraron un grado de asociación significativo. Debemos tener en cuenta la participación de los informantes en relación a esta respuesta. En el caso de Valladolid participaron $n=27$ docentes (de un total de 33 informantes) $\mathrm{y}$ en el de Austin $\mathrm{n}=40$ (100\% de la muestra) formando un total de $\mathrm{N}=64$ informantes. 
Los siguientes gráficos de barras agrupadas (Gráfico 41 y Gráfico 42) indican los resultados analizados para Valladolid y Austin.

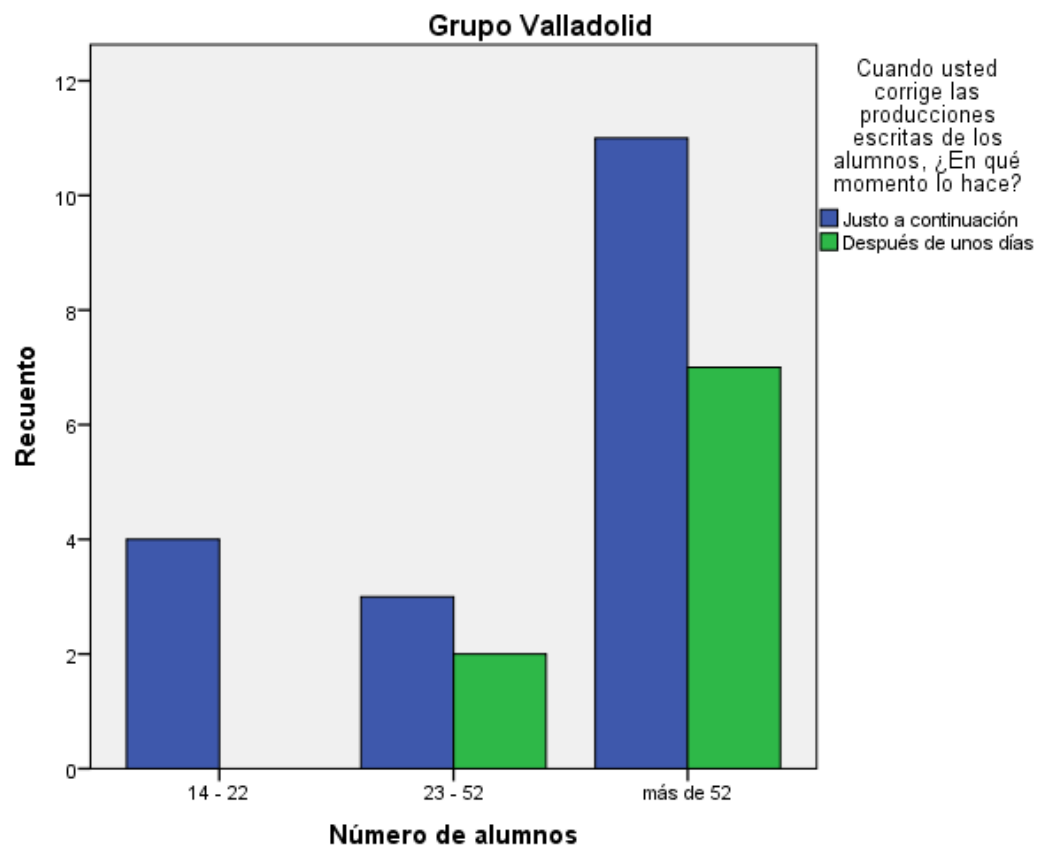

Gráfico 41. Recuento Número de alumnos - Momento idóneo de corrección - Grupo Valladolid

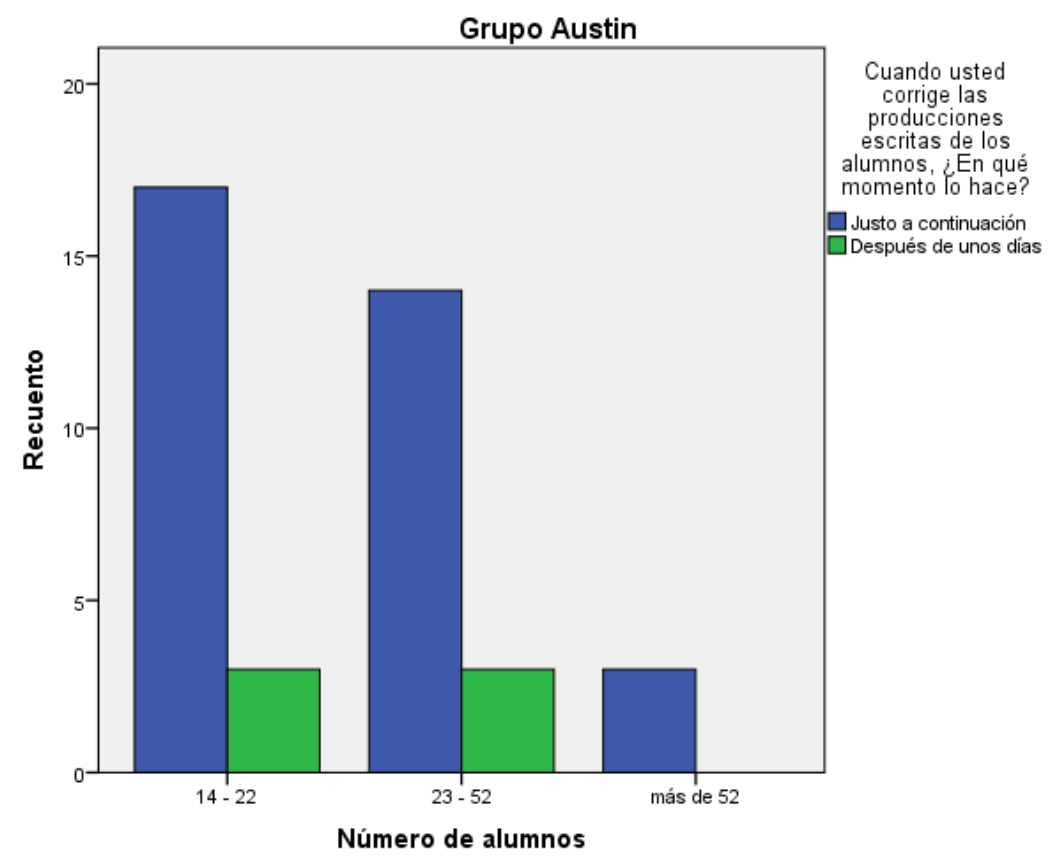

Gráfico 42. Recuento Número de alumnos - Momento idóneo de corrección - Grupo Austin 
Los resultados del análisis estadístico en torno a los conocimientos sobre el "momento idóneo de corrección” en relación con el "número de alumnos” también indican que no existe una relación significativa entre las variables. En relación a la información encontrada en los gráficos, encontramos que los profesores de Valladolid realizan un tipo de corrección en diferido solo cuando cuentan con un número elevado de alumnos. Como ya adelantábamos en el epígrafe 1.1.2, la tarea de corregir puede llegar a convertirse en una experiencia difícil para el profesor (Dulay, Burt y Krashen, 1982) especialmente cuando se encuentran ante un grupo numeroso de alumnos. Es posible que estos profesores lleven al aula las técnicas de borradores encadenados cuando se encuentren desarrollando su actividad en clases poco numerosas. Sin embargo, ante un elevado número de alumnos puede que opten por actividades en las que se solicita al alumno que lleve a cabo una producción escrita por su cuenta (sin la intervención o respuesta por parte del profesor o de otro alumno del aula).

Por su parte, los profesores del contexto educativo de Austin, realizan las correcciones con los propios alumnos, sin dar importancia al número de estudiantes a los que atienden. Nos atrevemos a inferir, a partir de esta información, que estos profesores hacen hincapié en la corrección inmediata acompañada de la intervención del profesor y posterior feedback. En este sentido, mostramos nuestro acuerdo con Ferris (2003) quien señalaba (como ya hemos mencionado en el epígrafe 1.1.3) la existencia de profesores que todavía corrigen a partir de un único borrador elaborado por el alumno. Consideramos que estos profesores del contexto de Valladolid se incluyen dentro de este grupo mencionado por Ferris (2003). No obstante, tal y como afirmaba la mencionada autora, "in North American academic settings, many teachers have made the shift 
over the past 15 years from being form-focused and product-oriented to providing feedback on a broad spectrum of issues in a multiple-draft, response-and-revision writing cycle" (p. 22). Desde nuestro punto de vista, la afirmación de Ferris (2003) corresponde con los resultados encontrados. Así es como Valladolid podría incluirse dentro de aquellos contextos en los que, según la autora, todavía se corrige señalando los errores en las propias producciones escritas, añadiendo una nota numérica y un feedback en forma de pequeñas anotaciones escritas en el propio texto. En cambio, Austin entraría a formar parte de aquellos contextos educativos en los que se corrige de forma individual con el propio alumno a partir de varios borradores que él mismo tendrá que reformular y modificar bajo la supervisión del profesor.

Como ya hemos venido defendiendo a lo largo de este documento de Tesis Doctoral, la técnica denominada por Zamel (1985) "cycles of revision" o borradores encadenados a la que hacíamos alusión en el epígrafe 3.1.2, favorece la interacción y la cooperación entre alumnoprofesor. Asimismo, se revela como provechosa en la enseñanza-aprendizaje de expresión escrita en L2 durante la etapa de Educación Primaria por permitir una corrección inmediata de los errores encontrados en cada uno de los borradores de los alumnos posibilitando que el alumno pueda recordar exactamente las razones que le llevaron a utilizar una forma concreta.

\subsection{Aptitudes en torno a la forma de proporcionar feedback}

En la presente investigación intentábamos indagar acerca de las aptitudes de los profesores respecto a la forma de proporcionar feedback como complemento a la corrección de las 
producciones escritas en L2 a través del ítem número 13 de nuestro cuestionario. Los resultados obtenidos a partir del análisis de datos en ambos contextos educativos se muestran en el epígrafe 7.5 de la presente Tesis Doctoral.

El mencionado ítem, aparecía bajo el enunciado: “¿De qué manera hace llegar a los alumnos sus comentarios o feedback sobre las producciones escritas que han realizado?" y las cinco respuestas propuestas fueron: "de forma oral individualmente con cada alumno", "de forma oral de manera conjunta (en voz alta) para que todos puedan aprender de los errores de sus compañeros", "escribiendo los comentarios que considere oportunos con tinta de otro color en el mismo papel donde se encuentra la producción escrita", "utilizo un código de corrección que mis alumnos ya conocen y lo escribo en las producciones escritas" y "otros". Esta última opción permitía a los informantes la posibilidad de añadir sus aportaciones personales, aunque dichas aportaciones se asociaron posteriormente a las cuatro respuestas propuestas originalmente.

A través de este ítem, nos proponíamos averiguar, por un lado, si los informantes facilitan el feedback durante el mismo proceso de producción escrita (a través de conferencias individuales o en grupo reducido haciendo uso de un tipo de corrección inmediata o bien lo hace en diferido (una vez concluida la actividad). Por otro, intentábamos averiguar si estos utilizan un enfoque metodológico de producción escrita basado en el proceso ("process-oriented pedagogy") o uno centrado en el producto ("product-oriented pedagogy").

Los porcentajes finales respecto a la elección de respuestas de nuestros informantes se indican en el epígrafe 7.5.1. Tal y como pudimos comprobar, el 36\% de los informantes 
vallisoletanos corrigen sus producciones y proporcionan feedback "de forma oral individualmente con cada alumno", el $42 \%$ lo hace "de forma oral en grupo (en voz alta) para que todos puedan aprender de los errores de sus compañeros", el 19\% suministra el feedback "escribiendo los comentarios que considere oportunos con tinta de otro color en el mismos papel donde se encuentra la producción escrita." y un 3\% "utiliza un código de corrección que sus alumnos ya conocen y lo escribe en las producciones escritas". En el caso de Austin, los porcentajes son muy diferentes. Un $82,5 \%$ elige la primera opción (feedback oral individual), un 7,5\% entrega el feedback de manera conjunta, un 7,5\% añade comentarios escritos a las producciones escritas y un $2,5 \%$ utiliza un código de corrección.

Los resultados obtenidos nos llevaron a concluir que los informantes del contexto educativo de Valladolid realizan generalmente una corrección en diferido haciendo uso de un enfoque metodológico centrado en el producto final lo cual nos permite inferir que estos no cuentan con unas aptitudes o capacidades óptimas respecto al uso del feedback ni tampoco cuentan con aptitudes óptimas respecto a la elección de métodos de corrección de las producciones escritas de L2. Por el contrario, los datos correspondientes al contexto educativo de Austin demostraron que estos informantes recurren a la corrección inmediata orientada al enfoque metodológico de producción escrita centrado en el proceso. Esto nos llevaba a concluir que, los profesores del contexto educativo de Austin (al contrario que los de Valladolid) apuestan por la consecución de un aprendizaje significativo en el que la interacción alumno-profesor juegue un papel fundamental dentro del proceso de producción escrita en L2 y en el que se conceda una importancia especial al factor afectivo. 
Tras este recorrido a través de las indagaciones sobre las aptitudes de los profesores respecto a la forma de proporcionar feedback expuestas en el epígrafe 7.5 nos disponemos a cruzar los datos obtenidos en dicho epígrafe (correspondientes a la variable resultante del ítem 13 a la que hemos denominado "Forma de proporcionar el feedback") con los relativos al perfil del informante (“Años de experiencia", "Edad", “Curso" y "Número de alumnos”). Para ello, se plantean una serie de análisis estadísticos cuyos resultados se reflejan en los subepígrafes que aparecen a continuación.

\subsubsection{Aptitudes en torno a la forma de proporcionar feedback en relación con los años de experiencia}

En el presente subepígrafe nos disponemos a abordar las aptitudes de nuestros informantes respecto a la forma de proporcionar feedback en relación con sus años de experiencia. En la tabla que se muestra a continuación (Tabla 43) se presentan las pruebas de chi-cuadrado "Años de experiencia" * "Forma de proporcionar el feedback" * "Grupo".

\begin{tabular}{|l|l|c|c|c|}
\hline \multicolumn{2}{|l|}{ Grupo } & Valor & gl & $\mathrm{p}$ \\
\hline Valladolid & Chi-cuadrado de Pearson & 3,022 & 6 &, 806 \\
\hline Austin & Chi-cuadrado de Pearson & 2,460 & 6 &, 873 \\
\hline Total & Chi-cuadrado de Pearson & 3,759 & 6 &, 709 \\
\hline
\end{tabular}
Tabla 43. Pruebas de chi-cuadrado "Años de experiencia" * "Forma de proporcionar el feedback" * "Grupo"


Los datos expuestos en la Tabla 43 demuestran que las variables implicadas no indican un grado de asociación significativo para el caso de Valladolid, tampoco para el de Austin ni para la muestra total (en todos los casos, $\mathrm{p}>.05)$

A continuación, presentamos la siguiente tabla de contingencia (Tabla 44) para las variables “Años de experiencia" * "Forma de proporcionar el feedback" * "Grupo". 


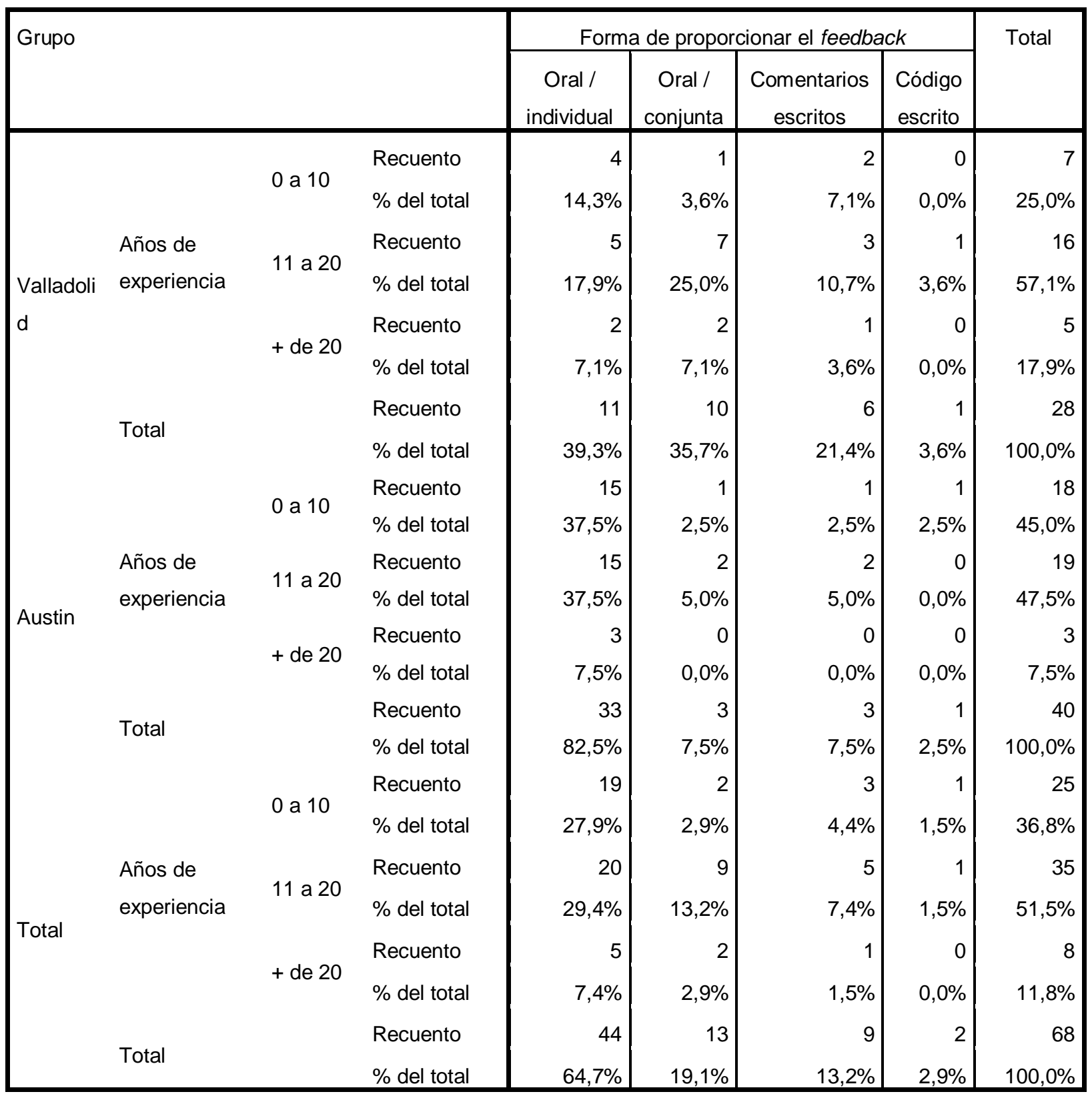

Tabla 44. Tabla de contingencia "Años de experiencia" * "Forma de proporcionar el feedback" * "Grupo"

En la tabla 44 observamos que no existe relación estadísticamente significativa entre los “Años de experiencia" y la variable "Forma de proporcionar el feedback". Independientemente de los años de experiencia, en el contexto educativo de Valladolid predomina el feedback oral proporcionado de manera conjunta (42\%) frente al feedback oral individual (36\%), a los comentarios escritos (19\%) y al uso de un código de corrección (3\%). No obstante, en el contexto 
de Austin, es la modalidad de feedback oral individual (82,5\%) la que predomina sobre el resto. Los comentarios y códigos escritos son poco utilizados por los participantes, independientemente de su origen cultural y del número de alumnos que atienden.

Debemos tener en cuenta que algunas de las categorías no tienen representantes dado que la variable relacionada con la forma de proporcionar el feedback a los alumnos tiene cuatro subcategorías que, ante una muestra pequeña (sobre todo en Valladolid, cuyos informantes no siempre responden a las preguntas) se traduce en un gran número de "subdivisiones". Resulta llamativo el escaso uso de un código de corrección entre los docentes de los dos contextos educativos. Además, en el caso de Austin, nos llama la atención el hecho de que todos los informantes que cuentan con más de 20 años de experiencia opten por el uso de un feedback oral individual. Es significativo el hecho de que los informantes de Valladolid recurran a un feedback oral proporcionado de manera conjunta (en voz alta) en un porcentaje tan elevado, sobre todo aquellos que cuentan con 11 a 20 años de experiencia (25\%) a diferencia de los q desarrollan su actividad en Austin (5\%).

En cuanto a la participación de los informantes en relación a esta respuesta encontramos en Valladolid $n=28$ profesores (de un total de 33) y en el de Austin n $=40$ (100\% de la muestra) formando un total de $\mathrm{N}=68$ informantes.

Los gráficos de barras agrupadas (Gráfico 43 y Gráfico 44) que aparecen a continuación exponen los resultados analizados para Valladolid y Austin. 


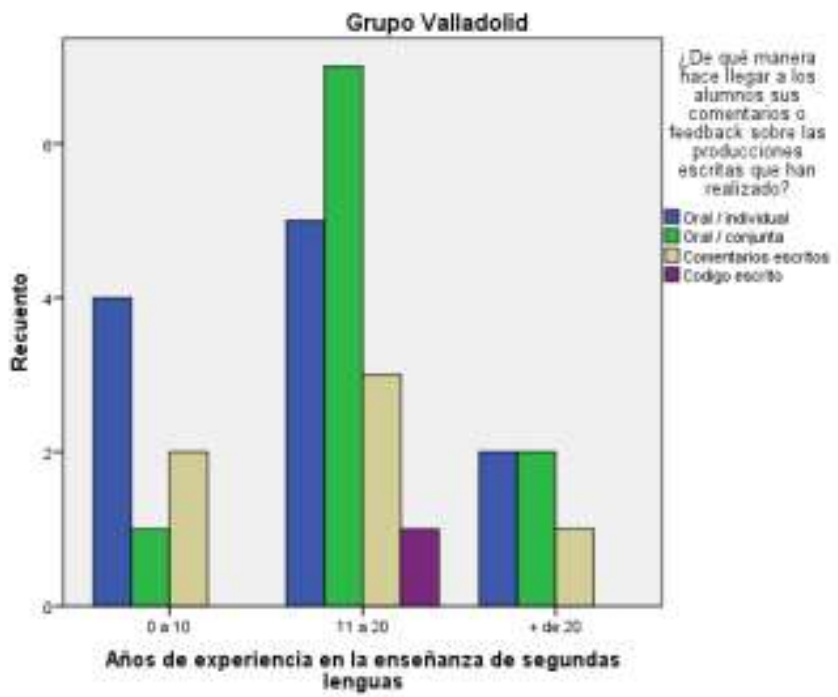

Gráfico 43. Recuento Años de experiencia - Forma de proporcionar el feedback - Grupo Valladolid

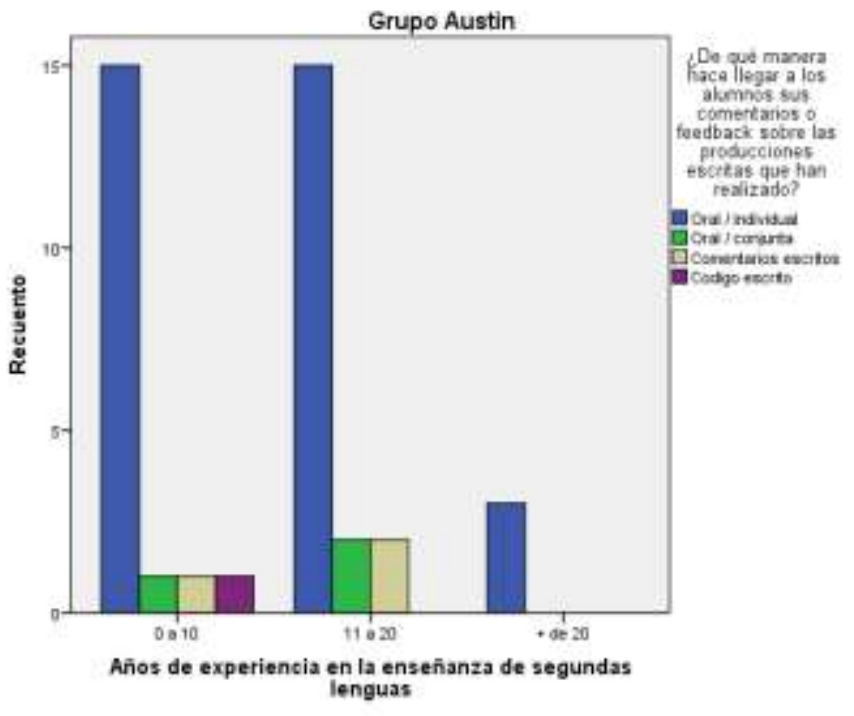

Gráfico 44. Recuento Años de experiencia - Forma de proporcionar el feedback - Grupo Austin

Como ya comentábamos en el epígrafe 7.5.2 de la presente Tesis Doctoral dedicado al componente competencial: Aptitudes en torno a la dotación de feedback que acompaña a la corrección de errores de una actividad de escritura libre en L2, en los centros educativos de Valladolid predomina el feedback oral proporcionado de manera conjunta, aunque también 
recurren a otros tipos de feedback. Por su parte, en los centros de Austin la modalidad de feedback oral individual predomina sobre el resto.

Tras cruzar la variable "Forma de proporcionar el feedback" con los "Años años de experiencia" encontramos que no existe una relación estadísticamente significativa entre estas. Sin embargo, los datos mostrados en los gráficos, aportan una información de gran trascendencia para nuestra investigación.

Los informantes de los centros educativos de Valladolid con menos años de experiencia recurren, de forma mayoritaria, al feedback oral individual. Por su parte, aquellos que cuentan con una experiencia más consolidada hacen uso de distintos tipos de feedback (oral individual, oral en voz alta, comentarios escritos, código escrito, etc.). A excepción del feedback oral individual, el resto se proporcionan una vez concluida la actividad y no durante el mismo proceso de producción escrita. Esto nos lleva a retomar la idea del uso de una corrección en diferido acompañada de un feedback que el profesor ha podido preparar de forma previa y que posteriormente podrá presentar tanto de forma oral al grupo de alumnos como de forma escrita (utilizando anotaciones que pueden ir acompañadas de nota numérica) como en forma de código de errores. Esto parece indicar la existencia de una formación (que empieza a apreciarse en los profesores con menos años de experiencia) dirigida a la dotación de un feedback automático que acompañe a una corrección inmediata. No obstante, la falta de consenso por parte de los profesores que llevan más tiempo ejerciendo su actividad docente, nos lleva a inferir la existencia de una falta de aptitud por parte de estos en cuanto a la forma de proporcionar feedback en las producciones escritas de L2. 
En lo que respecta a las aptitudes por parte de los profesores del contexto educativo de Austin, destacamos el hecho de que en todas las franjas de años de experiencia los informantes optan de forma mayoritaria por el uso de un feedback oral individual aunque son aquellos que tienen más de 20 años de experiencia los que recurren de forma unánime a dicha modalidad, la cual, tal y como mencionábamos en el epígrafe 1.3, concede al profesor la posibilidad de motivar al alumno y de transmitirle esa idea de autonomía y de cooperación bidireccional a la que hacíamos referencia en el epígrafe 1.1.3. Nos atrevemos a suponer que los profesores de este contexto educativo (a diferencia del anterior, en el que se empieza a divisar la existencia de una formación específica) cuentan con una formación consolidada en la que, durante años se ha insisitido en la adquisición de unas aptitudes dirigidas a la dotación de un feedback de calidad que acompañe a la corrección de errores. Un feedback que, situándonos en la línea de López (2009) asociábamos en el epígrafe 1.1.3 a "una respuesta al error" (p. 66) y que se entendía como un mensaje emitido por el profesor intentando, en primer lugar, destacar el "valor comunicativo de la práctica de los alumnos" (López Hernández, 2009, p. 71) y, en segundo lugar, transmitir tanto los aciertos como los errores que aparecen en la producción escrita en L2.

\subsubsection{Aptitudes en torno a la forma de proporcionar feedback en relación con la edad de los informantes}

En el presente epígrafe nos aproximamos a las aptitudes de nuestros informantes respecto a la forma de proporcionar feedback en relación con su edad. 
A continuación, se presenta la tabla de las pruebas chi-cuadrado (Tabla 45) que muestra los datos relativos a la "Edad" * "Forma de proporcionar el feedback" * "Grupo".

\begin{tabular}{|l|l|c|c|c|}
\hline \multicolumn{2}{|l|}{ Grupo } & Valor & gl & $\mathrm{p}$ \\
\hline Valladolid & Chi-cuadrado de Pearson & 8,181 & 6 &, 225 \\
\hline Austin & Chi-cuadrado de Pearson & 2,382 & 6 &, 881 \\
\hline Total & Chi-cuadrado de Pearson & 9,470 & 6 &, 149 \\
\hline
\end{tabular}

Tabla 45. Pruebas de chi-cuadrado "Edad" * "Forma de proporcionar el feedback" * "Grupo"

Como podemos observar a partir de los datos expuestos en la Tabla 45 las variables implicadas no indican un grado de asociación significativo para el caso de Valladolid, tampoco para el de Austin ni para la muestra total (en todos los casos, $\mathrm{p}>.05$ ).

La siguiente tabla de contingencia (Tabla 46) expone los datos para las variables "Edad" * "Forma de proporcionar el feedback" * "Grupo". 


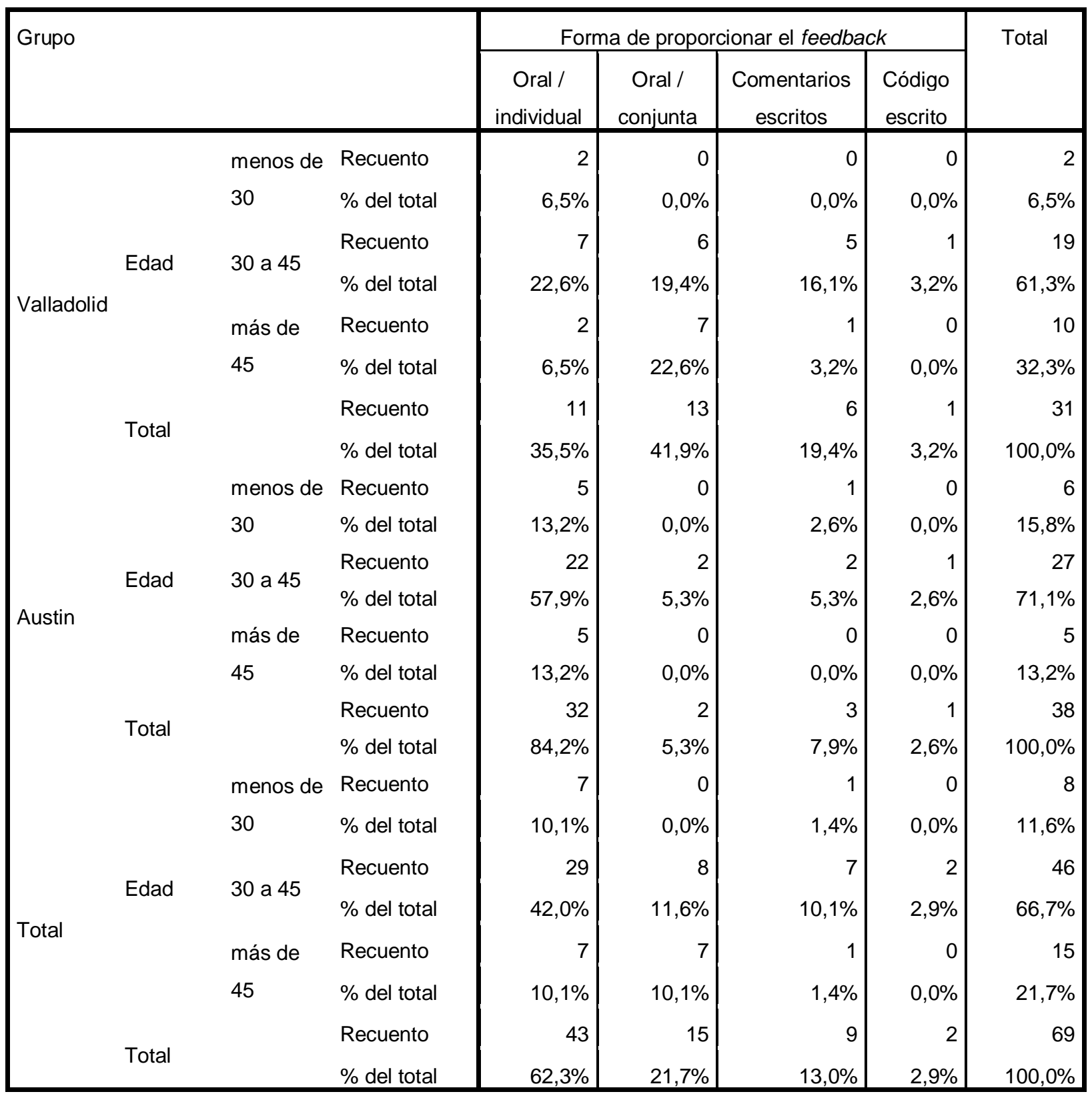

Tabla 46. Tabla de contingencia "Edad" * "Forma de proporcionar el feedback" * "Grupo"

La tabla de contingencia (Tabla 46) pone de manifiesto que no existe relación estadísticamente significativa entre la "Edad" y la variable "Forma de proporcionar el feedback". De nuevo nos encontramos con la ausencia de representantes en alguna de las categorías por tener la variable relacionada con la forma de proporcionar el feedback a los alumnos cuatro subcategorías. Nos 
llama la atención el hecho de que los informantes menores de 30 años (tanto de Valladolid como de Austin) apenas cuentan con representantes en las subcategorías correspondientes a "de forma oral de manera conjunta", "Escribiendo los comentarios..." o "Utilizando un código de corrección". Prácticamente todos ellos acuden al feedback oral individual. En el caso de Austin, aquellos informantes mayores de 45 años también recurren a la misma modalidad de feedback sin que existan representantes del resto de subcategorías. Esto nos permite afirmar que, en este contexto educativo, son los profesores de 30 a 45 años los que pueden mostrarse abiertos a otras modalidades de feedback (aunque se trata de porcentajes muy pequeños). Debemos decir que, de forma general, la mayor parte de estos muestran una tendencia muy generalizada hacia la corrección inmediata acompañada de feedback oral individual lo cual indica que la formación de estos profesores está orientada hacia el uso de esta. Por el contrario, en el caso de Valladolid, encontramos datos dispersos lo cual indica una falta de formación dirigida hacia una modalidad de corrección y de feedback en particular. Consideramos por tanto que los profesores de Valladolid, al no recibir una formación específica respecto a la corrección y el feedback, recurren a la modalidad que a ellos les parece más adecuada o a aquella que pueda resultar más fácil o pueda estar mejor adaptada a las características del aula.

Los informantes que participaron en esta respuesta fueron: en Valladolid $n=31$ profesores (de una muestra de 33 informantes) y en Austin $n=38$ (de una muestra de 40 informantes) formando un total de $\mathrm{N}=69$ informantes.

Los resultados analizados para Valladolid y Austin pueden consultarse en los gráficos de barras agrupadas (Gráfico 45 y Gráfico 46) que aparecen a continuación. 


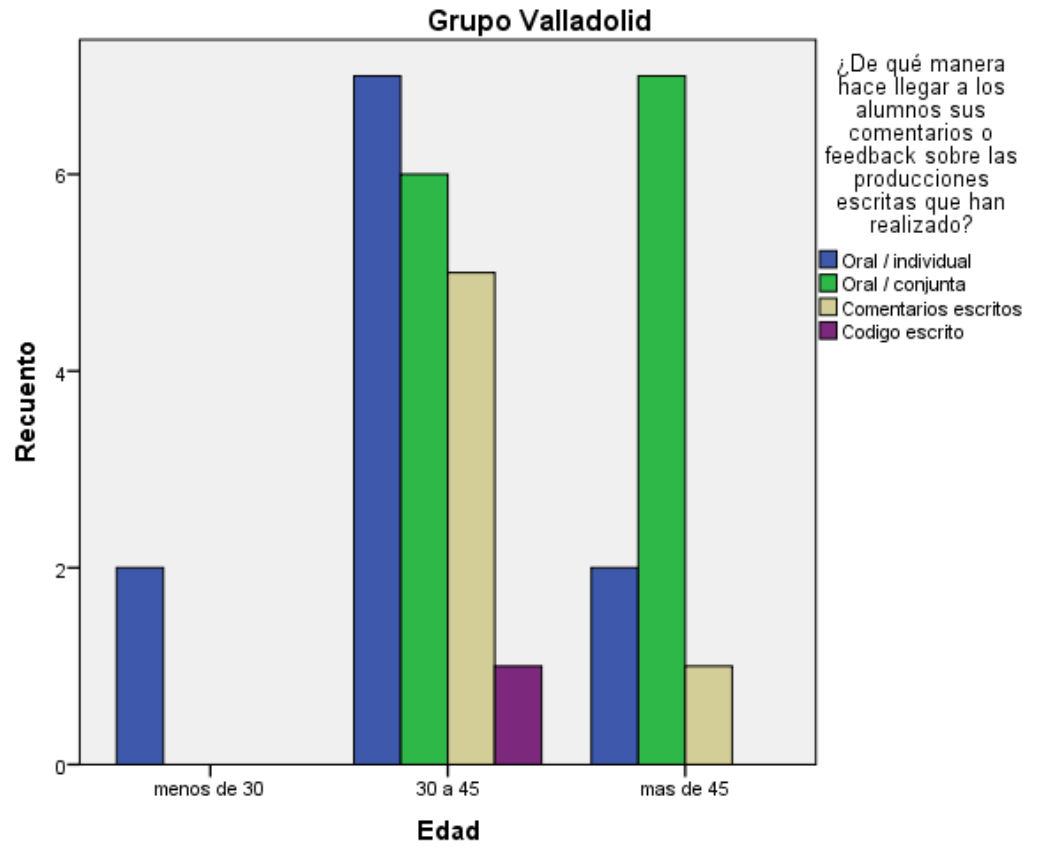

Gráfico 45. Recuento Edad - Forma de proporcionar el feedback - Grupo Valladolid

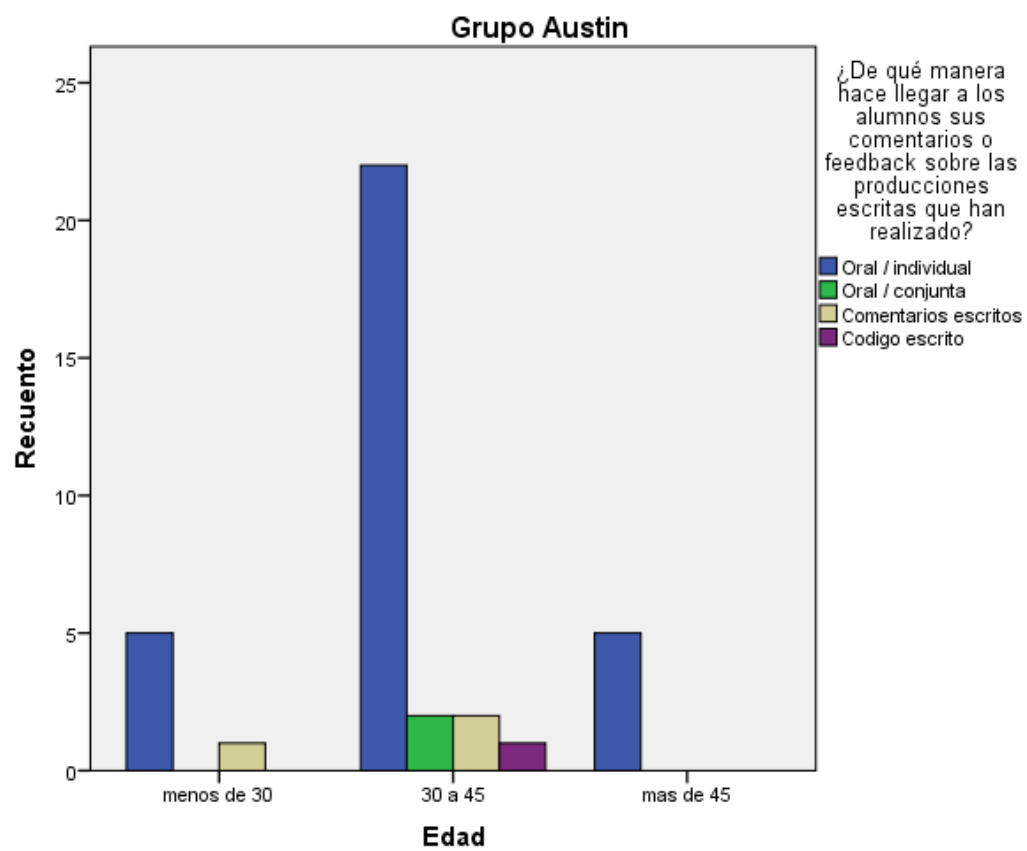

Gráfico 46. Recuento Edad - Forma de proporcionar el feedback - Grupo Austin 
En lo que respecta al cruce de variables entre "Forma de proporcionar el feedback" y "Edad" podemos afirmar que tampoco se advierte una relación significativa entre estas. A pesar de ello, los datos nos permiten sacar conclusiones acerca de las dos realidades que representan los contextos educativos estudiados.

Así pues, los informantes más jóvenes del contexto educativo de Valladolid muestran unas aptitudes respecto a la elección de una modalidad de feedback apropiada (oral individual) la cual, permite al alumno detectar sus propios errores y, posteriormente, corregirlos (bajo la supervisión del profesor). Cabe la posibilidad de que este perfil de profesores cuente con una formación en cuanto a su competencia lingüística en inglés que les haga sentirse seguros a la hora de proporcionar feedback de manera inmediata. Por su parte, los profesores con más años de 45 años optan, generalmente, por otras modalidades de feedback que quizá les haga sentir más cómodos por tener la oportunidad de preparar su discurso previamente. Modalidades que hacen alusión al "modelo dicotómico" (Cassany, 1993) al que hacíamos referencia en el epígrafe 1.2.1 mediante el cual el alumno "se convierte en mero receptor callado del trabajo del maestro" (p. 18).

Sin embargo, tal y como podemos observar, en la ciudad de Austin, la tendencia general es la de proporcionar un feedback oral en el que el profesor pueda llevar a cabo entrevistas individuales con el alumno en las que la interacción entre profesor-alumno juegue un papel fundamental y durante las cuales, el profesor tenga ocasión de proporcionar ayuda al alumno durante el proceso de producción, así como una corrección inmediata acompañada de un feedback oral, individual. Toda esta información tiene que ver con el grado de importancia que se otorga al factor afectivo y a ese vínculo profesor-alumno que, tal y como mencionábamos en el epígrafe 
1.2.3 situándonos en la línea de Gardner (2010), influye de una manera decisiva en las actitudes de los alumnos hacia su L2.

\subsubsection{Aptitudes en torno a la forma de proporcionar feedback en relación con el curso}

En el presente epígrafe nos proponemos indagar acerca de las aptitudes de nuestros informantes respecto a la forma de proporcionar feedback en relación con el curso escolar en el que imparten sus clases de L2.

Las pruebas chi-cuadrado en relación al "Curso" * "Forma de proporcionar el feedback" * “Grupo" se exponen en la Tabla 47 que aparece a continuación:

\begin{tabular}{|l|l|c|c|c|}
\hline \multicolumn{2}{|l|}{ Grupo } & Valor & gl & $p$ \\
\hline Valladolid & Chi-cuadrado de Pearson & 10,302 & 3 &, 016 \\
\hline Austin & Chi-cuadrado de Pearson & 4,569 & 3 &, 206 \\
\hline Total & Chi-cuadrado de Pearson & 5,292 & 3 &, 152 \\
\hline
\end{tabular}

Tabla 47. Pruebas de chi-cuadrado "Curso" * "Forma de proporcionar el feedback" * "Grupo"

Se han detectado resultados estadísticamente significativos. Así pues, como podemos observar en la Tabla 47 existe relación significativa para el contexto educativo de Valladolid entre el curso impartido (en dos categorías) y la variable "Forma de proporcionar el feedback" $\left(\chi_{3}^{2}=10.30 ; \mathrm{p}=\right.$ $.016)$. 
La siguiente tabla de contingencia (Tabla 48) expone los datos para las variables "Curso" * "Forma de proporcionar el feedback" * "Grupo".

\begin{tabular}{|c|c|c|c|c|c|c|c|c|}
\hline \multicolumn{4}{|l|}{ Grupo } & \multicolumn{4}{|c|}{ Forma de proporcionar el feedback } & \multirow[t]{2}{*}{ Total } \\
\hline & & & & $\begin{array}{c}\text { Oral / } \\
\text { individual }\end{array}$ & $\begin{array}{c}\text { Oral / } \\
\text { conjunta }\end{array}$ & $\begin{array}{c}\text { Comentarios } \\
\text { escritos }\end{array}$ & $\begin{array}{l}\text { Código } \\
\text { escrito }\end{array}$ & \\
\hline \multirow{4}{*}{\multicolumn{2}{|c|}{ Valladolid }} & \multirow{2}{*}{$1^{0}$ a $3^{\circ}$} & Recuento & 0 & 6 & 0 & 0 & 6 \\
\hline & & & $\%$ del total & $0,0 \%$ & $19,4 \%$ & $0,0 \%$ & $0,0 \%$ & $19,4 \%$ \\
\hline & & \multirow{2}{*}{$4^{\circ}$ a $6^{\circ}$} & Recuento & 11 & 7 & 6 & 1 & 25 \\
\hline & & & $\%$ del total & $35,5 \%$ & $22,6 \%$ & $19,4 \%$ & $3,2 \%$ & $80,6 \%$ \\
\hline \multirow{2}{*}{\multicolumn{2}{|c|}{ Total }} & \multirow{4}{*}{$1^{\circ}$ a $3^{\circ}$} & Recuento & 11 & 13 & 6 & 1 & 31 \\
\hline & & & $\%$ del total & $35,5 \%$ & $41,9 \%$ & $19,4 \%$ & $3,2 \%$ & $100,0 \%$ \\
\hline \multirow{6}{*}{ Austin } & \multirow{4}{*}{ Curso } & & Recuento & 14 & 0 & 0 & 0 & 14 \\
\hline & & & $\%$ del total & $35,0 \%$ & $0,0 \%$ & $0,0 \%$ & $0,0 \%$ & $35,0 \%$ \\
\hline & & \multirow{2}{*}{$4^{\circ}$ a $6^{\circ}$} & Recuento & 19 & 3 & 3 & 1 & 26 \\
\hline & & & $\%$ del total & $47,5 \%$ & $7,5 \%$ & $7,5 \%$ & $2,5 \%$ & $65,0 \%$ \\
\hline & \multirow{2}{*}{ Total } & & Recuento & 33 & 3 & 3 & 1 & 40 \\
\hline & & \multirow{3}{*}{$1^{\circ}$ a $3^{\circ}$} & $\%$ del total & $82,5 \%$ & $7,5 \%$ & $7,5 \%$ & $2,5 \%$ & $100,0 \%$ \\
\hline \multirow{6}{*}{ Total } & \multirow{4}{*}{ Curso } & & Recuento & 14 & 6 & 0 & 0 & 20 \\
\hline & & & $\%$ del total & $19,7 \%$ & $8,5 \%$ & $0,0 \%$ & $0,0 \%$ & $28,2 \%$ \\
\hline & & \multirow{2}{*}{$4^{\circ}$ a $6^{\circ}$} & Recuento & 30 & 10 & 9 & 2 & 51 \\
\hline & & & $\%$ del total & $42,3 \%$ & $14,1 \%$ & $12,7 \%$ & $2,8 \%$ & $71,8 \%$ \\
\hline & \multirow{2}{*}{ Total } & & Recuento & 44 & 16 & 9 & 2 & 71 \\
\hline & & & $\%$ del total & $62,0 \%$ & $22,5 \%$ & $12,7 \%$ & $2,8 \%$ & $100,0 \%$ \\
\hline
\end{tabular}

Tabla 48. Tabla de contingencia "Curso" * "Forma de proporcionar el feedback" * "Grupo"

Tal y como podemos observar en el presente análisis, un 19\% $(\mathrm{n}=6)$ de los 31 participantes vallisoletanos (todos ellos profesores de $1^{\circ}$ a $3^{\circ}$ de Educación Primaria) eligen la modalidad de feedback oral de manera conjunta (en voz alta) mientras que en los cursos de $4^{\circ}$ a $6^{\circ}$ predominó la corrección "oral - individual" ( $\mathrm{n}=11 ; 36 \%)$ seguida de la "oral - conjunta", a pesar de que también hubo representación del resto de modalidades. 
Encontramos resultados muy similares en los dos contextos educativos. En el caso de Austin, no existen diferencias significativas ni tampoco a nivel de la muestra total. Los resultados correspondientes a este contexto educativo ponen de manifiesto algunas similitudes con el de Valladolid. La mayoría de profesores utilizaron, independientemente del curso que impartían, la modalidad "oral - individual" y muy de lejos estuvieron representadas el resto de modalidades de corrección (ver Gráfico 48 de barras agrupadas). Además, en el presente contexto educativo (a diferencia del contexto de Valladolid) todos los profesores que impartían clase entre $1^{\circ}$ y $3^{\circ}$ de Educación Primaria manifestaron utilizar la corrección “oral - individual”.

Observamos la existencia de un alto grado de participación en los dos contextos educativos. Desde esta consideración, encontramos en Valladolid: $n=31$ profesores (de una muestra de 33 informantes) y en Austin: $\mathrm{n}=40$ (100\% de la muestra) formando un total de $\mathrm{N}=71$ informantes. Nos atrevemos a suponer que este alto nivel de participación por parte de los informantes pueda estar relacionado con la existencia de una relación significativa. Esto nos hace pensar que la escasa participación por parte de algunos informantes pueda indicar la falta de dichas relaciones significativas en otros análisis llevados a cabo en el presente estudio.

Los siguientes gráficos de barras agrupadas (Gráfico 47 y Gráfico 48) indican los resultados analizados para Valladolid y Austin. 


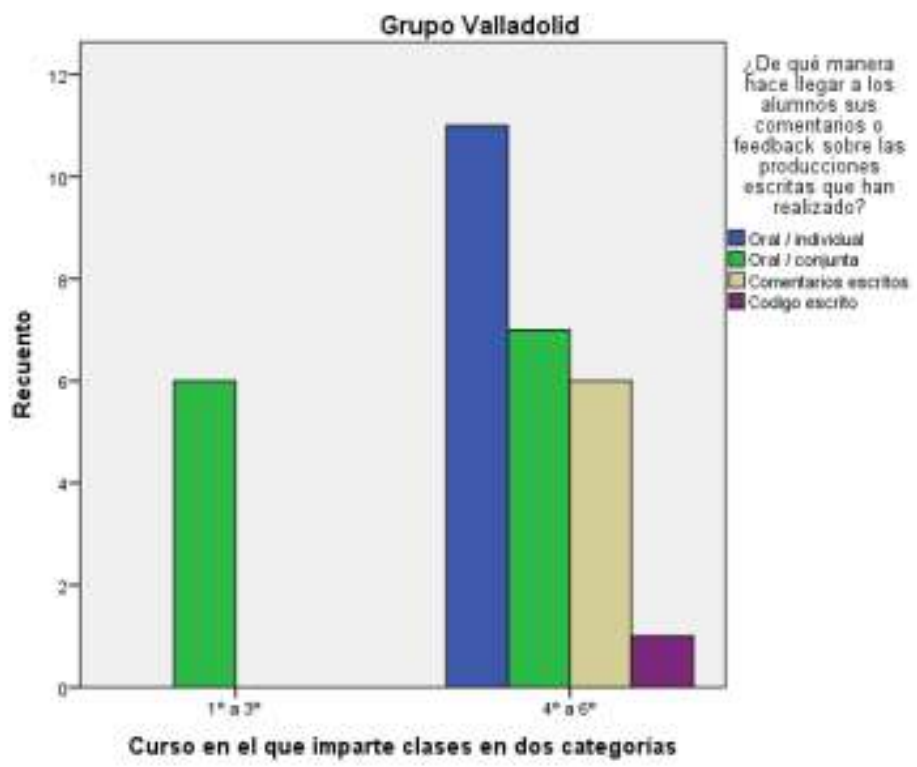

Gráfico 47. Recuento Curso - Forma de proporcionar el feedback - Grupo Valladolid

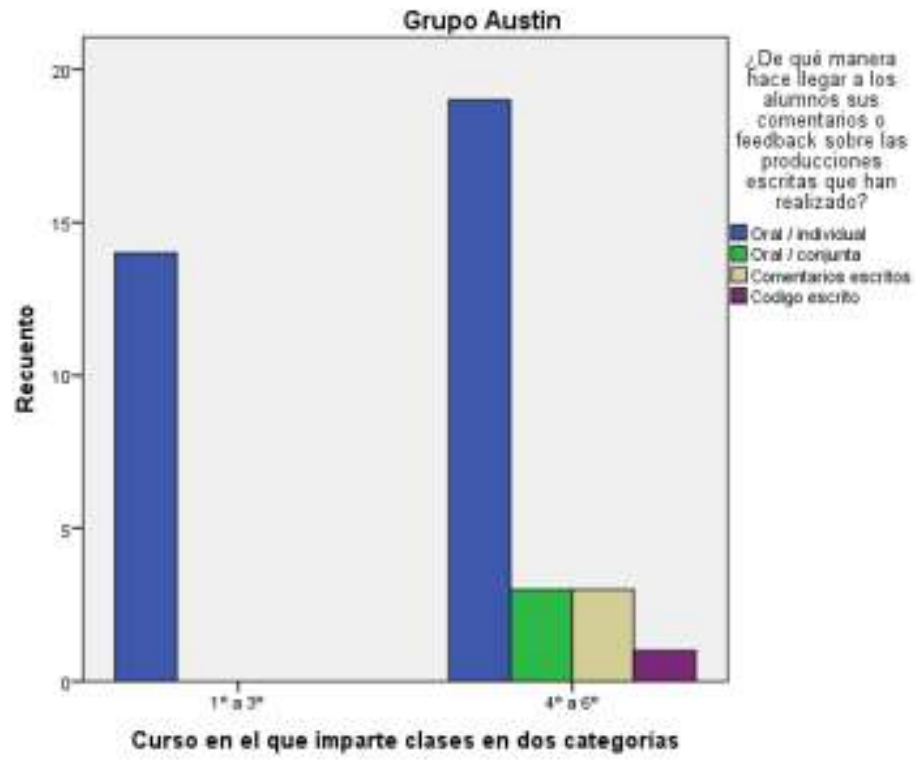

Gráfico 48. Recuento Curso - Forma de proporcionar el feedback - Grupo Austin 
Al analizar los datos relativos a la variable "Forma de proporcionar el feedback" se han detectado resultados estadísticamente significativos cuando se relaciona con el "Curso" en el que imparten sus clases los profesores del contexto educativo de Valladolid.

Observamos, a partir de los gráficos 47 y 48, que los informantes de los cursos más bajos en Valladolid optan por un tipo de feedback oral transmitido de forma conjunta al grupo-clase. La elección de este tipo de feedback de forma unánime puede estar vinculada a la idea de que, en la corrección de las producciones escritas, no se estima necesaria la presencia de un feedback oral individual elaborado por tratarse estas de producciones escritas formadas por estructuras lingüísticas de poca complejidad.

A diferencia de Valladolid, todos los profesores de Austin que imparten los cursos de $1^{\circ}$ a $3^{\circ}$ dotan a sus alumnos de un feedback oral individual. Estos resultados parecen indicar que en Austin se otorga gran importancia a la destreza comunicativa de expresión escrita en los cursos inferiores de Educación Primaria y, en este sentido, los profesores recurren al tipo de corrección y feedback que mejor se adapte a sus necesidades educativas. Cabe la posibilidad de que, en este contexto, se intente hacer al alumno partícipe del proceso de corrección otorgándole un papel activo mientras que, en Valladolid, no sientan la necesidad de hacerlo con los alumnos más jóvenes. También es posible que los profesores del contexto educativo de Austin, sientan la necesidad de mostrar su papel de guía ante este tipo de alumnos que empiezan a crear sus propias producciones escritas. Para ello, recurren al uso de un enfoque metodológico de producción escrita centrado en el proceso 
(en el que tiene lugar este tipo de corrección y de dotación de feedback) con el propósito de que estos alumnos trabajen en un ambiente distendido y de confianza que les permita expresar sus ideas de una manera libre (tal y como indicábamos en el epígrafe 2.2.3) con la ayuda del profesor.

\subsubsection{Aptitudes en torno a la forma de proporcionar feedback en relación con el número de alumnos}

En el presente epígrafe abordamos las aptitudes de nuestros informantes respecto a la forma de proporcionar feedback en relación con el número de alumnos a los que atiende el profesor.

A continuación, se presenta la tabla de las pruebas chi-cuadrado (Tabla 49) que muestra los datos relativos al "Número de alumnos" * "Forma de proporcionar el feedback" * "Grupo".

\begin{tabular}{|l|l|c|c|c|}
\hline \multicolumn{1}{|l|}{ Pruebas de chi-cuadrado } \\
\hline Grupo & Valor & gl & $\mathrm{p}$ \\
\hline Valladolid & Chi-cuadrado de Pearson & 8,550 & 6 &, 201 \\
\hline Austin & Chi-cuadrado de Pearson & 9,825 & 6 &, 132 \\
\hline Total & Chi-cuadrado de Pearson & 11,162 & 6 &, 083 \\
\hline
\end{tabular}
Tabla 49. Pruebas de chi-cuadrado "Número de alumnos" * "Forma de proporcionar el feedback" * "Grupo"

En la presente tabla (Tabla 49) las variables implicadas no indican un grado de asociación significativo para el caso de Valladolid, tampoco para el de Austin ni para la muestra total (en todos los casos, $\mathrm{p}>.05)$.

En la siguiente tabla de contingencia (Tabla 50) exponemos los datos para las variables "Edad" * "Forma de proporcionar el feedback" * "Grupo" en la siguiente tabla de contingencia (Tabla 50): 


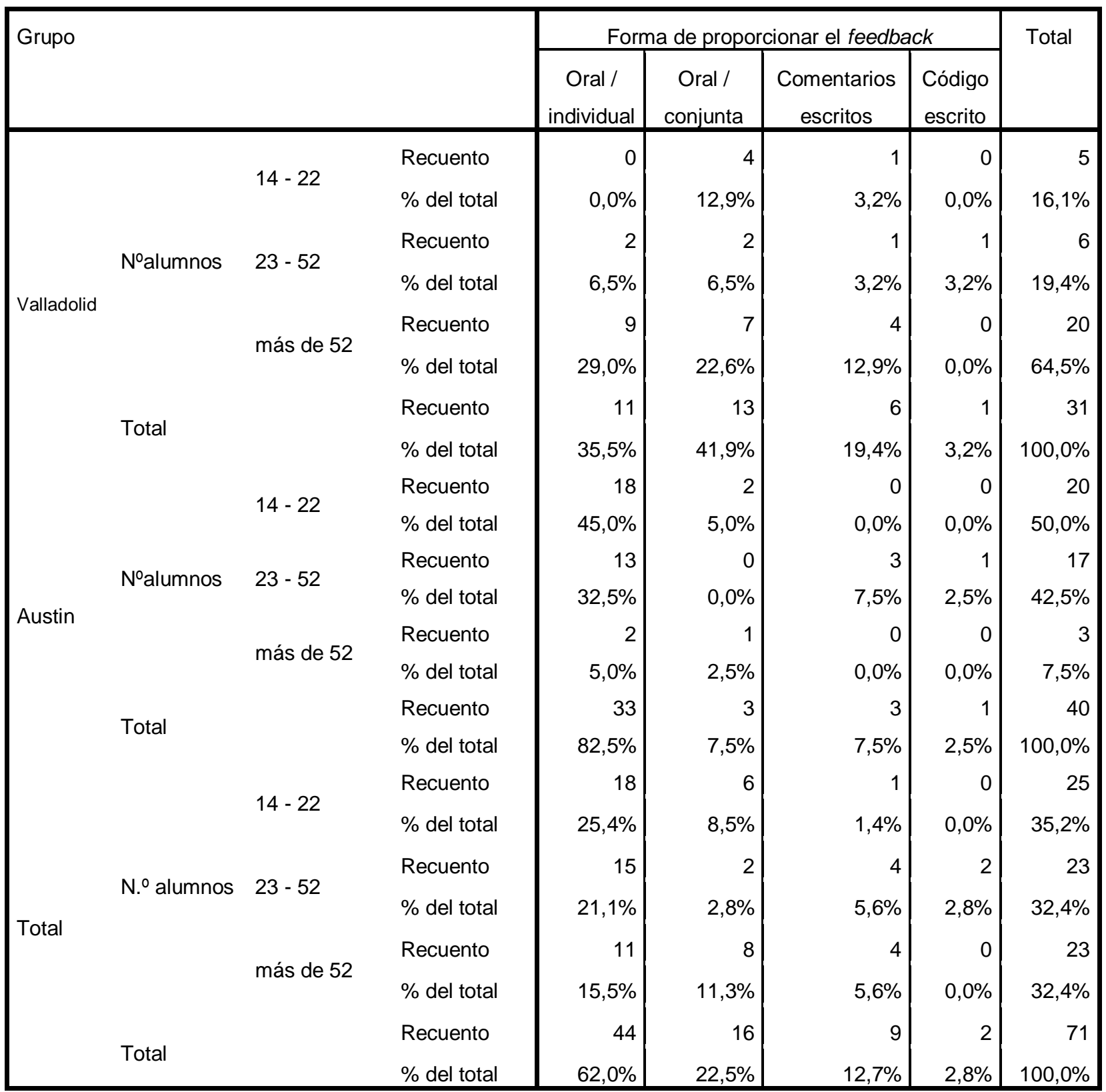

Tabla 50. Tabla de contingencia "Número de alumnos" * "Forma de proporcionar el feedback" * "Grupo"

Según se puede observar en la tabla de contingencia (Tabla 50) no existe relación estadísticamente significativa entre el Número de alumnos" y la variable "Forma de proporcionar el feedback". Destacamos el hecho de que los informantes de Valladolid con más de 52 alumnos cuentan con un porcentaje elevado de representantes que proporcionan feedback "de forma oral 
individual" (29\%) respecto a los informantes de Austin con más de 52 alumnos (5\%). Asimismo, el porcentaje de informantes que proporciona feedback oral de manera conjunta que cuenta con un número de alumnos mayor de 52 es elevado en el caso de Valladolid $(22,6 \%)$ respecto al de Austin (2,5\%). En cuanto a la modalidad de código escrito, observamos que no se utiliza por los informantes de menor (de 14 a 22) y mayor (más de 52) número de alumnos (en ninguno de los dos contextos). Solo aquellos con un número intermedio de alumnos (entre 23 y 52) utilizan este tipo de feedback. Los datos analizados demuestran que los informantes de Valladolid recurren a la modalidad que a ellos les parece más adecuada en función de sus necesidades y, en contraposición, los informantes de Austin recurren de manera generalizada al uso del feedback oral individual que asociamos a un tipo de corrección inmediata centrada en el producto en la que se da gran importancia a la comunicación entre alumno-profesor y al componente afectivo.

Los informantes que participaron en esta respuesta fueron: en Valladolid $n=31$ profesores (de una muestra de 33 informantes) y en el de Austin $\mathrm{n}=40$ (100\% de la muestra total) formando un total de $\mathrm{N}=71$ informantes.

Los siguientes gráficos de barras agrupadas (Gráfico 49 y Gráfico 50) que aparecen a continuación exponen los resultados analizados para los contextos de Valladolid y Austin. 


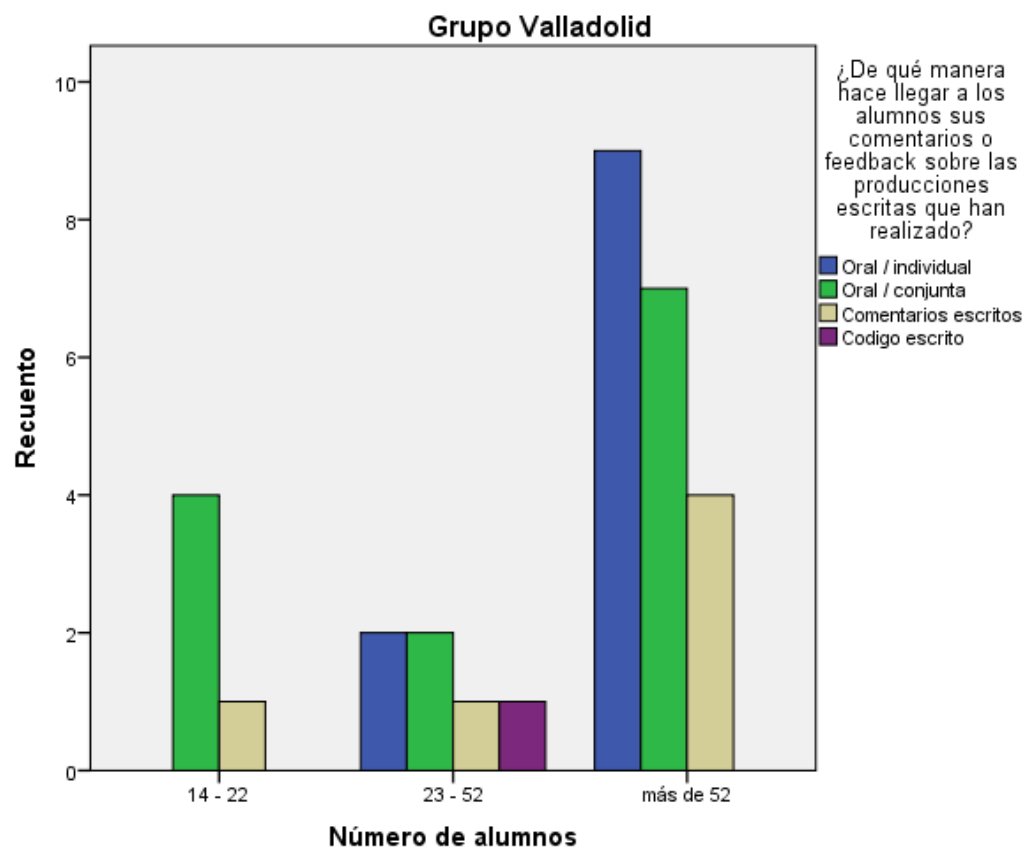

Gráfico 49. Recuento Número de alumnos - Forma de proporcionar el feedback - Grupo Valladolid

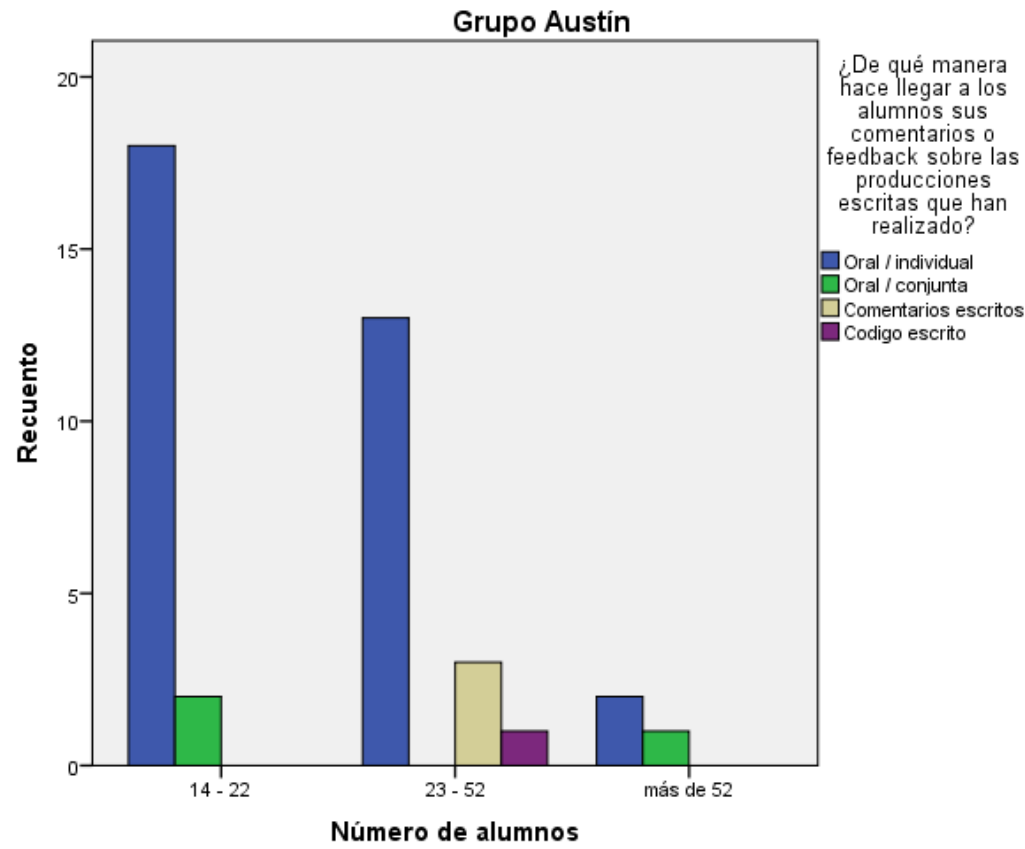

Gráfico 50. Recuento Número de alumnos - Forma de proporcionar el feedback - Grupo Austin 
Los resultados del análisis en torno a las aptitudes sobre la "Forma de proporcionar feedback" en relación con el "Número de alumnos" a los que atiende el profesor indican que no existe una relación significativa entre las variables. A pesar de esto, de acuerdo con la información que nos llega a través de los gráficos 49 y 50 podemos decir que los informantes de Valladolid acuden a varios tipos de feedback para acompañar a la corrección de producciones escritas de L2 (sobre todo aquellos que tienen más de 22 alumnos). Nos llama la atención el hecho de que, aquellos profesores que cuentan con un mayor número de alumnos (más de 52) recurran de forma particular a la modalidad de feedback oral individual y a la modalidad de feedback oral general.

En contraposición, los informantes de Austin utilizan de manera generalizada el feedback oral individual que asociamos a un tipo de corrección inmediata centrada en el proceso. De forma particular, aquellos que cuentan con un número menor de alumnos.

Encontramos por tanto opiniones contrarias por parte de los informantes de ambos contextos. Podemos afirmar que tanto los informantes vallisoletanos como aquellos que desempeñan su actividad docente en la ciudad de Austin recurren a la modalidad de corrección y de dotación de feedback que mejor se adapta a sus necesidades y a las características del centro.

\subsection{Actitudes ante la utilidad de la corrección de errores y el feedback}

El análisis del ítem número 17 nos permitió indagar acerca de las actitudes de los informantes ante la posible utilidad de la corrección de errores y la dotación de feedback en las producciones escritas en L2 en los contextos educativos de Valladolid y Austin. Los datos 
obtenidos a partir de las respuestas a este ítem se muestran en el epígrafe 8.2 de la presente Tesis Doctoral. Estos datos nos proporcionaron información acerca de la postura de los informantes en torno a la corrección y su disposición hacia la idea de proporcionar feedback al alumno como complemento de la corrección de una actividad de producción escrita en L2.

En el ítem 17 solicitábamos a nuestros informantes que calificasen en qué medida la corrección de errores acompañada del feedback es útil o va a ser útil...

- a. Para que el alumno sea consciente de su propio proceso de aprendizaje

- b. Le permita establecer conexiones entre su lengua materna y su L2

- c. Le aporte información sobre cómo trabajar las distintas destrezas comunicativas

- d. Le ayude a ver los errores no como algo negativo sino como indicador de su progreso en el proceso de aprendizaje.

A través de cuatro subapartados (a, b, c y d), proponíamos a los informantes un ejercicio de reflexión sobre el papel que desempeña el error, la corrección y el feedback en el proceso de enseñanza-aprendizaje de una L2 y su posible utilidad. Las opciones de respuesta de los informantes las clasificábamos bajo la forma: "Mucho", "Bastante”, "Poco", "Muy poco"y "Nada.

Según los resultados obtenidos (presentados en el subepígrafe 8.2.1) pudimos concluir que los informantes vallisoletanos muestran actitudes positivas hacia la corrección de errores y el feedback que lo acompaña. Así pues, estos dos elementos se configuran, desde su punto de vista, como muy útiles o bastante útiles en la perspectiva de intentar alcanzar determinados objetivos 
docentes: que el alumno sea consciente de su propio proceso de enseñanza-aprendizaje, aportar información sobre cómo trabajar las distintas destrezas comunicativas y, por último, permitir que reconozca los errores no como algo negativo sino como indicador de su progreso en el proceso de enseñanza-aprendizaje de la L2. En lo que respecta al contexto educativo de Austin, también encontrábamos una mayoría de informantes que defendía los efectos beneficiosos de la exposición del alumno ante el error, la corrección y el feedback.

Tras este recorrido a través de la investigación llevada a cabo sobre las actitudes de los profesores ante la utilidad de la corrección de errores y el feedback expuestas en el epígrafe 8.2 nos disponemos a cruzar los datos obtenidos en dicho epígrafe (correspondientes a la variable resultante del ítem 17 "Utilidad de la corrección de errores y del feedback") con los relativos al perfil del informante (“Años de experiencia", "Edad", "Curso" y "Número de alumnos"). Para ello, se plantean una serie de análisis estadísticos cuyos resultados se reflejan en los subepígrafes que aparecen a continuación.

\subsubsection{Actitudes ante la posible utilidad de la corrección de errores y el feedback en relación con los años de experiencia}

En el presente subepígrafe nos acercamos a las actitudes de nuestros informantes ante la posible utilidad de la corrección de errores y el feedback en relación con sus años de experiencia. Como 
ya hemos venido mencionando, la variable "Utilidad de la corrección de errores y del feedback" presenta cuatro subdivisiones que se presentan en la forma:

- 17a. Utilidad de la corrección de errores y del feedback [para que el alumno sea consciente de su propio proceso de enseñanza-aprendizaje].

- 17b. Utilidad de la corrección de errores y del feedback [le permita establecer conexiones entre su lengua materna y su L2].

- $\quad$ 17c. Utilidad de la corrección de errores y del feedback [le aporte información sobre cómo trabajar las distintas destrezas comunicativas].

- $17 \mathrm{~d}$. Utilidad de la corrección de errores y del feedback [le ayude a ver los errores no como algo negativo sino como indicador de su propio proceso de aprendizaje].

Por lo tanto, en el presente subepígrafe presentaremos cuatro tablas de pruebas chicuadrado, cuatro tablas de contingencia y ocho gráficos de barras agrupadas (dos para cada una de las cuatro variables).

Nos acercamos, en primer lugar, a la variable "17a. Utilidad de la corrección de errores y del feedback" en cuanto a ayudar al alumno a ser consciente de su propio proceso de enseñanzaaprendizaje que relacionaremos con los años de experiencia de los informantes.

En la tabla que se muestra a continuación (Tabla 51) se presentan las pruebas de chi-cuadrado cuadrado "Años de experiencia" * "Utilidad de la corrección de errores y del feedback" [para que el alumno sea consciente de su propio proceso de aprendizaje]* “Grupo". 


\begin{tabular}{|l|l|c|c|c|}
\hline \multicolumn{2}{|l|}{ Grupo } & Valor & gl & p \\
\hline Valladolid & Chi-cuadrado de Pearson & ---- & --- & --- \\
\hline Austin & Chi-cuadrado de Pearson & 1,254 & 2 &, 534 \\
\hline Total & Chi-cuadrado de Pearson & 1,665 & 2 &, 435 \\
\hline
\end{tabular}

Tabla 51. Pruebas de chi-cuadrado "Años de experiencia" * "Utilidad de la corrección de errores y del feedback" [para que el alumno sea consciente de su propio proceso de aprendizaje]* "Grupo"

Los datos expuestos en la Tabla 51 demuestran que las variables implicadas no tienen un grado de asociación significativo para el caso de Austin ni para la muestra total. En el caso de Valladolid no se calcula chi-cuadrado respecto a dicha variable porque es una constante ya que todos los participantes contestaron "útil".

A continuación, se expone la siguiente tabla de contingencia (Tabla 52) para las variables “Años de experiencia" * "Utilidad de la corrección de errores y del feedback" [para que el alumno sea consciente de su propio proceso de aprendizaje]* “Grupo”. 


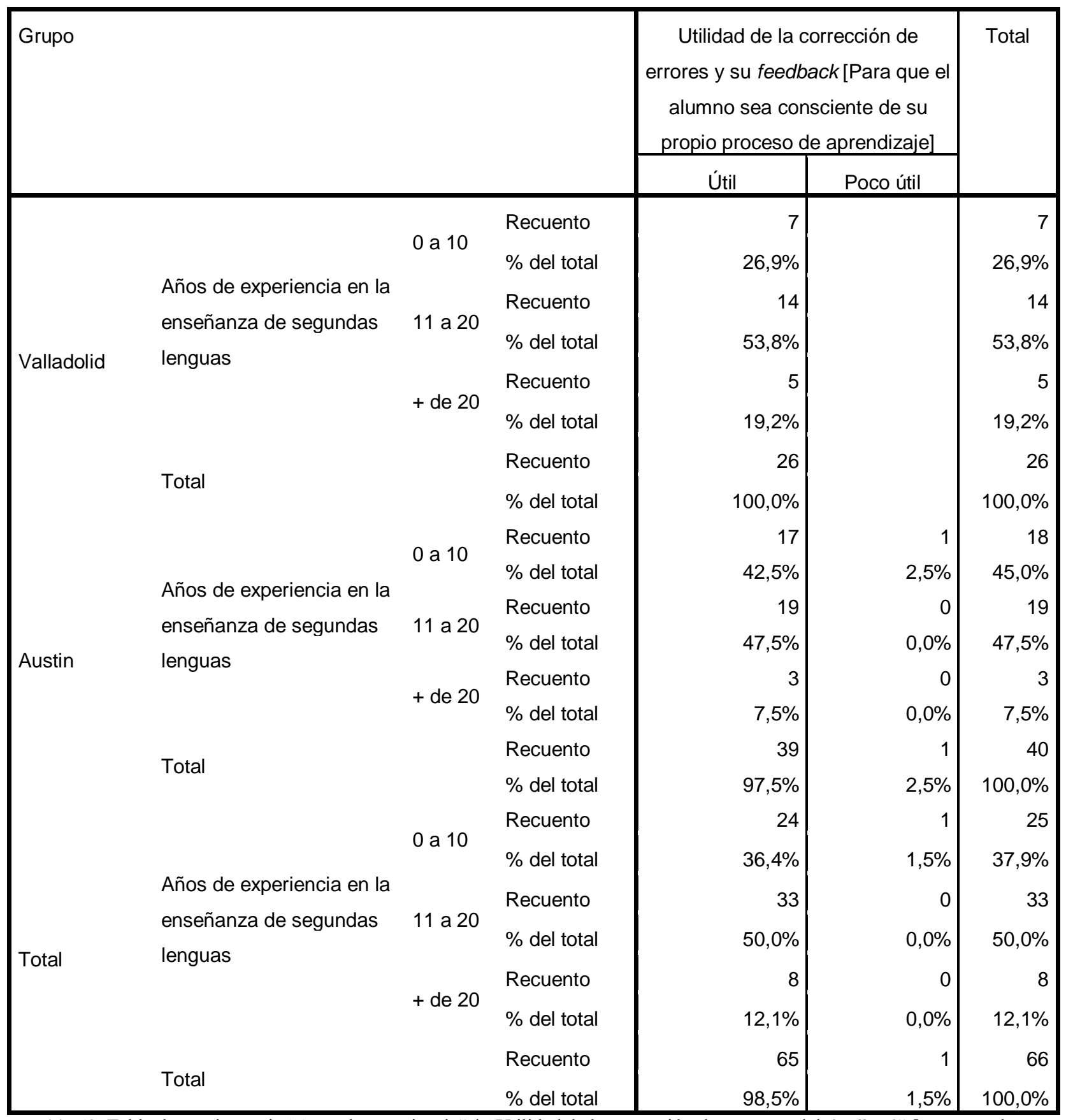

Tabla 52. Tabla de contingencia "Años de experiencia" * "Utilidad de la corrección de errores y del feedback" [para que el alumno sea consciente de su propio proceso de aprendizaje]* "Grupo"

La tabla 52 no mostró una asociación estadísticamente significativa y en esta se refleja cómo, independientemente del contexto educativo (Valladolid o Austin) y de los años de experiencia en la docencia, prácticamente todos los informantes reconocen que la corrección de errores y el 
feedback es útil para que el alumno sea consciente de su propio proceso de aprendizaje de la L2. En el caso de Valladolid no hablamos de variables sino de constante ya que el 100\% elige la opción “útil". En el caso de Austin, el porcentaje es muy similar, un 97,5\% opina que es útil y solo un informante con menos de 10 años de experiencia (correspondiente a un 2,5\%) se incluye dentro de la opción "poco útil". Hablamos por tanto de porcentajes prácticamente idénticos (téngase en cuenta que los porcentajes son totales y por tanto hacen referencia al número de participantes dentro de cada categoría para cada contexto educativo y la muestra total).

En cuanto a participación de los informantes en esta respuesta nos encontramos ante $\mathrm{n}=$ 26 docentes (de los 33 que representan la muestra total de Valladolid) y a n = 40 (es decir, el 100\% de la muestra total de Austin) formando un total de $\mathrm{N}=66$ informantes.

Los siguientes gráficos de barras agrupadas (gráficos 51 y 52) reflejan de forma gráfica los resultados comentados.

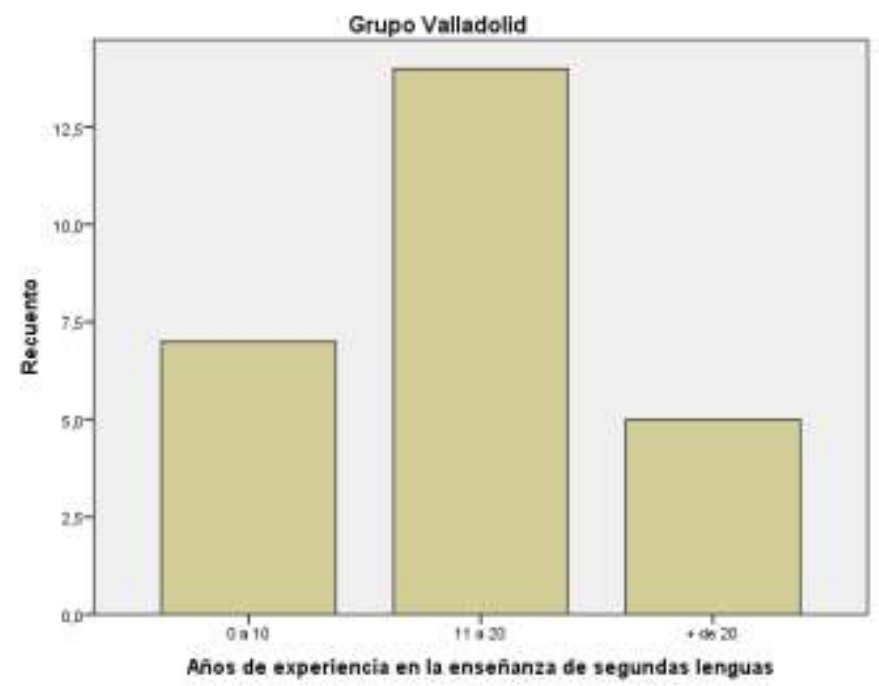

Gráfico 51. Recuento Años de experiencia - Utilidad de la corrección de errores y del feedback" [para que el alumno sea consciente de su propio proceso de aprendizaje] - Grupo Valladolid 


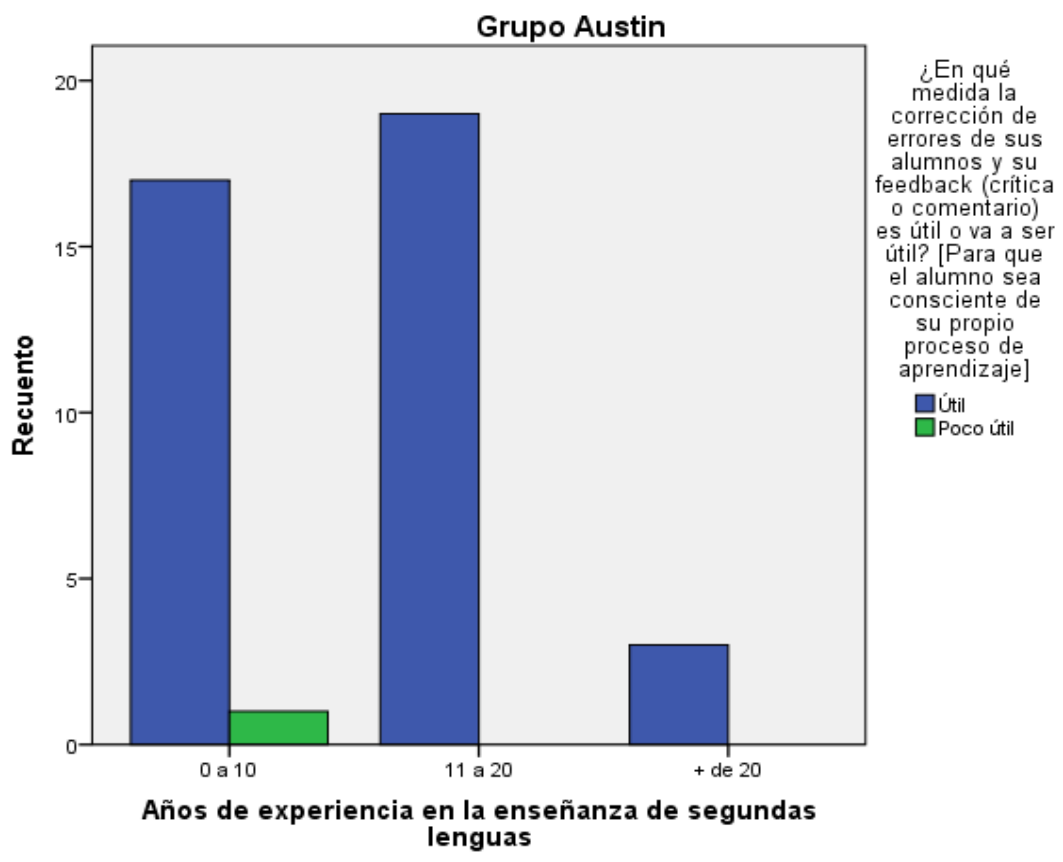

Gráfico 52. Recuento Años de experiencia - Utilidad de la corrección de errores y del feedback" [para que el alumno sea consciente de su propio proceso de aprendizaje] - Grupo Austin

Tal y como apuntábamos en el epígrafe 8.2.2 de la presente Tesis Doctoral dedicado al componente competencial: Actitudes ante la posible utilidad de la corrección de errores y el feedback tanto los informantes de un contexto educativo como del otro presentan actitudes positivas ante el error, la corrección y el feedback. Así es como, la gran mayoría defiende no solo la presencia del error como objeto de aprendizaje e indicador de progreso en la L2, sino también la importancia de que los alumnos reciban las producciones escritas con las correspondientes correcciones. Asimismo, a nivel declarativo, los informantes de los dos contextos defienden el uso de una modalidad de feedback que favorezca el acercamiento entre profesor y alumno. Las respuestas al ítem 17 nos acercaron, por tanto, a posturas o actitudes semejantes por parte de los dos contextos educativos. Sin embargo, tal y como comentábamos en el epígrafe 8.2.2, los datos obtenidos a partir de las respuestas al resto de ítems que conforman el cuestionario parecen indicar 
que dichas actitudes no se manifiestan en la práctica. Esto nos permite afirmar que ambos contextos educativos difieren en la praxis o aplicación de dichas creencias a la realidad educativa.

Tras cruzar las variables "Utilidad de la corrección de errores y del feedback [para que el alumno sea consciente de su propio proceso de aprendizaje]" (correspondiente al ítem 17a) y “Años años de experiencia” no advertimos una relación estadísticamente significativa. Los datos obtenidos en los gráficos 51 y 52 nos permiten afirmar que prácticamente todos los informantes (en el caso de Valladolid, hablamos de mayoría absoluta) reconocen que la corrección de errores y el feedback es útil para que el alumno sea consciente de su propio proceso de aprendizaje de la L2.

Dado que no existen diferencias significativas entre los dos contextos educativos estudiados, nos atrevemos a suponer que, a nivel declarativo, aquellos profesores que ejercen su actividad docente tanto en centros educativos de la ciudad de Valladolid como en los de Austin (independientemente de los años de experiencia que tengan) muestran una postura de gran optimismo hacia el feedback y, por tanto, en ambos contextos, se valora su presencia como acompañante de la corrección de las producciones escritas de L2.

Cabe la posibilidad de que estas manifestaciones de confianza hacia el feedback como elemento que permite al alumno tomar conciencia de su propio proceso de aprendizaje se lleven a la práctica o, por el contrario, el feedback siga siendo desaprovechado sin llegar a ser integrado en la enseñanza-aprendizaje de expresión escrita en L2. 
En segundo lugar, nos aproximamos a la variable "17b. Utilidad de la corrección de errores y delfeedback" por cuanto que estos permitan o ayuden al alumno a establecer conexiones entre su lengua materna y la L2 en relación con los años de experiencia de los informantes.

En la tabla que se muestra a continuación (Tabla 53) se presentan las pruebas de chi-cuadrado "Años de experiencia" * "Utilidad de la corrección de errores y del feedback" [le permita establecer conexiones entre su lengua materna y la L2]* “Grupo”.

\begin{tabular}{|l|l|c|c|c|}
\hline \multicolumn{2}{|l|}{ Grupo } & Valor & gl & p \\
\hline Valladolid & Chi-cuadrado de Pearson & 3,687 & 2 &, 158 \\
\hline Austin & Chi-cuadrado de Pearson & 1,579 & 2 &, 454 \\
\hline Total & Chi-cuadrado de Pearson & 0,527 & 2 &, 769 \\
\hline
\end{tabular}

Tabla 53. Pruebas de chi-cuadrado "Años de experiencia" * "Utilidad de la corrección de errores y del feedback" [le permita establecer conexiones entre su lengua materna y la L2]* "Grupo"

Los datos expuestos en la Tabla 53 demuestran que las variables implicadas no tienen un grado de asociación significativo para el caso de Valladolid, ni para el de Austin ni para la muestra total (en todos los casos, $\mathrm{p}>.05)$.

La siguiente tabla de contingencia (Tabla 54) muestra la relación entre las variables "Años de experiencia" * "Utilidad de la corrección de errores y del feedback" [le permita establecer conexiones entre su lengua materna y la L2]* "Grupo". 


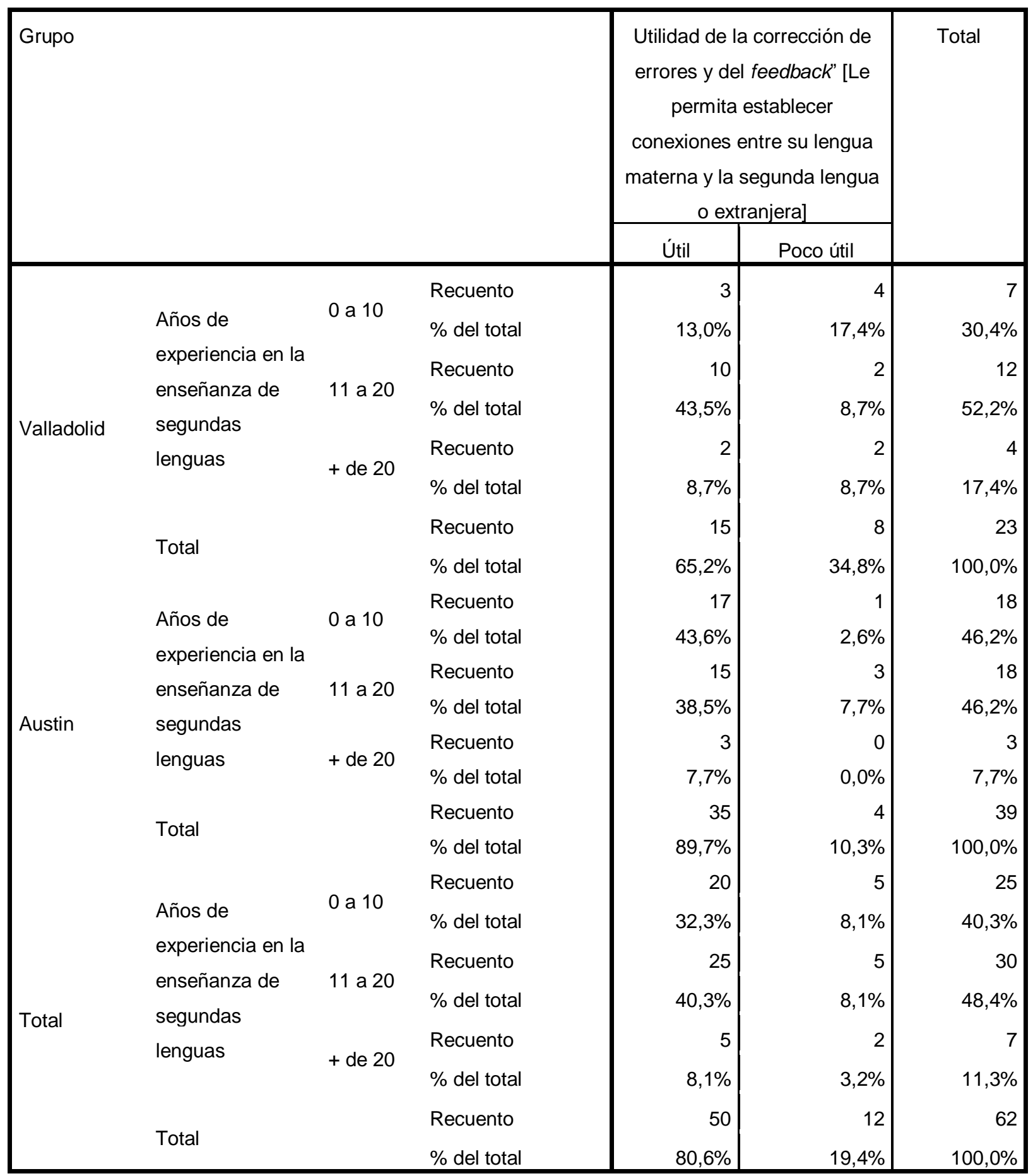

Tabla 54. Tabla de contingencia "Años de experiencia" * "Utilidad de la corrección de errores y del feedback" [le permita establecer conexiones entre su lengua materna y la L2]* "Grupo" 
Tampoco existe asociación estadísticamente significativa entre las variables, como podemos observar en la tabla 54. En esta se refleja cómo, independientemente del contexto educativo (Valladolid o Austin) y de los años de experiencia, una parte importante de los informantes reconoce que la corrección de errores y el feedback es útil en la perspectiva de permitir o favorecer que el alumno pueda establecer conexiones entre su lengua materna y la L2. En Valladolid, la diferencia en porcentajes no es tan significativa $(65,2 \%=$ útil, $34,8 \%=$ poco útil) como la de la ciudad de Austin $(89,7 \%=$ =útil, 10,3\%=poco útil) aunque en los dos hablamos de una mayoría. Nos llama la atención el porcentaje de informantes vallisoletanos con menos experiencia (de 0 a 10 años). Un 17,4\% opina que la corrección de errores y el feedback son "poco útiles" en la perspectiva de favorecer que el alumno establezca conexiones entre su lengua materna y la L2. Nos encontramos ante un porcentaje ligeramente superior al de informantes con menos de 10 años de experiencia que consideran que es "útil" en el mismo contexto educativo (13\%) y nos encontramos ante una diferencia notable con los correspondientes en la ciudad de Austin (profesores con menos de 10 años de experiencia que consideran "poco útil": 2,6\%).

En cuanto al resto de porcentajes, podemos hablar de resultados muy similares por lo que, podemos decir que, nuestros informantes, de forma general, tienen en consideración la importancia de la corrección y del feedback desde la óptica de que ambos favorecen que los alumnos puedan establecer conexiones entre su lengua materna y la L2. Sin embargo, existe un porcentaje significativo de informantes vallisoletanos con menos de 10 años de experiencia que no lo tienen en consideración.

En cuanto a participación de los informantes en esta respuesta nos encontramos ante $\mathrm{n}=$ 23 docentes (de los 33 que representan la muestra total de Valladolid) y a $n=39$ (de los 40 
informantes que forman el $100 \%$ de la muestra total de Austin) formando un total de $\mathrm{N}=62$ informantes.

Los siguientes gráficos de barras agrupadas (gráficos 53 y 54) reflejan de forma gráfica los resultados comentados.

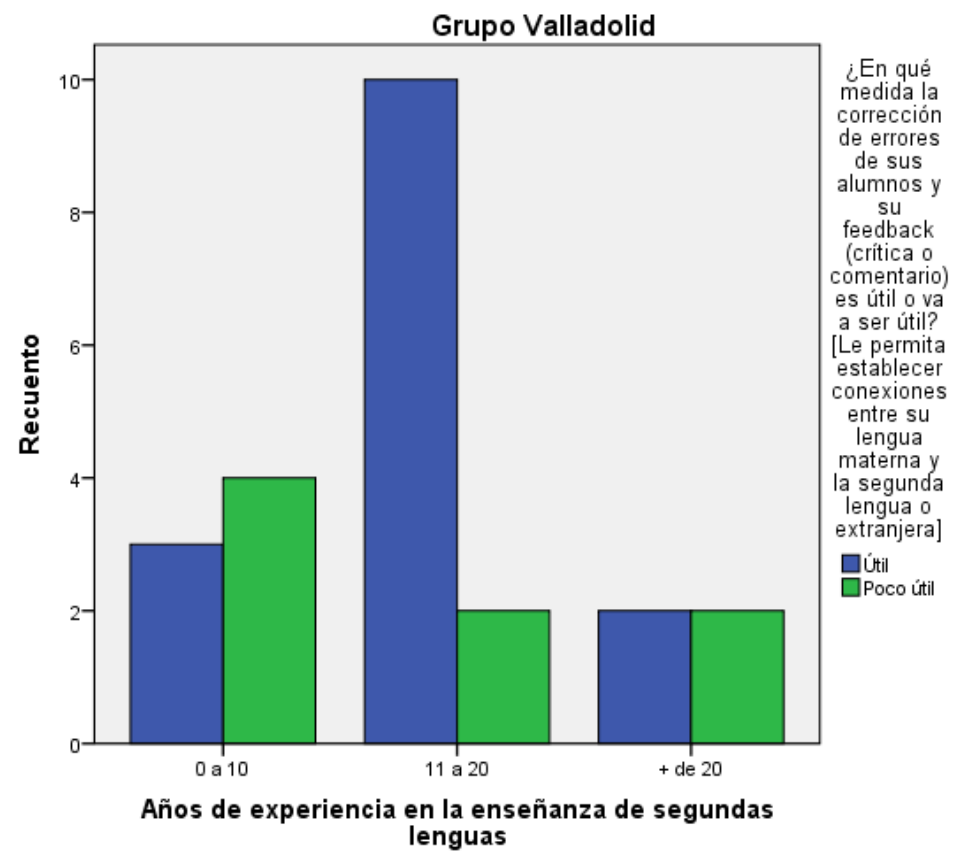

Gráfico 53. Recuento Años de experiencia - Utilidad de la corrección de errores y del feedback" [le permita establecer conexiones entre su lengua materna y la L2] - Grupo Valladolid 


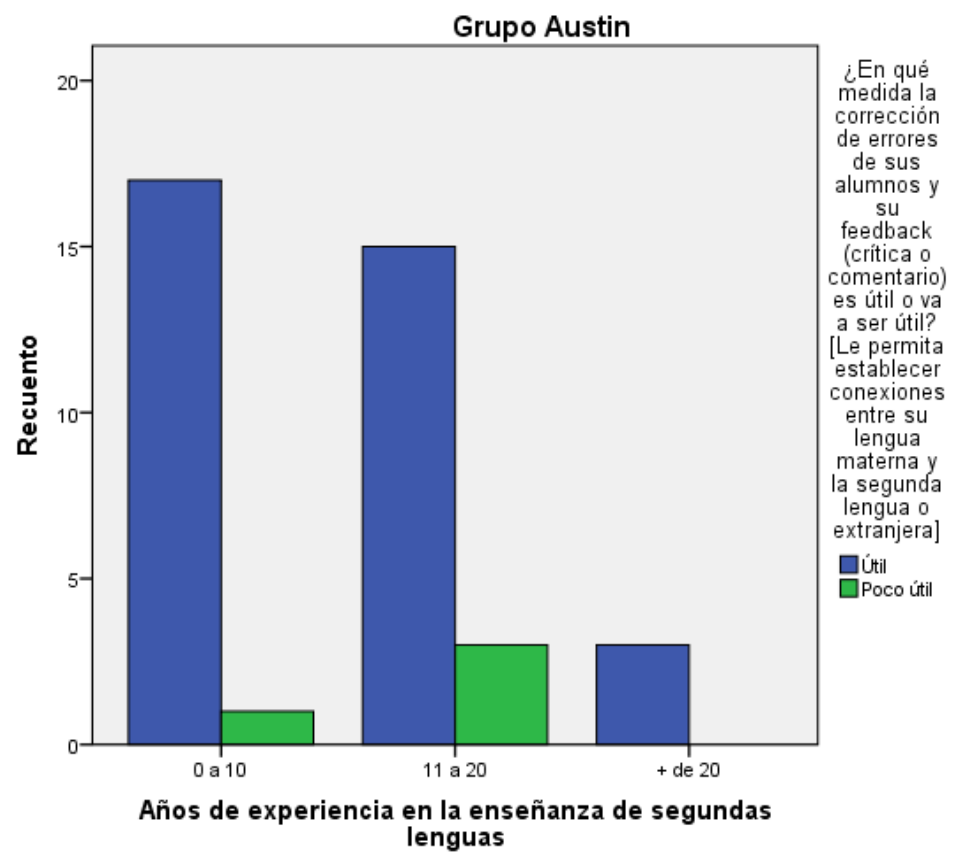

Gráfico 54. Recuento Años de experiencia - Utilidad de la corrección de errores y del feedback” [le permita establecer conexiones entre su lengua materna y la L2] - Grupo Austin

Los datos obtenidos en los gráficos 53 y 54 nos permiten afirmar que, en el contexto de Valladolid, una parte importante de los informantes tienen en consideración la importancia de la corrección y del feedback y entienden dichos procesos como una ayuda para que el alumno pueda establecer una conexión entre su lengua materna y la L2. No obstante, encontramos un porcentaje significativo de sujetos con menos 10 años de experiencia y una parte importante de sujetos con más de 10 años de experiencia que no identifican dicha utilidad. En lo que respecta al contexto educativo de Austin, la mayoría de los profesores reconoce la utilidad del feedback por cuanto que este favorece las conexiones entre la L1 y la L2 de los propios alumnos.

En este sentido, podemos inferir que una parte importante de la población de profesores vallisoletanos presentan dudas sobre la contribución del feedback al enriquecimiento de los 
conocimientos que tienen sobre su L1 y su L2. Además, el hecho de contar con un porcenaje elevado de sujetos menos experimentados que elije la opción "poco útil" nos hace pensar en la posibilidad de que en los más recientes planes de formación del profesorado se defienda esta falta de confianza en el feedback como nexo de unión entre la L1 y la L2.

A continuación, examinamos la variable "17c. Utilidad de la corrección de errores y del feedback" en la perspectiva de que estos puedan aportar información al alumno sobre cómo trabajar las distintas destrezas comunicativas en relación con los años de experiencia de los informantes.

En la Tabla 55 presentamos las pruebas de chi-cuadrado "Años de experiencia” * "Utilidad de la corrección de errores y del feedback" [le aporte información sobre cómo trabajar las distintas destrezas comunicativas]* “Grupo”.

\begin{tabular}{|l|l|c|c|c|}
\hline Grupo & Valor & gl & $\mathrm{p}$ \\
\hline Valladolid & Chi-cuadrado de Pearson & 4,167 & 2 &, 125 \\
\hline Austin & Chi-cuadrado de Pearson & 2,053 & 2 &, 358 \\
\hline Total & Chi-cuadrado de Pearson & 3,718 & 2 &, 156 \\
\hline
\end{tabular}

Tabla 55. Pruebas de chi-cuadrado "Años de experiencia" * "Utilidad de la corrección de errores y del feedback" [le aporte información sobre cómo trabajar las distintas destrezas comunicativas]* "Grupo"

Como podemos observar en la Tabla 55, las variables implicadas no tienen un grado de asociación significativo para el caso de Valladolid, ni para el de Austin ni para la muestra total (en todos los casos, $\mathrm{p}>.05)$.

A partir de la siguiente tabla de contingencia (Tabla 56) podemos observar la relación entre las variables "Años de experiencia" * "Utilidad de la corrección de errores y del feedback" [le aporte información sobre cómo trabajar las distintas destrezas comunicativas]* "Grupo". 


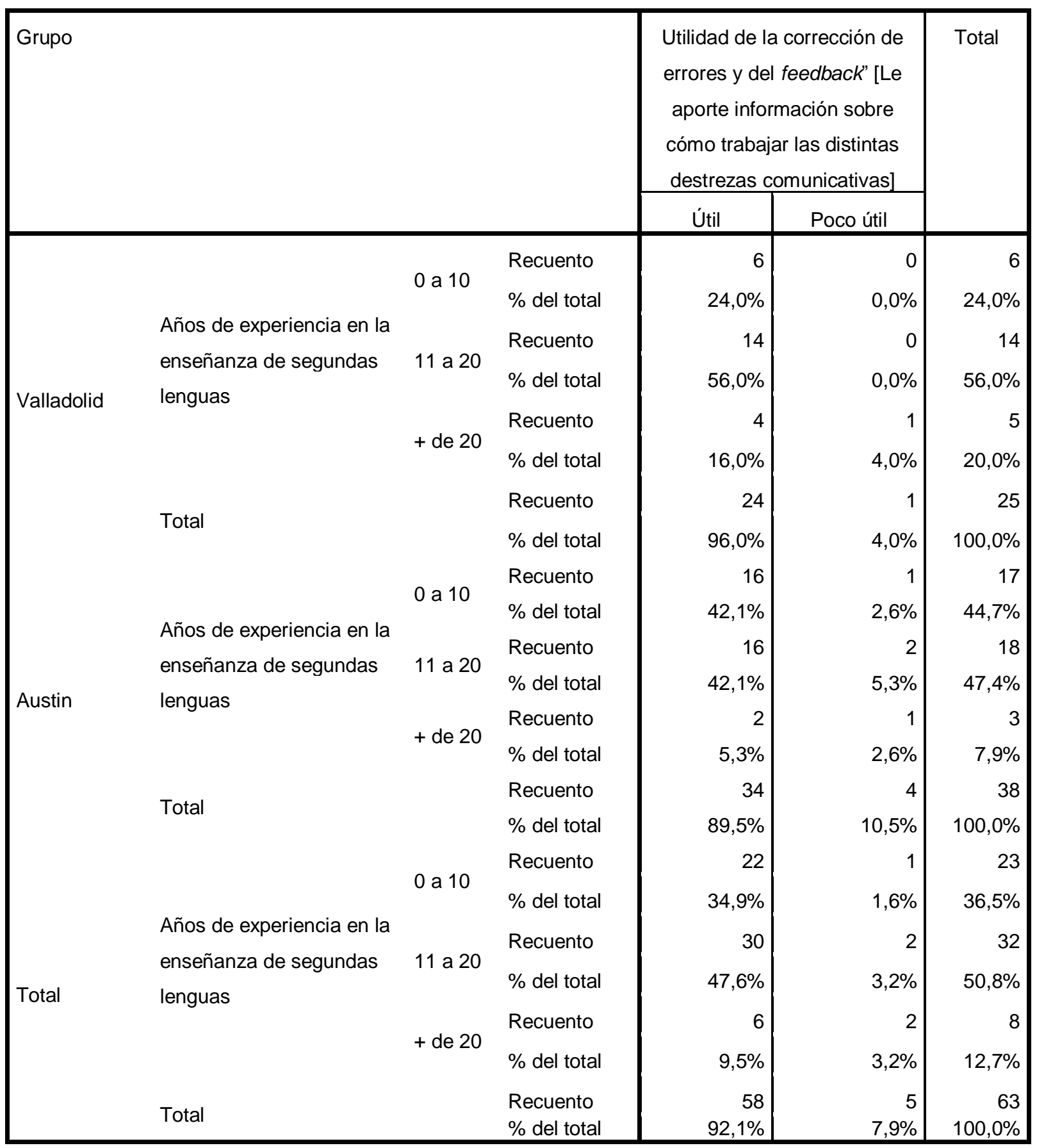

Tabla 56. Tabla de contingencia "Años de experiencia" * "Utilidad de la corrección de errores y del feedback" [le aporte información sobre cómo trabajar las distintas destrezas comunicativas]* "Grupo" 
La tabla 56 no muestra una asociación estadísticamente significativa. Esto nos hace pensar que, independientemente del contexto educativo (Valladolid o Austin) y de los años de experiencia en la docencia, prácticamente todos los informantes reconocen que la corrección de errores y el feedback es útil en la medida en que le aporta información necesaria acerca de cómo trabajar las distintas destrezas comunicativas. Nos encontramos ante porcentajes muy similares (téngase en cuenta que los porcentajes son totales y por tanto hacen referencia al número de participantes dentro de cada categoría para cada contexto educativo y en la muestra total). Así es como, el 96\% de los informantes de Valladolid reconocen la utilidad de estos respecto al $4 \%$ que no lo reconoce. En Austin, un 89,5\% lo considera útil respecto al 10,5\% que lo considera "poco útil”.

En cuanto a participación de los informantes en esta respuesta nos encontramos ante $\mathrm{n}=$ 25 docentes (de los 33 que representan la muestra total de Valladolid) y a $n=38$ (de los 40 que forman la muestra de Austin) formando un total de $\mathrm{N}=63$ informantes.

Los siguientes gráficos de barras agrupadas (gráficos 55 y 56) reflejan de forma gráfica los resultados comentados. 


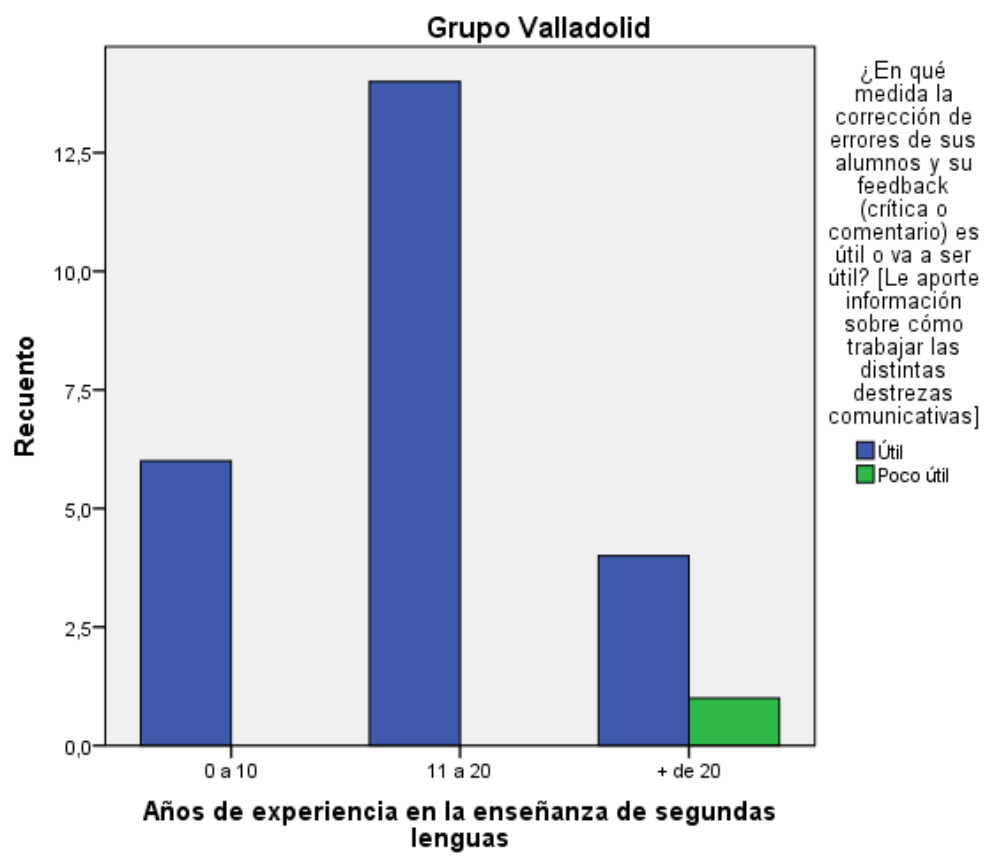

Gráfico 55. Recuento Años de experiencia - Utilidad de la corrección de errores y del feedback" [le aporte información sobre cómo trabajar las distintas destrezas comunicativas] - Grupo Valladolid

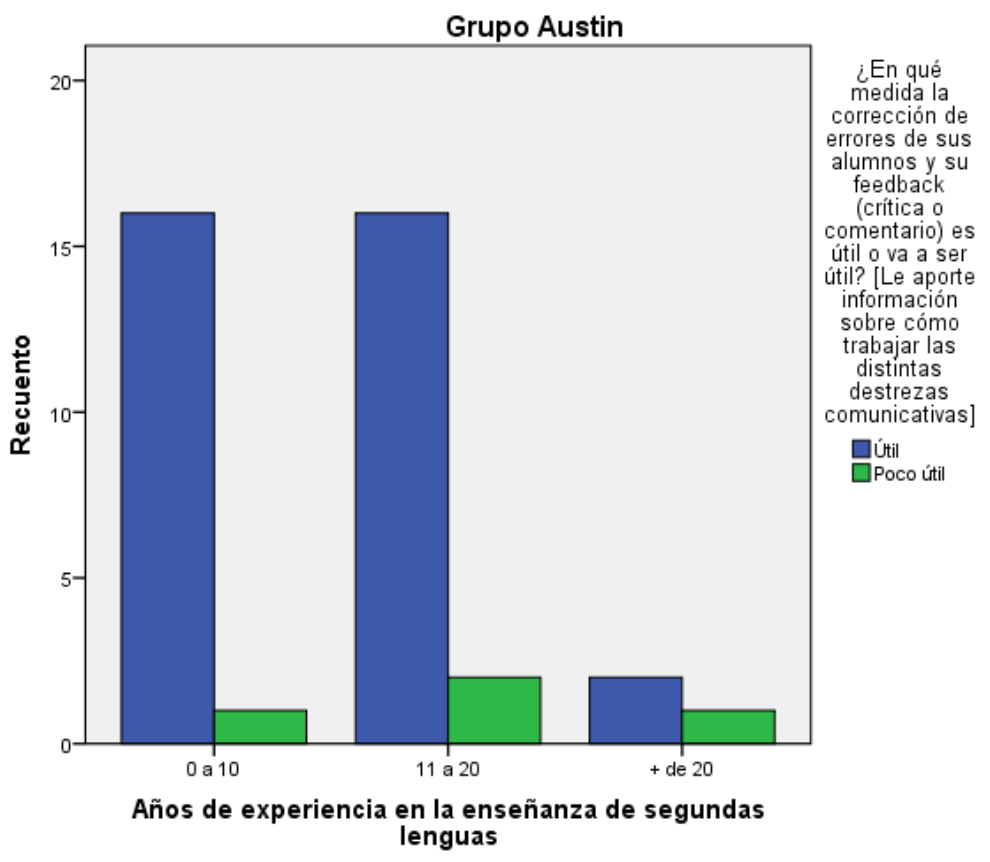

Gráfico 56. Recuento Años de experiencia - Utilidad de la corrección de errores y del feedback" [le aporte información sobre cómo trabajar las distintas destrezas comunicativas] - Grupo Austin 
Los datos obtenidos en los gráficos 55 y 56 ponen de manifiesto una actitud positiva generalizada tanto por parte de los sujetos de Valladolid como por los de Austin. En todas las franjas de años de experiencia se muestra una clara mayoría de profesores que reconocen las posibilidades que tiene el feedback de contribuir en la propia formación del alumno en las distintas destrezas comunicativas; a saber: expresión oral, expresión escrita, comprensión oral y comprensión escrita.

Nos atrevemos a reconocer por tanto la existencia de una confianza generalizada en el feedback como canal de información a través del cual se transmite al alumno información sobre sus propios errores y sobre ciertos mecanismos de la L2.

En lo relativo a esta actitud de confianza hacia el feedback podríamos hablar de "actitud real" o de "actitud simulada" que puede o no llevarse a la realidad del aula.

Nos disponemos, por último, a examinar la variable 17d. Utilidad de la corrección de errores y del feedback" por cuanto que estos ayuden al alumno a ver los errores no como algo negativo sino como indicador de su progreso en el proceso de aprendizaje en relación con los años de experiencia de los informantes.

Las pruebas de chi-cuadrado "Años de experiencia" * "Utilidad de la corrección de errores y delfeedback" [le ayude a ver los errores no como algo negativo sino como indicador de su progreso en el proceso de aprendizaje]* "Grupo" se presentan en la Tabla 57 que mostramos a continuación: 


\begin{tabular}{|l|l|c|c|c|}
\hline Grupo & Valor & gl & $p$ \\
\hline Valladolid & Chi-cuadrado de Pearson & ---- & --- & --- \\
\hline Austin & Chi-cuadrado de Pearson & 0,176 & 2 &, 916 \\
\hline Total & Chi-cuadrado de Pearson & 0,356 & 2 &, 837 \\
\hline
\end{tabular}

Tabla 57. Pruebas de chi-cuadrado "Años de experiencia" * "Utilidad de la corrección de errores y del feedback" [le ayude a ver los errores no como algo negativo sino como indicador de su progreso en el proceso de aprendizaje]* "Grupo"

Las variables implicadas (como podemos observar en la Tabla 57) no indican un grado de asociación significativo para el caso de Austin ni para la muestra total. En el caso de Valladolid no se calcula chi cuadrado respecto a dicha variable porque es una constante puesto que todos los participantes consideran que la corrección de errores y el feedback son "útiles" puesto que ayudan al alumno a ver los errores no como algo negativo sino como indicador de su propio aprendizaje.

La siguiente tabla de contingencia (Tabla 58) se lleva a cabo en torno a las variables “Años de experiencia" * "Utilidad de la corrección de errores y del feedback" [le ayude a ver los errores no como algo negativo sino como indicador de su progreso en el proceso de aprendizaje]* "Grupo". 


\begin{tabular}{|c|c|c|c|c|c|c|}
\hline \multirow[t]{2}{*}{ Grupo } & & & & \multicolumn{2}{|c|}{$\begin{array}{l}\text { Utilidad de la corrección de } \\
\text { errores y del feedback [Le } \\
\text { ayude a ver los errores no } \\
\text { como algo negativo sino como } \\
\text { indicador de su progreso en el } \\
\text { proceso de aprendizaje] }\end{array}$} & \multirow[t]{2}{*}{ Total } \\
\hline & & & & Útil & Poco útil & \\
\hline \multirow{8}{*}{ Valladolid } & & & Recuento & 6 & & 6 \\
\hline & & a d I & $\%$ del total & $22,2 \%$ & & $22,2 \%$ \\
\hline & Años de experiencia en la & & Recuento & 16 & & 16 \\
\hline & lenquas & & $\%$ del total & $59,3 \%$ & & $59,3 \%$ \\
\hline & & + de 20 & Recuento & 5 & & 5 \\
\hline & & & $\%$ del total & $18,5 \%$ & & $18,5 \%$ \\
\hline & Total & & Recuento & 27 & & 27 \\
\hline & Tula & & $\%$ del total & $100,0 \%$ & & $100,0 \%$ \\
\hline \multirow{6}{*}{ Austin } & \multirow{6}{*}{$\begin{array}{l}\text { Años de experiencia en la } \\
\text { enseñanza de segundas } \\
\text { lenguas }\end{array}$} & 0 a 10 & Recuento & 17 & 1 & 18 \\
\hline & & & $\%$ del total & $43,6 \%$ & $2,6 \%$ & $46,2 \%$ \\
\hline & & 11 a 20 & Recuento & 17 & 1 & 18 \\
\hline & & & $\%$ del total & $43,6 \%$ & $2,6 \%$ & $46,2 \%$ \\
\hline & & + de 20 & Recuento & 3 & 0 & 3 \\
\hline & & & $\%$ del total & $7,7 \%$ & $0,0 \%$ & $7,7 \%$ \\
\hline \multirow{10}{*}{ Total } & \multirow{3}{*}{ Total } & & Recuento & 37 & 2 & 39 \\
\hline & & & $\%$ del total & $94,9 \%$ & $5,1 \%$ & $100,0 \%$ \\
\hline & & 0 a 10 & Recuento & & 1 & \\
\hline & \multirow{5}{*}{$\begin{array}{l}\text { Años de experiencia en la } \\
\text { enseñanza de segundas } \\
\text { lenguas }\end{array}$} & & & $34,8 \%$ & $1,5 \%$ & $36,4 \%$ \\
\hline & & 11 a 20 & Recuento & & 1 & 34 \\
\hline & & & & $50,0 \%$ & $1,5 \%$ & $51,5 \%$ \\
\hline & & + de 20 & necuento & & 0 & \\
\hline & & & $\%$ del total & $12,1 \%$ & $0,0 \%$ & $12,1 \%$ \\
\hline & \multirow{2}{*}{ Total } & & Recuento & 64 & 2 & \\
\hline & & & $\%$ del total & $97,0 \%$ & $3,0 \%$ & $100,0 \%$ \\
\hline
\end{tabular}

Tabla 58. Tabla de contingencia "Años de experiencia" * "Utilidad de la corrección de errores y del feedback" [le ayude a ver los errores no como algo negativo sino como indicador de su progreso en el proceso de aprendizaje]* "Grupo"

En la presente tabla de contingencia (Tabla 58) no se expone una asociación estadísticamente significativa y, en este sentido, independientemente del contexto educativo (Valladolid o Austin) y de los años de experiencia en la docencia, prácticamente todos los informantes (a excepción de dos en la ciudad de Austin) reconocen que la corrección de errores y el feedback es útil puesto que 
ayuda al alumno a ver los errores no como algo negativo sino como indicador de su progreso en el proceso de aprendizaje. En el caso de Valladolid no hablamos de variables sino de constante ya que el 100\% elige la opción "útil”. En el caso de Austin, el porcentaje es prácticamente el mismo, un $94,9 \%$ opina que es útil y solo dos informantes (uno de ellos con menos de 10 años de experiencia y el otro con una experiencia de 11 a 20 años) (que forman un total del 5,1\%) opinan que la corrección y el feedback son "poco útiles" a la hora de ayudar al alumno a ver sus errores como síntoma de aprendizaje. Se observa la coincidencia de los porcentajes (téngase en cuenta que los porcentajes son totales y por tanto hacen referencia al número de participantes dentro de cada categoría para cada contexto educativo y la muestra total).

En cuanto a participación de los informantes en esta respuesta nos encontramos ante $\mathrm{n}=$ 27 docentes (de los 33 que representan la muestra total de Valladolid) y a $n=39$ (de los 40 que forman la muestra de Austin) formando un total de $\mathrm{N}=62$ informantes.

A continuación, presentamos los siguientes gráficos de barras agrupadas (gráficos 57 y 58) que exponen los resultados comentados. 


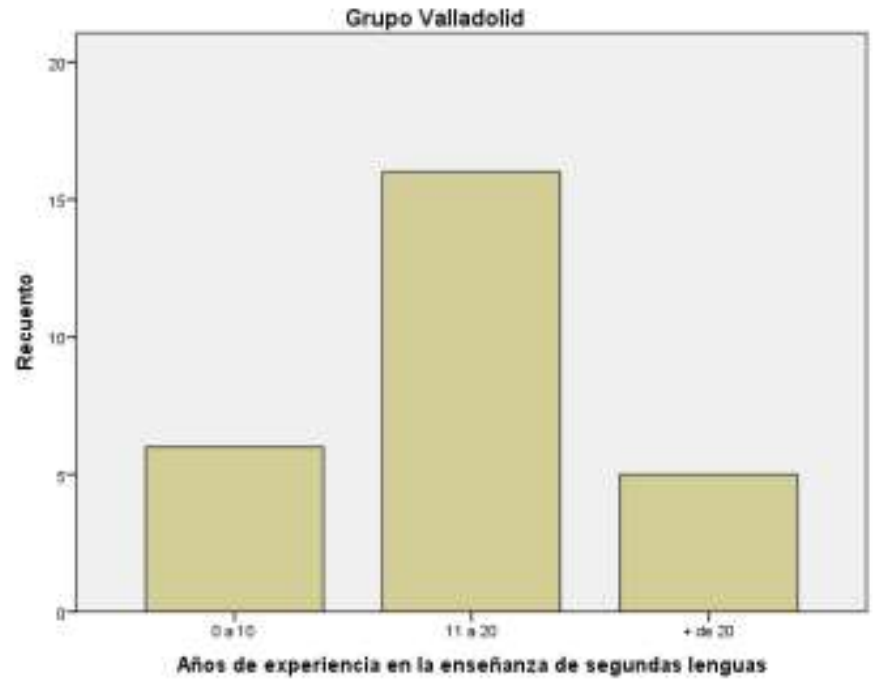

Gráfico 57. Recuento Años de experiencia - Utilidad de la corrección de errores y del feedback” [le ayude a ver los errores no como algo negativo sino como indicador de su progreso en el proceso de aprendizaje] - Grupo Valladolid

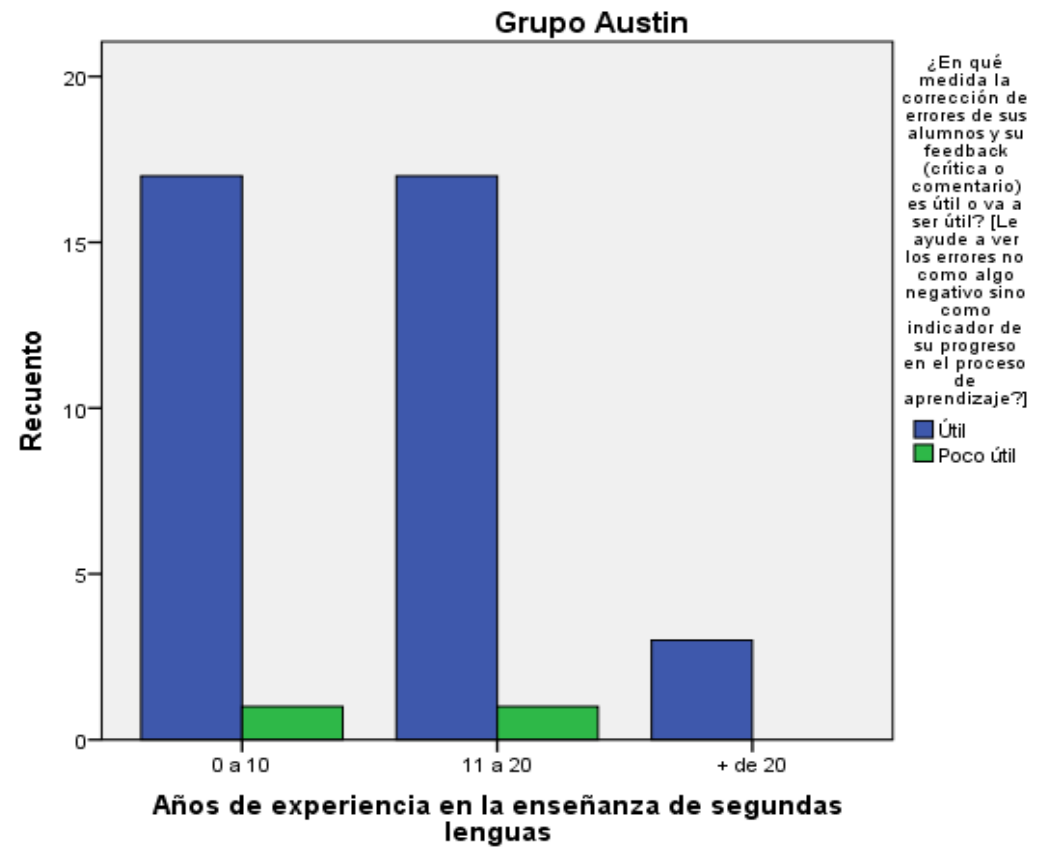

Gráfico 58. Recuento Años de experiencia - Utilidad de la corrección de errores y del feedback" [le ayude a ver los errores no como algo negativo sino como indicador de su progreso en el proceso de aprendizaje] - Grupo Austin 
Los datos obtenidos en los gráficos 57 y 58 indican que los participantes del contexto educativo de Valladolid (independientemente de los años de experiencia que tengan en la enseñanza de L2) apuestan de forma unánime por el uso de un feedback que ayude al alumno a considerar los errores como una muestra de progreso en el aprendizaje de la L2, tal y como proponían autores como Dolz, Gagnon, Mosquera y Sánchez (2013); Durán (2011); Ellis (2008); Fernández (1997); Giovannini et al. (1996) y Torijano Pérez (2004) a quienes citábamos en el epígrafe 1.1.1. Asimismo, los participantes del contexto educativo de Austin, también reconocen dicha utilidad de forma generalizada ( $\sin$ que existan diferencias significativas respecto a sus años de experiencia en la enseñanza de L2).

Como ya venimos apuntando, las actitudes de confianza hacia el feedback como elemento que permite entender el error como algo positivo fomentan un aprendizaje significativo de la L2. Tal y como hemos manifestado, todos los informantes muestran en sus respuestas una tendencia general hacia este tipo de actitudes. Sin embargo, tras el análisis de datos del resto de ítems hemos podido observar que en el contexto de Valladolid todavía existe una tendencia a marcar los errores del alumno y a considerarlos un símbolo de "incapacidad".

\subsubsection{Actitudes ante la posible utilidad de la corrección de errores y el feedback en relación con la edad}

A continuación, analizamos las actitudes de nuestros informantes ante la posible utilidad de la corrección de errores y el feedback en relación con su edad. La variable "Utilidad de la corrección de errores y delfeedback" presenta cuatro subdivisiones, como ya hemos mencionado previamente 
(17a, 17b, 17c y 17d) por lo que presentaremos cuatro tablas de pruebas chi-cuadrado, cuatro tablas de contingencia y ocho gráficos de barras agrupadas (dos para cada una de las cuatro variables).

Relacionamos la primera variable, que aparece bajo la forma "17a. Utilidad de la corrección de errores y del feedback" desde la óptica de permitir que el alumno sea consciente de su propio proceso de aprendizaje con los años de experiencia de los informantes.

En la tabla que se muestra a continuación (Tabla 59) se presentan las pruebas de chi-cuadrado "Edad" * "Utilidad de la corrección de errores y del feedback" [para que el alumno sea consciente de su propio proceso de aprendizaje]* "Grupo".

\begin{tabular}{|l|l|c|c|c|}
\hline \multicolumn{2}{|l|}{ Grupo } & Valor & gl & $p$ \\
\hline Valladolid & Chi-cuadrado de Pearson & ---- & --- & ---- \\
\hline Austin & Chi-cuadrado de Pearson & 0,418 & 2 &, 811 \\
\hline Total & Chi-cuadrado de Pearson & 0,531 & 2 &, 767 \\
\hline
\end{tabular}

Tabla 59. Pruebas de chi-cuadrado "Edad" * "Utilidad de la corrección de errores y del feedback" [para que el alumno sea consciente de su propio proceso de aprendizaje]* "Grupo"

Según podemos observar en la Tabla 59 las variables implicadas no indican un grado de asociación significativo para el caso de Austin ni para la muestra total. Respecto al caso Valladolid, es una constante, todos los participantes han contestado "útil”, por lo que no se realiza en este caso la prueba chi-cuadrado para este grupo. 
La siguiente tabla de contingencia (Tabla 60) se realiza para las variables "Edad" * "Utilidad de la corrección de errores y del feedback" [para que el alumno sea consciente de su propio proceso de aprendizaje]* "Grupo".

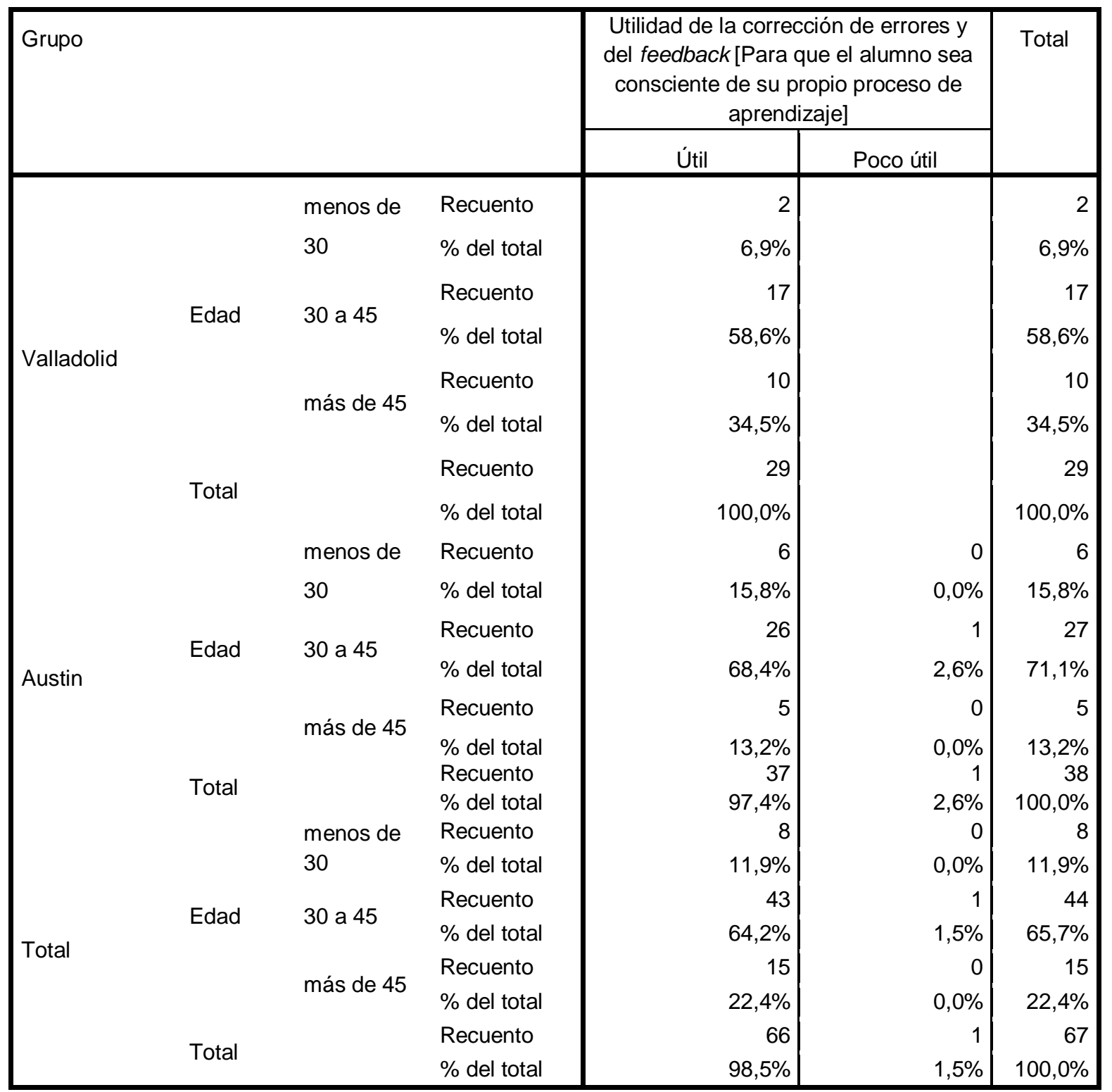

Tabla 60. Tabla de contingencia "Edad" * "Utilidad de la corrección de errores y del feedback" [para que el alumno sea consciente de su propio proceso de aprendizaje]* "Grupo" 
En tabla 60 de contingencia se observa que no existe una asociación estadísticamente significativa y, en este sentido, independientemente del contexto educativo (Valladolid o Austin) y de los años de experiencia en la docencia, una gran mayoría de informantes reconocen que la corrección de errores y el feedback son útiles para que el alumno sea consciente de su propio proceso de aprendizaje. En el caso de Valladolid nos encontramos ante una constante ya que el 100\% elige la opción "útil”. En el caso de Austin, el porcentaje es prácticamente el mismo, un 97,4\% declara que es útil y solamente encontramos la presencia de dos informantes (que forman un total del 2,6\%), uno de ellos menor de 30 años y el otro entre 30 y 45 que consideran la corrección de errores y el feedback como algo "poco útil” para que el alumno sea consciente de su propio proceso de aprendizaje. Desde esta consideración, podemos afirmar que contamos con porcentajes prácticamente similares (téngase en cuenta que los porcentajes son totales y por tanto hacen referencia al número de participantes dentro de cada categoría para cada contexto educativo y para la muestra total).

En lo que respecta a la participación en el presente ítem encontramos $n=29$ docentes (de los 33 que representan la muestra total de Valladolid) y $n=38$ (de los 40 que forman la muestra de Austin) formando un total de $\mathrm{N}=67$ informantes.

Los siguientes gráficos de barras agrupadas (gráficos 59 y 60) muestran los resultados que hemos comentado previamente. 


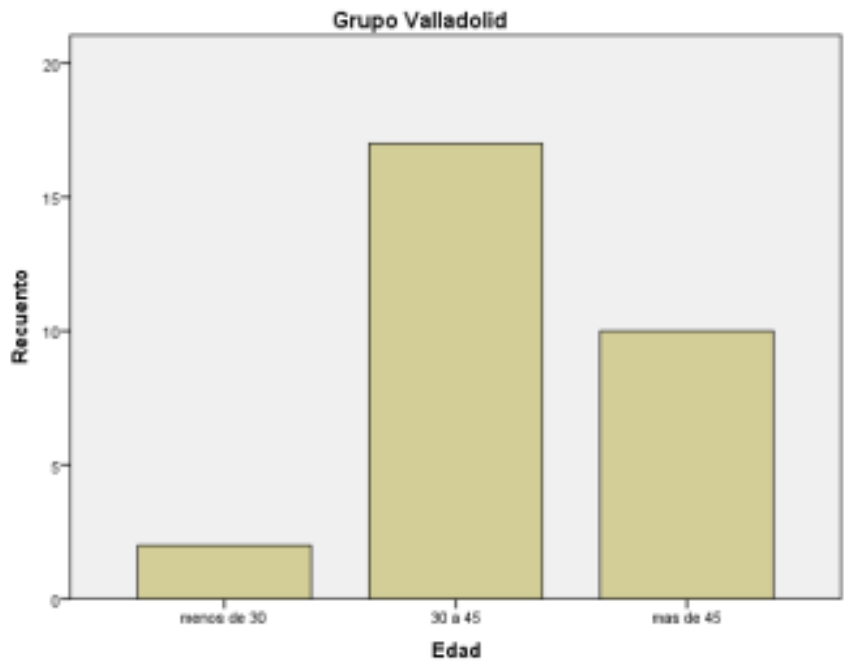

Gráfico 59. Recuento Edad - Utilidad de la corrección de errores y del feedback” [para que el alumno sea consciente de su propio proceso de aprendizaje] - Grupo Valladolid

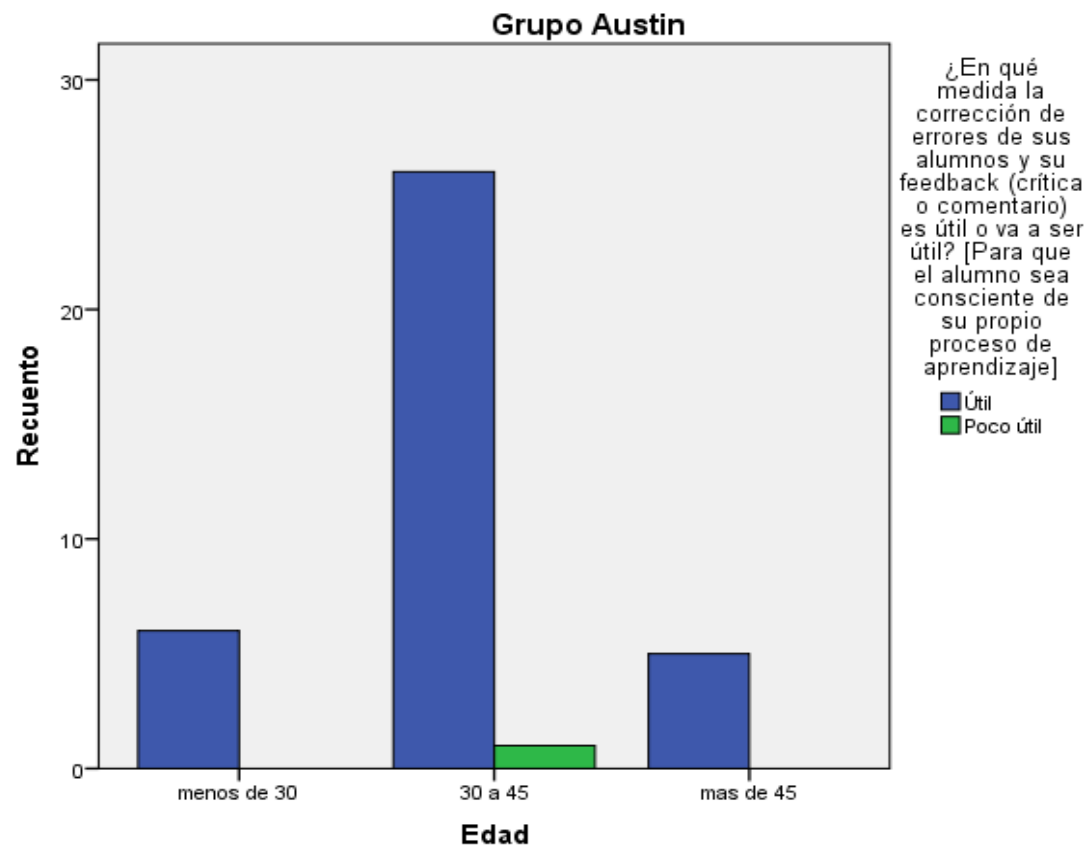

Gráfico 60. Recuento Edad - Utilidad de la corrección de errores y del feedback” [para que el alumno sea consciente de su propio proceso de aprendizaje] - Grupo Austin

Los datos obtenidos en los gráficos 59 y 60 nos permiten afirmar que prácticamente todos los informantes (en el caso de Valladolid, hablamos del 100\%) reconocen que la corrección de 
errores y el feedback es útil para que el alumno sea consciente de su propio proceso de aprendizaje de la L2.

Los dos contextos educativos estudiados muestran resultados muy semejantes por lo que nos atrevemos a suponer que, a nivel declarativo, prácticamente todos los profesores que ejercen su actividad docente tanto en centros educativos de la ciudad de Valladolid como en los de Austin muestran una postura de gran optimismo hacia el feedback. Como podemos observar, la edad de los sujetos no plantea ninguna diferencia respecto a sus respuestas, así es como, tanto los profesores más jóvenes como los más mayores manifiestan su confianza hacia el feedback como elemento que permite al alumno ser consciente de su propio proceso de aprendizaje.

A continuación, nos disponemos a cruzar los datos relativos a la variable 17b: "Utilidad de la corrección de errores y del feedback [le permita establecer conexiones entre su lengua materna y la L2]" con la edad de los informantes.

En la Tabla 61 que aparece a continuación se presentan las pruebas de chi-cuadrado "Edad" * "Utilidad de la corrección de errores y del feedback" [le permita establecer conexiones entre su lengua materna y la L2]* “Grupo”.

\begin{tabular}{|l|l|c|c|c|}
\hline \multicolumn{2}{|l|}{ Grupo } & Valor & $\mathrm{gl}$ & $\mathrm{p}$ \\
\hline Valladolid & Chi-cuadrado de Pearson & 4,875 & 2 &, 087 \\
\hline Austin & Chi-cuadrado de Pearson & 0,996 & 2 &, 608 \\
\hline Total & Chi-cuadrado de Pearson & 2,655 & 2 &, 265 \\
\hline
\end{tabular}

Tabla 61. Pruebas de chi-cuadrado "Edad" * “Utilidad de la corrección de errores y del feedback” [le permita establecer conexiones entre su lengua materna y la L2]* "Grupo" 
De acuerdo con los datos analizados en la Tabla 61 no existe relación significativa entre la edad de los participantes y la utilidad de la corrección de errores y del feedback en la medida en que permitan al alumno establecer conexiones entre su lengua materna y la L2 (en todos los casos, p > $.05)$.

A continuación, se muestra la tabla de contingencia (Tabla 62) para las variables "Edad" * "Utilidad de la corrección de errores y del feedback" [le permita establecer conexiones entre su lengua materna y la L2]* "Grupo". 


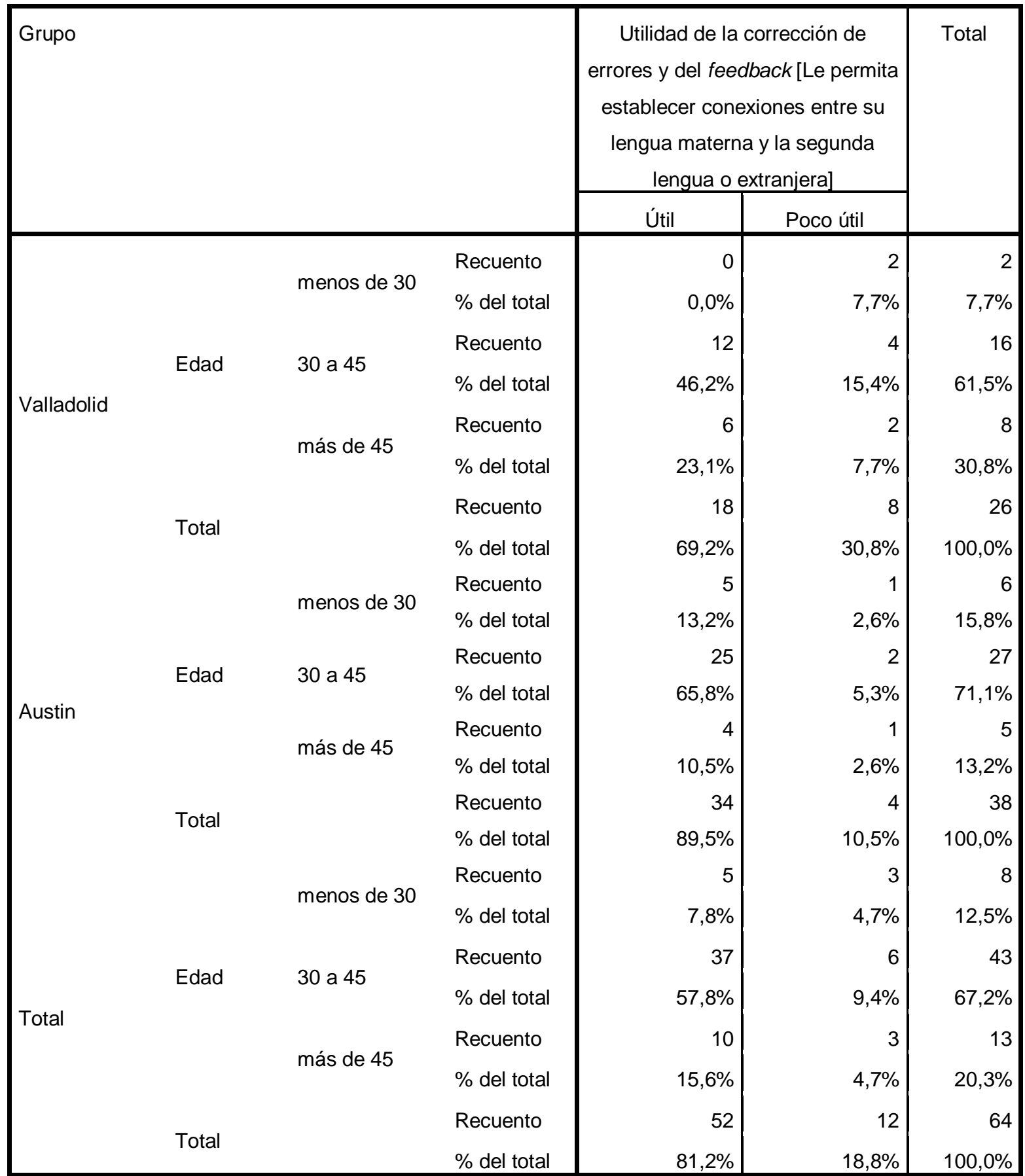

Tabla 62. Tabla de contingencia "Edad" * "Utilidad de la corrección de errores y del feedback" [le permita establecer conexiones entre su lengua materna y la L2]* "Grupo"

Observamos en la Tabla 62 que no existe una relación estadísticamente significativa entre las variables. A partir de estos datos, podemos afirmar que, independientemente del contexto 
educativo (Valladolid o Austin) y de la edad, la mayor parte de los informantes considera que la corrección de errores y el feedback es útil por cuanto que favorece que el alumno pueda establecer conexiones entre su lengua materna y la L2. Si bien en los dos contextos encontramos una amplia mayoría de informantes que considera "útil” la corrección y elfeedback, en Valladolid la diferencia en porcentajes no es tan significativa $(69,2 \%=$ útil, $30,8 \%=$ poco útil) como la de la ciudad de Austin $(89,5 \%=$ útil, $10,5 \%=$ poco útil $)$.

Observamos que los informantes más jóvenes (menores de 30 años) del contexto de Valladolid eligen la opción "poco útil". Estos representan un porcentaje reducido $(7,7 \%)$ de la muestra total dentro de este contexto educativo, pero resulta significativo el hecho de que todos ellos consideren que la corrección de errores y el feedback son "poco útiles" en la perspectiva de favorecer que el alumno establezca conexiones entre su lengua materna y la L2.

Encontramos por tanto cifras muy similares y, en este sentido, afirmamos que nuestros informantes, de forma general, consideran que la corrección y el feedback tienen una gran relevancia por permitir que los alumnos puedan establecer conexiones entre su lengua materna y la L2. A pesar de esto, existe un porcentaje de informantes vallisoletanos (30,8\%) que consideran que estos son "poco útiles", entre ellos, todos los informantes menores de 30 años incluidos en la muestra.

En cuanto a participación de los informantes en esta respuesta nos encontramos ante $\mathrm{n}=$ 26 docentes (de los 33 que representan la muestra total de Valladolid) y a $n=38$ (de los 40 
informantes que forman el $100 \%$ de la muestra total de Austin) formando un total de $\mathrm{N}=65$ informantes.

Los siguientes gráficos de barras agrupadas (gráficos 61 y 62) reflejan de forma gráfica los resultados comentados.

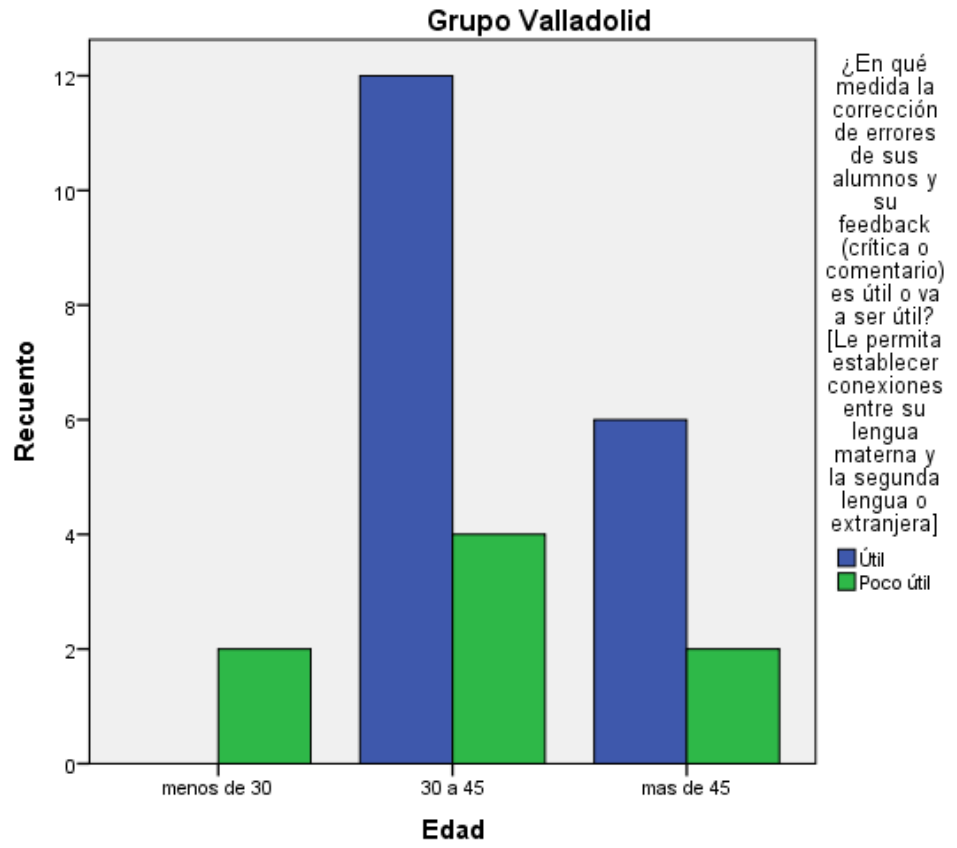

Gráfico 61. Recuento Edad - Utilidad de la corrección de errores y del feedback" [le permita establecer conexiones entre su lengua materna y la L2- Grupo Valladolid 


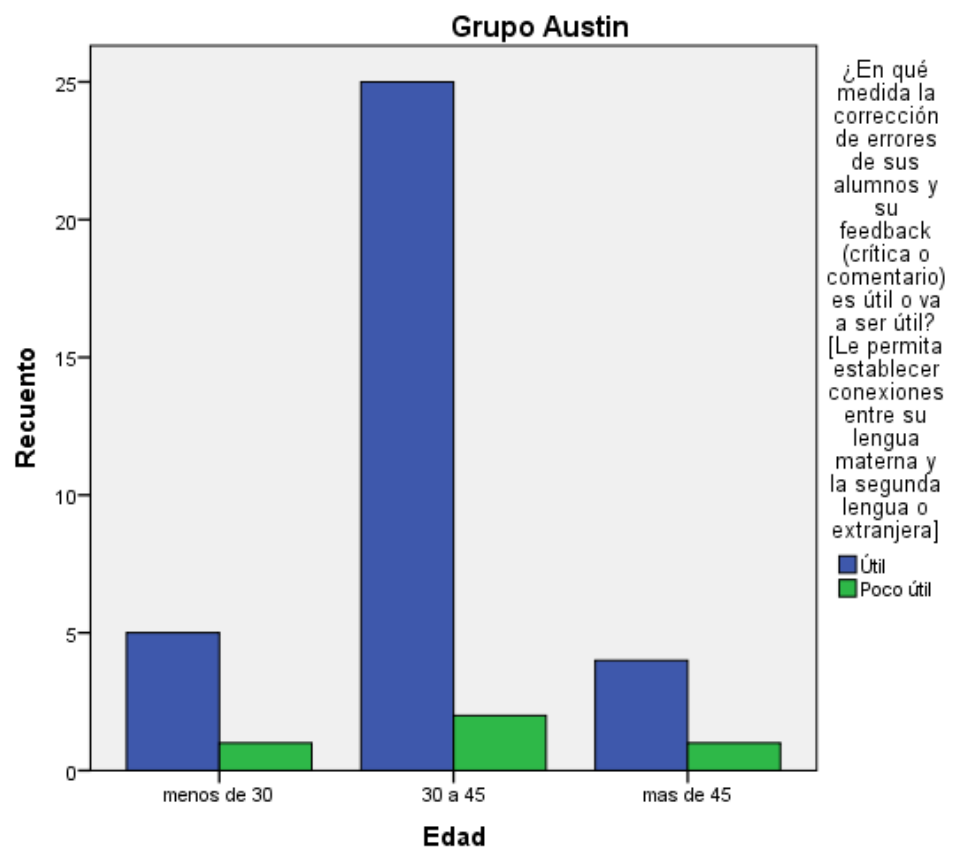

Gráfico 62. Recuento Edad - Utilidad de la corrección de errores y del feedback” [le permita establecer conexiones entre su lengua materna y la L2- Grupo Austin

A partir de los gráficos 61 y 62 observamos que, en el contexto de Valladolid, a pesar de que la mayoría reconoce la utilidad del de la corrección y del feedback y entienden dichos procesos como una ayuda para que el alumno pueda establecer una conexión entre su lengua materna y la L2 que no lo hace. Estos sujetos se extienden en los tres rangos de edad: menos de 30, de 30 a 45 y más de 45. Sin embargo, nos llama la atención el hecho de que todos los sujetos menores de 30 años decidan optar por la respuesta: "poco útil”.

Por otro lado, los informantes del contexto educativo de Austin (independientemente de su edad) reconocen de forma mayoritaria la utilidad del feedback por cuanto que este puede ayudar al alumno a entender su L1 y su L2 y le permite establecer conexiones entre estas. 
Desde esta consideración, reconocemos la existencia de un porcentaje significativo de profesores vallisoletanos que presentan dudas respecto a los beneficios del feedback en cuanto a sus producciones en L2 y a las conexiones con su L1. Teniendo en cuenta que todos los sujetos menores de 30 años rechazan la idea de utilidad del feedback podemos plantear la posibilidad de que en los planes de formación del profesorado no se recurra a teorías de adquisición lingüística que tengan en consideración el feedback como nexo de unión entre la L1 y la L2. Como ya mencionábamos en el epígrafe 9.4.1, puede que estos profesores más jóvenes no cuenten con una formación respecto a la importancia del feedback como elemento de unión entre las dos lenguas.

Nos proponemos analizar la variable 17c: "Utilidad de la corrección de errores y del feedback" por cuanto que estos aporten información al alumno sobre cómo trabajar las distintas destrezas comunicativas en relación con la edad de los informantes.

En la siguiente tabla (Tabla 63) se presentan las pruebas de chi-cuadrado "Edad" * "Utilidad de la corrección de errores y del feedback" [le aporte información sobre cómo trabajar las distintas destrezas comunicativas]* “Grupo”.

\begin{tabular}{|l|l|c|c|c|}
\hline \multicolumn{2}{|l|}{ Grupo } & Valor & gl & $\mathrm{p}$ \\
\hline Valladolid & Chi-cuadrado de Pearson & 1,867 & 2 &, 393 \\
\hline Austin & Chi-cuadrado de Pearson & 0,914 & 2 &, 633 \\
\hline Total & Chi-cuadrado de Pearson & 1,441 & 2 &, 487 \\
\hline
\end{tabular}

Tabla 63. Pruebas de chi-cuadrado "Edad" * "Utilidad de la corrección de errores y del feedback" [le aporte información sobre cómo trabajar las distintas destrezas comunicativas]* "Grupo" 
En la Tabla 63 observamos que no existe relación significativa entre la edad de los participantes y la utilidad de la corrección de errores y del feedback en la medida en que estos aporten información al alumno sobre cómo trabajar las distintas destrezas comunicativas (en todos los casos, $\mathrm{p}>.05)$.

La siguiente tabla de contingencia (Tabla 64) se calcula para las variables "Edad" * "Utilidad de la corrección de errores y del feedback" [le aporte información sobre cómo trabajar las distintas destrezas comunicativas]* “Grupo”. 


\begin{tabular}{|c|c|c|c|c|c|c|}
\hline \multirow[t]{2}{*}{ Grupo } & & & & \multicolumn{2}{|c|}{$\begin{array}{c}\text { Utilidad de la corrección de } \\
\text { errores y del feedback [Le aporte } \\
\text { información sobre cómo trabajar } \\
\text { las distintas destrezas } \\
\text { comunicativas] }\end{array}$} & \multirow[t]{2}{*}{ Total } \\
\hline & & & & Útil & Poco útil & \\
\hline \multirow{10}{*}{ Valladolid } & \multirow{6}{*}{ Edad } & \multirow{2}{*}{ menos de 30} & Recuento & 2 & 0 & 2 \\
\hline & & & $\%$ del total & $7,1 \%$ & $0,0 \%$ & $7,1 \%$ \\
\hline & & \multirow{2}{*}{30 a 45} & Recuento & 16 & 0 & 16 \\
\hline & & & $\%$ del total & $57,1 \%$ & $0,0 \%$ & $57,1 \%$ \\
\hline & & \multirow{2}{*}{ más de 45} & Recuento & 9 & 1 & 10 \\
\hline & & & $\%$ del total & $32,1 \%$ & $3,6 \%$ & $35,7 \%$ \\
\hline & \multirow{2}{*}{ Total } & \multirow{4}{*}{ menos de 30} & Recuento & 27 & 1 & 28 \\
\hline & & & $\%$ del total & $96,4 \%$ & $3,6 \%$ & $100,0 \%$ \\
\hline & \multirow{6}{*}{ Edad } & & Recuento & 5 & 1 & 6 \\
\hline & & & $\%$ del total & $13,5 \%$ & $2,7 \%$ & $16,2 \%$ \\
\hline \multirow{4}{*}{ Austin } & & \multirow{2}{*}{30 a 45} & Recuento & 24 & 2 & 26 \\
\hline & & & $\%$ del total & $64,9 \%$ & $5,4 \%$ & $70,3 \%$ \\
\hline & & \multirow{2}{*}{ más de 45} & Recuento & 4 & 1 & 5 \\
\hline & & & $\%$ del total & $10,8 \%$ & $2,7 \%$ & $13,5 \%$ \\
\hline \multirow{10}{*}{ Total } & \multirow{2}{*}{ Total } & \multirow{4}{*}{ menos de 30} & Recuento & 33 & 4 & 37 \\
\hline & & & $\%$ del total & $89,2 \%$ & $10,8 \%$ & $100,0 \%$ \\
\hline & \multirow{6}{*}{ Edad } & & Recuento & 7 & 1 & 8 \\
\hline & & & $\%$ del total & $10,8 \%$ & $1,5 \%$ & $12,3 \%$ \\
\hline & & \multirow{2}{*}{30 a 45} & Recuento & 40 & 2 & 42 \\
\hline & & & $\%$ del total & $61,5 \%$ & $3,1 \%$ & $64,6 \%$ \\
\hline & & \multirow{2}{*}{ más de 45} & Recuento & 13 & 2 & 15 \\
\hline & & & $\%$ del total & $20,0 \%$ & $3,1 \%$ & $23,1 \%$ \\
\hline & \multirow{2}{*}{ Total } & & Recuento & 60 & 5 & 65 \\
\hline & & & $\%$ del total & $92,3 \%$ & $7,7 \%$ & $100,0 \%$ \\
\hline
\end{tabular}

Tabla 64. Tabla de contingencia "Edad" * "Utilidad de la corrección de errores y del feedback" [le aporte información sobre cómo trabajar las distintas destrezas comunicativas]* "Grupo"

En la tabla de contingencia (Tabla 64) encontramos de nuevo la presencia de datos que no muestran ninguna asociación estadísticamente significativa. Desde esta consideración, podemos 
afirmar que, independientemente del contexto educativo (Valladolid o Austin) y de su edad, prácticamente todos los informantes reconocen que la corrección de errores y el feedback son útiles en la medida en que le aporta información necesaria acerca de cómo trabajar las distintas destrezas comunicativas. Nos encontramos ante porcentajes altos en torno a la utilidad de la corrección y del feedback que, en ambos casos, se aproximan mucho al 100\%. Así es como, en el caso de Valladolid, el 96,4\% reconoce la utilidad de estos respecto al 3,6\% que no lo reconoce. Por su parte, en Austin, un 89,2\% considera que estos son útiles respecto al 10,8\% que lo considera "poco útiles". Debemos tener en cuenta que los porcentajes son totales y por tanto hacen referencia al número de participantes dentro de cada categoría para cada contexto educativo y la muestra total.

En cuanto a participación de los informantes en esta respuesta nos encontramos ante $\mathrm{n}=$ 28 docentes (de los 33 que representan la muestra total de Valladolid) y a $n=37$ (de los 40 que forman la muestra de Austin) formando un total de $\mathrm{N}=65$ informantes.

A partir de los siguientes gráficos de barras agrupadas (gráficos 63 y 64) se podrán examinar los resultados comentados. 


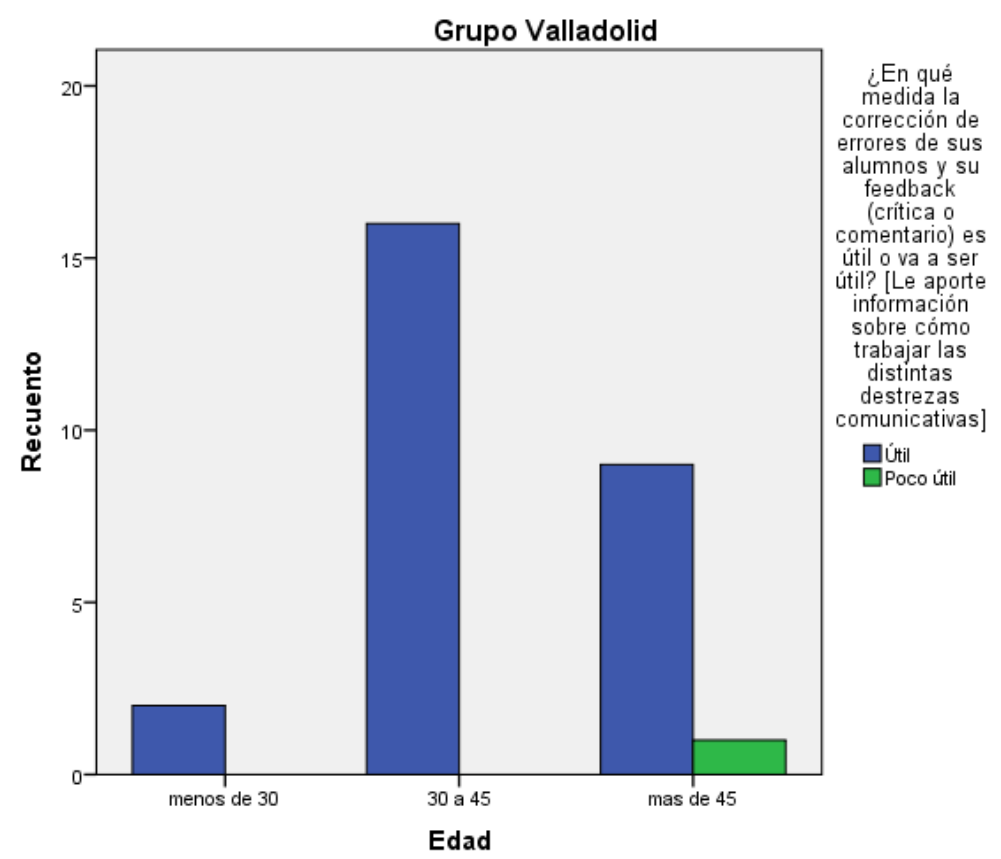

Gráfico 63. Recuento Edad - Utilidad de la corrección de errores y del feedback” [le aporte información sobre cómo trabajar las distintas destrezas comunicativas] - Grupo Valladolid

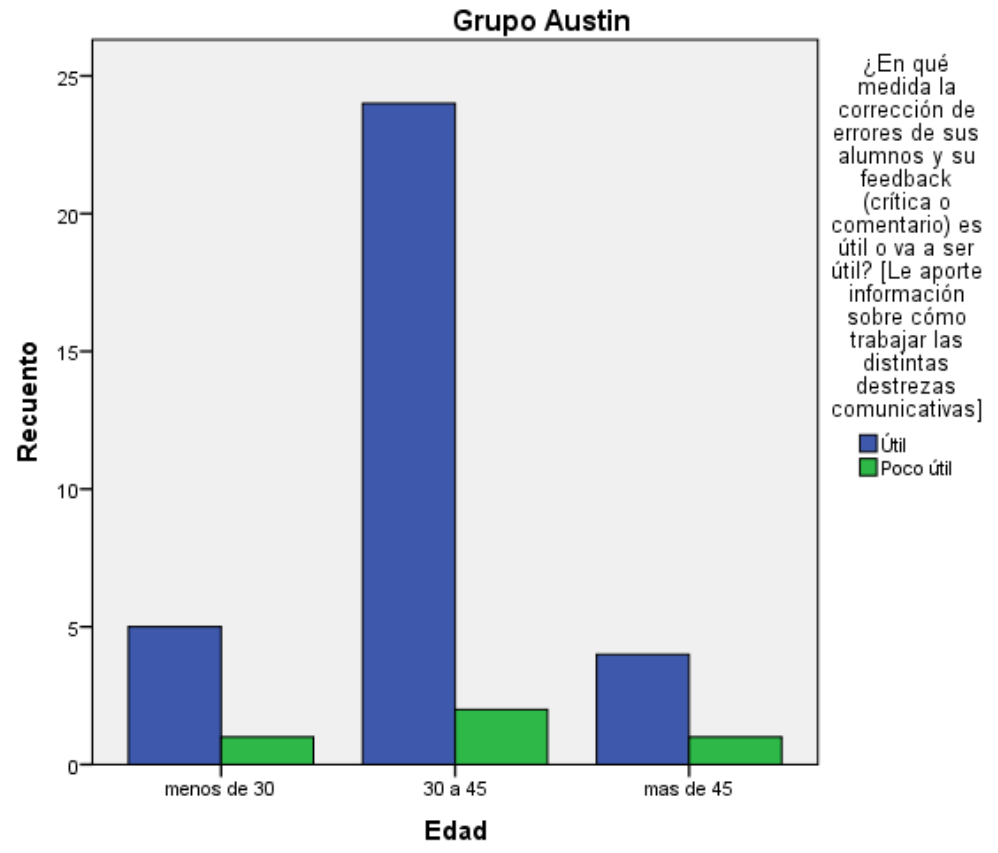

Gráfico 64. Recuento Edad - Utilidad de la corrección de errores y del feedback” [le aporte información sobre cómo trabajar las distintas destrezas comunicativas] - Grupo Austin 
Los gráficos 63 y 64 presentan una actitud positiva generalizada tanto por parte de los sujetos de Valladolid como por los de Austin. La mayoría de los profesores, independientemente de su edad, reconoce las posibilidades que tiene el feedback de aportar información sobre cómo trabajar las destrezas comunicativas.

Como ya mencionábamos en epírafe 9.4.1, estas actitudes positivas de confianza hacia el feedback se muestran por parte de los sujetos de los dos contextos educativos. No obstante, cabe la posibilidad de que dichas actitudes sean mostrada en la teoría, pero no siempre sean llevadas al aula de L2. El análisis de los ítems del cuestionario nos ha llevado a la conclusión de que no siempre estas actitudes se corresponden con las prácticas de aula.

Examinamos la variable 17d: "Utilidad de la corrección de errores y del feedback" por cuanto que ayude al alumno a ver dichos errores no como algo negativo sino como indicador de su progreso en el proceso de aprendizaje en relación con la edad de los informantes.

La Tabla 65 muestra las pruebas de chi-cuadrado "Edad" * "Utilidad de la corrección de errores y del feedback" [le ayude a ver los errores no como algo negativo sino como indicador de su progreso en el proceso de aprendizaje]* "Grupo".

\begin{tabular}{|l|l|c|c|c|}
\hline \multicolumn{2}{|l|}{ Grupo } & Valor & gl & p \\
\hline Valladolid & Chi-cuadrado de Pearson & ---- & ---- & --- \\
\hline Austin & Chi-cuadrado de Pearson & 0,860 & 2 &, 650 \\
\hline Total & Chi-cuadrado de Pearson & 1,053 & 2 &, 591 \\
\hline
\end{tabular}

Tabla 65. Pruebas de chi-cuadrado "Edad" * "Utilidad de la corrección de errores y del feedback" [le ayude a ver los errores no como algo negativo sino como indicador de su progreso en el proceso de aprendizaje]* "Grupo" 
Según podemos observar en la Tabla 65 las variables implicadas no indican un grado de asociación significativo para el caso de Austin ni para la muestra total (en todos los casos, p > .05). Respecto al caso Valladolid, nos encontramos ante una constante puesto que todos los participantes han contestado "útil". Así es como, no se realiza la prueba chi-cuadrado para este grupo.

A continuación, nos disponemos a examinar la siguiente tabla de contingencia (Tabla 66) para las variables "Edad" * "Utilidad de la corrección de errores y del feedback" [le ayude a ver los errores no como algo negativo sino como indicador de su progreso en el proceso de aprendizaje]* "Grupo". 


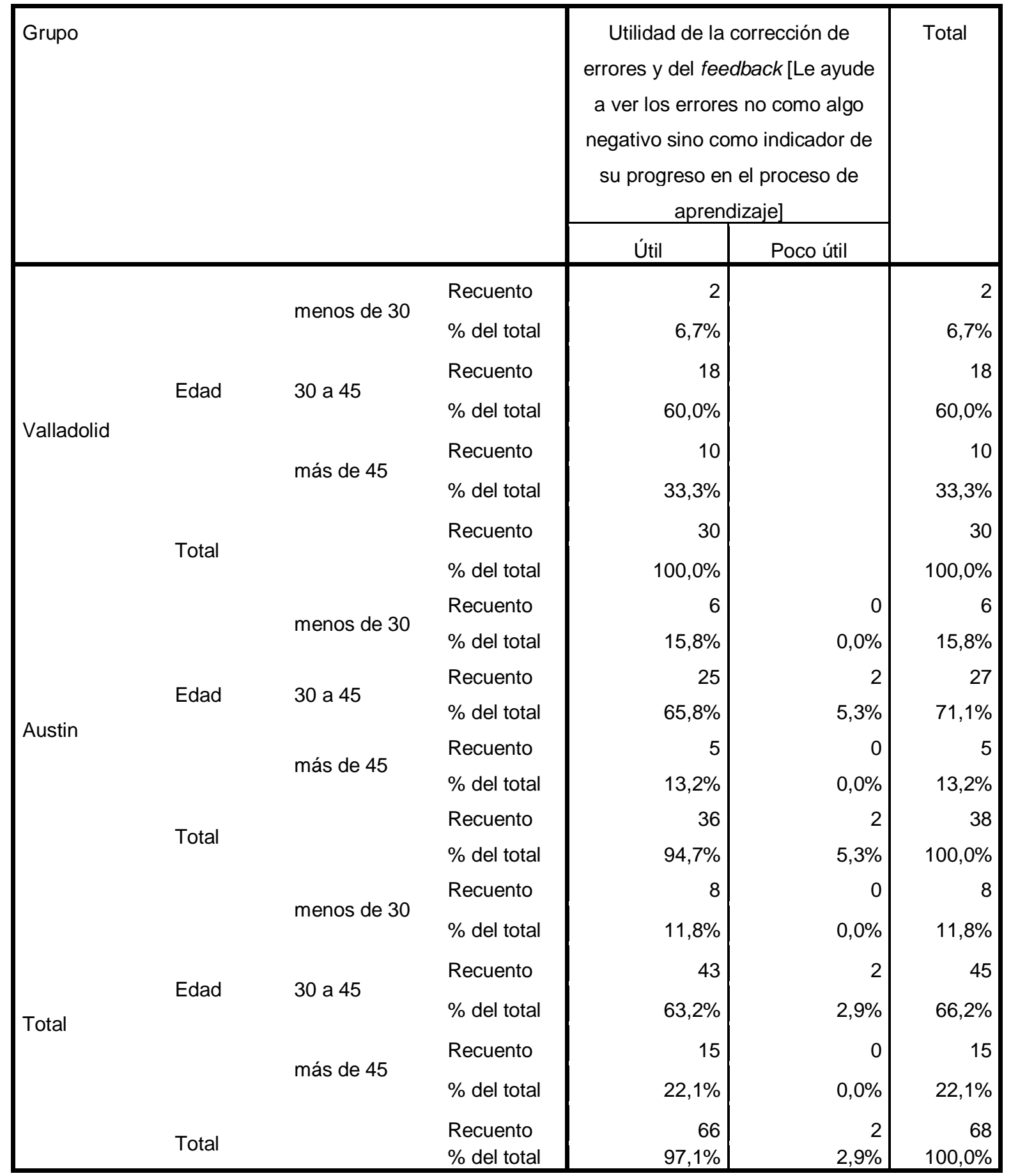

Tabla 66. Tabla de contingencia "Edad" * "Utilidad de la corrección de errores y del feedback" [le ayude a ver los errores no como algo negativo sino como indicador de su progreso en el proceso de aprendizaje]* "Grupo"

Tras estudiar la presente tabla (Tabla 66) estimamos que no existe una asociación estadísticamente significativa y, en este sentido, para los dos contextos educativos (Valladolid y Austin) e independientemente de la edad, la mayoría de informantes reconocen que la corrección 
de errores y el feedback es útil para que el alumno sea consciente de su propio proceso de enseñanza-aprendizaje. En el caso de Valladolid nos encontramos ante una constante ya que el 100\% elige la opción “útil”. En el caso de Austin, el porcentaje es muy similar, un 94,7\% declara que es útil y solamente encontramos la presencia de dos informantes de la ciudad de Austin (que forman un total del 5,3\%) entre 30 y 45 años que consideran que la corrección de errores y el feedback son "poco útiles" y que, por tanto, no ayudan al alumno a que sea consciente de su propio proceso de enseñanza-aprendizaje. Nos encontramos ante porcentajes prácticamente idénticos. Dichos porcentajes son totales y por tanto hacen referencia al número de participantes dentro de cada categoría para cada contexto educativo y la muestra total.

Los siguientes gráficos de barras agrupadas (Gráfico 65 y 66) representan los datos expuestos y aportan una explicación de forma gráfica:

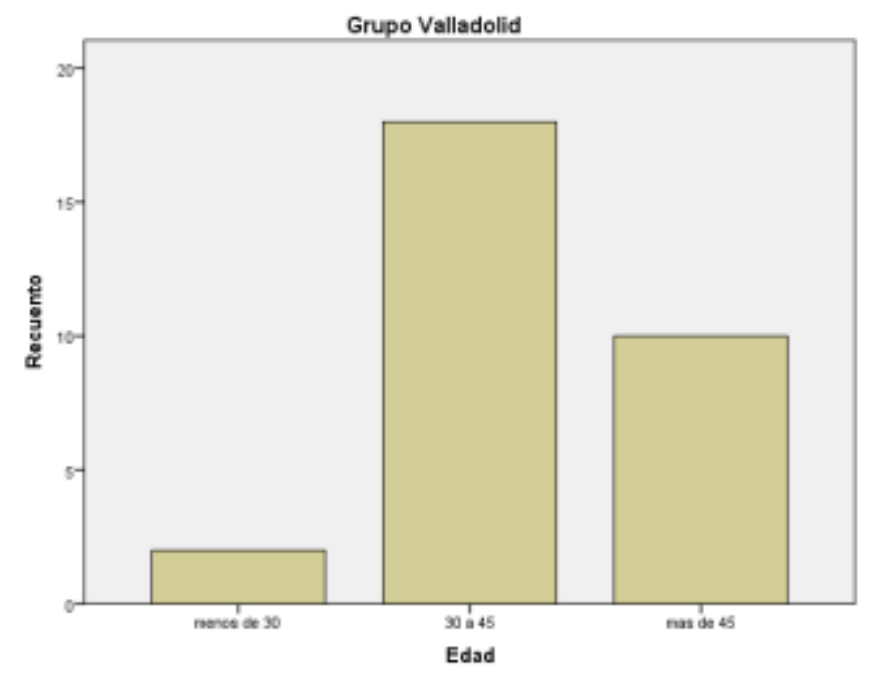

Gráfico 65. Recuento Edad - Utilidad de la corrección de errores y del feedback" [le ayude a ver los errores no como algo negativo sino como indicador de su progreso en el proceso de aprendizaje] - Grupo Valladolid 


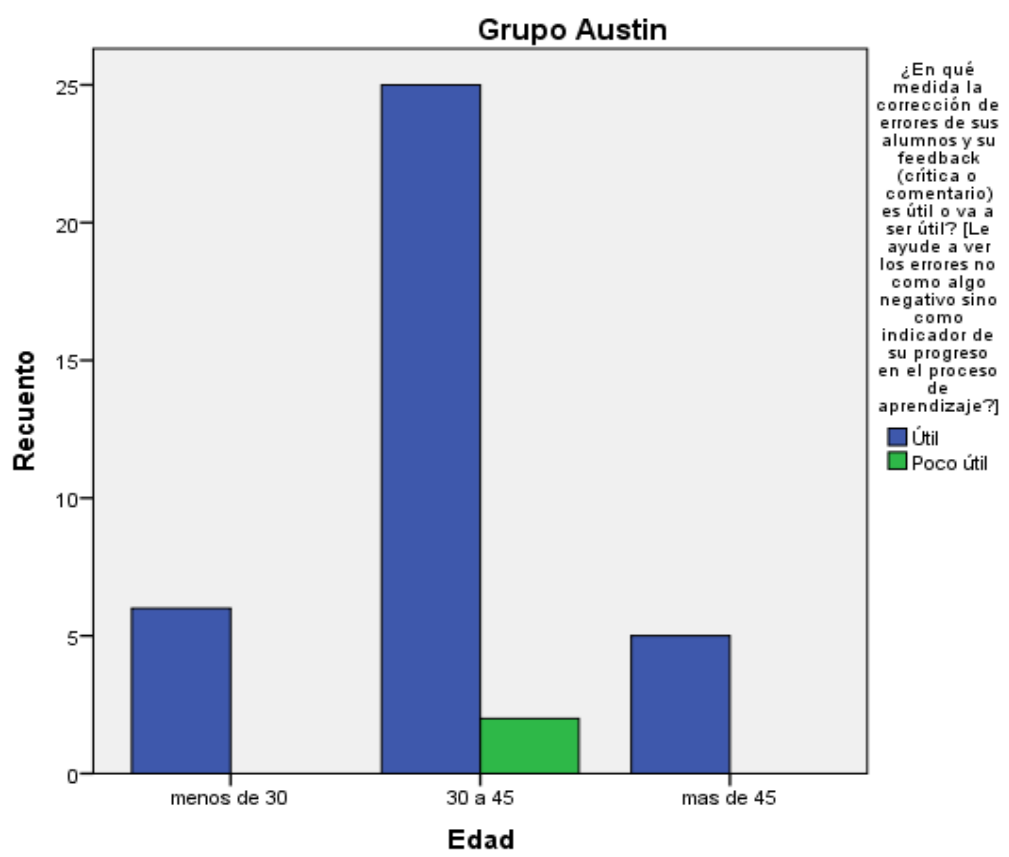

Gráfico 66. Recuento Edad - Utilidad de la corrección de errores y del feedback" [le ayude a ver los errores no como algo negativo sino como indicador de su progreso en el proceso de aprendizaje] - Grupo Austin

Estos gráficos (65 y 66) indican que los participantes del contexto educativo de Valladolid apuestan de forma unánime por el uso de un feedback que ayude al alumno a considerar los errores como una muestra de progreso en el aprendizaje de la L2 (como proponíamos en el epígrafe 9.4.1) o como una muestra de que "l'aprentissage se fait" (Gallison \& Coste, 1982, p. 216) autores a los que hacíamos referencia en el epígrafe 1.1.1. Por su parte, los sujetos del contexto educativo de Austin, también reconocen que el feedback puede ser un instrumento de provecho por cuanto que se revela como un instrumento de evaluación del propio aprendizaje del alumno. 


\subsubsection{Actitudes ante la posible utilidad de la corrección de errores y el feedback en relación con el curso}

En el presente subepígrafe nos disponemos a estudiar las actitudes de nuestros informantes ante la posible utilidad de la corrección de errores y el feedback en relación con el curso escolar en el que ejercen su actividad docente. La variable "Utilidad de la corrección de errores y del feedback" presenta cuatro subdivisiones, como ya venimos apuntando (17a, 17b, 17c y 17d) que vendrán representadas por cuatro tablas de pruebas chi-cuadrado, cuatro tablas de contingencia y ocho gráficos de barras agrupadas (dos para cada una de las cuatro variables).

Analizamos la primera variable: "17a. Utilidad de la corrección de errores y del feedback" para ayudar al alumno a ser consciente de su propio proceso de aprendizaje en relación con el curso escolar que imparten los informantes.

En la tabla que se muestra a continuación (Tabla 67) se exponen las pruebas de chi-cuadrado "Curso" * "Utilidad de la corrección de errores y del feedback" [para que el alumno sea consciente de su propio proceso de aprendizaje]* "Grupo". 


\begin{tabular}{|l|l|c|c|c|}
\hline \multicolumn{2}{|l|}{ Grupo } & Valor & gl & $\mathrm{p}$ \\
\hline Valladolid & Chi-cuadrado de Pearson & ---- & --- & --- \\
\hline Austin & Chi-cuadrado de Pearson &, 552 & 1 &, 457 \\
\hline Total & Chi-cuadrado de Pearson &, $414^{\mathrm{a}}$ & 1 &, 520 \\
\hline
\end{tabular}

Tabla 67. Pruebas de chi-cuadrado "Curso" * "Utilidad de la corrección de errores y del feedback" [para que el alumno sea consciente de su propio proceso de aprendizaje]* "Grupo"

Las variables implicadas que encontramos en la Tabla 67 no muestran un grado de asociación significativo para el caso de Austin ni para la muestra total (en todos los casos, $\mathrm{p}>.05$ ). Dado que en Valladolid nos encontramos ante una constante puesto que todos los participantes consideran que la corrección de errores y feedback son "útiles", no se realiza la prueba chi-cuadrado para este grupo.

A partir de aquí, confeccionamos la siguiente tabla de contingencia (Tabla 68) para las variables "Curso" * "Utilidad de la corrección de errores y del feedback" [para que el alumno sea consciente de su propio proceso de aprendizaje]* "Grupo". 


\begin{tabular}{|c|c|c|c|c|c|c|}
\hline \multirow[t]{2}{*}{ Grupo } & & & & \multicolumn{2}{|c|}{$\begin{array}{l}\text { Utilidad de la corrección de } \\
\text { errores y del feedback [Para que } \\
\text { el alumno sea consciente de su } \\
\text { propio proceso de aprendizaje] }\end{array}$} & \multirow[t]{2}{*}{ Total } \\
\hline & & & & Útil & Poco útil & \\
\hline \multirow{6}{*}{ Valladolid } & \multirow{4}{*}{ Curso } & \multirow{3}{*}{$1^{\circ}$ a $3^{\circ}$} & Recuento & 6 & & 6 \\
\hline & & & $\%$ del total & $20,7 \%$ & & $20,7 \%$ \\
\hline & & & Recuento & 23 & & 23 \\
\hline & & $4^{\circ}$ a $6^{\circ}$ & $\%$ del total & $79,3 \%$ & & $79,3 \%$ \\
\hline & \multirow{2}{*}{ Total } & \multirow{4}{*}{$1^{\circ}$ a $3^{\circ}$} & Recuento & 29 & & 29 \\
\hline & & & $\%$ del total & $100,0 \%$ & & $100,0 \%$ \\
\hline \multirow{6}{*}{ Austin } & \multirow{4}{*}{ Curso } & & Recuento & 14 & 0 & 14 \\
\hline & & & $\%$ del total & $35,0 \%$ & $0,0 \%$ & $35,0 \%$ \\
\hline & & $40 \bigcirc$ & Recuento & 25 & 1 & 26 \\
\hline & & 4 a & $\%$ del total & $62,5 \%$ & $2,5 \%$ & $65,0 \%$ \\
\hline & Total & & Recuento & 39 & 1 & 40 \\
\hline & & \multirow{3}{*}{$1^{\circ}$ a $3^{\circ}$} & $\%$ del total & $97,5 \%$ & $2,5 \%$ & $100,0 \%$ \\
\hline \multirow{6}{*}{ Total } & \multirow{4}{*}{ Curso } & & Recuento & 20 & 0 & 20 \\
\hline & & & $\%$ del total & $29,0 \%$ & $0,0 \%$ & $29,0 \%$ \\
\hline & & & Recuento & 48 & 1 & 49 \\
\hline & & $4=\mathrm{do}^{-}$ & $\%$ del total & $69,6 \%$ & $1,4 \%$ & $71,0 \%$ \\
\hline & \multirow{2}{*}{ Total } & & Recuento & 68 & 1 & 69 \\
\hline & & & $\%$ del total & $98,6 \%$ & $1,4 \%$ & $100,0 \%$ \\
\hline
\end{tabular}

Tabla 68. Tabla de contingencia "Curso" * "Utilidad de la corrección de errores y del feedback" [para que el alumno sea consciente de su propio proceso de aprendizaje]* "Grupo"

De acuerdo con los datos de la Tabla 68 apreciamos que no existe una asociación estadísticamente significativa. La mayor parte de los informantes de los dos contextos educativos que enseñan distintos cursos escolares reconocen la utilidad de la corrección de errores y del feedback para que el alumno sea consciente de su propio proceso de aprendizaje. Los datos de Valladolid presentan una constante (el 100\% elige la opción “útil”). Respecto a la ciudad de Austin, nos encontramos ante resultados prácticamente idénticos ya que un 97,5\% declara que es útil y solamente encontramos la presencia de dos informantes de este contexto educativo (el 2,5\% 
del total) que afirman que la corrección de errores y el feedback son "poco útiles" y que, por tanto, no ayudan al alumno a que sea consciente de su propio proceso de aprendizaje. Estos dos informantes se encuentran ejerciendo su actividad docente entre $1^{\circ}$ y $3^{\circ}$ y entre $4^{\circ}$ y $6^{\circ}$. Volvemos a encontrarnos ante porcentajes muy similares. Estos, como ya hemos venido mencionando, hacen referencia al número de participantes dentro de cada categoría para cada contexto educativo y la muestra total.

A partir de los gráficos de barras agrupadas (Gráficos 67 y 68) que aparecen a continuación se puede reflexionar sobre los datos presentados.

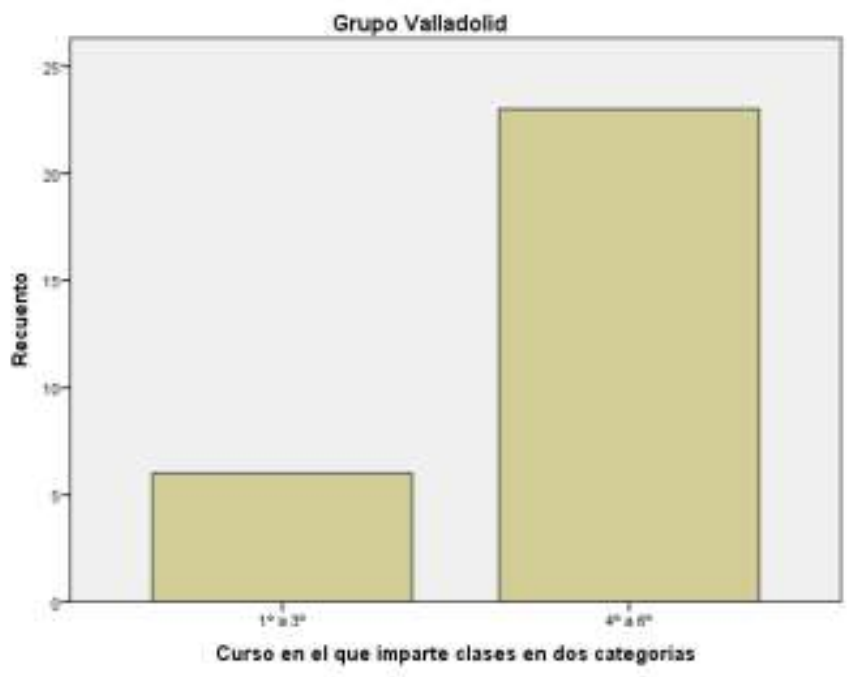

Gráfico 67. Recuento curso - Utilidad de la corrección de errores y del feedback” [para que el alumno sea consciente de su propio proceso de aprendizaje] - Grupo Valladolid 


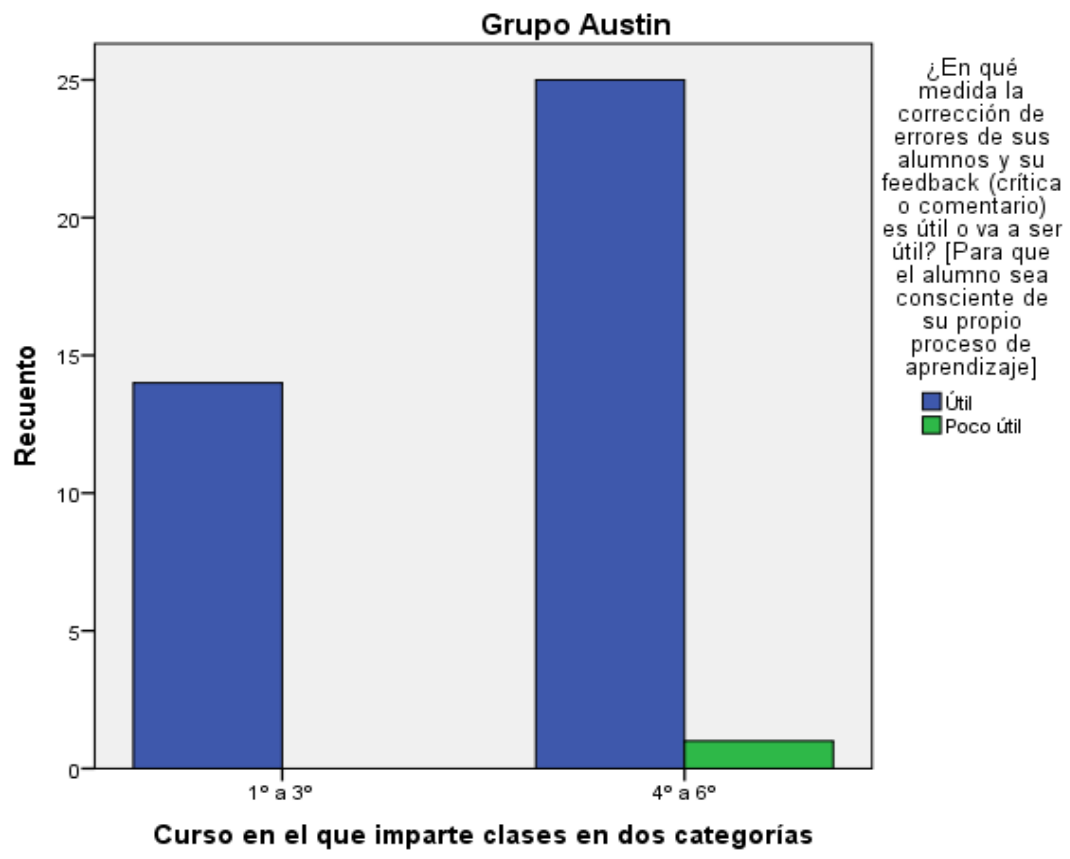

Gráfico 68. Recuento Curso - Utilidad de la corrección de errores y del feedback” [para que el alumno sea consciente de su propio proceso de aprendizaje] - Grupo Austin

Los datos obtenidos en los gráficos 67 y 68 nos permiten afirmar que prácticamente todos los informantes (todos los que conforman el contexto educativo de Valladolid y prácticamente todos los que constituyen el contexto de Austin) reconocen la utilidad del feedback por ayudar a que el alumno sea consciente de su propio proceso de aprendizaje de la L2.

Tras comprobar que los datos relativos a los dos contextos educativos son muy semejantes, podemos afirmar que, el curso en el que los informantes ejercen su labor docente no plantea ninguna diferencia respecto a sus respuestas. Por lo tanto, aquellos profesores que desarrollan su docencia en los cursos de $1^{\circ}$ a $3^{\circ}$ y aquellos que lo hacen de $4^{\circ}$ a $6^{\circ}$ (en los dos contextos) manifiestan su confianza hacia el feedback como un instrumento didáctico muy eficaz por ayudar a que el alumno pueda ser consciente de su propio proceso de aprendizaje. 
En segundo lugar, nos disponemos a analizar la segunda variable: "17b. Utilidad de la corrección de errores y del feedback" en la medida en que estos permitan al alumno establecer conexiones entre su lengua materna y la L2 en relación con el curso escolar en el que los informantes imparten la L2.

Para ello, elaboramos la siguiente tabla (Tabla 69) que contiene las pruebas de chi-cuadrado “Curso" * "Utilidad de la corrección de errores y del feedback" [le permita establecer conexiones entre su lengua materna y la L2]* "Grupo".

\begin{tabular}{|l|l|c|c|c|}
\hline Grupo & Valor & gl & $\mathrm{p}$ \\
\hline Castilla-León & Chi-cuadrado de Pearson &, $248^{\mathrm{c}}$ & 1 &, 619 \\
\hline Austin & Chi-cuadrado de Pearson &, $230^{\mathrm{d}}$ & 1 &, 632 \\
\hline Total & Chi-cuadrado de Pearson &, $127^{\mathrm{a}}$ & 1 &, 721 \\
\hline
\end{tabular}

Tabla 69. Pruebas de chi-cuadrado "Curso" * "Utilidad de la corrección de errores y del feedback" [le permita establecer conexiones entre su lengua materna y la L2]* "Grupo"

En la Tabla 69 observamos que no existe relación significativa entre el curso en que enseñan L2 los participantes y la utilidad de la corrección de errores y del feedback en la medida en que estos permitan al alumno establecer conexiones entre su lengua materna y la L2 (en todos los casos, $\mathrm{p}>.05)$.

La siguiente tabla de contingencia (Tabla 70) se calcula para las variables "Curso" * "Utilidad de la corrección de errores y del feedback" [le permita establecer conexiones entre su lengua materna y la L2]* “Grupo". 


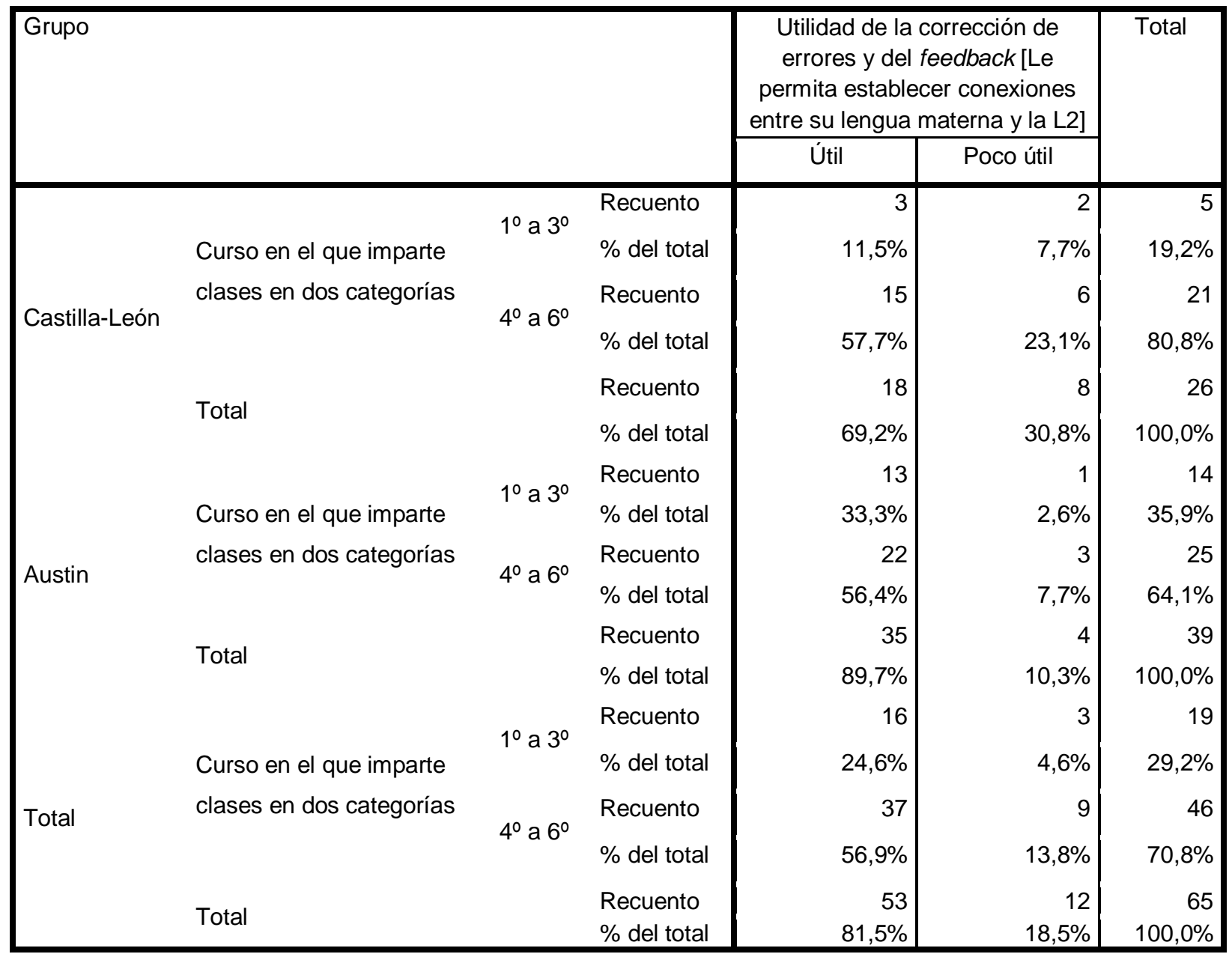

Tabla 70. Tabla de contingencia "Curso" * "Utilidad de la corrección de errores y del feedback" [le permita establecer conexiones entre su lengua materna y la L2]* "Grupo"

De acuerdo con los datos analizado en la Tabla 70 no existe una relación estadísticamente significativa entre las variables. Por tanto, podemos afirmar que, independientemente del contexto educativo (Valladolid o Austin) y del curso en el que enseñan L2 la mayor parte de los informantes consideran que la corrección de errores y el feedback es útil por cuanto que ayudan a que el alumno pueda establecer conexiones entre su lengua materna y la L2. Tanto en el contexto de Valladolid como en el de Austin encontramos una mayoría de informantes que reconocen la utilidad de la corrección y del feedback. Sin embargo, encontramos una ligera diferencia entre ambos. Así es como, en Valladolid el porcentaje que elige la opción "útil" es el 69,2\% y un 30,8\% afirma que 
son "poco útiles". Por su parte, en la ciudad de Austin un 89,7\% elige la respuesta "útil" y solamente un 10,5\% se inclina por la opción "poco útil”.

Observamos que los informantes vallisoletanos son aquellos que eligen en una proporción más alta la opción "poco útil". A pesar de encontrarnos ante porcentajes similares (lo cual nos lleva a afirmar que nuestros informantes, de forma general, reconocen la utilidad de la corrección y del feedback por cuanto que estos favorecen las conexiones entre la lengua materna y la L2 del alumno) existe un porcentaje significativo de informantes de Valladolid (30,8\%) que no reconoce dicha utilidad. Dentro de dicho porcentaje existe una proporción considerable de participantes que ejercen la docencia en los cursos más bajos: de $1^{\circ}$ a $3^{\circ}$ de Educación Primaria. En este sentido, podríamos afirmar que, aunque muchos de ellos muestran su acuerdo reconociendo la utilidad de la corrección y del feedback, destacamos la existencia de un tercio de informantes de Valladolid que no lo hace.

En cuanto a participación de los informantes en esta respuesta nos encontramos ante $\mathrm{n}=$ 26 docentes (de los 33 que representan la muestra total de Valladolid) y a $n=39$ (de los 40 informantes que forman el $100 \%$ de la muestra total de Austin) formando un total de $\mathrm{N}=65$ informantes.

Los siguientes gráficos de barras agrupadas (gráficos 69 y 70) reflejan de forma gráfica los resultados comentados. 


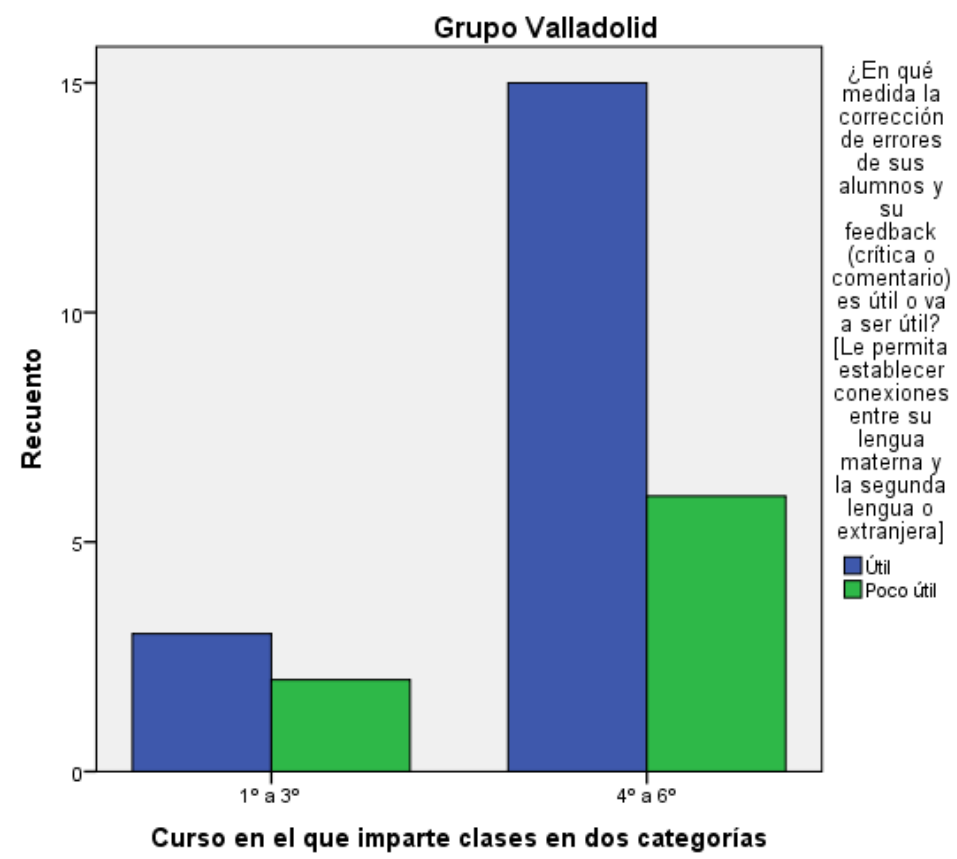

Gráfico 69. Recuento Curso - Utilidad de la corrección de errores y del feedback" [le permita establecer conexiones entre su lengua materna y la L2]- Grupo Valladolid

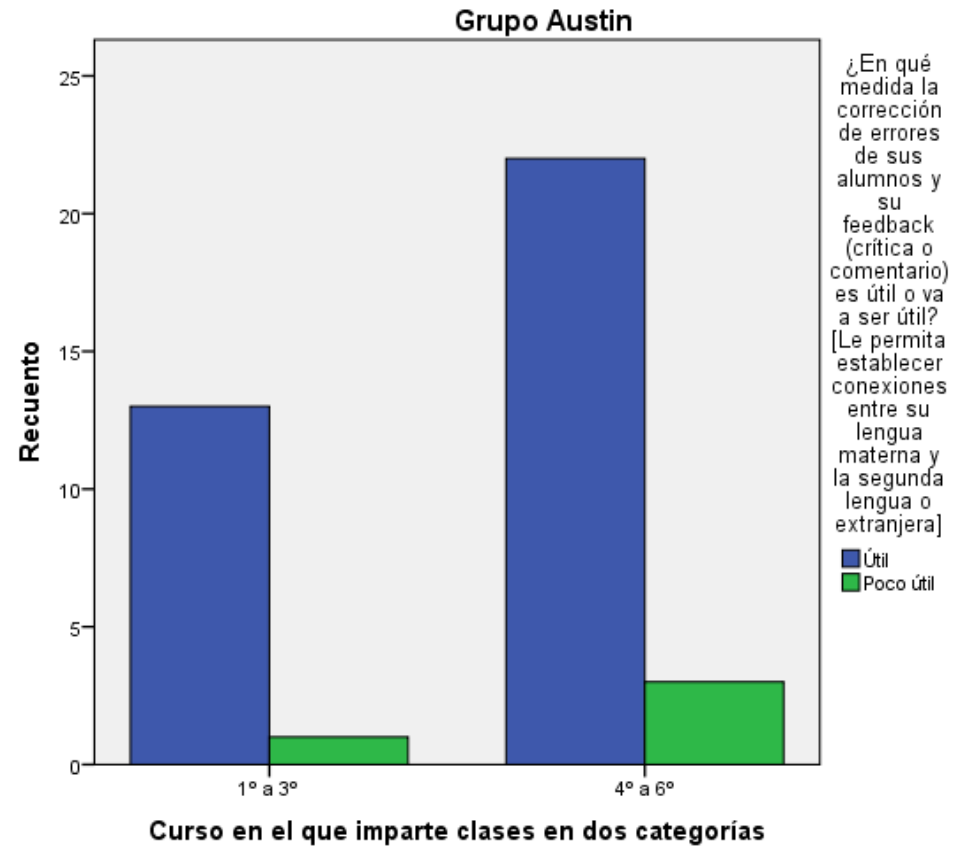

Gráfico 70. Recuento Curso - Utilidad de la corrección de errores y del feedback” [le permita establecer conexiones entre su lengua materna y la L2]- Grupo Austin 
En los gráficos 69 y 70 observamos que, la mayor parte de los informantes del contexto de Valladolid reconoce la utilidad del feedback por cuanto que permite que el alumno pueda establecer conexiones entre su lengua materna y la L2. No obstante, un porcentaje de estos sujetos (entre estos, una proporción importante de aquellos que ejercen su actividad docente en los cursos inferiores: de $1^{\mathrm{o}}$ a $3^{\circ}$ de Educación Primaria) no reconoce dicha utilidad.

En contraposición, la mayor parte de los informantes del contexto educativo de Austin (independientemente del curso en el que se encuentren ejerciendo su docencia) aceptan la utilidad del feedback por cuanto que este puede ayudar al alumno a establecer conexiones entre la L1 y la L2.

Nos llama la atención el hecho de que los informantes del contexto español muestren sus dudas sobre el papel del feedback y resulta llamativo el hecho de que sean aquellos que imparten clases en cursos inferiores los que presentan dudas respecto a los beneficios del feedback en cuanto a sus producciones en L2 y a las conexiones con su L1. Nos atrevemos a suponer que los profesores de este contexto educativo (de forma particular, aquellos que enseñan en cursos inferiores) carecen de una formación respecto a la importancia del papel del feedback para que el alumno pueda conectar las dos lenguas.

A continuación, nos acercamos a la siguiente variable: “17c. Utilidad de la corrección de errores y del feedback" por cuanto que aporten al alumno información sobre cómo trabajar las distintas destrezas comunicativas. 
La Tabla 71 encierra las pruebas de chi-cuadrado "Curso" * "Utilidad de la corrección de errores y del feedback" [le aporte información sobre cómo trabajar las distintas destrezas comunicativas]* “Grupo".

\begin{tabular}{|l|l|c|c|c|}
\hline \multicolumn{2}{|l|}{ Grupo } & Valor & gl & $\mathrm{p}$ \\
\hline Castilla-León & Chi-cuadrado de Pearson & 0,283 & 1 &, 595 \\
\hline Austin & Chi-cuadrado de Pearson & 2,608 & 1 &, 106 \\
\hline Total & Chi-cuadrado de Pearson & $2,352^{\mathrm{a}}$ & 1 &, 125 \\
\hline
\end{tabular}

Tabla 71. Pruebas de chi-cuadrado "Curso" * "Utilidad de la corrección de errores y del feedback" [le aporte información sobre cómo trabajar las distintas destrezas comunicativas]* "Grupo"

De acuerdo con los datos, no existe relación significativa entre el curso en que enseñan L2 los participantes y la utilidad de la corrección de errores y del feedback en la medida en que le aporten información sobre cómo trabajar las distintas destrezas comunicativas (en todos los casos, $\mathrm{p}>.05)$

La siguiente tabla de contingencia (Tabla 72) se calcula para las variables "Curso" * "Utilidad de la corrección de errores y del feedback" [le permita establecer conexiones entre su lengua materna y la L2]* "Grupo". 


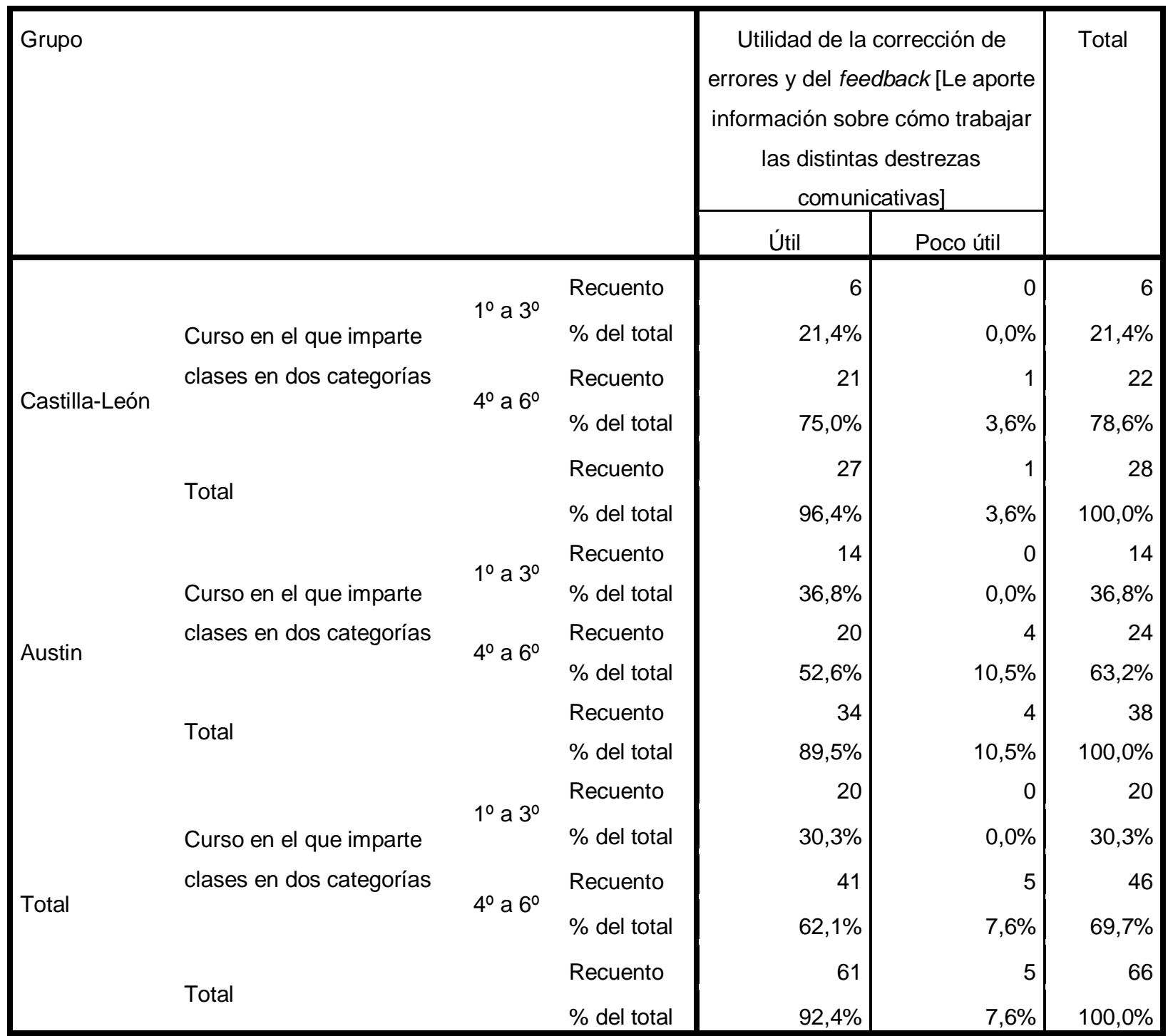

Tabla 72. Tabla de contingencia "Curso" * "Utilidad de la corrección de errores y del feedback" [le aporte información sobre cómo trabajar las distintas destrezas comunicativas]* "Grupo"

Como podemos observar en la Tabla 72 no existe una relación estadísticamente significativa entre las variables. Nos atrevemos por tanto a afirmar que, independientemente del contexto educativo (Valladolid o Austin) y del curso en el que enseñan L2 la mayoría de los informantes consideran que la corrección de errores y el feedback es útil y, en este sentido, le aportan información que le ayudará a trabajar las distintas destrezas comunicativas. 
Nos encontramos ante un 96,4\% que elige la opción "útil” y un 3,6\% que elige la respuesta contraria en Valladolid. En la ciudad de Austin un 89,5\% considera que estos son "útiles" respecto al 10,5\% que los reconocen como "poco útiles".

Así es como, los informantes vallisoletanos eligen en una proporción más alta la opción "útil”" respecto a los de Austin, aunque la diferencia no es significativa. Por otro lado, observamos que ninguno de los participantes que enseñan en los cursos inferiores (de $1^{\circ}$ a $3^{\circ}$ ) elige la opción "poco útil" tanto en un contexto como en el otro. Esto nos permite afirmar que, aunque la mayoría muestra su acuerdo respecto a la utilidad de la corrección de errores y del feedback en cuanto a aportar información al alumno y ayudarle a trabajar las destrezas comunicativas en su L2, de forma particular, los informantes que enseñan $1^{\circ}$ a $3^{\circ}$ tanto en Valladolid como en Austin son los que muestran su apoyo absoluto hacia dicha respuesta.

El número de participantes en esta respuesta es de $n=28$ docentes (de los 33 que representan la muestra total de Valladolid) y n $=38$ (de los 40 informantes que forman el 100\% de la muestra de Austin) formando un total de $\mathrm{N}=66$ informantes.

En los Gráficos 71 y 72 que aparecen a continuación se muestran los resultados comentados de forma gráfica. 


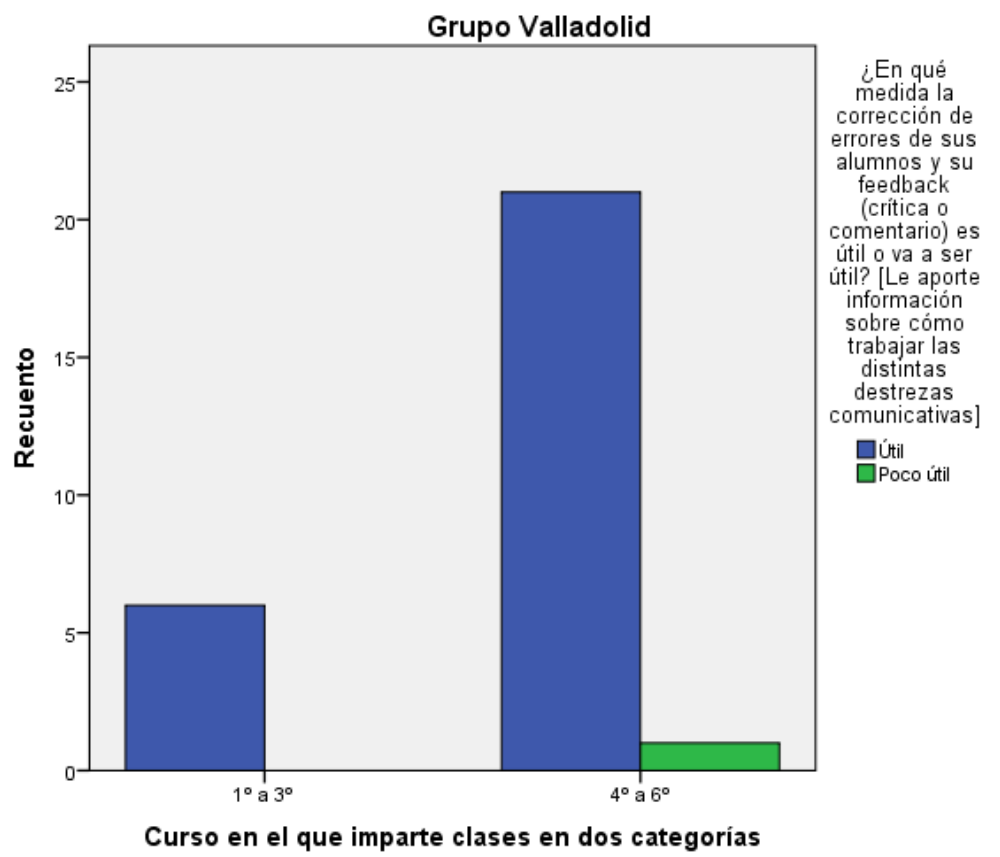

Gráfico 71. Recuento Curso - Utilidad de la corrección de errores y del feedback” [le aporte información sobre cómo trabajar las distintas destrezas comunicativas]- Grupo Valladolid

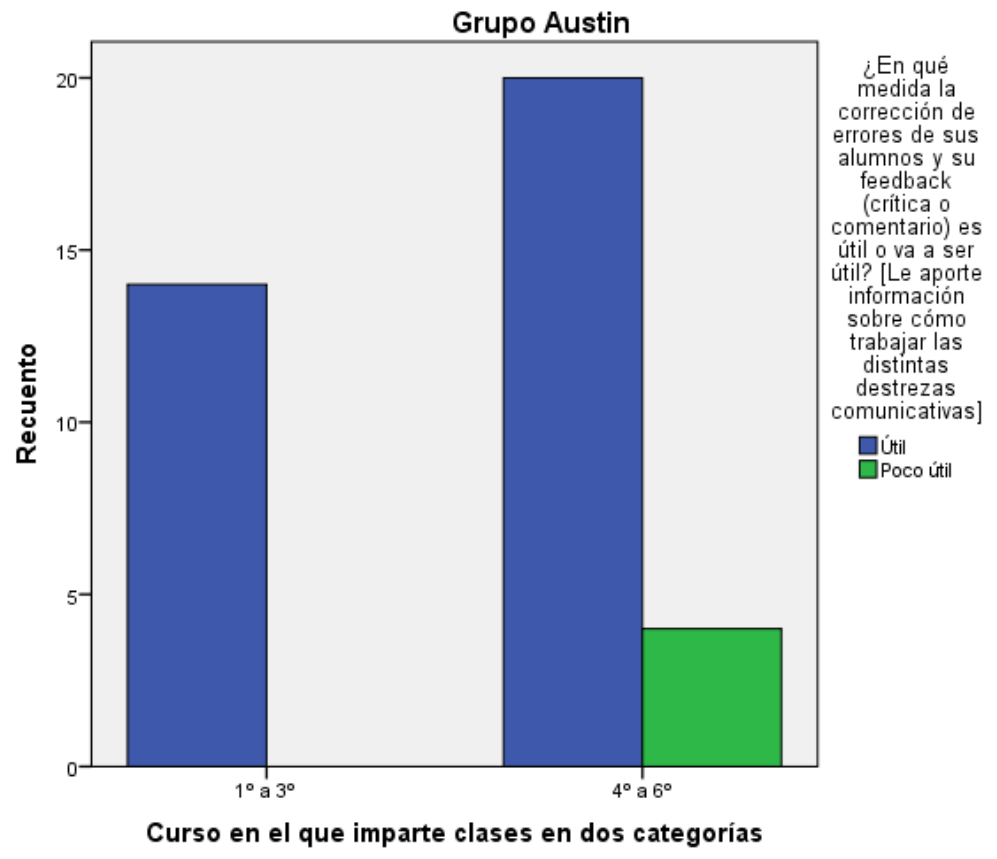

Gráfico 72. Recuento Curso - Utilidad de la corrección de errores y del feedback” [le aporte información sobre cómo trabajar las distintas destrezas comunicativas]- Grupo Austin 
En los que respecta a la información de los gráficos 71 y 72 encontramos una actitud positiva generalizada tanto por parte de los sujetos de Valladolid como por los de Austin. Así es como, la gran mayoría entiende el concepto de feedback como un instrumento que permite aportar información al alumno sobre cómo trabajar las destrezas comunicativas.

Nos llama la atención el hecho de que, de forma particular, los profesores de $1^{\circ}$ a $3^{\circ}$ de Primaria (por parte de los dos contextos educativos) elijan de forma unánime la opción "útil”. Es posible que la utilidad del feedback respecto a aportar información a los alumnos sobre las destrezas comunicativas sea más visible en los niveles inferiores respecto a los superiores.

A partir de estas afirmaciones observamos que, a nivel declarativo, la mayor parte de los sujetos presenta actitudes de confianza hacia el feedback. Sin embargo, como ya venimos apuntando, podríamos encontrarnos ante "actitudes simuladas" que no siempre corresponden con la realidad del aula.

Finalmente, nos acercamos a la variable: "17d. Utilidad de la corrección de errores y del feedback" por cuanto que ayuden al alumno a ver los errores no como algo negativo sino como indicador de su propio proceso de aprendizaje.

En la Tabla 73 que aparece a continuación se exponen las pruebas de chi-cuadrado "Curso" * "Utilidad de la corrección de errores y del feedback" [le ayude a ver los errores no como algo negativo sino como indicador de su propio proceso de aprendizaje]* "Grupo”. 


\begin{tabular}{|l|l|c|c|c|}
\hline \multicolumn{2}{|l|}{ Grupo } & Valor & $\mathrm{gl}$ & $\mathrm{p}$ \\
\hline Castilla-León & Chi-cuadrado de Pearson & ---- & --- & --- \\
\hline Austin & Chi-cuadrado de Pearson & 1,181 & 1 &, 277 \\
\hline Total & Chi-cuadrado de Pearson & 0,841 & 1 &, 359 \\
\hline
\end{tabular}

Tabla 73. Pruebas de chi-cuadrado "Curso" * "Utilidad de la corrección de errores y del feedback" [le ayude a ver los errores no como algo negativo sino como indicador de su propio proceso de aprendizaje]* "Grupo"

A partir de las pruebas de chi-cuadrado (Tabla 73) observamos que no existe relación significativa entre el curso en que enseñan L2 los participantes y la utilidad de la corrección de errores y del feedback en la medida en que ayuden al alumno a ver los errores no como algo negativo sino como indicador de su propio proceso de aprendizaje (en todos los casos, $\mathrm{p}>.05$ ).

Se realiza la siguiente tabla de contingencia (Tabla 74) para las variables "Curso" * "Utilidad de la corrección de errores y del feedback" [le ayude a ver los errores no como algo negativo sino como indicador de su propio proceso de aprendizaje]* "Grupo". 


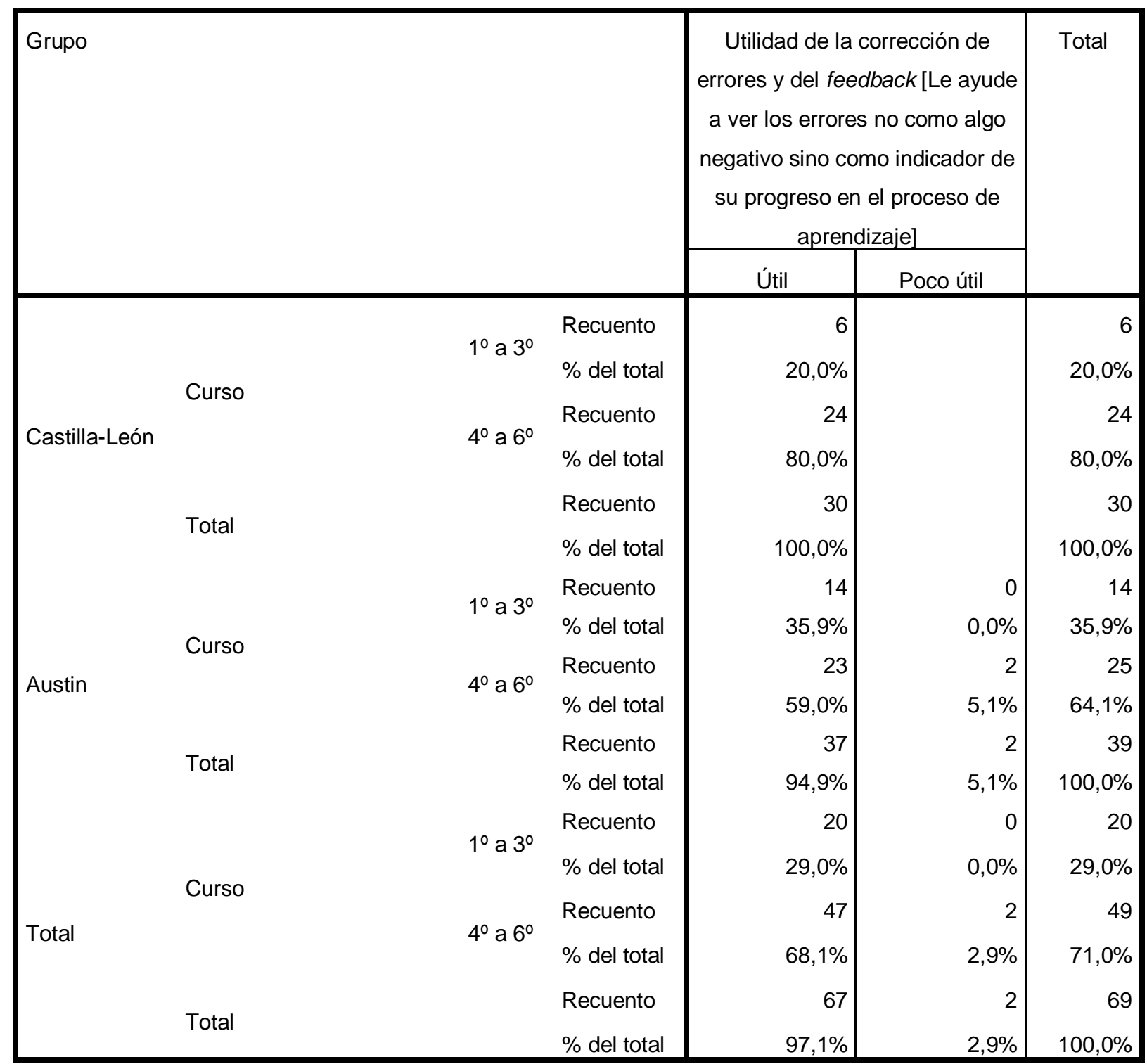

Tabla 74. Tabla de contingencia "Curso" * "Utilidad de la corrección de errores y del feedback" [le ayude a ver los errores no como algo negativo sino como indicador de su propio proceso de aprendizaje]* "Grupo"

A partir de los datos presentados en la Tabla 74 podemos afirmar que no existe una asociación estadísticamente significativa. Casi todos los informantes de los dos contextos educativos, independientemente del curso escolar en el que ejercen su docencia reconocen la utilidad de la corrección de errores y del feedback puesto que ayudan al alumno a ver los errores no como algo negativo sino como indicador de su propio proceso de aprendizaje. Los datos de Valladolid presentan una constante (el 100\% elige la opción "útil”) y los de la ciudad de Austin son prácticamente 
idénticos. En este sentido, un 94,9\% declara que son útiles y solamente encontramos la presencia de dos informantes de Austin (el 2,9\% del total) ejerciendo su actividad docente entre $4^{\circ}$ y $6^{\circ}$ que afirman que la corrección de errores y el feedback son "poco útiles” y que, por tanto, no ayudan al alumno a que sea consciente de su propio proceso de aprendizaje. Nos encontramos, por tanto, ante porcentajes similares.

A partir de los gráficos de barras agrupadas (Gráficos 73 y 74) que aparecen a continuación se puede reflexionar sobre los datos presentados.

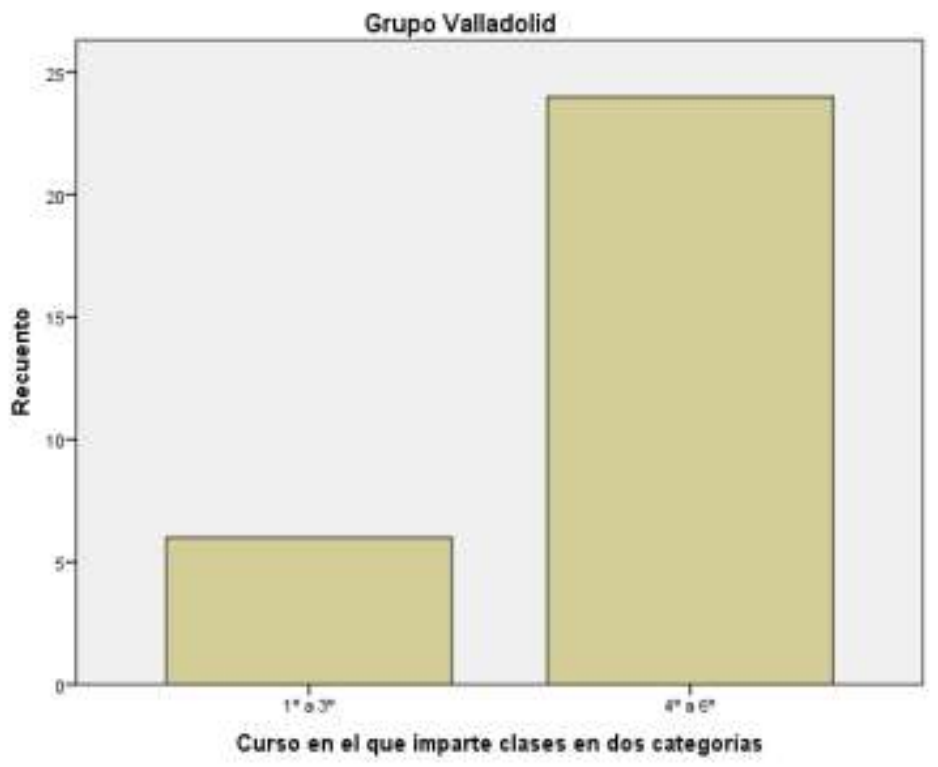

Gráfico 73. Recuento Curso - Utilidad de la corrección de errores y del feedback" [le ayude a ver los errores no como algo negativo sino como indicador de su propio proceso de aprendizaje]- Grupo Valladolid 


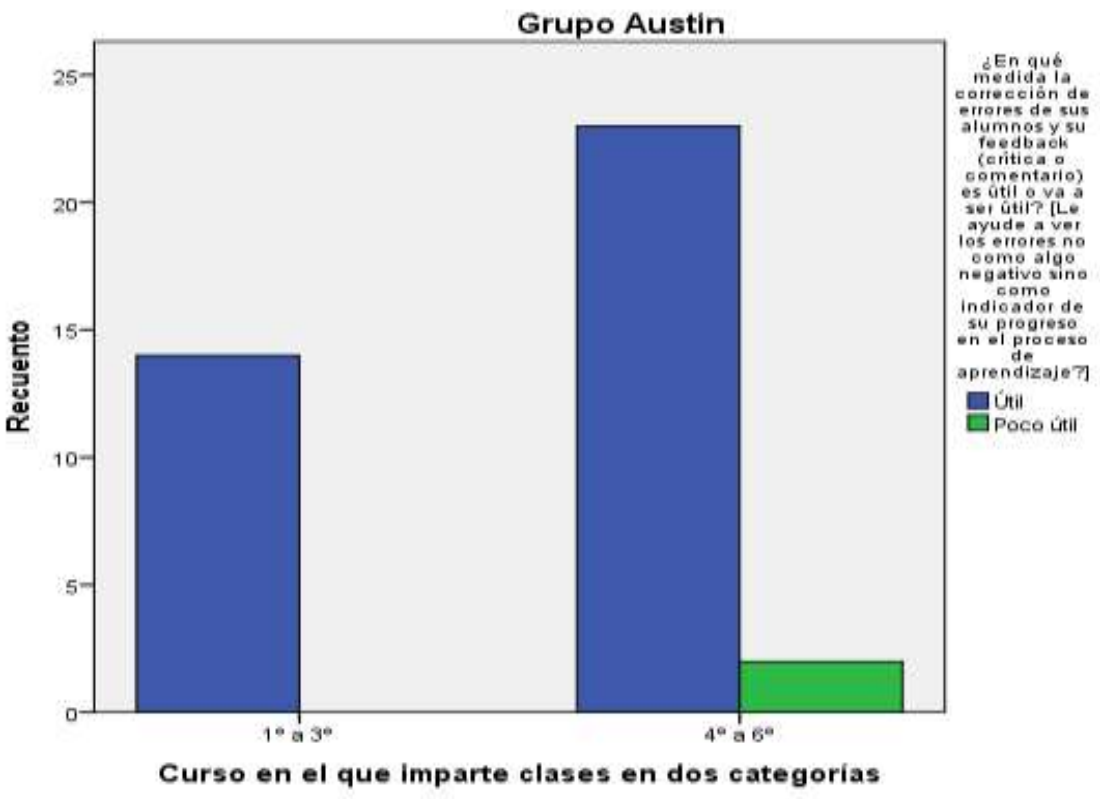

Gráfico 74. Recuento Curso - Utilidad de la corrección de errores y del feedback" [le ayude a ver los errores no como algo negativo sino como indicador de su propio proceso de aprendizaje]-Grupo Austin

Los gráficos 73 y 74 advierten que los sujetos de los dos contextos educativos coinciden en afirmar que el uso de una modalidad adecuada de feedback fomentará en el alumno actitudes positivas hacia el error favoreciendo que este entienda dicho concepto como una muestra de progreso en el aprendizaje de la L2. En el contexto de Valladolid lo reconocen de forma unánime, por su parte, los sujetos del contexto educativo de Austin lo hacen de manera mayoritaria, independientemente del curso educativo en el que se encuentren ejerciendo la docencia.

\subsubsection{Actitudes ante la posible utilidad de la corrección de errores y el feedback en relación con el número de alumnos}

El último subepígrafe está dedicado a analizar las actitudes de nuestros informantes ante la posible utilidad de la corrección de errores y el feedback en relación con el curso escolar en el 
que ejercen su actividad docente. La variable "Utilidad de la corrección de errores y del feedback" se presenta en cuatro subdivisiones (17a, 17b, 17c y 17d) representadas por cuatro tablas de pruebas chi-cuadrado, cuatro tablas de contingencia y ocho gráficos de barras agrupadas (dos para cada una de las cuatro variables).

La siguiente serie de análisis estadísticos cuantitativos se lleva a cabo con el propósito de valorar el grado de asociación entre la variable “17a. Utilidad de la corrección de errores y del feedback" en la perspectiva de que estos ayuden al alumno a que sea consciente de su propio proceso de aprendizaje en relación con el "Número de alumnos" que tienen los informantes.

En la tabla que se muestra a continuación (Tabla 75) se exponen las pruebas de chicuadrado "Número de alumnos" * "Utilidad de la corrección de errores y del feedback" [para que el alumno sea consciente de su propio proceso de aprendizaje]* “Grupo".

\begin{tabular}{|l|l|c|c|c|}
\hline \multicolumn{2}{|l|}{ Grupo } & Valor & gl & p \\
\hline Castilla-León & Chi-cuadrado de Pearson & ---- & --- & --- \\
\hline Austin & Chi-cuadrado de Pearson & 1,388 & 2 &, 500 \\
\hline Total & Chi-cuadrado de Pearson & 2,029 & 2 &, 363 \\
\hline
\end{tabular}

Tabla 75. Pruebas de chi-cuadrado "Número de alumnos" * "Utilidad de la corrección de errores y del feedback" [para que el alumno sea consciente de su propio proceso de aprendizaje]* "Grupo"

Las pruebas de chi-cuadrado (expuestas en la Tabla 75) demuestran que no existe relación significativa entre el número de alumnos que tienen los participantes y la utilidad de la corrección de errores y del feedback en la medida en que ayuden al alumno a que sea consciente de su propio proceso de aprendizaje (en todos los casos, $\mathrm{p}>.05$ ). 
La siguiente tabla de contingencia (Tabla 76) se lleva a cabo en función de las variables "Número de alumnos" * "Utilidad de la corrección de errores y del feedback" [para que el alumno sea consciente de su propio proceso de aprendizaje]* "Grupo".

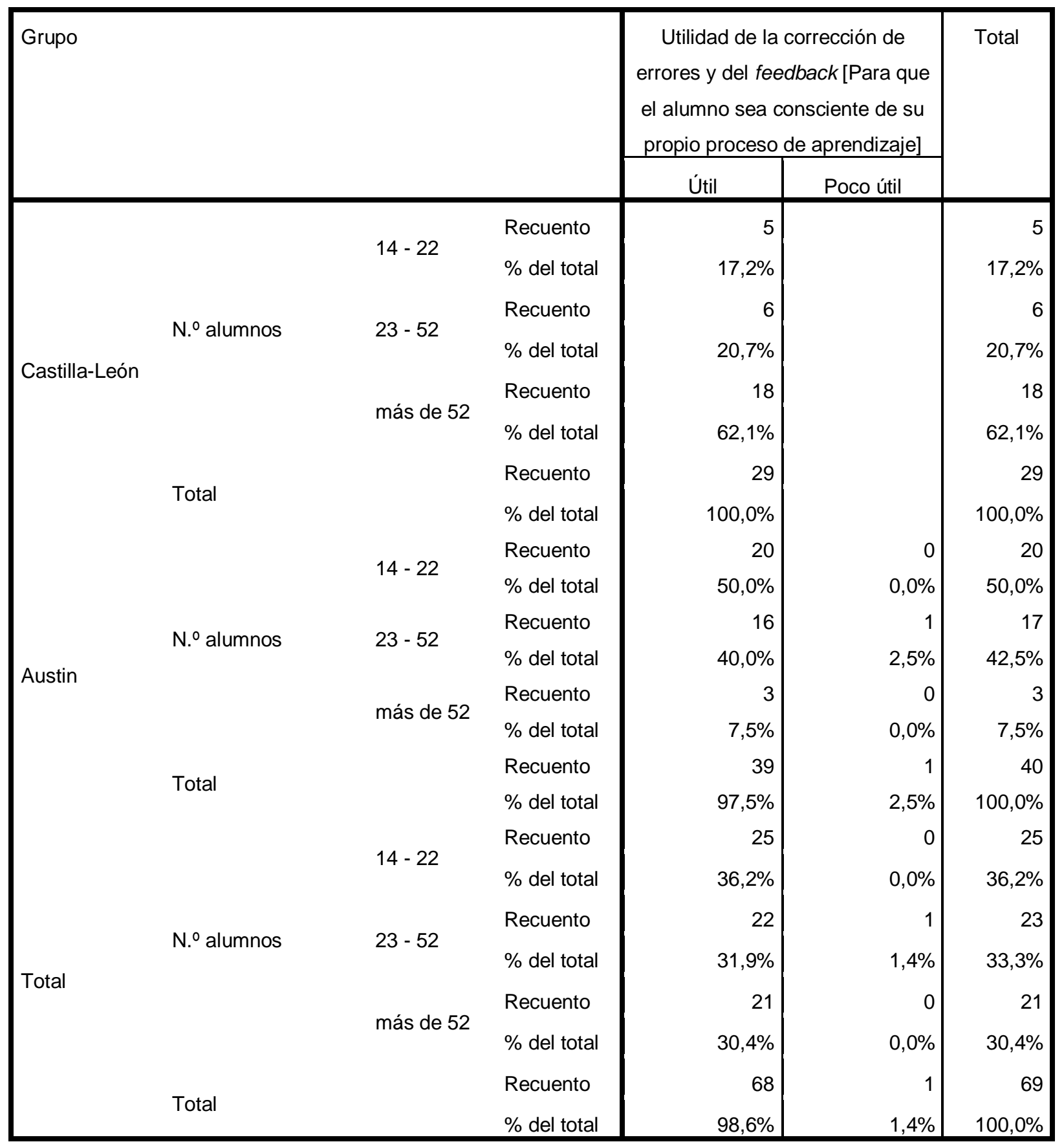

Tabla 76. Tabla de contingencia "Número de alumnos" * "Utilidad de la corrección de errores y del feedback" [para que el alumno sea consciente de su propio proceso de aprendizaje]* "Grupo" 
Como podemos observar en la Tabla 76 no existe una asociación estadísticamente significativa entre las variables. Prácticamente todos los informantes de ambos contextos educativos, independientemente del número de alumnos que tengan admiten que la corrección de errores y el feedback son útiles para que el alumno sea consciente de su propio proceso de aprendizaje. Nos encontramos ante una constante en Valladolid (el 100\% elige la opción "útil”) mientras que, en Austin lo elige un $97,5 \%$. Solo un informante de este contexto (que tienen entre 23 y 52 alumnos) afirma que la corrección de errores y el feedback son "poco útiles" para que el alumno sea consciente de su propio proceso de aprendizaje. Nos encontramos, por tanto, ante porcentajes prácticamente idénticos.

A partir de los gráficos de barras agrupadas (Gráficos 75 y 76) que aparecen a continuación se puede reflexionar sobre los datos presentados.

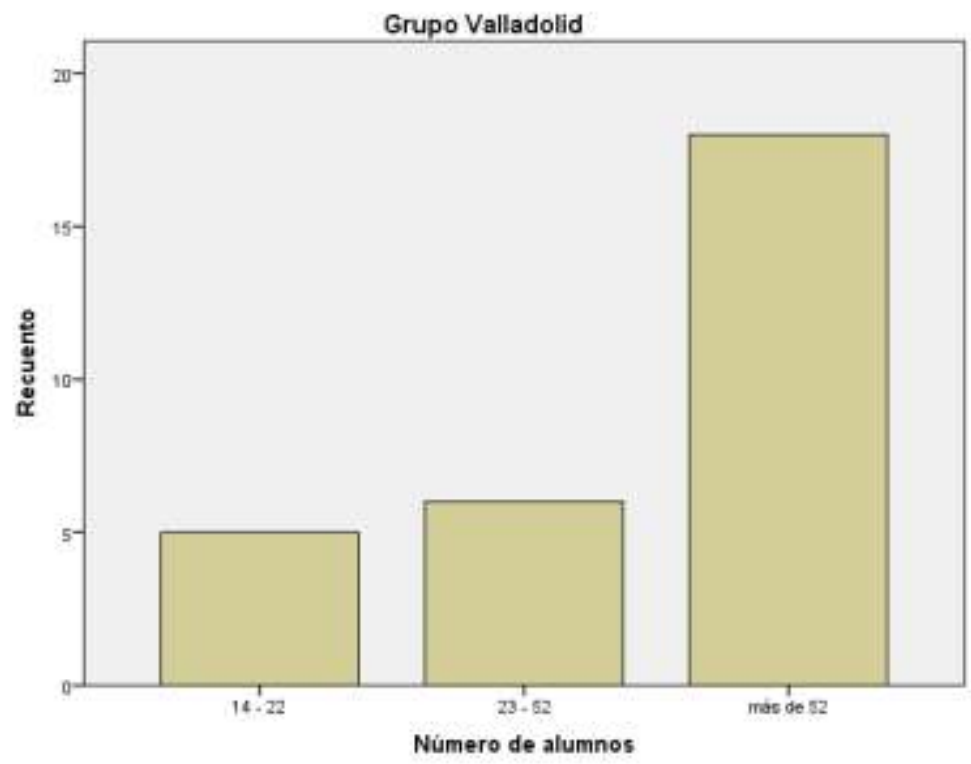

Gráfico 75. Recuento Número de alumnos - Utilidad de la corrección de errores y del feedback” [para que el alumno sea consciente de su propio proceso de aprendizaje]-Grupo Valladolid 


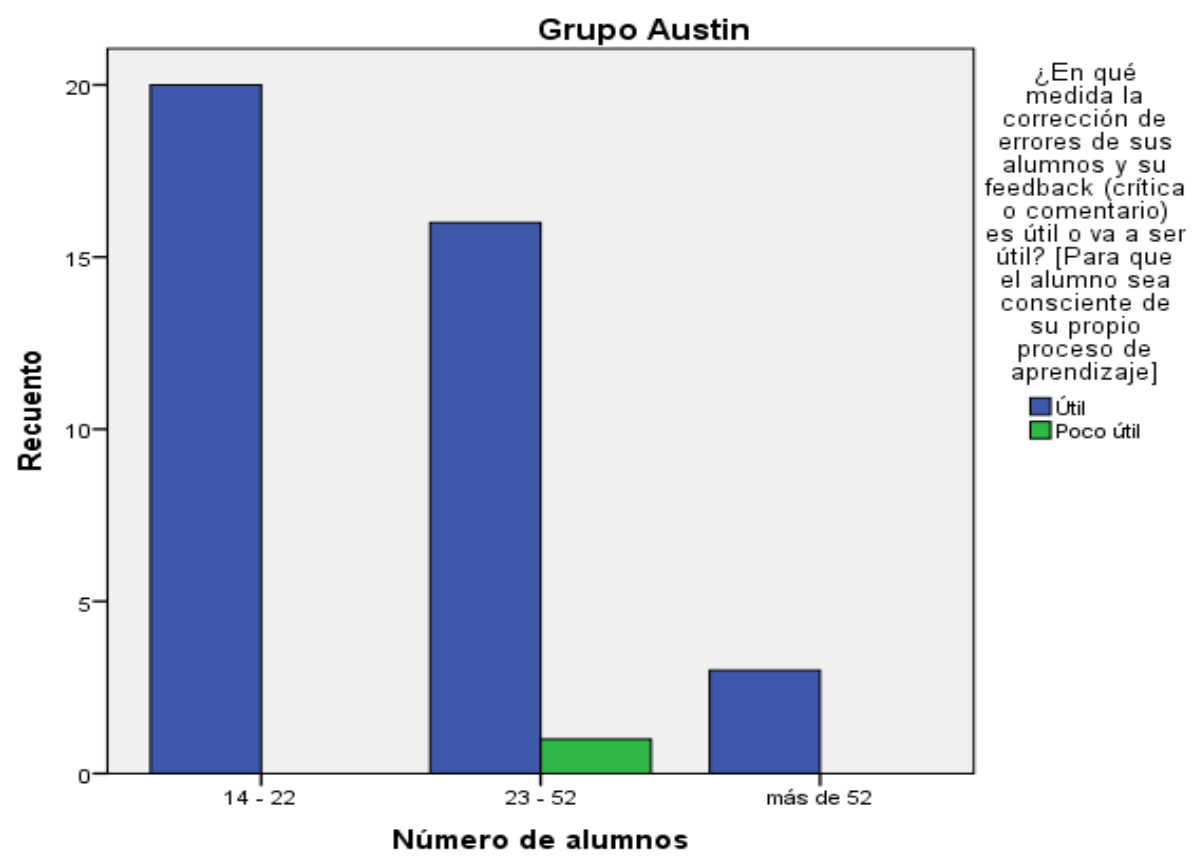

Gráfico 76. Recuento Número de alumnos - Utilidad de la corrección de errores y del feedback” [para que el alumno sea consciente de su propio proceso de aprendizaje]- Grupo Austin

Los datos obtenidos a partir de los gráficos 75 y 76 reflejan unanimidad por parte de los sujetos (todos aquellos que se encuentran en el contexto educativo de Valladolid y prácticamente todos los que constituyen el contexto de Austin) reconocen la utilidad del feedback por ayudar a que el alumno sea consciente de su propio proceso de aprendizaje de la L2.

Así pues, de forma generalizada y sin que el número de alumnos influya directamente en los resultados, los informantes expresan su confianza hacia el feedback como instrumento didáctico que ayuda al alumno a ser consciente de su propio proceso de aprendizaje. 
Como ya venimos apuntando, cabe la posibilidad de que estas afirmaciones respecto a los beneficios del feedback puedan hacer referencia a "actitudes reales" o bien a "actitudes simuladas" por no representar la realidad educativa en el aula de L2. Los resultados obtenidos a partir del presente trabajo de investigación indican que, si bien muchos profesores reconocen los beneficios del feedback, en la práctica, la corrección no siempre aparece acompañada de un feedback significativo ni adaptado a las necesidades educativas del alumno.

Con la intención de valorar el grado de asociación entre la variable “17b. Utilidad de la corrección de errores y del feedback" por cuanto que estos elementos permitan al alumno establecer conexiones entre su lengua materna y la L2 en relación con el "Número de alumnos" que tienen los informantes realizamos los siguientes análisis estadísticos.

En la siguiente tabla (Tabla 77) se exponen las pruebas de chi-cuadrado "Número de alumnos" * "Utilidad de la corrección de errores y del feedback" [le permita establecer conexiones entre su lengua materna y la L2]* "Grupo".

\begin{tabular}{|l|l|c|c|c|}
\hline \multicolumn{2}{|l|}{ Grupo } & Valor & gl & p \\
\hline Castilla-León & Chi-cuadrado de Pearson & 2,821 & 2 &, 244 \\
\hline Austin & Chi-cuadrado de Pearson & $6,727^{c}$ & 2 &, 335 \\
\hline Total & Chi-cuadrado de Pearson & $8,967^{\mathrm{a}}$ & 2 &, 111 \\
\hline
\end{tabular}

Tabla 77. Pruebas de chi-cuadrado "Número de alumnos" * "Utilidad de la corrección de errores y del feedback" [le permita establecer conexiones entre su lengua materna y la L2]* "Grupo"

Las pruebas de chi-cuadrado (Tabla 77) demuestran que no hay una relación significativa entre el número de alumnos que tienen los participantes y la utilidad de la corrección de errores y del 
feedback por cuanto que permitan al alumno establecer conexiones entre su lengua materna y la L2. Dicha relación no existe en el grupo Valladolid, ni en el de Austin ni a nivel total (en todos los casos, $\mathrm{p}>.05)$.

La siguiente tabla de contingencia (Tabla 78) se realiza para las variables "Número de alumnos" * "Utilidad de la corrección de errores y del feedback" [le permita establecer conexiones entre su lengua materna y la L2]* "Grupo". 


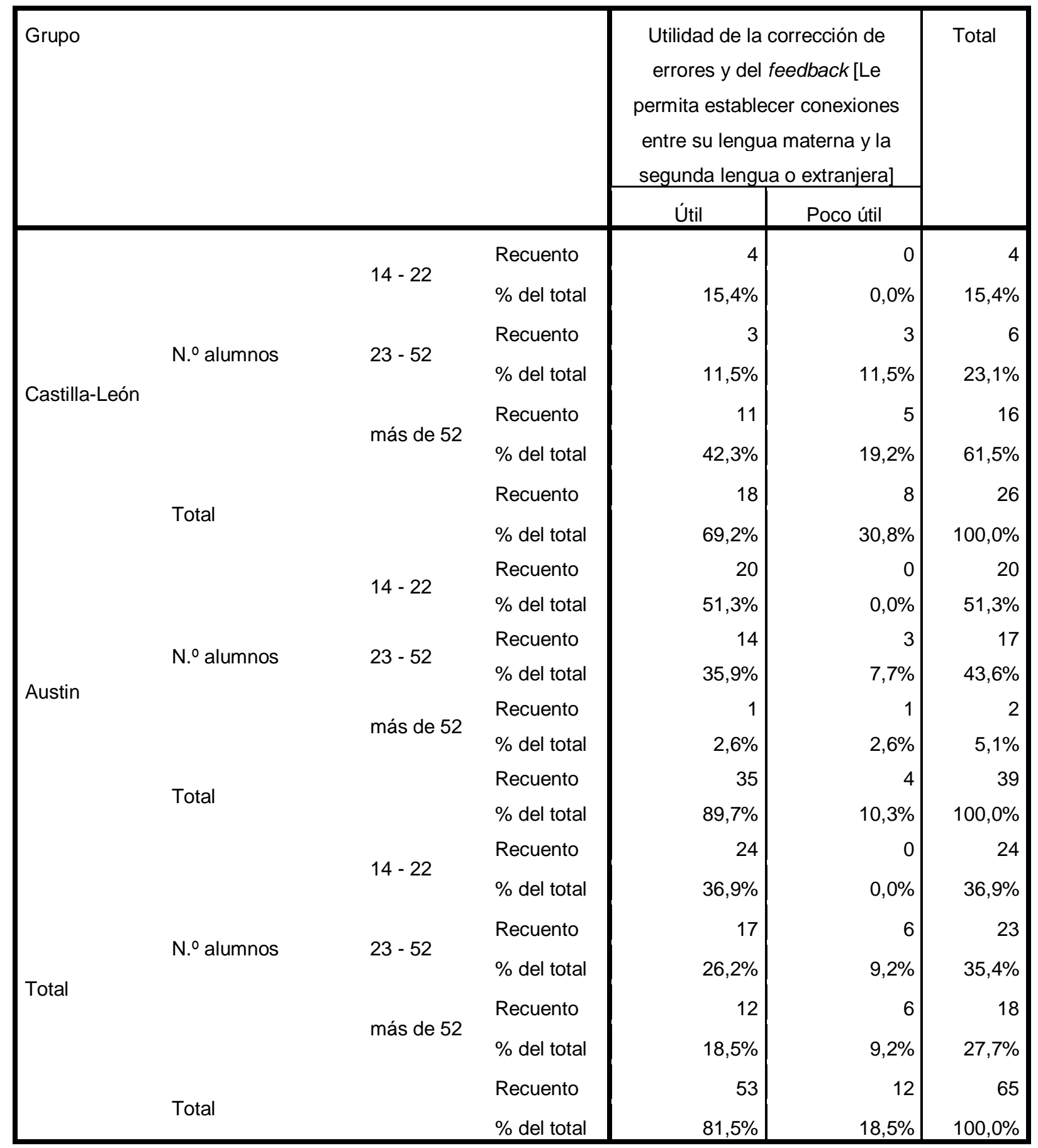

Tabla 78. Tabla de contingencia "Número de alumnos" * "Utilidad de la corrección de errores y del feedback" [le permita establecer conexiones entre su lengua materna y la L2]* "Grupo"

Tal y como podemos observar en la Tabla 78 no existe una relación estadísticamente significativa entre las variables. Esto nos hace pensar que, independientemente del contexto 
educativo (Valladolid o Austin) y del curso en el que enseñan L2 la mayoría de los informantes considera que la corrección de errores y el feedback es útil por permitir al alumno establecer conexiones entre su lengua materna y la L2.

Observamos que un 69,2\% elige la opción "útil" y un 30,8\% elige la respuesta contraria en Valladolid. En Austin, nos encontramos ante un 89,7\% de informantes que considera que estos son "útiles" respecto al 10,3\% que los reconoce como "poco útiles".

Nos encontramos, por tanto, ante porcentajes cercanos, aunque observamos la existencia de un número representativo de informantes vallisoletanos que elige la opción "poco útil” (un 30,8\%) respecto a los de Austin (10,3\%). Cabe señalar que la mayor parte de estos informantes cuentan con un alto número de alumnos (más de 23). Por otro lado, observamos que ninguno de los participantes que tienen menos de 23 alumnos elige la opción "poco útil" tanto en un contexto como en el otro. Estos resultados parecen indicar que, aunque la mayoría muestra su acuerdo respecto a la utilidad de la corrección de errores y del feedback por permitir al alumno establecer conexiones entre su lengua materna y la L2, de forma particular, todos aquellos que cuentan con un número reducido de alumnos tanto en Valladolid como en Austin muestran su acuerdo respecto a dicha afirmación. Además, cabe mencionar el hecho de que un grupo considerable de informantes de Valladolid (que cuentan con un número elevado de alumnos) no reconoce dicha utilidad.

Podríamos afirmar, por tanto, que la mayoría de los informantes destaca la utilidad de la corrección y del feedback (de forma particular, aquellos que cuentan con un número reducido de 
alumnos) en ambos contextos. No obstante, en Valladolid, existen voces que rechazan dicha utilidad (de forma particular, aquellos informantes que cuentan con un gran número de alumnos).

El número de participantes en esta respuesta es de $n=26$ docentes (de los 33 que representan la muestra total de Valladolid) y $n=39$ (de los 40 informantes que forman el 100\% de la muestra de Austin) formando un total de $\mathrm{N}=65$ informantes.

Los siguientes gráficos de barras agrupadas (Gráficos 77 y 78) que aparecen a continuación nos muestran los datos presentados de forma gráfica.

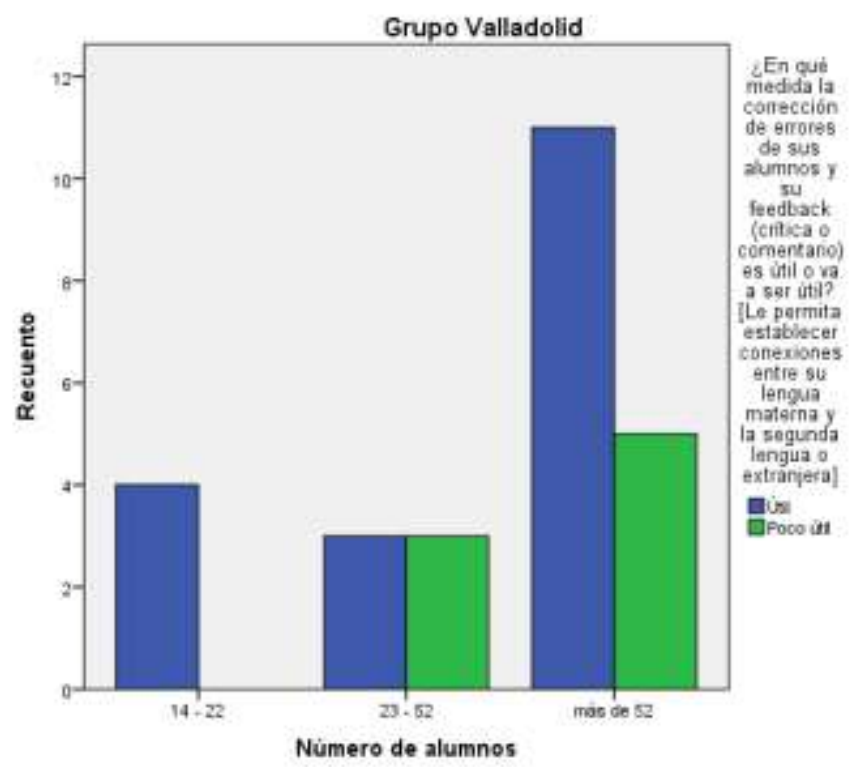

Gráfico 77. Recuento Número de alumnos - Utilidad de la corrección de errores y del feedback" [le permita establecer conexiones entre su lengua materna y la L2]- Grupo Valladolid 


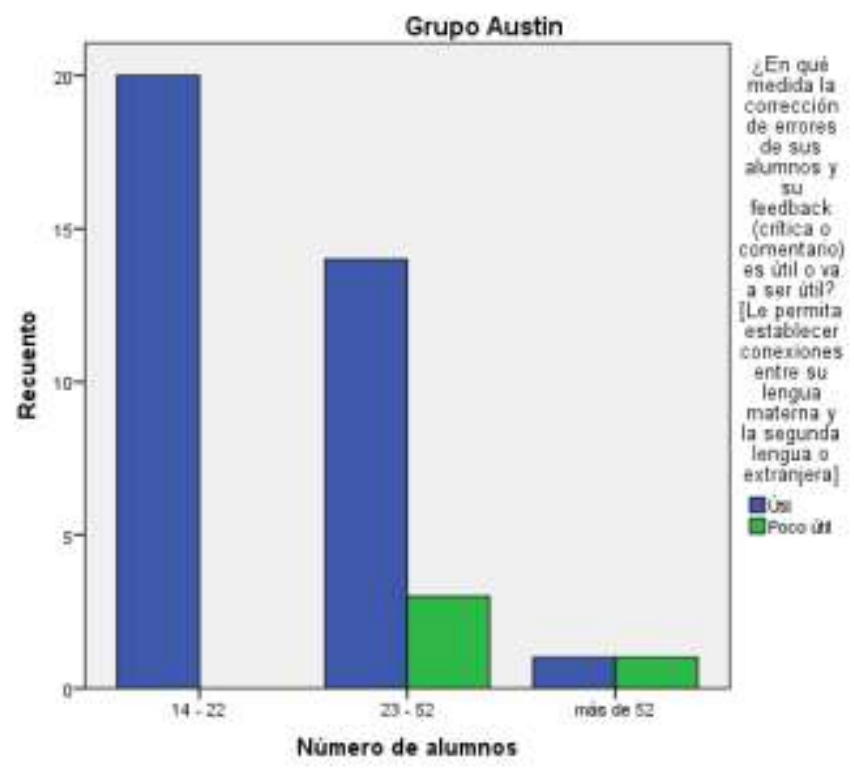

Gráfico 78. Recuento Número de alumnos - Utilidad de la corrección de errores y del feedback" [le permita establecer conexiones entre su lengua materna y la L2]- Grupo Austin

En los gráficos 77 y 78 encontarmos una mayoría de informantes (por parte de los dos contextos educativos) que reconoce la utilidad del feedback por permitir al alumno establecer conexiones entre su lengua materna y la L2. A pesar de la existencia de esta mayoría, hay un porcentaje significativo de informantes que no reconocen dicha utilidad. De forma particular, son aquellos que cuentan con un mayor número de alumnos en los dos contextos educativos (aunque la proporción es mayor en el de Valladolid).

Nos encontramos por tanto ante una mayoría de sujetos que confía en la eficacia del feedback por permitir al alumno establecer conexiones entre su lengua materna y la L2 aunque contamos con la presencia de informantes que no muestran esa confianza hacia los beneficios del feedback. Es posible que algunos de los que cuentan en el aula con este número elevado de alumnos 
no puedan llevar a cabo el proceso de corrección ni el de dotación de feedback de la forma más adecuada por falta de tiempo.

A continuación, nos disponemos a valorar el grado de asociación entre la variable “17c. Utilidad de la corrección de errores y del feedback" por cuanto que estos aporten al alumno información sobre cómo trabajar las distintas destrezas comunicativas en relación con el "Número de alumnos" que tienen los informantes.

En la tabla 79 se exponen las pruebas de chi-cuadrado "Número de alumnos" * "Utilidad de la corrección de errores y del feedback" [le aporte información sobre cómo trabajar las distintas destrezas comunicativas]* "Grupo".

\begin{tabular}{|l|l|c|c|c|}
\hline Grupo & Valor & gl & p \\
\hline Castilla-León & Chi-cuadrado de Pearson & 0,671 & 2 &, 715 \\
\hline Austin & Chi-cuadrado de Pearson & 4,024 & 2 &, 134 \\
\hline Total & Chi-cuadrado de Pearson & 0,765 & 2 &, 682 \\
\hline
\end{tabular}

Tabla 79. Pruebas de chi-cuadrado "Número de alumnos" * "Utilidad de la corrección de errores y del feedback" [le aporte información sobre cómo trabajar las distintas destrezas comunicativas]* "Grupo"

Dichas pruebas (Tabla 79) demuestran que no existe una relación significativa entre el número de alumnos que tienen los participantes y la utilidad de la corrección de errores y del feedback por cuanto que aporten información al alumno y le ayuden a trabajar las distintas destrezas comunicativas (en todos los casos, $\mathrm{p}>.05$ ). 
Realizamos la siguiente tabla de contingencia (Tabla 80) para las variables "Número de alumnos" * "Utilidad de la corrección de errores y del feedback" [le aporte información sobre cómo trabajar las distintas destrezas comunicativas]* "Grupo". 


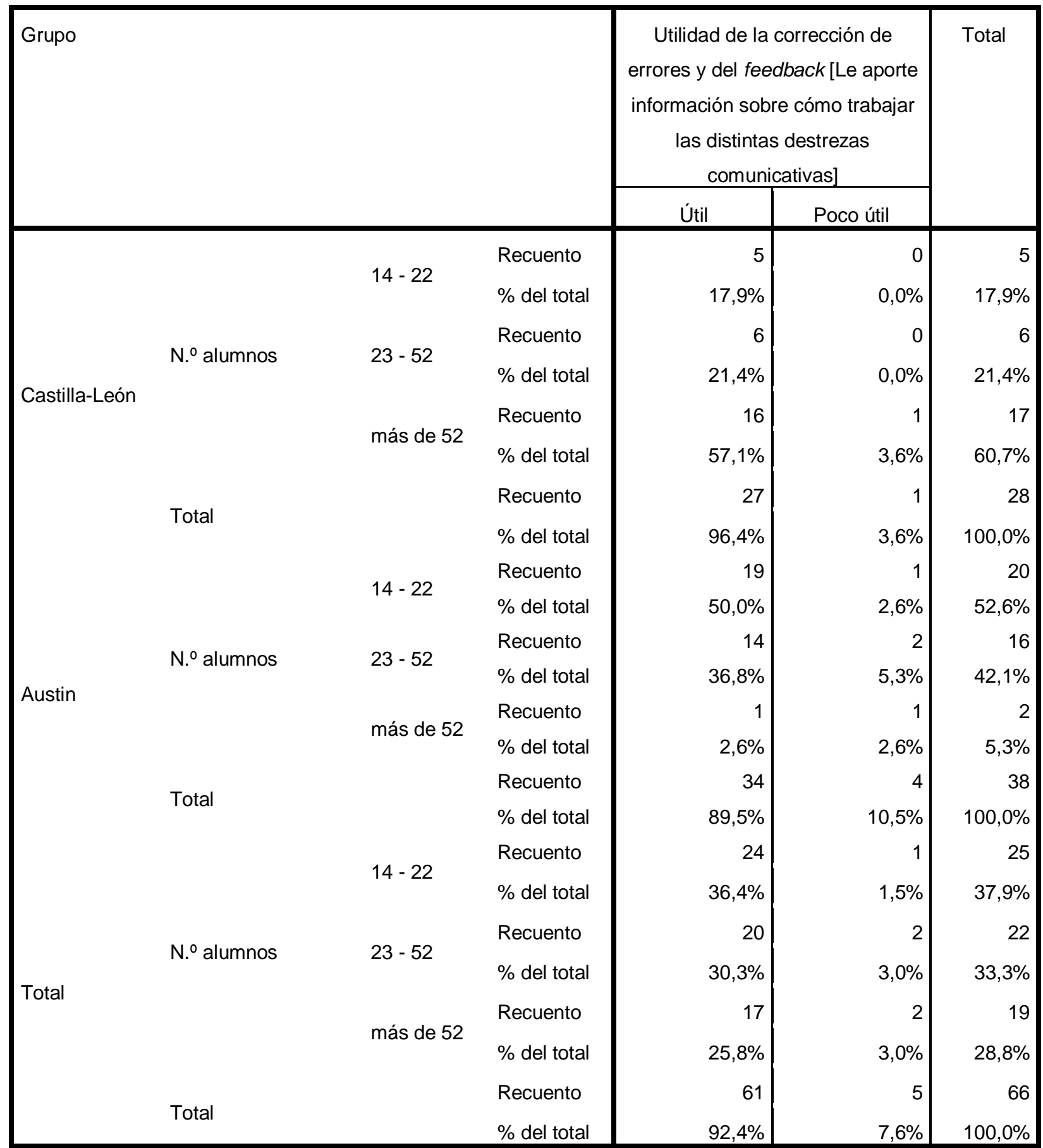

Tabla 80. Tabla de contingencia "Número de alumnos" * "Utilidad de la corrección de errores y del feedback" [le aporte información sobre cómo trabajar las distintas destrezas comunicativas]* "Grupo"

Como podemos observar en la Tabla 80 no existe una relación estadísticamente significativa entre las variables estudiadas. En consecuencia, podemos afirmar que, independientemente del 
contexto educativo (Valladolid o Austin) y del número de alumnos, la mayoría de los informantes consideran que la corrección de errores y el feedback es útil por cuanto que aportan información al alumno para poder trabajar las distintas destrezas comunicativas.

Nos encontramos ante un 96,4\% que elige la opción "útil" frente a un 3,6\% que elige la respuesta "poco útil" en Valladolid. En la ciudad de Austin un 89,5\% considera que estos son "útiles" respecto al 10,5\% que los reconocen como "poco útiles".

Los resultados son prácticamente idénticos y la diferencia en porcentajes no es significativa. En Valladolid solo encontramos un participante (con más de 52 alumnos) que no reconoce dicha utilidad mientras que en Austin son cuatro los que no la reconocen (en este caso, con distinto número de alumnos). Podríamos decir, por tanto, que prácticamente todos los informantes eligen la opción útil y que, además, en Valladolid el único informante que opta por la respuesta “poco útil” es el que cuenta con un número elevado de alumnos.

El número de participantes en esta respuesta es de $n=28$ docentes (de los 33 que representan la muestra total de Valladolid) y n = 38 (de los 40 informantes que forman el 100\% de la muestra de Austin) formando un total de $\mathrm{N}=66$ informantes.

En los Gráficos 79 y 80 que aparecen a continuación se presentan de forma gráfica los resultados comentados. 


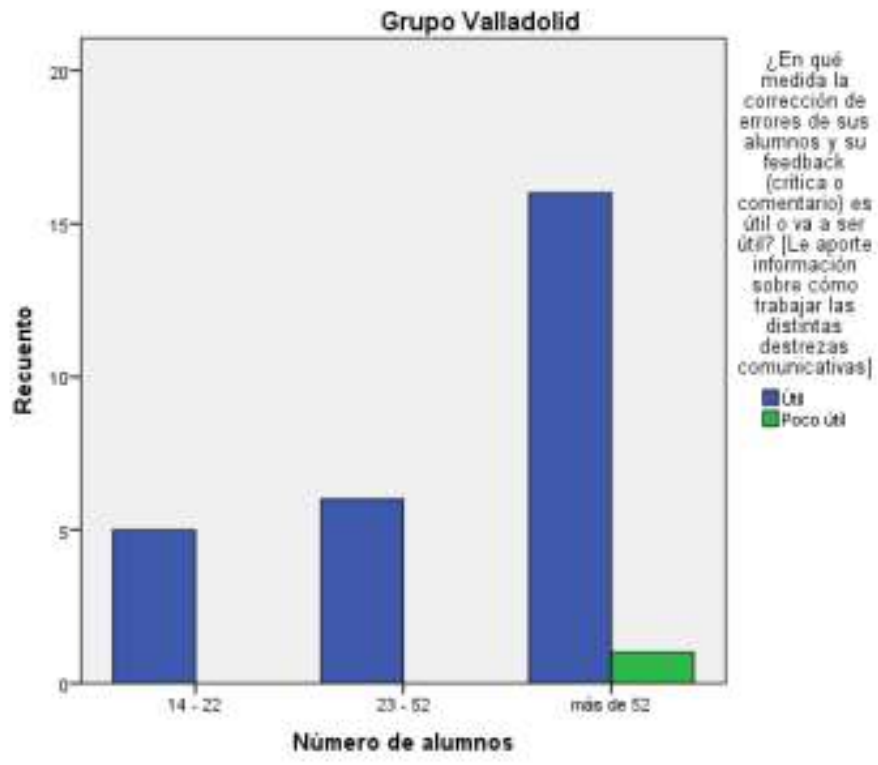

Gráfico 79. Recuento Número de alumnos - Utilidad de la corrección de errores y del feedback” [le aporte información sobre cómo trabajar las distintas destrezas comunicativas]- Grupo Valladolid

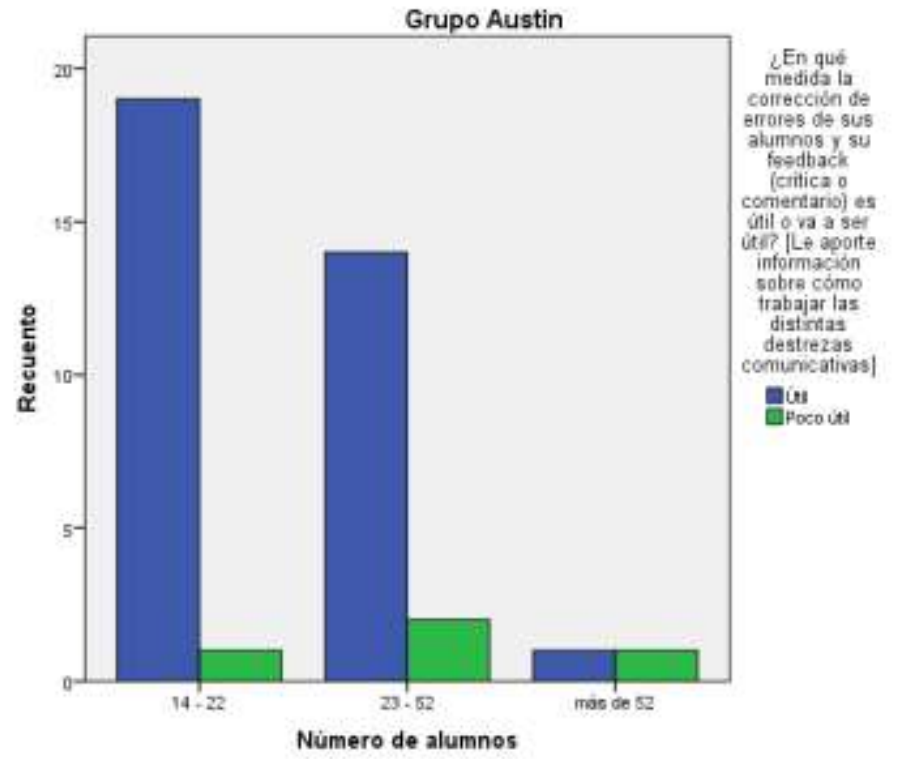

Gráfico 80. Recuento Número de alumnos - Utilidad de la corrección de errores y del feedback" [le aporte información sobre cómo trabajar las distintas destrezas comunicativas]- Grupo Austin

Nos aproximamos a los gráficos 79 y 80 que nos muestran la existencia de una actitud positiva generalizada tanto por parte de los sujetos de Valladolid como por los de Austin 
(independientemente del número de alumnos a los que atiendan). Así pues, el concepto de feedback se revela, por la mayor parte de los informantes, como un instrumento que permite aportar información al alumno sobre cómo trabajar las destrezas comunicativas.

Encontramos un número reducido de informantes del contexto de Austin que no reconoce los beneficios del feedback, pero se trata de una proporción no significativa. Por consiguiente, nos atrevemos a afirmar que, a nivel declarativo, la mayor parte de los sujetos presenta actitudes de confianza hacia el feedback como instrumento de ayuda para que el alumno aprenda a trabajar las destrezas comunicativas.

Para concluir, analizamos el grado de asociación entre la variable " $17 \mathrm{~d}$. Utilidad de la corrección de errores y del feedback" en la medida en que ayuden al alumno a ver los errores no como algo negativo sino como indicador de su progreso en el proceso de aprendizaje en relación con el número de alumnos que tienen los informantes.

En la siguiente tabla (Tabla 81) se presentan las pruebas de chi-cuadrado "Número de alumnos" * "Utilidad de la corrección de errores y del feedback" [le ayude a ver los errores no como algo negativo sino como indicador de su progreso en el proceso de aprendizaje]* "Grupo". 


\begin{tabular}{|l|l|c|c|c|}
\hline \multicolumn{2}{|l|}{ Grupo } & Valor & $\mathrm{gl}$ & $\mathrm{p}$ \\
\hline Castilla-León & Chi-cuadrado de Pearson & ---- & ---- & ---- \\
\hline Austin & Chi-cuadrado de Pearson &, 129 & 2 &, 938 \\
\hline Total & Chi-cuadrado de Pearson &, 906 & 2 &, 636 \\
\hline
\end{tabular}

Tabla 81. Pruebas de chi-cuadrado "Número de alumnos" * "Utilidad de la corrección de errores y del feedback" [le ayude a ver los errores no como algo negativo sino como indicador de su progreso en el proceso de aprendizaje]* "Grupo"

A partir de estas pruebas de chi-cuadrado (Tabla 81) podemos inferir que no existe una relación significativa entre el número de alumnos que tienen los participantes y la utilidad de la corrección de errores y del feedback por cuanto que ayude a los alumnos a ver los errores no como algo negativo sino como indicador de su progreso en el proceso de aprendizaje (en todos los casos, $\mathrm{p}>.05)$.

La tabla de contingencia (Tabla 82) que aparece a continuación se realiza para las variables "Número de alumnos" * "Utilidad de la corrección de errores y del feedback" [le ayude a ver los errores no como algo negativo sino como indicador de su progreso en el proceso de aprendizaje]* "Grupo". 


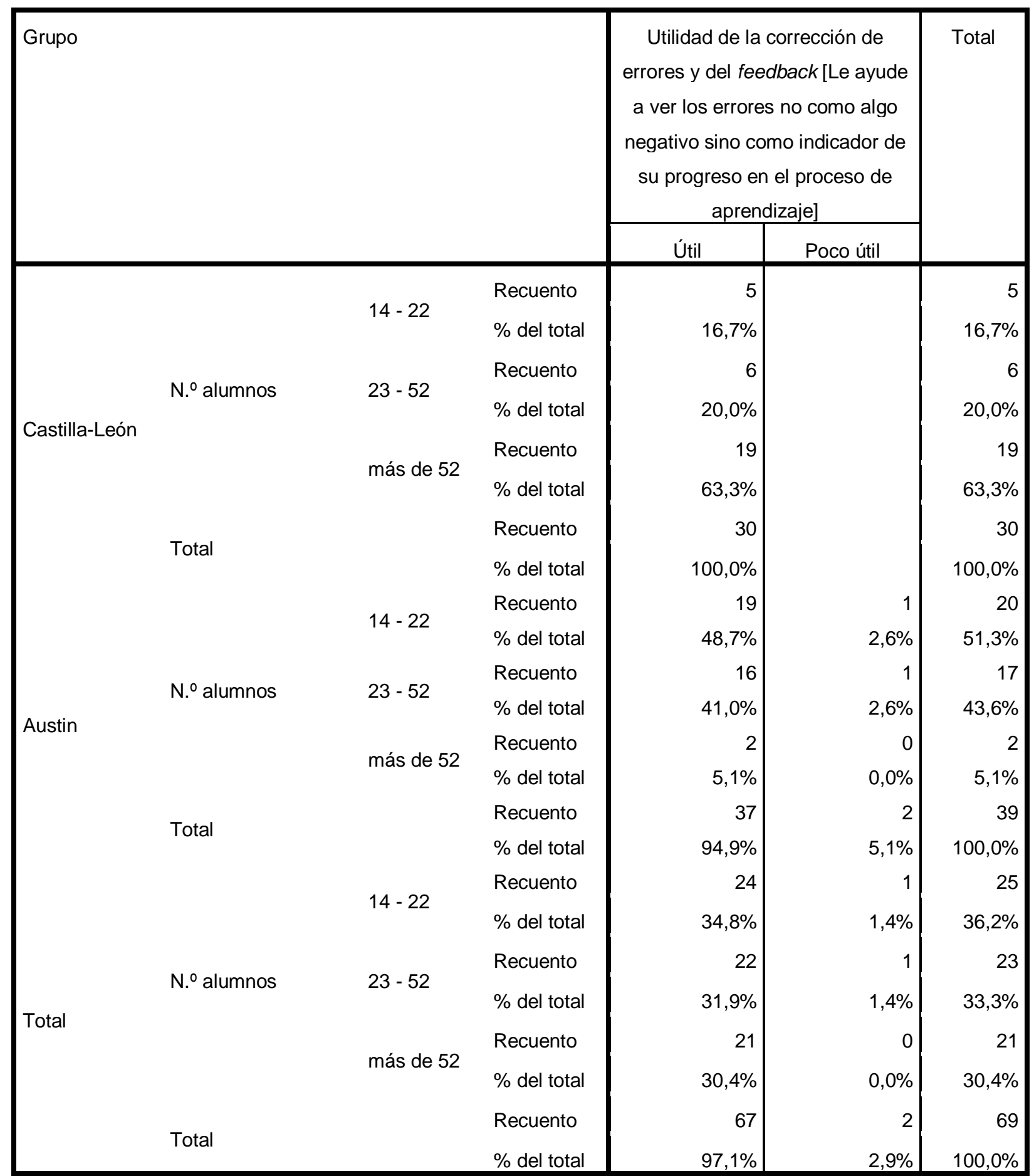

Tabla 82. Tabla de contingencia "Número de alumnos" * "Utilidad de la corrección de errores y del feedback" [le ayude a ver los errores no como algo negativo sino como indicador de su progreso en el proceso de aprendizaje]* "Grupo" 
A partir de los datos de la Tabla 82 reconocemos que no existe una asociación estadísticamente significativa entre las variables. Casi todos los informantes de ambos contextos educativos, independientemente del número de alumnos que tengan, admiten que la corrección de errores y el feedback son útiles puesto que permiten al alumno ver los errores no como algo negativo sino como indicador de su progreso en el proceso de aprendizaje. En Valladolid nos encontramos ante una constante ya que el $100 \%$ elige la opción "útil" mientras que, en la ciudad de Austin lo elige un $94,9 \%$. Solo hay dos informantes de este contexto (uno de ellos tiene entre 14 y 22 alumnos, el otro entre 23 y 52 alumnos) que no reconocen la utilidad de la corrección de errores y del feedback en la perspectiva de mostrar al alumno que el error no es algo negativo sino un indicador de su progreso en el proceso de aprendizaje. Nos encontramos, por tanto, ante porcentajes prácticamente idénticos.

En los gráficos de barras agrupadas (Gráficos 81 y 82) que aparecen a continuación se presentan, de forma gráfica, los datos analizados.

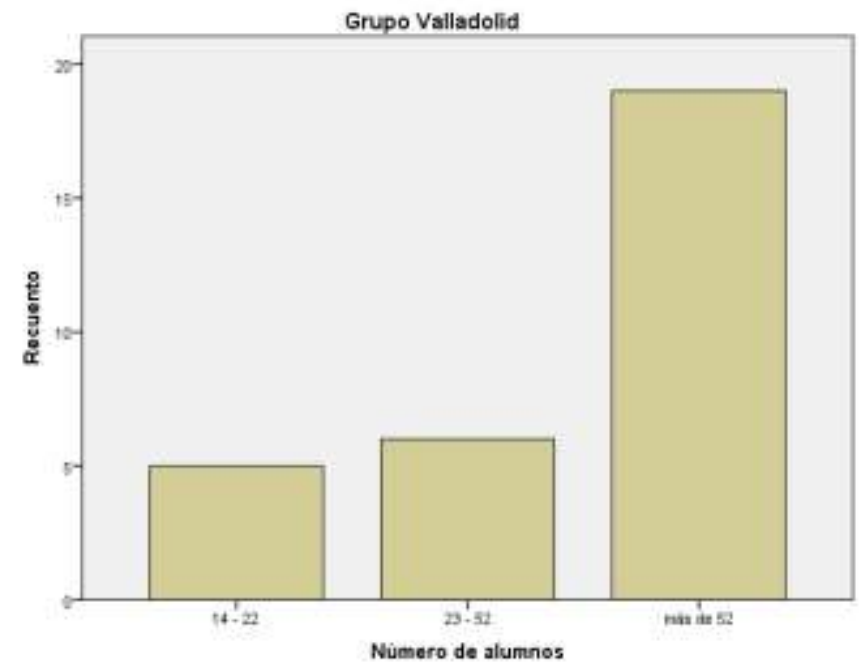

Gráfico 81. Recuento Número de alumnos - Utilidad de la corrección de errores y del feedback” [le ayude a ver los errores no como algo negativo sino como indicador de su progreso en el proceso de aprendizaje]- Grupo Valladolid 


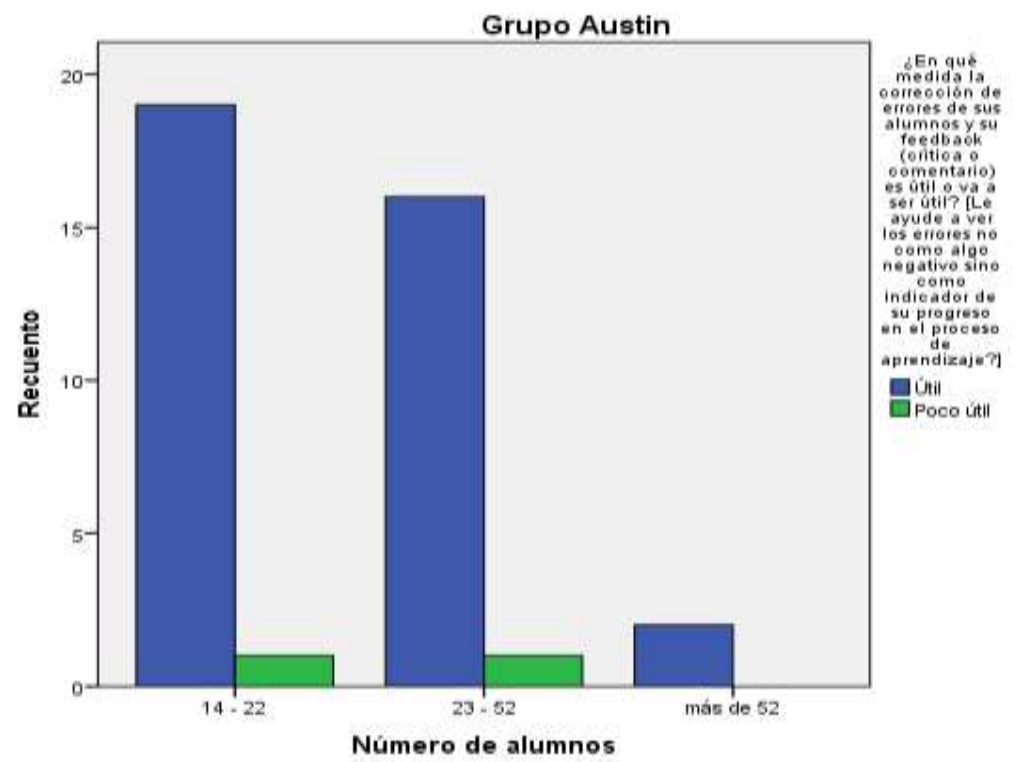

Gráfico 82. Recuento Número de alumnos - Utilidad de la corrección de errores y del feedback" [le ayude a ver los errores no como algo negativo sino como indicador de su progreso en el proceso de aprendizaje]- Grupo Austin

La información de los gráficos 81 y 82 evidencia una actitud positiva generalizada tanto por parte de los sujetos de Valladolid como por los de Austin (independientemente del número de alumnos con los que cuentan en clase). Así es como, la gran mayoría entiende el concepto de feedback como un instrumento que permite otorgar al alumno una visión positiva sobre el error.

Como hemos venido apuntando a lo largo del presente trabajo de investigación, la elección del tipo de corrección de errores y del feedback que lo acompaña es una de las decisiones más importantes que debe plantearse todo profesor de L2. En este sentido, con el fin de alcanzar un tipo de aprendizaje significativo, dicho feedback debe contener comentarios por parte del profesor en el que se comenten los progresos de los alumnos, así como sus errores. Además, como ya mencionábamos en el epígrafe 3.3.2 situándonos en la perspectiva de Vázquez (2000), debe incluir 
recomendaciones, consejos y frases de ánimo dirigidas a motivar al alumno en sus futuras producciones escritas.

En contraposición, encontramos otras modalidades de feedback en las que se marcan los errores, se añaden comentarios propios (marcas y anotaciones escuetas) que suelen ir acompañados de una nota numérica. Este tipo de feedback suele acompañar a una corrección en diferido orientada a un enfoque metodológico de producción escrita centrada en el producto final.

Los gráficos nos muestran unas actitudes positivas comunes a los dos contextos educativos (independientemente del número de alumnos). Sin embargo, cabe la posibilidad de encontrarnos ante actitudes "simuladas" respecto a la elección de una tipología de feedback.

\subsection{Interpretación de los resultados obtenidos a partir del análisis correlacional}

Las conclusiones en torno al análisis correlacional ponen de manifiesto la ausencia de asociación estadística significativa entre las variables escogidas. Desde esta consideración, podemos afirmar que, de forma general, no existe correlación entre el momento idóneo de corrección, la forma de proporcionar el feedback o la posible utilidad de la corrección de errores y del feedback respecto a los años de experiencia, la edad, el curso o el número de alumnos que atienden los profesores dentro de los contextos educativos de Valladolid o de Austin. No obstante, creemos que esto se debe a que la cantidad de profesores de L2 en Educación Primaria constituye un número tan bajo en términos absolutos que produce un corpus de población demasiado pequeño como para aplicarle un análisis correlacional, a pesar de que las respectivas muestras estudiadas 
rondan el $40 \%$ del total de profesores implicados en el estudio. A pesar de ello, el análisis cualitativo de los gráficos resultantes de realizar las correlaciones constituye una gran aportación al conocimiento de la situación y aporta luz a las conclusiones de la presente Tesis Doctoral.

Las únicas variables que presentaron una asociación estadísticamente significativa en el presente estudio fueron la variable "Curso" y la variable "Forma de proporcionar el feedback" por parte de los profesores que formaron parte de la muestra intencional de la ciudad de Valladolid. De acuerdo con esto podríamos afirmar que los informantes de este contexto educativo hacen uso de una modalidad de feedback específica en función del curso que imparten. En este sentido, aquellos que ejercen su actividad docente en los primeros cursos de Educación Primaria recurrirán a un tipo determinado de corrección de errores y de feedback distinto al que usarán los profesores de los cursos más altos de la etapa educativa.

A pesar de la ausencia generalizada de relaciones significativas entre las variables, los datos analizados en el presente análisis correlacional nos aportan información muy valiosa respecto a los conocimientos, las aptitudes y las actitudes de los informantes que conforman esta muestra en torno al error, a la corrección y al feedback. De forma particular, indagamos acerca de los conocimientos que tienen los informantes con respecto al momento idóneo de corrección, las aptitudes en torno a la forma de proporcionar feedback y las actitudes ante la utilidad de la corrección de errores y del feedback todos ellos en relación con sus años de experiencia, su edad, el curso escolar en el que ejercen su actividad docente y el número de alumnos a los que atienden. 
Respecto a los conocimientos de los informantes sobre el momento idóneo de corrección en relación con los años de experiencia, observábamos que, como norma general, no existe una relación estadísticamente significativa entre las variables estudiadas. De forma generalizada, los informantes, independientemente del contexto educativo y de sus años de experiencia, conocen la importancia de corregir las producciones escritas de los alumnos de forma inmediata. No obstante, podemos identificar la existencia de una diferencia relevante entre el porcentaje de profesores que, situándose en la misma franja en cuanto a años de experiencia, en función del contexto educativo en el que se encuentren inmersos, deciden optar por una forma de corrección u otra. Así es como, entre los docentes que cuentan con 11 a 20 años de experiencia encontramos un $25 \%$ de vallisoletanos que realizan la corrección al cabo de unos días. Por lo que se refiere a los informantes de Austin solo un 7,5\% lo hace "después de unos días". Estamos, por tanto, ante una diferencia significativa que nos hace afirmar que, aunque la mayoría de profesores intentan corregir las producciones escritas justo en el momento en que se están realizando, en Valladolid, aquellos que cuentan con una experiencia intermedia (entre 11 y 20 años) no se muestran tan interesados en corregir lo antes posible.

En lo concerniente a la elección del momento idóneo de corrección en relación con la edad de los informantes, se observa la falta de una relación significativa entre estas variables. Si bien ningún informante vallisoletano menor de 30 años ha elegido la opción de corregir "después de unos días", en el contexto educativo de Austin no existen informantes mayores de 45 años que declaren corregir las producciones escritas de sus alumnos transcurridos unos días. Todo ello nos permite afirmar que, en Valladolid, los informantes más jóvenes son más conscientes de la importancia de una corrección inmediata orientada hacia el uso de un enfoque metodológico de 
producción escrita centrada en el proceso (“process-oriented pedagogy"). En el caso de Austin existe una amplia mayoría de informantes en todos los rangos de edad que realizan una corrección inmediata centrada en el proceso. No obstante, son los informantes de mayor edad (mayores de 45 años) quienes recurren de forma unánime a este tipo de corrección. Como ya hemos comentado, los resultados parecen indicar la presencia de una formación del profesorado respecto al uso de una forma de corrección y dotación de feedback orientada al proceso de producción escrita muy enraizada y que cuenta ya con una larga tradición en el estado de Texas en general y en la ciudad de Austin de forma particular. Nos atrevemos a suponer que este tipo de formación centrada en la corrección comience a llevarse a cabo en el contexto educativo de Valladolid de una manera relativamente reciente en relación a Austin.

Si bien los análisis estadísticos cuantitativos que valoran el grado de asociación entre las variables: "momento idóneo de corrección” y "curso escolar en el que los informantes ejercen su actividad docente" demostraron que, para la presente muestra, no existe una asociación significativa entre dichas variables, los datos obtenidos nos ofrecen información significativa que nos disponemos a interpretar. Como norma general, los profesores apuestan por la corrección inmediata, Sin embargo, en el contexto educativo de Valladolid contamos con un 29,6\% de informantes cuyos alumnos están entre $4^{\circ}$ y $6^{\circ}$ de Educación Primaria que corrigen las producciones escritas "después de unos días". Nos encontramos ante un porcentaje significativamente superior al de profesores que enseñan L2 en los cursos que transcurren entre $1^{\circ}$ y $3^{\circ}$ de Educación Primaria (3,7\%). Esto nos hace suponer que los profesores vallisoletanos apoyan la corrección inmediata como norma general, pero prestan especial interés a la corrección de aquellos alumnos que se encuentran en cursos inferiores. Interpretamos, por tanto, que los 
informantes de este contexto educativo apoyan la corrección inmediata y el uso del enfoque metodológico centrado en el proceso propio de escritura sobre todo durante los primeros cursos de la etapa educativa.

Los resultados del análisis en torno a los conocimientos sobre el "momento idóneo de corrección" en relación con el "número de alumnos" también indican que no existe una relación significativa entre las variables. A pesar de ello, encontramos una diferencia llamativa entre los profesores que cuentan en el aula con más de 52 alumnos en Valladolid, de los cuales un 25,9\% reconocen realizar la corrección “después de unos días” y los de la ciudad de Austin, de los cuales, ninguno se inclina por esta opción. Así es como, todos los informantes de Austin con más de 52 alumnos en el aula (100\%) corrigen “justo a continuación” y, por tanto, eligen un tipo de corrección centrada en el propio proceso de producción escrita. Los resultados parecen indicar que, a pesar de la dificultad que supone la corrección inmediata ante un número de alumnos elevado, los docentes de la ciudad de Austin utilizan un tipo de corrección inmediata por ser esta la más apropiada para los alumnos.

Todas estas observaciones nos permiten afirmar, respecto a los conocimientos de los informantes en torno al error y a la corrección que la formación en torno a la elección de una metodología de corrección y de dotación de feedback apropiados cuenta con una larga trayectoria en la ciudad de Austin. Por su parte, en Valladolid, la mayor parte de los informantes apoya la corrección inmediata. Sin embargo, existe un perfil específico formado por aquellos informantes más mayores, con un grado de experiencia entre los 11 y los 20 años que enseñan L2 en los cursos más altos (de $4^{\circ}$ a $6^{\circ}$ ) y que cuentan con un mayor número de alumnos que expresa en porcentajes 
significativos su postura respecto a la corrección "después de unos días". Son aquellos que optan por un enfoque metodológico centrado en el producto o borrador final y que normalmente eligen proporcionar un tipo de feedback que incluye una serie de marcas gráficas y breves anotaciones acompañadas de una nota numérica. Este tipo de feedback incide de forma negativa en las actitudes de los alumnos al tiempo que reduce significativamente su participación activa y su entusiasmo por aprender una L2. Esto nos permite afirmar que conciben el error como resultado de una regla no interiorizada, un fallo que entorpece la comprensión del texto.

En lo que respecta a las aptitudes en torno a la forma de proporcionar feedback en relación con los años de experiencia, tal y como señalábamos, no existe una relación estadísticamente significativa entre dichas variables. A pesar de ello, destacábamos el escaso uso de un código de corrección entre los docentes de los dos contextos educativos por un lado y, por otro, el hecho de que, en el contexto de Austin, todos los informantes con más de 20 años de experiencia opten por el uso de un feedback oral individual. Es significativo el hecho de que los informantes de Valladolid recurran a un feedback oral proporcionado de manera conjunta (en voz alta) en un porcentaje tan elevado, sobre todo aquellos que cuentan con 11 a 20 años de experiencia (25\%) en comparación con sus equivalentes en la ciudad de Austin (5\%).

Encontramos por tanto una tendencia general en la ciudad de Valladolid hacia una forma de feedback general (en voz alta) dirigido al grupo-clase. El rango de años de experiencia en el que se puede apreciar de forma más clara la diferencia entre un contexto educativo y otro es el de 11 a 20 años. Por su parte, en Austin (de forma particular, en los informantes con un mayor grado de experiencia) la tendencia general es la de proporcionar un feedback oral en el que el profesor 
pueda llevar a cabo entrevistas individuales con el alumno en las que la interacción entre profesoralumno juegue un papel fundamental y durante las cuales, el profesor tenga ocasión de proporcionar ayuda al alumno durante el proceso de producción, así como una corrección inmediata acompañada de un feedback oral individual.

En cuanto a las aptitudes en torno a la forma de proporcionar feedback en relación con la edad de los informantes, observamos que los datos de Valladolid se encuentran repartidos entre las cuatro modalidades propuestas, lo cual, puede estar relacionado con una falta de formación dirigida hacia la elección de un tipo de corrección y de feedback que favorezcan el uso de un método moderno de enseñanza de expresión escrita centrado en el proceso de escritura. Consideramos, pues, que los profesores de Valladolid, al no recibir una formación específica respecto a la corrección y al feedback, recurren a la modalidad que a ellos les parece más adecuada o que pueda estar mejor adaptada a las características del aula. Como excepción, encontramos a los informantes menores de 30 años, los cuales utilizan un feedback oral individual demostrando contar con formación al respecto. En el caso de Austin, de forma general, los informantes utilizan una corrección inmediata acompañada de feedback oral individual (en particular, los menores de 30 años y mayores de 45) lo cual nos hace pensar que los profesores de este contexto cuentan con un tipo de formación orientada hacia el uso de estos. Dentro de este contexto, son los profesores de 30 a 45 años los que se muestran más abiertos a otras modalidades de feedback.

En lo que respecta a las aptitudes de los informantes en torno a la forma de proporcionar feedback se han detectado resultados estadísticamente significativos cuando lo relacionamos con el curso escolar en el que imparten sus clases en el contexto educativo de Valladolid. Desde esta 
óptica, se puso de manifiesto que un $19 \%$ todos ellos profesores de $1^{\circ}$ a $3^{\circ}$ de Educación Primaria, eligen la modalidad de feedback oral de manera conjunta (en voz alta) mientras que en los cursos de $4^{\circ}$ a $6^{\circ}$ predomina la corrección “oral - individual" (36\%) seguida de la "oral - conjunta" aunque también encontramos representación del resto de modalidades.

Si bien los resultados son muy similares en los dos contextos educativos, en el caso de Austin, no existen diferencias significativas ni tampoco a nivel de la muestra total. La mayoría de profesores utilizaron, independientemente del curso que impartían, la modalidad "oral individual" (en el caso particular de los profesores que impartían entre $1^{\circ}$ y $3^{\circ}$, todos manifestaron su preferencia por esta) y muy de lejos estuvieron representadas el resto de modalidades de corrección.

Encontramos que los informantes de los cursos más bajos en Valladolid optan claramente por un tipo de feedback oral transmitido de forma conjunta al grupo-clase a diferencia del contexto de Austin en el que todos los profesores de $1^{\circ}$ a $3^{\circ}$ dotan a sus alumnos de un feedback oral individual. Concluimos, a partir de los datos que la formación que reciben respecto a la corrección y dotación de feedback en los cursos más bajos es completamente contradictoria en un contexto respecto al otro. Cabe la posibilidad de que en el contexto educativo de Castilla y León (concretamente en los centros de Valladolid) no se otorgue la misma importancia a la destreza comunicativa de expresión escrita en los cursos más bajos en relación al contexto del estado de Texas (representados, en este caso por aquellos que se encuentran ubicados en la ciudad de Austin). 
Podría ser que no exista una formación específica dirigida al profesorado de los primeros cursos de Educación Primaria de Castilla y León orientada a la elección de un tipo de corrección y de dotación de feedback específico.

Respecto a las aptitudes de los informantes en torno a la forma de proporcionar feedback en relación con el número de alumnos encontramos que, independientemente de la cantidad de alumnos de los participantes y del contexto educativo en el que se encuentren, los resultados son similares y, en este sentido, no existe relación significativa entre las variables. Destacamos el hecho de que el porcentaje de informantes que proporciona feedback oral de manera conjunta cuando cuentan con un número elevado de alumnos (mayor de 52) es mucho más alto en el contexto de Valladolid (22,6\%) respecto al de Austin (2,5\%) lo cual nos hace pensar en la elección de una modalidad que facilite su trabajo de corrección y de dotación de feedback. En lo que respecta a la forma de feedback como un código escrito, observamos que casi no se utiliza en ninguno de los dos contextos. Solo aquellos con un número intermedio de alumnos (entre 23 y 52) utilizan este tipo de feedback de forma eventual.

También podemos inferir que los informantes de Valladolid recurren a la modalidad de corrección y de dotación de feedback que mejor se adapte a sus necesidades y a las características del centro y, en contraposición, los informantes de Austin recurren de manera generalizada al uso del feedback oral individual que asociamos a un tipo de corrección inmediata centrada en el proceso. 
Todo el análisis llevado a cabo nos permite concluir, respecto a las aptitudes de los informantes en torno al error y la corrección, que los informantes vallisoletanos, de forma general no cuentan con unas aptitudes óptimas respecto a la elección de la modalidad de corrección y de dotación de feedback. Así es como, los datos parecen indicar que estos recurren al feedback oral proporcionado de manera conjunta, especialmente aquellos mayores de 30 años que cuentan con una experiencia intermedia (de 11 a 20 años) en la enseñanza de L2 que enseñan a alumnos de $1^{\circ}$ a $3^{\circ}$ de Primaria y que cuentan con un número elevado de alumnos (mayor de 52). Podríamos hablar de un perfil de profesores que basan su sistema de elección en sus propias necesidades y que es posible que no hayan recibido una formación orientada a la elección de un tipo de corrección adecuada al grupo de alumnos. Cabe la posibilidad de que en este contexto educativo no se atribuya un alto grado de importancia a la destreza de la expresión escrita (sobre todo en los primeros cursos de Educación Primaria).

Por su parte, en la ciudad de Austin, observamos una tendencia general hacia el uso de un sistema de corrección y de dotación de feedback basado en una serie de entrevistas individuales con el alumno en las que el componente afectivo y la interacción jueguen un papel relevante. De forma particular, los profesores del contexto educativo de Austin que más se acercan a este tipo de sistema de corrección son aquellos menores de 30 y mayores de 45 años con más de 20 años de experiencia que enseñan cualquier curso de Educación Primaria (en particular de $1^{\circ}$ a $3^{\circ}$ ya que todos los informantes incluidos en este rango eligieron la opción de feedback oral individual) independientemente del número de alumnos presentes en sus aulas. Estos profesores, a diferencia de los del contexto de Valladolid, conocen la importancia del componente afectivo en la enseñanza-aprendizaje de L2 e intentan llevar al aula modalidades de corrección y de dotación de 
feedback en las que la interacción profesor-alumno juegue un papel fundamental. Además, conociendo la importancia que tiene la destreza comunicativa de la expresión escrita, impulsan a sus alumnos a trabajar en dicha destreza desde los primeros cursos de la etapa de Educación Primaria.

Analizamos también el grado de asociación entre las actitudes de los informantes ante la posible utilidad de la corrección de errores y del feedback en relación con las variables correspondientes al perfil de los informantes.

Al abordar la correspondencia entre los años de experiencia de los informantes, como variable, y la utilidad de la corrección y del feedback para que el alumno sea consciente de su propio aprendizaje observamos la falta de una relación estadísticamente significativa entre ellas. Desde esta consideración, destacamos que, prácticamente todos los informantes reconocen que la corrección de errores y el feedback es útil para que el alumno sea consciente de su propio proceso de aprendizaje de la L2.

Además, aunque de forma general podemos decir que los informantes tienen en consideración la importancia de la corrección y del feedback en el sentido de entender dichos procesos como una ayuda para que el alumno pueda establecer una conexión entre su lengua materna y la L2 encontramos un porcentaje significativo de informantes vallisoletanos con menos 10 años de experiencia que no identifican dicha utilidad. 
En cuanto a los análisis de datos correspondientes a la posible utilidad de la corrección y del feedback por cuanto que estos aportan información al alumno sobre cómo desarrollar las destrezas comunicativas y, además le ayuda a tener una percepción positiva sobre el error y a entenderlo como indicador de su progreso en el proceso de aprendizaje podemos hablar de diferencias muy significativas entre los porcentajes "a favor" y los que se manifiestan "en contra". Observamos que en los dos contextos educativos prácticamente todos los participantes son conscientes y defienden la utilidad de la corrección de errores y de la dotación de feedback.

Nos encontramos, por tanto, ante actitudes muy positivas hacia la corrección de errores y hacia la dotación de feedback en la perspectiva de utilizarlos en el aula con el propósito de ayudar al alumno tanto por parte de profesores sin mucha experiencia como de profesores que cuentan con más de 10 años de experiencia docente en los dos contextos educativos.

Por lo que se refiere a las actitudes de los informantes ante la corrección de errores y la dotación de feedback en relación con su edad, volvemos a encontrarnos con la falta de una relación estadísticamente significativa entre las variables. Se detectan actitudes muy positivas en cuanto a la corrección de errores y al feedback como elementos que ayudan al alumno a ser consciente de su propio proceso de aprendizaje.

En cuanto a la consideración de su utilidad por permitir al alumno establecer conexiones con su lengua materna, encontramos que, alrededor del $30 \%$ de informantes vallisoletanos (muchos de ellos menores de 30 años) no la reconocen. No obstante, el resto de participantes (de Valladolid y de Austin) se manifiestan a favor de dicha utilidad. 
En las respuestas aportadas en torno a las dos variables restantes encontramos que prácticamente todos los informantes de los dos contextos que forman parte de nuestra investigación defienden el uso de la corrección y del feedback por aportar información valiosa al alumno que le permita desarrollar las distintas destrezas comunicativas y por ayudarle a ver los errores como indicador de su progreso en el proceso de aprendizaje de la L2.

Desde esta consideración, las actitudes hacia la corrección y el feedback se revelan como muy positivas independientemente de la edad y del contexto educativo de los informantes. La gran mayoría muestra este tipo de actitudes a excepción de un grupo de informantes de Valladolid (muchos de ellos menores de 30 años) que no reconocen la utilidad de la corrección y del feedback en cuanto a ayudar al alumno a establecer conexiones entre su lengua materna y la L2.

Asimismo, examinamos las actitudes de los informantes ante la corrección de errores y la dotación de feedback en relación con el curso en el que ejercen su docencia. Desde esta perspectiva, encontramos que tampoco existe una relación estadísticamente significativa entre las variables. Así pues, los informantes vuelven a mostrar actitudes positivas ante la corrección de errores y la dotación de feedback como elementos que ayudan al alumno a ser consciente de su propio proceso de aprendizaje.

En lo relativo a las actitudes de los informantes respecto a la utilidad de la corrección y del feedback, por permitir estos que el alumno establezca conexiones entre la lengua materna y la L2, volvemos a encontrar un porcentaje significativo de informantes de Valladolid (alrededor de un 
$30 \%$ ) que no reconocen dicha utilidad. Una parte considerable de este porcentaje son profesores que enseñan en los primeros cursos de Educación Primaria (de $1^{\circ}$ a $3^{\circ}$ ). En cuanto al resto de informantes (tanto vallisoletanos como de Austin) todos muestran una actitud positiva reconociendo la utilidad de la corrección y del feedback.

En lo que respecta a sus actitudes ante la corrección y el feedback por cuanto que ayudan a trabajar las destrezas comunicativas en su L2 y a ver los errores como algo positivo y como indicador de su progreso, prácticamente todos los informantes manifiestan actitudes positivas por cuanto que reconocen su utilidad en el aula de L2.

En virtud de ello, las actitudes hacia la corrección y el feedback se manifiestan como muy positivas independientemente del curso escolar en el que los informantes desempeñen su profesión y del contexto educativo en el que se incluyan. Como excepción, encontramos a un grupo de participantes vallisoletanos (muchos de ellos profesores de $1^{\circ}$ a $3^{\circ}$ de Educación Primaria) que no reconocen la utilidad de la corrección y del feedback en cuanto a ayudar al alumno a establecer conexiones entre su lengua materna y la L2.

Con respecto a las actitudes de los informantes ante la corrección de errores y la dotación de feedback en relación con el número de alumnos, volvemos a mencionar que tampoco existe una relación estadísticamente significativa entre las variables. Destacamos la presencia de actitudes muy positivas por reconocer estos que son de gran utilidad en la concienciación del proceso de aprendizaje. Sin embargo, aunque en gran medida se defiende dicha utilidad por permitir al alumno establecer conexiones entre su lengua materna y la L2, en Valladolid existen voces que rechazan 
dicha utilidad (en este grupo de informantes destacamos la presencia de un grupo importante que cuenta con un número elevado de alumnos).

En lo referente a su utilidad por aportar información sobre cómo trabajar las destrezas y por ayudar al alumno a ver los errores como algo positivo, encontramos una gran mayoría de profesores que muestran una actitud positiva.

Por todo ello, nos atrevemos a afirmar que el número de alumnos con los que cuentan los informantes no interfiere en las actitudes que muestran hacia la corrección de errores y hacia el feedback. La gran mayoría manifiesta actitudes muy positivas a excepción de un número de informantes de Valladolid (algunos de estos con un número elevado de alumnos) que no muestran actitudes positivas hacia la corrección de errores y hacia el feedback por no considerar que estos permitan al alumno establecer conexiones entre su lengua materna y la L2.

Los datos analizados nos permiten extraer algunas conclusiones en torno a las actitudes de los informantes ante el error, la corrección y el feedback las cuales guardan relación directa con las conclusiones que obteníamos en el epígrafe 8.2. de la presente Tesis Doctoral. En general, todos los sujetos muestran actitudes muy positivas respecto a la corrección de errores y al feedback por cuanto que permiten al alumno ser consciente de su propio proceso de aprendizaje, le permiten establecer conexiones entre su lengua materna y la L2, le aportan información sobre cómo trabajar las destrezas comunicativas y, por último, le ayudan a reconocer los errores como algo positivo y como un indicador de su progreso en el proceso de aprendizaje. Como excepción, destacamos la existencia de un número reducido de informantes que forman parte de la muestra intencional de la 
ciudad de Valladolid con menos de 10 años de experiencia, menores de 30 años, que ejercen su docencia en los primeros cursos de Primaria (de $1^{\circ}$ a $3^{\circ}$ ) y que cuentan con un elevado número de alumnos que no reconocen la utilidad de la corrección y del feedback por cuanto que estos permitan al alumno establecer conexiones entre su lengua materna y la L2.

De acuerdo con estas declaraciones, podemos inferir que todos ellos hacen uso de metodologías actuales de expresión escrita que impulsan a los alumnos hacia un acercamiento a su profesor en forma de entrevistas individuales. También podemos inferir que dichas actitudes contribuyen a la existencia de un filtro afectivo bajo en los alumnos de L2 que fomenta una mayor predisposición a recibir mayor cantidad de información, reduce su nivel de ansiedad ante las actividades de producción escrita y ante los errores y, genera un mayor grado de confianza en sí mismos. Así pues, podríamos afirmar que los profesores de los dos contextos no solo muestran unas actitudes de aceptación y de apertura ante el error sino también de cercanía y confianza hacia el propio alumno.

Sin embargo, se pone de manifiesto una gran variedad de diferencias en torno a las declaraciones de los profesores del contexto educativo de Valladolid y las conclusiones que hemos podido extraer en torno a las respuestas aportadas en el resto de los ítems del cuestionario. Así es como, estos informantes manifiestan, a nivel declarativo tener una actitud de confianza ante el error y su corrección. No obstante, a partir de sus respuestas interpretamos que en su actividad de enseñanza no aprovechan al máximo la presencia del error en el sentido de no preocuparse por realizar una tipología de errores, ni de recurrir a un determinado sistema de corrección para seguir de cerca el proceso de evolución del aprendizaje de la L2 o de dotar de feedback motivacional que 
acompañe el proceso de aprendizaje. En virtud de ello, consideramos que, para los informantes del contexto de Valladolid, el error no llega a convertirse en un auténtico instrumento pedagógico dentro del proceso de enseñanza-aprendizaje de la L2.

Por otra parte, en lo que respecta a los informantes pertenecientes al contexto educativo de la ciudad de Austin, identificamos en las respuestas en torno a las actitudes ante el error y la corrección una determinada correlación entre lo que se afirma y lo que se presenta en la parte expositiva. Detectamos en este grupo de informantes la presencia de unos sólidos conocimientos teóricos sobre el error que vienen a ser respaldados por la presencia de unas aptitudes en torno a la corrección en el sentido de estar orientadas a la interacción oral con el alumno (dotación de feedback oral), así como de unas actitudes de respeto y de apertura hacia el error y, consecuentemente, hacia la corrección y el feedback. 


\section{CONCLUSIONES}





\section{CONCLUSIONES}

En el presente documento de Tesis Doctoral nos aproximamos a las actitudes de los profesores ante la presencia de errores en las producciones escritas de los alumnos de L2 - desde la perspectiva de la corrección y la dotación de retroalimentación o feedback, como complemento a la corrección-Se trata de actitudes que, junto con los conocimientos y la aptitud, entran a formar parte de la competencia profesional docente en torno al error, a la corrección de errores y al feedback. El trabajo de investigación se ha revelado útil y pertinente puesto que nos ha permitido el acceso a un tipo de información acerca del componente afectivo que influye directa e indirectamente en la enseñanza-aprendizaje de una L2.

La investigación llevada a cabo nos ha permitido obtener una visión global en torno a la valoración del error y a la actitud docente ante la presencia de este, su corrección y su correspondiente feedback. Asimismo, partimos de las numerosas teorías existentes alrededor de los beneficios del uso del error en el aula y su posible integración en la enseñanza-aprendizaje de una L2 y, acorde al objeto de estudio planteado, decidimos realizar un estudio comparativo. Por otra parte, el presente estudio investigador, desde un profundo proceso de reflexión y autorreflexión en torno al propio trabajo docente, nos ha remitido a la necesidad de entrar en contacto con otras realidades educativas para poder entender mejor la práctica docente.

Dicho estudio se ha llevado a cabo en dos contextos educativos muy distintos: por una parte, centros de Educación Primaria emplazados en la ciudad de Valladolid, España y, por otra, 
centros de Educación Primaria ubicados en la ciudad de Austin, EEUU. Los factores sociales, culturales e institucionales que los determinan nos han facilitado el acceso a aquellas actitudes de los profesores en torno al error, a la corrección de errores y al feedback que son tan diferentes y, a la vez, tan parecidas. Por un lado, actitudes que se aproximan a una pedagogía tradicional orientada predominantemente a la marcación de errores centradas en la desconfianza hacia las posibilidades que ofrecen la corrección y el correspondiente feedback en contraposición con unas actitudes de respeto y de apertura ante el error.

Las indagaciones bibliográficas realizadas nos han confirmado el hecho de que el error es un concepto complejo que supone la presencia de diferentes aportaciones realizadas por el profesor a la producción escrita de los alumnos de L2. Aportaciones que incluyen comentarios, tanto orales como escritos, mensajes de apoyo, símbolos, marcas, notas numéricas, etc. y que, subsidiariamente, implican la presencia intrínseca de un componente afectivo que puede ser entendido desde distintas perspectivas, entre estas, la de la Semiótica paralingüística (en cuanto al feedback, al tipo de lenguaje y tono de voz utilizados por el profesor, los gestos, la expresión facial y otros rasgos suprasegmentales como la entonación y el acento). A la vez, analizamos las aptitudes en torno al feedback desde sus múltiples acepciones incluidas las de posición que ocupa el profesor en la mesa, su postura y la relación interhumana que establece con el alumno, como parte de la denominada comunicación no verbal que se lleva a cabo entre profesor y alumno.

Además, el recorrido teórico y conceptual realizado nos ha permitido adentrarnos en las distintas consideraciones en torno al error, desde su apreciación como algo totalmente negativo (fallo, muestra de una producción incorrecta), hasta su identificación -con la llegada del proceso 
de enseñanza centrado en el alumno- como marcador y signo positivo de la evolución del proceso mismo de aprendizaje. El error, considerado como desviación sistemática de las reglas, ha sido objeto de investigación de numerosos estudios que han replanteado este concepto, en relación con el llamado análisis del error o pedagogía del error. Las reacciones ante este planteamiento se han centrado en dos polos opuestos: por una parte, de rechazo y, por otra, de confianza ante las posibilidades que podría aportar el nuevo enfoque científico del error.

La importancia misma de los factores social, cultural, y pedagógico-educativo en la consideración del error incide en las actitudes de profesores y alumnos ante este y, a nuestro parecer, una de las aportaciones más interesantes de esta Tesis Doctoral reside precisamente en los resultados obtenidos en torno al componente afectivo que ejerce una clara influencia en la corrección del error. La investigación llevada a cabo nos ha permitido llegar a una primera conclusión en relación al grado de entusiasmo hacia el aprendizaje de una L2, el cual, dependerá directamente del contexto social y cultural al que los alumnos hayan sido expuestos. Por su parte, los profesores también mostrarán distintas actitudes ante la enseñanza de una determinada lengua en función del grado de estima asociado a dicha lengua o variedad dialectal. Asimismo, son muchas las razones de carácter político, cultural y económico que pueden determinar el hecho de que una lengua alcance un determinado prestigio social. Dicho prestigio, asociado a una determinada lengua, podrá ejercer una clara influencia tanto en alumnos como en profesores y delimitará el tipo de actitud que se adopte. Así pues, las ideas preconcebidas derivadas del contexto social en el que viven producirán una serie de actitudes positivas o negativas hacia la enseñanzaaprendizaje de esa lengua, lo cual ejercerá una clara influencia en su motivación. 
Las matizaciones en torno a las actitudes del profesor de L2 ante el error, la corrección y el feedback como objeto de estudio nos permitieron:

- acercarnos a las correspondientes formas de tratamiento del error en función de los contextos educativos;

- acceder a distintos enfoques respecto a los conceptos de error, corrección y feedback, en función del contexto educativo: un enfoque tradicional frente a un enfoque abierto, de aprovechamiento y respeto hacia el error como signo de aprendizaje e instrumento de diagnóstico.

- localizar la existencia de diferentes muestras de actitudes en torno al error, a su corrección y al feedback que lo acompaña;

- observar que el feedback suministrado por los profesores y que acompaña a la corrección de errores juega un papel fundamental en la corrección de las producciones escritas de los alumnos de L2, constituyéndose en un elemento que va mucho más allá de un simple comentario en el que se muestran los aspectos susceptibles de mejora de la producción escrita;

El análisis de la información recogida a través del cuestionario como instrumento elegido y diseñado para la presente investigación nos ha permitido:

- poner de manifiesto la existencia de posturas afines en relación a la necesidad de mostrar actitudes positivas ante la presencia del error y ante el uso apropiado de la corrección de errores y del feedback por parte de los profesores que desarrollan su 
actividad docente en los dos contextos educativos analizados. Sin embargo, a pesar de la identificación de estas posturas semejantes, observamos, que los profesores de los dos contextos educativos optan por una aplicación diferente en torno a la integración del error dentro del proceso de enseñanza-aprendizaje de la L2 en la realidad educativa del aula.

- observar que la propuesta de las actividades de producción escrita llevadas al aula por los profesores del contexto educativo de Valladolid está orientada a una exposición directa de los alumnos ante una hoja de papel en blanco sin aportar el suficiente input comprensible ni las estrategias necesarias para el desarrollo de la tarea. Durante el proceso de corrección, es el profesor quien asume el rol de autoridad sin que se produzca interacción oral centrada en el análisis de los errores con el alumno.

- inferir que los informantes del contexto educativo de Austin conocen la importancia que tiene la presencia del componente afectivo en el aula de L2 y, en este sentido, presentan las actividades de expresión escrita de una forma atractiva. Además, intervienen de forma activa en el proceso de producción textual orientando y aportando sugerencias al alumno y utilizando modalidades de corrección que fomenten un aprendizaje significativo. De acuerdo con esto podemos afirmar que los informantes del mencionado contexto educativo cuentan con aptitudes respecto al uso de un tipo de feedback oral, individual en el que se intenta desarrollar la interacción entre alumno y profesor lo cual confirma el uso de una corrección inmediata orientada al enfoque metodológico de producción escrita centrada en el proceso de escritura y no en el producto final. Y son los informantes del contexto educativo de Austin los que plantean una tipología de corrección y un feedback adaptados a las necesidades educativas de 
los alumnos que favorezcan la reflexión y el aprendizaje significativo de la L2 y que, además, permitan que el alumno pueda sentir que es parte del proceso de corrección y de evaluación.

En consecuencia, podemos afirmar que el itinerario investigador realizado confirma la hipótesis que planteábamos en la Introducción del presente documento de Tesis Doctoral: la existencia de una actitud positiva generalizada de los profesores en torno a la presencia de los errores en las producciones escritas de L2 de los alumnos, como paso previo hacia el éxito del propio proceso de enseñanza-aprendizaje. No obstante, estas actitudes positivas se revelan como “actitudes simuladas" puesto que no siempre se manifiestan en las prácticas de corrección. Así pues, mientras que, en los dos contextos educativos que forman parte de nuestra investigación, los profesores presentan, a nivel declarativo, actitudes positivas en torno al error, en las prácticas educativas hay orientaciones muy distintas en cuanto a los conocimientos, las aptitudes y las actitudes ante el error, la corrección de errores y el feedback.

A tenor de los resultados, la tendencia a marcar los errores de los alumnos está todavía muy presente en la memoria colectiva de los profesores pertenecientes al contexto educativo de Valladolid, a pesar de que estos, en general, muestran un fuerte conocimiento sobre las nuevas teorías de tratamiento del error y, además, admiten que este puede ser una herramienta didáctica muy útil en la enseñanza-aprendizaje de una L2. En contraste con lo anterior, los profesores que ejercen su actividad en los centros educativos de la ciudad de Austin, no solo conocen dichas teorías, sino que, además, las ponen en práctica utilizando modelos de corrección acordes con la 
edad y las necesidades educativas de los alumnos. Estos modelos están centrados en la corrección inmediata y en la interacción oral con el alumno.

Las conclusiones del presente estudio comparativo nos llevan a observar un marcado contraste entre el nivel declarativo y el práctico-actitudinal de los profesores respecto a la corrección de errores y al uso del feedback. Así, pues, el error sigue siendo desaprovechado en el contexto educativo de Valladolid sin llegar a ser integrado en la enseñanza-aprendizaje de una L2. En virtud de ello, nos encontramos en situación de:

- concluir que, en Valladolid, se usa un método más tradicional de enseñanza de expresión escrita y de corrección de errores;

- constatar la existencia de diferencias significativas en cuanto a la valoración del error y al planteamiento de la corrección de errores en las producciones escritas de los alumnos en un contexto español respecto a uno norteamericano;

- dar cuenta de que, los profesores del contexto educativo español, a pesar de tener conocimientos sobre los beneficios del uso del error en el aula, siguen desaprovechando su presencia sin llegar a integrarlo dentro del proceso de enseñanza-aprendizaje de una L2;

- deducir que, en este contexto educativo, se sigue relacionando la presencia del error con sentimientos de rechazo y con un impacto negativo en el aprendizaje de lenguas;

- suponer que la importancia concedida a los exámenes estandarizados en las distintas destrezas lingüísticas en el contexto educativo norteamericano tiene su repercusión en la 
mejora de la formación del profesorado de L2; una formación orientada a la integración del error como instrumento en la enseñanza-aprendizaje de una L2;

- advertir, por tanto, la existencia de un desconocimiento por parte de los informantes del contexto educativo de Valladolid de la importancia que tiene el componente afectivo en el aula de L2 en general y la repercusión que puede tener en las producciones escritas del alumno.

- dar cuenta de la presencia, en las aulas de Valladolid, de una metodología de corrección dirigida al producto o borrador final y no al propio proceso de producción textual.

En consonancia con lo que hemos venido apuntando en torno a las teorías de adquisición lingüística, podemos afirmar que el componente afectivo está directamente relacionado con el proceso de adquisición de la L2. De acuerdo con la hipótesis del filtro afectivo formulada por Krashen (1982), las variables afectivas, a saber: actitudes de los alumnos hacia su L2, su estado emocional, el grado de ansiedad, de motivación, de confianza en sí mismo, etc., contribuirán de forma significativa en la adquisición de la L2.

Se han combinado dos métodos de análisis: cualitativo y cuantitativo. De las conclusiones de dichos análisis se desprende que las actitudes de los profesores del contexto educativo de la ciudad de Valladolid estimulan la existencia de un filtro afectivo alto -materializado en un elevado nivel de ansiedad y en un bajo nivel de autoestima y de participación en el aula- que puede impedir o bloquear el proceso de adquisición del alumno. Como ya venimos señalando en los apartados correspondientes a la interpretación de los resultados de nuestro análisis, estos utilizan técnicas tradicionales de exposición de los alumnos ante las actividades de escritura libre y, a pesar de 
mostrar un claro interés en presentar este tipo de actividades de una forma atractiva y de contar con aptitudes en torno al grado de intervención en estas actividades, no promueven un acercamiento al alumno que fomente la creación de un ambiente relajado en el aula reduciendo así sus niveles de ansiedad ni realizan indagaciones acerca del momento idóneo para la corrección de errores. Todo esto se concreta en unas actitudes que no favorecen la creación de una relación de confianza con el alumno ni el respeto hacia el error durante el proceso de corrección de errores y posterior dotación de feedback. A nuestro juicio, se precisa un cambio de actitud por parte de los profesores de inglés como L2 en el contexto educativo de Valladolid. Los resultados del análisis de los datos nos han revelado que las actitudes manifestadas por estos no influyen de una manera decisiva en el aprendizaje, ni están orientadas a motivar a los alumnos en el proceso de producción escrita en L2. Como hemos venido manifestando, la dimensión afectiva está adquiriendo tal protagonismo, hoy en día, que se puede afirmar que las actitudes y las emociones influyen tanto en el éxito como en el bajo rendimiento de los alumnos en el aprendizaje en general y en el aprendizaje de una L2 en nuestro caso particular.

Es evidente que, tanto desde la Psicología, como desde la Lingüística aplicada a la enseñanza de L2, se está concediendo una atención específica a la dimensión afectiva debido al impacto que tiene en el propio proceso de enseñanza-aprendizaje de L2. Los resultados correspondientes al contexto americano respaldan la hipótesis inicial respecto a la influencia en el éxito y el rendimiento de los alumnos. Esto nos determina a considerar necesario un replanteamiento de la dimensión afectiva y de su impacto en nuestra cultura educativa. 
En contraste con lo anterior, a partir de los resultados obtenidos en el presente estudio investigador, podemos decir que, aquellos profesores que ejercen su actividad en el contexto educativo de Austin conocen la importancia del componente afectivo en la enseñanza-aprendizaje de L2 y, consecuentemente, intentan llevar al aula actividades atractivas en las que la interacción profesor-alumno juegue un papel fundamental. Además, hacen uso de metodologías actuales de producción escrita que impulsan a los alumnos hacia un acercamiento a su profesor en forma de entrevistas individuales durante las cuales, el profesor no solo proporciona ayuda al alumno durante el proceso de producción sino también una corrección inmediata acompañada de un feedback oral, individual. Por todo ello, podemos afirmar que las actitudes presentadas por dichos profesores (cuyos parámetros vienen definidos por sus conocimientos y aptitudes) contribuyen a la existencia de un filtro afectivo bajo en los alumnos de L2 que posibilita que estos presenten una mayor predisposición a recibir mayor cantidad de información, reduzcan su nivel de ansiedad ante las actividades de producción escrita y ante los errores y, finalmente generen un mayor grado de confianza en sí mismos y en las personas que lo rodean (profesores y compañeros). Los profesores de este contexto no solo muestran unas actitudes de aceptación y de apertura ante el error sino también de cercanía y confianza hacia el propio alumno. En este trabajo de investigación nos hemos aproximado a dichas actitudes, las cuales, como ya mencionábamos en la Introducción, se revelan como favorables para el aprendizaje de una L2 y, por tanto, pueden llegar a contribuir de manera decisiva en la motivación del alumno y en el rendimiento respecto al aprendizaje de la L2.

Como hemos venido destacando, en la presente Tesis Doctoral, damos cuenta de la existencia de una serie de componentes cognitivos, afectivos y conductuales comunes que entran a formar parte de la actitud. Por otro lado, el análisis de los datos deja entrever que, además de 
estos componentes comunes, también existen diferencias significativas respecto a aquellos elementos o rasgos específicos para cada uno de los dos contextos educativos analizados, a saber: una formación diferente respecto a las nuevas teorías de adquisición de L2 y una política educativa diferente respecto a la enseñanza-aprendizaje de L2. Así pues, el contexto educativo de Valladolid, a diferencia del contexto de Austin, no reconoce la existencia de una modalidad de corrección adaptada a las necesidades educativas del alumno, ni tampoco considera la existencia de un momento idóneo para la corrección. Asimismo, no se concede una atención especial al feedback que el profesor ha de proporcionar al alumno ni se establece un momento determinado en la clase en el que el profesor se reúna de manera individual con el alumno para realizar un trabajo cooperativo de elaboración de la producción escrita. En este sentido, en el contexto educativo de Valladolid, no se insiste tanto en fomentar las relaciones interpersonales entre alumno y profesor. Por su parte, los profesores de Austin defienden la idea del uso de una corrección inmediata acompañada de un tipo de feedback que facilite la interacción entre alumno y profesor.

En relación con todo lo expuesto, se impone una formación del profesorado orientada a las actitudes, las cuales, como hemos podido comprobar, se adquieren tanto de manera consciente como inconsciente y se basan en la experiencia profesional docente. En sintonía con esto, podemos afirmar que la actitud está en estrecha relación con lo cognitivo -entendido como el conocimiento de los profesores sobre las nuevas teorías de adquisición de L2 respecto al tratamiento del error, el estatus del feedback en el aprendizaje y su impacto tanto en la motivación como en el rendimiento del alumno- y con lo afectivo -entendido como la personalidad del profesor la cual incide en la actitud hacia el tratamiento del error. 
Encontramos, por ende, actitudes positivas manifestadas tanto por los profesores de Valladolid, como también por los de Austin en torno a la presencia del error en las producciones escritas de los alumnos de L2. Sin embargo, tal y como presentábamos en nuestra hipótesis de investigación estas actitudes positivas se presentan de formas distintas. Por un lado, las encontramos en un tipo de corrección en diferido y explícita (en la que los errores se subrayan y/o se sancionan). Corrección que puede ser fuente de bloqueos para los alumnos en edades tempranas impidiendo que estos puedan apreciarla y entender su significado (contexto de Valladolid). Por otro lado, las localizamos en una corrección inmediata acompañada de un feedback oral, individual, orientado a motivar al alumno, a animarlo y a proporcionarle un soporte con el objetivo de que este mantenga una actitud positiva en torno al papel del error en el aprendizaje (contexto de Austin). En los dos contextos, el error se entiende como síntoma de aprendizaje y, consecuentemente, se le considera parte integrante del proceso de enseñanza-aprendizaje de una L2.

Nos referimos a la actitud como una manifestación subjetivo-afectiva que no es observable de manera directa y, de ahí, la dificultad a la hora de establecer unos parámetros de medición. El carácter estable de las actitudes viene determinado por el contexto educativo en el que se ha formado el profesor, así como las teorías de enseñanza-aprendizaje que sustentan su propia formación, las cuales, influirán de una manera decisiva en sus actitudes hacia el error, la corrección y el feedback. Aunque a los profesores se les obliga a reciclarse constantemente, es decir, a actualizar sus conocimientos sobre las nuevas teorías de adquisición de L2, esto no asegura un cambio de actitud en la práctica. Asimismo, es difícil identificar la distancia entre el nivel declarativo y el nivel práctico-actitudinal en la actividad docente. A nivel declarativo, los 
profesores defienden la idea de aportar feedback, pero la realidad de la práctica docente demuestra lo contrario. En conclusión, así como hemos venido apuntando, se impone la necesidad de incluir, dentro de la formación, tanto inicial como continua del profesorado, aspectos relacionados con la actitud hacia el tratamiento del error (en la perspectiva de la corrección y del feedback) según el objetivo marcado para la enseñanza-aprendizaje de L2 en cada contexto educativo.

Tal y como venimos destacando, los contextos educativos a los que acudimos para llevar a cabo la presente Tesis Doctoral plantean objetivos diferentes en cuanto a las producciones escritas de los alumnos de Educación Primaria que estudian L2. Todo ello supone la existencia subyacente de una determinada concepción del error, una determinada actitud ante este y su corrección, así como un estatus asignado al correspondiente feedback.

Según se ha podido observar, en el contexto de Valladolid, la atención se centra en el producto final o el resultado de la actividad de escritura en L2. Acorde a este objetivo, los profesores vallisoletanos eligen proporcionar un tipo de feedback que abarca una serie de marcas gráficas y breves anotaciones acompañadas de una nota numérica. Este tipo de feedback incide de forma negativa en las actitudes de los alumnos al tiempo que reduce significativamente su participación activa y su entusiasmo por aprender una L2. Esto nos permite afirmar que conciben el error como resultado de una regla no interiorizada, un fallo que entorpece la comprensión del texto. Todo lo cual pone de manifiesto una perspectiva cerrada y poco comprensiva por parte del profesor. 
En cambio, en lo que se refieren al contexto educativo de Austin, la atención está orientada hacia el propio proceso de escritura del alumno. El feedback oral e individual se une a la corrección, que se realiza de forma inmediata, formando un todo indisoluble. Así es como, en la cultura norteamericana, a diferencia de la europea, el feedback adquiere mayor protagonismo a lo largo de todo el proceso. La corrección acompañada del feedback se materializa en una serie de entrevistas individuales en las que profesor y alumno analizan de manera colaborativa tanto los aciertos como los errores presentes en la producción escrita. Al final de todo el proceso, el profesor ofrece una serie de sugerencias bajo la forma de frases de apoyo con el objetivo último de motivar al alumno.

Habida cuenta de las diferencias existentes en torno al feedback en los dos contextos educativos examinados, se revela como necesidad la presencia de una reflexión en torno a las culturas que los representan. Hablamos de objetivos y procesos diferentes para cada uno de los contextos educativos ya que cada uno se centra en un determinado componente de la producción escrita en L2. Como aspecto llamativo y sumamente interesante destacamos el hecho de que el feedback americano está orientado a desarrollar una serie de relaciones interpersonales entre profesor-alumno, así como entre los propios compañeros del aula que pueden intervenir en el proceso de corrección. No obstante, el feedback que se proporciona en los centros educativos europeos no tiene un carácter afectivo tan marcado puesto que se transmite de forma escrita sin que exista interacción oral. Todo esto nos lleva a afirmar que los procesos de corrección y feedback presentan una dimensión más humana en el continente americano respecto a Europa. Hablamos, por tanto, de un feedback afectivo-emocional que implica de manera intrínseca la presencia de relaciones interpersonales y de empatía entre profesor-alumno. La dimensión afectivo-emocional 
es uno de los múltiples factores que inciden en la calidad de los resultados. Así pues, unas óptimas relaciones alumno-profesor basadas en la confianza y el respeto mutuo pueden influir de manera decisiva en la actitud de los alumnos hacia la L2.

Las conclusiones del análisis correlacional llevado a cabo en el presente trabajo refuerzan las afirmaciones que abordamos en torno a los conocimientos, las aptitudes y las actitudes de los profesores de los dos contextos educativos analizados. A pesar de encontrar actitudes positivas en torno al error manifestadas por los profesores de los dos contextos educativos, estas no siempre tienen presencia en el aula de L2.

Los resultados de dicho estudio evidencian una falta de visión constructiva del error por parte de los informantes que ejercen su docencia en los centros educativos de Valladolid, desaprovechando su presencia como instrumento pedagógico dentro del proceso de enseñanzaaprendizaje de expresión escrita en L2. Los datos analizados nos permiten afirmar que estos no muestran interés suficiente en la consecución de un buen nivel de competencia en expresión escrita. En este sentido, no involucran al alumno en el proceso de escritura, ni recurren a un determinado sistema de corrección que permita un seguimiento del proceso de evolución del aprendizaje de la L2. Tampoco recurren a una dotación de feedback motivacional que acompañe el proceso de aprendizaje.

En contraposición, los informantes pertenecientes al contexto educativo de Austin se preocupan por crear situaciones de aprendizaje en las que poder mostrar al alumno que los errores son símbolo de su progreso en el aprendizaje de una L2. Además, incluyen en sus clases 
actividades dirigidas a estimular el acercamiento entre profesor y alumno fomentando las actitudes positivas y otorgando un papel relevante al factor afectivo. Tal y como hemos podido comprobar, estos profesores cuentan con conocimientos teóricos sobre el error apoyados por la presencia de unas aptitudes en torno a la corrección orientadas a la interacción oral con el alumno, así como de unas actitudes de respeto y de apertura hacia el error y, consecuentemente, hacia la corrección y el feedback.

Nos aproximamos, por tanto, a dos contextos educativos diferentes con rasgos identificativos propios que responden a la elección de opciones diferentes en torno a los procesos de corrección y de feedback. Sin embargo, no nos proponemos en ningún caso realizar afirmaciones en torno a la idoneidad de uno respecto al otro. En virtud de ello, nuestro objetivo se circunscribe a la observación reflexiva de determinados aspectos relacionados con la corrección y el feedback correspondientes a otros modelos educativos que puedan inspirarnos en nuestras prácticas docentes con el fin de intentar mejorarlas.

El presente trabajo de investigación contribuye a aclarar algunas incógnitas, pero, al mismo tiempo, genera nuevas preguntas y abre nuevas líneas de investigación como la formación del profesorado de L2 en torno al error y a su corrección. Puede ser útil extender esta búsqueda de información y efectuar un estudio detallado del modo en que se enfoca la formación del profesorado en el tratamiento del error. En nuestra opinión, una formación orientada, por un lado, a la observación y al uso de instrumentos de diagnóstico de errores y, por otro, a la importancia de la actitud ante el error que se revela como un elemento imprescindible dentro de la formación profesional docente puesto que afecta a la evaluación como APD. Una formación que proporcione 
un mejor conocimiento sobre el funcionamiento de la L2 y sobre las actitudes típicas ante el error y que, además, ayude a detectar las dificultades de aprendizaje más comunes de los alumnos puesto que, una corrección de errores adecuada permitirá al docente llegar a un buen diagnóstico del nivel de competencia en L2 de los alumnos. En nuestro caso, la investigación realizada nos conduce a defender la necesidad de una formación del profesor de L2 orientada a los conocimientos, las aptitudes y las actitudes en torno al error y a su corrección - revelándose estos como componentes competenciales clave debido al fuerte impacto que unos conocimientos exhaustivos, unas aptitudes profesionales docentes óptimas y unas actitudes positivas orientadas al error, a la corrección y al feedback producirán en el nivel de motivación del alumno.

El estudio de las actitudes del alumno ante la presencia del error, la corrección y el feedback podría constituir el punto de interés de otras investigaciones. Un posible análisis comparativo entre las actitudes del alumno y las del profesor enfocado desde la perspectiva formativa. Asimismo, cabría considerar el planteamiento de un análisis comparativo entre los centros que formaron parte de nuestra investigación y una serie de centros educativos emplazados en áreas rurales de la provincia de Valladolid y del estado de Texas.

Consideramos que el presente trabajo es un estudio prospectivo que podría abrir otros caminos hacia la realización de una serie de estudios exhaustivos llevados a cabo por investigadores interesados en el tema. Dada la diversidad de contextos educativos en los que tiene lugar la enseñanza-aprendizaje de L2, se podrían plantear investigaciones paralelas centradas en otras zonas de la provincia de Valladolid y del estado de Texas (incluidas las zonas rurales). Los futuros proyectos de investigación, partiendo de una base empírica más amplia en la que poder 
aplicar otro tipo de análisis estadísticos podrían validar o invalidar nuestras conclusiones, así como aportar datos que incidan de manera significativa tanto en la mejora de la enseñanza-aprendizaje de L2 como en la formación del profesorado. 


\section{CONCLUSIONS}





\section{CONCLUSIONS}

The present doctoral dissertation whose subject matter is the attitudes of teachers towards the presence of errors in students' written productions, from the perspective of correction and the provision of feedback as a complement to correction, has proved to be useful and relevant. The cross-cultural research has allowed us to access information about the affective component that directly and indirectly influences in second language (L2) teaching and learning. Attitudes, as well as knowledge and aptitude, become part of the teacher's professional competence with regard to error, correction and feedback.

Our research allowed us to gain a global vision of the appreciation of error and the teacher's attitude to the presence of error, its correction and the corresponding feedback. We decided to conduct a comparative study based on the theories surrounding the benefits of using error in the classroom and the possibility of integrating it into the L2 teaching-learning process. The present research study, based on a profound process of reflection and self-reflection around the teaching work itself, has motivated us to investigate other educational situations in order to better understand teaching practice.

The study has been carried out in two very different educational contexts: Elementary Schools located in Valladolid, Castilla y León, Spain and Elementary Schools located in Austin, Texas, United States of America. The social, cultural and institutional factors that underlie these two contexts have provided diverse educator attitudes towards error, error correction and feedback. On the one hand, we find attitudes related to a traditional pedagogy focused on the identification of errors. These attitudes do not rely on the possibilities offered by correction and the 
corresponding feedback. On the other hand, we find attitudes of respect, openness and potential for positive outcomes when identifying error.

The bibliographical research widely supports the fact that the error in L2 written productions is a complex concept that deserves an in-depth analysis. Its first effect is seen on the teachers' contributions by means of comments (both oral and written), supporting messages, symbols, marks, grades, etc., which introduce the presence of the affective component that can be understood from different approaches such as the Paralinguistic Semiotics perspective. From this approach, we analyzed teacher's skills at providing feedback to L2 students in the classroom. This involves a wide range of different aspects, including the position of teacher and student around the table, spatial proximity and the teacher-student connections, as part of the so-called non-verbal communication between teacher and student.

Errors, are viewed as systematic deviations from the rules. They have been the focus of attention of many studies that have reconsidered this concept in relation to the so-called error analysis or error pedagogy. Reactions to this approach have been centered on two opposing poles: on the one hand, rejection and, on the other, confidence in the possibilities the new scientific approach to error could bring. Our theoretical and conceptual research has allowed us to explore the different considerations surrounding the error, from its perception as something totally negative (failure, sign of incorrect production), to its use as an identifier of evolution in the learning process.

The importance of social, cultural, and pedagogical-educational factors in the consideration of error affects teacher and student's attitudes towards it. The present research allowed us to draw 
a first conclusion regarding the enthusiasm for learning a L2, which will depend directly on the student's social and cultural context. As for teachers, they will also show different attitudes towards teaching a particular language depending on the high esteem associated with that particular language or dialectal variety. There are also many political, cultural and economic reasons that can determine the fact that a language achieves a certain social status. This reputation, associated to a given language, will be able to clearly influence both students and teachers and will determine the type of attitude adopted. Thus, preconceived ideas arising from the social context will produce a number of positive or negative attitudes towards both teaching and learning a language. These will clearly influence students' and teachers' motivation.

The clarifications around L2 teacher's attitudes towards error, error correction and feedback as an area of study allowed us to:

- $\quad$ approach the different ways of treating error in terms of educational contexts;

- access different approaches regarding error, correction and feedback, depending on the educational context;

- identify the existence of different attitudes towards error, its correction and the feedback that goes with it;

- determine that the feedback provided by teachers that complements error correction plays a major role in the correction of written L2 students' contributions constituting an element that goes far beyond a simple comment showing the aspects that can be improved in written productions. 
The analysis of the information collected through the questionnaire as the instrument chosen and designed for this research has enabled us to:

- prove that there are similar positions from teachers in both educational contexts on the necessity to maintain a positive attitude towards the presence of error, the appropriate use of it, its correction and feedback. However, despite the identification of these similar positions, we observe that teachers in both educational contexts choose different approaches to the integration of error into the L2 teaching-learning process.

- ascertain that written activities proposed by the teachers from Valladolid are designed to expose students to a blank piece of paper without providing enough input nor information on the strategies required. During the process of editing, the teacher assumes the role of authority with no oral interaction with the student.

- discover that informants from the Austin are are more aware of the importance of the affective component in the L2 classroom and therefore present the written activities in an appealing and engaging way. They also take part actively in the textbased process by guiding and providing suggestions to students and by using corrective techniques that promote significant knowledge.

In contrast with educators from Valladolid, those in Austin display distinctive aptitudes for the use of a kind of oral feedback. They promote interaction between the learner and teacher, which confirms that an immediate methodological approach is used. Teachers are encouraged to use this methodological approach to written production centered on the writing process rather than the final product. It is the 
process-oriented methodology that proposes a kind of correction and feedback adapted to the students' educational needs that will encourage significant learning about L2 and will also enable the students feel they are part of the process of correction and evaluation.

The documented outcomes of our research confirm our hypothesis: the generalized and positive attitude of teachers towards the presence of errors in L2 written productions sets a preliminary stage for the success of the teaching-learning process. However, these are demonstrated as "simulated attitudes" since they are not necessarily reflected in correction practices. Thus, while in both educational contexts teachers have positive attitudes towards error at the declarative level, there are very different orientations in terms of understanding, skills as well as attitudes about error, correction and feedback.

In contrast with their peers in Valladolid, teachers working in Austin schools are not only familiar with these theories, but they also apply them using age-appropriate models of correcting students. The focus is on immediate correctness as well as on the oral interactions with the students.

The findings from this comparative research study suggest a stark difference between the declaratory and practical-attitudinal states of teachers with regards to correcting errors as well as using the feedback. As a consequence, error loses its value as a skill building event in the context of Valladolid without ever been incorporated in the L2 teaching-learning. For this reason, we conclude the following: 
- a more-traditional teaching methodology is used for teaching writing and for correcting errors in Valladolid;

- $\quad$ substantial discrepancies exist in error assessment and in the approach to correcting errors in the written productions of students;

- the benefits of using errors as a learning-teaching tool are widely wasted in Spanish classrooms despite educator's awareness of them;

- the presence of the error continues to be linked with feelings of rejection and with negative effects on the learning process in the Spanish educational context;

- standardized tests in the various language-related skills in the US context have an impact on improving L2 teacher training; including the skill of integrating errors into the teachinglearning process of L2;

- informants from Valladolid are unaware of the importance of the affective component in the L2 classroom, the repercussions of which directly impact students' written products;

- the tendency, in the schools placed in Valladolid includes a corrective methodology addressed to the final product or final draft (product-oriented methodology) and not to the actual textual production process.

As we have pointed out regarding linguistic acquisition theories, we can state that the emotional dimension of language acquisition is directly related to the acquisition process of L2. According to the affective filter hypothesis formulated by Krashen (1982), the affective variables, that is: students' attitudes towards their L2, emotional state, anxiety, self-confidence, motivation, etc., will significantly contribute to L2 acquisition. 
From the analysis conducted in the present research work, we can infer that teachers' attitudes in the educational context of Valladolid promote the existence of a high affective filter (in the form of high anxiety and low self-esteem and participation in the classroom) which can impede or obstruct the acquisition process of the student. As we have already pointed out under the sections corresponding to the interpretation of our analysis results, when it comes to exposing students to free writing activities, they use traditional techniques despite showing a clear interest in presenting these types of activities in an attractive way and despite having skills regarding the degree of involvement in these activities. They do not promote an approach to the student that fosters the creation of a relaxed environment in the classroom. They do not reduce their levels of anxiety or make inquiries about the ideal time for error correction. This is all materialised in attitudes that do not encourage the creation of a trusting relationship with the learner nor respect for the error during the process of correcting errors and providing feedback. In our opinion, there is a need for a change in English teachers' attitude in the educational context of Valladolid. The results from the data analysis have revealed that these attitudes do not have a decisive influence on learning, and are not intended to motivate students in the L2 written production process. As we have been stating, the affective dimension is gaining a prominent role nowadays. This means that attitudes and emotions have an impact on students' success in both general learning and in the learning of an L2 in our particular case.

Psychology and Applied Linguistics to the teaching of L2, are clearly giving specific attention to the emotional dimension due to the impact it has on the L2 teaching and learning process itself. The findings from the American context support the initial hypothesis regarding its influence on 
student success and performance. As a result, we consider that it is necessary to re-examine the emotional dimension and its impact on our educational culture.

In contrast to the above, we can say that those teachers who carry out their work in Austin are aware of the importance that the affective component has in the teaching-learning of L2. They consequently attempt to take to the classroom engaging activities in which teacher-student interactions will play an essential role. Moreover, they use current written methodologies that encourage students to approach their teachers through individual interviews. For this reason, we can state that the attitudes displayed by such teachers help to ensure a low level of affective filter in L2 students. The students have a greater willingness to receive more information, they reduce their anxiety about written activities and errors and, finally, they generate a higher level of selfconfidence. In this research work we approached these attitudes, which as mentioned in the Introduction, are shown to be beneficial for L2 learning. They can therefore make a significant contribution to student motivation and learning performance in L2.

As we have been highlighting, in this doctoral dissertation we are aware of the existence of a number of cognitive, affective and behavioural components included in the attitude that may be described as commonly shared elements. The analysis of the data shows that there are also significant differences regarding the specific characteristics of the two educational contexts analysed: they both have a different background in the new L2 acquisition theories and a different education policy regarding the L2 teaching and learning. As a result, teachers in Valladolid, unlike those in Austin, do not recognize the existence of a correction system adapted to the student's educational needs and do not consider the need for an appropriate time for correction. No special 
attention is paid to the feedback that the teacher has to provide to the student. Teachers do not consider that there should be a specific time in the class when the teacher and the student meet individually to work together on a cooperative basis to develop written production. Thus, in the educational context of Valladolid there is less emphasis on promoting interpersonal relations between students and teachers. As for the teachers from Austin, they support the idea of the use of immediate correction accompanied by a type of feedback that facilitates interaction between students and teachers.

The above requires teacher training based on attitudes which as we have already mentioned are acquired both consciously and unconsciously and they are based on professional teaching experience. We can state that the attitude is clearly closely related to the cognition -understood as teachers' knowledge of the new L2 acquisition theories regarding the treatment of error, the status of feedback in learning and its impact on both student motivation and performance- and the affectivity -understood as the teacher's personality which affects the attitude towards the treatment of error.

We find, therefore, positive attitudes shown by both teachers from Valladolid and from Austin regarding the presence of error in the written productions of L2 students. However, as we suggested in our research hypothesis, these positive attitudes can be seen in different ways. On the one hand, we find them in a kind of correction that is delayed and explicit (in which errors are underlined and/or penalised). This correction can be a source of barriers for students at an early age, preventing them from appreciating it and understanding its meaning (context of Valladolid). On the other hand, we find them in an immediate correction followed by an oral, individual 
feedback. This feedback is oriented to motivate the student, to encourage him/her and to provide him/her with a support so that he/she maintains a positive attitude about the role of error in learning (Austin context). In both contexts, error is understood as a learning symptom and, consequently, it is considered an integral part of the L2 teaching and learning process.

Attitude is a subjective-affective expression that can not be directly observed. This is why it is difficult to establish measurement parameters. The lasting nature of attitudes is determined by the educational context in which the teacher has been trained, as well as the teaching and learning theories that support the teacher's own training. This training will have a significant influence on the teacher's attitudes towards error, correction and feedback. Although teachers are constantly being required to update their knowledge of the new L2 acquisition theories, this does not ensure attitudinal change in practice. It is also difficult to identify the distance between the declaratory and practical-actitudinal levels in teaching activity. At the declarative level, teachers defend the idea of giving feedback but do not always do so in practice. According to the objectives set for L2 teaching and learning process in each educational context, we consider that it is necessary to include aspects related to the attitude towards the treatment of error (in the perspective of correction and feedback) within the initial and in-service training of teachers.

As we have been stressing, the educational contexts that we are attending for the present doctoral thesis present different objectives in terms of written productions of L2 students in Primary Education. This implies the underlying existence of a specific understanding of error, a specific attitude towards it and its correction, as well as a certain status assigned to the corresponding feedback. 
As we can see, in the context of Valladolid the focus is on the final product of the writing activity in L2. For this purpose, teachers from Castilla-León choose to provide a type of feedback that includes a series of graphic marks and brief notes accompanied by a numerical grade. This type of feedback has a negative impact on learners' attitudes and significantly reduces their active participation and enthusiasm for learning a L2. This means that they see error as the result of a rule that is not assimilated, a failure that complicates comprehension over the text. All of this highlights that the teacher has a closed and not very understanding perspective.

When it comes to the educational context from Austin, however, the focus is on the student's own writing process. Oral and individual feedback comes together with correction, which is accomplished immediately, becoming an indissoluble whole. In the American culture, in contrast to the European one, feedback acquires greater importance throughout the whole process. The correction accompanied by the feedback is materialized in a number of individual interviews in which teacher and student analyze in a collaborative way both the strengths and weaknesses presented in the written production. At the end of the whole process, the teacher provides the student with a number of suggestions under the form of support phrases intended to motivate the student.

Considering the differences between the two educational contexts in terms of feedback, there is a strong need to reflect on the cultures that represent them. We can say that there are different objectives and processes for each educational context, as each one focuses on a specific component of the written production in L2. As a remarkable but highly interesting aspect, we 
would like to highlight the fact that American feedback is aimed at developing a series of interpersonal relationships between teacher and student, as well as between classmates who can take part in the correction process. However, the feedback provided in European schools does not have such a strong emotional nature as it is presented in a written form without any oral interaction. This all leads us to state that the correction and feedback processes present a more personal dimension in the American continent compared to Europe. It is therefore an affective-emotional feedback that intrinsically implies interpersonal relationships and the presence of a teacher-student empathy. The affective-emotional dimension is one of the many influences that affect quality of results. Therefore, optimal teacher-student relations based on a sense of confidence and mutual respect can have a significant influence on students' attitudes towards L2.

The results of this study show a lack of a constructive view of the error on the part of the informants who teach in the schools of Valladolid, wasting their presence as a teaching tool within the teaching-learning process of written expression in L2. The analyzed data allow us to state that they do not show enough interest in achieving a good competence level in written expression. They do not involve students in the writing process, nor do they use a specific correction system that allows monitoring the evolution process of L2 learning. In addition, they do not use motivational feedback to support the learning process.

In contrast, informants in Austin' educational context are concerned with creating learning situations in which they can show students that errors are a symbol of their progress in learning an L2. In addition, they include in their classes activities designed to stimulate the approach between teacher and student, encouraging positive attitudes and giving a relevant role to the affective factor. As we can see, these teachers have a knowledge of the theory of error, reinforced by the presence 
of correction skills oriented towards oral interaction with the student, as well as attitudes of respect and openness towards error and, consequently, towards correction and feedback.

We are therefore approaching two different educational contexts with different identifying features that reflect the choice of different options in terms of correction and feedback processes. However, we do not intend to make statements about the suitability of one over the other. Therefore, our objective focuses on the reflective observation of certain aspects related to correction and feedback from other educational models that may inspire us in our teaching practices in order to try to improve them.

Although the present research work helps to clarify some uncertainties, it also generates new questions as it opens up new research lines such as L2 teacher education on error and its correction. It may be useful to extend this search and conduct a detailed study of how teacher education approaches the treatment of error. In our opinion, training oriented not only towards the observation and the use of error diagnosis instruments but also to the role that attitude plays in dealing with error is an essential element in professional teacher training. A training that provides a better understanding of how a L2 operates and also a better idea about typical attitudes to error would also help to identify some of the more common problems in learning. An adequate error correction will allow teachers to diagnose the students' L2 competence. This research has shown the need for teacher training in L2 focused on the three key competence components: knowledge, skills and attitudes regarding error and its correction. In-depth knowledge, optimized professional teaching skills and positive attitudes towards error, correction and feedback will positively impact on students' level of motivation. 
Another potential point of interest is the observation of the student's attitudes to the presence of error, correction and feedback. Since such attitudes have a direct relationship to the teacher's own behaviour, it may be useful to conduct some research around this topic, for example: a comparative analysis of the attitudes of the student and the teacher from the triple perspective of error, correction and feedback so as to determine the degree in which these attitudes coincide or differ.

This work is seen as a prospective study that could lead to a series of in-depth studies carried out by researchers interested in the subject. Given the diversity of educational contexts in which L2 teaching-learning takes place, parallel research focused on other areas of the province of Valladolid and the state of Texas (including rural areas) could be considered. Future research projects, based on a larger empirical basis where other types of statistical analysis can be applied, could validate or invalidate our conclusions, as well as provide data that have a significant impact both on the improvement of L2 teaching-learning and on teacher training. 


\section{BIBLIOGRAFÍA DE REFERENCIA Y CONSULTA}

\section{Bibliografía general}

2. Fuentes bibliográficas electrónicas

3. Disposiciones oficiales y documentos institucionales de referencia 


\section{Bibliografía general}

Ancker, W. (2000). Errors and corrective feedback: Updated theory and classroom practice. English Teaching Forum, 38(4), 20-25.

Agustín Llach, M. P. (2005). La competencia pragmática y los errores pragmático-léxicos en la clase de ELE. En A. Álvarez, C. de la Hoz, L. Barrientos, I. Iglesias. M. Brafia, P. Martínez, V. Coto, M. Prieto, M. Cuevas \& A. Turza (Eds.), XVI Congreso Internacional de ASELE. La Competencia Pragmática y la Enseñanza del Español como Lengua Extranjera (pp. 96102). Oviedo, España.

Agustín Llach, M. P. (2011). Lexical errors and accuracy in foreign language writing. Bristol: Multilingual Matters.

Alfieri Lane, L. G. (1997). Error correction: An investigation of teachers ideas and attitudes. Tesis de Magister no publicada. University of Texas at Austin, Texas, Estados Unidos de América. 
Álvarez Piñeiro, M. \& Camiña Salgado, S. (2005). Los errores en la publicidad escrita. Propuestas didácticas en la clase de E/LE. En M.A. Castillo Carballo, O. Cruz Moya, J. M. García Platero, \& J. P. Mora Gutiérrez (Coords.), XV Congreso Internacional de ASELE. Las Gramáticas y los Diccionarios en la Enseñanza del Español como Segunda Lengua: Deseo y Realidad (pp. 128-132). Sevilla, España.

Anguera Argilaga, M. T. (1990). Metodología observacional. En J. Arnau Gras, M T. Anguera Argilaga \& J. Gómez Benito. Metodología de la Investigación en Ciencias del Comportamiento (pp. 125-238). Murcia: Universidad de Murcia.

Avalos, M. A., Zisselsberger, M., Langer-Osuna, J. \& Secada, W. (2015). Building teacher knowledge of academic literacy and language acquisition. A framework for teachers'crossdisciplinary professional learning. En D. Molle, Daniella, E. Sato, T. Boals, \& C. A. Hedgspeth (Eds.), Multilingual learners and academic literacies: Sociocultural contexts of literacy development in adolescents (pp. 255-276). New York, NY: Routledge.

Baralo, M. (1999). La adquisición del español como lengua extranjera. Madrid: Arco Libros.

Barron, A. (2001). Acquisition Interlanguage Pragmatics: Learning how to do things with words in a study abroad context. Amsterdam: John Benjamins. 
Barros Díez, E. (2008). Evaluar y aprender. La evaluación del análisis de errores en la expresión escrita. En S. Pastor Cesteros \& Santiago Roca Marín (Eds.), XVIII Congreso internacional ASELE. La evaluación en el aprendizaje y la enseñanza del español como lengua extranjera/segunda lengua (pp.199-204). Alicante, España.

Bou Franch, P. \& Gregori Signes, C. (1998). Pragmática intercultural: emisiones del oyente en inglés británico y español peninsular. En A. Sánchez Macarro, V. Salvador Liern \& J-R. Gómez Molina (Eds.), Pragmática Intercultural. Quaderns de filología. Estudis lingüístics, 4 (1) (pp. 123-134). Valencia: Universitat de Valencia.

Bueno Hudson, R. (2013). Propuestas para la enseñanza de la pronunciación y corrección fonética en español como lengua extranjera. En A. Blas Nieves \& J. Corros (Eds.), I Congreso Internacional de Didáctica de Español como Lengua Extranjera del Instituto Cervantes de Budapest (pp. 15-36). Budapest, Hungría.

Burt, M. (1975). Error Analysis in the Adult EFL Classroom. TESOL Quarterly, 9(1), 53-63.

Buzea, O. (2013). The Importance of Writing Skills in Teaching English. Analele Universităţii Spiru Haret. Seria Filologie. Limbi şi Literturi străine, 18, 31-36.

Campbell, C. (1998). Teaching Second-Language Writing: Interacting with a Text. Scarborough, Canadá: Heinle \& Heinle. 
Canale, M. (1983). De la competencia comunicativa a la pedagogía comunicativa del lenguaje. En M. Llobera et al. Competencia comunicativa. Documentos básicos en la enseñanza de lenguas extranjeras (pp. 63-83). Madrid: Edelsa.

Cantero Serena, F.J. \& Mendoza Fillola, A. (2003). Conceptos básicos en Didáctica de la Lengua y la Literatura. En A. Mendoza (Coord.), Didáctica de la Lengua y la Literatura para Primaria (pp. 33-78). Madrid: Pearson/Prentice Hall

Carless, D. (2013). Trust and its role in facilitating dialogic feedback. En D. Boud \& E. Molloy (Coords.), Feedback in Higher and Professional Education. Understanding it and doing it well (pp. 90-103). New York, NY: Routledge

Cassany, D. (1993). Reparar la escritura. Didáctica de la corrección de lo escrito. Barcelona: Graó.

Cassany, D., Luna, M., \& Sanz, G. (1994). Enseñar lengua. Barcelona: Graó.

Cassany, D. (1996). Describir el escribir: cómo se aprende a escribir. Barcelona: Paidós.

Cassany, D. (1997). La cocina de la escritura. Barcelona: Anagrama.

Cassany, D. (2005). Expresión escrita en L2/LE. Madrid: Arco Libros. 
Cenoz Iragui, J. (2004). El concepto de competencia comunicativa. En J. Sánchez Lobato \& I. Santos Gargallo (Dirs.), Vademécum para la formación de profesores. Enseñar español como segunda lengua/lengua extranjera (pp. 449-465). Madrid: SGEL.

Chomsky, N. (1975). Aspects of the theory of syntax. Cambridge, MA: The MIT Press.

Constantinescu, I. (2011). Dictionnaire pratique de didactique du français langue étrangère (F.L.E). Bucureşti: Fundaţia România de Mâine.

Cook, V. \& Singleton, D. (2014). Key topics in second language acquisition. Bristol, Reino Unido: Multilingual Matters.

Corder, S. P. (1967). The Significance of Learners' errors. International Review of Applied Linguistics, 5, 161-170.

Corder, S. P. (1973). Introducing applied linguistics. Harmondsworth, Reino Unido: Penguin Education.

Corder, S. P. (1981). Error Analysis and Interlanguage. Oxford: Oxford University Press.

Corpas, M. D. \& Madrid, D. (2007). Desarrollo de la producción escrita en inglés al término de la Educación Secundaria Obligatoria Española. Porta Linguarum, 8, 173-195. 
Cumming, A. H. (2006). Introduction, purpose and conceptual foundations. En A. Cumming (Ed.), Goals for academic writing: ESL students and their instructors (pp. 1-17). Amsterdam: John Benjamins Pub. Co.

d’Aquino, A. (2016). ¡De los errores se aprende! La corrección como instrumento didáctico. Textos. Didáctica de la Lengua y de la Literatura, 71, 7-13.

Davidson, D. M. (1978). Assessing writing ability of ESL college freshmen. En R. L. Light \& A. H. Osman (1978). (Eds.), Collected papers in teaching English as a second language and bilingual education: Themes, practices, viewpoints (pp. 86-101). New York, NY: New York State English to Speakers of Other Languages and Bilingual Educators Association.

de la Torre, S., Mallart, J., Tort, Ll., Rajadell, N., Laffitte, R. \& Oliver, C. (1994). Errores y currículo. Tratamiento didáctico de los errores en la enseñanza. Barcelona: Promociones y publicaciones universitarias.

Diop, P. M. (2008). Autonomía y profesionalización de los profesores de lenguas en Senegal. Estudio de los actos profesionales docentes desde las estrategias de formación continua. Tesis Doctoral. Universidad de Valladolid. Facultad de Educación y Trabajo Social. Departamento de Didáctica de la Lengua y la Literatura. Valladolid. 
Dolz, J., Gagnon, R., Mosquera, S. \& Sánchez, V. (2013). Producción escrita y dificultades de aprendizaje. Barcelona: Graó.

Domínguez, G \& Barrio, J. L. (1997). Los primeros pasos hacia el lenguaje escrito. Una mirada al aula. Madrid: La Muralla.

Dulay, H, Burt, M. \& Krashen, S. (1982). Language two. New York, NY: Oxford University Press.

Dulay, H. C. \& Burt, M. K. (1984). You can’t learn without goofing. En J.C. Richards (Ed.), Error Analysis. Perspectives on Second Language Acquisition (pp. 95-123). London: Longman.

Dumbravescu, D.-G. (2014). Estatus de los Manuales Escolares y Formación Inicial del Profesorado de ELE: Indicadores de Actualización para el Ámbito Académico de Rumanía. Tesis Doctoral. Universidad de Valladolid. Facultad de Educación y Trabajo Social. Departamento de Didáctica de la Lengua y la Literatura. Valladolid.

Durán, R. (2011). Guidelines for Error Correction in the EFL Classroom. En S. House (Coord.), Inglés. Investigación, innovación y buenas prácticas (pp. 61-67). Barcelona: Graó.

Durão, A. B. d. A. B. (2007). La interlengua. Madrid: Arco-Libros.

Ellis, R. (2008). The study of second language acquisition. Oxford: Oxford University Press. 
English, G. (2004). Managing information and human performance. Strategies and methods for knowing your workforce and organization. Amherst, MA: HRD Press.

Evans, N. W., Hartshorn, K. J., McCollum, R. M. \& Wolfersberger, M. (2010a). Contextualizing corrective feedback in second language writing pedagogy. Language Teaching Research $14(4), 445-463$.

Evans, N. W., Hartshorn, K. J. \& Tuioti, E. A. (2010b). Written corrective feedback: the practitioners' perspective. International Journal of English Studies, 10(2), 47-77.

Fabián Martín-Arroyo, M.D. (2016). El temido bolígrafo rojo. La elaboración de sistemas de corrección para la expresión escrita. En M.A. Lamolda González (Comp.), XXVI Congreso internacional ASELE. La formación y competencias del profesorado de ELE (pp. 307-316). Granada, España.

Fathman, A. K. \& Whalley, E. (1990). Teacher response to student writing: focus on form versus content. En B. Kroll (Ed.), Second Language Writing. Research insights for the classroom (pp. 178-190). Cambridge: Cambridge University Press.

Fernández, A. (2010). First steps of CLIL in a spanish monolingual community: the case of La Rioja. En D. Lasagabaster \& Y. Ruiz de Zarobe (Eds.), CLIL in Spain. Implementation, results and teacher training (pp. 79-94). Newcastle upon Tyne, Reino Unido: Cambridge Scholars Publishing. 
Fernández, S. (1997). Interlengua y análisis de errores en el aprendizaje del español como lengua extranjera. Madrid: Edelsa.

Fernández López, S. (1995). Errores e interlengua en el aprendizaje del español como lengua extranjera. Didáctica, 7, 203-216. Madrid: Universidad Complutense de Madrid.

Ferris, D. \& Hedgcock, J. (1998). Teaching ESL composition: Purpose, process, and practice. Mahwah, NJ: Lawrence Erlbaum Associates.

Ferris, D. (2002). Treatment of error in second language student writing. Ann Arbor, MI: University of Michigan Press.

Ferris, D. (2003). Response to Student Writing: Implications for Second Language Students. Mahwah, NJ: Routledge.

Fonseca Mora, M. C. (2005). El Componente Afectivo en el aprendizaje de lenguas. En M. Navarro et al. (Eds.), Nuevas tendencias en lingüística aplicada (pp. 55-79). Murcia: Servicio Publicaciones UCAM.

Flynn, S. (1989). Second language acquisition and grammatical theory. En F. J. Newmeyer (Ed.), Linguistics: the Cambridge Survey. II, Linguistic Theory: extensions and implications (pp. 53-73). Cambridge: Cambridge University Press. 
Galisson, R. \& Coste D. (Dirs.) (1982). Dictionnaire de didactique des langues. París: Hachette.

García Córdoba F. (2004). El cuestionario: recomendaciones metodológicas para el diseño de un cuestionario. México D.F: Editorial Limusa.

García-Heras Muñoz, A. (2004). Lingüística y enseñanza: el tratamiento de los errores en la enseñanza del inglés como lengua extranjera. Docencia e investigación: revista de la Escuela Universitaria de Magisterio de Toledo, 14, 49-70.

García, R. T. (1996). The relation among college student attitudes, motivation and aptitude to foreign language achievement: A test of Gardner's model. Tesis Doctoral inédita. Universidad de Houston.

Gardner, R. C. (1985). Social psychology and second language learning: The role of attitudes and motivation. London: E. Arnold.

Gardner, R. C. (2010). Motivation and second language acquisition: The socio-educational model. New York, NY: Peter Lang.

Gascoigne, C. (2004). Examining the Effect of Feedback in Beginning L2 Composition. Foreign Language Annals, 37(1), 71-76. 
Gentil, G. (2006). Variations in goals and activities for multilingual writing. En A. Cumming (Ed.), Goals for academic writing: ESL students and their instructors (pp. 142-156). Amsterdam: John Benjamins Pub. Co.

Giovannini, A. Martín Peris, E., Rodríguez Castilla, M., \& Simón Blanco, T. (1996). Profesor en acción 2. Madrid: Edelsa.

Giroux, S. \& Tremblay, G. (2004). Metodología de las ciencias humanas: la investigación en acción. México DF: Fondo de Cultura Económica.

Goldstein, L. M. (2008). Teacher Written Commentary in Second Language Writing Classrooms. Ann Arbor, MI: University of Michigan Press.

Goode, W. \& Hatt, P. K. (1970). Métodos de investigación social. México DF: Trillas.

Guillén Díaz, C. \& Castro Prieto, P. (1998). Manual de autoformación para una didáctica de la lengua-cultura extranjera. Madrid: La Muralla.

Guillén Díaz, C. (2002). La dimensión cultural de la enseñanza/aprendizaje de lenguas extranjeras. En A. M. Peña Ortega (Coord.), Lenguas para abrir camino (pp. 193-226). $\quad$ Madrid: Ministerio de Educación, Cultura y Deporte. Secretaría General de Educación y Formación Profesional, Instituto Superior de Formación del Profesorado. 
Guillén Díaz, C. (2004). Error. En F. Salvador Mata, J. L. Rodríguez Diéguez \& A. Bolívar Botía (Dirs.), Diccionario Enciclopédico de Didáctica. Málaga: Aljibe.

Hammarberg, B. (1979). The Insufficiency of Error Analysis. En D. Nehls (Ed.), Studies in Contrastive Linguistics and Error Analysis. I: The Theoretical Background. (Studies in Descriptive Linguistics, 2) (pp. 107-114). Heidelberg, Alemania: Groos

Heinemann, K. (2003). Introducción a la metodología de la investigación empírica en las ciencias del deporte. Barcelona: Editorial Paidotribo.

Henderson, M. M. T. (1985). The interlanguage notion. Journal of Modern Language Learning, 21, 23-27.

Hendrickson, J. (1978). Error correction in foreign language teaching: Recent theory, research, and practice. Modern Language Journal, 62, 387-398.

Hobbs, V. (2011). The importance of teachers' thoughts and beliefs. En S. House (Ed.), Theory and Practice in English Language Teaching (pp. 147-159). Barcelona: Grao.

Howard, E. R., Lindholm-Leary, K. J., Rogers, D., Olague, N., Medina, J., Kennedy, B., Sugarman, J., \& Christian, D. (2018). Guiding Principles for Dual Language Education (3rd ed.). Washington, DC: Center for Applied Linguistics. 
Hymes, D. (1972): Acerca de la competencia comunicativa. En M. Llobera, M. et al. (1995). Competencia comunicativa. Documentos básicos en la enseñanza de lenguas extranjeras (pp. 27- 46). Madrid: Edelsa.

Jiménez González, J. E. \& Muñetón Ayala, A. (2002). Dificultades de aprendizaje de la escritura. Aplicaciones de la psicolingüística y de las nuevas tecnologías. Madrid: Trotta.

Knutson, S. (2003). Experimental learning in second-language classrooms. TESL Canada Journal/Revue TESL du Canada, 20(2), 52-64.

Koike, D. (2012). Variation in NS-learner interactions. Frames and expectations in pragmatic coconstruction. En J. C. Félix-Brasdefer \& D. A. Koike (Eds.), Pragmatic variation in first and second language contexts. Methodological issues (pp. 175-208). Amsterdam: John Benjamins Publishing Company.

Krashen, S.D. (1985). The Input Hypothesis: Issues and Implications. New York, NY: Longman.

Krashen, S. D. (1982). Principles and Practice in Second Language Acquisition. London: Prentice Hall International.

Krashen, S. D. (1988). Second Language Acquisition and Second Language Learning. New York, NY: Prentice Hall International. 
Krashen, S. (2013). Second Language Acquisition. Theory, Applications, and some Conjectures. Cambridge: Cambridge University Press.

Kroll, J. F., Michael, E. Tokowicz, N. \& Dufour, R. (2002). The development of lexical fluency in a second language. Second Language Research, 18(2), 137-171.

Lado, R. (1964a). Language teaching: a scientific approach. New York, NY: MacGraw-Hill

Lado, R. (1964b). Language testing: the construction and use of foreign language tests. A teacher's book. London: Longmans, Green and Co. Ltd.

Lado, R. (1990). Linguistics across cultures: applied linguistics for language teachers. Ann Harbor, MI: University of Michigan Press.

Larsen-Freeman, D. \& Long, M. H. (1992). An introduction to second language acquisition research. London: Longman.

Lasagabaster D. \& Sierra, J. M. (2005). Error Correction: Students' Versus Teachers' Perceptions. Language Awareness, 14(2\&3), 112-127.

Latorre Beltrán, A.; Rincón Igea, D. \& Arnal Agustín, J. (1996). Bases metodológicas de investigación educativa. Barcelona: Jordi Hurtado Mompeó. 
Lee, I. (2003). L2 writing teachers' perspectives, practices and problems regarding error feedback. Assessing Writing, 8, 216-237.

Leki, I. (1990). Coaching from the margins: issues in written response. En B. Kroll (Ed.), Second Language Writing. Research insights for the classroom (pp. 57-68). Cambridge: Cambridge University Press.

Leki, I. (2001). Introduction: Accessing Communities and Disciplines Through L2 Writing Programs. En I. Leki (Ed.), Academic Writing Programs (pp. 1-4). Alexandria, VA: Teachers of English to Speakers of Other Languages, Inc. (TESOL).

Leki, I. (2007). Undergraduates in a Second Language. Challenges and Complexities of Academic Literacy Development. New York, NY: Lawrence Erlbaum Associates.

Leki, I., Cumming, A. H., \& Silva, T. J. (2008). A synthesis of research on second language writing in English. New York, NY: Routledge.

Llinares, A. \& Dafouz, E. (2010). Content and language integrated programmes in the Madrid region: overview and research findings. En D. Lasagabaster \& Y. Ruiz de Zarobe (Eds.), CLIL in Spain. Implementation, results and teacher training (pp. 95-114). Newcastle upon Tyne, Reino Unido: Cambridge Scholars Publishing. 
Loaiza Villalba, N. \& Galindo Martínez, A. (2014). Estilos de aprendizaje de segundas lenguas y formación bilingüe consecutiva en educación primaria, secundaria y superior: hacia un estado del arte. Lenguaje, 42(2), 291-314

Lorenzo, F., Trujillo, F. \& Vez, J. M. (2011). Educación bilingüe. Integración de contenidos y segundas lenguas. Madrid: Síntesis.

Lyster, R. \& Ranta, L. (1997). Corrective feedback and learner uptake: Negotiation of form in communicative classrooms. Studies in Second Language Acquisition, 19, 37-66.

Mallart, J. (2004). Aptitud. En F. Salvador Mata, J. L. Rodríguez Diéguez \& A. Bolívar Botía (Dirs.), Diccionario Enciclopédico de Didáctica. Málaga: Aljibe.

Martín Peris, E. (1998). El profesor de lenguas: papel y funciones. En A. Mendoza Fillola (Coord.), Conceptos clave en didáctica de la lengua y la literatura (pp. 87-100). Barcelona: Horsori.

Mayor, J. (1994). Adquisición de una segunda lengua. En J. Sánchez Lobato \& I. Santos Gargallo (Eds.), IV Congreso Internacional de ASELE. Problemas y métodos en la enseñanza del español como lengua extranjera (pp. 21-57). Madrid, España.

Mendoza, A.; López, A. \& Martos, E. (1996): Didáctica de la Lengua para la Enseñanza Primaria y Secundaria. Madrid: Akal. 
Mendoza Fillola, A. (1998). Introducción. En A. Mendoza Fillola (Coord.), Conceptos clave en didáctica de la lengua y la literatura (pp. i-1). Barcelona: Horsori.

Merino Mañueco, S. (2015). El arte como medio para la enseñanza/aprendizaje de español como lengua extranjera. Intertext Scientific Journal, 3-4, 84-87. Chisinau: ULIM.

Merino Mañueco, S. (en prensa). La corrección de errores en las producciones escritas de alumnos de L2. Intertext Scientific Journal.

Montrul, S. (2008). Incomplete acquisition in bilingualism: re-examining the age factor. Amsterdam: John Benjamins.

Muñoz Liceras, J. M. (Comp.). (1992). La adquisición de lenguas extranjeras: hacia un modelo de análisis de la interlengua. Madrid: Visor.

Noguerol Rodrigo, A. (1998). Investigación y didáctica de la lengua y la literatura. En A. Mendoza Fillola (Coord.), Conceptos clave en didáctica de la lengua y la literatura (pp. 61-74). Barcelona: Horsori

Norrish, J. (1983). Language learners and their errors. London: The MacMillan Press Limited. 
Núñez-Méndez, E. (2001): Corregir o no los errores en la clase de español como LE. En Center for Applied Linguistics (Ed.), VII Simposium of Social Communication: Vol. 2 (pp. 132-138). Santiago de Cuba, Cuba.

Nyquist, E. B. (1978). Bilingual education, TESL, and ethnicity in New York State. En R. L. Light \& A. H. Osman (Eds.), Collected papers in teaching English as a second language and bilingual education: Themes, practices, viewpoints (pp. 25-33). New York, NY: New York State English to Speakers of Other Languages and Bilingual Educators Association.

Park, C (2003). Engaging Students in the Learning Process: the learning journal. Journal of geography in higher education, 27(2), 183-199.

Peters, J. J. (1984). Teaching: Intentionality, reflection and routines. En R. Halkes, R. \& K. K. Olson (Eds.), Teacher Thinking. A new perspective on persisting problems in education (pp. 19-34). Lisse, Holanda: Swets and Zeitlinger.

Polio, C. \& Williams, J. (2009). Teaching and Testing Writing. En M. H. Long \& C. J. Doughty (Eds.), The Handbook of Language Teaching (pp. 486-517). Oxford: Wiley-Blackwell.

Potowski, K. (2007). Language and identity in a dual language immersion school. Clevedon: Multilingual Matters. 
Potowski, K. (2016). Intra-Latino language and identity: MexiRican Spanish. Amsterdam: John Benjamins.

Rach, S., Ufer, S. \& Heinze, A. (2013). Learning from errors: Effects of teachers training on students' attitudes towards and their individual use of errors. PNA 8(1), 21-30.

Reguera, A. (2008). Metodología de la investigación lingüística: prácticas de escritura. Córdoba: Editorial Brujas.

Richards, J. C. (1984). A Non-Constrastive Approach to Error Analysis. En J. C. Richards (Ed.), Error Analysis. Perspectives on Second Language Acquisition (pp. 172-188). London: Longman.

Richelle, M. (1998). Error. En R. Doron, \& F. Parot (Dirs.), Diccionario Akal de Psicología. Madrid: Akal.

Ringbom, H. (1982). The influence of other languages on the vocabulary of foreign language learners. En G. Nickel \& D. Nehl (Eds.), Error analysis, contrastive linguistics and second language learning (pp. 85-96). Heidelberg, Alemania: Groos.

Rogers, R. (2001). Reflection in higher education: A concept analysis. Innovative Higher Education, 26, 37-57. 
Roy, D. (1991). Les enseignants et les enseignantes exercent-ils une réelle influence sur l'apprentissage au collégial? Pédagogie collégiale, 5(1), 37-40.

Sáez López, J.M. (2017). Investigación educativa. Fundamentos teóricos, procesos y elementos prácticos (enfoque práctico con ejemplos, esencial para TFG, TFM y tesis). Madrid: UNED.

Salvador Mata, F. (1997). Dificultades en el aprendizaje de la expresión escrita. Una perspectiva didáctica. Archidona, España: Aljibe.

Sánchez Godoy, I. \& Casal Madinabeitia, S. (2016). El desarrollo de la autonomía mediante las técnicas de aprendizaje cooperativo en el aula de L2. Porta Linguarum, 25, 179-190.

Santos Gargallo, I. (1994). Análisis de errores: valoración gramatical y comunicativa en la expresión escrita de estudiantes de ELE. Una propuesta didáctica. En S. Montesa Peydró \& A. Garrido Moraga (Eds.), Segundo Congreso Nacional de ASELE (Madrid). Español para extranjeros: didáctica e investigación (pp. 169-174). Madrid, España.

Santos Gargallo, I. \& Alexopoulou, A. (2014). Creencias y actitudes de profesores y alumnos griegos de español ante las técnicas de corrección en la interacción oral: estudio comparativo intragrupos. Didáctica. Lengua y Literatura, 26, 429 - 446. 
Selinker, L. (1979). Interlanguage. En D. Nehls (Ed.), Studies in descriptive linguistics. Studies in contrastive linguistics and error analysis I. The theoretical background (pp. 55-78). Heidelberg, Alemania: Julius Groos Verlag.

Serkan Ülgü, I. S. \& Griffiths, C. (2013). Error correction in language teaching: The teachers' perspective. International Journal of Arts \& Sciences, 6(3), 229-241.

Serra, M., Serrat, E., Solé, R., Bel, A. \& Aparici, M. (2000). La adquisición del lenguaje. Barcelona: Ariel.

Shaw, H. (1967). Errors in English and ways to correct them. New York, NY: Barnes \& Noble.

Sheen, Y. \& Ellis, R. (2011). Corrective Feedback in Language Teaching. En E. Hinkel (Ed.), Handbook of Research in Second Language Teaching and Learning, II (pp. 593-610). New York, NY: Routledge.

Silva Cruz, M. I. (2013). La retroalimentación en la corrección de la escritura: Corrección y autocorrección en el aprendizaje de alumnos norteamericanos. Revista Nebrija de Lingüística Aplicada, 7(11), 104-120. 
Smolcic, E. (2011). Becoming a culturally responsive teacher. Personal transformation and shifting identities during an immersion experience abroad. En K. E. Johnson \& P. R. Golombek (Eds.), Research on second language teacher education: A sociocultural perspective on professional development (pp. 15-30). New York, NY: Routledge.

Sommers, N. (1982): Responding to student writing. En B. Leeds (Ed.), Writing in a Second Language: Insights from first and second language teaching and research (pp. 148-154). White Plains, NY: Longman/Addison Wesley.

Spillner, B. (1991). Error Analysis: A Comprehensive Bibliography. Amsterdam: Benjamins.

Stern. H.H. (1983). Fundamental Concepts of Language Teaching. Oxford: Oxford University Press.

Stockman, I. J. \& Pluut, P. (1999). Segment Composition as a Factor in the Syllabification Errors of Second-Language Speakers. Language Learning, 49(1), 185-209.

Südkamp, A. Kaiser, J. \& Möller, J. (2014). Teachers' judgments of students' academic achievement: Results from field and experimental studies. En S. Krolak-Schwerdt, S. Glock \& M. Böhmer. Teachers' Professional Development. Assessment, Training and Learning (pp. 5- 26). Rotterdam, Holanda: Sense Publishers.

Teberosky, A. (1992). Aprendiendo a escribir. Cuadernos de educación, (8). Barcelona: Horsori. 
Torijano Pérez, J.A. (2004). Errores de aprendizaje, aprendizaje de los errores. Madrid: Arco Libros.

Torres Gonzáles, J. A. (1996). La formación del profesor tutor como orientador. Análisis de las necesidades de formación del profesor-tutor en el marco de la atención a la diversidad para desempeñar tareas de orientación en el aula. Jaén: Universidad de Jaén.

Torres-Guzmán, M. E., \& Etxeberria, F. (2005). Modelo B / Dual language programmes in the Basque country and the USA. The International Journal of Bilingual Education and Bilingualism, 8 (6), 506-528.

Truscott, J. (1996). The case against grammar correction in L2 writing classes. Language Learning,46 (2), 327-369.

Truscott, J. (2007). The effect of error correction on learners' ability to write accurately. Journal of Second Language Writing, 16, 255-272.

Uribe, Gutiérrez \& Madrid (2008). Las actitudes del alumnado hacia el aprendizaje del inglés como idioma extranjero: estudio de una muestra en el sur de España. Porta Linguarum, 10, 85-100.

Vasilescu, R. (2009). Testarea competenţei communicative în domeniul limbilor străine cu aplicaţie la limba engleza. Bucureşti. Editura Fundaţiei România de Mâine. 
Vázquez, G. (2000). La destreza oral. Programas de Autoformación de Perfeccionamiento del Profesor. Madrid: Edelsa.

Vez, J. M. (Ed.), Guillén, C. \& Alario, C. (2002). Didáctica de la lengua extranjera en educación infantil y primaria. Madrid: Síntesis.

Viñao Frago, A. (2002). La Enseñanza de la Lectura y la Escritura: Análisis Socio-Histórico. Anales de Documentación, 5, 345-359.

Widdowson, H. G. (1996). Linguistics. Oxford: Oxford University Press.

Widdowson, H.G. (2001). Aspects of Language Teaching. Oxford: Oxford University Press.

Woodfield, H. (2012). Pragmatic variation in learner perception: the role of retrospective verbal report in L2 speech act research. En J. C. Félix-Brasdefer \& D. A. Koike (Eds.), Pragmatic variation in first and second language contexts. Methodological issues (pp. 209-237). Amsterdan: John Benjamins Publishing Company.

Zydatiß, W. (1979). A 'Kiss of Life' for the Notion of Error. En Dietrich Nehls (Ed.), Studies in Contrastive Linguistics and Error Analysis. I: The Theoretical Background. (Studies in Descriptive Linguistics, 2) (pp. 115-121). Heidelberg, Alemania: Groos. 


\section{Fuentes bibliográficas electrónicas}

Alexopoulou, A. (2010). La función de la interlengua en el aprendizaje de lenguas extranjeras. Análisis de errores en la interlengua de aprendientes griegos de español. Revista Nebrija de Lingüística aplicada a la enseñanza de las lenguas, 9, 84-99.

Recuperado el 17 octubre, 2017, del sitio Web de la Universidad de Nebrija: https://www.nebrija.com/revistalinguistica/files/articulosPDF/articulo_530b6242baf90.pdf

Alexopoulou, A. (2012). Bases de la Lingüística Aplicada a la enseñanza del español como lengua extranjera. Recuperado el 21 agosto, 2018, del sitio Web de la Universidad Nacional y Kapodistríaca de Atenas:

http://www.spanll.uoa.gr/fileadmin/spanll.uoa.gr/uploads/ALEXOPOULOU/BIBLIA_DI DAKTIKA/4._Bases_de_la_LA.pdf

Blanco, M.P. \& Garrido, M.C. (2013). Lenguas de especialidad e interacción oral en el sector turístico: Reflexiones sobre su implicación en el Espacio Europeo de Educación Superior. Revista Electrónica Interuniversitaria de Formación del Profesorado, 16(1), 25-40. doi: http://dx.doi.org/10.6018/reifop.16.1.179421 
Bourque, L. B \& Fielder, E. P. (2003). Format of the Questionnaire. How to Conduct SelfAdministered and Mail Surveys. Thousand Oaks, CA: SAGE Publications, Inc. doi: http://dx.doi.org/10.4135/9781412984430.n4

Cassany, D. (2009). La composición escrita en E/LE. Monográficos marco ELE. Didáctica del Español como Lengua Extranjera. Expolingua, 9, 47-66. Recuperado el 18 marzo, 2016, de http://marcoele.com/descargas/expolingua_1999.cassany.pdf

Coward, M. (2017, marzo 1). We need hope for the future of bilingual education in Texas. Dallas News.

Recuperado el 11 junio, 2017, de https://www.dallasnews.com/opinion/commentary/2017/03/01/hope-future-bilingualeducation-Texas

Díaz Martínez, J. (2012). Autonomía del alumno en la clase de L2. Actitud reflexiva y atmósfera afectiva, ejes de un aprendizaje ecológico-transformativo. Marcoele revista de Didáctica español como lengua extranjera,15

Recuperado el 19 octubre, 2017, de http://marcoele.com/descargas/15/diaz-autonomia.pdf 
Díaz Rodríguez, L. (2010). Entrevista a Muñoz Liceras, J. M. (Universidad de Ottawa, Canadá) a cargo de Lourdes Díaz Rodríguez (Universidad Pompeu Fabra, Barcelona). MarcoELE. Revista de Didáctica Español Lengua Extranjera, 11

Recuperado el 17 agosto, 2016, de https://dialnet.unirioja.es/servlet/revista?codigo=7656

Erdocia, I. (2016). Dimensión contextual y autonomía del aprendiente de lenguas. [Con]textos, 5(20), 35-43.

doi: $10.21774 /$ ctx.v5i20.756

Fernández March, A. (2010). La evaluación orientada al aprendizaje en un modelo de formación por competencias en la educación universitaria. Revista de docencia universitaria, 8(2), 11-34.

Recuperado el 13 mayo, 2017, de http://red-u.net/redu/documentos/vol8_n1_completo.pdf

Fernández, S. (2012). Los errores en el proceso de aprendizaje. Tratamiento y superación. XI Encuentro práctico de profesores ELE. Barcelona: Difusión. Recuperado el 19 septiembre, 2017, de http://www.encuentro-practico.com/pdf/fernandez.pdf 
Ferris, D. R. (2004). The “Grammar Correction”' Debate in L2 Writing: Where are we, and where do we go from here? (and what do we do in the meantime . . .?). Journal of Second Language Writing 13, 49-62.

doi: 10.1016/j.jslw.2004.04.005.

Fonseca Mora, M. C. (2005). El componente afectivo en el aprendizaje de lenguas. En M. Navarro et al. (Eds.), Nuevas tendencias en lingüística aplicada (pp. 55-79). Murcia: Servicio Publicaciones UCAM.

Recuperado el 6 Noviembre, 2017, de https://www.researchgate.net/publication/309583526_El_componente_afectivo_en_el_ap rendizaje_de_lenguas

García Muñoz. T. (2003, marzo). El cuestionario como instrumento de investigación/evaluación. Recuperado el 11 noviembre, 2015, de http://www.univsantana.com/sociologia/El_Cuestionario.pdf

Ghosh, B., Meghan, H., Zachary, H., Miriam, M. \& Baoqiang, S. (2008). En L. L. Taylor (Coord.), Bilingual Education in Texas: Exploring Best Practices Final Report. Recuperado el 10 Junio, 2017, de http://bush.tamu.edu/psaa/capstones/projects/2008/Bilingual_Education_in_Texas.pdf 
Gómez Pazos, M. \& Hernando Gómez, A. (2016). Experiencia docente acerca del uso didáctico del aprendizaje cooperativo y el trabajo de campo en el estudio del fenómeno de influencia social. Revista Electrónica Interuniversitaria de Formación del Profesorado, 19(2), 331-346.

doi: http://dx.doi.org/10.6018/reifop.19.2.206921

Gorbet, F. (1974). Error Analysis: what the teachers can do. Errors: a new perspective. Ottawa: Directorate of Studies.

Recuperado el 17 septiembre, 2016, de http://files.eric.ed.gov/fulltext/ED100193.pdf

Haded, M. S. (1998). The Merits of Exploiting Error Analysis in Foreign Language Teaching and Learning. RELC Journal, 29(1), 55-65.

doi: $10.1177 / 003368829802900104$.

Jericó, P. (2013, Julio 9). Cómo dar un buen “feedback”. El País. Recuperado el 10 noviembre, 2017, de https://elpais.com/elpais/2013/07/09/laboratorio_de_felicidad/1373353794_137335.html

Lacorte, M. \& Suárez García, J. (2014). La enseñanza del español en los Estados Unidos: panorama actual y perspectivas de futuro. Journal of Spanish Language Teaching, 1(2), 129-136, doi: 10.1080/23247797.2014.970358 
Lamus, D. R. (2008). Bilingual education in the USA: A transition to monolingualism? En M. S. Plakhotnik \& S. M. Nielsen (Eds.), Proceedings of the Seventh Annual College of Education Research Conference: Urban and International Education Section, 80-85. Miami: Florida International University. Recuperado el 31 julio, 2018, de http://coeweb.fiu.edu/research_conference/

Llopis García, R. (2007). Escribir sin pensar, ¡ni pensarlo! Organizar la expresión escrita. En M. J. Fernández Colomer \& M. Albelda Marco (Eds.), Foro de Profesores de E/LE (3), 133142. Universidad de Valencia, 23 y 24 de febrero, 2007.

Recuperado el 10 noviembre, 2017, de https://dialnet.unirioja.es/descarga/articulo/4900528.pdf

López Hernández, A. (2009). Feedback y corrección de errores en el aula de L2 (I): actividades orales. Educación y futuro: revista de investigación aplicada y experiencias educativas, $20,65-78$.

Recuperado el 14 mayo, 2016, de https://dialnet.unirioja.es/servlet/articulo?codigo=3233775

Lyster R. \& Panova, I. (2002). Patterns of corrective feedback and uptake in an adult ESL classroom. TESOL QUARTERLY, 36(4), 573-595. John Wiley \& Sons, Inc. doi: $10.2307 / 3588241$ 
Martínez-Salanova Sánchez, E. (2007). Instrumentos para recabar datos. Educación y Didáctica. Recuperado el 12 noviembre, 2015, del sitio web Portal de la Educomunicación. Enrique Martínez-Salanova

Sánchez: http://www.uhu.es/cine.educacion/didactica/0093instrumentosrecabardatos.htm

Myhill, D. \& Watson, A. (2011). The role of grammar in the writing curriculum: A review of the literature. Child language teaching and therapy. 30(1), 41-62 doi: $10.1177 / 0265659013514070$

Morales Ardaya, F. (2003). Evaluar la escritura, sí... Pero ¿Qué y cómo evaluar? Acción Pedagógica, 13(1) 2004, 38-49.

Recuperado el 7 noviembre, 2017, de https://dialnet.unirioja.es/descarga/articulo/2971903.pdf

Pawlak, M. (2014). Error correction in the foreign language classroom. Reconsidering the issues. Heidelberg, Alemania: Springer-Verlag. doi: 10.1007/978-3-642-38436-3_4

Pérez, A., Crawford, S. \& Mejía, J. (2005). Bilingual and Dual Language Education. Major Historical Antecedents to Texas Bilingual Legislation. Latino Education Policy in Texas. Recuperado el 11 junio, 2017, del sitio Web del College of Education, University of Texas: http://www.edb.uTexas.edu/latino/bilingual_edu_page.html 
Rodríguez, R. (2010). Bilingual Education. Handbook of Texas Online.

Recuperado el 11 junio, 2017, del sitio Web of Texas State Historical Association. https://www.tshaonline.org/handbook/online/articles/khb02

Rodríguez García, C. (2017). Actitudes y creencias de estudiantes universitarios checos y eslovacos ante la corrección de sus errores en la expresión oral en español. Revista electrónica de didáctica del español lengua extranjera, 29, 3.

Recuperado el 18 octubre, 2017, de

https://www.mecd.gob.es/dam/jcr:db6752ef-df53-4ebd-b0adcb7d88876e46/redele2920173rodriguezgarciacristina-pdf.pdf

Santamaría Martínez, R. (2016). La competencia sociocultural en el aula de español L2/LE: una propuesta didáctica.

Recuperado el 18, marzo, 2017, del sitio Web Biblioteca Virtual Miguel de Cervantes. http://www.cervantesvirtual.com/nd/ark:/59851/bmc156j6

Santos Maldonado, M. J. (2002): El error en las producciones escritas del francés como lengua extranjera: análisis de interferencias léxicas y propuestas para su tratamiento didáctico. Tesis Doctoral inédita. Valladolid: Universidad de Valladolid. Recuperado el 16 noviembre, 2017, del sitio Web Biblioteca Virtual Miguel de Cervantes http://www.cervantesvirtual.com/nd/ark:/59851/bmcv69c3 
Solias Arís, T. (2007). Tipología protolingüística y surgimiento del lenguaje. Revista Española de Lingüística (RSEL), 37, 65-101.

Recuperado el 10 mayo, 2017, de http://www.sel.edu.es/pdf/ene-dic-07/RSEL-37-Solias.pdf

Tedick, D. J. \& de Gortari, B. (1998). Research on Error Correction and Implications for Classroom Teaching. The Bridge: From Research to Practice 1(1.3.), 1-4.

Recuperado el 20 agosto, 2016, de carla.umn.edu/immersion/acie/vol1/Bridge1.3.pdf

Thomas, W.P. \& Collier, V.P. (1997). School Effectiveness for Language Minority Students. NCBE Resource Collection Series, No. 9. Washington D.C.: Center for the Study of Language and Education.

Recuperado el 31 agosto, 2018, de http://www.thomasandcollier.com/assets/1997_thomas-collier97-1.pdf

Van Kuler, P. E. (2012). La enseñanza bilingüe en los Estados Unidos de América: análisis de los métodos bilingües más implementados. Trabajo Fin de Máster en Lengua y Cultura Española.

Recuperado el 5 noviembre, 2017, del sitio Web de Utrecht University http://docplayer.es/15377649-La-ensenanza-bilingue-en-los-estados-unidos-deamerica.html 
Vargas Venegas, G. (2008). Desarrollo de la fluidez oral en ELE mediante los periódicos, las canciones, las películas y los juegos. Memoria de Máster en Formación de profesores de español como lengua extranjera. Universidad de León en colaboración con la Fundación Universitaria Iberoamericana (FUNIBER).

Recuperado el 31 octubre, 2017, del sitio Web del MECD

https://www.mecd.gob.es/dam/jcr:10d0a665-9f07-4c61-927d-7b4681ed482c/2010-bv11-21 vargas-pdf.pdf

Vázquez, G. (2009). Análisis de errores, el concepto de corrección y el desarrollo de la autonomía. Revista Nebrija de Lingüística Aplicada, 5.

Recuperado el 29 noviembre, 2017, del sitio web de la Universidad de Nebrija www.nebrija.com/revista-linguistica/numero-5-2009

Zamel, V. (1985). Responding to Student Writing. TESOL Quarterly, 19(1), 79-101. doi: $10.2307 / 3586773$ 


\section{Disposiciones oficiales y documentos institucionales de referencia}

Comunicación de la Comisión al Consejo, al Parlamento Europeo, al Comité Económico y Social y al Comité de las Regiones (2003). Promover el aprendizaje de idiomas y la diversidad lingüística: Un Plan de acción 2004-2006. Bruselas, 24.07.2003 [COM(2003) 449 final].

Comisión de las Comunidades Europeas (2005). Propuesta de recomendación del Parlamento Europeo y del Consejo sobre las competencias clave para el aprendizaje permanente. Bruselas. [Diario Oficial L 394 de 30.12.2006].

Consejo de Europa (2002). Marco Común Europeo de referencia para las lenguas: aprendizaje, enseñanza, evaluación. Estrasburgo-Madrid: División de Políticas Lingüísticas. Instituto Cervantes. Ministerio de Educación y Ciencia. Anaya.

Corrección (s.f.). En el diccionario de la Real Academia Española. (23 ${ }^{\mathrm{a}}$ ed.). Recuperado el 28 agosto, 2017, de http://cvc.cervantes.es/ensenanza/biblioteca_ele/diccio_ele/diccionario/errorpragmatico.h tm 
Error pragmático. En el Diccionario de Términos Clave de ELE. Centro Virtual Cervantes (19972017).

Recuperado el 28 agosto, 2017, de

http://cvc.cervantes.es/ensenanza/biblioteca_ele/diccio_ele/diccionario/errorpragmatico.h $\operatorname{tm}$

España, Ministerio de Educación, Cultura y Deporte. (2011). Resolución de la Secretaría de Estado de Educación y Formación Profesional por la que se establece el currículo de la Sección Española del Programa de Estudios lnternacionales del Distrito Escolar público del condado de Miami-Dade del estado de Florida (Estados unidos).

Recuperado el 15 agosto, 2016, de http://www.mecd.gob.es/dms-static/6dab6548-6bb5-4d4d-b2e827b6bffa9b0f/consejerias-exteriores

España, Ministerio de Educación, Cultura y Deporte. (2016). Descripción del sistema educativo de Estados Unidos.

Recuperado el 12 diciembre, 2017, de https://www.mecd.gob.es/eeuu/dms/consejerias-exteriores/eeuu/Estudiar-en-EstadosUnidos/DESCRIPCI-N-DEL-SISTEMA-EDUCATIVO-DE-ESTADOSUNIDOS/DESCRIPCI\%C3\%93N\%20DEL\%20SISTEMA\%20EDUCATIVO\%20DE\%2 0ESTADOS\%20UNIDOS.pdf 
Eurydice (2006). Content and Integrated Learning (CLIL) at School in Europe. Brussels: Eurydice European Unit.

Feedback (s.f.). En el Diccionario de la Real Academia Española (23 ${ }^{\text {a }}$ ed.). Diccionario Panhispánico de dudas (DPD).

Recuperado el 14 Julio, 2016, de http://lema.rae.es/dpd/?key=feedback

Feedback>Retroalimentación (s.f.). En el Diccionario de Términos Clave de ELE. Centro Virtual Cervantes (1997-2017).

Recuperado el 27 febrero, 2017, de http://cvc.cervantes.es/ensenanza/biblioteca_ele/diccio_ele/diccionario/retroalimentacion. htm

Instituto Cervantes. (2012). Las competencias clave del profesorado de lenguas segundas y extranjeras.

Recuperado el 22, septiembre, 2017, de http://cfp.cervantes.es/imagenes/File/competencias_profesorado.pdf 


\section{ÍNDICE DE CUADROS, FIGURAS, TABLAS Y GRÁFICOS}

1. Índice de cuadros

2. Índice de figuras

3. Índice de tablas

4. Índice de gráficos 


\section{ÍNDICE DE CUADROS}

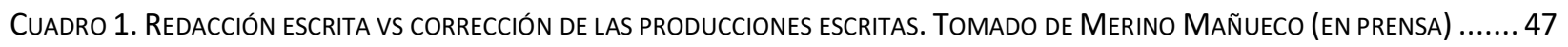

CUADRo 2. FórmULAS DIRECTAS E INDIRECTAS PARA LA CORRECCIÓN INMEDIATA. TOMADO DE VEZ ET AL. (2002, P. 256) .............. 100

CUADRO 3. ÍTEMS DE LOS CUESTIONARIOS DIRIGIDOS A LA RECOPILACIÓN DE INFORMACIÓN ACERCA DEL PERFIL DEL INFORMANTE ........ 216

CUADRO 4. ÍTEMS DE LOS CUESTIONARIOS DIRIGIDOS A LA RECOPILACIÓN DE INFORMACIÓN ACERCA DE LOS CONOCIMIENTOS DEL INFORMANTE

CUADRO 5. ÍTEMS DE LOS CUESTIONARIOS DIRIGIDOS A LA RECOPILACIÓN DE INFORMACIÓN ACERCA DE LAS APTITUDES DEL INFORMANTE 305

CUADRO 6. ÍTEM DE LOS CUESTIONARIOS DIRIGIDO A LA RECOPILACIÓN DE INFORMACIÓN ACERCA DE LAS ACTITUDES DEL INFORMANTE 366

\section{ÍNDICE DE FIGURAS}

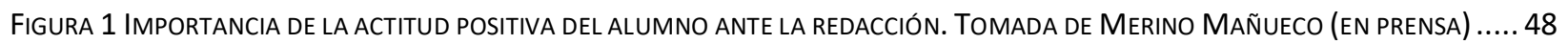
FigURA 2. CRITERIOS de CORRECCIÓN AdOPTADOS POR EL PROFESOR. TOMADA DE SÜDKAMP, KAISER Y MölLeR $(2014$, P. 6) ............ 97

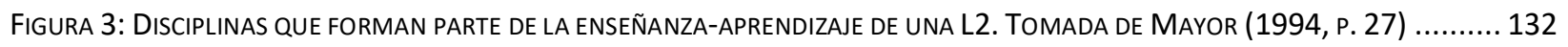

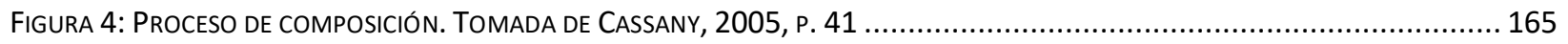

\section{ÍNDICE DE TABLAS}

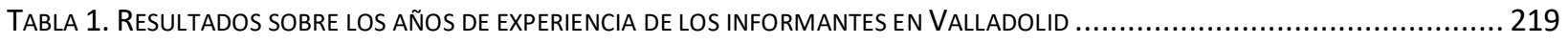

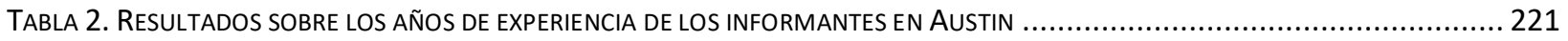

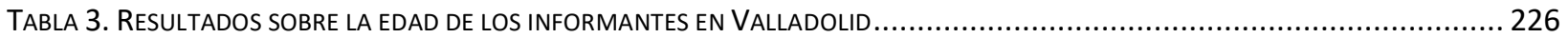

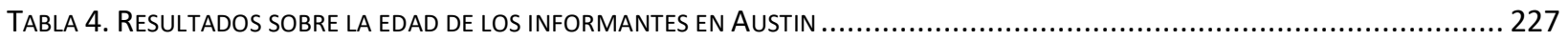

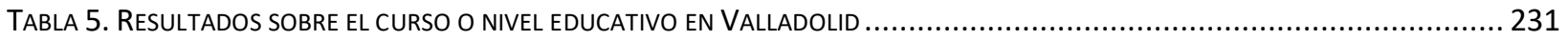

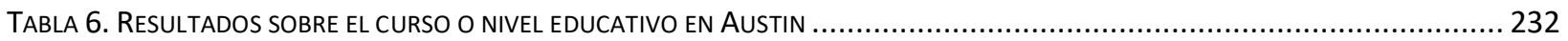

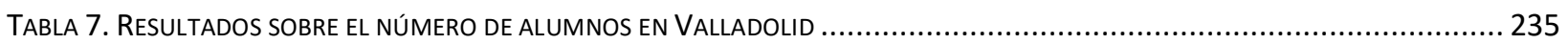

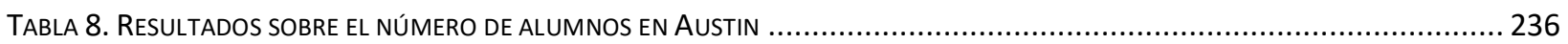

TABLA 9. RESULTADOS SOBRE LA ACTITUD DE LOS ALUMNOS ANTE UNA ACTIVIDAD DE ESCRITURA DIRIGIDA EN VALLADOLID .................247

TABLA 10. RESULTADOS SOBRE LA ACTITUD DE LOS ALUMNOS ANTE UNA ACTIVIDAD DE ESCRITURA DIRIGIDA EN AUSTIN ................... 249

TABLA 11. RESULTADOS SOBRE LA ACTITUD DE LOS ALUMNOS ANTE UNA ACTIVIDAD DE ESCRITURA LIBRE EN VALLADOLID .................. 255

TABLA 12. RESULTADOS SOBRE LA ACTITUD DE LOS ALUMNOS ANTE UNA ACTIVIDAD DE ESCRITURA LIBRE EN AUSTIN.........................257

TABLA 13. RESULTADOS SOBRE LA REACCIÓN DE LOS ALUMNOS ANTE LA AYUDA OFRECIDA EN VALLADOLID.................................263

TABLA 14. RESULTADOS SOBRE LA REACCIÓN DE LOS ALUMNOS ANTE LA AYUDA OFRECIDA EN AUSTIN ........................................265

TABLA 15. RESULTADOS SOBRE LA UTILIDAD DE LAS ACTIVIDADES DE EXPRESIÓN ESCRITA LIBRE EN L2 EN VALLADOLID ....................... 271

TABLA 16. RESULTADOS SOBRE LA UTILIDAD DE LAS ACTIVIDADES DE EXPRESIÓN ESCRITA LIBRE EN AUSTIN................................... 273

TABLA 17. RESULTADOS SOBRE EL MOMENTO IDÓNEO PARA LA CORRECCIÓN DE LAS PRODUCCIONES ESCRITAS EN L2 EN VALLADOLID .. 278

TABLA 18. RESULTADOS SOBRE EL MOMENTO IDÓNEO PARA LA CORRECCIÓN DE LAS PRODUCCIONES ESCRITAS EN L2 EN AUSTIN ......... 280

TABLA 19. RESULTADOS SOBRE LOS TIPOS DE ERRORES QUE DEBEN SER CORREGIDOS EN LAS PRODUCCIONES ESCRITAS EN L2 EN

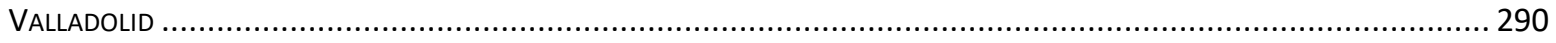

TABLA 20. RESULTADOS SOBRE LOS TIPOS DE ERRORES QUE DEBEN SER CORREGIDOS EN LAS PRODUCCIONES ESCRITAS EN L2 EN AUSTIN293

TABLA 21. RESULTADOS SOBRE LA PRESENTACIÓN DE UNA ACTIVIDAD DE ESCRITURA LIBRE EN L2 EN VALLADOLID ........................... 309

TABLA 22. RESULTADOS SOBRE LA PRESENTACIÓN DE UNA ACTIVIDAD DE ESCRITURA LIBRE EN L2 EN AUSTIN ................................ 311

TABLA 23. RESULTADOS SOBRE LAS APTITUDES DEL INFORMANTE ORIENTADAS A LA AYUDA PROPORCIONADA DURANTE LA REALIZACIÓN DE

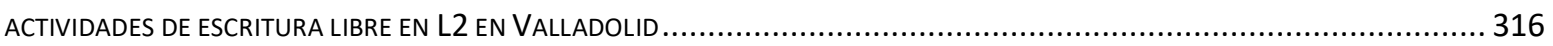

TABLA 24. RESULTADOS SOBRE LAS APTITUDES DEL INFORMANTE ORIENTADAS A LA AYUDA PROPORCIONADA DURANTE LA REALIZACIÓN DE ACTIVIDADES DE ESCRITURA LIBRE EN L2 EN AUSTIN..... 318

TABLA 25. RESULTADOS SOBRE LAS APTITUDES DEL INFORMANTE EN CUANTO A LA ELECCIÓN DE MODALIDADES DE CORRECCIÓN DE LAS ACTIVIDADES DE ESCRITURA LIBRE EN L2 EN VALLADOLID....... 326 
TABLA 26. RESULTADOS SOBRE LAS APTITUDES DEL INFORMANTE EN CUANTO A LA ELECCIÓN DE MODALIDADES DE CORRECCIÓN DE LAS ACTIVIDADES DE ESCRITURA LIBRE EN L2 EN AUSTIN

TABLA 27. RESULTADOS SOBRE LAS APTITUDES DEL INFORMANTE EN TORNO AL FEEDBACK QUE ACOMPAÑA A LA CORRECCIÓN DE ERRORES DE UNA ACTIVIDAD DE ESCRITURA LIBRE EN L2 EN VALLADOLID

TABLA 28. RESULTADOS SOBRE LAS APTITUDES DEL INFORMANTE EN TORNO AL FEEDBACK QUE ACOMPAÑA A LA CORRECCIÓN DE ERRORES DE UNA ACTIVIDAD DE ESCRITURA LIBRE EN L2 EN AUSTIN

TABLA 29. RESULTADOS SOBRE LAS APTITUDES DEL INFORMANTE EN TORNO A LA EVALUACIÓN DE UNA ACTIVIDAD DE ESCRITURA LIBRE EN L2 EN VALLADOLID

TABLA 30. RESULTADOS SOBRE LAS APTITUDES DEL INFORMANTE EN TORNO A LA EVALUACIÓN DE UNA ACTIVIDAD DE ESCRITURA LIBRE EN L2 EN AUSTIN

TABLA 31. RESULTADOS SOBRE LAS APTITUDES DEL INFORMANTE EN CUANTO A CONJUNCIÓN DE CORRECCIÓN, FEEDBACK Y NOTA NUMÉRICA EN VALLADOLID.

TABLA 32. RESULTADOS SOBRE LAS APTITUDES DEL INFORMANTE EN CUANTO A CONJUNCIÓN DE CORRECCIÓN, FEEDBACK Y NOTA NUMÉRICA EN AUSTIN.

TABLA 33. RESULTADOS SOBRE LAS ACTITUDES DEL INFORMANTE ANTE LA CORRECCIÓN DE ERRORES Y EL FEEDBACK EN UNA PRODUCCIÓN ESCRITA EN L2 EN VALLADOLID

TABLA 34. RESULTADOS SOBRE LAS ACTITUDES DEL INFORMANTE ANTE LA CORRECCIÓN DE ERRORES Y EL FEEDBACK EN UNA PRODUCCIÓN ESCRITA EN L2 EN AUSTIN

Tabla 35. Pruebas de Chi-Cuadrado “AÑos de experiencia” * “Momento idóneo de Corrección” * “Grupo" .................. 385

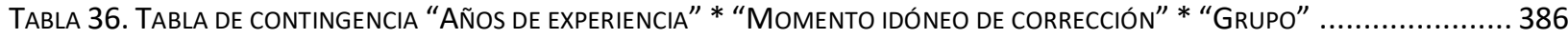

TABLA 37. PRUEBAS DE CHI-CUADRADO “EdAD” * “MOMENTO IDÓNEO DE CORRECCIÓN" * “GRUPO” ....................................390

TABLA 38. TABLA DE CONTINGENCIA “EdAD" * "MoMENTO IDÓNEO DE CORRECCIÓN" * "GRUPO" ...................................... 392

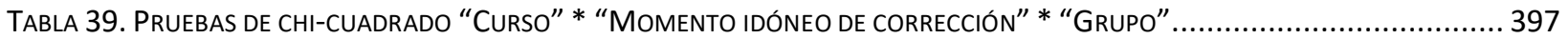

TABLA 40. TABLA DE CONTINGENCIA “CURSO" * “MOMENTO IDÓNEO DE CORRECCIÓN" * "GRUPO" ...................................... 398

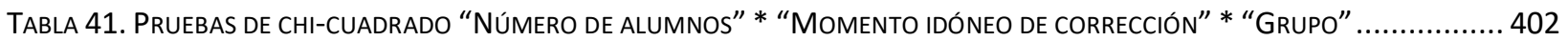

TABLA 42. TABLA dE CONTINGENCIA "NúMERO dE ALUMNOS" * "MOMENTO IDÓNEO dE CORRECCIÓN" * "GRUPO" .................... 403

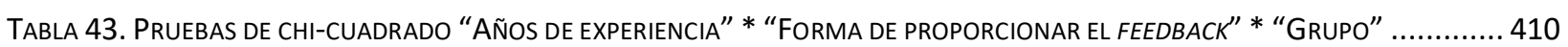

TABLA 44. TABLA DE CONTINGENCIA "AÑOS DE EXPERIENCIA" * "FORMA DE PROPORCIONAR EL FEEDBACK" * "GRUPO" ............... 412

TABLA 45. PRUEBAS DE CHI-CUADRADO “EDAD" * "FoRMA DE PROPORCIONAR EL FEEDBACK" * "GRUPO" .............................. 417

TABLA 46. TABLA DE CONTINGENCIA “EDAD” * "FORMA DE PROPORCIONAR EL FEEDBACK" * "GRUPO" ...................................418

TABLA 47. PRUEBAS DE CHI-CUADRAdo “CURSO" * "FoRMA DE PROPORCIONAR EL FEEDBACK" * "GRUPO" ...............................422

TABLA 48. TABLA DE CONTINGENCIA "CURSO" * "FormA DE PROPORCIONAR EL FEEDBACK" * "GrUPO" ................................ 423

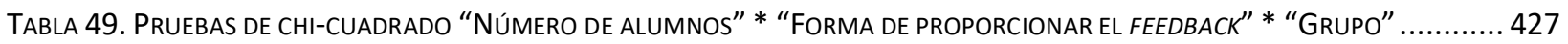

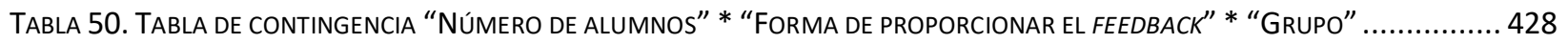

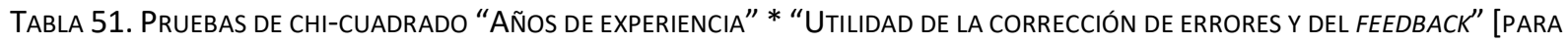
QUE EL ALUMNO SEA CONSCIENTE DE SU PROPIO PROCESO DE APRENDIZAJE]* “GRUPO” ...................................... 435

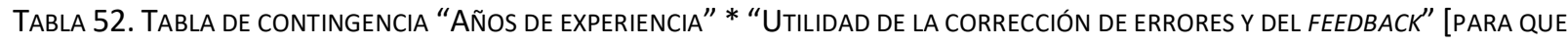
EL ALUMNO SEA CONSCIENTE DE SU PROPIO PROCESO DE APRENDIZAJE]* “GRUPO" 436

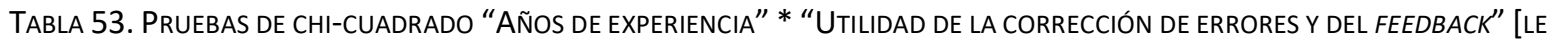
PERMITA ESTABLECER CONEXIONES ENTRE SU LENGUA MATERNA Y LA L2] * “GRUPO” ...........................................440

TABLA 54. TABLA de CONTINGENCIA “AÑOS DE EXPERIENCIA” * “UtILIDAD DE LA CORRECCIÓN DE ERRORES Y DEL FEEDBACK” [LE PERMITA eStABLECER CONEXIONES ENTRE SU LENGUA MATERNA Y LA L2]* “GRUPo" 441

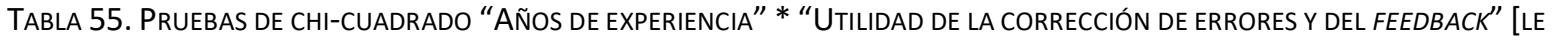
APORTE INFORMACIÓN SOBRE CÓMO TRABAJAR LAS DISTINTAS DESTREZAS COMUNICATIVAS]* “GRUPO” ..........................445

TABLA 56. TABLA DE CONTINGENCIA “AÑOS DE EXPERIENCIA" * “UTILIDAD DE LA CORRECCIÓN DE ERRORES Y DEL FEEDBACK” [LE APORTE INFORMACIÓN SOBRE CÓMO TRABAJAR LAS DISTINTAS DESTREZAS COMUNICATIVAS] * "GRUPO” ..................................446

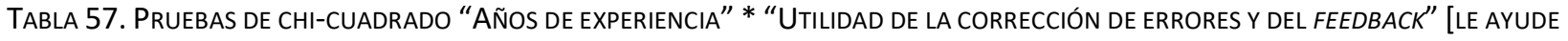
A VER LOS ERRORES NO COMO ALGO NEGATIVO SINO COMO INDICADOR DE SU PROGRESO EN EL PROCESO DE APRENDIZAJE]* "GRUPO"

TABLA 58. TABla de CONTINGENCIA “AÑOS DE EXPERIENCIA" * “UTILIDAD DE LA CORRECCIÓN DE eRRORES Y DEL FEEDBACK" [LE AYUDE A VER LOS ERRORES NO COMO ALGO NEGATIVO SINO COMO INDICADOR DE SU PROGRESO EN EL PROCESO DE APRENDIZAJE]* “GRUPO” 


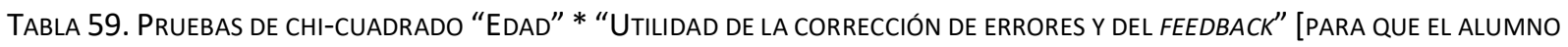
SEA CONSCIENTE DE SU PROPIO PROCESO DE APRENDIZAJE]* “GRUPO".....

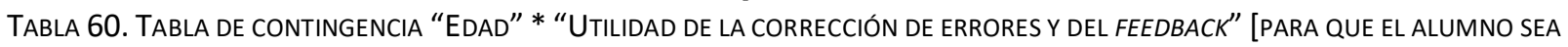
CONSCIENTE DE SU PROPIO PROCESO DE APRENDIZAJE]* “GRUPO” ......................................................456

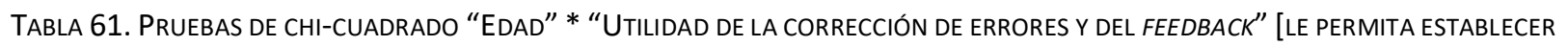
CONEXIONES ENTRE SU LENGUA MATERNA Y LA L2]* "GRUPO" .

TABLA 62. TABLA de CONTINGENCIA “EdAD” * “UTILIDAD DE LA CORRECCIÓN DE ERRORES Y DEL FEEDBACK” [LE PERMITA ESTABLECER CONEXIONES ENTRE SU LENGUA MATERNA Y LA L2]* "GRUPO"

TABLA 63. PRUEBAS DE CHI-CUADRADO “EdAD” * “UTILIDAD DE LA CORRECCIÓN DE ERRORES Y DEL FEEDBACK” [LE APORTE INFORMACIÓN SOBRE CÓMO TRABAJAR LAS DISTINTAS DESTREZAS COMUNICATIVAS] “ “GRUPO" .................................................465

TABLA 64. TABLA DE CONTINGENCIA "EdAD” * “UTILIDAD DE LA CORRECCIÓN DE ERRORES Y DEL FEEDBACK" [LE APORTE INFORMACIÓN SOBRE CÓMO TRABAJAR LAS DISTINTAS DESTREZAS COMUNICATIVAS]* “GRUPO” ............................................. 467

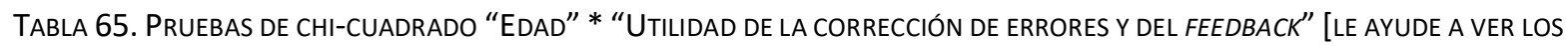
ERRORES NO COMO ALGO NEGATIVO SINO COMO INDICADOR DE SU PROGRESO EN EL PROCESO DE APRENDIZAJE]* “GRUPO” .... 470

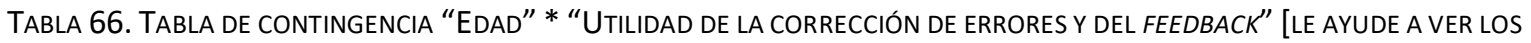
ERRORES NO COMO ALGO NEGATIVO SINO COMO INDICADOR DE SU PROGRESO EN EL PROCESO DE APRENDIZAJE]* “GRUPO” .... 472

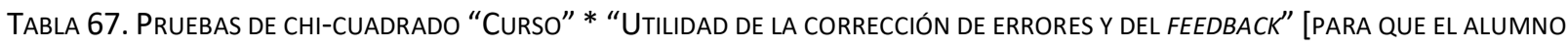

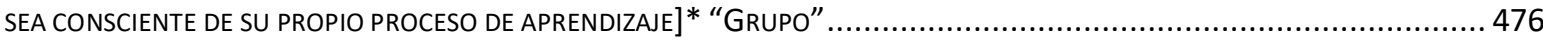

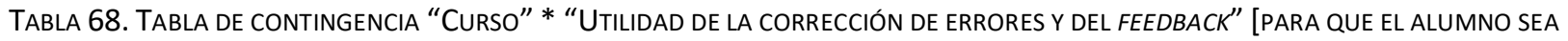

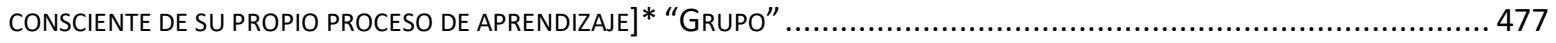

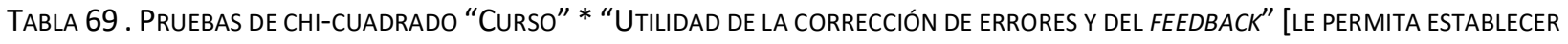

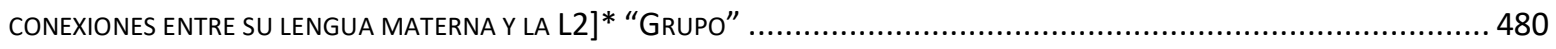

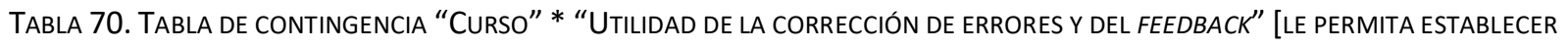

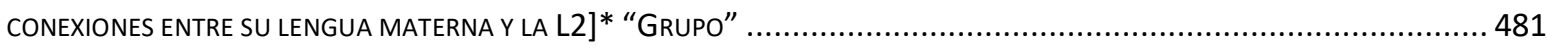

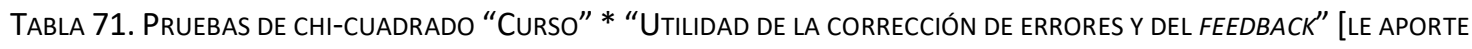
INFORMACIÓN SOBRE CÓMO TRABAJAR LAS DISTINTAS DESTREZAS COMUNICATIVAS] * "GRUPO"

TABLA 72. TABLA DE CONTINGENCIA “CURSO” * “UtILIDAD DE LA CORRECCIÓN DE ERRORES Y DEL FEEDBACK” [LE APORTE INFORMACIÓN SOBRE CÓMO TRABAJAR LAS DISTINTAS DESTREZAS COMUNICATIVAS]* “GRUPO”

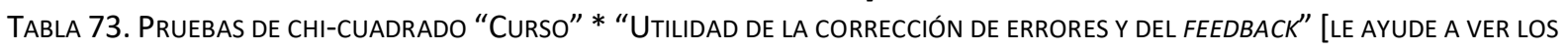
ERRORES NO COMO ALGO NEGATIVO SINO COMO INDICADOR DE SU PROPIO PROCESO DE APRENDIZAJE]* "GRUPO"

TABLA 74. TABLA DE CONTINGENCIA “CURSO" * “UTILIDAD DE LA CORRECCIÓN DE ERRORES Y DEL FEEDBACK" [LE AYUDE A VER LOS ERRORES NO COMO ALGO NEGATIVO SINO COMO INDICADOR DE SU PROPIO PROCESO DE APRENDIZAJE]* “GRUPO”.....

TABla 75. PRUEBAS de CHI-CUAdRAdo “NúMERO dE ALUMNOS" * “UTILIDAD DE LA CORRECCIÓN DE ERRORES Y DEL FEEDBACK" [PARA QUE EL ALUMNO SEA CONSCIENTE DE SU PROPIO PROCESO DE APRENDIZAJE] * “GRUPO” ............................................494

TABLA 76. TABLA de CONTINGENCIA “NúMERO de ALUMNOS" * “UTILIDAD DE LA CORRECCIÓN DE ERRORES Y DEL FEEDBACK" [PARA QUE EL ALUMNO SEA CONSCIENTE DE SU PROPIO PROCESO DE APRENDIZAJE]* “GRUPO"

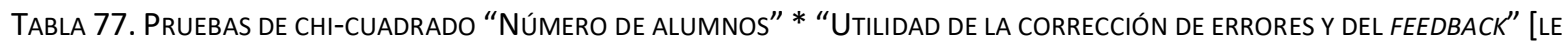
PERMITA ESTABLECER CONEXIONES ENTRE SU LENGUA MATERNA Y LA L2] * "GRUPO” ...........................................498

TABLA 78. TABLA dE CONTINGENCIA “NúMERO DE ALUMNOS" * “UTILIDAD DE LA CORRECCIÓN DE ERRORES Y DEL FEEDBACK" [LE PERMITA ESTABLECER CONEXIONES ENTRE SU LENGUA MATERNA Y LA L2]* “GRUPO” ....................................................50

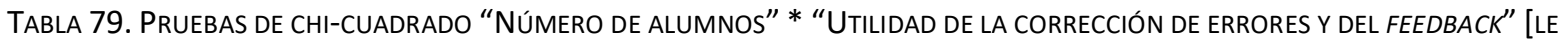
APORTE INFORMACIÓN SOBRE CÓMO TRABAJAR LAS DISTINTAS DESTREZAS COMUNICATIVAS]* “GRUPO” ...........................504

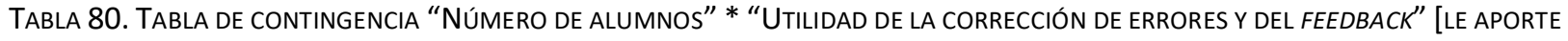
INFORMACIÓN SOBRE CÓMO TRABAJAR LAS DISTINTAS DESTREZAS COMUNICATIVAS] * “GRUPO” ..................................506

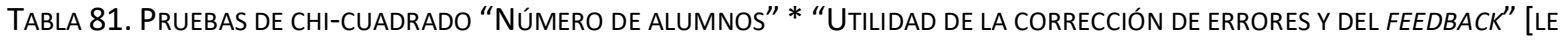
AYUDE A VER LOS ERRORES NO COMO ALGO NEGATIVO SINO COMO INDICADOR DE SU PROGRESO EN EL PROCESO DE APRENDIZAJE]* "GRUPO"

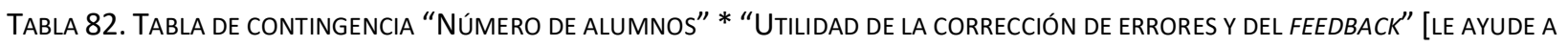
VER LOS ERRORES NO COMO ALGO NEGATIVO SINO COMO INDICADOR DE SU PROGRESO EN EL PROCESO DE APRENDIZAJE]* “GRUPO” 


\section{ÍNDICE DE GRÁFICOS}

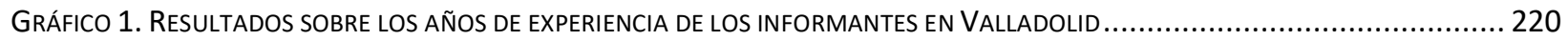

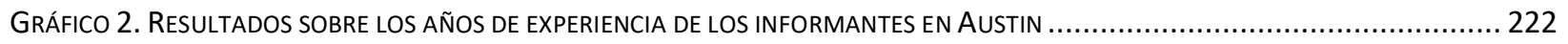

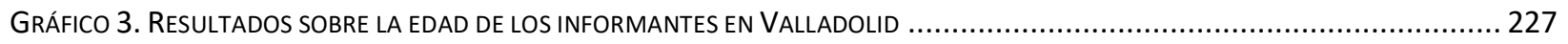

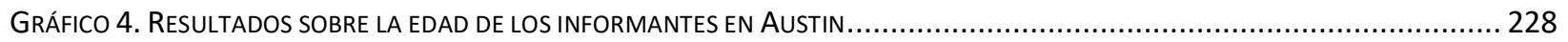

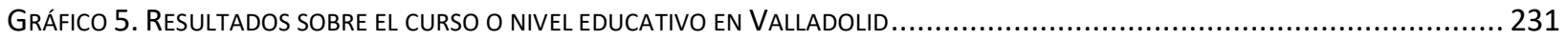

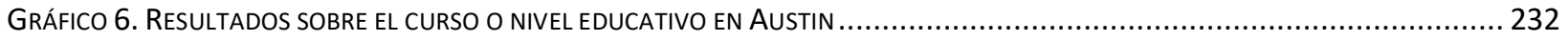

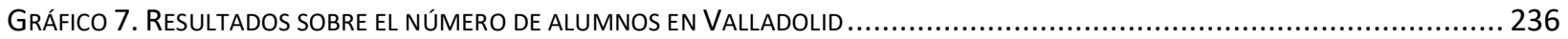

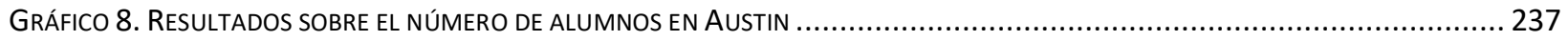

GRÁFICO 9. RESULTADOS SOBRE LA ACTITUD DE LOS ALUMNOS ANTE UNA ACTIVIDAD DE ESCRITURA DIRIGIDA EN VALLADOLID ............248

GRÁFICO 10. RESULTADOS SOBRE LA ACTITUD DE LOS ALUMNOS ANTE UNA ACTIVIDAD DE ESCRITURA DIRIGIDA EN AUSTIN ................. 250

GRÁFICO 11. RESULTADOS SOBRE LA ACTITUD DE LOS ALUMNOS ANTE UNA ACTIVIDAD DE ESCRITURA LIBRE EN VALLADOLID ............... 255

GRÁFICO 12. RESULTADOS SOBRE LA ACTITUD DE LOS ALUMNOS ANTE UNA ACTIVIDAD DE ESCRITURA LIBRE EN AUSTIN ..................... 258

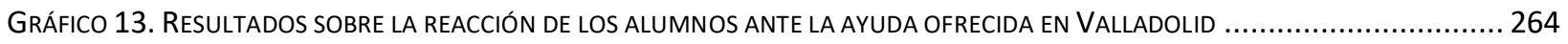

GRÁFICO 14. RESULTADOS SOBRE LA REACCIÓN DE LOS ALUMNOS ANTE LA AYUDA OFRECIDA EN AUSTIN................................... 266

GRÁFICO 15. RESULTADOS SOBRE LA UTILIDAD DE LAS ACTIVIDADES DE EXPRESIÓN ESCRITA LIBRE EN L2 EN VALLADOLID.................... 272

GRÁFICO 16. RESULTADOS SOBRE LA UTILIDAD DE LAS ACTIVIDADES DE EXPRESIÓN ESCRITA LIBRE EN AUSTIN ................................ 274

GRÁFICO 17. RESULTADOS SOBRE EL MOMENTO IDÓNEO PARA LA CORRECCIÓN DE LAS PRODUCCIONES ESCRITAS EN L2 EN VALLADOLID278

GRÁFICO 18. RESULTADOS SOBRE EL MOMENTO IDÓNEO PARA LA CORRECCIÓN DE LAS PRODUCCIONES ESCRITAS EN L2 EN AUSTIN ...... 281

GRÁFICO 19. RESULTADOS SOBRE LOS TIPOS DE ERRORES QUE DEBEN SER CORREGIDOS EN LAS PRODUCCIONES ESCRITAS EN L2 EN

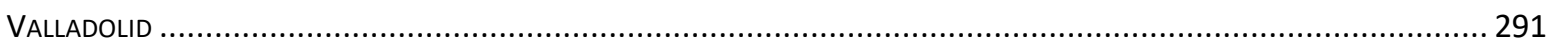

GRÁFICO 20. RESULTADOS SOBRE LOS TIPOS DE ERRORES QUE DEBEN SER CORREGIDOS EN LAS PRODUCCIONES ESCRITAS EN L2 EN AUSTIN

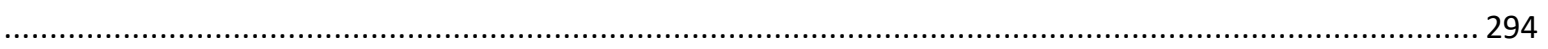

GRÁFICO 21. RESULTADOS SOBRE LA PRESENTACIÓN DE UNA ACTIVIDAD DE ESCRITURA LIBRE EN L2 EN VALLADOLID ......................... 310

GRÁFICO 22. RESULTADOS SOBRE LA PRESENTACIÓN DE UNA ACTIVIDAD DE ESCRITURA LIBRE EN L2 EN AUSTIN ............................. 312

GRÁFICO 23. RESULTADOS SOBRE LAS APTITUDES DEL INFORMANTE ORIENTADAS A LA AYUDA PROPORCIONADA DURANTE LA REALIZACIÓN

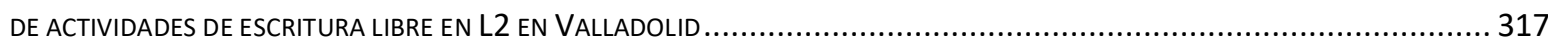

GRÁFICO 24. RESULTADOS SOBRE LAS APTITUDES DEL INFORMANTE ORIENTADAS A LA AYUDA PROPORCIONADA DURANTE LA REALIZACIÓN

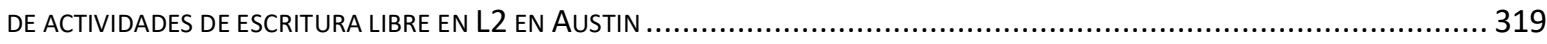

GRÁFICO 25. RESULTADOS SOBRE LAS APTITUDES DEL INFORMANTE EN CUANTO A LA ELECCIÓN DE MODALIDADES DE CORRECCIÓN DE LAS ACTIVIDADES DE ESCRITURA LIBRE EN L2 EN VALLADOLID ............................................................................... 326

GRÁFICO 26. RESULTADOS SOBRE LAS APTITUDES DEL INFORMANTE EN CUANTO A LA ELECCIÓN DE MODALIDADES DE CORRECCIÓN DE LAS

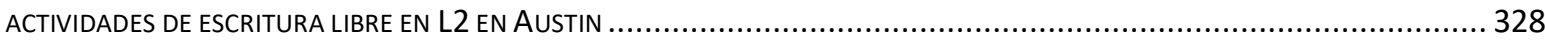

GRÁFICO 27. RESULTADOS SOBRE LAS APTITUDES DEL INFORMANTE EN TORNO AL FEEDBACK QUE ACOMPAÑA A LA CORRECCIÓN DE

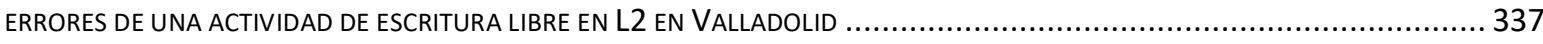

GRÁFICO 28. RESULTADOS SOBRE LAS APTITUDES DEL INFORMANTE EN TORNO AL FEEDBACK QUE ACOMPAÑA A LA CORRECCIÓN DE

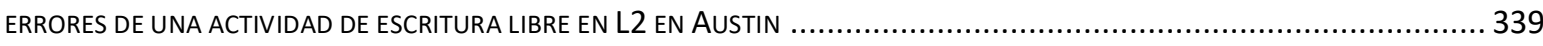

GRÁFICO 29. RESULTADOS SOBRE LAS APTITUDES DEL INFORMANTE EN TORNO A LA EVALUACIÓN DE UNA ACTIVIDAD DE ESCRITURA LIBRE

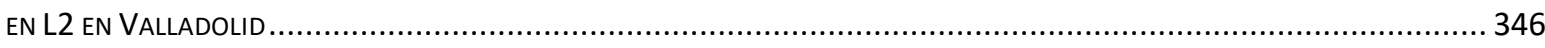

GRÁFICO 30. RESULTADOS SOBRE LAS APTITUDES DEL INFORMANTE EN TORNO A LA EVALUACIÓN DE UNA ACTIVIDAD DE ESCRITURA LIBRE

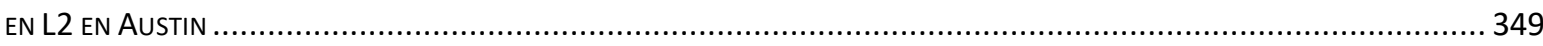

GRÁFICO 31. RESULTADOS SOBRE LAS APTITUDES DEL INFORMANTE EN CUANTO A CONJUNCIÓN DE CORRECCIÓN, FEEDBACKY NOTA

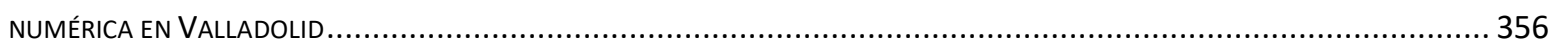

GRÁFICO 32. RESULTADOS SOBRE LAS APTITUDES DEL INFORMANTE EN CUANTO A CONJUNCIÓN DE CORRECCIÓN, FEEDBACK Y NOTA

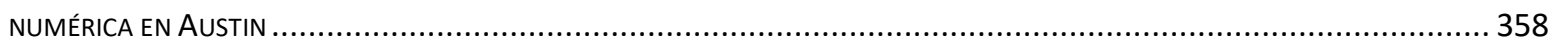

GRÁFICO 33. RESULTADOS SOBRE LAS ACTITUDES DEL INFORMANTE ANTE LA CORRECCIÓN DE ERRORES Y EL FEEDBACK EN UNA PRODUCCIÓN

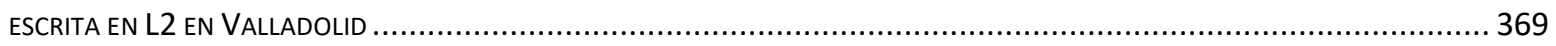

GRÁFICO 34. RESULTADOS SOBRE LAS ACTITUDES DEL INFORMANTE ANTE LA CORRECCIÓN DE ERRORES Y EL FEEDBACK EN UNA PRODUCCIÓN

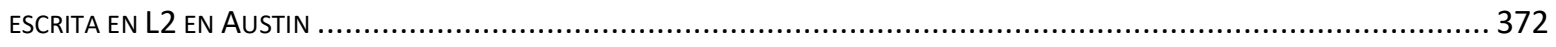

GRÁFICO 35. RECUENTO AÑOS DE EXPERIENCIA - MOMENTO IDÓNEO DE CORRECCIÓN- GRUPO VALLADOLID.................................388

GRÁFICO 36. RECUENTO AÑOS DE EXPERIENCIA - MOMENTO IDÓNEO de CORRECCIÓN - GRUPO AUSTIN .......................................388 


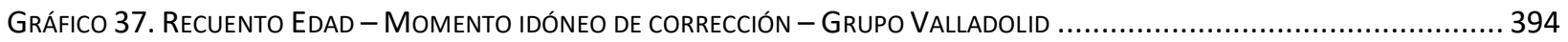

GRÁFICO 38. RECUENTO EDAD - MOMENTO IDÓNEO DE CORRECCIÓN - GRUPO AUSTIN ................................................. 395

GRÁFICO 39. RECUENTO CURSO - MOMENTO IDÓNEO DE CORRECCIÓN - GRUPO VALLADOLID................................................ 400

GRÁFICO 40. RECUENTO CURSO - MOMENTO IDÓNEO DE CORRECCIÓN - GRUPO AUSTIN ................................................. 400

GRÁFICO 41. RECUENTO NÚMERO DE ALUMNOS - MOMENTO IDÓNEO DE CORRECCIÓN - GRUPO VALLADOLID ........................... 405

GRÁFICO 42. RECUENTO NÚMERO DE ALUMNOS - MOMENTO IDÓNEO DE CORRECCIÓN - GRUPO AUSTIN ..................................405

GRÁFICO 43. RECUENTO AÑOS DE EXPERIENCIA - FoRMA DE PROPORCIONAR EL FEEDBACK - GRUPO VALLADOLID ....................... 414

GRÁFICO 44. RECUENTO AÑOS DE EXPERIENCIA - FORMA DE PROPORCIONAR EL FEEDBACK - GRUPO AUSTIN............................. 414

GRÁFICO 45. RECUENTO EDAD - FORMA DE PROPORCIONAR EL FEEDBACK - GRUPO VALLADOLID .........................................420

GRÁFICO 46. RECUENTO EDAD - FORMA DE PROPORCIONAR EL FEEDBACK - GRUPO AUSTIN ............................................. 420

GRÁFICO 47. RECUENTO CURSO - FORMA DE PROPORCIONAR EL FEEDBACK - GRUPO VALLADOLID...................................... 425

GRÁFICO 48. RECUENTO CURSO - FORMA DE PROPORCIONAR EL FEEDBACK - GRUPO AUSTIN ......................................... 425

GRÁFICO 49. RECUENTO NÚMERO DE ALUMNOS - FoRMA DE PROPORCIONAR EL FEEDBACK - GRUPO VALLADOLID ....................... 430

GRÁFICO 50. RECUENTO NÚMERO DE ALUMNOS - FORMA DE PROPORCIONAR EL FEEDBACK - GRUPO AUSTIN ........................... 430

GRÁFICO 51. RECUENTO AÑOS DE EXPERIENCIA - UTILIDAD DE LA CORRECCIÓN DE ERRORES Y DEL FEEDBACK" [PARA QUE EL ALUMNO SEA

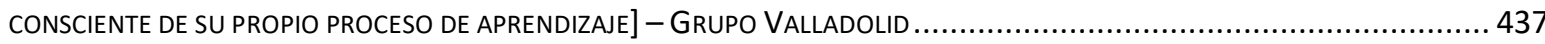

GRÁFICO 52. RECUENTO AÑOS DE EXPERIENCIA - UtILIDAD DE LA CORRECCIÓN DE ERRORES Y DEL FEEDBACK" [PARA QUE EL ALUMNO SEA

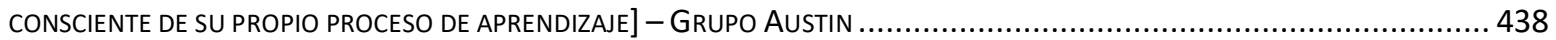

GRÁFICO 53. RECUENTO AÑOS DE EXPERIENCIA - UTILIDAD DE LA CORRECCIÓN DE ERRORES Y DEL FEEDBACK" [LE PERMITA ESTABLECER

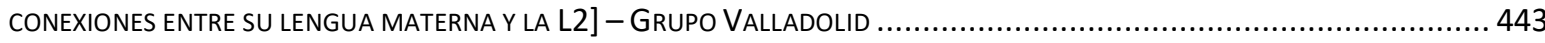

GRÁFICO 54. RECUENTO AÑOS DE EXPERIENCIA - UTILIDAD DE LA CORRECCIÓN DE ERRORES Y DEL FEEDBACK" [LE PERMITA ESTABLECER

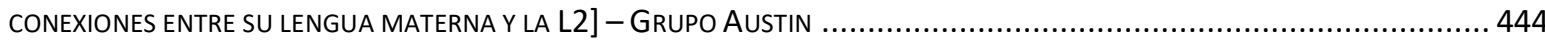

GRÁFICO 55. RECUENTO AÑOS DE EXPERIENCIA - UTILIDAD DE LA CORRECCIÓN DE ERRORES Y DEL FEEDBACK" [LE APORTE INFORMACIÓN SOBRE CÓMO TRABAJAR LAS DISTINTAS DESTREZAS COMUNICATIVAS] - GRUPO VALLADOLID .....................................448

GRÁFICO 56. RECUENTO AÑOS DE EXPERIENCIA - UTILIDAD DE LA CORRECCIÓN DE ERRORES Y DEL FEEDBACK" [LE APORTE INFORMACIÓN SOBRE CÓMO TRABAJAR LAS DISTINTAS DESTREZAS COMUNICATIVAS] - GRUPO AUSTIN ......................................... 448

GRÁFICO 57. RECUENTO AÑOS DE EXPERIENCIA - UTILIDAD DE LA CORRECCIÓN DE ERRORES Y DEL FEEDBACK" [LE AYUDE A VER LOS ERRORES NO COMO ALGO NEGATIVO SINO COMO INDICADOR DE SU PROGRESO EN EL PROCESO DE APRENDIZAJE] - GRUPO VALLADOLID

GRÁFICO 58. RECUENTO AÑOS DE EXPERIENCIA - UTILIDAD DE LA CORRECCIÓN DE ERRORES Y DEL FEEDBACK" [LE AYUDE A VER LOS ERRORES NO COMO ALGO NEGATIVO SINO COMO INDICADOR DE SU PROGRESO EN EL PROCESO DE APRENDIZAJE] - GRUPO AUSTIN

GRÁFICO 59. RECUENTO EDAD - UTILIDAD DE LA CORRECCIÓN DE ERRORES Y DEL FEEDBACK" [PARA QUE EL ALUMNO SEA CONSCIENTE DE SU PROPIO PROCESO DE APRENDIZAJE] - GRUPO VALLADOLID

GRÁFICO 60. RECUENTO EDAD - UTILIDAD DE LA CORRECCIÓN DE ERRORES Y DEL FEEDBACK" [PARA QUE EL ALUMNO SEA CONSCIENTE DE SU PROPIO PROCESO DE APRENDIZAJE] - GRUPO AUSTIN

GRÁFICO 61. RECUENTO EdAD - UTILIDAD DE LA CORRECCIÓN DE ERRORES Y DEL FEEDBACK" [LE PERMITA ESTABLECER CONEXIONES ENTRE SU LENGUA MATERNA Y LA L2-GRUPO VALLADOLID.

463

GRÁFICO 62. RECUENTO EDAD - UTILIDAD DE LA CORRECCIÓN DE ERRORES Y DEL FEEDBACK" [LE PERMITA ESTABLECER CONEXIONES ENTRE SU LENGUA MATERNA Y LA L2- GRUPO AUSTIN ....................................................................... 464

GRÁFICO 63. RECUENTO EDAD - UTILIDAD DE LA CORRECCIÓN DE ERRORES Y DEL FEEDBACK" [LE APORTE INFORMACIÓN SOBRE CÓMO

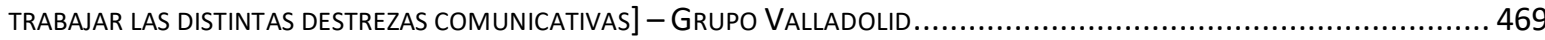

GRÁFICO 64. RECUENTO EDAD - UTILIDAD DE LA CORRECCIÓN DE ERRORES Y DEL FEEDBACK" [LE APORTE INFORMACIÓN SOBRE CÓMO

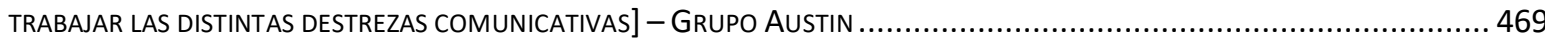

GRÁFICO 65. RECUENTO EDAD - UTILIDAD DE LA CORRECCIÓN DE ERRORES Y DEL FEEDBACK" [LE AYUDE A VER LOS ERRORES NO COMO ALGO NEGATIVO SINO COMO INDICADOR DE SU PROGRESO EN EL PROCESO DE APRENDIZAJE] - GRUPO VALLADOLID............... 473

GRÁFICO 66. RECUENTO EDAD - UTILIDAD DE LA CORRECCIÓN DE ERRORES Y DEL FEEDBACK" [LE AYUDE A VER LOS ERRORES NO COMO ALGO NEGATIVO SINO COMO INDICADOR DE SU PROGRESO EN EL PROCESO DE APRENDIZAJE] - GRUPO AUSTIN.

GRÁFICO 67. RECUENTO CURSO - UTILIDAD DE LA CORRECCIÓN DE ERRORES Y DEL FEEDBACK" [PARA QUE EL ALUMNO SEA CONSCIENTE DE SU PROPIO PROCESO DE APRENDIZAJE] - GRUPO VALLADOLID

GRÁFICO 68. RECUENTO CURSO - UTILIDAD DE LA CORRECCIÓN DE ERRORES Y DEL FEEDBACK" [PARA QUE EL ALUMNO SEA CONSCIENTE DE SU PROPIO PROCESO DE APRENDIZAJE] - GRUPO AUSTIN 
GRÁFICO 69. RECUENTO CURSO - UtILIDAD DE LA CORRECCIÓN DE ERRORES Y DEL FEEDBACK" [LE PERMITA ESTABLECER CONEXIONES ENTRE SU LENGUA MATERNA Y LA L2]-GRUPO VALLADOLID.....

GRÁFICO 70. RECUENTO CURSO - UTILIDAD DE LA CORRECCIÓN DE ERRORES Y DEL FEEDBACK" [LE PERMITA ESTABLECER CONEXIONES ENTRE SU LENGUA MATERNA Y LA L2]-GRUPO AUSTIN.....

GRÁFICO 71. RECUENTO CURSO - UTILIDAD DE LA CORRECCIÓN DE ERRORES Y DEL FEEDBACK" [LE APORTE INFORMACIÓN SOBRE CÓMO TRABAJAR LAS DISTINTAS DESTREZAS COMUNICATIVAS]- GRUPO VALLADOLID ..................................................... 488

GRÁFICO 72. RECUENTO CURSO - UTILIDAD DE LA CORRECCIÓN DE ERRORES Y DEL FEEDBACK" [LE APORTE INFORMACIÓN SOBRE CÓMO

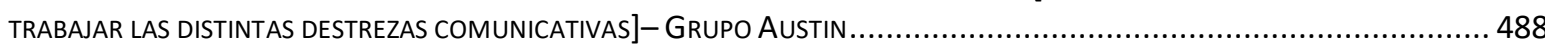

GRÁFICO 73. RECUENTO CURSO - UtILIDAD DE LA CORRECCIÓN DE ERRORES Y DEL FEEDBACK" [LE AYUDE A VER LOS ERRORES NO COMO ALGO NEGATIVO SINO COMO INDICADOR DE SU PROPIO PROCESO DE APRENDIZAJE]-GRUPO VALLADOLID.

GRÁFICO 74. RECUENTO CURSO - UTILIDAD DE LA CORRECCIÓN DE ERRORES Y DEL FEEDBACK" [LE AYUDE A VER LOS ERRORES NO COMO ALGO NEGATIVO SINO COMO INDICADOR DE SU PROPIO PROCESO DE APRENDIZAJE]-GRUPO AUSTIN

GRÁFICO 75. RECUENTO NúMERO DE ALUMNOS - UTILIDAD DE LA CORRECCIÓN DE ERRORES Y DEL FEEDBACK" [PARA QUE EL ALUMNO SEA CONSCIENTE DE SU PROPIO PROCESO DE APRENDIZAJE]-GRUPO VALLADOLID ............................................................ 496

GRÁfICO 76. RECUENTO NÚMERO DE ALUMNOS - UTILIDAD DE LA CORRECCIÓN DE ERRORES Y DEL FEEDBACK" [PARA QUE EL ALUMNO SEA CONSCIENTE DE SU PROPIO PROCESO DE APRENDIZAJE]-GRUPO AUSTIN 497

GRÁFICO 77. RECUENTO NÚMERO DE ALUMNOS - UTILIDAD DE LA CORRECCIÓN DE ERRORES Y DEL FEEDBACK" [LE PERMITA ESTABLECER

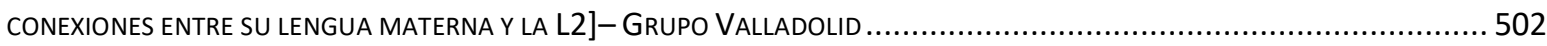

GRÁFICO 78. RECUENTO NÚMERO DE ALUMNOS - UTILIDAD DE LA CORRECCIÓN DE ERRORES Y DEL FEEDBACK" [LE PERMITA ESTABLECER

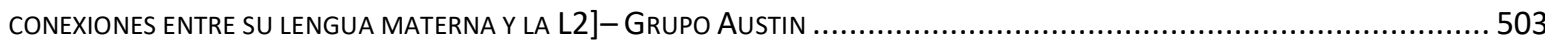

GRÁFICO 79. RECUENTO NÚMERO DE ALUMNOS - UTILIDAD DE LA CORRECCIÓN DE ERRORES Y DEL FEEDBACK" [LE APORTE INFORMACIÓN SOBRE CÓMO TRABAJAR LAS DISTINTAS DESTREZAS COMUNICATIVAS]- GRUPO VALLADOLID .......................................... 508

GRÁFICO 80. RECUENTO NÚMERO DE ALUMNOS - UTILIDAD DE LA CORRECCIÓN DE ERRORES Y DEL FEEDBACK" [LE APORTE INFORMACIÓN SOBRE CÓMO TRABAJAR LAS DISTINTAS DESTREZAS COMUNICATIVAS]-GRUPO AUSTIN.

GRÁfico 81. RECUENTO NúMERO de ALUMNOS - UtILIDAD DE LA CORRECCIÓN DE ERRORES Y DEL FEEDBACK" [LE AYUDE A VER LOS ERRORES NO COMO ALGO NEGATIVO SINO COMO INDICADOR DE SU PROGRESO EN EL PROCESO DE APRENDIZAJE]- GRUPO VALLADOLID

GRÁFICO 82. RECUENTO NÚMERO DE ALUMNOS - UTILIDAD DE LA CORRECCIÓN DE ERRORES Y DEL FEEDBACK" [LE AYUDE A VER LOS ERRORES NO COMO ALGO NEGATIVO SINO COMO INDICADOR DE SU PROGRESO EN EL PROCESO DE APRENDIZAJE]- GRUPO AUSTIN 

ANEXOS 



\section{Anexo I}

\section{Cuestionario I. Cuestionario para profesores de Educación Primaria que imparten enseñanzas oficiales de inglés como segunda lengua (L2) en la ciudad de Valladolid, España}

1. Años de experiencia en la enseñanza de una segunda lengua (L2) ....

2. Edad: $\square$ Menor de 30

De 30 a 45

$\square$ Más de 45

Sin respuesta

3. Curso en el que imparte sus clases: $\square 1^{\circ} \quad \square 2^{\circ} \quad \square 3^{\circ} \quad \square 4^{\circ} \quad \square 5^{\circ} \quad \square 6^{\circ}$

4. Número de alumnos en el aula:

5. Ante una actividad de escritura dirigida, los alumnos muestran una actitud:
Positiva
Negativa
De indiferencia
Otros

6. Ante una actividad de escritura libre, los alumnos muestran una actitud:
Positiva
Negativa
De indiferencia
Otros .

7. ¿De qué manera presenta una actividad de escritura libre a sus alumnos?

- Como algo divertido

- Como si se tratase de un juego

- Como cualquier otra actividad

- Otros.

8. Durante la realización de una actividad de escritura libre, ¿el alumno recibe alguna ayuda por su parte o por parte de otro profesional de la educación que se encuentre en el aula?

- $\quad$ Sí, yo le dirijo durante el transcurso de la actividad

- $\quad$ No, se trata de una actividad completamente libre

- Otros.

9. ¿Cómo reaccionan los estudiantes ante esa ayuda?

- La mayoría lo pide cuando lo necesita

- La mayoría no pide ayuda e intenta realizar la actividad por su cuenta

- Otros.

10. ¿En qué medida considera que las actividades de expresión escrita libres en una L2 sirven a la hora de mejorar los siguientes aspectos?

\begin{tabular}{|ll|ccccr|}
\hline a) & $\begin{array}{l}\text { Mostrar la destreza de un alumno a la hora de } \\
\text { expresarse en una L2 }\end{array}$ & $\begin{array}{c}\text { Mucho } \\
\square\end{array}$ & $\begin{array}{c}\text { Bastante } \\
\square\end{array}$ & $\begin{array}{c}\text { Poco } \\
\square\end{array}$ & $\begin{array}{c}\text { Muy poco } \\
\square\end{array}$ & Nada \\
$\square$
\end{tabular}


11. ¿Quién corrige las producciones escritas de sus alumnos?

- $\quad$ Siempre yo

- Mi asistente

- Los alumnos se corrigen unos a otros

- Los alumnos se corrigen a sí mismos (autocorrección)

- Otros.

12. Cuando usted corrige las producciones escritas de los alumnos, ¿En qué momento lo hace?

- Justo a continuación

- Después de unos días

- Otros. .

13. ¿De qué manera hace llegar a los alumnos sus comentarios o feedback sobre las producciones escritas que han realizado?

- De forma oral individualmente con cada alumno

- $\quad$ De forma oral de manera conjunta (en voz alta) para que todos puedan aprender de los errores de sus compañeros

- Escribiendo los comentarios que considere oportunos con tinta de otro color en el mismo papel donde se encuentra la producción escrita

- Utilizo un código de corrección que mis alumnos ya conocen y lo escribo en las producciones escritas

- Otros.

14. ¿Cómo evalúa las producciones escritas?

- $\quad$ Asigno una nota numérica o general: excelente, muy bien, bien, regular, ...

- $\quad$ Utilizo un método de autoevaluación guiada

- Otros.

15. ¿Qué tipos de errores son, bajo su punto de vista, los que necesitan ser corregidos?

- Todos los errores

- $\quad$ Los errores ortográficos

- Los que dificultan la comprensión general del texto

- $\quad$ Ninguno, lo importante es que el alumno produzca en otra lengua

- Otros.

16. ¿Devuelve usted el trabajo corregido a sus alumnos con las correcciones, comentarios y/o nota numérica?
$\square$ Siempre
$\square$ A veces
$\square$ Otros:

17. Califique ¿en qué medida la corrección de errores de sus alumnos y su feedback (crítica o comentario) es útil o va a ser útil?

\begin{tabular}{|c|c|c|c|c|c|c|}
\hline a) & Para que el alumno sea consciente de su propio proceso de aprendizaje & $\begin{array}{l}\text { Mucho } \\
\square\end{array}$ & $\begin{array}{c}\text { Bastante } \\
\square\end{array}$ & $\begin{array}{c}\text { Poco } \\
\square\end{array}$ & $\begin{array}{c}\text { Muy poce } \\
\square\end{array}$ & $\begin{array}{r}\text { Nada } \\
\square\end{array}$ \\
\hline b) & Le permita establecer conexiones entre su lengua materna y la L2 & Mucho & $\begin{array}{c}\text { Bastante } \\
\square\end{array}$ & $\begin{array}{c}\text { Poco } \\
\square\end{array}$ & Muy poce & $\begin{array}{r}\text { Nada } \\
\square\end{array}$ \\
\hline c) & $\begin{array}{l}\text { Le aporte información sobre cómo trabajar las distintas destrezas } \\
\text { comunicativas }\end{array}$ & $\begin{array}{l}\text { Mucho } \\
\square\end{array}$ & $\begin{array}{c}\text { Bastante } \\
\square\end{array}$ & $\begin{array}{c}\text { Poco } \\
\square\end{array}$ & $\begin{array}{r}\text { Muy po } \\
\square\end{array}$ & $\begin{array}{r}\text { Nada } \\
\square\end{array}$ \\
\hline d) & $\begin{array}{l}\text { Le ayude a ver los errores no como algo negativo sino como indicador de su } \\
\text { progreso en el proceso de aprendizaje }\end{array}$ & Mucho & $\begin{array}{c}\text { Bastante } \\
\square\end{array}$ & $\begin{array}{c}\text { Poco } \\
\square\end{array}$ & $\begin{array}{c}\text { Muy poce } \\
\square\end{array}$ & $\begin{array}{r}\text { Nada } \\
\square\end{array}$ \\
\hline
\end{tabular}




\section{Anexo II \\ Cuestionario II. Cuestionario para profesores de Educación Primaria que imparten enseñanzas oficiales de español como segunda lengua (L2) en la ciudad de Austin, Estados Unidos de América}

1. Años de experiencia en la enseñanza de una segunda lengua (L2)

2. Edad: $\square$ Menor de 30

De 30 a 45

$\square$ Más de 45

Sin respuesta

3. Curso en el que imparte sus clases: $\square 1^{\circ} \quad \square 2^{\circ} \quad \square 3^{\circ} \quad \square 4^{\circ} \quad \square 5^{\circ}$

4. Número de alumnos en el aula:

5. Ante una actividad de escritura dirigida, los alumnos muestran una actitud:
Positiva
Negativa
De indiferencia
Otros

6. Ante una actividad de escritura libre, los alumnos muestran una actitud:
Positiva
Negativa
De indiferencia
Otros

7. ¿De qué manera presenta una actividad de escritura libre a sus alumnos?

- Como algo divertido

- Como si se tratase de un juego

- Como cualquier otra actividad

- Otros.

8. Durante la realización de una actividad de escritura libre, ¿el alumno recibe alguna ayuda por su parte o por parte de otro profesional de la educación que se encuentre en el aula?

- $\quad$ Sí, yo le dirijo durante el transcurso de la actividad

- $\quad$ No, se trata de una actividad completamente libre

- Otros.

9. ¿Cómo reaccionan los estudiantes ante esa ayuda?

- La mayoría lo pide cuando lo necesita

- La mayoría no pide ayuda e intenta realizar la actividad por su cuenta

- Otros.

10. ¿En qué medida considera que las actividades de expresión escrita libres en una L2 sirven a la hora de mejorar los siguientes aspectos?

\begin{tabular}{|c|c|c|c|c|c|c|}
\hline a) & $\begin{array}{l}\text { Mostrar la destreza de un alumno a la hora de } \\
\text { expresarse en una L2 }\end{array}$ & $\begin{array}{c}\text { Mucho } \\
\square\end{array}$ & $\begin{array}{c}\text { Bastante } \\
\square\end{array}$ & $\begin{array}{c}\text { Poco } \\
\square\end{array}$ & $\begin{array}{c}\text { Muy poco } \\
\square\end{array}$ & $\begin{array}{r}\text { Nada } \\
\square\end{array}$ \\
\hline b) & Servir de apoyo en el aprendizaje de una L2 & $\begin{array}{c}\text { Mucho } \\
\square\end{array}$ & $\begin{array}{c}\text { Bastante } \\
\square\end{array}$ & $\begin{array}{c}\text { Poco } \\
\square\end{array}$ & $\begin{array}{c}\text { Muy poco } \\
\square\end{array}$ & $\begin{array}{r}\text { Nada } \\
\square\end{array}$ \\
\hline c) & $\begin{array}{l}\text { Ofrecer al profesor una muestra sobre el nivel de } \\
\text { conocimiento que tiene el alumno de la L2 }\end{array}$ & $\begin{array}{c}\text { Mucho } \\
\square\end{array}$ & $\begin{array}{c}\text { Bastante } \\
\square\end{array}$ & $\begin{array}{c}\text { Poco } \\
\square\end{array}$ & $\begin{array}{c}\text { Muy poco } \\
\square\end{array}$ & $\begin{array}{r}\text { Nada } \\
\square\end{array}$ \\
\hline d) & $\begin{array}{l}\text { Mejorar los conocimientos sobre su lengua } \\
\text { materna }\end{array}$ & $\begin{array}{c}\text { Mucho } \\
\square\end{array}$ & $\begin{array}{c}\text { Bastante } \\
\square\end{array}$ & $\begin{array}{c}\text { Poco } \\
\square\end{array}$ & $\begin{array}{c}\text { Muy poco } \\
\square\end{array}$ & $\begin{array}{r}\text { Nada } \\
\square\end{array}$ \\
\hline
\end{tabular}


11. ¿Quién corrige las producciones escritas de sus alumnos?

- $\quad$ Siempre yo

- $\quad$ Mi asistente

- Los alumnos se corrigen unos a otros

- $\quad$ Los alumnos se corrigen a sí mismos (autocorrección)

- Otros.

12. Cuando usted corrige las producciones escritas de los alumnos, ¿En qué momento lo hace?

- Justo a continuación

- Después de unos días

- Otros.

13. ¿De qué manera hace llegar a los alumnos sus comentarios o feedback sobre las producciones escritas que han realizado?

- De forma oral individualmente con cada alumno

- $\quad$ De forma oral de manera conjunta (en voz alta) para que todos puedan aprender de los errores de sus compañeros

- Escribiendo los comentarios que considere oportunos con tinta de otro color en el mismo papel donde se encuentra la producción escrita

- Utilizo un código de corrección que mis alumnos ya conocen y lo escribo en las producciones escritas

- Otros.

14. ¿Cómo evalúa las producciones escritas?

- $\quad$ Asigno una nota numérica o general: excelente, muy bien, bien, regular, ...

- $\quad$ Utilizo un método de autoevaluación guiada

- Otros.

15. ¿Qué tipos de errores son, bajo su punto de vista, los que necesitan ser corregidos?

- Todos los errores

- $\quad$ Los errores ortográficos

- Los que dificultan la comprensión general del texto

- $\quad$ Ninguno, lo importante es que el alumno produzca en otra lengua

- Otros.

16. ¿Devuelve usted el trabajo corregido a sus alumnos con las correcciones, comentarios y/o nota numérica?
$\square$ Siempre
$\square$ A veces
$\square$ Otros:

17. Califique ¿en qué medida la corrección de errores de sus alumnos y su feedback (crítica o comentario) es útil o va a ser útil?

\begin{tabular}{|c|c|c|c|c|c|c|}
\hline e) & Para que el alumno sea consciente de su propio proceso de aprendizaje & $\begin{array}{l}\text { Mucho } \\
\square\end{array}$ & $\begin{array}{c}\text { Bastante } \\
\square\end{array}$ & $\begin{array}{c}\text { Poco } \\
\square\end{array}$ & $\begin{array}{c}\text { Muy poco } \\
\square\end{array}$ & $\begin{array}{r}\text { Nada } \\
\square\end{array}$ \\
\hline f) & & $\begin{array}{l}\text { Mucho } \\
\square\end{array}$ & $\begin{array}{c}\text { Bastante } \\
\square\end{array}$ & $\begin{array}{c}\text { Poco } \\
\square\end{array}$ & $\begin{array}{c}\text { Muy poco } \\
\square\end{array}$ & \\
\hline g) & $\begin{array}{l}\text { Le aporte información sobre cómo trabajar las distintas destrezas } \\
\text { comunicativas }\end{array}$ & $\begin{array}{l}\text { Mucho } \\
\square\end{array}$ & $\begin{array}{c}\text { Bastante } \\
\square\end{array}$ & $\begin{array}{c}\text { Poco } \\
\square\end{array}$ & $\begin{array}{c}\text { Muy poco } \\
\square\end{array}$ & $\begin{array}{r}\text { Nada } \\
\square\end{array}$ \\
\hline h) & $\begin{array}{l}\text { Le ayude a ver los errores no como algo negativo sino como indicador de su } \\
\text { progreso en el proceso de aprendizaje }\end{array}$ & Mucho & $\begin{array}{c}\text { Bastante } \\
\square\end{array}$ & $\begin{array}{c}\text { Poco } \\
\square\end{array}$ & $\begin{array}{c}\text { Muy poco } \\
\square\end{array}$ & \\
\hline
\end{tabular}




\title{
Anexo III
}

\section{Carta de Presentación para profesores que imparten enseñanzas de inglés como segunda lengua en la ciudad de Valladolid, España. Modalidad de entrega del cuestionario: en mano}

\begin{abstract}
El cuestionario adjunto está dirigido a profesores que desarrollan su actividad profesional docente en centros de enseñanza de inglés como segunda lengua en la ciudad de Valladolid, España.
\end{abstract}

A partir del análisis de las respuestas recogidas intentaremos llevar a cabo un estudio que gira en torno a la valoración del error por parte del profesor de Educación Primaria en las producciones escritas de alumnos de segundas lenguas.

Agradecemos de antemano su colaboración y le aseguramos que la información recogida estará protegida bajo el anonimato y la confidencialidad y solo se utilizará de forma colectiva en el contexto de este estudio.

Pautas generales

Lea atentamente las consignas y marque la casilla correspondiente. Cuando la información no se corresponda con ninguna de las opciones propuestas, puede marcar la casilla Otros y añadir la información que considere relevante. 



\section{Anexo IV}

\section{Carta de Presentación para profesores que imparten enseñanzas de español como segunda lengua en la ciudad de Austin, Estados Unidos de América. Modalidad de entrega del cuestionario: en mano}

El cuestionario adjunto está dirigido a profesores que desarrollan su actividad profesional docente en centros de enseñanza de español como segunda lengua en la ciudad de Austin, Estados Unidos de América.

A partir del análisis de las respuestas recogidas intentaremos llevar a cabo un estudio que gira en torno a la valoración del error por parte del profesor de Educación Primaria en las producciones escritas de alumnos de segundas lenguas.

Agradecemos de antemano su colaboración y le aseguramos que la información recogida estará protegida bajo el anonimato y la confidencialidad y solo se utilizará de forma colectiva en el contexto de este estudio.

Pautas generales

Lea atentamente las consignas y marque la casilla correspondiente. Cuando la información no se corresponda con ninguna de las opciones propuestas, puede marcar la casilla Otros y añadir la información que considere relevante. 



\title{
Anexo V
}

\section{Carta de Invitación para profesores que imparten enseñanzas de inglés como segunda lengua en la ciudad de Valladolid, España. Modalidad de entrega de los cuestionarios: enlace que da acceso al cuestionario online}

\begin{abstract}
El cuestionario que podrán encontrar en el siguiente enlace: https://survey.zohopublic.com/zs/aeyJ0i está dirigido a profesores que desarrollan su actividad profesional docente en centros de enseñanza de inglés como segunda lengua en la ciudad de Valladolid, España.
\end{abstract}

A partir del análisis de las respuestas recogidas intentaremos llevar a cabo un estudio que gira en torno a la valoración del error por parte del profesor de Educación Primaria en las producciones escritas de alumnos de segundas lenguas.

A través de esta carta queremos invitarle a colaborar en nuestra investigación y agradecer de antemano su colaboración. Le aseguramos que la información recogida estará protegida bajo el anonimato y la confidencialidad y solo se utilizará de forma colectiva en el contexto de este estudio.

Pautas generales

Lea atentamente las consignas y marque la casilla correspondiente. Cuando la información no se corresponda con ninguna de las opciones propuestas, puede marcar la casilla Otros y añadir la información que considere relevante. 



\title{
Anexo VI
}

\section{Carta de Invitación para profesores que imparten enseñanzas de español como segunda lengua en la ciuad de Austin, Estados Unidos de América. Modalidad de entrega de los cuestionarios: enlace que da acceso al cuestionario online}

\begin{abstract}
El cuestionario que podrán encontrar en los siguientes enlaces: https://survey.zohopublic.com/zs/YEylfz y https://survey.zohopublic.com/zs/76yFLd está dirigido a profesores que desarrollan su actividad profesional docente en centros de enseñanza de inglés como segunda lengua en la ciudad de Austin, Estados Unidos de América.
\end{abstract}

A partir del análisis de las respuestas recogidas intentaremos llevar a cabo un estudio que gira en torno a la valoración del error por parte del profesor de Educación Primaria en las producciones escritas de alumnos de segundas lenguas.

A través de esta carta queremos invitarle a colaborar en nuestra investigación y agradecer de antemano su colaboración. Le aseguramos que la información recogida estará protegida bajo el anonimato y la confidencialidad y solo se utilizará de forma colectiva en el contexto de este estudio.

Pautas generales

Lea atentamente las consignas y marque la casilla correspondiente. Cuando la información no se corresponda con ninguna de las opciones propuestas, puede marcar la casilla Otros y añadir la información que considere relevante. 
